\title{
II. TRADUZIONE \\ IL LIBRO DELLE RISPOSTE ARABE \\ NEL COMMENTO DEI CONSIGLI DI YŪSUF
}

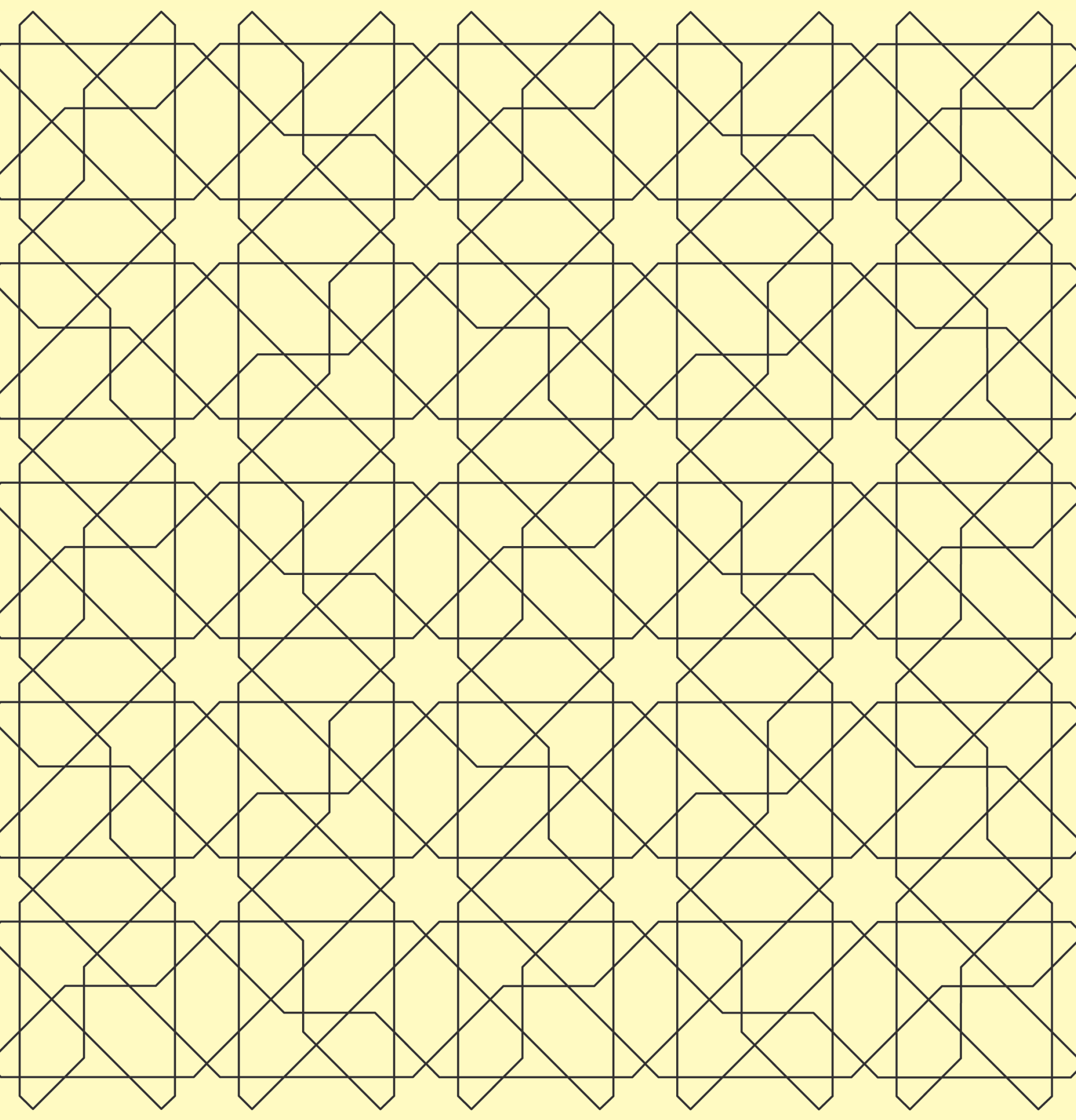




\section{IL LIBRO DELLE RISPOSTE ARABE NEL COMMENTO DEI CONSIGLI DI YŨSUF}

Del nostro signore, il Maestro, l'Imām, il sapiente dominicale (rabbāñ̄) Muḥyīddīn Abū 'Abd Allāh Muḥammad ibn 'Alī ibn Muḥammad ibn Aḥmad ibn 'Abd Allāh ibn al-'Arabī aṭ-Ṭầ'̄ al-Ḥātimī, Allah abbia misericordia di lui.

[1] Nel Nome di Allah, il Misericordioso, il Clemente, e la mia riuscita (tawfìq) non è se non per Allah.

Il commento dell'Imām, il sapiente, il profondo conoscitore (rāsiḩ), l'erede più perfetto, Abū 'Abd Allāh Muḥammad ibn 'Alī ibn al-'Arabī, aț-Ṭā̄è, al-Ḥātimī, Allah sia soddisfatto di lui.

La lode spetta ad Allah che ci ha guidati a questo, e non saremmo stati guidati se Allah non ci avesse guidato: "Invero sono venuti i messaggeri del nostro Signore con la verità" (Cor. VII 43).

Quanto segue. Questo è il commento di ciò che ha proferito la spiritualità (rūhâniyya) del servitore preso da follia (muwallah o mülah), il cui cuore è pazzo d'amore (mudallah), 'Alī al-Kurdī, tramite la lingua di chi conosceva il suo stato e che si basava su di lui [come autorità], Yūsuf ibn Ibrāhīm aš-Šāfí̄ ǧărī ma'a-hu fì s-sabab) $\left({ }^{2}\right)$. La materia è siriana e damascena $\left(^{3}\right)$, ed egli non l'ha trasgredita, ma così come l'ha appresa l'ha espressa, ed essa è tra gusto $(\underline{d} a w q)$ e proiezione spirituale $(i l q \bar{a})$, in essa non c'è scrittura $(k i t a \bar{b} a)\left(^{4}\right)$ né incontro $\left.\left(l i q \bar{a}^{9}\right){ }^{5}\right)$ - così mi disse il possessore della lingua [cioè Yūsuf ibn Ibrāhīm] - e l'inizio di quello fu che disse e spiegò:

"La prima cosa che è necessaria per l'aspirante (murīd) è di spogliarsi del suo arbitrio (ihtiyār), di essere di fronte al Maestro come il morto di fronte al lavatore (mugassil), di fare una sadaqa quando si reca dal suo Maestro, [camminando] in uno stato di abbassamento (dilla), di indigenza (maskana) e di spezzamento (inkisār), che la sua marcia sia nella parte bassa della via battuta, che nella sua anima vi sia [la convinzione] di essere inferiore a chiunque incontri nella sua via verso il Maestro, e così in tutti i suoi stati, e quando è vicino alla dimora del Maestro, se lì vi è una moschea vi entri, faccia una salāt e chieda ad Allah, sia Egli esaltato, di disporre favorevolmente verso di lui il cuore del Maestro, e quando ha finito di fare la salāt si rechi alla porta del Maestro e si fermi a distanza dalla porta, mostrando adab di fronte a lui".

1) Entrambi erano curdi di origine.

2) L'espressione sembra riferirsi al mantenimento del legame con il Maestro anche dopo la sua morte.

3) Ibn 'Arabī sembra qui attribuire un carattere locale alle raccomandazioni in oggetto, a cui contrappone il carattere "arabo" delle sue risposte.

4) Ad eccezione del manoscritto Yūsuf Aga, tutti gli altri riportano kināya, ma il ternario ilq $\bar{a}$ ', kitāba e liqqà è attestato nei capitoli 2 [I 90.1], 145 [II 231.7], 307 [III 31.13] e 314 [III 56.7] delle Futūhāt, e nel Kitāb mawāqi an-nuğūm, Širkat al-quds, Il Cairo, 2016, pag. 161, linea 11.

5) Cioè l'insegnamento impartito al riguardo da 'Alī al-Kurdī a Yūsuf ibn Ibrāhīm non fu né scritto, né orale, ma puramente spirituale. Nel seguito del testo Ibn 'Arabī spiegherà le modalità di questo insegnamento. 
[2] Commento. Quanto al suo detto: "La prima cosa che è necessaria per l'aspirante (murīd) è di spogliarsi del suo arbitrio", per aspirante intende colui che vuole l'istruzione iniziatica (tarbiya), cioè colui che è al servizio (hidma) di un Maestro $\left(^{6}\right)$, ed ha correlato a lui [cioè all'aspirante] la spoliazione, ponendo in ciò la priorità $(f a d l)$ per lui $\left(^{7}\right)$. Invero il patto (bay $\left.{ }^{\complement} a\right)$ si basa sull'ascolto, sull'obbedienza in ciò che piace ed in ciò che non piace (fî̀ l-manšat wa-l-makrah), e sulla realtà essenziale (haquqqa): questa è la caratteristica (sifa) del credente $\left({ }^{8}\right)$, ed a maggior ragione dell'aspirante $\left(^{9}\right)$.

L'aspirante [lett. Il volente] si chiama così solo perché è dotato di una volontà $(i r a \bar{d} a)\left({ }^{10}\right)$ : in effetti è indispensabile che egli voglia ciò che vuole il suo Maestro e quindi è necessario che sussista in lui una volontà. Come ha detto Abū Yazīd [al-Bisțamī] $\left({ }^{11}\right)$ : "Voglio non volere" (12), ed ha affermato per se

6) Negli Aperçus sur l'initiation [Éditions Traditionnelles, 1977, pag. 235], René Guénon precisa: “Quant au «service» d'un guru, si l'on tient à employer ce mot, là où une telle chose existe, ce n'est, redisons-le, qu'à titre de discipline préparatoire, concernant uniquement ce qu'on pourrait appeler les «aspirants», et non point ceux qui sont déjà parvenus à une initiation effective".

7) In tre manoscritti si legge $f q$ al posto di $f a d l$, per cui la traduzione sarebbe: "attribuendone a lui l'atto".

8) L'espressione: «Noi ascoltiamo ed obbediamo», indicante una delle caratteristiche fondamentali del credente, ricorre quattro volte nel Corano: II-285, IV-46, V-7 e XXIV-51, oltre che in molti hadīt.

9) Il riferimento al patto ed al servizio del Maestro mostrano che l'aspirante di cui si parla non è colui che cerca un Maestro, ma colui che lo ha trovato e che vuole l'istruzione iniziatica.

10) Talvolta irāda viene tradotto come desiderio, ma René Guénon, nel suo Corso di Psicologia [Archè, 2001, pag. 229], precisa: "Nous avons déjà signalé les principales différences qui existent entre le désir et la volonté: on peut désirer l'impossible, on ne veut que le possible; on peut avoir en même temps plusieurs désirs différents et même contradictoires, on n'a jamais qu'une seule volonté; enfin le désir est éminemment impulsif, tandis que la volonté est toujours plus ou moins réfléchie. Tout cela prouve suffisamment qu'il y a bien là deux choses essentiellement différentes [...]. Nous ferons encore remarquer qu'au simple désir ne se joint pas l'idée de la responsabilité qui se joint à la volonté: cette idée d'ailleurs ne prouve pas par elle-même que la liberté existe, mais seulement qu'on croit à la liberté, et si la liberté est prouvée d'autre part, elle permettra de distinguer encore plus nettement la volonté de toute autre impulsion. Cependant, tout en distinguant la volonté du désir, il faut reconnaître qu'il y a le plus souvent des désirs qui sollicitent la volonté et que celle-ci, à son tour, peut susciter bien des désirs qu'on n'avait pas tout d'abord; mais ce n'est pas, parce que ces deux ordres de faits s'accompagnent d'ordinaire, réagissent l'un sur l'autre et se ressemblent dans une certaine mesure, qu'il faut les confondre, et, même si l'on peut désirer vouloir et vouloir désirer, cela prouve encore qu'ils sont vraiment différents".

11) Abū Yazìd, celebre sưfì del III secolo dall'Egira, è certamente il Maestro più citato da Ibn 'Arabī nelle Futühăt, ove il suo nome ricorre quasi 150 volte, come pure nel testo che stiamo traducendo, ove il suo nome è riportato 40 volte. Visse la maggior parte della sua vita a Bistām, e non lasciò nulla di scritto, ma un suo nipote raccolse circa 500 tra detti ed aneddoti, a cui Ibn 'Arabī dedicò un'opera di cui non è rimasto alcun manoscritto.

12) Ibn 'Arabī riporta questo detto nei seguenti capitoli delle Futūhăt: 73 [II 19.3]; 93 [II 178.6], ove afferma che "il più grande Abū Yazīd disse: "La rinuncia (zuhd) non è una stazione spirituale per me; io ho rinunciato per tre giorni: il primo giorno ho rinunciato a questo mondo, il secondo giorno ho rinunciato all'aldilà, il terzo giorno ho rinunciato a tutto ciò che è altro che Allah. Allora il Vero mi chiamò: "Cosa vuoi?" ed io risposi: «Voglio non volere, poiché io sono colui che è voluto (murād) e Tu sei Colui che vuole (murīd)!»”; 226 [II 521.33] ove precisa: "Secondo Abū Yazīd al-Bisțāmī, la vera volontà è l'abbandono della propria volontà ed a questo 
stesso una volontà ed ha cercato di escludere che la sua volontà dipendesse dalla sua anima [o da lui stesso], ed ha chiesto ad Allah che la sua volontà, di cui non poteva fare a meno, seguisse soltanto la volontà del suo Padrone (mawlā), e voleva sapere ciò che voleva il suo Signore, per poi volerlo, e questo è il più alto grado in questo campo $(b \bar{a} b)$. Quanto al grado che è inferiore ad esso in questo campo, esso è più elevato nella stazione (maqām) nella dimora dell'incombenza legale (taklîf) [cioè in questo mondo], ed è una faccenda semplice per chi è assistito (muwaffaq) [da Allah] ${ }^{(13}$ ).

Allah, sia Egli esaltato, ha dettato le regole $(a h k \bar{a} m)$ e le ha completate, e con questo atto ha sottratto la volontà da ogni credente in Allah, poiché [il credente] non vuole cosa se non ciò che Allah, quanto è Potente e Magnificente, ha voluto nella Sua Legge, e quindi egli non ha volontà per se stesso, poiché la sua volontà è ciò che è voluto da Lui. Il Vero lo ha spiegato ai credenti con ciò che ha legiferato per essi, e per questo il credente è ossequiente (yushibu), e non è ossequiente se non al regime (hukm) della sua fede, come il Profeta, che Allah faccia scendere su di lui la Sua salāt e la Pace, non è ossequiente a nessuno se non alla sua Profezia, poiché egli è [tale] in base a (bi-ḥkmi) ciò che gli viene rivelato, non in base alla sua anima, ed il credente [è tale] in base alla sua fede, non in base alla sua anima, ed il Re [è tale] in base al suo Regno (mulk), non in base a qualcuno, e quindi non è ossequiente se non al suo Regno, e in base ad esso egli giudica.

Allo stesso modo il vero e sincero aspirante non è ossequiente se non al suo Maestro, [3] e non ha volontà per se stesso se non ciò che vuole da lui il suo Maestro, e per questo ha detto: “... di spogliarsi del suo arbitrio (ihtiyār) $\left({ }^{14}\right)$ ", ed abbia quindi una sola volontà, che non è altro che la volontà del suo

riguardo, allorché era in uno stato $(h \bar{a} l)$ in cui sussisteva ancora la volontà propria, disse: «Voglio non volere!», esprimendo così l'intenzione di cancellare la volontà dalla sua anima (nafs); poi, rivolgendosi ad Allah, completò la frase dicendo: «poiché io sono colui che è voluto e Tu sei Colui che vuole»"; 298 [II 687.21] ove ribadisce: "Venne chiesto ad Abū Yazīd: "Cosa vuoi?", ed egli rispose: "Voglio non volere". In altre parole: "Fammi volere ogni cosa che Tu vuoi", così che non ci sia altro che ciò che il Vero, Gloria a Lui, vuole"; e 374 [III 464.14] ove afferma: "Non dire come dice chi ignora la realtà e cerca l'impossibile, dicendo "Voglio non volere": la vera ricerca, che è conferita dalla realtà essenziale dell'uomo, è che dica "Voglio ciò che Tu vuoi" [...] Analogamente non è corretto dire "È opportuno che il servitore sia con Allah senza volontà", mentre sarebbe corretto dire "Il servitore è colui la cui volontà è correlata con ciò che vuole Allah", poiché non può fare a meno di una volontà. Chi cerca la visione del Vero per ordine del Vero è un servitore che si conforma all'ordine del suo Signore, mentre chi cerca la visione del Vero senza l'ordine del Vero è inevitabile che soffra quando non trova ciò con cui ha correlato la sua volontà, ed è colui che fa del male a se stesso [...] Nella notificazione divina è riportato: «O Mio servitore, tu vuoi ed lo voglio [; se tu lasci a Me ciò che tu vuoi ti darò ciò che voglio lo; se tu ti opponi a Me in ciò che voglio, ti darò della pena in ciò che tu vuoi] e non ci sarà altro che ciò che voglio lo»". L'irāda non è qui intesa come facoltà, ma come atto; il «murīd» pertanto non è colui che rinuncia alla facoltà di volere, bensì colui che rinuncia a ciò che «lui» vuole, per volere ciò che vuole Allah.

13) Nell'ambito exoterico, che riguarda coloro che sono soggetti all'osservanza delle regole, il Volere divino è chiaramente espresso nella Legge e si applica a tutta la comunità dei credenti, mentre nell'ambito iniziatico "le vie verso Dio sono tanto numerose quanto le anime degli uomini” [René Guénon, Aperçus sur l'ésotérisme islamique et le Taoisme, Gallimard, 1973, pag. 15].

14) Il verbo ihtāara, di cui ihtiyār è un infinito, al pari di hìyara e di hiyyār, significa letteralmente scegliere. Nel 
Maestro riguardo a lui. E non ha detto: “... di spogliarsi della sua volontà”, poiché ciò non è possibile: egli si spoglia del suo arbitrio e non sceglie se non ciò che vuole il suo Maestro, e ciò che egli vuole è ignoto per lui finché egli non gli ordina ciò che gli ordina ed allora egli vuole, necessariamente, ciò che vuole il suo Maestro. Se non è così, egli non è un aspirante ad una istruzione iniziatica e non arriverà mai nulla da lui, e se crede di essere un aspirante ad una istruzione iniziatica, ed è alla presenza del suo Maestro ed agisce liberamente nella sua faccenda da se stesso, senza l'autorizzazione $(\underline{i d n})$ del suo Maestro al riguardo, è un bugiardo (kadd $\underline{a} b)$.

È opportuno per lui, quando gli passa per la mente una faccenda che deve necessariamente essere gestita - e ciò ha numerosi aspetti: vi è ciò che egli detesta e ciò che gli piace (yuhibbu) - [dicevo che] è opportuno per lui che esponga al suo Maestro ciò che gli è venuto in mente, affinché il Maestro stabilisca per lui uno dei modi della gestione riguardo a quello. Se stabilisce [che egli deve fare] ciò che detesta, quella avversione diventa piacere per quel modo di gestire (tasrî́f), poiché l'ha stabilito per lui il Maestro, e se è ciò che gli piace, allora è bene su bene. E se è colui che fa ciò che detesta per la scelta del Maestro contro voglia e non volentieri, egli è dedito al combattimento interiore (muğāhada) ed alla sopportazione (mukābada), e sa di essere necessariamente più in basso di colui a cui ciò che è detestabile diventa piacevole $(m a h b u \bar{u} b)$, e non cessa di combattere finché ciò che è detestabile gli diventa necessariamente piacevole. Entrambi gli aspiranti sono [però] caratterizzati dal fatto di essere spogliati dall'arbitrio.

Il Maestro realizzato è lungi dall'assecondare per principio l'intento (garad) dell'aspirante, ma il Maestro scruta i suoi stati, se sa della sincerità $(s i d q)\left({ }^{15}\right)$ dell'aspirante nel suo ossequio (suhba) e sa che egli aspira al grado elevato, ed ogni volta che vede in lui un intento che gli piace verso una cosa, lo conduce a [fare] l'opposto di ciò che vuole, poiché il Maestro è come la pettinatrice della sposa $\left(^{16}\right)$. Il Maestro prende per lui il posto del Vero, e non gli ordina se non ciò che sa che il Vero, sia Egli esaltato, vuole da lui, [4] e quindi l'aspirante non cessa di procedere per la volontà del suo Maestro

linguaggio teologico ihtiy $\bar{a} r$ ha assunto il significato di libera scelta o libero arbitrio, in contrapposizione a idtirār, necessità, e a $t \bar{a}^{c} a$, obbedienza. La scelta è un atto logicamente antecedente alla volontà, ma l'oggetto della volontà può dipendere anche dall'obbedienza ad una autorità a cui si è scelto di sottomettersi: l'aspirante continua a volere ma deve rinunciare al suo libero arbitrio per scegliere solo ciò che vuole il suo Maestro.

15) In arabo il termine șidq può indicare sia la sincerità, intesa come coerenza tra ciò che si dice e ciò che si pensa o crede, sia la veridicità, che oltre alla sincerità implica anche la coerenza con il vero; per questo a seconda del contesto l'ho tradotto talora con sincerità e talora con veridicità. Quanto allo stato ed alla stazione spirituale della veridicità, nel Cap. 136 [II 222.20] Ibn 'Arabī precisa: "La veridicità è intensità (šidda) e forza (saläba) nella religione (dīn) e lo zelo (gayra) per Allah è tra le sue condizioni. Colui che l'ha realizzata (mutahaqqiq) possiede la facoltà di agire per mezzo dell'aspirazione (al-fi l bi-l-himma), corrispondente alla forza della fede".

16) Lo stesso esempio è riportato nel Cap. 181 [II 365.16]. All'epoca di Ibn 'Arabī la donna si occupava personalmente della sua pettinatura, salvo che in occasione del matrimonio, in cui la sua pettinatura veniva affidata ad una pettinatrice, che la acconciava in modo che si presentasse nel migliore dei modi al suo futuro sposo. 
per lui, finché si abitua a quello - ed il bene è un'abitudine $\left({ }^{17}\right)$ - e ciò diventa gradito per lui. Se l'aspirante perde il Maestro, per la sua morte, o per un viaggio, egli si comporta con il Vero in quel modo e con quell'attributo: questa è la stazione del dare ascolto al Vero. E soprattutto se l'aspirante ha una casa, con una moglie e dei figli, ed ama i figli con l'amore naturale ed ama la moglie con l'amore del tutto per la sua parte, e questo è l'amore del desiderio ( $s a h w a)$, il Maestro realizzato, per come dispone (yusarrifu) di lui, si frappone tra lui e tra ciò che egli ama per i suoi figli per sua moglie.

17) Riferimento ad uno hadīt riportato da Ibn Māğah: "Il bene è abitudine, il male è pervicacia (al-hayr 'āda wa-ร̌-šarr lağağăa)". Ibn 'Arabī lo cita nel Cap. 560 [IV 463.33] e lo commenta nel Cap. 345 [III 182.24 e 26], ove precisa: "Poiché la religione $(d \bar{\imath} n)$ è operare il bene e la religione è l'abitudine, egli, su di lui la Pace, ha menzionato che il bene è abitudine. Questa menzione è una buona novella - da parte di uno che sa le cose, l'Inviato, che Allah faccia scendere su di lui la Sua salāt e la Pace - che l'anima è buona per essenza, e non accetta il male se non per pervicacia da parte del compagno (qarinn) [cioè Satana], in ciò su cui insiste con essa: Egli non ha quindi definito il male come una parte dell'anima. Per questo egli, che Allah faccia scendere su di lui la Sua șalāt e la Pace, ha detto: "Il bene è abitudine, il male è pervicacia". Quando il compagno fa pressione sull'anima e la tormenta con il male, che si identifica con l'opposizione all'ordine ad alla proibizione di Allah, e le toglie il respiro con questa pressione ed insistenza, Allah le ispira, anzi le parla dal volto specifico che l'Angelo non conosce, di accettare da lui il male con cui la tormenta. Poi il Vero vede che l'anima è terrorizzata e teme l'inganno (makr) divino, ed allora le fa contemplare la Presenza della Trasmutazione (tabdīl) e che l'esito finale di coloro che sono tenuti all'osservanza delle norme è la Misericordia. Egli le recita: "Allah trasmuterà le loro opere cattive in buone" (Cor. XXV-70), e le recita riguardo ai trasgressori: "Non disperate della Misericordia di Allah, poiché Allah perdona tutti i peccati" (Cor. XXXIX-53). Egli fa così cessare il suo terrore, e l'anima accetta dal compagno il male con cui è venuto da essa. Il compagno si rallegra per l'accettazione che ha luogo da parte di essa, per la sua ignoranza della onni-comprensività della Misericordia, dell'indulgenza e del perdono e del fatto che Allah concede l'indulgenza solo alla classe di coloro che ricevono il male apportato da Satana, il compagno. Egli non sa che Allah ha assegnato all'anima che accetta il male dal compagno per la sua insistenza ed oppressione il rango di colui che è costretto, e colui che è costretto non è punibile. [Il Profeta] ha quindi denominato il male pervicacia - buona novella divina di cui non tutti sono consapevoli - ed ha fatto del bene una abitudine. L'anima è per essenza buona, poiché suo padre è il puro Spirito Santo, e quindi la sua natura è il bene, niente altro".

Nel suo Corso di Psicologia [pag. 249], René Guénon precisa: "L’habitude peut être définie d'une façon générale comme la tendance de l'activité à reproduire les mêmes actes avec une facilité croissante à mesure qu'ils sont plus fréquemment répétés. Cependant il y a lieu de distinguer deux formes de l'habitude: en premier lieu, l'habitude sous la forme de l'assimilation, qui est une disposition ou une manière d'être au sens de «habitus», et en second lieu, l'habitude sous la forme de la répétition, au sens du latin «consuetudo». C'est la première de ces deux formes qui est, à proprement parler, la véritable habitude, celle dont on peut dire avec Aristote qu'elle est une seconde nature. L'habitude ainsi entendue naìt avec le premier acte; la répétition ne la produit pas, elle la développe seulement, par suite l'habitude n'est pas seulement proportionnée au nombre et à la fréquence des actes accomplis, elle l'est aussi et peut-être même surtout à leur énergie et à leur durée. L'habitude rend les actes plus faciles et elle les rend aussi plus nécessaires: en premier lieu, plus l'acte se répète, plus l'effort diminue, par conséquent, l'acte finit par s'accomplir comme de lui-même, il devient ainsi plus rapide, mais en même temps plus automatique et de moins en moins clairement conscient. En second lieu, plus l'acte devient facile, plus deviennent difficiles par là même les actes qui lui sont contraires ou qui en sont très différents: il faut un effort non plus pour faire l'acte, mais pour ne pas le faire".

In arabo, il termine ' $\bar{a} d a$ deriva da una radice verbale che significa ritornare, ripetere. 
Se egli lo sopporta è sincero $(s \bar{a} d i q)$ e se ama ciò quando il Maestro lo vuole è un confessore $(s i d d \bar{q} q)\left({ }^{18}\right)$ perfetto, il grado supremo della conoscenza da parte di colui che ha pazienza (sābir).

Non vedi ciò che ha detto Abū Yazīd $\left({ }^{19}\right)$ al suo Signore: "Voglio Te, non voglio Te per la ricompensa $(t a w a \bar{a} b) "$ ?, - poiché essa è ciò che è amato dalle anime, cioè la ricompensa - "ma voglio Te per il castigo ("a $\underline{d} \bar{a} b)$ " - poiché il castigo non è oggetto di piacere (mald $\underline{u} \underline{d})$ per le anime $\left({ }^{20}\right)$.

Poi ha detto: "Tutti i miei desideri (ma ārib) li ho ottenuti" - Egli dice: "Tutto ciò che Tu hai voluto da me di quello che amavo, mi hai ordinato di farlo, ed io mi sono dilettato di ciò laddove il Tuo ordine corrispondeva alla mia passione (hawā) per quello".

Poi ha detto: “... salvo l'oggetto di piacere del mio provare il castigo" $\left({ }^{21}\right)$ - Egli dice: "Voglio da Te che Tu mi ordini ciò che detesto fare per la passione della mia anima, e provo il piacere nel farlo dopo l'avversione", e per questo ha detto: "l'oggetto di piacere del mio provare il castigo", cioè "provo il piacere in ciò che detesto come lo provo in ciò che amo" cercando la stazione elevata, della quale ci ha informato.

Ed ha detto: "Ogni giorno, mio Signore, mi mandi il mio pane, e non mi mandi una tribolazione $\left(b a l \bar{a}^{\prime}\right)$ di cui io mi nutra". Non c'è [5] dubbio che l'uomo che si nutre ama le pietanze $(\bar{a} d \bar{a} m)$ e si diletta di ciò, mentre egli cercava il diletto nella tribolazione.

18) Nel Cap. 73 [II 24.15] Ibn 'Arabī precisa: "Allah, sia Egli esaltato, ha detto riguardo a coloro che credono in Allah e nel Suo Inviato: "Costoro sono i confessori (as-siddīqūn)" (Cor. LVII-19). Il confessore è colui che crede in Allah e nel Suo Inviato sulla parola di colui che informa (muhbir) e non su una prova $($ dali $l)$, tranne la luce della fede che egli trova nel suo cuore, la quale gli impedisce che un'esitazione o un dubbio si insinui in lui al riguardo delle parole dell'Inviato che informa”. Da parte sua 'Abd al-Qādir al-Ǧîlānī, nell'ultimo capitolo del suo Al-gunya li tạlibì tarìqat al-haqq, precisa che "il veridico (sādiq) è colui che è veridico nelle sue parole, mentre il confessore $(s i d d \bar{\imath} q)$ è colui che è veridico nelle sue parole ed in tutti i suoi atti e stati".

19) I seguenti versi sono riportati anche da Ibn al-'Arïf nei suoi Mahāsin al-mağălis [pagg. 40-41 della traduzione di Asín Palacios, Librairie Orientaliste Paul Geuthner, 1933], ove afferma che "si dice che siano stati recitati da Abū Yazīd". Massignon, nella sua ricostruzione del Dīwān di al-Hallāğ [Cahiers du Sud, 1955, pag. 42], ha attribuito invece questi versi ad al-Ḥallāğ, malgrado le ripetute affermazioni di Ibn 'Arabī, che pure cita, in senso contrario.

20) Nel Cap. 294 [II 673.26] Ibn 'Arabī precisa che il castigo "è stato chiamato 'adāa $b$ in quanto esso è piacevole $(y a d u b u)$ in un certo stato per certa gente con una complessione che lo esige", e nel Cap. 541 [IV 185.21] aggiunge che: "il termine 'ad $\bar{d} \bar{b} b$ deriva dalla gradevolezza ('ud $\underline{u} b a)$, che consiste nel provare piacere per la faccenda".

21) Ibn 'Arabī riporta questo detto nei seguenti capitoli delle Futūhāt: 69 [I 511.21]; 72 [I 746.1]; 198 [II 408.10]; 227 [II 524.19]; 280 [II 614.15]; 292 [II 657.35]; e 541 [IV 185.23]. Cfr. Binyamin Abrahamov, Ibn al- 'Arabī and the Sufis, Anqa Publishing, 2014, pag. 51. 
La gente di Allah dice: "Non destano meraviglia delle rose nel giardino - riferendosi a colui a cui viene ordinato di fare ciò che ama fare - ma destano meraviglia delle rose nel pozzo del fuoco" (22).

Essi parlano alludendo a colui a cui viene ordinato ciò che detesta, e che diventa piacevole per lui in quanto gli è stato ordinato e lo fa con il piacere che proverebbe nel fare ciò che ama se gli venisse ordinato, ma per colui che è elevato i due piaceri si equivalgono, oppure egli preferisce il piacere di fare ciò che detesta piuttosto che ciò che ama, ed egli è al di sotto di colui per cui le due cose si equivalgono, poiché l'equivalenza nel piacere che prova nelle due cose non ha luogo se non per chi è realizzato ed ha il piede saldo nella volontà del suo Padrone (mawlā).

Quanto a colui per cui il piacere dell'ordine di ciò che detesta è superiore al piacere dell'ordine di ciò che ama, egli è elevato nella guerra interiore (ǧih $\bar{a} d)$, ma non è realizzato.

Quanto ai conoscitori del Vero, che sono [con Lui] a guisa degli aspiranti con i Maestri che li istruiscono, essi si sono spogliati del loro arbitrio con il Vero, per una contemplazione autentica della realtà delle cose, ed il gusto spirituale conferisce loro la spoliazione dell'arbitrio dalle loro anime. Essi sono con ciò che il Vero sceglie per loro e per mezzo di loro, ed essi, in tutto ciò in cui sono fatti sussistere, lo sono per il loro Signore, non per loro stessi, ed il loro grado di contemplazione in quello è il detto di Allah, sia Egli esaltato: "Il Mio servitore non cessa di avvicinarsi a Me con gli atti supererogatori finché Io lo amo, e quando lo amo sono il suo udito con cui egli sente..."(23).

Ed il Vero ha comunicato che Egli è tutte le facoltà di questo servitore, e dell'insieme di queste facoltà fa parte la volontà, poiché essa è uno dei Suoi Attributi, ed Egli, sia Egli esaltato, è la volontà con cui egli vuole. Se questo Vero è identico alla volontà di questo conoscitore, ed il Vero è Volente, quella volontà esteriore [6], che è connessa da parte di questo servitore con qualsiasi cosa sia voluta, è la Volontà del Vero, non la sua volontà, poiché in realtà egli non ha volontà.

Se l'aspirante è in questo modo con il Maestro, allora è obbligatorio per il Maestro, se sa che l'aspirante si è vestito per lui di questo abito, di sparire per lui, e di fargli apparire il Vero nella forma del Maestro, per la facoltà che ha [di farlo]. Se [l'aspirante] si è coperto di tale abito e procede secondo la sua abitudine $\left({ }^{24}\right)$ con lui nel regime [aspirante/Maestro], gli viene tolto il velo dalla visione interiore (bașira) ed egli vede che è il Vero che lo educava nella forma del Maestro e nella sua materia $\left({ }^{25}\right)$, e dopo questo svelamento non vi è più alcun velo, e questa è la stazione più elevata a cui

22) Ibn 'Arabī riporta questo detto nei seguenti capitoli delle Futūhāt: 227 [II 524.21]; 294 [II 673.23]; e 558 [IV 307.35].

23) Hadīt riportato da al-Buhāāī, LXXXI-38, e da Ibn Ḥanbal.

24) In latino vi è un'assonanza fonetica, se non una comunanza etimologica, tra habitum, abito, e habitus, abitudine, attitudine. Analogamente, dal latino consuetudo è derivato il termine costume, che ha anche il significato di abito.

25) In Initiation et réalisation spirituelle [Éditions traditionnelles, 1964, pag. 165] René Guénon precisa: "le Guru humain lui-même n'est au fond que la représentation extériorisée et comme «matérialisée» du véritable 
arriva il servitore in questo campo, cioè nel campo della spoliazione dall'arbitrio in tutte le azioni ed i comportamenti.

Per la lode di Allah non c’è stato per me nella Via nulla di più facile (ashal) di questa stazione, né di più semplice (ahwan) per me, poiché l'ho gustata dal primo passo, e per me era indifferente il piacere che provavo in ciò che amavo e in ciò che detestavo, e mi venne tolto l'amore per le cose e l'avversione per esse, e non contemplavo di esse se non la loro stessa esistenza, senza amore né avversione, ed ero preparato, e compivo [le opere] perché il Vero me le aveva ordinate nella forma del Maestro e tramite la sua lingua, e non mi sopravveniva riguardo ad esse alcun pensiero di amore, né di avversione, per il prevalere della mia contemplazione di Lui in quello: dopo questo stato (hăl) non c'è stato che sia più perfetto di esso in questo specifico campo.

Da qui il servitore si trasferisce verso lo stato $(h \bar{a} l)$ della soddisfazione (rid $\bar{a}$ ) e della collera (gadab), che sono entrambi attributi estrinseci $(n u \bar{u} t)$ divini in quanto Egli ha la soddisfazione $\left({ }^{26}\right)$ e la collera $\left({ }^{27}\right)$, ed [il servitore] è soddisfatto per Allah (li-Llāhi) per mezzo di Allah (bi-Llāhi), ed è in collera per Allah per mezzo di Allah, e quello ha luogo in circostanze (mawātin) $\left({ }^{28}\right)$ note, in cui [il servitore] fa uso di esse $\left(^{29}\right)$. Non tutti sono capaci della soddisfazione e della collera per mezzo di Allah, e non è che chi ama in Allah ( $f \bar{\imath} L l a \bar{h} \imath$ ) e chi odia in Allah entri in questa stazione (maqām), ma può succedere che colui che è soddisfatto in Allah [7] e colui che è in collera in Allah abbiano lo stato della soddisfazione per mezzo di Allah e della collera per mezzo di Allah.

«Guru intérieur», et sa nécessité est due à ce que l'initié, tant qu'il n'est pas parvenu à un certain degré de développement spirituel, est incapable d'entrer directement en communication consciente avec celui-ci. Qu'il y ait ou non un Guru humain, le Guru intérieur est, lui, toujours présent dans tous les cas, puisqu'il ne fait qu'un avec le «Soi» lui-même; et, en définitive, c'est à ce point de vue qu'il faut se placer si l'on veut comprendre pleinement les réalités initiatiques".

26) Più volte nel Corano è affermato: "Egli è soddisfatto di loro ed essi sono soddisfatti di Lui" (V-119, IX-100, LVIII-22, XCVIII-8). Nei capitoli 128 e 129 Ibn 'Arabī spiega che la soddisfazione è connessa con il poco (qalīl) e con l'esiguo (yasīr): Allah è soddisfatto del servitore per il poco che egli fa, purché sia al massimo della sua capacità, ed il servitore è soddisfatto di Allah per il poco che gli conferisce, rispetto all'immensità che è presso di Lui. Nel linguaggio corrente si dimentica spesso che soddisfazione deriva dalla radice latina satis-facere, ove satis significa abbastanza, così come contentezza deriva dalla radice latina continere, che significa trattenere entro certi limiti. Ibn 'Arabī precisa però che la soddisfazione deve riguardare solo Allah o il Suo Decreto, e non ciò che è stato decretato, e che il servitore deve continuare a chiedere, sull'esempio del Profeta, che, pur avendo ottenuto la scienza dei primi e degli ultimi, doveva chiedere: "O mio Signore, accrescimi in scienza".

27) Cfr. Cor. IV-93 e XXIV-9.

28) Il termine mawätin, plurale di mawtin, ricorre in Cor. IX-25 e deriva dalla radice watana, abitare, risiedere. Esso ha come primo significato dimore, sedi, ma quando si riferisce a qualcosa di non spaziale può essere tradotto come circostanze.

29) Mentre prima il servitore provava amore ed avversione in base a criteri o motivi soggettivi ed individuali, ora la Soddisfazione e la Collera di Allah sono la sua soddisfazione e la sua collera, così come la Volontà di Allah è la sua volontà. 
Invero questa stazione in cui si trasferisce [il servitore] esiste solo nel tempo dell'incombenza legale

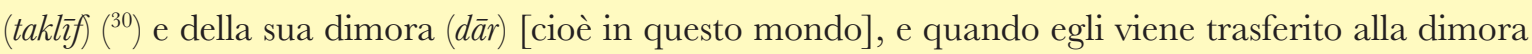
dell'aldilà questo attributo [cioè l'incombenza legale] cessa per lui $\left({ }^{31}\right)$, come pure il comando (amr) [prescrittivo], che egli attualizza con la sua stessa esistenza (wuğūd), e non resta con lui nell'aldilà se non il puro trovare piacere (iltid $\underline{d} \underline{a} \underline{d}$ ) di ogni cosa, ed egli è il piacere (lad $\underline{d} d a)$ stesso ed egli è identico a colui che prova piacere, ed è tutto piacere, e tutto ad un tratto non procede da lui se non ciò che egli ama. La circostanza [o la sede (mawtin)] dell'aldilà comporta quello per lui, così come la circostanza dell'incombenza legale comporta ciò che abbiamo affermato [cioè la soddisfazione e la collera], in quanto le circostanze hanno la giurisdizione (al-mawātin hăkima) ${ }^{\left({ }^{32}\right)}$, nell'eterno e nel nuovo.

Non vedi come la circostanza della preghiera da parte del servitore comporta necessariamente la risposta da parte del Vero? Non c’è nessuno che dica "O Allah!”, senza che il Vero gli dica: "EccoMi da te (labbay-ka)" e gli risponda necessariamente. Egli è Veridico nella promessa e nella parola ed ha detto: "Io rispondo all'invocazione di colui che invoca quando invoca Me!" (Cor. II-186) e la risposta non ha luogo se non dopo la preghiera, ciò fa parte del regime della circostanza. Non vedi che il servitore provoca la collera di Allah e la Sua soddisfazione, come è riportato nella Legge? Anche questo fa parte del regime della circostanza, cioè che Allah pone se stesso nella collera e nella soddisfazione in base al modo di gestire (tașriff) del servitore. Poi, nell'altra parte (ğuz') [del Libro] ${ }^{(33)}$, gli ha comunicato che è Lui, sia Egli esaltato, Colui che gestisce (musarrif), e quindi Egli non è soddisfatto se non di Se stesso, e non è in collera se non per Se stesso, ed il gestire appartiene a Lui, non al servitore.

Da qui [il servitore] si eleva verso la condizione in cui si trovava inizialmente $\left.{ }^{34}\right)$, del disporre (tasrīf $)$ del Vero da parte del servitore in base allo stato in cui si trova, ma con un altro immenso gusto spirituale che si chiama il segreto del Destino (sirr al-qadar) ${ }^{(35}$ ), che consiste nell'essere la scienza seguente al suo

30) Il termine taklī $f$ viene spesso tradotto come responsabilità, ma quest'ultima è in realtà la conseguenza dell'essere tenuti all'osservanza delle norme e dell'essere dotati di libero arbitrio.

31) Nel Cap. 296 [II 682.8] Ibn 'Arabī precisa che "La dimora dell'aldilà non è una dimora di incombenza legale" e nel Cap. 355 [III 248.14] ribadisce: "l'aldilà non è una dimora di incombenza legale, ma una dimora di adorazione ('ibāda)" e poco oltre [III 249.32] aggiunge: "Questo perché Egli ti ha ordinato di adorarLo nella Sua Terra solo fintanto che il tuo spirito abita nella terra del tuo corpo: quando il tuo spirito si separerà da esso l'incombenza legale (takliff) decadrà per te, anche se il tuo corpo continuerà ad esistere nella Terra, sepolto in essa".

32) Cioè il giudizio $(\mathrm{hukm})$ dipende dalla circostanza. Tale concetto ricorre più volte nelle Futūhăt, ad esempio nel Cap. 73, questione CXI [II 106.22], nel Cap. 474 [IV 108.18] e nel Cap. 558 [IV 257.23].

33) Si riferisce probabilmente a Cor. XXXVII-96: "Ed Allah ha creato voi e ciò che voi fate".

34) Questa "ascesa" verso la condizione di partenza richiama le considerazioni sviluppate da René Guénon sulla realizzazione "discendente" nell'ultimo capitolo di Initiation et réalisation spirituelle.

35) Avicenna ha scritto un breve trattato sul segreto del Destino, tradotto da G. Hourani nel N. di aprile 1963 della rivista The Muslim World, in cui commenta con una prospettiva strettamente teologica una tradizione, non 
oggetto $\left(^{36}\right)$. Il sapiente è tale in virtù (bi-hukm) dell'oggetto della scienza, non è l'oggetto della scienza a dipendere dal sapiente, e questa è la scienza che afferma ogni essere dotato di ragione e che nel contempo ignora: chi è velato non vede qual è il motivo [8] di quello, ed egli sa ciò che ignora $\left({ }^{37}\right)$.

Quando il servitore viene trasferito a questa stazione non è vincolato se non da ciò con cui lo vincola il suo oggetto della scienza, e da quel momento egli è tutto Verità e non vuole da se stesso se non ciò che vuole da lui la sua anima, ed il Vero resta nascosto $(g \bar{a} b a)$ in occasione di quello che abbiamo affermato. Il comando (amr) e la creazione appartengono a Lui [cfr. Cor. VII-54] ed egli contempla il comando con la contemplazione che di esso ha il Vero. Non dispone (tasarrafa) di noi altri che noi, ed il Vero non dispone di noi se non per mezzo di noi, e questo grado di contemplazione è più perfetto

recensita nelle raccolte canoniche, che recita: "Il Destino è il segreto di Allah: non rivelate il segreto di Allah". Il segreto a cui allude Ibn 'Arabī non è il contenuto del Destino, a cui si riferisce verosimilmente questo hadīt, bensì il fondamento metafisico del Destino stesso, che egli ha esposto non in modo unitario, ma disseminandone il contenuto in numerosi capitoli delle Futūhăt [quelli in cui è citato esplicitamente il segreto del Destino sono i seguenti: 2 (I 90.26), 17 (I 162.33 e 163.3), 47 (I 259.8), 69 (I 405.7), 73, questione XXXIII (II 63.35 e 64.20 ) e questione XXXV (II 65.16), 220 (II 513.7), 270 (II 573.20), 305 (III 22.5), 345 (III 162.11, 12 e 23), 447 (IV 62.10), 532 (IV 176.27), 538 (IV 182.30), 558 (IV 235.25, 237.8, 240.4, 245.25) e 559 (IV 344.12)] e nel capitolo dei Fusüs al-hikam dedicato al Verbo di 'Uzayr.

Bakri Aladdin ha pubblicato su questo argomento "The Mistery of Destiny in Ibn 'Arabi and al-Qunawī, nel N. 49, 2011, del Fournal of the Muhyiddin Ibn 'Arabi Society.

36) Ibn 'Arabī si riferisce qui ad un punto dottrinale che nessuno prima di lui aveva evidenziato, come egli stesso precisa nel Cap. 411 [IV 16.22], e cioè che la scienza segue, o dipende da, l’oggetto della scienza, al- ilm tābi li-l-ma qūm o al- $\{l m$ yattabiu l-ma qüm. Questo insegnamento è riportato nei capitoli 71 [I 643.17], 411 [IV 16.21], 413 [IV 18.26], 434 [IV 46.8], 463 [IV 84.24], 538 [IV 182.12 e 30], 558 [IV 222.34, 228.15, 242.27, 247.31, 258.26, 318.6 e 7, 326.14] e 560 [IV 475.13] delle Futūhāt, e nei capitoli VIII, XI e XIII dei Fusūss alhikam. In particolare, nel Cap. 558 [IV 318.5] precisa: "Non accade nell'esistenza una possibilità senza che la Scienza divina non lo preveda (sabaqa), e quindi il suo accadimento (wuqū) è inevitabile. Allah non ha Scienza di un oggetto della scienza se non di come esso è in se stesso: quindi la Scienza è subordinata al suo oggetto, ma non è subordinata all'esistenza contingente, cioè l'accadimento temporale (hudūt) dell'esistenza dipende dalla Scienza e la Scienza dipende dal suo oggetto. Questo oggetto della Scienza è la possibilità nel suo stato di non-esistenza e nella realtà (šay’iyya) della sua immutabilità (tubüt) secondo questa proprietà con cui si manifesta nella sua esistenza".

37) Nel Cap. 69 [I 405.4] Ibn 'Arabī precisa: "La trasposizione simbolica della fissazione (tahdìd) della qibla è l'escludere il servitore dalla sua scelta (ihtiy $\bar{a} r)$. La sua radice (asl) e la radice di tutto ciò che è altro che Allah è la necessità $(i d t i r a \bar{r}$ ) e la obbligatorietà $(i g ̌ b a \bar{r} r)$ : persino nella sua scelta il servitore è obbligato. E sebbene Allah sia Agente e scelga, per via del Suo detto: "ed Egli sceglie" (Cor. XXVIII-68) e del Suo detto: "e se avessimo voluto" (Cor. VII-176), Egli non fa se non ciò che sa, ed il cambiamento della Scienza è impossibile. Egli ha detto, sia Egli esaltato: "La Parola non cambia presso di Me ed Io non sono ingiusto con i servitori" (Cor. L-29), ed ha detto: "e ad Allah appartiene l'argomento decisivo" (Cor. VI-149). Non ho visto nessuno che abbia compreso questo detto divino: il suo significato è estremamente chiaro e tuttavia per l'intensità della sua chiarezza è nascosto. Noi ne abbiamo parlato in questo libro e lo abbiamo spiegato: esso è il segreto del Destino. Chi comprende questa questione non si oppone ad Allah in nulla di ciò che Egli decreta e fa accadere ai Suoi servitori, in essi e da essi. Per questo ha detto: "Egli non sarà interrogato riguardo a ciò che fa, ma essi saranno interrogati!" (Cor. XXI-23). Se tu fossi intelligente avresti capito da Allah: questo versetto ti sarebbe bastato per lo scopo". 
del grado di contemplazione (mašhad) che comporta una suddivisione (qisma) dell'Atto/atto ${ }^{38}$ ) tra l'effusione $(f a y d)$ [divina] e la ricettività ( $q a b \bar{u} l)$ [da parte del servitore o del possibile] $\left({ }^{39}\right)$.

Invero, in uno dei gradi della contemplazione, il comando della generazione (amr at-takwīn) $\left({ }^{40}\right)$ è tra noi e tra il Vero e la generazione non ha luogo se non per il Suo comando, sia Egli esaltato, nel Suo detto "Sii (kun)" (Cor. III-47) e per la nostra ricettività $\left({ }^{41}\right)$, e la conseguenza non si manifesta se non da due cose, che sono le premesse. Dopo questa stazione ci innalziamo verso ciò che abbiamo

38) Nel Cap. 69 [I 507.23] Ibn 'Arabī precisa: "Tutto ciò che è passivo (munfa il) ha il rango della femmina, e [nel Mondo] non c'è altro che ciò che è passivo. L'atto $(f i \mathcal{i})$ in realtà è suddiviso tra colui che fa e ciò che è fatto: da parte di Colui che fa c'è la Podestate (iqtidār) e da parte di ciò che è fatto c'è la ricettività alla Podestate", e nel Cap. 73, q. XXXIII [II 64.9] aggiunge: "Non si addice agli Atti del Vero di essere causati, poiché non c'è causa che renda necessaria la genesi (takwīn) di una cosa se non l'Esistenza stessa dell'Essenza e la ricettività dell'entità del possibile alla manifestazione dell'esistenza". La distinzione tra il Potere (qudra) e la Podestate è spiegata da Ibn 'Arabī nel Cap. 558 [IV 296.34]: "Il regime di "Colui che ha la Podestate (al-muqtadir)" è un altro regime, non è il regime del Potente (al-qādir). La Podestate è il regime del Potente nel manifestare le cose per mano delle cause seconde $(a s b \bar{a} b)$, e le cause seconde sono caratterizzate dall'acquisizione del potere. Esse sono dotate di podestate, cioè si esercitano nella podestate, ma non si tratta che del Vero, sia Egli esaltato, poiché è Lui che ha la Podestate su tutto ciò a cui dà l'esistenza [cfr. Cor. XVIII-45] in occasione di una causa seconda o per mezzo di una causa seconda, dillo come vuoi. Ciò corrisponde al Suo detto: "Non appartiene forse a Lui la creazione", e ciò a cui non dà l'esistenza per mezzo di una causa seconda corrisponde a: "e il comando?" (Cor. VII-54). Per questo la Gente di Allah, quando parla in gergo del Mondo della creazione e del comando, intende per il mondo della creazione ciò a cui Allah dà l'esistenza per mano delle cause seconde, e ciò corrisponde al Suo detto: "di ciò che hanno fatto le Mie mani" (Cor. XXXVI-71), che non sono altro che le "mani" delle cause seconde [...] e per il mondo del comando ciò che non è stato esistenziato in occasione di una causa seconda. Quindi Allah è il Potente in quanto all'ordine, ed ha la Podestate in quanto alla creazione [...] Il Potere è più nascosto della Podestate, in quanto la Podestate è uno stato del Potente, come il dare il nome è uno stato di colui che dà il nome".

39) Questa complementarietà tra effusione e ricettività è menzionata nei capitoli 73, questione CXVI [II 112.27], 349 [III 209.29], 357 [III 260.23], 369 [III 366.14] e 447 [IV 62.23] senza però essere direttamente riferita all'atto.

40) Sulla distinzione tra il comando della generazione (al-amr at-takwiñ $\overrightarrow{\text { ) }}$ e il comando della incombenza legale

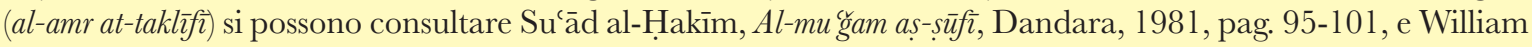
Chittick, The Sufi Path of Knowledge, SUNY Press, 1989, pag. 292-293.

41) Nel Cap. 470 [IV 101.8], Ibn 'Arabī precisa: "Non vi può essere esistenza se non da due radici: la prima radice è la Podestate ed essa è quella che è prossima al Lato del Vero, e la seconda radice è la ricettività, ed essa è quella che è prossima al lato del possibile. Nessuna delle due radici è indipendente per l'esistenza, né per l'esistenziazione. La cosa che ottiene l'esistenza non la ottiene se non da se stessa, per mezzo della sua ricettività, e da Colui che esercita in essa la Sua Podestate, cioè il Vero" e nel Cap. 476 [IV 111.9] aggiunge: "Colui che è ricettivo ha bisogno di Colui che ha la Podestate e Colui che ha la Podestate ricerca la ricettività da parte di chi riceve; è quindi corretta la suddivisione tra noi e Lui, sia Egli esaltato, poiché Egli è il Veridico ed ha detto: "Ho suddiviso la salāt tra Me ed il Mio servitore in due metà: una metà appartiene a Me ed una metà al Mio servitore". La Podestate è da parte Sua e la ricettività da parte nostra e per mezzo di esse il Mondo si manifesta nell'esistenza. La prova è che l'impossibile (muhāl) non riceve l'esistenza e la Podestate non ha influenza in esso, in quanto fa parte della realtà essenziale della Podestate il collegarsi solo con il possibile, e non c'è significato per il possibile se non la ricettività". 
menzionato, e cioè che il disporre di noi con la generazione ha luogo per mezzo di noi in noi; il Vero ci dice "sii" e per mezzo di noi siamo. Ed è così chiaro per te che la spoliazione dall'arbitrio è implicita nella generazione $\left({ }^{42}\right)$.

Quanto alla realtà essenziale, essa è immutabile (tābita) per il servitore [stesso], non per altri che lui, ed il Vero non ci vuole se non per noi $\left({ }^{43}\right)$, e noi siamo la Sua vista con cui Egli vede, il Suo udito con

42) Nel manoscritto Ḥusein Celebi al posto di takwīn si trova sulūk, il percorso della Via, ed anche questa lettura è coerente con il testo.

43) Nel Cap. 17 [I 162.22], Ibn 'Arabī precisa: "Quando Allah ha dato l'esistenza alle entità, ha dato loro l'esistenza per loro, non per Lui, ed esse sono conformemente alla loro condizione $(h \bar{a} l a)$ - per i loro luoghi ed i loro tempi - secondo le differenze dei loro luoghi e dei loro tempi. Ed Egli svela loro le loro entità ed i loro stati, cosa dopo cosa, indefinitamente, secondo il succedersi ed il susseguirsi [di esse]. In relazione ad Allah il comando $(a m r)$ è unico, come ha detto, sia Egli esaltato: "Il Nostro comando non è che uno, come un batter d'occhio" (Cor. LIV-50) e la molteplicità è nelle cose numerabili stesse . [...] Per ciò che concerne lo sguardo (nazra) del Vero non c'è tempo passato né futuro, ma tutte le cose sono note a Lui [nell'eterno presente] nei loro gradi, con la numerosità delle loro forme in essi [...] In questo modo è la percezione da parte del Vero, sia Egli esaltato, del Mondo e di tutte le possibilità, nello stato della loro non-esistenza e della loro esistenza. E gli stati si diversificano per esse nella loro immaginazione (haya $\bar{l}$ ), non nella loro scienza, ed esse apprendono dal loro svelamento di quello una scienza che non avevano, non una condizione in cui non si trovavano. Realizza ciò, poiché si tratta di una questione nascosta ed oscura, che è connessa al segreto del Destino, e tra i nostri compagni sono pochi che ci sono arrivati [...] Quanto alla scienza del Suo essere uno che sceglie (muhtār), la scelta è contraddetta dall'unità del Volere, e la sua attribuzione al Vero, quando è caratterizzato da essa, dipende dalla situazione del possibile (mumkin), non dalla situazione del Vero. Egli ha detto, sia Egli esaltato: "[Se avessimo voluto avremmo dato ad ogni anima la sua guida], ma la Mia Parola è realizzata" (Cor. XXXII-13), ed ha detto, sia Egli esaltato: "Colui contro cui è realizzata la parola del castigo" (Cor. XXXIX-19), ed ha detto: "La Parola non cambia presso di Me" - e quanto è bello il modo in cui conclude il versetto - "ed Io non sono ingiusto con i servitori" (Cor. L-29). Egli richiama qui l'attenzione sul segreto del Destino, ed è per esso che ad Allah appartiene l'argomento decisivo contro le Sue creature. Questo è ciò che si addice da parte del Vero; quanto a ciò che riguarda l'essere contingente (kawn), "Se avessimo voluto avremmo dato ad ogni anima la sua guida" (Cor. XXXII-13), e non abbiamo voluto, e "ma" [la Mia Parola è realizzata] è una restrizione per la congiunzione (tawsint) [tra la parte del versetto riguardante il Vero e quella riguardante l'essere contingente]. Invero il possibile è ricettivo alla guida ed alla deviazione, per quanto concerne la sua realtà essenziale, ed esso è la sede della divisione (inqisām) e su di esso ha luogo la ripartizione. In realtà Allah ha riguardo ad esso un solo comando, che è noto ad Allah dalla direzione dello stato del possibile". Sono le possibilità stesse, o le entità immutabili, che determinano il destino degli esseri, ma nel loro stato di non-esistenza o non-manifestazione esse non hanno scienza di loro stesse: dando loro l'esistenza Allah non determina il destino degli esseri ma fa loro conoscere le loro realtà essenziali $(h a q \bar{a}\urcorner q)$, che per definizione sono immutabili. René Guénon, ne Les états multiples de l'être [Les Éditions Véga, 1973, pag. 96], precisa: “Toute possibilité de manifestation, avons-nous dit plus haut, doit se manifester par là même qu'elle est ce qu'elle est, c'est-à-dire une possibilité de manifestation, de telle sorte que la manifestation est nécessairement impliquée en principe par la nature même de certaines possibilités. Ainsi, la manifestation, qui est purement contingente en tant que telle, n'en est pas moins nécessaire dans son principe, de même que, transitoire en elle-même, elle possède cependant une racine absolument permanente dans la Possibilité universelle; et c'est là, d'ailleurs, ce qui fait toute sa réalité", e poco oltre [pag. 100] aggiunge: "Une conséquence fort importante de ceci, c'est qu'on peut dire que tout être porte en lui-même sa destinée, soit d'une façon relative (destinée individuelle), s'il s'agit seulement de l'être envisagé à l'intérieur d'un certain état conditionné, soit d'une façon absolue, s'il s'agit 
cui Egli sente, e la Sua volontà con cui Egli vuole, e la faccenda si rovescia, se hai capito $\left.{ }^{44}\right)$.

Questo è il segreto del Destino, la cui scienza è stata nascosta alle creature, non a chi Allah ha tolto il velo alla sua visione interiore e gli fa vedere il vero come vero e gli concede di seguirlo, e gli fa vedere il falso come falso e lo aiuta ad evitarlo, e qui viene tolto lo sconcerto dal servitore e la realtà si risolve infine in ciò che è in se stessa.

Questa è la sede del Suo detto, sia Egli esaltato: "ad Allah appartiene l'argomento decisivo" (Cor. VI149) e se la realtà non fosse così non sarebbe mai valido il Suo detto: "ad Allah appartiene l'argomento decisivo", e per questo, sia Egli esaltato, ha detto: "se volesse vi guiderebbe tutti" (Cor. ibidem), [9] ed ha introdotto "se (law)" che è una particella che indica l'impossibilità della cosa per l'impossibilità di ciò che è altro che essa $\left.{ }^{45}\right)$, e non ha reso impossibile la cosa se non per l'impossibilità di ciò che è altro che essa, il che è identico a quanto abbiamo detto.

Egli non vuole se non ciò che sa e non sa se non ciò che l'oggetto della scienza è in se stesso, e quindi il regime appartiene all'oggetto della scienza, non alla scienza, ed è soltanto l'occhio della comprensione (fahm) ad essere coperto.

de l'être dans sa totalité, car «le mot «destinée» désigne la véritable raison d'être des choses»". Infine, in una recensione pubblicata in Études sur l'Hindouisme [Éditions traditionnelles, 1966, pag. 209], precisa: "L'éternité se reflète ou s'exprime dans le «maintenant» qui, en tout temps, sépare et unit à la fois le passé et le futur; et même ce «maintenant», en tant qu'il est réellement sans durée, et par conséquent invariable et immuable en dépit de l'illusion de «mouvement» due à une conscience soumise aux conditions de temps et d'espace, ne se distingue pas véritablement de l'éternité elle-même, à laquelle l'ensemble du temps est toujours présent dans la totalité de son extension. L'indépendance essentielle et absolue de l'éternité à l'égard du temps et de toute durée, que la plupart des modernes semblent avoir tant de difficulté à concevoir, résout immédiatement toutes les difficultés soulevées au sujet de la Providence et de l'omniscience divine: celles-ci ne se réfèrent pas au passé et au futur comme tels, ce qui n'est que le point de vue contingent et relatif de l'être conditionné par le temps, mais bien à une simultanéité totale, sans division ni succession d'aucune sorte. On peut, à cet égard, comparer le rapport de l'éternité au temps à celui du centre à la circonférence: tous les points de la circonférence et tous les rayons sont toujours visibles simultanément du centre, sans que cette vue interfère en rien avec les mouvements qui se produisent sur la circonférence ou suivant les rayons, et qui ici représenteront respectivement la détermination (enchaīnement des événements dans le parcours ordonné de la circonférence) et la libre volonté (mouvement centripète ou centrifuge) avec lesquelles il ne saurait par conséquent y avoir aucun conflit”.

44) Nel grado di realizzazione precedente è Allah ad essere l'udito con cui il servitore sente e la vista con cui egli vede, mentre in questo è il servitore ad essere l'udito con cui Allah sente e la vista con cui Egli vede. Nelle Futūhāt [Cap. 73, questione XXXV (II 65.21), ove ricorda che gli atti supererogatori implicano una libera scelta, mentre gli atti obbligatori la escludono; Cap. 90 (II 168.20 e 173.8); e Cap. 178 (II 354.19)], Ibn 'Arabī correla il primo di questi gradi di realizzazione con gli atti supererogatori (nawāfil), conformemente allo hadīt riportato nel testo [pag. 5 del manoscritto], e il secondo con gli atti obbligatori (farā’id).

45) Cioè Egli non vuole perché sa che essi non si faranno guidare. 
Quanto al suo detto, Allah sia soddisfatto di lui: "di essere di fronte al Maestro come il morto di fronte al lavatore" $\left({ }^{46}\right)$ egli intende dire che [il Maestro] dispone di lui in base a ciò che conferisce lo stato del morto, ed in realtà è il morto che con il suo stato conferisce al lavatore questo comportamento (tașriff) nei suoi confronti. Invero il giudice è tale in base allo stato di coloro che disputano (husūm) e quindi non giudicano su di essi se non loro stessi, e colui che apparentemente funge da giudice è un loro strumento, e questo è identico a ciò che abbiamo detto. Questo è uno dei cinque gradi in cui la via impone al servitore di porsi con il Vero nella condotta (tasarruf), ed analogamente l'aspirante con il Maestro.

Il primo grado è che il servitore sia con Allah, sia Egli esaltato, e l'aspirante con il Maestro, come lo schiavo ('abd) con il suo signore (sayyid), e la situazione è ben nota e il comportamento in quello è noto, poiché lo schiavo è identico al suo valore (qīma) e quindi a ciò che rappresenta il suo prezzo (taman) nei riguardi del proprietario (mālik): è opportuno che quello sia lo stato dello schiavo, e quindi la sua costante vigilanza (murāqaba) del suo prezzo nel disporre di lui da parte del signore $\left({ }^{47}\right)$.

Il secondo [grado] è che egli sia con lui come il bambino (tifl) con i suoi genitori, poiché egli [il Maestro] lo alleva. Uno dei conoscitori mi chiese riguardo all'aspirante che, preso dal momento, ha una polluzione. Noi gli rispondemmo: "Tu non biasimi il lattante che urina nei suoi abiti, e questo è un aspirante, e questo non è che un aspirante in crescita”, ed egli si rallegrò (surra) della risposta, poiché mi aveva menzionato ciò nel momento di criticare (intiqa $\bar{d}$ ) quell'aspirante, ed è indispensabile che il sapiente per Allah non critichi nessuno che veda fare ciò che comporta il suo stato ed il suo rango, in quanto [10] la critica riguarda colui in cui si manifesta ciò che non comporta la sua stazione, o per una caduta da essa o per una pretesa salita, che è la situazione di colui che è portato gradualmente alla perdizione (mustadrağ).

Per il conoscitore non viene mai meno la bilancia $(m \bar{\imath} z \bar{a} n)$ del suo stato con le cose che gli arrivano (wāridāt [da Allah]; con essa egli pesa lo stato in cui si trova e ciò che arriva su di lui dal Vero, e se questo corrisponde al suo stato, allora è riconoscente ad Allah, quanto è Potente e Magnificente, e

46) Riferimento ad un detto di Sahl ibn 'Abd Allāh at-Tustarī, secondo cui "la prima stazione nell'abbandono fiducioso [ad Allah] (tawakkul) è che il servitore stia di fronte ad Allah, quanto è Potente e Magnificente, come il morto di fronte al lavatore (gāsil), che lo rivolta come vuole, mentre [il morto] non ha movimento né governo (tadbīr)" [al-Qušayrī, ar-Risāla, Il Cairo, 1959, pag. 83]. Ibn 'Arabī cita l'esempio del morto nelle mani del lavatore, senza mai citare Sahl, nei seguenti capitoli: 69 [I 408.18], 118 [II 200.26], 146 [II 233.22] e 559 [IV 368.14]; inoltre esso è riportato anche nel capitolo finale del Kitāb at-tadbīrāt al-ilāhiyya fì ișlāh al-mamlaka alinsāniyya, a pag 226 dell'edizione di Nyberg.

47) Nel Cap. 70 [I 570.10], Ibn 'Arabī precisa: "La ragione della zakāt per l'uomo libero è la sua pretesa al possesso, e lo schiavo non ha pretesa su nulla. Lo schiavo è identico al suo valore (qīma), cioè al prezzo (taman) per cui è stato comprato, e come non è concepibile nel suo prezzo una pretesa né un rifiuto di come il padrone vuole disporre di esso, così è anche per lo schiavo. Un servitore che non consideri che il suo prezzo implica la possibilità di commercio da parte del suo padrone, non ha alcuna realizzazione della servitù, né conoscenza della sua anima [o di se stesso]. Questa è la dottrina unanime del gruppo degli iniziati” 
Gli chiede di non limitare a quello la quota (hazz) del suo stato qui. Se invece [ciò che arriva] non corrisponde [al suo stato] allora si guarda dall'astuzia ( $m a k r$ ) di Allah in quello e non crede di essere al sicuro dall'astuzia di Allah, poiché solo un ignorante stupido $(g a b \vec{\imath})$ crede di essere al sicuro dall'astuzia di Allah, ed Allah non prende come amico (walt) un ignorante.

Il terzo grado è che egli sia con lui come il procuratore (wakīl) con colui che gli ha dato la procura (muwakkil) e che lo ha assunto, ed egli è quindi consigliato nella sua opera e nella sua condotta, e prende in quello il posto di colui che gli ha dato la procura, tanto da essere come lui, ed in ciò ha bisogno di molta scienza e di intelligenza ('aql).

Il quarto grado è che sia con lui come il morto nelle mani del lavatore, che lo rigira come vuole. Uno di loro ha detto riguardo a questa stazione che egli sia con lui come l'ombra con la persona, e questa è la dottrina del nostro Maestro Abū al-'Abbās al-'Uryanī $\left({ }^{48}\right)$, Allah abbia Misericordia di lui. Ho sentito dire quello da lui, e tra i due esempi vi è una grande differenza (furqān), di cui abbiamo già parlato nelle nostre opere $\left({ }^{49}\right)$ ed è una differenza che non è nascosta a nessuno, ed il suo versetto è: "Non vedi come il tuo Signore estende l'ombra?" (Cor. XXV-45).

Il gusto spirituale $(\underline{d} a w q)$ della gente di Allah arriva solo fino al quarto grado, per la loro disattenzione (gafla), mentre coloro che hanno la scienza di Lui e che sono saldi nella loro scienza aggiungono, rispetto alla gente di Allah - coloro cha hanno la scienza della presenza (hudūr) con Lui - quello che è

48) Si tratta del primo Maestro che Ibn 'Arabī cita nella Epistola dello Spirito della Santità (risāla rūh al-quds), attribuendogli la kunya Abū Ğáfar, e di uno dei più citati, tra quelli della sua epoca, nelle stesse Futūhāt: Cap. 25 [I 186.2], Cap. 36 [I 223.19], Cap. 42 [I 244.16], Cap. 67 [I 329.2], Cap. 70 [I 574.26], Cap. 92 [II 177.14], Cap. 178 [II 325.9], Cap. 298 [II 687.3], Cap. 349 [III 208.27], Cap. 386 [III 532.25], Cap. 388 [III 539.26], Cap. 464 [IV 89.13], Cap. 487 [IV 123.22], Cap. 558 [IV 241.13 e 243.29], Cap. 560 [IV 482.21 e 529.26]. Nel manoscritto autografo delle Futūhāt come pure nel più antico manoscritto della Risāla rūh al-quds il suo nome di origine (nisba) è al-'Uraybī, ma in testi posteriori si trova al-'Uryan̄i, forse per una confusione con l'appellativo al-'Ulyānī, in quanto era originario di al-'Ulyā, Loulé, nell'attuale Portogallo. Secondo José Garcia Domingues, che ha dedicato uno studio a al-'Uraybī [Portugal e o al-Andalus, Hugin Editores, Lisboa, 1997, pagg. 213-236] egli fu discepolo di Ibn Qasī. Secondo quanto riferisce Ibn 'Arabī stesso nel Cap. 388, al-'Uraybī fu il suo primo Maestro "terreno".

49) Ancorché nelle Futūhāt Ibn 'Arabī ricorra più volte al simbolo dell'ombra di una persona [Cap. 69 (I 397.26, 459.2 e 15), Cap. 130 (II 214.23), Cap. 136 (II 223.8), Cap. 177 (II 304.1), Cap. 279 (II 607.14), Cap. 331 (III 116.32), Cap. 346 (III 187.16), Cap. 347 (III 196.33), Cap. 360 (III 276.9) e Cap. 559 (IV 435.5), ove afferma: "Il Vero ha voluto che tu fossi con Lui come la tua ombra con te, privo di resistenza con Lui in ciò che Egli ti fa fare $[. .$.$] ed in quello ti fa anche notare che il tuo movimento è identico al Suo far muovere, e così pure la tua$ quiescenza. Non è l'ombra che fa muovere la persona: è così che devi essere con Allah!'], non stabilisce mai un confronto con il cadavere nelle mani del lavatore. Neppure nelle opere dedicate al rapporto discepolo-Maestro, citate nella parte introduttiva, ho trovato questo confronto, per cui non sono riuscito a stabilire a quali opere si riferisca. In entrambi casi, l'ombra ed il cadavere vengono mossi da altri e non sono dotati di moto proprio, ma nell'esempio dell'ombra il discepolo fa ciò che fa il Maestro, mentre in quello del cadavere il lavatore fa compiere al cadavere i movimenti che sono necessari per soddisfare le prescrizioni rituali previste per il lavaggio del morto. 
il nostro punto di vista, e cioè che egli sia con Lui come colui che dà la procura con il suo procuratore $\left.{ }^{50}\right)$, conformemente all'ordine di Allah, sia Egli esaltato, e si affidi al suo Signore per tutto ciò di cui ha bisogno la sua costituzione (naša) naturale e spirituale, e ciò corrisponde al Suo detto: "Non c'è Dio se non Lui, prendeteLo quindi come Procuratore" (Cor. LXXIII-9).

Egli ci ha infatti ordinato di prenderLo come procuratore, per la nostra scienza della Sua Scienza [11] delle cose profittevoli (masāilih) [cioè delle cose che conducono al bene] e per la nostra ignoranza di esse $\left(^{51}\right)$, ed il Procuratore ha determinato per noi il modo in cui è necessario che noi ci comportiamo, e lo ha definito per noi affinché lo conoscessimo, e ci ha fatto prendere il Suo posto, e quindi noi siamo i procuratori del Procuratore. Ciò corrisponde al Suo detto: "e spendete di ciò di cui Egli vi ha reso depositari" (Cor. LVII-7) per ciò di cui voi Mi avete nominato Procuratore, e noi Lo abbiamo nominato Procuratore per il Suo detto: "le vostre ricchezze non vi distraggano" (Cor. LXIII-9), e: "invero le vostre ricchezze ed i vostri figli sono una prova (fina)" (Cor. LXIV-15). Ed Egli ha attribuito a noi le ricchezze e le ha fatte essere nostra proprietà (milk), e noi, per ordine Suo, Lo abbiamo nominato Procuratore nella loro gestione, e Lo abbiamo preso come Procuratore per Suo ordine ${ }^{(52}$ ).

Questo per un principio (aṣl) permanente che non viene meno, poiché Egli ha detto a Mosè: "Ho creato le cose per te" $\left({ }^{53}\right)$, ed è affermato che le ricchezze appartengono a noi e siamo noi a fruire di esse, non Lui, e ciò che fornisce lo svelamento vero è che Egli ha creato le cose affinché esse glorificassero con la Sua lode $\left({ }^{54}\right)$, e noi traiamo profitto [di esse] in modo subordinato, non per lo scopo primario [per cui sono state create] ${ }^{(55}$ ), ed è questo ciò che veramente ritorna a Lui (huwa as ${ }^{-}$ sahīh al-marğū'ilay-hi).

Poiché è fermamente stabilito che Egli ha creato le cose per noi e noi Lo abbiamo preso come Procuratore nella gestione di esse, è per la Sua Scienza delle cose profittevoli che Egli ha determinato

50) Si tratta quindi di un "rovesciamento" del terzo grado, in cui il servitore si comporta come il procuratore.

51) Nel Cap. 558 [IV 280.28], Ibn 'Arabī precisa: "Il possessore di questa Presenza si chiama il servitore del Procuratore (al-wakīl). Per mezzo di questo Nome è dimostrata la proprietà (milk) ed il regno (mulk) da parte delle creature, poiché noi non Lo nominiamo procuratore se non nella gestione delle nostre faccende riguardo a ciò che ci appartiene, per la nostra scienza della perfezione della Sua Scienza di noi. Egli infatti sa di noi ciò che noi non sappiamo di noi stessi, e non Gli ha conferito la Scienza se non noi stessi, nello stato della nostra immutabilità [principiale]. Noi dunque siamo i sapienti ignoranti, ed Egli è il Sapiente che non ignora".

52) Queste considerazioni sono più ampiamente sviluppate nel Cap. 118, dedicato alla conoscenza della stazione del tawakkul, che è stato tradotto da Eric Winkel in The Inter-actions fourneys 13-14, 2016, pag. 317-322.

53) "O figlio di Adamo, ho creato le cose per te ed ho creato te per Me: non intaccare dunque ciò che ho creatoper Me con ciò che ho creato per te". Questa frase, che Ibn 'Arabī afferma essere tratta dalla Torāh, è citata nei capitoli 60 [I 295.32], 72 [I 685.26], 73, questione L [II 74.11], 118 [II 200.7], 178 [II 354.11], 333 [123.14] di cui costituisce il titolo, 412 [IV 16.33] e 560 [IV 527.29].

54) Cfr. Cor. XVII-44.

55) Una analoga frase si trova nel Cap. 134 [II 221.30]. 
per noi ciò che dobbiamo fare di quello, ed ha detto: "e spendete di ciò di cui Egli vi ha reso depositari" (Cor. LVII-7), e secondo ciò che siamo inclini a credere siamo noi i depositari di ciò che possediamo, per ciò che ci siamo immaginati a causa dell'attribuire a noi il loro possesso. Egli però ci ha spiegato che quello appartiene a Lui non a noi, ed abbiamo realizzato che Egli non ha creato le cose se non perché glorificassero con la Sua lode, non per noi, ed ha quindi dato loro l'esistenza per le loro [stesse] entità. E Colui che ha dato in deposito la gestione di ciò che Egli possiede, ci ha posti come procuratori di Colui a cui abbiamo affidato la procura per la Sua Scienza delle cose profittevoli, che noi non abbiamo, ed Egli vede come profittevole che noi gestiamo ciò che di cui ci ha assegnato la gestione, ed Egli gestisce ciò che Egli ritiene profittevole nei nostri riguardi che sia Lui a gestire. $\left({ }^{56}\right)$

56) Nel Cap. 72 [I 671.23], Ibn 'Arabī precisa: "ed ha detto riguardo alla maggioranza [degli uomini]: "e spendete di ciò di cui Egli vi ha nominato depositari" (Cor. LVII-7), e l'essere nominato depositario (istihläf) equivale alla luogotenenza (niyāba), poiché la ricchezza appartiene ad Allah ed il tuo disporre di essa dipende dal fatto che Egli ti ha nominato Suo rappresentante riguardo ad essa. Tutto questo riguarda la luogotenenza del servitore nei confronti di Allah nelle faccende. Quanto alla luogotenenza del Vero nei confronti del servitore, ad essa si riferisce il suo detto, sia Egli esaltato, ai figli di Israele: “... che non prendiate Procuratore (wakīl) al di fuori di Me!" (Cor. XVII-2), ed ha anche detto, in modo imperativo: "Non c'è Dio se non Lui, prendeteLo dunque come Procuratore!" (Cor. LXXVIII-9), ed egli, che Allah faccia scendere su di lui la Sua salät e la Pace, rivolgendosi al suo Signore ha detto: "Allāhumma, Tu sei il Compagno nel viaggio ed il Califfo nella famiglia!", e la procura (wakāla) è una luogotenenza a favore di colui che delega (muwakkil) in ciò in cui lo ha delegato a prendere il suo posto. Quindi Egli, sia Egli esaltato, ha affermato per te la cosa e ti ha chiesto di chiederGli la luogotenenza in quello per mezzo del regime della procura. È valida la luogotenenza dal punto di vista della realtà essenziale o no? Tra di noi c'è chi sostiene che essa è valida dal punto di vista della realtà essenziale, poiché le ricchezze non sono state create che per noi, in quanto Allah non ha bisogno di esse, e quindi esse ci appartengono realmente. Poi noi abbiamo dato al Vero, sia Egli esaltato, la procura di disporre per noi di esse, poiché sappiamo che Egli è più sapiente riguardo a ciò che è profittevole (masālih); ed il Vero [ne] dispone sotto il profilo della Saggezza, che esige che a colui che delega torni un beneficio da esse. Quindi, questo Procuratore, cioè il Vero, sia Egli esaltato, dilapida la sua ricchezza con un naufragio, un incendio, uno sprofondamento, o ciò che vuole, realizzando un commercio (tiǧăra) a suo favore poiché per quello gli farà acquisire nella dimora dell'aldilà più di quanto è detto. Secondo le apparenze si tratta di una rovina, ma non lo è, anzi è un commercio di vendita a credito: una cosa simile si chiama commercio in perdita (ruz') ma il suo guadagno è immenso. Questa è una scienza che conosce il Procuratore, non colui che delega, ed Egli preserva per lui la sua ricchezza per un interesse che la Sua scienza riguardo ad esso comporta. Tra di noi c’è chi si affida (wakkala) ad Allah [cioè Lo delega come Procuratore] ed il Procuratore lo nomina depositario nel disporre [delle ricchezze o delle cose] nel limite tracciato dal Procuratore, per la scienza che ha il Procuratore di ciò che è profittevole per lui. Quindi colui che delega diventa il procuratore al posto del suo Procuratore, ed egli è colui che nel suo disporre non trasgredisce l'ordine prescritto dalla Legge. Quindi, anche se la ricchezza appartiene a Lui, il disporre di essa è a giudizio del Suo procuratore, e questa è una prospettiva insolita! Tra di noi c'è chi sostiene che la luogotenenza non è valida dal punto di vista della realtà essenziale, poiché Allah non ha creato le cose - e le ricchezze fanno parte delle cose - se non per Sé, sia Egli esaltato, affinché esse Lo glorifichino. Il beneficio per noi ha luogo per il regime della subordinazione. Per questo ha detto: "Non c'è cosa che non Lo glorifichi con la Sua lode" (Cor. XVII-44). Poiché Allah ha creato le cose a causa Sua e non a causa nostra, non c'è cosa che possiamo delegare a Lui, bensì siamo noi i Suoi procuratori nelle cose, ed Egli ha stabilito per noi dei limiti e noi disponiamo di esse conformemente a ciò che ha stabilito per noi. Se noi aggiungiamo a ciò che ha tracciato per noi o diminuiamo, ci punisce. Se le ricchezze appartenessero a noi, il nostro disporre di esse sarebbe incondizionato, ma la realtà non è così, anzi Egli ci ha posto restrizioni nel disporre di esse, e quindi non si tratta di una procura 
Questo è il quinto grado in questo capitolo, [12] il più grande dei gradi nel deferimento (tafwīe), nella sottomissione (tastīm), nell'abbandono fiducioso (tawakkul) $\left(^{57}\right.$ ) e nell'ubbidienza (inqiyād). Ciò corrisponde al Suo detto, sia Egli esaltato: "Non prendete Procuratore al di fuori di Me" (Cor. XVII2), proibendolo, ed ha detto: "PrendeteLo come procuratore" (Cor. LXXIII-9) (58), ordinando, e questo è il massimo della conferma $(t a k \bar{\imath} d)$ : al di là di questo grado non c'è grado intelligibile nella Via di Allah, ma in esso vi è distinzione, oscurità (gumüd) e compenetrazione (tadăhul), poiché i rami di questo grado si intrecciano tra di loro, ed essi cambiano velocemente in ciò che si presenta alla coscienza, e quindi esigono una immensa concentrazione (hudūr) ed una vigilanza costante, poiché Egli, sia Egli esaltato, vigila su ogni cosa $\left({ }^{59}\right)$.

È indispensabile che il servitore sia attento al suo Signore nel Suo disporre di lui, e non è capace di quello se non per l'Assistenza (tawfìq) di Allah, sia Egli esaltato, per mezzo della sua scienza della bilancia di ciò che è stato legiferato per lui, poiché Egli ha posto la bilancia sulla Terra ed essa è ciò che Egli ha stabilito come Legge, non altro, e non c’è sconto né riduzione.

Ed a quest'uomo [cioè 'Alī al-Kurdī] il suo stato non ha concesso se non di dire: "di essere di fronte al Maestro come il morto di fronte al lavatore", ed a ciò si arresta la maggioranza della gente di Allah, ed essi non gustano spiritualmente questo quinto grado in questo campo, tranne pochi della gente di Allah.

Tra le cose più stupefacenti è che tutte le creature sono in questo quinto grado, che si tratti di massa o di élite, e non se ne accorgono, e la gente (ahl) di Allah, saldamente ancorata nella dignità (ahliyya) ${ }^{(60)}$ specifica, non ha successo se non per mezzo della conoscenza di quello.

plenipotenziaria, bensì di una procura condizionata per aspetti specifici dal Signore della ricchezza, che è il Vero, Colui che delega. Da ogni punto di vista dunque risulta la luogotenenza, o da parte Sua, sia Egli esaltato, o da parte nostra, ed è saldamente stabilita da qualsiasi lato [la si consideri]".

57) Nel Kitāb al inbāh 'alā tarn̄q Allah di 'Abd Allāh Badr al-Habašī, edito e tradotto da Denis Gril negli Annales Islamologiques N. 15, 1979, è riportato a pag. 129-130 un paragrafo (27) in cui sono riassunti questi cinque gradi.

58) Il titolo del Cap. 367, dedicato alla descrizione del viaggio notturno (isrā') di Ibn 'Arabī, è [III 340.13]: "la conoscenza della dimora iniziatica del quinto abbandono fiducioso (at-tawakkul al-hămis), che nessuno dei realizzati ha svelato, per la rarità di coloro che sono atti a riceverla e per l'inadeguatezza delle comprensioni a coglierla"; verso la fine del capitolo [III 351.22] Ibn 'Arabī precisa: "Ho visto in essi [i forzieri di questa dimora] la scienza di colui che agisce con moderazione (itta'ada), facendo affidamento su Allah, e questo è il quinto abbandono fiducioso, che corrisponde al Suo detto, sia Egli esaltato, nella Sûra di colui che è avvolto [in un mantello] (al-muzzammil): "PrendeteLo come procuratore" (Cor. LXXIII-9)".

59) Cfr. Cor. XXXIII-52.

60) Il termine ahliyya è un aggettivo sostantivato di ahl, che in quanto sostantivo significa "gente", mentre come aggettivo ha il significato di "degno di, meritevole, adatto". Per un lettore arabo il termine ahliyya è in questo caso strettamente connesso con la caratteristica di far parte della "gente di Allah", ma non essendovi in italiano un termine che esprima questa connessione ho adottato la traduzione "dignità". Ibn 'Arabī distingue una "dignità" generale, che è comune a tutti gli esseri, ed una "dignità" specifica, che è propria dei realizzati; nel 
Quando l'aspirante è come il morto nelle mani del lavatore, questi lo rivolta nel momento del suo lavaggio come gli è stato prescritto dalla Legge di lavarlo, e la maggior parte di questa raccomandazione riguarda il lavatore, non il morto, poiché colui che gestisce è il lavatore. È come se egli dicesse che l'aspirante deve stare fermo sotto le occorrenze (mağār $\grave{\imath}$ ) della gestione del Maestro riguardo a lui, ed egli impara da quello star fermo sotto le occorrenze dei decreti (aqdār) divini $\left({ }^{61}\right)$. [13]

Sennonché in questa questione vi è una cosa importante (hatir) e cioè che l'aspirante sappia che questo Maestro è nel grado della Maestria, che Allah gli ha assegnato riguardo alle creature, e non è un falso Maestro (mutašayyih ), poiché il falso Maestro si manifesta nella forma [del Maestro] senza averne la scienza né la realizzazione, e nel nostro tempo sono tanti.

È raro nel nostro tempo vedere un Maestro che conosca la Legge ed i suoi segreti ( ${ }^{62}$ ). Essi stanno al Maestro come il falso Profeta al Profeta e come il falso medico al medico, e la rovina nel seguire [loro] è la cosa più rapida; ma l'aspirante non ha scienza di quello, come può quindi sfuggirvi? Questo aspirante, quando considera ciò che gli abbiamo detto, cade dunque in uno sconcerto immenso per la sua ignoranza della scienza che conduce ad Allah, sia Egli esaltato, che non è altro che la Legge che è stata rivelata, ma noi speriamo, se Allah vuole, anzi lo affermo in modo perentorio, che se l'aspirante

Cap. 70 [I 574.31] precisa: "Non si addice che si nutra dei benefici di Allah se non la gente di Allah e per questa essi sono stati creati. Gli altri si nutrono di essi in modo subordinato. Essi [la gente di Allah] sono i destinatari dei benefici e gli altri, come abbiamo detto, invero si nutrono di essi di conseguenza, [questo] nell'insieme. Quanto al dettaglio non c'è nella persona una singola sostanza né un suo accidente che non glorifichi Allah: quindi ogni persona fa parte della gente di Allah. Non c'è nel Mondo nessuno che sfugga a questa dignità (ahliyya) generale, e l'élite non si distingue se non perché ha conoscenza di questo tramite svelamento".

61) Questa espressione ricorre anche nel Cap. 73 [II 36.29], nel Cap. 84 [II 158.33], nel Cap. 175 [II 294.29], ove afferma: "Lo star fermi (sukūn) è preferibile al movimento, poiché al servitore è stato ordinato di star fermo sotto le occorrenze dei decreti divini ed a ciò che Allah gli fa arrivare di notte e di giorno. Ed ha detto, biasimando chi anticipa i decreti [suicidandosi]: "Il Mio servitore ha anticipato [il Mio Decreto] riguardo alla sua anima ed Io gli ho proibito il Paradiso" e l'anticipare è un movimento. Allah non ci ha ordinato: "PrendeteLo come Procuratore" (Cor. LXXIII-9) se non perché noi stessimo fermi e fosse Lui, Gloria a Lui, a gestire la faccenda del Suo servitore"; e nel Cap. 376 [III 481.4], ove precisa: "Il meschino [(miskin), participio attivo di sakana, stare fermi] è colui che sta fermo sotto le occorrenze dei decreti".

62) René Guénon, in Initiation et réalisation spirituelle [pagg. 167-170] afferma: "Ce qui est le plus difficile, et surtout à notre époque, ce n'est certes pas d'obtenir un rattachement initiatique, ce qui peut-être n'est même parfois que trop aisé; mais c'est de trouver un instructeur vraiment qualifié, c'est-à-dire capable de remplir réellement la fonction de guide spirituel, ainsi que nous venons de le dire, en appliquant tous les moyens convenables à ses propres possibilités particulières, en dehors desquelles il est évidemment impossible, même au Maître le plus parfait, d'obtenir aucun résultat effectif. [...] Il est cependant un caractère auquel beaucoup de ceux-ci, sinon tous, peuvent être reconnus assez facilement, et, bien que ce ne soit là en somme qu'une conséquence directe et nécessaire de tout ce que nous avons constamment exposé au sujet de l'initiation, nous ne croyons pas inutile, en présence des questions qui nous ont été posées en ces derniers temps à propos de divers personnages plus ou moins suspects, de le préciser encore d'une façon plus explicite. Quiconque se présente comme un instructeur spirituel sans se rattacher à une forme traditionnelle déterminée ou sans se conformer aux règles établies par celles-ci ne peut pas avoir véritablement la qualité qu'il s'attribue". 
è veridico nella sua ricerca del suo Signore, Allah, quanto è Potente e Magnificente, gli fa trovare un Maestro, un Maestro vero, dotato di visione interiore (bașīra) da parte di Allah. E se non esiste [un Maestro vero] nel posto in cui si trova questo aspirante ed egli si imbatte in un falso Maestro, Allah, sia Egli esaltato, per la veridicità di questo aspirante, conferisce a questo falso Maestro l'apertura (fath) voluta nei riguardi di questo aspirante e della sua purificazione (tahlīss), ed il Maestro viene costretto (mağbūr) alla verità ed ottiene per causa di questo aspirante delle scienze che non conosceva, e talvolta diventa per lui il ben guidato in esse ed il [falso] Maestro ne trae profitto: questo è ciò su cui concorda la gente di Allah, Gloria a Lui.

Sappi che il nostro commento (šarh) al discorso di questa persona [cioè 'Alī al-Kurdī], come di altri appartenenti alla gente della Via, non corrisponde a come le cose stanno in realtà, ma è conforme a ciò a cui arriva il loro svelamento e quello dei loro simili, e quello è il punto di arrivo della loro scienza. Se dovessimo parlare di come le cose stanno realmente, le facoltà di comprensione (afhām) della gente della Via non vi arriverebbero [14], ed a maggior ragione quelle di coloro che sono più in basso di loro.

Allah ha [diverse] lingue riguardo ai suoi servitori: "E non abbiamo inviato un Messaggero se non con la lingua della sua gente" (Cor. XIV-4) e quindi l'Inviato nel suo discorso non esorbita da ciò su cui si intende la gente della sua lingua. La stessa cosa si applica ai più grandi della gente di Allah: nel loro discorso essi seguono solo questo metodo ed [il loro linguaggio] è quello su cui si intende la gente di questa Via. Quanto alla loro élite (hawāss ), essa ha un linguaggio che la caratterizza e che non comprendono gli altri.

Quindi, chi ha compreso ciò che abbiamo detto sa che non abbiamo commentato questo ed altri discorsi se non con ciò che concorda con esso, e mi giustifica e non mi critica (y a qaridu). Noi abbiamo già parlato con la lingua di come stanno realmente le cose nel libro "al-Futūhāt al-makkiyya", disseminando [il nostro discorso] in capitoli diversi, affinché non abbia luogo una chiara esposizione di quello, e non si acceleri verso di esso la negazione di coloro che negano ciò che ignorano, "che conoscono il lato esteriore della vita di quaggiù ma che sono noncuranti dell'aldilà" (Cor. XXX-7) (63). Vi sono tra

63) Nella Introduzione alle Futūhāt Ibn 'Arabī precisa [I 33.2]: "Ogni scienza il cui significato sia facilmente comprensibile, una volta inteso il modo di esprimersi, o che sia facilmente accessibile all'ascoltatore sagace, fa parte della ragione speculativa, in quanto appartiene alle sue capacità di comprensione ed è tra le cose che essa riesce a fare da sola riflettendovi. Ciò non è il caso della "scienza dei segreti", poiché quando la [facoltà] interpretativa si trova ad affrontarla, tale scienza diventa ributtante, irta e difficile da capire, e talvolta gli intelletti deboli e fanatici, che non sono riusciti ad usare bene la verità che Allah ha posto in loro [affinché la usassero] per la speculazione e la ricerca, la rigettano. Per questo motivo, il possessore di questa scienza [dei segreti] il più delle volte la rende più adatta alle capacità di comprensione usando espressioni simboliche e discorsi di tipo poetico" e conclude [I 47.7]: "Questo è il Credo dell'élite tra la Gente di Allah. Quanto al Credo della quintessenza dell'élite al riguardo di Allah, si tratta di un argomento che va al di là di questo, e che abbiamo sparso lungo questo Libro, perché la maggior parte degli intelletti, essendo velati dai loro pensieri, non riesce a percepirlo a causa della sua mancanza di spogliazione (tağrìd $)^{\prime \prime}$ 
gli uomini coloro a cui viene tolto il velo nell'aldilà e comprendono le cose come realmente sono, e coloro a cui non viene tolto né in questo mondo né nell'altro, anche se sono tra i beati.

Quanto al suo detto: "di fare una sadaqa quando si reca dal suo Maestro" Commento: ciò affinché compia un dovere che gli è stato assegnato, in quanto l'erede (wārit $\underline{\text { t }}$ dell'Inviato [cioè il Maestro], su di lui la Pace, svolge la mansione dell'Inviato, su di lui la Pace, poiché l'erede nei confronti di questa persona è l'inviato a lui da parte del Vero. Essi [i Maestri] sono informati dal Vero, come ha detto Abù Yazīd: "Voi prendete la vostra scienza morto da morto, e noi prendiamo la nostra scienza dal Vivente che non muore" (64); noi sappiamo invero che l'Inviato di Allah, che Allah faccia scendere su di lui la Sua șalāt e la Pace, ha appreso da Gabriele [15], su di lui la Pace, ma non diciamo per questo che egli è l'Inviato di Gabriele, su di lui la Pace, ma diciamo ciò che ha detto di lui Allah, sia Egli esaltato, e cioè che egli è l'Inviato di Allah [cfr. Cor. VII-158]. Allo stesso modo dico di colui che trasmette (mublig) da parte del Vero, quale che sia la modalità di rivelazione (wahy), che egli è l'inviato del Vero verso di noi. Ed Allah, quanto è Potente e Magnificente, ha detto: "O voi che credete, quando avete un colloquio con l'Inviato, fate precedere il vostro colloquio da una sadaqa" (Cor. LVIII-12) ed ha usato l'espressione "I'Inviato" e non ha detto "I'Inviato di Allah", poiché talora veniva informato da Allah per mezzo di ciò che Allah gli rivelava nel suo intimo senza intermediario, e talora veniva informato da Allah per mezzo di ciò che lo Spirito fedele faceva discendere sul suo cuore, e quindi veniva informato dall'interprete (tarğumān) che gli ordinava di trasmettere da parte di Allah, e per questo ha usato l'espressione "l'Inviato" con l'articolo determinativo senza riferirlo ad alcuno, ed egli in entrambi i casi è senza dubbio l'Inviato di Allah a noi.

Il Maestro è l’inviato di Allah verso di noi, poiché egli è la guida (muršid) ed il trasmettitore per noi, ed è proibito criticarlo. Come non si addice a noi di pesare con la bilancia della ragione ciò che l'Inviato ci apporta riguardo ad Allah, sia Egli esaltato, applicando a Lui gli attributi degli esseri contingenti che gli argomenti razionali rifiutano, così non si addice a noi di pesare ciò che il Maestro realizzato, che è il trasmettitore da parte del Vero, ci apporta, poiché è da quel forziere (hizāna) che egli attinge ed è con quella merce $\left(b i d \bar{a}^{c} a\right)$ che è connesso, che sono gli aliti (nafahăt $)$ del nostro Signore che egli coglie.

In un accadimento spirituale (wāqi $\left.i^{\top} a\right)$ ho visto una persona che venne da me mentre ero in compagnia e mi disse: "Io sono l'inviato del Vero verso di voi", poi raccontò ciò con cui era venuto da noi e disse: "Sappiate che il bene è nell'esistenza e che il male è nella non-esistenza. Egli ha dato l'esistenza all'uomo per la Sua Magnanimità (ǧŭd), e lo ha fatto unico (waḥdān $\vec{\imath}$ ) nella Sua Esistenza: egli è caratterizzato (tahallaqa) con i Suoi Nomi [16] ed i Suoi Attributi, e si estingue da essi per mezzo della contemplazione della Sua Essenza, e quindi vede Se stesso per mezzo di Se stesso, e ritorna ('āda al'awd) ad Allah, sia Egli esaltato, ed è Lui e non tu'" (65)

64) Ibn 'Arabī riporta questo detto nei seguenti capitoli delle Futūhāt: Introduzione [I 31.9], 29 [I 198.26], 54 [I 280.25], 155 [II 253.34], 336 [III 140.1] e 370 [III 412.35].

65) Questo episodio è riportato da Ibn ‘Arabī nel suo Kitāb muhādarāt al-abrār, Dār Sāder, senza data, Vol. II, pag. 
Ruwaym $\left({ }^{66}\right)$ ha detto: $\left({ }^{67}\right)$ "Chi sta seduto con questo gruppo e li contraddice in qualcosa che essi hanno realizzato, Allah toglie la luce della fede dal suo cuore" (68), ed Abū Yazīd ha detto: "Quando vedi chi ha fede nel discorso della gente di questa Via, digli di pregare per te, poiché la sua preghiera è esaudita" $\left.{ }^{69}\right)$.

$\grave{E}$ evidente che il discepolo (tilm $\bar{\imath} \underline{d}$ ) non si reca dal Maestro se non per colloquiare con lui in qualsiasi lingua, ed abbiamo detto "in qualsiasi lingua", in quanto in un accadimento spirituale ho colloquiato con l'Inviato di Allah, che Allah faccia scendere su di lui la Sua salāt e la Pace, solo con lo sguardo, ed ho capito da lui tutto ciò che intendeva dire ed egli ha capito da me tutto ciò che volevo dire, e l'organo della lingua non si è mosso tra di noi, né da parte sua, né da parte mia, ed abbiamo già spiegato ciò che egli disse in quel genere di colloquio, riguardo ai sogni portatori di buona novella

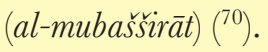

Il poeta $\left({ }^{71}\right)$ ha detto:

Di noi parlano nei volti i nostri occhi:
noi siamo silenziosi e la passione (hawā) parla!

54: "Trascorsi la notte in compagnia di un gruppo di uomini pii, tra cui Abū l-'Abbās al-Harī̄ī [o al-Harrār], Imām di Zuqāq al-Qanādīl al Cairo, suo fratello Muḥammad al-Ḩayyāt, 'Abd Allāh al-Marūzī, Muhammad al-Hāšimī al-Yaškarī e Muḥammad ibn Abū l-Faḍl. Mentre dormivo vidi me stesso e gli altri in una casa molto buia in cui non c'era altra luce che quella che emanava da noi stessi e le luci si estendevano su di noi dai nostri corpi e risplendevamo di esse. Entrò da noi una persona dal volto e dal linguaggio bellissimi, che disse: "Io sono l'inviato del Vero verso di voi!", al che gli chiesi: "E cosa porti nella tua missione?", ed egli rispose: "Sappiate che il bene è nell'esistenza ed il male nella non-esistenza!'. Nel Cap. 69 [I 410.7] Ibn 'Arabī precisa che fu in compagnia di Abū l-'Abbās al-Harīīi al Cairo nell'anno 603 dall'Egira.

66) Abū Muhammad Ruwaym ibn Aḥmad morì a Bagdād nell'anno 303 dall'Egira. Al-Qušayrī gli dedica una breve notizia nella sua Epistola, ove riporta anche le parole qui citate.

67) Il testo del manoscritto Yūsuf Aga 4860 comincia a questo punto.

68) Ibn 'Arabī riporta questo detto nei seguenti capitoli delle Futūhạt: 2 [I 79.31], 181 [II 366.8] e 286 [II 634.14].

69) Ibn 'Arabī riporta questo detto nei seguenti capitoli delle Futūhāt: 2 [I 79.30], 73 [II 6.15] e 289 [II 646.14].

70) Questo termine ricorre in Cor. XXX-46, ove ha il significato di messaggeri di buona novella. Ibn 'Arabīsi riferisce probabilmente alla sua Risāla al-mubašsiriāt [RG 485] in cui riporta 18 di questi sogni, o suoi o riferiti a lui, o al suo Kitāb al-mubaššriāt min al-ahlām [RG 486], di cui non sembra essere rimasto alcun manoscritto. Nelle Futūhăt Ibn 'Arabī cita e commenta più volte un hadīt riportato da at-Tirmidīi, XXXII-8, secondo cui i sogni portatori di buona novella sono una delle parti della Profezia che Allah ha fatto restare [Cap. 54 (I 280.30), Cap. 69 (I 545.13), Cap. 188 (II 376.20 e 377.1), Cap. 314 (III 56.13), Cap. 328 (III 103.26), Cap. 371 (III 435.20), e Cap. 419 (IV 27.28)]. Nel Cap. 207 [II 491.6] inoltre identifica i sogni portatori di buona novella con gli accadimenti spirituali $\left(w a q \bar{a} \imath^{\prime}\right)$ e precisa che essi possono verificarsi non solo durante il sonno, ma anche nello stato di estinzione ( $f a n \bar{a})$ e nella veglia.

71) Si tratta di al-'Abbās ibn al-Aḥnaf, morto a Bașra nell'anno 193 dall'Egira. 
E noi abbiamo detto riguardo a quello:

E la passione tra di noi proferisce un discorso buono e melodioso senza lingua $\left({ }^{72}\right)$

Ed egli, su di lui la Pace, ha detto del suo Signore, quanto è Potente e Magnificente, che Egli batté con la Sua mano tra le sue due scapole, e sentì il freddo dei Suoi polpastrelli nel suo petto, e seppe la scienza dei primi e degli ultimi $\left.{ }^{73}\right)$. Questo è un colloquio senza alcuna lettera sentita dall'orecchio, né suono, in quanto il colloquio ha molti linguaggi. È indispensabile che tu ti attenda da parte del Maestro il colloquio verbale con l'organo della lingua, poiché il conciliabolo è inevitabile tra il Maestro ed il discepolo, ed è quindi necessario che il discepolo faccia precedere ad esso una sadaqa.

Ed ogniqualvolta il discepolo chiede al Maestro: "Perché?" egli non avrà successo e non verrà mai nulla da parte sua: su questo è unanimemente d'accordo il magistero (mašyaha) della gente di Allah, sia Egli esaltato.

Egli non [17] deve quindi chiedere ragione al Maestro di ciò che dice, né chiedere il motivo di ciò che gli ha ordinato, così come all'Inviato non chiede ragione di ciò che ha ordinato e non gli chiede il motivo, e nel colloquio intimo con il Vero non chiede ragione di ciò che Egli ha ordinato e non Gli chiede il motivo, bensì colui che ascolta esegue l'ordine senza indugio. E se il Vero, o chi ci menziona il Suo ordine ed il Suo discorso, dà una spiegazione, ciò spetta a Lui ed il profitto torna a noi, come ha detto: "Nel taglione (qișās) c’è vita per voi”" (Cor. II-179) $\left({ }^{74}\right)$, ed Egli ci ha ordinato la șadaqa, in quanto si tratta di una faccenda dura per l'anima $\left({ }^{75}\right)$.

La più eccellente delle șadaqāt è quella che colui che fa la șadaqa elargisce a se stesso $\left.{ }^{76}\right)$ : Le șadaqāt

72) Gli stessi versi sono riportati nel Cap. 73, questione VIII [II 46.14].

73) Hadīt riportato da at-Tirmidīi, XLIV, Sūra XXXVIII, 2-4, Abū Dāwud, XXVII-12, ad-Dārimī, e da Ibn Hanbal, e citato nei capitoli 10 [I 137.15] e 34 [I 217.17] delle Futūhāt.

74) La legge del taglione impone la punizione del solo colpevole e vieta la vendetta estesa anche ad altri, come era consuetudine presso gli arabi.

75) Analogamente, nel Cap. 70 [I 548.1] Ibn 'Arabī precisa: "Per questo Allah l'ha chiamata șadaqa, cioè essa è una faccenda dura per l'anima. L'arabo dice: "una lancia dura $(s a d q)$ ", cioè robusta, possente e forte, cioè l'anima prova per l'elargizione di questo bene per Allah difficoltà e ristrettezza, come ha detto Tálaba ibn Hāṭib”.

76) Nel Cap. 70, Ibn 'Arabī precisa [I 574.19]: "Ciò che di più prossimo (aqrab) una persona ha della sua famiglia $(a h l)$ è la sua anima. Invero Allah da parte Sua ha detto riguardo alla Sua prossimità: "Egli è più prossimo a lui della sua vena giugulare" (Cor. L-16), come se Egli dicesse: "Egli è più prossimo a lui della sua anima". Essa dunque ha la priorità a ricevere ciò che viene dato come elemosina rispetto ad altri. Così pure Allah ha la priorità a ricevere il prestito poiché è più vicino a lui della sua anima. Per ognuno che dà la sadaqa vi è una sadaqa che spetta a lui tra le creature, poi [spetta] alle sue membra, poi al più prossimo a lui dopo quello, cioè alla famiglia, poi al figlio, poi al servitore, poi alla parentela ed al vicino; analogamente egli fa l'elemosina al suo allievo ed a chi cerca il vantaggio da lui”. 
sono di vari tipi: vi è la șadaqa in senso ordinario e la șadaqa nota per la Legge, ed Egli [nel Suo ordine] ha incluso la șadaqa in senso ordinario e quella non in senso ordinario. Egli ha detto: "Al mattino ad ogni vena (sulāmā) di ciascuno di voi compete una șadaqa, ed ogni glorificazione (tasbīh) è una șadaqa ed ogni lode ad Allah (tahmīd) è una șadaqa" ${ }^{77}$ ), affermando che lo dikkr fa parte delle șadaqāt elargite dall'uomo a se stesso. Il portare sulla retta via chi è deviato è una șadaqa, il togliere l'ostacolo dalla via è una șadaqa, e tutte le opere di pietà (birr) sono tutte una șadaqa da parte del servitore a se stesso o ad altri. Chi fa una șadaqa ad altri invero fa una șadaqa a se stesso, ma non ogni șadaqa fatta a se stessi comporta il suo trasferimento ad altri: c'è caso e caso. Ed Allah è stato onnicomprensivo riguardo alle sadaqāt in ciò che ha spiegato, dicendo: "[Vi è di peso far precedere] il vostro colloquio da delle sadaqāt??" (Cor. LVIII-13), senza specificare una șadaqa ad esclusione di un'altra, e poiché ha usato il plurale, a colui che ascolta è imposto di fare il più piccolo multiplo di șadaqa, cioè tre o più sadaqāt di qualsivoglia tipo delle sadaqāt prescritte dalla Legge, "ed Allah ricompensa coloro che fanno delle sadaqūt" (Cor. XII-88).

Se la șadaqa fosse quella nota in senso ordinario, chi non la [18] trova [cioè non ha i mezzi per farla] non avrebbe accesso a questa contemplazione $(\check{s} u h \bar{u} d)$, ma poiché la Legge ha generalizzato le sadaqāt con ciò che ha spiegato, non c'è insolvente (muflis) e non insolvente che non sia in grado di fare una sadaqa, e quindi il bene è generale, e la lode spetta ad Allah.

Tutto questo se la $f \bar{a}$ [di $f \hat{\imath}$ (in)] sta ad indicare "nel" suo recarsi alla sua porta, ma se invece è un sostituto ('iwạ) della $b \bar{a}^{\prime}$ [di $b i$ (per mezzo di)] allora la sua șadaqa va al Maestro, e la șadaqa è magnificata dalla grandezza di colui a cui viene elargita, o per la grandezza del suo rango, o per la grandezza del rango dello stato (manzilat al-hâal), ed il rango dello stato è come chi fa la șadaqa di un sorso d'acqua a chi morirebbe se non lo bevesse, ed in quello è uno che dà la vita ad una persona, "e chi dà la vita ad essa è come se avesse dato la vita all'intera umanità" (Cor. V-32), e questo è ciò che conferisce lo stato.

Ed è noto che se l'aspirante è veridico nel rivolgersi (tawağğuh) al Maestro, Allah conferisce al Maestro, nel suo cuore, ciò per cui ha luogo l'avanzamento (irtiq $\bar{a})$ di quell'aspirante. Talvolta il Maestro non ha scienza di ciò prima di quello, sennonché ciò gli viene rivelato per la veridicità di quell'aspirante che ha il proposito (qas d): quindi l'aspirante fa una sadaqa per mezzo del suo recarsi dal Maestro, senza accorgersene e senza averne il proposito. E quando [questa scienza] è acquisita dal Maestro per il dirigersi dell'aspirante verso di lui, egli viene a sapere ciò che non gli era noto prima di quello. Quanto alla presenza [dell'aspirante dal Maestro], malgrado una scienza che egli [il Maestro] già aveva prima di quello, è tuttavia indispensabile che vi sia un accrescimento (ziy a da), e cioè che il Maestro venga a sapere, in quel momento, ciò di cui non aveva scienza, cioè la sua scienza dello stato di quell'aspirante in quel momento [in cui è presente da lui] e della connessione del suo stato con la scienza che il

77) Had̄̄t riportato da al-Buhārī, LIII-1 1, LVI 72 e 128, Muslim, VI-84, XII-56, Abū Dāwūd, V-12, XL-160, e da Ibn Hanbal, e citato nei capitoli 70 [I 559.15 e 573.13], 71 [I 628.13], 73, questione IX [II 47.9], 457 [IV 72.2] e 560 [IV 482.33] delle Futūhāt. 
Maestro gli comunica, questo è indispensabile. È quindi necessario che il recarsi dell'aspirante dal Maestro sia una șadaqa da parte dell'aspirante al Maestro, senza che l'aspirante ne sia consapevole. Noi stessi lo abbiamo provato personalmente e lo abbiamo sentito dire dai nostri Maestri. Essi dicono che talvolta viene data un'apertura al Maestro [19], grazie al proposito dell'aspirante $\left({ }^{78}\right)$ ed alla sua veridicità, ad una scienza che è al di sopra del grado del Maestro, per lo stato dell'aspirante, non per lo stato del Maestro.

Quindi il Maestro ottiene dal suo Signore per il proposito di questo aspirante ciò a cui non arrivava l'aspirazione (himma) $\left(^{79}\right)$ del Maestro, né la sua stazione spirituale, e che non aveva ricevuto. Noi abbiamo visto qualche aspirante che aveva una aspirazione nella ricerca superiore a quella che

78) Si tratta evidentemente del proposito di ricevere un aiuto dal Maestro, non quella di dare a lui una șadaqa.

79) La povertà lessicale delle lingue occidentali rende spesso difficile tradurre adeguatamente i termini arabi che esprimono gradi e sfumature diverse di uno stesso concetto. Nel gergo del Tașawwuf il termine himma indica un grado di volontà intermedio tra l'iräda e la niyya; in mancanza di altri termini l'ho tradotto come "aspirazione", ma ciò genera inevitabilmente confusione con il termine "aspirante". Nel suo "Trattato sulla terminologia dei Süfì (kitāb al-istilāh as-süfyya)", Ibn 'Arabī riporta come prima definizione quella del pensiero (häğis): "Con questo termine viene indicato il primo pensiero (hätir) che affiora alla coscienza, cioè il pensiero di origine dominicale, che non è mai sbagliato. Sahl [at-Tustārī] lo ha chiamato la causa prima e lo schioccare del pensiero. Se questo pensiero si conferma nell'anima viene chiamato volontà (iräda), e quando ricorre per la terza volta viene chiamato aspirazione (himma). Alla quarta volta viene chiamato determinazione ('azm). Quando implica l'orientarsi verso l'azione, se si tratta di un pensiero di azione, viene chiamato proposito ( $q$ asd), mentre se si tratta di azioni rituali viene chiamato intenzione (niyya)". Nel Cap. 33 [I 213.15] aggiunge: "Essi hanno la conoscenza del pensiero (hăğis), della aspirazione (himma), della determinazione, della volontà e del proposito, e tutti questi sono stati (ahwāl) preliminari all'intenzione (niyya). E l'intenzione è ciò che dipende da lui nell'intraprendere i suoi atti, ed è quella che è considerata nella Legge divina; ed essa è quella che essi esaminano a fondo ed è connessa con il culto sincero (ihlās). Il nostro sapiente, l'Imām Sahl ibn 'Abd Allāh, ha studiato minuziosamente questa faccenda ed è lui che ha posto l'attenzione allo schioccare del pensiero, ed ha detto: "L'intenzione è quel pensiero, ed esso è la causa prima nel manifestarsi (hudūt) della aspirazione (hamm), della determinazione, della volontà e del proposito", e su ciò si è basato e per noi era nel giusto". Ma l'aspirazione legata alla volontà è solo uno dei tre significati attribuiti nel gergo del Tasawwuf al termine himma; nel Cap. 229, dedicato alla himma, Ibn 'Arabī precisa [II 526.22]: "Sappi che gli iniziati (al-qawm) usano il termine himma riguardo alla spoliazione (tağrīe del cuore per [lasciarvi solo] gli oggetti del desiderio (munā), nei riguardi dell'inizio della veridicità (sidq) dell'aspirante e nei riguardi della concentrazione $\left(\stackrel{g}{g} a \mathrm{~m}^{c}\right)$ delle energie interiori (himam) per mezzo della purezza dell'ispirazione (ilhäm); essi dicono che la himma ha tre gradi: la himma della presa di coscienza (tanabbuh), la himma della volontà (iräda) e la himma della realtà essenziale (haqīqa). La himma caratteristica della presa di coscienza consiste nel risveglio del cuore a ciò che conferisce la realtà essenziale dell'uomo quanto a ciò che è connesso con il desiderio (tamanna $)$, che si tratti di una cosa impossibile o possibile non fa differenza [...] Quanto alla himma della volontà essa è l'inizio della veridicità dell'aspirante ed è una himma concentrata a cui nulla resiste: questa himma si trova molto in un gruppo chiamato in Africa gli 'Azābiyya, che per mezzo di essa uccidono coloro che vogliono. L'anima, quando si concentra, ha un'influenza sui corpi del mondo e sulle sue condizioni a cui nulla può contrapporsi [...] Quanto alla himma della realtà essenziale essa è la concentrazione delle aspirazioni per mezzo della purezza dell'ispirazione: si tratta delle aspirazioni dei più grandi Maestri tra la gente di Allah, coloro che concentrano le loro aspirazioni sul Vero e le rendono una sola, in ragione dell'Unità di Colui al quale ci si collega in questo modo, fuggendo la molteplicità e cercando l'Unità di ciò che è molteplice o l'Unità pura". 
comportava il grado di uno dei Maestri, e l'aspirante era certo che non avrebbe ottenuto quello se non da questo Maestro, ed Allah, sia Egli esaltato, ha conferito a questo Maestro la predisposizione (isti $d \bar{a} d)$ nello stato presente per ricevere la illuminazione (tağalli $)$ divina che era conferita da questa domanda con cui era connessa l'aspirazione di quell'aspirante, per la sua elevatezza $\left.{ }^{80}\right)$.

In effetti, il magistero in questa Via non è la più elevata delle stazioni e degli stati spirituali $\left({ }^{81}\right)$, poiché è a guisa della scienza del medico rispetto alla scienza della Natura, ed è una scienza speciale che vale per l'istruzione iniziatica, in quanto [il Maestro] è come il medico per il malato e la nutrice (dāya) per la crescita, nient'altro. Talvolta il Maestro ha un grado superiore a quello che ha in quanto Maestro istruttore e che è conforme a ciò che la Sollecitudine di Allah comporta per lui, e chi conosce il grado dei Maestri attribuisce loro il giusto posto e non oltrepassa con loro ciò che non è implicito nel grado della Maestria. Nella totalità dei suoi stati il Maestro è occupato con il suo Signore e non gli viene in mente ciò che serve ai discepoli se non nel momento in cui essi sono presenti da lui, o nella connessione delle loro aspirazioni con lui, o nel momento in cui il Maestro li evoca nel suo intimo (bātin), e basta.

Come l'aspirante, anche il Maestro è uno che cerca da Allah ciò che non ha, come Allah, sia Egli esaltato, ha ordinato [di fare] al Suo Profeta, su di lui la Pace, dicendogli: "Dì: o mio Signore, accrescimi in scienza" (Cor. XX-114), e l'ordine non si arresta ad un limite massimo e "al di là di Allah non c’è bersaglio (marmā) [che si possa raggiungere]" ( $\left.{ }^{82}\right)$. Il viaggio (safar) in Lui [20] per mezzo delle aspirazioni e delle intelligenze è senza fine, ed esso è il viaggio più elevato; quanto al viaggio che è inferiore a quello è il viaggio verso di Lui $\left.{ }^{83}\right)$. Sappi ciò!

Se si è assimilato questo aspetto, cioè l'elargizione della șadaqa per mezzo del recarsi dal Maestro ed il fatto che è lo stato $(h \bar{a} l)$ che la conferisce, è indispensabile che essa non sia intenzionale per il discepolo. Se è intenzionale ed egli ritiene di fare una șadaqa al Maestro perché si reca da lui, quell'aspirante

80) Nel Cap. 229 [II 526.29] Ibn 'Arabī precisa: "[L'aspirazione della volontà] ha della forza (quwwea), in quanto, quando sussiste nell'aspirante, esercita un effetto nei Maestri perfetti, sì che essi [gli aspiranti] dispongono di loro per mezzo di essa. Talvolta il Maestro ottiene un'apertura $(f a t h)$ su una scienza che non aveva e che non era voluta da lui, per mezzo della himma di questo aspirante che ritiene che essa si trovi presso questo Maestro; ed il Maestro ottiene in modo accidentale quella scienza al momento, affinché la trasmetta a questo cercatore dotato della himma, poiché egli non la accetta se non da lui. Ciò avviene perché questo aspirante ha concentrato la sua himma su questo Maestro riguardo a questa questione, ed i racconti riguardo a ciò sono noti e menzionati”.

81) Analoga affermazione è riportata nel suo Kitäb al amr al-muhkam [cfr. Asín Palacios, El Islam Cristianizado, Editorial Plutarco, Madrid, 1931, pagg. 303].

82) Hadìt riportato solo da Mālik, XLIII, ma spesso citato e commentato da Ibn 'Arabī: cfr. l'Introduzione [I 38.27], ed i capitoli 72 [I 721.9], 130 [II 214.35], 133 [II 220.24], 198 [II 436.15], 250 [II 552.4], 344 [III 177.9], 355 [III 247.35], 410 [IV. 13.32 e 14.4], 514 [IV 154.3], 553 [IV 193.20], 558 [IV 214.12 e 324.29], e 559 [IV 330.5 e 399.11$]$.

83) La distinzione tra questi due viaggi è riportata nel Kitāb al-isfär 'an natāiğ al-asfầr, edito e tradotto da Denis Gril, con il titolo Le dévoilement des effets du voyage, Éditions de l'éclat, 1994, pagg. 3 e 4. 
non avrà successo poiché non mira se non ad un povero ( $f a q \bar{\imath} r)$, mentre non deve mirare se non ad un ricco, che abbia ciò che egli [senza saperlo, tramite Allah,] gli elargisce come sadaqa $\left({ }^{84}\right)$ e non deve preoccuparsi di sbagliare in quello riguardo a questo Maestro o di non sbagliare, ma deve dare alla stazione spirituale ciò che le spetta e dare al grado ciò che gli spetta, poiché in realtà egli non mira se non ad Allah, ma Egli si manifesta a lui nella forma di colui a cui mira.

Per questo, sia Egli esaltato, Egli ha detto: "Chi obbedisce all'Inviato, invero obbedisce ad Allah" (Cor. IV-80), poiché Egli Si manifesta nella forma dell'Inviato, e chi obbedisce a coloro di noi che sono dotati di comando $(\bar{u} l \bar{u} l$-amr $)$ invero obbedisce ad Allah, poiché Colui che ha ordinato di obbedire ad Allah è Colui che ha ordinato di obbedire all'Inviato ed a coloro che detengono il comando [cfr. Cor. IV-59] ed ha congiunto [quest'ultima espressione] con la particella "e (wa)" senza [ripetere] l'ordine di obbedire, in quanto coloro che sono dotati di comando sono dello stesso genere dell'Inviato.

Ma non ha fatto lo stesso riguardo all'obbedienza all'Inviato, bensì, dopo la congiunzione, ha ribadito l'ingiunzione di obbedire, per distinguere colui con cui ha luogo la correlazione (munāsaba) [cioè l'Inviato] da Colui con cui non ha luogo la correlazione, in quanto non c'è cosa simile a Lui. Egli ha detto: "O voi che credete, obbedite ad Allah ed obbedite all'Inviato" (Cor. IV-59) ed ha ricominciato (ista'nafa) con l'obbedienza, poi ha detto "ed a coloro che detengono il comando" (Cor. ibidem) e tu capisci il resto [cioè l'obbedienza] da [quanto è stato detto riguardo a] colui che è connesso [cioè l'Inviato], così come sai ciò che Egli ha lasciato sussistere della corrispondenza (tanāsub) [tra Allah e il Suo Inviato], per mezzo della Teofania, nel Suo detto: "ed obbedite ad Allah ed al Suo Inviato" (Cor. VI-1) in cui non ha ribadito l'ingiunzione $\left(^{85}\right)$.

"Chi obbedisce all'Inviato, invero obbedisce ad Allah" (Cor. IV-80), sotto i due aspetti, in quanto l'Inviato è il supporto di manifestazione [21] del comando [divino], ed in quanto Allah ha ordinato di obbedire all'Inviato, e chi gli obbedisce, obbedisce ad Allah, "e chi volge le spalle" (Cor. ibidem) cioè non obbedisce - "non ti abbiamo inviato a loro come custode" (Cor. ibidem), "non hai potere su di loro!" (Cor. LXXXVIII-22), "a te spetta solo la trasmissione” (Cor. XLII-48), "tu hai trasmesso e ciò che c'è tra Me ed i Miei servitori è lasciato libero: il Mio Volere riguardo a loro è compiuto" $\left.{ }^{86}\right)$.

Poi disse: "[camminando] in uno stato di abbassamento (dilla), di indigenza (maskana) e di spezzamento (inkisār)". Commento: in quanto l'Inviato di Allah, che Allah faccia scendere su di lui la Sua salāt e la Pace, ci ha ordinato di venire al [la șalāt del] venerdì con questa attitudine, e questo venire (ityān) è il venire di chi cerca il colloquio intimo con il suo Signore nella stazione della sintesi (ğam ), cioè la sintesi

84) Cioè deve essere convinto che il Maestro a cui si rivolge abbia ciò di cui ha bisogno, indipendentemente dal fatto che il Maestro lo sappia già o che lo venga a sapere da Allah in virtù del suo recarsi da lui.

85) Le stesse considerazioni si trovano nel Cap. 48 [I 264.10].

86) Hadīt quds̄̄ non recensito nelle raccolte canoniche e non riportato nelle Futūhāt. 
dei Nomi divini per mezzo di un unico Imām nella città $($ mișr $)\left({ }^{87}\right)$, di modo che non associ nessuno nell'adorazione del suo Signore.

È stato tramandato che colui che fa la salātè in colloquio intimo con il suo Signore $\left.{ }^{88}\right)$ ed è indispensabile che egli non colloqui con altri che Lui nella sua salāt. Analogamente, chi si reca dal suo Maestro, che è il rappresentante $\left(n \bar{a}^{\prime} \mathfrak{i} b\right)$ di Allah nei riguardi di questo aspirante, è indispensabile che nell'andare da lui abbia questa attitudine, e non colloqui nel suo intimo con altri che lui, poiché Allah, sia Egli esaltato, ha spartito la salāt tra Lui ed il Suo servitore $\left({ }^{89}\right)$, ed in questa situazione non ha fatto entrare un terzo che renda dispari questa parità.

Venne detto a Qaḍīb al-Bān (90): "Per Allah, fai la șalāt con noi"” $\left.{ }^{91}\right)$, ed egli rispose di sì e si avviò con il richiedente alla șalāt del venerdì, ma quando l'Imām pronunciò la formula di sacralizzazione [cioè Allahu akbar] e stava per inclinarsi nella prima raḱat, Qaḍīb al-Bān abbandonò la șalāt e si allontanò.

Quando il richiedente ebbe finito la șalāt con l'Imām e vide Qạ̣īb al-Bān, gli disse: "Fratello mio, oggi mi hai rallegrato con la tua șalāt con noi, poi mi hai rattristato con il tuo abbandono della salāt e la tua uscita", ed egli rispose: "Non vedevo dietro a chi fare la șalāt, poiché ho visto l'Imām abbandonare la șalāt ed andarsene dal suo mihrāa [22] verso la Porta di Kunda $\left({ }^{92}\right)$ per comperare

87) In arabo l'espressione usata per indicare il venerdì è "il giorno dell'assemblea (ğumu'a)", e la șalāt del venerdì è l'unica salät che non si possa fare da soli, poiché implica la riunione (ğam ${ }^{c}$ o sintesi di una molteplicità. Nel Cap. 69 [I 461.29], Ibn 'Arabī, pur affermando che è lecito che nella stessa città la șalāt del venerdì venga fatta in più moschee, raccomanda, quando è possibile, di farla in una unica moschea, con un unico Imām, per tutta la città.

88) Hadīt riportato da al-Buhārī, IX-8 e citato decine di volte nelle Futūhāt.

89) Riferimento ad uno hadịt riportato da Muslim, IV-38 e 40, Abū Dāwud, II-132, at-Tirmid̄̄in, an-Nasā’̄ī, Ibn Māğah, e da Ibn Ḥanbal.

90) Abū'Abd Allāh al-Ḥasan al-Mawșilī, denominato Qaḍīb al-Bān, di origini curde, nacque nell'anno 471 dall'Egira a Mossul, ove morì nell'anno 570 o 573. Fu compagno di 'Abd al-Qādir al-Ǧīlānī, a cui diede in sposa una figlia di nome Hadīğa. Ibn 'Arabī lo cita più volte nelle Futūhăt: Cap. 23 [I 182.7], ove gli riconosce il grado di malämī; Cap. 25 [I 187.1]; Cap. 47 [I 259.34]; Cap. 71 [I 621.3], in cui precisa: "Un solo spirito governa numerosi corpi $(a g ̆ s \bar{a} d)$ se gli è stato dato potere di farlo: in questo mondo ciò costituisce una rottura del corso abituale degli eventi per l'Intimo, mentre nell'aldilà ciò è implicito nella costituzione (naša) dell'uomo. Qaḍīb al-Bān fu tra coloro che ebbero questo potere, come pure Dū n-Nūn al-Mișrī”; Cap. 73, [II 14.7], in cui gli riconosce il dominio del Malaküt; Cap. 73, questione XXXVI [II 65.31]; Cap. 178 [II 333.33]; Cap. 285 [II 632.7] in cui afferma che egli era tra coloro che ricevevano l'ispirazione (wahy) in forma scritta; Cap. 311 [III 42.25] e Cap. 414 [IV 19.20].

91) Qadīib al-Bān veniva accusato dai suoi concittadini di non fare le salāt, ma quando ciò venne riferito ad 'Abd al-Qādir al-Ǧīlānī egli rispose: "Egli fa la șalāt senza che voi lo vediate, ma io lo vedo quando fa la salāt a Mossul o in altri orizzonti della Terra: egli si prosterna alla porta della Ka'bah" [al-Munāwī, Kitāb al-kawākib ad-durriyyah, Vol. II, pag. 276].

92) Le mura della città di Mossul (al-mawsil), situata sul fiume Tigri di fronte alle rovine dell'antica Ninive, avevano nove porte: la Porta di Kunda era una delle porte occidentali. 
dei cocomeri, e non vedendolo nel mihrāb non ho trovato dietro a chi fare la salät e sono uscito". Il richiedente tornò dal predicatore $(h a t i ̄ b)$ e gli chiese: "Che cosa ti è passato per la mente nella prima rak'at della salāt del venerdì?", e l'Imām rispose: "Mi è venuto in mente di uscire verso la Porta di Kunda per comperare dei cocomeri: che cosa vuoi dire con ciò?” $\left({ }^{93}\right)$, ed egli rispose: "Qadị̂ al-Bān mi ha informato di quello".

Gli Intimi (awliyā') di Allah sono con ciò che viene loro svelato, poiché essi sono le spie dei cuori $\left({ }^{94}\right)$, e Qaḍīb al-Bān non ha fatto altro che applicare la Legge, poiché il Vero non gli ha fatto vedere se non l'allontanamento dell'Imām ed il suo abbandono della șalāt e del miḥrāb, e non vide quindi nel miḥāa nessuno dietro a cui fare la salāt.

Chi è in colloquio intimo con il suo Signore, non colloquia con Lui se non con abbassamento (dilla), indigenza (maskana) ${ }^{95}$ ) e spezzamento (inkisār) ${ }^{96}$ ), poiché Egli, sia Egli esaltato, è il Potente ('azīz), e chi è dotato di potenza non ha accesso a Lui per la sua potenza, ma per un abbassamento.

Il Maestro, per il suo regime, è il sostituto di Allah nei confronti del discepolo, ed è indispensabile che il discepolo che intende avere accesso al Maestro sia ossequiente a questa situazione, poiché egli è un povero e bisognoso che chiede, e colui che chiede è umile e necessariamente con il cuore affranto (munkasir al-qalb) per il suo bisogno. Allah, quanto è Potente e Magnificente, ha detto: "Io sono presso coloro che hanno il cuore infranto a causa Mia" $\left({ }^{97}\right)$

93) Nel Cap. 560 [IV 481.34] Ibn 'Arabī precisa: “Tuttavia qui c’è una condizione che il sapiente non trascura: quando egli recita questi versetti [nella salāt] non li recita ripetendo semplicemente le parole, poiché quello non gli sarebbe di alcun vantaggio in ciò che abbiamo affermato ed in ciò che si vuole da lui. Invero Allah, sia Egli esaltato, non gli ha prescritto di recitare il Corano e di invocarLo con questo $\underline{d i k r}$ se non per insegnargli come invocarLo e perché Lo invocasse con una invocazione di richiesta, di bisogno, di necessità e di presenza di coscienza (hudūr) nel suo richiedere al suo Signore ciò che Egli gli ha prescritto di chiedere. Questi è colui a cui il Vero risponde quando egli Gli chiede. Se egli recita ripetendo semplicemente le parole, allora non è uno che chiede e se non chiede ma ripete semplicemente la formula di richiesta, il Vero non esaudisce chi è caratterizzato in questo modo. Sicuramente ciò che prevale in coloro che recitano è la ripetizione verbale, poiché essi non ne ricavano alcun frutto: essi recitano il Corano con la loro lingua, ma non vanno oltre quello, ed i loro cuori sono distratti (lähiyya) nel momento della sua recitazione e nel momento del suo ascolto". Shakespeare, nell'Amleto, atto III, scena terza, fa dire a Claudio, il fratricida, mentre prega il suo Signore di perdonarlo: "My words fly up, my thoughts remain below. Words without thoughts never to heaven go".

94) Lo Šayh at-Tādilī riporta ne La vie traditionnelle c'est la sincérité [Éditions Traditionnelles, 1971, pag. 15] la massima: "Quand vous êtes en compagnie des Sūfis, soyez le avec sincérité, car ce sont des espions des cœurs. Ils entrent dans vos cœurs et en sortent d'une manière que vous ne prévoyez pas".

95) Questi due termini ricorrono insieme in Cor. II-61.

96) Il termine inkisār è l'infinito della settima forma del verbo kasara, che significa letteralmente rompere, spezzare, fratturare, ed in senso traslato abbattere, battere, piegare. Quando è isolato l'ho tradotto con spezzamento, nel senso di "essere a pezzi", mentre quando è riferito al cuore l'ho tradotto come "essere affranto" o "essere infranto".

97) Hadīt qudsī non recensito nelle raccolte canoniche. Ibn 'Arabī lo cita nei capitoli 69 [I 434.34], 376 [III 
Il discepolo non si reca dal Maestro se non a causa di Allah, non per il Maestro stesso, e per questo gli ha raccomandato questa attitudine. Quando l'aspirante si reca dal Maestro per amore di Allah, Allah gli regala, al posto dell'abbassamento, la veste d'onore $\left(\right.$ hil $\left.{ }^{\prime} a\right)\left({ }^{98}\right)$ della potenza, e ciò corrisponde al Suo detto, sia Egli esaltato: "La Potenza appartiene ad Allah, al Suo Inviato ed ai credenti, ma gli ipocriti non lo sanno" (Cor. LXIII-8) $\left(^{99}\right)$, poiché ad essi non è svelato nell'abito del credente il vestito della Potenza divina. E ['aspirante] esce dal Maestro con questa veste d'onore, ed Egli, in sostituzione dell'essere a pezzi, gli regala la veste d'onore della ricomposizione ( $ّ a b r)$ per la Sua prossimità a lui $\left({ }^{100}\right)$, e gli regala, al posto [23] dell'indigenza, la veste d'onore del disporre liberamente (tasarruf) nel mondo. Nella misura degli abiti che egli indossa quando si presenta a lui, Egli gli regala, in cambio di ognuno di quegli abiti, un abito che gli corrisponde; e questo Maestro non ha menzionato se non tre abiti con cui [l'aspirante] entra da lui [il Maestro] e quindi esce con tre vesti d'onore, la veste d'onore della potenza, della ricomposizione e del disporre liberamente. Ed il marchio di chi si reca dal Maestro con questi stati è che scopre queste vesti d'onore che Allah gli ha regalato per mezzo del Maestro $\left.{ }^{101}\right)$.

481.6], e 471 [IV 103.30] delle Futūhāt e lo commenta alle pag. 295-296 di questo manoscritto.

98) Il termine hil'a indica una veste che uno si toglie per darla ad un altro, poiché il primo significato del verbo hala'a è togliersi, deporre, come in Cor. XX-12: "...togliti i tuoi sandali".

99) Questo versetto sarà ulteriormente commentato a pag. 109 e 118 del manoscritto. Nel Cap. 410 [IV 15.12] Ibn 'Arabī precisa: "“La Potenza spetta ad Allah, al Suo Inviato ed ai credenti” (Cor. LXIII-8), e ad Allah la Potenza spetta per principio, ed al Suo Inviato ed ai credenti come veste d'onore divina, non per principio", e nel Cap. 304 [III 20.21] afferma: "Tutte le volte che nel Corano l'uomo viene descritto con ciò che non gli appartiene realmente, è soltanto come contropartita di una cosa che è asserita da chi non è della sua gente, e questi viene ripagato dal suo [stesso] genere, affinché ciò sia più dannoso nei suoi confronti. A questo proposito 'Abd Allāh ibn Ubayya ibn Salūl [il capo degli ipocriti a Medina] disse: "Quando torneremo a Medina i più potenti scacceranno i più umili” (Cor. LXIII-8) e faremo uscire da essa Muhammad ed i suoi Compagni [...] ed Allah attribuì la potenza al Suo Inviato ed ai credenti in contrapposizione alla asserzione degli ipocriti dicendo, sia Egli esaltato: "Essi dicono: Quando torneremo a Medina i più potenti scacceranno i più umili. La Potenza spetta ad Allah, al Suo Inviato ed ai credenti, e gli ipocriti non sanno" (Cor. LXIII-8) a chi attribuiscono la Potenza", e nella sezione del Cap. 558 dedicata al Nome "Colui che rende potenti (al-mu izz)" [IV 229.21], aggiunge: "Questa Presenza rende il servitore inaccessibile $(m a n \bar{\imath} `$ al-hima $)$ e gli conferisce la predominanza (galaba) e la forza incoercibile ( $q a h r$ ) a chi si oppone a lui nella sua stazione con una asserzione falsa che non ha posto nella verità, e che è colui che si sente potente a causa della stima della creatura [e non per effetto di questa Presenza]".

100) Il significato letterale del verbo ğabara è ricomporre una frattura ossea. Quanto alla Sua prossimità, si riferisce alla affermazione: "Io sono presso coloro che hanno il cuore infranto a causa Mia".

101) Nel Cap. 560 [IV 529.26] Ibn 'Arabī riferisce: "Il mio Maestro, Allah abbia misericordia di lui, mi fece una raccomandazione la prima volta che entrai da lui, prima di vedere il suo volto. Avendogli detto: "Fammi una raccomandazione prima che tu mi veda. Io serberò da parte tua la tua raccomandazione e tu non mi guarderai finché non vedrai la tua veste di onore su di me", egli, Allah sia soddisfatto di lui, mi disse: "Questa è una aspirazione elevata e nobile, ragazzo mio. Chiudi la porta, rompi i legami (asbāb), e stai seduto in compagnia di Colui che dona: Egli ti parlerà senza velo". Misi in pratica questa raccomandazione finché vidi la sua "baraka", dopo di che rientrai da lui ed egli vide la sua [della baraka] veste d'onore su di me e disse: "Va bene così, altrimenti no"', Si tratta dello Šayh Abû-l-'Abbâs al-'Uryabî, che Ibn 'Arabî incontrò a Siviglia nell'anno 580 
E quando l'aspirante non si accorge di ciò che si è aggiunto nel suo arrivo dal Maestro e nella sua presenza presso di lui, allora non è sincero nel suo recarsi [da lui], esamina se stesso, si pente e chiede perdono, e sa che non si è recato da lui se non per se stesso [e non per Allah]. "Ed il tuo Signore non fa torto a nessuno" (Cor. XVIII-49), poiché il giudice non ti giudica se non in base allo stato in cui ti trovi nella tua faccenda, e che sia a tuo favore o contro di te, il giudice [ti giudica] in base al tuo regime $(h u k m)$ in ogni caso.

Alla stessa maniera si comporta il Vero con i Suoi servitori e per questo "ad Allah appartiene l'argomento decisivo" (Cor. VI-149), ed i giudici sono i sostituti del Vero e ad essi appartiene l'argomento decisivo nei confronti di colui che è giudicato, se essi giudicano secondo la verità, ma se talora sono ingiusti e talora sono giusti allora non sono i sostituti di Allah nei loro giudizi ed hanno un interesse personale (garad).

L'aspirante sincero deve quindi vigilare sui suoi stati nei suoi movimenti con il suo Maestro e deve prendere ciò che risulta dalla sua situazione come suo testimone riguardo alla sincerità del suo stato. Se esce con ciò con cui è entrato ha perso il suo tempo ed in realtà non è entrato né è venuto, ed è un adoratore della sua passione. Per questo i Maestri dicono, di colui che si reca da loro, che egli esce con ciò con cui è venuto, e se viene con il suo Signore esce con Lui e se viene con la sua anima esce con essa. Egli dice: "se la sua situazione lo comporta, il Vero gli regala vesti d'onore, ma se non comporta quello entra come possessore di un'anima ed esce allo stesso modo".

Chiunque entra [24] dal Maestro o si reca da lui senza considerare in se stesso che quella entrata è da Allah e che quel recarsi è verso Allah, non entra e non si reca.

Allo stesso modo per chi entra dai Re è necessario che entri da loro in base al grado che essi hanno e per il quale sono chiamati Re e rispetti l'adab nella visita, ed allora trarrà beneficio dalla visita a loro; quando invece entra da loro in quanto essi sono simili a lui nell'umanità e non osserva il rango, non ottiene assolutamente alcuna elargizione dal rango e fallisce l'adab ed esce bandito, esteriormente se ha fatto male esteriormente ed interiormente se ha fatto male interiormente, e quello è il perdente. Non c'è dubbio che questo Maestro ha voluto significare in questa sua raccomandazione che l'uomo deve essere consapevole della sua condizione di servitù e niente altro, poiché in essa vi è la totalità del bene ed il fondamento (malāk) della faccenda, in quanto il servitore è colui che è basso $(\underline{d} a l \bar{\imath} l)$.

Poi ha detto: "che la sua marcia sia nella parte battuta della via". Commento: questo Maestro temeva la disattenzione da parte dell'aspirante ed ingiungendogli di cercare la parte battuta della via voleva facilitargli la faccenda, facendogli vedere la via che deve percorrere, al contrario della parte dura e aspra della via che ti distrae dall'obiettivo (maqsüd) per la difficoltà che essa comporta.

dall'Egira, quando aveva 20 anni. Lo stesso episodio è infatti riportato nella "Risāla rūh al-quds", nel capitolo dedicato a questo Maestro [pag.61 della traduzione francese intitolata Les Soufis d'Andalousie] 
Invero Allah, sia Egli esaltato, non ha reso piana $(\underline{d} a l \bar{u} l)$ se non la Terra $(\operatorname{ard})\left({ }^{102}\right)$, e questo nome deriva dal [verbo] ha reso trattabile, rende trattabile $(r \bar{a} d a-y a r \bar{u} d u)$, cioè ha reso piana se stessa $\left({ }^{103}\right)$. Ed è assolutamente risaputo che la persona non abbassa se stessa se non messa a confronto con una potenza, e questa persona [cioè l'aspirante] non ha scopo (maqsid) nel Maestro se non Allah, il Potente, ed è quindi inevitabile che per questa visione diretta (šuhūd) abbassi se stessa. È come se egli [il Maestro] gli avesse ordinato di vigilare sul suo stato nel recarsi dal Maestro, e la parte battuta della via, quando è l'obiettivo dell'aspirante, protegge per lui lo stato di abbassamento con cui si reca e facilita per lui la sua ricerca.

Una sera mi trovavo alla Mecca con Mūsā ibn Muḥammad al-Qabbāb (104), che era dotato di presenza di spirito (hudūr), ed eravamo [25] presso la moschea di Abū Bakr, che si trovava su un terreno appianato, al cui fianco c'era la parete (sudd) di un monte dal terreno aspro e duro, con rocce appuntite, ed in quel terreno impervio c'era la casa di 'Umar ibn al-Ḩațāb. Mūsā ibn Muhammad mi disse: "O nostro signore, osserva quanto è stupefacente questa cosa", ed io gli chiesi: "Quale?”, ed egli soggiunse: "La moschea di ciascuna di queste due persone è in un luogo che corrisponde al suo carattere (huluq). Questa è la casa di Abū Bakr in un posto piano e battuto - e così era il suo carattere - in un posto corrispondente al suo carattere, e nel carattere di 'Umar c'era durezza (huzūna) ed egli ha preso dimora in un posto aspro e duro". Mi stupii della sua prontezza di spirito (tanabbuh) e della sua bella osservazione.

Per questo il Maestro ha ordinato che egli camminasse nella parte battuta della via, per via del fatto che ciò costituisce un incentivo per colui che controlla i suoi stati [non distraendolo] ed è più rapido e più facile per soddisfare il bisogno. Non vedi che l'Inviato di Allah, che Allah faccia scendere su di lui la Sua șalāt e la Pace, camminava come se egli scendesse il pendio con passi veloci? E a questo riguardo disse che quel modo di marciare è più negativo per l'alterigia (kibr) e più veloce per soddisfare il bisogno $\left({ }^{105}\right)$, poiché una persona non cammina se non per un bisogno, necessariamente.

102) Cfr. Cor. LXVII-15. Nel Cap. 69 [I 410.1] Ibn 'Arabî precisa: "La servitù è l'abbassamento. Descrivendo la Terra Egli, sia esaltato, ha detto che l'ha resa piana per noi affinché camminassimo sulla sua superficie, ed essa è sotto i nostri piedi, il che è il massimo dell'abbassamento: l'essere calpestati da chi è basso. Poiché essa è a questo grado dell'abbassamento, Egli ci ha ordinato di porre su di essa ciò che abbiamo di più nobile nel nostro aspetto esteriore, cioè la faccia, e noi la sfreghiamo sulla terra. Egli ha fatto ciò per ricomporre lo spezzamento della terra che è calpestata da chi è basso, cioè il servitore: nella prosternazione la faccia del servitore e la faccia della Terra sono riunite e così viene riparata la sua frattura, poiché Allah è presso coloro che hanno il cuore infranto". Un analogo commento è riportato nel Cap. 72 [I 750.34].

103) La stessa definizione è riportata nel Cap. 558 [IV 216.23].

104) Originario di Cordoba era stato a Fes discepolo di Abū l-Hasan ibn Harāzim, il Maestro di Abū Madyan, ed all'epoca dell'episodio qui riportato [intorno all'anno 599 dall'Egira] era muezzin ( $m u$ 'addin) della Moschea sacra della Mecca. Cfr. Cap. 71 [I 603.14], Cap. 161 [II 262.3] e Cap. 466 [IV 96.5].

105) Riferimento ad uno hadīt riportato da at-Tirmid̄ī, XLVI-8, e da Ibn Hanbal. La stessa frase si trova nel Cap. 560 [IV 504.32]. 
Poi disse: "che nella sua anima vi sia [la convinzione] di essere inferiore a chiunque incontri nella sua via verso il Maestro, e così in tutti i suoi stati". Commento: invero il Maestro gli ha indicato questa attitudine, nella sua raccomandazione, in quanto [l'aspirante] è uno che cerca saggezza e dovunque la trova la registra (qayyada), chiunque sia a proferirla $\left(^{106}\right)$. E questo aspirante la scorge in quanto Allah, sia Egli esaltato, fa proferire a questa persona ciò in cui vi è per lui senza dubbio della sollecitudine [divina], in proporzione al rango di quella saggezza che proferisce; ed anche se colui che la proferisce non conosce il valore di ciò che proferisce, Colui che fa proferire (munattiq) $\left({ }^{107}\right)$ sa il valore di ciò che fa proferire, e chi ascolta non vede se non colui che è fatto proferire e non c'è dubbio che egli ['aspirante] è inferiore a colui che è fatto proferire, ed [26] è inferiore a tutti coloro da cui si manifesta quella saggezza quando viene proferita, poiché senza saperlo essi sono un supporto di manifestazione (mağlā) divino ${ }^{(108)}$.

Il lato destro della montagna non era informato del fatto che Allah, sia Egli esaltato, parlava da esso al Suo servitore Mosè, "e lo abbiamo chiamato dal lato destro della montagna e lo facemmo avvicinare in segreto colloquio" (Cor. XIX-52), ed allo stesso modo l'albero non sapeva che Allah, sia Egli esaltato, parlava da esso al Suo servitore Mosè.

E questo Maestro, in questa sua raccomandazione, gli ha indicato in questo modo una stazione spirituale maestosa ed una dimora spirituale elevata, anche se in essa vi è la visione dell'altro, e se non fosse che per il suo seguire la via, il cui percorso lo conduce alla casa del Maestro, è inevitabile che veda degli altri. Ed egli deve convincersi che essi sono dei contenitori (aw fya) per ciò che il Vero

106) Nel Cap. 519 [IV 161.16] Ibn 'Arabī precisa: "Ogni cosa che si muove nel Mondo si trasferisce, ed essa è un messaggero $(r a s \bar{l} l)$ divino, quale che sia la cosa che si muove, poiché anche la più piccola di esse non si muove se non per la Sua autorizzazione, sia Gloria a Lui. Il conoscitore osserva ciò che esse apportano nel loro movimento, ed ottiene con ciò una scienza che non aveva, ma l'apprendimento da parte dei conoscitori da questi messaggeri è diverso a seconda dei messaggeri: il loro apprendere dai messaggeri che hanno le indicazioni [per farlo], la Pace di Allah sia su di loro, non è come il loro apprendere dai messaggeri che sono tali per l'autorizzazione e non ne sono consapevoli [...] Tutto il Mondo è per il conoscitore un messaggero da Allah verso di lui".

107) Cfr. Cor. XLI-21: "Ci ha fatto parlare Allah, che fa parlare ogni cosa".

108) René Guénon, in Initiation et réalisation spirituelle, pag. 162, precisa: "Si l'on parle souvent du rôle initiatique du Guru ou du Maître spirituel (ce qui d'ailleurs, bien entendu, ne veut certes pas dire que ceux qui en parlent le comprennent toujours exactement), il est, par contre, une autre notion qu'on passe généralement sous silence: c'est celle de ce que la tradition hindoue désigne par le mot upaguru. Il faut entendre par là tout être, quel qu'il soit, dont la rencontre est pour quelqu'un l'occasion ou le point de départ d'un certain développement spirituel; et, d’une façon générale, il n'est aucunement nécessaire que cet être lui-même soit conscient du rôle qu’il joue ainsi. Du reste, si nous parlons ici d'un être, nous pourrions tout aussi bien parler également d'une chose ou même d'une circonstance quelconque qui provoque le même effet; cela revient en somme à ce que nous avons déjà dit souvent, que n’importe quoi peut, suivant les cas, agir à cet égard comme une «cause occasionnelle»; il va de soi que celle-ci n'est pas une cause au sens propre de ce mot, et qu'en réalité la cause véritable se trouve dans la nature même de celui sur qui s'exerce cette action, comme le montre le fait que ce qui a un tel effet pour lui peut fort bien n'en avoir aucun pour un autre individu". 
getta in essi, ed ottiene nella sua via, se ha questa attitudine, numerose scienze prima del suo arrivo dal Maestro.

Invero l'aspirante va dal Maestro solo per poter trarre insegnamento da lui e sa di essere inferiore al suo Maestro, ed è per questo che va da lui: se tale attitudine lo accompagna nella sua via e nei suoi stati con tutti coloro che incontra, chiunque lo incontri è nei suoi riguardi un Maestro.

Non vedi come si rivolse Abū Yūsuf al-Hamadānī $\left({ }^{109}\right)$ a quell'aspirante che lo aveva reclamato con il suo pensiero improvviso (hātir) perché gli spiegasse il suo accadimento? (110) Egli gli disse: "Figlio mio, se ti viene in mente qualcosa che ti è oscuro, non farmi affaticare: chiedi della mia casa ed io ti spiegherò il tuo accadimento", e l'aspirante gli rispose: "O Abū Yūsuf, quando mi capita un accadimento io sollevo ogni pietra e trovo presso di essa un Abū Yūsuf come te" - indicando ciò che ha detto questo Maestro nella sua raccomandazione - ed Abū Yūsuf disse: "Seppi così che l'aspirante sincero fa muovere [27] il Maestro con la sua aspirazione (himma), mi rivolsi pentito ad Allah e me ne andai" $\left({ }^{111}\right)$

Chiunque ottiene o cerca un profitto $(f \bar{a} \hat{\imath} d a)$ è necessariamente inferiore a colui da cui spera di ottenere quel profitto, e l'aspirante è uno che cerca saggezza da ogni cosa ed in ogni cosa ed è necessario che egli in se stesso sia in questo modo, tanto da essere in questa maniera anche con se stesso, ed allora ottiene da se stesso, per la sua vigilanza (murāqaba), le saggezze che Allah gli accorda nei suoi movimenti, nelle sue soste e nelle sue membra, sì che una parte è di profitto all'altra, come ha detto Ibn Zuhr nella sua poesia $\left({ }^{112}\right)$ :

109) Il curatore dell'edizione a stampa lo identifica ad Abū Ya'qūb Yūsuf ibn Ayyūb al-Hamadānī, nato nell'anno 440 dall'Egira e morto nell'anno 535. Anche nelle Parole di Sūfì di Farīduddīn al-'Ațāàr, Boringhieri, 1964, pag. 38, è citato Abū Yūsuf al-Hamadānī, ma il traduttore, più prudentemente, si limita ad affermare che potrebbe trattarsi di Abū Ya'qūb Yūsuf ibn Ayyūb al-Hamadānī. In effetti Ibn 'Arabī si riferisce ad un Maestro che aveva come kunya Abū Yūsuf, senza riportarne il nome (ism), mentre l'altro ha come kunya Abū Ya'qūb e come nome Yūsuf. Quest'ultimo, era considerato il Polo (gawt) della sua epoca, e quando era a Bagdād, aveva preannunciato al giovane 'Abd al-Qādir al-Ǧìlānī [470-561 H] il suo futuro luminoso [Mehmmed Ali Ainī, 'Abd-al-Kadir Guilāñ̄, Geuthner, 1967, pag. 53], e tra i suoi carismi vi era il dono dell'ubiquità.

110) Abū Yūsuf era solito non uscire dalla sua zawiya se non per recarsi alla salāt del venerdì, ma un certo giorno gli si presentò il pensiero improvviso di uscire, senza sapere perché, ed allora salì sul suo Asíno e lasciò che Allah lo guidasse laddove Egli voleva, sicché l'Asíno lo condusse fuori dalla città in una piccola moschea dove era seduto un giovane, che aveva bisogno di chiarimenti da parte di un Maestro. Nel suo Kitāb al amr almuhkam, Ibn 'Arabī precisa che questo episodio ebbe luogo dopo che Abū Yūsuf aveva esercitato il magistero per più di 70 anni, e doveva quindi essere novantenne.

111) Questo aneddoto venne riportato ad Ibn 'Arabī da Awhāduddīn al-Kirmānī nell'anno 602 dall'Egira a Qunya, come egli stesso riferisce nel suo Kitäb al amr al-muhkam [cfr. Asín Palacios, "El Islam Cristianizado", Editorial Plutarco, Madrid, 1931, pagg. 310].

112) Abū Marwān 'Abd al-Malik ibn Zuhr, originario di Siviglia, ove morì nell'anno 557 dall'Egira, è noto in occidente come Avenzoar. Fu un celebre medico, maestro in questa disciplina di Averroé, ma fu anche autore di poesie. 
Una parte di me compiange con me una parte di me

e fa si che parte di lui aiuti una sua parte

Avvertimento (tanbīh) riguardo a ciò a cui abbiamo alluso del fatto che l'uomo trae profitto da se stesso se è uno che cerca saggezza, ed in tutti i suoi stati egli continua ad apprendere, poiché egli continua nella sua vigilanza, e questa è la condizione dell'ascoltare (sam $\left.\bar{a}^{\complement}\right)$ Allah, sia Egli esaltato, in ogni cosa e da ogni cosa. Sennonché, rispetto a colui che ascolta Allah, questo aspirante ha in più il fatto che egli sente da se stesso ciò che gli è di profitto, in quanto egli [stesso] è un supporto di manifestazione divino che viene fatto parlare o muovere da Allah, e per questa condizione è più perfetto di colui che ascolta Allah, quanto è Potente e Magnificente.

Poi disse: "e quando è vicino alla dimora del Maestro, se lì vi è una moschea vi entri, faccia una șalāt e chieda ad Allah, sia Egli esaltato, di disporre favorevolmente verso di lui il cuore del Maestro".

Commento: se il suo procedere ed il suo camminare verso la casa del Maestro dipendono dalla direttiva datagli dal Maestro di recarsi da lui, non vi è divergenza nel gruppo degli iniziati sul fatto di non fare la șalāt, né altre cose, se non di recarsi dal Maestro. Il loro fondamento in quello è l'episodio riguardo a cui è stato rivelato "O voi che credete, rispondete ad Allah ed all'Inviato quando [28] vi chiamano a ciò che vi dà vita" (Cor. VIII-24) $\left.{ }^{113}\right)$. Per noi è noto che il Maestro non chiede all'aspirante di venire da lui per sé stesso, bensì per il beneficio dell'aspirante, e se il bisogno fosse del Maestro, egli non farebbe venire l'aspirante per esso e per soddisfarlo tramite lui, se non per un beneficio divino che in quello ritornerebbe a lui, vivificando con esso il suo cuore ed essendovi in esso un avvicinamento ad Allah. L'uomo riguardo a cui è stato rivelato questo versetto stava facendo la salāt e l'Inviato di Allah, che Allah faccia scendere su di lui la Sua șalāt e la Pace, lo chiamò e la salāt gli impedì di rispondere, e quindi discese il versetto.

Di questo capitolo fa parte la questione dell'adoratore che la madre chiamava mentre faceva la șalāt. Egli disse: "Allāhumma, mia madre e la mia șalāt", poi si dedicò alla sua șalāt e tralasciò di rispondere a sua madre. Ella lo chiamò una seconda volta ed egli disse: "Allăhumma, mia madre e la mia salāt", e si dedicò alla sua salāt $\mathrm{e}$ tralasciò di rispondere a sua madre. Ella disse allora: "Allāhumma, non farlo morire finché non gli hai fatto vedere i volti delle prostitute (mümisāt)", cioè delle meretrici. Allah lo mise alla prova con una donna adultera che pretendeva di essere stata messa incinta da lui, e la gente demolì la sua cella e lo picchiarono. Ed egli disse: "Non fatelo, chiamate la donna ed il bimbo che ella ha generato". Essi fecero venire il bimbo e la madre prostituta, ed ella disse di fronte al Re: "Questo è il figlio di questo adoratore!". L'adoratore disse al bimbo: "Chi è tuo padre?”, ed egli rispose: "Il pastore". La gente si scusò con lui e ricostruì la sua cella così come era, ed ebbe effetto in lui l'appello $($ da wa $)$ di sua madre $\left({ }^{114}\right)$.

113) Il capitolo 519 delle Futūhăt è dedicato a questo versetto.

114) Ibn 'Arabī si riferisce ad uno ḥad̄̄t trasmesso da Abū Hurayra e riportato da al-Buhāāī, XXI-7, XLVI-35, 
Non c'è dubbio che al Maestro è dovuta [da parte dell'aspirante] una più grande riverenza (hurma) che a sua madre, poiché egli è per la sua vita tradizionale $(d \bar{\imath} n)$ ed è l'erede dell'Inviato di Allah nella guida di lui, e l'Inviato di Allah, che Allah faccia scendere su di lui la Sua șalāt e la Pace, ha detto: "Un servitore non ha fede finché io non sono più caro per lui della sua famiglia, della sua ricchezza, della sua progenie e degli uomini tutti insieme" $\left({ }^{115}\right)$.

Se invece [29] il suo recarsi dal Maestro dipende da una iniziativa personale, senza essere chiamato, allora farà quello che ha menzionato il Maestro riguardo all'entrare nella moschea e fare la salät, poiché l'Inviato di Allah, che Allah faccia scendere su di lui la Sua salāt e la Pace, quando era di ritorno dal suo viaggio per prima cosa entrava nella moschea e vi faceva due rak'at $\left({ }^{116}\right)$ : e questo Maestro ha considerato questa misura nella sua raccomandazione di fare una șalät se sulla via dell'aspirante si trova una moschea.

Quanto alla sua raccomandazione di chiedere ad Allah di disporre favorevolmente verso di lui il cuore del suo Maestro, nella maggior parte dei momenti il Maestro è occupato con il suo Signore e quindi può essere che lo trovi occupato in altro che lui. Se l'aspirante va da lui ed ha fatto una simile richiesta ad Allah, sia Egli esaltato, e trova il Maestro occupato con il suo Signore nel suo ritiro spirituale, non è improbabile che Allah risponda alla sua richiesta e che il Vero dica al Maestro nel suo intimo: "È arrivato questo tale: soddisfa la sua richiesta per la quale è venuto da te!".

Ero passato dal più grande $\left(a^{c} z a m\right)\left({ }^{117}\right)$ Maestro che ho incontrato, che si chiamava Ṣāliḥ al-'Adawī $\left({ }^{118}\right)$ e lo avevo salutato, ed egli, che era malato, mi aveva reso il saluto a bassa voce [lett. tra le sue labbra] tanto che mi dissi che forse mi aveva reso il saluto o forse non me lo aveva reso, ed ero in dubbio al riguardo, così come era rimasto in dubbio uno dei tre che Allah ha menzionato nel Corano $\left({ }^{119}\right)$ quando l'Inviato di Allah, che Allah faccia scendere su di lui la Sua salāt e la Pace, lo aveva scansato

LX-48, Muslim, XLV-7 e 8, e da Ibn Hanbal.

115) Hadīt riportato da al-Buhārī, II-8, LXXXIII-3, Muslim, I-69 e 70, an-Nasā’̄̄, Ibn Māğah, e da Ibn Ḥanbal.

116) Hadīt riportato da al-Buhārī, VIII-59, LVI-198 e 199, LXIV-79, Muslim, VI-74, Abū Dāwud, XV-16 e 166, an-Nasā'̄î̀, ad-Dārimī, e da Ibn Hanbal.

117) A 'zam è il superlativo di 'ažim che significa "grande" nella considerazione degli altri, mentre kabīr, il cui superlativo akbar, significa "grande" in se stesso.

118) Si tratta del terzo Maestro che Ibn 'Arabī cita nell'Epistola dello Spirito della Santità (risāla rūh al-quds) ed è lo stesso che è menzionato quattro volte nelle Futūhạt con il nome di Sālị̣ al-Barbarī [capitoli 32 (I 206.16), 73 (II 15.25), 309 (III 34.12) ove gli attribuisce la stazione spirituale dei Malämiyya, e 378 (III 488.16)]. Sālih al-'Adawī trascorse i primi 40 anni della sua vita senza fissa dimora e gli ultimi 40 a Siviglia, ove morì. Ibn 'Arabī riferisce di averlo incontrato agli inizi della sua via e di averlo frequentato per circa tredici anni, per cui l'episodio qui riferito deve aver avuto luogo quando Ibn 'Arabī era sulla trentina.

119) Ibn 'Arabī si riferisce a Kacb ibn Mālik, che è uno dei tre a cui fa riferimento il versetto 118 della Sūra IX. Cfr. gli ahạdīt riportati da al-Buhārī, LXIV-79, LXXIX-21, XCIII-53, Muslim, XLIX-53 a 55, Abū Dāwud, XXXIX-2, at-Tirmid̄ī, XLIV, ad Sūra IX-17, an-Nasā̄̄î, VIII-37, XXVII-18 e da Ibn Ḥanbal. 
mentre entrava nella moschea, ed egli aveva salutato l'Inviato di Allah, che Allah faccia scendere su di lui la Sua șalāt e la Pace. Questo compagno dubitò che l'Inviato di Allah, che Allah faccia scendere su di lui la Sua șalāt e la Pace, gli avesse reso il saluto per la sua impercettibilità (hafā').

Mancò poco che mi sciogliessi sul posto, temendo l'esecrazione (maqt) di Allah, quanto è Potente e Magnificente, e restai a tremare, mentre il Maestro era accigliato in volto e non mi guardava, avendo lo sguardo rivolto a terra. Ripetei allora il saluto a voce alta, ed egli sollevò lo sguardo verso di me, mi sorrise e mi rese il saluto, accogliendomi cordialmente. Io dissi: "Per Allah, o mio signore, il tuo scansarti da me mi ha ucciso" ed egli rispose: "Prima che tu arrivassi [30] c'era da me un tale esecrabile ed è da lui che mi scansavo; si era alzato e se ne era andato senza che me ne accorgessi, tanto lo evitavo, ed eri arrivato tu e non sapevo del tuo arrivo, e quando mi hai salutato la prima volta credevo che tu fossi quella persona. Quanto a me, figlio (walad) mio, per Allah io ti amo intensamente". Quella notte stessa il Maestro morì ed io osservai lo stato di quell'aspirante ed egli non cessò di allontanarsi dalla sua tradizione $(d \bar{\imath} n)$ finché non uscì completamente da essa, e manifestò chiaramente le violazioni nel patto ('aqd).

Per questo l'aspirante deve chiedere che Allah disponga favorevolmente verso di lui il cuore del Maestro, e non il suo volto, poiché il Profeta, che Allah faccia scendere su di lui la Sua salāt e la Pace, accolse favorevolmente e sorridendo colui di cui aveva detto, quando lo aveva intravisto prima del suo arrivo da lui: "Che malvagio figlio della tribù" e quindi non sorrise di fronte a lui se non per premunirsi contro il suo male: così disse l'Inviato di Allah, che Allah faccia scendere su di lui la Sua salāt e la Pace $\left({ }^{120}\right)$.

Perciò questo Maestro ha specificato che la richiesta di questo aspirante fosse di disporre favorevolmente verso di lui il cuore del Maestro, in quanto il cuore è la dimora del Vero, che esso comprende $\left({ }^{121}\right)$, e se il cuore del Maestro è disposto favorevolmente verso di lui, è disposto favorevolmente verso di lui il Vero, per come è conosciuto da quel Maestro, poiché il grado (qadr) del Vero in ogni cuore è in proporzione alla conoscenza che esso ha di Lui.

Già conoscete il racconto di Abū Yazīd riguardo a ciò nei riguardi di un aspirante a cui uno dei suoi compagni aveva detto: "Perché non vai a casa di Abū Yazīd per vederlo?", e l'aspirante rispose: "Ho visto Allah e ciò mi permette di fare a meno di Abū Yazìd". L’uomo gli disse allora: "Che tu veda Abū Yazīd una volta è meglio per te che vedere Allah mille volte", riferendosi a ciò che abbiamo menzionato del fatto che il Vero nella conoscenza di Abū Yazīd era più perfetto di quello di cui aveva conoscenza questo aspirante. E l'aspirante, che era sincero, volle [31] verificare la veridicità di costui che aveva parlato.

120) Hadīt riportato da al-Buhārī, LXXVIII-38 e 48, Muslim, XLV-73, Abū Dāwud, XL-6, Mālik, e da Ibn Hanbal.

121) Riferimento allo hadīt qudsĩ: "I Miei Cieli e la Mia Terra non Mi comprendono, ma il cuore del Mio servitore credente Mi comprende", non recensito nelle raccolte canoniche. 
Capitò che Abū Yazīd passò e l'uomo disse [all'aspirante]: "Questo è Abū Yazīd", e quell'aspirante lo osservò e morì all'istante. Abū Yazīd venne interrogato al riguardo e disse ciò che abbiamo detto: "Il Vero era presso di lui secondo il suo grado ed il nostro grado è più grande del suo, e la nostra conoscenza di Allah è più grande della sua conoscenza di Lui. Quando ci ha visto, Allah ha tolto il velo alla sua visione interiore ed egli ha visto il Vero conformemente al nostro grado, non al suo, non ha resistito ed è morto. Così accadde a Mosè, su di lui la Pace, quando svenne per l'immensità della teofania (tağallî), allorché la montagna si sgretolò $\left({ }^{122}\right)$. Il suo sgretolarsi fu per ('an) $\left({ }^{123}\right)$ Allah, poiché Allah non Si manifestò alla montagna se non in conformità al grado della scienza di Lui che aveva la montagna, ed essa resistette, e per questo ha detto: "ed Egli la fece (ğáala-hu) diventare polvere" (Cor. VII-143) e non ha detto: "Quando il suo Signore Si manifestò alla montagna, la montagna si sgretolò da se stessa", ma il suo sgretolarsi fu l'esito del fare (ğa $\ell$ [divino] ( $\left.{ }^{124}\right)$. Essa era il velo di Mosè e quando venne meno Mosè vide ciò che vide la montagna e svenne da se stesso alla sua visione e non resistette, anche se sappiamo che egli possedeva la conoscenza del suo Signore nel suo cuore, e se Egli Si fosse manifestato a lui in conformità al grado della sua scienza di Lui non sarebbe svenuto" (125)

La nostra dottrina (madhab) è la stessa, come la dottrina di Sahl [at-Tustarīi] e della gente delle realtà essenziali, per ciò che riguarda i minerali, e cioè che essi hanno una scienza più grande di Allah [rispetto all'uomo], e sono stati creati secondo la [loro] scienza di Allah, a differenza dell'uomo nel suo insieme, per il quale è chiamato uomo $($ insān $)\left({ }^{126}\right)$.

122) Riferimento al versetto 143 della Sūra VII: "E quando Mosè venne al Nostro appuntamento e il suo Signore ebbe parlato con lui, Mosè disse: "O mio Signore, mostrati a me affinché possa vederti”. Rispose: "Tu non Mi vedrai, ma guarda la montagna, e se rimarrà ferma al suo posto, allora tu Mi vedrai”. E quando Allah Si manifestò alla montagna la fece diventare polvere e Mosè cadde svenuto. Quando tornò in sé disse: "Gloria a Te, io torno pentito a Te e sono il primo dei credenti".

123) Questa preposizione indica in questo caso la causa.

124) Come verrà spiegato nel seguito, la conoscenza che ha del Vero la montagna è superiore a quella che aveva Mosè: il Vero Si manifestò alla montagna conformemente al suo grado di conoscenza, per cui essa resistette alla visione, e si sgretolò solo per il Volere divino, mentre Mosè non resistette e svenne.

125) Nel testo arabo non vi sono virgolette che delimitano una citazione, per cui non sono certo che tutte queste siano parole di Abū Yazīd. Lo stesso episodio è riportato nel Cap. 331 [III 117.26], ove il commento di Abū Yazīd è più succinto, ma include il paragone con lo svenimento di Mosè, e nel Cap. 559 [IV 433.12].

126) Nel Cap. 72 [I 710.6] Ibn 'Arabī afferma: "Già ti abbiamo spiegato che i minerali sono tra tutti gli esseri generati quelli che più conoscono Allah e che più Lo adorano. Essi sono stati creati nella conoscenza, senza avere né ragione ('aql), né desiderio, né libertà di movimento, a meno che siano spostati. Essi quindi sono mobili non per loro stessi, bensì a causa di altri, ma non c'è "motore (musarrif)" se non Allah e quindi essi sono mossi per decisione di Allah. Le piante, anche se sono state create nella conoscenza, come i minerali, tuttavia abbandonano il rango dei minerali e cercano di innalzarsi al di sopra di esso da sole, in quanto fanno parte degli esseri che che si nutrono e ciò comporta la crescita e la ricerca dell'elevatezza. I minerali non sono così: l'elevazione non fa parte del loro movimento naturale e quando essi sono fatti salire in alto e poi lasciati, per la loro natura essi cercano il basso. Questa è la realtà essenziale della servitù ('ubüdiyya), mentre l'elevazione è un attributo estrinseco divino, ed Egli è l'Elevato. [...] Per questo Allah ha affermato: "Tra esse", riferendosi alle pietre, "ve ne sono che sprofondano per timore di Allah" (Cor. II-74), facendo derivare la loro caduta (hubüt) 
Se dici: "Il senso letterale del versetto implica che Mosè non vide il suo Signore, poiché la condizione $\left({ }^{127}\right)$ stabilita per la Sua visione non si verificò", noi rispondiamo: "Egli ha escluso con la condizione solo ciò che lo ha salvato (hallasa-hu) dal ricominciare (isti $n \bar{a} f$ ) la visione $\left({ }^{128}\right)$, ed egli non ricominciò la visione, bensì Lo vide in quel momento $(h \bar{a} l)\left({ }^{129}\right)$, per chi ben comprende il versetto trasmesso al riguardo. E lo svenimento spiega ciò che abbiamo indicato, poiché lo sgretolarsi della montagna non fece svenire né Mosè né altri; il suo velo era la montagna, che Allah gli aveva ordinato di osservare, [32] ed Allah la cancellò, sollevando così il suo velo, e Mosè vide al momento ciò che vide la montagna, come quell'aspirante vide ciò che vedeva Abū Yazīd per la sua scienza di Allah. E questa questione, su cui questo Maestro ha richiamato l'attenzione nella sua raccomandazione, ha molti rami e molti aspetti e palesa una conoscenza completa riguardo alla spiritualità di Damasco $\left({ }^{130}\right)$, e ci limitiamo a questo grado di segnalazione per chi intende da noi ciò che vogliamo dire.

da un timore. Quindi la pietra ha connaturato il timore verso Allah e la contemplazione le appartiene per sua essenza. "Invero tra i Suoi servitori sono i sapienti che Lo temono" (Cor.XXXV-28) e colui che ha timore sa chi teme. Questo era il punto di vista di Sahl ibn 'Abd Allāh at-Tustarī”, e nel Cap. 326 [III 99.8] aggiunge "Questi spiriti particolari sono di ranghi diversi per quanto concerne la scienza delle cose: ve ne sono che conoscono molte cose ed altri che ne conoscono poche. Non c'è spirito che abbia più scienza di Allah di quanta ne hanno gli spiriti delle forme che non hanno bisogno di essere governate, cioè gli spiriti dei minerali; di grado inferiore ad essi, nella scienza di Allah, sono gli spiriti dei vegetali, ed ancora più in basso sono gli spiriti degli animali. Ciascuna di queste categorie è stata creata (mafțür) per la scienza di Allah e la conoscenza di Lui, e la loro unica preoccupazione è di glorificarLo con la Sua lode, sia Egli esaltato. La categoria più bassa di tutte, per ciò che concerne la scienza di Allah, è quella degli spiriti degli uomini. Quanto agli Angeli, essi, come i minerali, sono stati creati per la scienza di Allah, e sono privi della ragione e del desiderio; gli animali sono stati creati per la scienza di Allah e per il desiderio, mentre gli uomini ed i ğinn sono stati creati per il desiderio e le conoscenze, per quanto riguarda le loro forme, non quanto ai loro spiriti, ed Allah ha dato loro la ragione affinché con essa rimettano il desiderio alla bilancia della Legge".

127) Cioè il fatto che la montagna rimanesse ferma al suo posto.

128) Se la montagna fosse rimasta ferma al suo posto Mosè avrebbe potuto vedere il suo Signore solo in un momento successivo, ricominciando la visione, mentre egli Lo vide nel momento stesso in cui vide la montagna sgretolarsi.

129) Nel Cap. 369 [III 395.11] Ibn 'Arabī afferma: "Lo vide al momento della sua richiesta, per la condizione che Egli stabilì per lui, come è riportato nel testo del Corano, o non Lo vide? Il versetto rende possibile il significato, poiché Egli non negò al tempo presente la connessione con la visione, ma negò soltanto il futuro con la particella sarefa. Non c'è dubbio che Allah Si manifestò alla montagna, che è creata (muhdat $)$, e la montagna fu ridotta in polvere per la Sua epifania; da questo deduciamo la visione da parte della montagna del Suo Signore, [visione] che rese necessaria la sua frantumazione. Quindi Lo vide una cosa creata: cosa impedisce dunque che Mosè, su di lui la Pace, Lo abbia visto nel momento della frantumazione, dato che la negazione riguardava il futuro? A questo non c'è alcun impedimento per chi capisce, tanto più che lo svenimento di Mosè, su di lui la Pace, tiene il posto della frantumazione della montagna".

130) Come il tempo, anche lo spazio ha delle caratteristiche qualitative, che fanno sì che un luogo sia diverso da un altro. Ibn 'Arabī spiega questa differenza nel Cap. 4 [I 99.1], ove afferma: "Come le dimore spirituali sono in un ordine gerarchico, così anche le dimore corporee hanno una gerarchia. Forse che la perla è simile alla pietra, se non per il possessore di uno stato spirituale transitorio? Quanto al perfetto, il possessore della stazione spirituale, egli distingue tra esse, così come le distingue il Vero. Forse che il Vero ha stabilito un'equivalenza tra una casa costruita di mattoni di terra e di paglia ed una casa costruita di mattoni di pietre preziose e d'argento? [...] Vi è molta differenza tra una città in cui sono coltivate soprattutto le passioni, ed una città in cui sono 
Poi ha detto: "e quando ha finito di fare la șalāt si rechi alla porta del Maestro e si fermi a distanza dalla porta, mostrando adab di fronte a lui". Commento.

Egli gli ha ordinato di fermarsi a distanza dalla porta del Maestro, affinché non si apra la porta del Maestro ed il Maestro esca in uno stato che l'aspirante non può sostenere $\left({ }^{131}\right)$ e non gli accada quindi ciò che è accaduto all'aspirante che vide Abū Yazīd con noncuranza.

Sulla luce del Maestro, per l'aspirante dotato di svelamento, non hanno potere (hukm) le distanze, con la loro lontananza e la loro vicinanza, poiché il tempo (zamān) del balenio del lampo (lam 'al-barq) è identico al tempo del tingersi (insib $\overline{a g}$ ) dell'aria per mezzo di esso, al tempo della manifestazione delle cose $\left.(a \check{s} y \bar{a}){ }^{132}\right)$ per esso ed al tempo dell'osservazione di chi le guarda. Non c’è un tempo tra quegli eventi, bensì il tempo è unico in quell'insieme, malgrado la nostra scienza che il balenio del lampo precede [logicamente] la colorazione dell'aria per mezzo di esso, e la colorazione dell'aria per mezzo di esso precede la manifestazione delle cose per esso, e manifestazione delle cose precede la percezione della vista da parte di colui che le guarda, ed è noto che il tempo è [sensibilmente] unico in tutto quello. Un caso analogo è la precedenza dei gradi (marātib), come la precedenza della causa

coltivati soprattutto i segni evidenti. Il mio amico ['Abd al-'Azīz al-Mahdawī], che Allah gli conceda lunga vita, non aveva forse convenuto con me che ciò che i nostri cuori trovano in certi posti è più di quello che trovano in altri? Egli, Allah sia soddisfatto di lui, aveva lasciato il ritiro spirituale nelle case di al-Munāra, la ben custodita, situata a oriente di Tunisi, sulla riva del mare, e si era trasferito nell'eremo che si trova in mezzo alle tombe che sono vicine a al-Munāra, dal lato della sua porta, e la cui origine viene fatta risalire al Hiḍr. Io lo interrogai in proposito ed egli mi rispose: "Invero, il mio cuore lo trovo più qui, che a al-Munāra ", ed anch'io provai in esso ciò che diceva lo Šayh. L'amico, che Allah gli conceda lunga vita, sapeva che ciò dipende da chi risiede attualmente in quel posto, come nel caso degli Angeli nobili o dei Ǧinn sinceri, o dall'aspirazione (himma) di chi vi era stato in passato, come nel caso della dimora di Abū Yazīd, chiamata la casa dei pii, della zawiya di al-Ǧunayd a Šunniziyya, della caverna di Ibn Adham a Yaqīn, o di altri luoghi dei pii che hanno abbandonato questa dimora terrena, ma le cui tracce restano in questi posti ed hanno un effetto sui cuori sottili". L'espressione "spiritualità di Damasco" sembra riferirsi soprattutto all'insieme delle tracce lasciate a Damasco dagli Intimi (aw liy $\bar{a})$ e dai Profeti che vi avevano soggiornato, tra cui lo Šayh Arslān, patrono di Damasco, Abū Sulaymān ad-Dāranī, e al-Gazālī, per non parlare del maqām del Profeta Abramo e del maqām dei 40 Abdāl sul monte Qāsiyūn. Quanto alla "completa conoscenza riguardo alla spiritualità di Damasco" da parte di 'Alī al-Kurdī, nel seguito del testo [pag. 288] Ibn 'Arabī formulerà su di essa alcune riserve.

131) Negli Aperçus sur l'initiation [Éditions Traditionnelles, 1977, pag. 60] René Guénon precisa: 'Dans l'Inde, nul disciple ne peut jamais s'asseoir en face du guru, et cela afin d'éviter que l'action du prâna qui est lié au souffle et à la voix, en s'exerçant trop directement, ne produise un choc trop violent et qui, par suite, pourrait n'être pas sans danger, psychiquement et même physiquement”.

132) In entrambi i manoscritti al posto di ašy $\bar{a}$ 's 's trova asma $\bar{a}$, cioè i Nomi, ma nel manoscritto Yūsuf Aga sopra ad $a s m \bar{a}^{\prime}$ è riportata come correzione $a \check{y} y \bar{a}$. Nel Cap. 72 [I 703.2] e nel Cap. 558 [IV 224.10] sono riportate le stesse considerazioni, ma al posto di ašy $\bar{a}^{\prime}$ si trova al-mahsususat, gli oggetti sensibili, o aSyann al-mahsūsāt, le entità degli oggetti sensibili, espressioni che corrispondono più alle cose che ai Nomi. Tuttavia va ricordato che nel Cap. 339 [III 151.30] Ibn 'Arabī afferma che: "le cose sono i Nomi del Vero", e nel Cap. 369 [III 373.1$]$ aggiunge: "Ogni nome con cui una cosa è denominata e che esprime un significato è il Nome di Allah". Pertanto entrambe le letture sono possibili. 
sul suo effetto, malgrado esso sia simultaneo a quella nell'esistenza $\left({ }^{133}\right)$.

Tuttavia è inevitabile che la lontananza abbia un effetto che non ha la vicinanza. Egli gli ha ordinato di tenere la distanza solo per via dell'adab, perché può darsi che Allah sveli al Maestro la sua venuta e ne risulti l'autorizzazione $(\underline{i d n})$ da parte del Maestro [33], tramite uno dei suoi compagni che gli ordini di entrare da lui, e ['aspirante] lasci quindi la sua via [volontaria] nella distanza che [ancora] lo separa dal Maestro per [seguire] la via dell'obbligatorietà per ciò che gli ha ordinato il Maestro e quindi lo incontri soddisfacendo un obbligo. Invero la visione di Allah, la visione del Suo Inviato e la visione del Maestro, che è tra coloro che sono dotati di comando nei confronti di questo aspirante, per la via dell'obbligatorietà e dell'adempimento degli obblighi di istituzione divina (fara perfetta (atamm) della visione che ottiene per mezzo degli atti supererogatori (nawäfil) e di obbedienza volontaria; ed è anche per questo motivo che gli ha ordinato di fermarsi a distanza.

Ed il suo detto: "mostrando adab con il Maestro": poiché [l'aspirante] non è nella dimora del Maestro, da cui è separato - ed è ininfluente per lui che la distanza sia tanta o poca - egli mostra adab, arrestandosi a distanza dalla porta del Maestro, di fronte al Maestro che è presente nel suo pensiero. [Con questa frase, egli] richiama la sua attenzione, se è noncurante, sul fatto che per l'aspirante è necessaria la sorveglianza (murāqaba) da parte del Maestro in tutti i suoi stati. Per questo ha detto: "mostrando adab di fronte a lui", anche se in quel momento [l'aspirante] è all'esterno, non di fronte a lui, in quanto egli [il Maestro] lo osserva, come se lo vedesse, ed egli [l'aspirante] è di fronte a lui. Nella notificazione autentica è stato tramandato ciò che corrobora questo, cioè il suo detto: "Adora Allah come se lo vedessi [poiché anche se tu non Lo vedi Egli comunque vede te]" $\left.{ }^{134}\right)$. E gli ha ordinato di mostrare $a d a b$ cercando di aver presente [il Maestro] nel suo pensiero, così come mostrerebbe $a d a b$ alla sua presenza, poiché egli ti vede anche se tu non lo vedi - cioè secondo l'aspetto esteriore della visione, poiché con quello interiore lo vede senza dubbio. E gli ha ordinato di mostrare $a d a b$ con la forma del Maestro che è nel suo intimo (bātin), e che la porta del Maestro sia per lui come lo specchio in cui si manifesta la forma del Maestro che è nel suo cuore, poiché l'aspirante non sa, per ciò che concerne la visione del Maestro quando lo vedrà con l'occhio della sua vista [esteriore], se lo vedrà con la forma che era stabilita (muqarrar) nel suo intimo, o se la forma risulterà essere diversa per

133) Nella Introduction générale à l'études des doctrines hindoues [Les Éditions Véga, 1976, pag. 246] René Guénon precisa: "Pour qu'une chose puisse être cause, il faut qu'elle existe actuellement, et c'est pourquoi le vrai rapport causal ne peut être conçu que comme un rapport de simultanéité: si on le concevait comme un rapport de succession, il y aurait un instant où quelque chose qui n'existe plus produirait quelque chose qui n'existe pas encore, supposition qui est manifestement absurde“. L'esempio riportato da Ibn 'Arabī mette in evidenza che il rapporto causale, che noi concepiamo logicamente come un rapporto di successione, è in realtà un rapporto di simultaneità.

134) Hadīt riportato da al-Buhārī, II-37, Muslim, I-1, 5 e 7, Abū Dāwud, XXXIX-16, at-Tirmidīī, XXXVIII-4, an-Nasā'ī, XLVII-5 e 6, Ibn Māğah, Introduzione-9, e da Ibn Hanbal, II-107 e 132. Nelle Futūhāt è menzionato una cinquantina di volte, in particolare nel Cap. 558 [IV 265.8 a 19], e sarà ulteriormente commentato nel manoscritto alle pagine 151, 193 e 243. 
lui in modo più perfetto rispetto a quella che aveva in sé. Questo vale per ogni visione, poiché la realtà è così in se stessa: Allah non Si manifesta mai in una stessa forma [34] due volte ad una persona $\left({ }^{135}\right)$, e ciò vale anche per le cose, e non resta se non che per te esiste quello che tu percepisci. Invero Allah, riguardo alle cose, è in ogni attimo (nafas) [occupato] in una nuova creazione ${ }^{136}$; ; chi sa ciò lo sa e chi

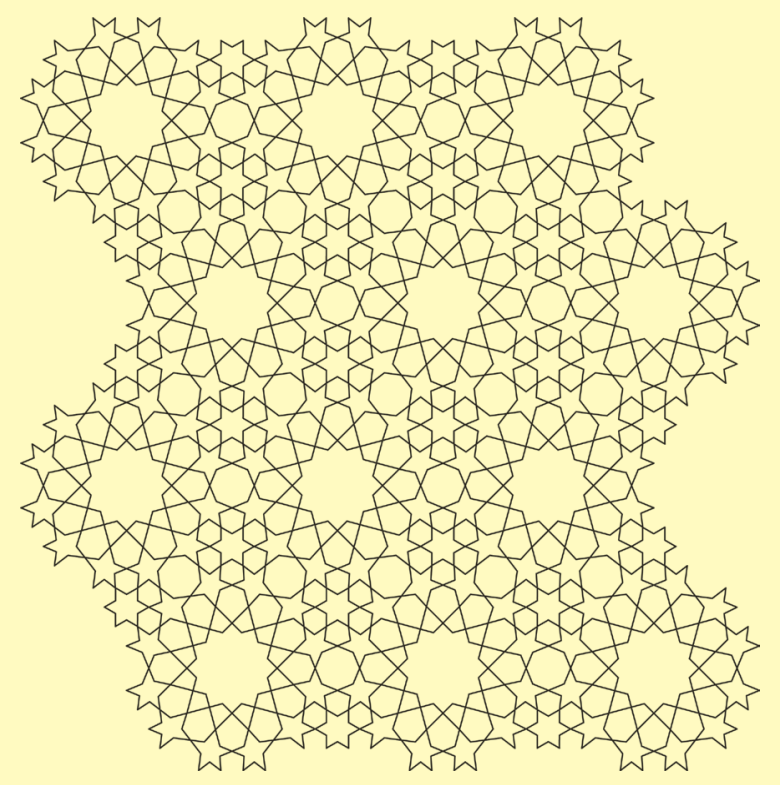

135) Questa affermazione è ribadita più volte nelle Futūhāt: Cap. 48 [I 266.10], Cap. 56 [I 285.29], Cap. 72 [I 679.8], Cap. 73, questione LV [II 77.27], Cap. 281 [II 616.3], Cap. 292 [II 657.13], Cap. 334 [III 127.32], Cap. 344 [III 178.23], Cap. 369 [III 384.30], Cap. 414 [IV 19.23], e Cap. 542 [IV 186.4].

136) L'espressione "nuova creazione (halq ğadīd)" ricorre numerose volte nel Corano: XIII-5, XIV-19, XVII49 e 98, XXXII-10, XXXIV-7, XXXV-16 e L-15. In decine di punti delle Futūhät Ibn 'Arabī precisa che la creazione, così come la teofania [tağallī, che si può tradurre anche come "manifestazione del Sé"], è continua e non si ripete mai; in questo senso non è corretto, come viene spiegato nel Cap. 334 [III 127.17], parlare di "rinnovamento della creazione", perché questa espressione implicherebbe una ripetizione, mentre la creazione è "nuova” in ogni attimo (nafas). Analogamente, ne L'erreur spirite [Éditions Traditionnelles, 1952, pag. 213-214], René Guénon precisa: "Or, supposer une répétition au sein de la Possibilité universelle, comme on le fait en admettant qu'il y ait deux possibilités particulières identiques, c'est lui supposer une limitation, car l'infinité exclut toute répétition: il n'y a qu'à l'intérieur d'un ensemble fini qu'on puisse revenir deux fois à un même élément, et encore cet élément ne serait-il rigoureusement le même qu'à la condition que cet ensemble forme un système clos, condition qui n'est jamais réalisée effectivement. Dès lors que l’Univers est vraiment un tout, ou plutôt le Tout absolu, il ne peut y avoir nulle part aucun cycle fermé: deux possibilités identiques ne seraient qu'une seule et même possibilité; pour qu'elles soient véritablement deux, il faut qu'elles diffèrent par une condition au moins, et alors elles ne sont pas identiques. Rien ne peut jamais revenir au même point, et cela même dans un ensemble qui est seulement indéfini (et non plus infini), comme le monde corporel: pendant qu'on trace un cercle, un déplacement s'effectue, et ainsi le cercle ne se ferme que d'une façon tout illusoire". 
lo ignora lo ignora, ed i simili $(a m t \bar{a} l)\left({ }^{137}\right)$ sono un velo sulla vista interiore ed esteriore $\left({ }^{138}\right)$, se non per colui che non è in dubbio riguardo a una nuova creazione: ognuno ha una [sua] visione delle cose e la forma è una forma che non appartiene ad altro che a quella visione.

Tra coloro che vedono c'è chi è testimone di ciò ed egli è il timorato (muttaq $\vec{\imath}$ a cui Allah ha dato una discriminazione (furqān) per il suo timore di Dio (taqwā), e c'è chi non è testimone di ciò ed egli non è timorato. Per mezzo di questa bilancia l'uomo pesa il suo stato nel timore di Dio, e sa se è timorato o se non lo è, poiché Allah, sia Egli esaltato, ha stipulato ciò dicendo: "Se avete timore di Allah Egli vi darà una discriminazione" (Cor. VIII-29), ed ha parlato di discriminazione in modo indeterminato e quindi ha generalizzato, poiché l'indeterminazione generalizza, soprattutto in una simile sede. E chi non conosce la discriminazione non pretenda di avere il timore di Dio, poiché la promessa di Allah è veridica.

Quanto al suo detto: "mostrando adab di fronte a lui”, l'adab è la somma (ğummać) del bene ed apporta tutto quello di fronte a lui, poiché [il termine adab] deriva dal banchetto (ma'duba), che è il riunirsi $($ iğtima $\bar{a})$ per il pasto $\left({ }^{139}\right)$. È quindi come se gli dicesse: "Abbi una buona opinione del tuo Maestro, riguardo ad ogni bene", poiché Allah, quanto è Potente e Magnificente, ha detto: "Io sono secondo

137) La concezione dei simili è strettamente legata alla dottrina della nuova creazione e dell'impossibilità della ripetizione. I simili sono come i fotogrammi di una pellicola cinematografica, che visti in rapida successione danno l'illusione di una continuità: la nostra forma o immagine dura un attimo, poi è sostituita da una nuova immagine che non è identica alla precedente, ma solo simile ad essa. Nel Cap. 192 [II 384.21] Ibn 'Arabī precisa: "Vi è divergenza di opinioni in merito alla persistenza dello stato ( $h \bar{a} l)$ : c'è chi afferma la sua persistenza e chi invece la nega sostenendo che lo stato dura solo il momento della sua venuta all'esistenza, come l'accidente per gli scolastici (mutakallimūn), ed è poi seguito dai "simili", che danno l'impressione illusoria che esso sia permanente. Quest'ultima è l'opinione corretta", e poco dopo [II 385.2] afferma: "Quando Allah crea lo stato, esso non ha altro ricettacolo che quello in cui è creato, e si infonde in esso per il tempo della sua esistenza [...] Non fa parte della sua realtà essenziale restare per due tempi, ed esso diviene inesistente nel tempo successivo a quello della sua esistenza, per se stesso, non per un agente che produca in lui la non-esistenza, poiché la nonesistenza non è passibile di subire un'azione, non essendo una cosa esistente, né per il cessare di una condizione, né per il contrario, in quanto tutto ciò è impossibile. È quindi inevitabile che esso cessi di esistere per se stesso, cioè, nel secondo tempo dopo quello della sua esistenza, la non-esistenza è per esso [lo stato] una condizione necessaria, ed il ricettacolo non ha permanenza senza di esso, o del suo simile o del suo contrario, e quindi in ogni tempo è dipendente per la sua permanenza dal suo Signore, che dà esistenza per lui a dei simili o a dei contrari. Quando Egli dà esistenza ai simili, ci si immagina che essi siano il primo [stato] e che esso sia rimasto come era, ma le cose non stanno così", e nel Cap. 198 [II 454.9] aggiunge: "In realtà non c'è cosa, tra quelle che non sussistono per loro stesse, che sia veramente permanente oltre al tempo della sua esistenza, ma alcune sono seguite dai simili ed altre non lo sono. Quanto alla cosa che è seguita dai simili, è quella che ci si immagina essere inerente (läzim) [alla sostanza], come il giallo dell'oro ed il nero dell'uomo negro. Quella che non è seguita dai simili si chiama accidente, mentre quella inerente si chiama attributo".

138) La stessa frase è riportata nel Cap. 72 [I 735.15] e nel Cap. 186 [II 372.22].

139) Le stesse considerazioni sono riportate nel Cap. 288 [II 640.23], nel Cap. 394 [III 556.3] e nel Cap. 559 [IV 365.33]. Il verbo adaba ha come primo significato quello di invitare al proprio banchetto, e come senso secondario quello di insegnare le regole di buona creanza. 
l'opinione che il Mio servitore ha di Me: abbia quindi una buona opinione di Me!" $\left({ }^{140}\right)$, e allo stesso modo il Maestro realizzato è secondo l'opinione che l'aspirante ha di lui, ed Allah, sia Egli esaltato, gli ha ordinato di essere secondo quella [opinione].

Osserva la profondità di questa raccomandazione: se essa deriva da uno svelamento e da conoscenza è bene su bene, se invece egli l'ha formulata senza intendere ciò che abbiamo spiegato, è tuttavia bella ed egli ha avuto in ciò l'assistenza di Allah, tanto da formularla in questo modo nei riguardi di questo aspirante: ed Allah è più sapiente su come stanno le cose.

Poi ha detto: "E si proponga di allontanare, per quanto gli è possibile, dalla sua anima le cattive fantasie (al-hayālāt ar-rad̄̄a) (141)". Commento [35]: cioè riguardo al suo Maestro, affinché non si trovi ad essere infirmato presso di lui e sia privato del vantaggio (manfáa) [che potrebbe ricavare] da lui. Invero Satana non cessa di riferire all'anima dell'aspirante ciò che rende il suo Maestro detestabile a lui, e per questo alcuni miseri aspiranti criticano i loro Maestri per ciò che essi vedono dei loro comportamenti, soprattutto se per il lato esteriore della Legge, sulla quale si basano i dottori della Legge (fuqaha $)\left({ }^{142}\right)$ dell'epoca, vi è un giudizio sancito su quel comportamento, soprattutto presso i seguaci delle quattro scuole.

140) Hadī qudsī non recensito in questa forma nelle raccolte canoniche, ma riportato una quindicina di volte nelle Futūhăt [capitoli: 56 (I 284.21), 69 (II 473.34, 527.14, 535.9), 70 (II 597.27), 72 (II 708.3), 102 (II 185.19), 124 (II 206.35), 198 (II 474.20 e 25), 229 (II 526.33), 369 (III 377.3) 403 (IV 5.7) e 560 (IV 446.14)].

141) Ibn 'Arabī riferisce qui le parole di un altro, adottando quindi la sua terminologia. In tutte le Futūhāt il termine hayālāt ricorre una sola volta [Cap. 360 (III 275.14)], e come si vedrà nel commento, l'espressione che usa Ibn 'Arabì è hawātir, plurale di hătiri, "proposito che si presenta alla coscienza". Anche il copista, nell'annotazione a margine del testo, scrive che si tratta degli al-hawētị ar-radī'a.

142) Il termine fuqah $\bar{a}$ 'è il plurale di faqīh, che deriva dal verbo faqiha, che significa avere scienza, conoscenza o comprensione. Nel Cap. 441 [IV 54.31] Ibn 'Arabī precisa che i termini 'ilm, márifa e fiqh "hanno tutti lo stesso senso; si comprende tuttavia che c'è una differenza tra di loro nel significato (dalāla), così come essi si differenziano nei termini”. In particolare il faqīh è colui che ha conoscenza della Legge tradizionale, in tutti i suoi aspetti, tra cui quello giuridico in senso occidentale non rappresenta quello più importante. La critica di Ibn 'Arabī non riguarda la funzione di dottori della Legge in quanto tale [nella Introduzione (I 36.1) egli precisa: "la teologia, nonostante la sua nobiltà, non è necessaria per la maggioranza degli uomini, bensì uno solo che se ne occupi nel territorio è sufficiente, come è per il medico! I dottori della Legge (fuqaha $\bar{a}$ ), cioè i sapienti dei rami della religione, non sono in questa situazione, dacché gli uomini hanno bisogno di molti sapienti della Legge. E nella Legge, per la lode di Allah, vi è la ricchezza e quanto basta"], ma il modo in cui essa era esercitata dai suoi contemporanei, che seguivano ciecamente i giudizi di coloro che ritenevano gli Imām della loro scuola, senza più fare uno sforzo di giurisprudenza (iğtihād). Ad esempio, nel Cap. 69 [I 494.19] egli parla dei: "dottori della Legge ( fuqah $\bar{a}$ ) che imitano la gente della giurisprudenza, come i dottori della Legge del nostro tempo: essi non hanno scienza né del Corano né della Sunna, ed anche se essi ricordano il Corano e vedono in esso ciò che contrasta con la scuola del loro Maestro, essi non se ne curano e non si conformano ad esso. Essi non lo recitano per cercare di ottenere la scienza e si attengono alla scuola del loro Imām che è in contrasto con questo versetto e con questa notificazione. Non vi sarà scusa presso Allah per loro riguardo a quello ed il primo che declinerà la sua responsabilità riguardo a loro nel Giorno della Resurrezione sarà il loro Imām”. Nel Vangelo l'espressione tradotta in italiano come "dottori della Legge" corrisponde al latino legisperiti ed al greco vouıко. 
Questi [aspiranti] non sanno che è impossibile che il Maestro renda lecito ciò che Allah ha proibito o che renda proibito ciò che Allah ha reso lecito, o formuli un giudizio che Allah non ha formulato, riguardo a ciò su cui dà un responso legale $($ fatwā), o che il Maestro indichi una cosa al suo aspirante o la faccia come lecita, e che essa sia proibita nel giudizio di Allah, sia Egli esaltato, tramite la lingua del Profeta Muhammad che è arrivato a noi con la Legge di Allah.

Talvolta [i Maestri], Allah sia soddisfatto di loro, per via dello svelamento da parte dell'Inviato di Allah, che Allah faccia scendere su di lui la Sua șalāt e la Pace, con una comunicazione verbale da parte sua, o per ispirazione (ilhām) $\left({ }^{143}\right)$ da parte di Allah, quanto è Potente e Magnificente, e per una proiezione $(i l q \bar{a})$ nei loro cuori secondo la via nota che è propria degli Intimi di Allah con Allah nei loro incontri (talaqqiyāt), vengono a sapere che il giudizio dell'Inviato da parte di Allah riguardo a quella faccenda è in un certo modo, diversamente da ciò che hanno giudicato le quattro scuole, o una di esse, anche se Allah ha stabilito la validità di quel giudizio rispetto a quel giurisprudente (muğtahid) $\left({ }^{144}\right)$ e a chi lo segue.

143) Il termine ilhām è l'infinito del verbo alhama che significa ispirare, suggerire, e che ricorre in Cor. XCI-7 e 8: "Per l'anima e per chi l'ha resa equilibrata * e le ispirò la sua sfrenatezza e il suo timor di Dio". Come Ibn 'Arabī spiegherà nel seguito di questo testo [pag. 42], l’ispirazione può essere di origine divina, angelica, psichica o satanica, analogamente a quanto avviene per i propositi che si presentano (hawātir). L'ispirazione divina può attualizzarsi tramite un intermediario angelico, che però resta invisibile, per cui colui a cui è destinata non sa da che parte gli venga l'ispirazione, a differenza di quanto avviene nella rivelazione (wahy) [Cap. 268 (II 569.8) e Cap. 353 (III 238.30)], oppure può attualizzarsi senza intermediario, caso che per Ibn 'Arabì è quello più frequente [Cap. 353 (III 239.3)]. In altri punti identifica l'ispirazione divina con l'insufflazione (nafti) dello Spirito santo [Cap. 73 (II 23.28) e Cap. 310 (III 39.15)], il che corrisponde all'affermazione del Vangelo di Giovanni, III-89: "Spiritus ubi vult spirat et vocem eius audis sed non scis unde veniat et quo vadat". Infine, per quanto riguarda l'ispirazione in generale, Ibn 'Arabī afferma che essa "è accidentale e fugace, va e viene", e che "può cogliere nel segno o sbagliare” [Cap. 57 (I 287.25 e 30)].

144) Muğtahid è il participio attivo del verbo iğtahada, VIII forma del verbo ğahada, che significa sforzarsi, applicarsi con zelo. Ho tradotto questo termine come "giurisprudente" per analogia con il latino juris prudentes, nome attribuito in epoca pre-repubblicana a Roma ai sacerdoti del collegio dei Pontefici che si pronunciavano sulla norma di diritto da applicare nei singoli casi concreti. All'epoca di Ibn 'Arabī i dottori della Legge delle quattro scuole avevano già sancito che la porta della giurisprudenza era chiusa e che tutto era ormai codificato nelle sentenze dei loro Imām, ma per Ibn 'Arabī [Cap. 69 (I 392.16)] "questa è una delle più grandi calamità nella religione! Questo equivale ad imporre la ristrettezza (harağ), mentre Allah ha detto: "Egli non ha posto per voi nella religione alcuna ristrettezza" (Cor. XXII-28) La Legge ha stabilito la validità del giudizio del giurisprudente (muğtahid) per quanto riguarda lui stesso e per chi lo segue. Ma i dottori della Legge del nostro tempo rifiutano sdegnosamente ciò. E ritengono che ciò porta a giocare (talä ub) con la religione. Questo è il colmo dell'ignoranza da parte loro". In numerosi punti delle Futūhāt, come pure in questo trattato, Ibn 'Arabī spiega le regole della giurisprudenza. Quanto all'affermazione che Allah ha stabilito la validità del giudizio del giurisprudente, più volte ripetuta nelle Futūhăt, il suo fondamento è lo hadît: "Quando un giudice (hăkim) formula un giudizio, avendo fatto uno sforzo di giurisprudenza (iğtahada), ed è nel giusto, vi saranno due ricompense per lui; e se egli formula un giudizio, avendo fatto uno sforzo di giurisprudenza, ma sbaglia, vi sarà una [sola] ricompensa per lui", riportato da al-Buhārī, XCVI-20 e 21, Muslim, XXX-15, Abū Dāwud, XXIII-2, anNasā̄ì, XLIX-3, Ibn Māğah, XIII-3 e da Ibn Ḥanbal, IV-198, 204 e 205. 
Ho visto l'Inviato di Allah, che Allah faccia scendere su di lui la Sua șalāt e la Pace, e gli ho chiesto riguardo alla donna ripudiata (mutallaqa) con la triplice formula in una stessa seduta: "Com'è il suo regime giuridico $(\mathrm{hukm})$ per te, o Inviato di Allah?”, ed egli rispose: "Essa è [ripudiata] tre volte, come Egli ha detto: "E non gli è lecita finché non ha sposato un altro uomo" (Cor. II-230). Gli dissi allora: "Ma un gruppo della gente dell'esteriore ha giudicato che esso vale come un ripudio singolo", ed egli aggiunse: "Costoro hanno giudicato in base a ciò a cui sono arrivati, ed hanno fatto bene, ma quanto a me, il mio giudizio [36] riguardo alla questione è ciò che ti ho menzionato", questo durante un lungo sogno. Da quel momento ho cominciato a sostenere questo giudizio, da parte dell'Inviato di Allah, che Allah faccia scendere su di lui la Sua salāt e la Pace $\left({ }^{145}\right)$.

Il Maestro che abbia questo svelamento non è tenuto a seguire un Imām nella sua giurisprudenza, come il giurisprudente non è tenuto a seguire un altro giurisprudente riguardo ad una questione, malgrado il suo sforzo di giurisprudenza. Non è peraltro lecito al giurisprudente formulare un giudizio riguardo ad un avvenimento (näzila), per mezzo della sua giurisprudenza, presupponendo che sia accaduto, finché esso non avviene, e quando avviene allora è prescritto il giudizio da parte sua riguardo ad esso in base a ciò a cui lo porta la sua giurisprudenza. E se il fatto avviene una seconda volta ed egli viene interrogato riguardo ad esso, deve ricominciare anche lo sforzo di giurisprudenza riguardo al giudizio e se esso corrisponde al primo dà il responso in base a questa giurisprudenza, e se non corrisponde e quindi giudica in modo diverso riguardo a quell'avvenimento, gli è proibito di giudicare riguardo ad esso se non secondo ciò che gli appare adesso, malgrado la validità del primo nel suo momento, non in quel momento $\left({ }^{146}\right)$.

145) Lo stesso episodio è riportato nel Cap. 560 [IV 552.9] "Ho sentito questa preghiera direttamente dall'Inviato di Allah, che Allah faccia scendere su di lui la Sua șalāt e la Pace, in un sogno, ed egli la recitò dopo che fu terminata la lettura del Libro "as-Sahīh", di al-Buhārī, nell'anno 599 alla Mecca, tra la porta di al-Ḥazzūra e la porta di al-Ağyād, lettura che fu fatta dal pio uomo Muhammad ibn Huâlid aṣ-Ṣadafĩ atTilimsānī, che è lo stesso che lesse in nostra presenza il Libro "Al-Ihyyā" di Abū Ḥāmid al-Gazālī. In quella visione interrogai l'Inviato di Allah, che Allah faccia scendere su di lui la Sua salāt e la Pace, su colei che è stata ripudiata tre volte in una sola formula, il che consiste nel dirle: "Tu sei ripudiata" per tre volte, ed egli, che Allah faccia scendere su di lui la Sua salāt e la Pace, rispose: "Ella è ripudiata tre volte, come ha detto, e non è lecito per lui risposarla finché ella non ha sposato un altro [cfr. Cor. II-230]". Dissi allora: "O Inviato di Allah, alcuni sapienti affermano che si tratta di un ripudio unico", ed egli, che Allah faccia scendere su di lui la Sua salāt e la Pace, rispose: "Costoro giudicano in base a ciò a cui sono arrivati, e sono nel giusto". Compresi da questa affermazione l'autorità di ogni giurisprudente (muğtahid) ed il fatto che ogni giurisprudente è nel giusto". Gli dissi ancora: "O Inviato di Allah, ciò che volevo sapere è come giudicheresti tu se ti venisse chiesto e cosa faresti se ti capitasse", ed egli rispose: "Ella è ripudiata tre volte, come ha detto, e non è lecito per lui risposarla finché ella non ha sposato un altro".".

146) Non c'è ripetizione nella manifestazione, per cui le situazioni, ancorché simili, non sono mai identiche ed esigono un rinnovato sforzo di giurisprudenza, che può condurre anche a giudizi differenti. 
Per questo Mālik ibn Anas $\left({ }^{147}\right)$, quando era interrogato riguardo ad una questione era solito chiedere: "È avvenuta?" e se gli veniva detto di sì considerava [la questione] e formulava il responso, e se gli veniva detto: "Non è avvenuta, ma abbiamo solo supposto il suo avvenimento!" non formulava alcun responso, a meno che non avvenisse. Osserva la correttezza (taḥrīr) di questo Imām, Allah sia soddisfatto di lui $\left({ }^{148}\right)$.

Ogni volta che vedi l'aspirante pesare il Maestro e i suoi movimenti per mezzo della bilancia della Legge stabilita secondo lui in base alla sua giurisprudenza o al suo seguire pedissequamente l'Imām, sappi che l'aspirante in ritirata $(i d b \bar{a} r)\left({ }^{149}\right)$ non ha mai successo, e per quello questo Maestro in questa raccomandazione ha affrontato il tema dei cattivi propositi che si presentano (hawätir) $\left({ }^{150}\right)$ riguardo al rendere lecito ciò che è proibito o al rendere proibito ciò che è lecito.

Quanto al fatto che il Maestro disobbedisca, ciò non è possibile dirlo con certezza di nessuno, né di un Maestro, né di altri. Venne chiesto ad Abū Yazīd: "Il conoscitore disobbedisce?” ed egli recitò: "E il Comando di Allah è una misura destinata" (Cor. XXXIII-38) ${ }^{151}$ ). È necessario che l'aspirante

147) Mālik ibn Anas morì nell'anno 179 dall'Egira all'età di 85 anni, dopo aver trascorso quasi tutta la sua vita a Medina. La sua opera principale è il Kitāb al-muwatta', o Libro della via appianata, che richiese 40 anni di lavoro e che costituisce una delle prime raccolte di hadït. Mālik ibn Anas è l'eponimo della "scuola (madhab)" malikita, ma come precisa Ibn 'Arabī nel Cap. 69 [I 494.19] né lui, né gli Imām eponimi delle altre tre scuole, intendevano fondare una scuola, tant'è che Mālik ibn Anas rifiutò la proposta del Califfo di adottare la sua opera come "codice" di comportamento. Il Kitäb al-muwatta' è stato tradotto recentemente da Roberto Tottoli per le edizioni Einaudi, Torino, 2011.

148) Lo stesso aneddoto è riportato nel Cap. 69 [I 499.33] e nel Cap. 88 [II 165.31].

149) Cioè l'aspirante che invece di procedere retrocede.

150) Il termine arabo hawātị, al singolare hățir, costituisce uno di quei termini tecnici di cui è difficile trovare un equivalente nelle lingue occidentali: spesso per tradurre questo termine viene impiegata l'espressione «pensieri che si presentano», ma riteniamo che l'espressione «propositi che si presentano» sia più adeguata. La parola «proposito» infatti, derivando dal verbo proporre, implica un senso di «formulazione discorsiva» (dell'intenzione) e di «discorso» che, presente nella lingua italiana in espressioni come «a questo proposito», è ancor più evidente nel suo equivalente francese «propos»; ora, Ibn 'Arabī insiste in modo particolare sul carattere «discorsivo» e non «figurato» o «formale» dei hawātir: nel Cap. 264 [II 563.34 e 565.33] egli precisa "i hawātị sono ciò che perviene del discorso (hitäb) al cuore ed alla coscienza senza avere permanenza, ed essi fanno parte di ciò che arriva (wäridāt) senza uno sforzo da parte tua; se essi sono dotati di permanenza allora non sono hawātir, ma si tratta di fantasticheria (hadīt nafsin) [...] I hawātir sono sempre di natura discorsiva [...] ed essi non hanno permanenza come non ha permanenza nell'esistenza la forma della lettera dopo che la lingua l'ha proferita, in quanto essa non dura che per il tempo in cui viene pronunciata, poi scompare e nell'intelligenza di chi ascolta resta soltanto una immagine della sua forma".

151) Questo detto è commentato nei capitoli 39 [I 233.9], 69 [I 516.20], 73 [II 23.14] e 207 [II 491.21], nel quale Ibn 'Arabī precisa: "Se dici: "È possibile che [il conoscitore] disobbedisca durante lo svelamento (kašf)?", noi rispondiamo: "No". A questo viene ribattuto: "E che ne è del detto di Abū Yazīd quando gli venne chiesto: "Il conoscitore disobbedisce?" - ed il conoscitore fa parte della gente dello svelamento - ed egli rispose: "e il Comando di Allah è una misura destinata (qadar maqdūr)" (Cor. XXXIII-38), e quindi lo ha ammesso?". Noi rispondiamo che questo è l'adab dei conoscitori con il Vero nelle loro risposte, poiché ha detto: "Se Allah ha 
non frequenti un Maestro per via dell’impeccabilità ('ișa) $\left.{ }^{152}\right)$ [37], bensì lo deve frequentare per via della [sua] scienza della via di Allah e deve osservare le sue parole ed i suoi responsi, non i suoi atti. Per questo Allah, sia Egli esaltato, ha detto: "Chiedete alla gente dello $\underline{d i k} r$ " (Cor. XVI-43) e non ci ha ordinato di imitare i loro atti, perché non c'è l'obbligo che essi siano impeccabili $\left({ }^{153}\right)$.

Ed ha detto riguardo ai Profeti, siccome Allah, sia Egli esaltato, li ha resi impeccabili: "In essi vi è per voi un bell'esempio" (Cor. LX-6), ed Egli, sia Egli esaltato, ha detto: "Nell'Inviato di Allah avete un bell'esempio" (Cor. XXXIII-21) e quindi noi seguiamo l'Inviato, in base al Suo detto, in tutti i suoi atti, salvo ciò che ha specificato per noi dei suoi atti che lo caratterizzano in modo esclusivo, e che non ci è concesso di compiere.

destinato quello per loro nella precedenza della Sua Scienza, allora ciò è inevitabile, ed è una disobbedienza"; ed è inevitabile il velo (hiǧăb), come ha detto, che Allah faccia scendere su di lui la Sua salāt e la Pace: "Quando Allah vuole il compimento del Suo Decreto ( $q a d \bar{a})$ e della Sua misura (qadar), toglie a coloro che sono dotati di intelletto il loro intelletto, fino a che, quando ha portato a compimento la Sua misura, lo restituisce a loro affinché essi considerino", e così è lo stato del conoscitore. Quando Allah vuole che da parte sua abbia luogo l'opposizione, che la sua conoscenza gli impedirebbe di commettere, allora Allah gli abbellisce quell'atto per mezzo di una interpretazione $\left(t a^{2} w \bar{l}\right)$ che gli capita di fare riguardo ad esso e che ha un aspetto rivolto verso il Vero, per cui il conoscitore non si propone di violare ciò che è proibito, come ha fatto Adamo e come fa il giurisprudente che si sbaglia. E quando ha luogo da lui ciò che è destinato, Allah gli fa apparire la falsità di quella interpretazione che lo ha portato a quell'atto, come ha fatto con Adamo, poiché egli ha disobbedito per l'interpretazione. E quando realizza, dopo l'accadimento, che egli ha sbagliato, sa che ha disobbedito ed è allora che la lingua dell'esteriore (lisān az-zāhir) giudica che egli è stato disobbediente, ed egli è stato effettivamente disobbediente. Quanto al momento dell'accadimento dell'atto da parte sua, non è così [cioè non ha disobbedito], a causa dell'ambiguità dell'interpretazione, come il giurisprudente al momento del suo responso su una certa faccenda, per convinzione da parte sua che esso corrisponde al giudizio prescritto dalla Legge riguardo alla questione; ed in un secondo momento gli appare, per mezzo della prova, che egli ha sbagliato e la lingua dell'esteriore lo accusa di avere sbagliato nel tempo dell'apparizione della prova, non prima di quello. E se il conoscitore è tra coloro a cui è stato detto tramite la lingua del legislatore: "Fai ciò che vuoi, Io ti ho già perdonato", egli non disobbedisce né esteriormente né interiormente, anche se la lingua dell'esteriore lo giudica colpevole di disobbedienza poiché non comprende l'abrogazione di essa per mezzo della legittimazione da parte del legislatore".

152) Ho tradotto il termine 'isma, che ha originariamente il senso di protezione e preservazione, come impeccabilità, riferendola al dominio dell'azione, perché l'infallibilità, riferita al dominio della conoscenza non è posta in discussione, tant'è che viene ingiunto di chiedere a coloro che sanno.

153) Nel Cap. 108 [II 190.22] Ibn 'Arabī precisa: "Quanto agli aspiranti, che sono sotto l'autorità (hukm) dei Maestri, essi sono in base a ciò che sono i loro Maestri. Se si tratta di Maestri veri, preposti da parte di Allah, essi [i Maestri] sono gli uomini di miglior consiglio verso i servitori di Allah; se invece non lo sono, su di essi e sui loro seguaci è il divieto (harağ) da parte di Allah. Allah infatti ha posto la bilancia (mīzann) legale nel mondo per pesare con essa le opere dei servitori. Ai Maestri va chiesto e le loro opere non vanno imitate, a meno che essi stessi non lo ordinino riguardo ad azioni determinate. Egli, sia esaltato, ha detto: "Chiedete alla gente dello dikr [se non sapete]" (Cor.XVI-43 e XXI-7), cioè la gente del Corano, la gente di Allah e la sua élite. La gente del Corano è costituita da coloro che lo mettono in pratica ed esso è la bilancia di cui parlavamo. Non si conviene che si imiti l'opera di qualcuno piuttosto che quella dell'Inviato di Allah, che Allah faccia scendere su di lui la Sua salāt e la Pace. Infatti gli stati degli uomini sono differenti: la stessa cosa che può essere di beneficio all'uno può essere di detrimento all'altro, se la mette in pratica. I sapienti che temono Allah sono i medici della religione di Allah, che allontanano le sue malattie e le sue debolezze e che conoscono i rimedi”. 
Ciò è chiaramente esposto, ed Egli ha rivelato (nazzala), per spiegare agli uomini ciò che ha rivelato loro, come il matrimonio della donna che si offre in dono (hiba) spetti a lui ad esclusione dei credenti, e non è quindi lecito per altri che lui sposare la donna che si offre in dono $\left({ }^{154}\right)$.

E se questo giudizio non si trovasse nel Corano o nella Sunna ininterrotta (mutawātir) $\left({ }^{155}\right)$ e si trovasse nella notificazione di un sola fonte, ritenuta valida dall'opinione prevalente, e poi vedessimo il nostro Maestro metterlo in atto, è ammissibile per noi che la notificazione sia in realtà debole $(w \bar{a} h \hat{\imath})$, anche se è valida per la trasmissione $(n a q l)$ per via della buona opinione riguardo ai trasmettitori $($ rawrwa $)\left({ }^{156}\right)$.

Sappi che questo è tra i più grandi rimedi per questa malattia ('illa) che colpisce l'aspirante da parte di Satana, e non c'è dubbio che l'anima malevola (habitta) accoglie immediatamente una simile proiezione $(i l q \bar{a})$, perché essa vede che il Maestro la giudica ed essa per natura non vuole essere giudicata da nessuno. E quando Iblīs le fa balenare un pensiero cattivo riguardo al Maestro, essa lo accetta per la sua malevolenza (hubt $)$, a meno che Allah non la assista.

Un veridico $(s \bar{a} d i q)$ era al servizio di un Maestro e lo vide fornicare con una donna, ed il Maestro venne a sapere che l'aspirante l'aveva visto, e poi vide che l'aspirante faceva ogni sforzo per riuscire a servirlo per come era e non cambiò nulla dell'attitudine che aveva. Il Maestro gli disse: "O tale, tu mi hai visto compiere ciò che ho fatto ed hai perseverato [38] nella tua via al mio servizio", ed egli rispose: "O mio signore, non ti frequento perché tu sei immune dai peccati, ma ti frequento perché sei sapiente della via di Allah, in cui è la mia guida, e tu sei con te stesso secondo ciò che Allah ha decretato per te", ed il Maestro concluse: "Uno come te è colui che è chiamato [giustamente] servo (hadīm)" $\left({ }^{157}\right)$.

154) Nel Cap. 560 [IV 456.17] Ibn 'Arabī precisa: "Voi avete nell'Inviato di Allah un bell'esempio" (Cor. XXXIII-21): questo versetto conferma l'impeccabilità (isma) dell'Inviato di Allah, che Allah faccia scendere su di lui la Sua salāt e la Pace, poiché se non fosse impeccabile non sarebbe giusto imitarlo. Noi imitiamo l'Inviato di Allah, che Allah faccia scendere su di lui la Sua salāt e la Pace, in tutti i suoi movimenti, soste, atti, stati e parole, salvo ciò che è stato proibito di fare in modo esplicito nel Libro o nella Sunna, come il matrimonio di colei che si concede in dono (hiba) - "un privilegio per te solo, non per i credenti!" (Cor.XXXIII-50)". L'esempio del matrimonio della donna che si concede in dono, quindi senza obbligo di dote, come prerogativa del Profeta è riportato anche nei capitoli 12 [I 146.4], 71 [I 637.12], 159 [II 259.8], 231 [II 531.8], 339 [III 153.10], e 382 [III 512.4 e 5$]$.

155) Questo aggettivo viene usato per indicare una tradizione la cui autenticità è attestata da molteplici catene di trasmissione che riportano lo stesso testo, come se il Profeta avesse parlato in presenza di più Compagni, ciascuno dei quali abbia generato una catena di trasmissione.

156) Nel Cap. 88 [II 164.3] Ibn 'Arabī precisa: "Se colui che è soggetto all'incombenza legale e che si conforma ciecamente [ad una delle scuole giuridiche] viene a conoscenza di un hadīt debole ( $d a \mathfrak{\imath} f)$ che risale all'Inviato di Allah, che Allah faccia scendere su di lui la Sua șalāt e la Pace, ed esso contraddice quanto ha detto uno degli Imām o un Compagno, e non si conosce l'indicazione su cui si basa quella affermazione, egli deve attenersi a quel hadīt debole ed abbandonare quella affermazione".

157) Lo stesso episodio è riportato nel Kitāb al-amr al-muhkam, a pag. 323 della traduzione di Asín Palacios già citata. 
Una cosa simile ci capitò con uno dei nostri Maestri e noi ci siamo comportati con lui come questo aspirante, e per Allah, né l'intimo né il cuore si modificarono nei confronti di un Maestro a causa del suo movimento o della sua assenza di movimento, poiché non lo frequentavo se non perché mi consigliasse con ciò che mi diceva, ed io seguivo le sue parole, non il suo operato. Ogni aspirante che si scosti da questa regola (qadiyya) non diventerà mai un iniziato (rağul).

Devi poi sapere che Allah ha dei servitori a cui ha detto: "Fate ciò che volete, Io vi ho perdonato!" $\left({ }^{158}\right)$, e come fai a sapere se questo Maestro non è uno di loro? La porta dell'aspirante è la buona opinione, non la cattiva opinione.

Sappi che quando Allah, quanto è Potente e Magnificente, dischiude nell'intimo di un servitore la cattiva opinione riguardo ad una delle creature di Allah, ciò dipende dall'esecrazione (maqt) di Allah nei suoi riguardi e dalla cecità della sua vista interiore. Presupporre l'impeccabilità di qualcuno è il colmo dell'ignoranza: le disobbedienze non alterano un musulmano ed egli non cambia per esse, e se vi è biasimo, questo riguarda l'atto non l'agente, poiché il potere della fede è più forte ed a lui basta, quando si ribella all'obbedienza, la sua convinzione che si tratta di una disobbedienza $\left({ }^{159}\right)$.

Chi è sincero con se stesso deve proteggere il suo intimo dai cattivi pensieri, sia riguardo ai credenti che ai miscredenti, poiché egli non sa quale sarà il destino finale di questo miscredente, caratterizzato in questo momento dalla miscredenza - ed invero è biasimata la miscredenza in quanto tale, non questo miscredente! A maggior ragione [deve comportarsi così] riguardo al credente.

Chiunque abbia una cattiva opinione di una delle creature di Allah, non c'è divergenza sul fatto che egli sia esecrato da Allah, e ciò non sarebbe che l'inizio della miseria (hirmān) e della via della perdizione (husrān), se ci fosse in lui solo la macchia (tadnīs) del proposito [39] e del cuore con il male [e non una disobbedienza], fintanto che Allah non gli ha imposto quello [cioè di non avere una cattiva opinione delle Sue creature].

158) Hadīt quds̄̄ riportato da al-Buhārī, LXIV-9 e 46, LXV, ad Sūra LX-1, Muslim, XLIV-161, e da Ibn Hanbal.

159) Nel Cap. 560 [IV 476.32] Ibn 'Arabī precisa: "Ciò vale persino per la disobbedienza: se fai un atto di disobbedienza fallo avendo in mente che si tratta di una disobbedienza e sarai ricompensato per aver avuto fede che si trattava di una disobbedienza. Per questo non capita mai una disobbedienza ad un credente senza che si associ ad essa un'opera buona, cioè la fede che si tratta di una disobbedienza. È a proposito di costoro che Allah ha detto: "Altri invece hanno riconosciuto i loro peccati ed hanno mescolato un'azione buona con una cattiva. [Può darsi che Allah ritorni su di loro]" (Cor. IX-102). Questo è il significato del mescolarsi: l'opera buona in questo caso è la fede che l'altra opera è cattiva, e il "può darsi" riferito ad Allah è una cosa obbligatoria $(w \bar{a} g ̆ i b a)$. Egli ritorna su di loro per la Misericordia e perdona loro quella disobbedienza per la fede che si mescola con essa, e ciò che in questo caso è attaccato al "può darsi" è il Suo ritorno, Gloria a Lui, su di loro per la Misericordia, non il loro ritorno verso di Lui, poiché Egli non ha attribuito loro un pentimento, come ha detto in un'altro posto: "Poi ritornò su di loro affinché si pentissero" (Cor. IX-118). In questo caso è venuto con un altro regime $(\mathrm{hukm})$, in cui non c'è menzione del loro pentimento, ma solo del ritorno di Allah, sia Egli esaltato, su di loro" 
Invero il Profeta, che Allah faccia scendere su di lui la Sua salāt e la Pace, ha detto: "Felicità (tūbā) a chi si occupa del suo difetto ('ayb) tralasciando i difetti degli [altri] uomini”" $\left({ }^{160}\right)$, e quale difetto è più grande della cattiva opinione degli uomini? E ciò non dipende forse dal fatto che questo misero uomo osserva i movimenti degli altri? Se si occupasse di se stesso non potrebbe occuparsi ad osservare gli altri, come ha detto uno dei nostri Maestri:

\section{Nella mia anima vi è per me una occupazione che mi tiene occupato! $\left({ }^{161}\right)$}

Allah abbia Misericordia di questo Maestro per ciò che ha raccomandato, e certo ha raccomandato un bene abbondante, sia lode ad Allah per questo.

Poi ha detto: "Non si sieda e non si appoggi ad alcuna cosa, e non muova per essa una delle sue membra senza esaminare il motivo per cui la muove, se è per il desiderio (hawa) della sua anima o per Allah, sia Gloria a Lui e sia Egli esaltato. Se è per il desiderio della sua anima, allora si astenga completamente da questo movimento; se invece è per Allah, allora lo pesi con la bilancia della Legge, e lo accompagni con una intenzione (niyya) sincera e pura, e così in tutti i suoi stati”.

Commento: sappi che questo iniziato è uscito dalla raccomandazione rivolta all'aspirante all'istruzione iniziatica per entrare nella raccomandazione rivolta alla gente di Allah che non è vincolata ad un Maestro. Infatti l'aspirante all'istruzione iniziatica, nel suo primo passo ha abbandonato il desiderio della sua anima e non c’è movimento né sosta se non per ordine del Maestro, e per questo abbiamo detto che egli ha lasciato la raccomandazione rivolta all'aspirante all'istruzione iniziatica per rivolgersi alla gente di Allah, con ciò con cui essi sono occupati.

Quanto al suo detto: "se è per il desiderio della sua anima si astenga completamente da questo movimento", questo non è esatto (muharrar), poiché le decisioni (ahkām) di Allah in certi momenti possono corrispondere al desiderio dell'anima di colui che è oggetto della decisione, e se vi è corrispondenza allora è riconoscente ad Allah, sia Egli esaltato, per la corrispondenza del desiderio della sua anima con la decisione di Allah, e fa quello in quanto è per Allah, [40] e si rallegra per ciò che è il desiderio della sua anima e per il fatto che Allah lo ha assecondato in quello senza che egli lo sapesse. Costui non si astiene dal compiere completamente il desiderio della sua anima, poiché se si astenesse da esso completamente si asterrebbe dal portare a compimento la decisione di Allah, sia Egli esaltato, e sarebbe disobbediente. Egli [nella sua raccomandazione] intendeva parlare del desiderio dell'anima che non corrisponde alla decisione di Allah, sia Egli esaltato, sennonché non è stato preciso nell'espressione.

160) Parte di una hutba del Profeta, trasmessa da Anas ibn Malik, ma non recensita nelle raccolte canoniche. Ibn 'Arabī cita questa frase anche nel Cap. 560 [IV 541.5].

161) Nel Cap. 560 [IV 534.9] questa frase venne riferita da un uomo, di cui non è riportato il nome, al secondo Califfo abbaside, al-Manșūr, mentre questi era alla Mecca per il pellegrinaggio. L'episodio è riportato in una forma più estesa nel Kitāb muhāạarat al-abrār, Dār Sāder, Vol. I, pag. 148-150. 
Quanto al suo detto: "e se quello è per Allah, allora lo pesi con la bilancia della Legge", si tratta di un discorso non preciso, poiché se egli sa che è per Allah allora non c’è bisogno di bilancia, che è la Legge stessa; sennonché egli voleva dire: e se quel [movimento] è in realtà per Allah e questa persona non lo sa, non avendo desiderio di quello nella sua anima, allora lo pesi con la bilancia della Legge e se è in accordo con la bilancia lo porti a compimento, altrimenti lo abbandoni. Questo ti mostra che il suo discorso è rivolto alla gente comune e non alla raccomandazione dell'aspirante all'istruzione iniziatica, in quanto l'aspirante non soppesa né l'ordine né lo stato del Maestro, essendo uno che abbandona [la sua volontà] a lui. Analogamente colui che segue ciecamente (muqallid) il responso legale $(f u t y \bar{a})$, quando gli capita un evento segue ciecamente il muftz̄ $\left({ }^{162}\right)$ nel responso che egli gli formula riguardo ad esso, e se è credente non trova difficoltà (harağ) nel responso che egli gli ha formulato ed in ciò che gli ha imposto e si sottomette a lui fiducioso; e se prima di ciò detestava quello, al momento del responso è ricondotto alla soddisfazione per ciò che gli è stato imposto; e quando non prova quello allora viola la sua fede, poiché Allah ha detto: "No, per il tuo Signore, essi non crederanno finché non ti avranno costituito giudice delle loro discordie ed allora non troveranno nelle loro anime alcuna difficoltà ad accettare la tua decisione e si sottometteranno fiduciosi” (Cor. IV-65).

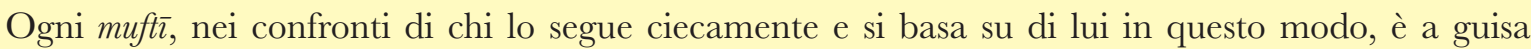
dell'Inviato presso di lui o è come se egli fosse presente, poiché il muftī [41] non trasmette se non il giudizio di Allah, sia Egli esaltato - cioè il giudizio che Allah ha stabilito al suo riguardo - così come l'Inviato non trasmette se non da Allah, ed "i sapienti sono gli eredi dei Profeti" ( $\left.{ }^{163}\right)$.

Per questo non è lecito a colui che segue ciecamente di formulare un responso legale, né al muftì di formulare un responso, in ogni momento, se non per uno sforzo di giurisprudenza nella ricerca della indicazione (dalīl), e se l'evento si ripetesse venti volte nello stesso giorno, egli è tenuto ogni volta a

162) Sul ruolo del muft̄̄ si può consultare l'articolo Fatwā nella Encyclopédie de l'Islam, seconda edizione, E.J. Brill, 1977, Vol. II, pag. 886. Per Ibn 'Arabī vi sono tre tipi di muftĩ: i giurisprudenti che si sforzano di trovare nel Libro sacro e nella Sunna una risposta al quesito che è stato loro posto, quelli che ricorrono alle risposte date dagli Imām della loro scuola giuridica ad un simile quesito, e quelli che esprimono la loro opinione personale. Solo i primi sono degni di essere ascoltati, come precisa nel Cap. 560 [IV 491.2]: "Ciò che ti raccomando, se sei sapiente, è di non comportarti in modo opposto a ciò che ti indica la tua indicazione (dalīl) e di non seguire ciecamente altri se sei in grado di ottenere l'indicazione; se invece non possiedi questo grado e quindi segui ciecamente, guardati dall'attenerti ad una scuola giuridica per se stessa, ma agisci come ti ha ordinato Allah. Invero Allah ti ha ingiunto, quando tu non sai, di chiedere alla gente dello $\underline{d i k r}$ [cf. Cor. XVI-43 e XXI-7], e la gente dello $\underline{d i k r}$ sono coloro che conoscono il Libro e la Sunna in quanto lo $\underline{d} i k r$ è per definizione il Corano. Cerca per quanto puoi di rimuovere la difficoltà nella tua faccenda (nāzala), poiché Allah, ha detto: "Egli non ha posto difficoltà per voi nella religione" (Cor. XXII-78) ed il Profeta, che Allah faccia scendere su di lui la Sua salāt e la Pace, ha detto: "La religione di Allah è facile". Cerca la facilitazione (ruhsa) nella questione finché la trovi e quando l'hai trovata comportati di conseguenza. Se il muft̄ ti dice: questo è il giudizio di Allah o il giudizio del Suo Inviato sulla tua questione, allora accettalo, ma se ti dice: questa è la mia opinione, non accettarla e chiedi ad un altro, e se vuoi prendere le decisioni ('azáa'im) nelle tue faccende (nawäzil) fallo, ma in ciò che è di tua competenza e l'allontanamento della difficoltà è la Sunna".

163) Hadīt non recensito nelle raccolte canoniche. Ibn 'Arabī ha dedicato ad esso il capitolo 380 delle Futūhāt. 
rinnovare lo sforzo di giurisprudenza e la considerazione delle indicazioni, ed ogni volta egli si deve basare su ciò che gli fornisce la sua indicazione, che egli ritiene verosimile essere una indicazione, ed allora è lecito per lui pronunciare il giudizio, e quello è il giudizio con cui Allah lo assoggetta.

Quanto al suo detto: "ed accompagni quello con una intenzione (niyya) sincera e pura, e così in tutti i suoi stati", egli si riferisce al suo detto, su di lui la Pace: "Invero le opere [valgono] per le intenzioni ed ogni uomo avrà ciò a cui tendeva. Chi è emigrato [dalla Mecca] verso Allah ed il Suo Inviato, la sua emigrazione (hiğra) è per Allah e per il Suo Inviato, e chi è emigrato per ottenere [qualcosa di] questo mondo o per sposare una donna, la sua emigrazione è per ciò verso cui è emigrato" $\left({ }^{164}\right)$ e questa notificazione è autentica. Ed il rango (martaba) dell'uomo presso Allah arriva nella dimora dell'aldilà laddove arriva la sua intenzione, anche se la sua opera non è all'altezza di ciò che egli cerca con la sua intenzione. Se però ha la capacità di fare ciò che cerca con la sua intenzione ma non compie l'opera, allora non ha questo grado e nel Giorno della Resurrezione non arriverà là dove lo avrebbe portato la sua intenzione, poiché egli era in grado di fare ciò che intendeva, ma avrà solo la ricompensa di chi ha avuto l'intenzione, non la ricompensa dell'intenzione $\left.{ }^{165}\right)$. Per questo egli, su di lui la Pace, ha detto, riguardo a colui a cui viene in mente di compiere un'opera buona (hasana) e non la compie, che gli viene ascritta un'opera buona $\left.{ }^{166}\right)$, che consiste nell'aver pensato di fare specificamente del bene, potendolo compiere, e nel non averlo fatto; se invece la compie gli vengono ascritte [42] dieci [opere] simili ad essa $\left({ }^{167}\right)$, e se non è in grado di compierla avrà la ricompensa di chi l'ha compiuta, cioè lui e colui che la compie avranno la stessa ricompensa. Questo è stato riportato riguardo all'uomo che aveva la ricchezza ed aveva fatto del bene con essa, e chi non aveva la ricchezza aveva detto: "Se avessi la stessa ricchezza di quel tale farei come lui", e l'Inviato di Allah, che Allah faccia scendere su di lui la Sua șalāt e la Pace, disse riguardo a quello: "Essi sono uguali nella ricompensa" (168).

Questo Maestro ha quindi raccomandato che in tutti i suoi stati l'uomo abbia l'intenzione di avvicinarsi ad Allah, e l'avvicinarsi non è conosciuto [nelle sue modalità] se non dalla Legge.

164) Hadīt riportato da al-Buhārī, I-1 e 41, XLIX-6, LXIII-45, LXVII-5, LXXXIII-23, XC-1, Muslim, XXXIII-55, Abū Dāwud, XIII-10, at-Tirmid̄ī, XX-16, an-Nasā̄î, I-59. Ibn Māğah, XXXVII-26, ad-Dārimī, XVI-23, e da Ibn Hanbal.

165) In entrambi i casi c'è stata solo l'intenzione, ma in uno mancava la capacità di attualizzarla, nell'altro invece la capacità c'era: il primo sarà ricompensato come se avesse realizzato l'intenzione [la ricompensa dell'intenzione], il secondo sarà ricompensato solo per avere avuto l'intenzione [la ricompensa di chi ha avuto l'intenzione].

166) Riferimento ad uno hadīt riportato da al-Buhārīi, LXXXI-31, XCVII-35, Muslim, I-203, 204, 206, 207, 209, e da Ibn Hanbal.

167) Riferimento ad uno hadīt riportato da al-Buhārī, I-31, XXX-2, 55 e 56, LX-37, XCVII-37, Muslim, XLVIII-22, an-Nasā̄̄î, VII-42, Ibn Māğah, XXV-32, ad-Dārimī, XX-50, e da Ibn Ḥanbal.

168) Hadīt riportato da Ibn Māğah, XXXVII-26, e da at-Tirmidīi, XXXIV-17. 
Poi ha detto: "Se arriva alla sua anima una ispirazione (ilhām) da parte del suo Maestro, l'aspirante deve essere sveglio (yaqazat $\left.{ }^{a n}\right)\left({ }^{169}\right)$ in essa e tenerla a mente [o ricordarla] intensamente, se è da parte del suo Maestro".

Commento: sappi che una cosa simile non può aver luogo da parte dell'aspirante se non dopo la sua conoscenza dei propositi che si presentano alla mente (hawätir) e della loro distinzione, e quando è in questa condizione allora sa discriminare, riguardo all'ispirazione che trova nella sua anima, quella che viene da parte del suo Maestro e quella che viene da un'altra parte. Invero non c’è uomo che sia esente da ispirazioni e non resta quindi da sapere se non chi gliele ha ispirate, se si tratta cioè di una ispirazione divina, satanica, psichica o angelica, o da parte di qualcuno diverso da coloro che abbiamo menzionato, come ad esempio nel caso menzionato [nella raccomandazione] in cui essa viene dal suo Maestro.

Ed egli [l'aspirante] sa, quando viene dal suo Maestro, da quale situazione (maqūm) arriva al Maestro l'ispirazione, [situazione] che ha fatto sì che il Maestro la inviasse all'aspirante - questa ispirazione che l'aspirante trova - se cioè gliel'ha conferita lo stato dell'aspirante, o se essa ha un'altra origine. Questo però non è possibile se non per chi ha una grande volontà o ha realizzato la veridicità nei confronti del suo Maestro, poiché l'aspirante, fintanto che il Maestro non prende [43] nel suo cuore il posto del Vero, non sa una cosa simile, ed il significato del "posto del Vero" per me è che non dispone di lui se non il suo Maestro, così come non dispone del Mondo se non il Vero, e dal Vero viene tutto ciò in cui il Mondo si trova.

Allo stesso modo questo aspirante $\left({ }^{170}\right)$ vede che tutto ciò che egli trova nella sua anima dipende dal disporre (tasarruf) del Maestro nei suoi riguardi, poiché egli è riempito (mal'ān) dal suo Maestro, che penetra in tutto il suo essere $\left({ }^{171}\right)$, in quanto non gli resta spazio $\left(\right.$ muttasa $\left.^{c}\right)$ per altri che il suo Maestro.

Oppure l'aspirante è dotato di svelamento, come capitò ad Abū Madyan (172): egli aveva un figlio

169) Il termine yaqaza viene generalmente utilizzato da Ibn 'Arabī per indicare la veglia, contrapposta al sonno [ad esempio nel Cap. 188 (II 375.8)], o il risveglio [Cap. 32 (I 207.19)], ma talora è contrapposto alla noncuranza (gafla) [Cap. 264 (II 564.19 e 20)], per cui può essere inteso come vigilanza ed attenzione; nel Cap. 73, questione CLIII [II 128.29] è definito come "la comprensione da Allah del Suo rimprovero (zağr), e se tu comprendi da Allah allora sei vigile".

170) Si tratta dell'aspirante che sa discriminare i propositi che si presentano alla sua mente e che ha una grande volontà (iräda) o che ha realizzato la veridicità (sidq).

171) Questo stato configura l'unione (ittihāed) tra l'aspirante ed il Maestro, di cui parlerà in seguito.

172) Abū Madyan Š́c'ayb ibn al-Ḥusayn al-Anșārī è il Maestro contemporaneo di Ibn 'Arabī più citato nelle Futūhăt, ove il suo nome ricorre più di sessanta volte. Nato nell'anno 509 dall'Egira nei pressi di Siviglia, si trasferì da giovane in Marocco, soggiornando a Marrakesh, a Fez, ove seguì gli insegnamenti di 'Alī ibn Ḥirzihim e di 'Alī ibn Halaf al-Qurašì, discepolo di Ibn al-'Arîf, ed in un villaggio del medio Atlante, ove seguì gli insegnamenti dello Šayh berbero Abū Yaczā, per poi insediarsi a Biǧāya, nell'attuale Algeria. Morì, secondo la notizia biografica di Ibn al-Zayyāt at-Tādilī [Regards sur le temps des Soufis, Editions Eddif, 1995, pag. 228], 
molto piccolo $\left({ }^{173}\right)$ che aveva appena cominciato a parlare, e questi, mentre era a Biğāya, svelava ciò che accadeva ad Alessandria, in Andalusia e nel paese che Allah voleva, dicendo: "È accaduto riguardo alla faccenda in tal posto così e così", ed era come diceva. Gli venne chiesto: "Come fai a vedere ciò di cui sei informato?", ed egli rispose: "Con il mio occhio", poi disse: "No, invero lo vedo con il mio cuore", poi disse: "No, invero lo vedo per mezzo di mio padre: quando è davanti a me vedo le cose per mezzo di lui, e se non è presente non vedo nulla", e quindi vedeva le cose da parte di suo padre ${ }^{\left({ }^{174}\right)}$. In un caso simile non si dice che egli era vigile, poiché lo svelamento è un dono (minha) e non è assimilabile all'essere vigili, e la misura ( $h a d d$ ) dell'essere vigile (yaqaza) in questo bambino, che era [figlio] di Abū Madyan, è il suo aver detto: "Per mezzo di mio padre vedo ciò che vedo", dopo aver gradualmente riferito la cosa dal suo occhio al suo cuore e poi a suo padre, ed è a questo punto che ci fu il risveglio (tayaqquz) nella sua natura (fitra).

Quanto al suo detto: "l'aspirante deve essere sveglio in essa", l'essere sveglio non è un atto dell'aspirante, poiché è insito nella sua natura, e ciò che egli acquisisce da esso lo acquisisce per mezzo di esso [e non di uno sforzo]. Questo Maestro intendeva qui l'essere sveglio [cioè il porre attenzione] solo riguardo alla conservazione di quella ispirazione, quando [44] viene dal suo Maestro, e l'aspirante all'istruzione iniziatica non ha mai una ispirazione se non da parte del Maestro nella sua anima. E della sua affermazione: "se è da parte del suo Maestro" non resta [da precisare] se non che il Maestro intendeva per l'ispirazione di quell'aspirante ciò che egli trova nella sua anima, non lo stato in cui si trova per l'unione (ittihāed) $\left.{ }^{175}\right)$ con il suo Maestro; è quindi indispensabile per lui distinguere,

nell'anno 594 o 588 a Tlemcen [Tilimsān] durante un viaggio verso Marrakesh ove era stato convocato dal Califfo almohade. Nel suo Kïtāb manzil al-qutb, Ibn 'Arabī precisa che Abū Madyan fu per molti anni l'Imām della sinistra, nella gerarchia suprema del Tașawwuf, e che nelle ultime due ore della sua vita assurse al rango del Polo.

173) Abū Madyan non si sposò mai, ma come gli aveva annunciato il suo Maestro Abū Ya'zā, ricevette in dono da un mercante una schiava abissina, da cui ebbe un figlio che venne però preso in carico da uno dei suoi discepoli, offertosi di sposare la schiava con cui Abū Madyan non voleva più avere relazioni [cfr. Vincent Cornell, The Way of Abu Madyan, Islamic Texts Society, 1996, pag. 14].

174) Ibn 'Arabī riporta questo aneddoto anche nel Cap. 35 [I 221.8], ove precisa: "Il Maestro Abū Madyan, che era dotato di vista [(nazar), cioè aveva ricevuto da Allah il dono di acquisire, tramite il solo senso della vista, la scienza delle cose che gli altri esseri percepiscono attraverso tutti cinque i sensi] aveva avuto un figlio da una donna nera, e questo bambino, che aveva sette anni, "vedeva" e diceva: "Io vedo nel mare, in un posto così e così, delle navi in cui si trova questo e quello". Dopo giorni, quando le navi arrivavano a Biğāya, che è il luogo dove stava il bambino, si trovava che le cose erano come le aveva descritte il bambino. Venne chiesto al bambino come avesse fatto a vedere ed egli rispose: "Con il mio occhio", poi disse: "No, invero ho visto con il mio cuore", poi disse: "No, invero ho visto per mezzo di mio padre: quando era davanti a me e lo guardavo, vedevo ciò che vi ho descritto, ma quando era assente non vedevo nulla di ciò".

175) Nel Cap. 73, questione CLIII [II 130.] Ibn 'Arabī definisce l'unione come: "due essenze che diventano una, sia servitore, sia Signore. Ciò può aver luogo solo per degli esseri sottoposti al numero ed alla Natura, e non è che uno stato transitorio (hâl $l$ ", ed altrove nello stesso capitolo [II 31.11] precisa: "l'Entità è una (wāhida), non unificata [o: diventata una] (muttahida), mentre nel servitore l'entità è unificata [o: diventata una], non una. Ad Allah appartiene l'Unità (ahadiyya), ed al servitore appartiene l'unione (ittihăd), non l'Unità, poiché il servitore 
nell'ispirazione che trova nella sua anima, se essa sia voluta dal Maestro o se dipenda dalla sua unione con il Maestro senza che il Maestro abbia scienza di ciò, come accadde ad Abū Madyan, che non aveva né scienza né proposito nello svelare a suo figlio ciò che gli svelava: il padre prese per il figlio il posto di uno specchio levigato in cui si manifestava a lui, quando guardava il padre, ciò che gli veniva comunicato e ciò che vedeva.

E quando l'ispirazione viene da parte del Maestro [l'aspirante] deve tenerla a mente intensamente per l'atto che ne consegue, poiché o si tratta di un ordine da parte del Maestro che gli viene ispirato, o di un divieto, o della notificazione di una cosa, ed egli deve sapere ciò al momento del suo incontro con il Maestro e menzionargli l'ispirazione che ha trovato nella sua anima. E se [l'ispirazione] viene dal Maestro questi gli ordina a voce ( $s_{i} i \bar{a} h^{a n}$ ) ciò che essa comporta e così gli fa sapere quello che egli intendeva, mentre se essa dipende dalla sua unione con il Maestro, il Maestro deve considerare se sia più vantaggioso per lui metterla in atto o tralasciarla. Per questo l'aspirante la deve tenere a mente finché non la espone al Maestro.

La gente di Allah è concorde sul fatto che l'aspirante non debba nascondere al suo Maestro nulla di ciò che gli accade o che trova nella sua anima $\left({ }^{176}\right)$, e finché non lo fa [1'aspirante] non sarà mai libero dalla malattia della sua anima e non sortirà nulla da lui: questo è il vantaggio del suo tenere a mente quello, poiché se dimentica ciò che ha trovato e non lo espone al Maestro resta con la sua opinione e non sa ciò che egli gli avrebbe spiegato [45] al riguardo. È quindi necessario che tenga a mente intensamente tutto ciò che gli accade.

Quanto alla sua frase successiva: "e pesi con quello gli atti della sua anima in tutti i suoi stati", l'allusione in questa frase è al tenere a mente, non all'ispirazione, ed è indispensabile che egli tenga a mente gli atti della sua anima, cioè tutto ciò per cui si muove, al fine di menzionarlo al suo Maestro. Egli non intende quindi la bilancia dell'ispirazione, poiché l’ispirazione gli viene riguardo ad una faccenda specifica, mentre il tenere a mente è generale.

Poi ha detto: "e sappia che il Maestro vuole vivificarlo (177) e dargli l'esistenza (yūgidu-hu), per autorizzazione $(\underline{i d n})\left({ }^{178}\right)$ di Allah, sia Egli esaltato". Ha detto: quando egli sa che quello viene da parte del Maestro e non

non è concepibile se non per altri che lui [cioè il Signore, di cui è servitore] e non per se stesso, ed egli non ha mai sentore dell'Unità". Nelle Futūhāt questo termine è anche usato in riferimento all'amante ed all'amato, ed alle lettere dell'alfabeto, ma non ai rapporti tra il Maestro e l'aspirante.

176) La stessa regola è riportata nel Kitāb al-amr al-muhkam, a pag. 314 della traduzione di Asín Palacios già citata.

177) Nel seguito del testo Ibn 'Arabī spiega che "con la scienza si vivificano i cuori”.

178) Il termine $i d n$, che ricorre 39 volte nel Corano, sempre riferito ad Allah [o direttamente, o tramite il Nome il Signore $(r a b b)$, o tramite dei pronomi], con l'unica eccezione di Cor. IV-25, viene utilizzato da Ibn 'Arabī prevalentemente nel senso di "autorizzazione", "permesso" [ad esempio nei capitoli 48 (I 263.34), 72 (I 737.33), 198 (II 406.30) e 284 (II 626.34)], ma talora [Cap. 74 (II 142.35)] anche nel senso più forte di “ordine”, "comando" (amr). 
dalla sua unione con il Maestro, sa in quel momento che il Maestro lo ama per ciò che gli ha ispirato, poiché vuole fargli trovare il risultato (natīğa) di quella ispirazione, cioè ciò che deriva dal fare quanto ha apportato quella ispirazione, o dalla sua astensione se si tratta di una ispirazione di divieto, o dalla notificazione di una faccenda, ed è indispensabile, per chi è in siffatto modo, che ci sia un risultato che il Maestro vuole fargli trovare $\left({ }^{179}\right)$.

Ed il suo detto: "per autorizzazione di Allah, sia Egli esaltato" si riferisce a ciò che ha detto Allah di Gesù riguardo alla vivificazione del morto, alla creazione dell'uccello ed al suo insufflare in esso lo Spirito $\left({ }^{180}\right)$, informando che tutto quello ebbe luogo per l'autorizzazione di Allah. E se è per autorizzazione di Allah, invero Allah non autorizza se non in questo modo specifico, non nel modo generale secondo il quale è noto che non c'è chi dispone del Mondo se non Allah; egli non intende questo, bensì intende l'autorizzazione specifica, cioè secondo la via che conoscono gli Inviati di Allah $\left({ }^{181}\right)$, e gli Intimi di Allah, in quanto Allah, sia Egli esaltato ha detto a proposito del perfezionamento $(i k m \bar{a} l)$ [della creazione dell'essere umano]: "Per l'anima e per Chi l'ha resa equilibrata e le ha ispirato" - per mezzo della natura primordiale (fitra) (182) - "la sua sfrenatezza e il suo timor di Dio" (Cor. XCI-7 e 8), cioè l'anima per la sua natura primordiale è timorata e per la sua natura primordiale intraprende ogni cosa che è nel suo potere, e questa è l'ispirazione generale.

L’ispirazione specifica [46] in questo perfezionamento è "e le ha ispirato la sua sfrenatezza", cioè [le ha fatto sapere] che essa è sfrenatezza, "e il suo timor di Dio", cioè che esso è timor di Dio $\left({ }^{183}\right)$, e per questo essa intraprende ciò che le è stato imposto per Legge di intraprendere ed evita quello che le è stato imposto di evitare, indipendentemente dal fatto che questa anima sia quella dell'Inviato o di colui a cui viene inviato [il Messaggio].

179) Nella raccomandazione, il verbo awğada, da cui deriva yūğidu, regge un solo accusativo, per cui il suo significato principale è quello di "far esistere", "dare l'esistenza". Nel commento di Ibn 'Arabī invece awğada regge due accusativi, ed ha quindi il significato di "far trovare", "procurare".

180) Cfr. Cor. III-49 e V-110. Il legame di questi versetti con il testo precedente non è solo il riferimento alla autorizzazione o ordine di Allah, ma anche al senso di "dare la vita e l'esistenza" implicito nel testo.

181) Cfr. Cor. IV-64: "Ogni Inviato, non lo abbiamo inviato se non perché fosse obbedito, con l'autorizzazione di Allah"; XIII-38 e XL-78: "[...] non è dato ad un Inviato di portare un segno se non con l'autorizzazione di Allah"; e XLII-51: "[...] o inviandogli un Messaggero che gli riveli, con la Sua autorizzazione, ciò che Egli vuole".

182) Per Ibn 'Arabī la fịtra è la natura dell'uomo in occasione del Patto primordiale (mitāq) [Cap. 90 (II 170.30) e 355 (III 248.31)], natura che implica la scienza dell'esistenza del Signore [Cap. 369 (III 383.2)], la scienza del Tawhìd [Cap. 2 (I 57.27)] e la fede originale [Cap. 281 (II 616.19)]. Il termine fitra ricorre in Cor. XXX-30 ed in alcuni ahädīt.

183) In questi versetti l'ispirazione generale consiste nell'ispirare all'anima la sfrenatezza ed il timor di Dio in quanto tali, senza riferimento ad un contesto "legale", mentre l'ispirazione specifica consiste nel far sapere all'anima che la sfrenatezza è biasimevole, e quindi va evitata, e che il timor di Dio è lodevole, e quindi va perseguito. Commentando questi versetti Ibn 'Arabī precisa che Allah ha ispirato, non ordinato, la sfrenatezza ed il timor di Dio [Cap. 353 (III 239.4 e 14) e Cap. 383 (III 521.21)]. 
Quanto al suo detto: "e sappia che questa ispirazione è più efficace (ablag) che ricordare le parole", l'espressione non è corretta, poiché egli vuole dire: e [sappia] che l'ispirazione che questo aspirante trova da parte del Maestro, è più efficace della sua conversazione con lui su di essa, ed il suo ricordare ciò che gli ha ispirato è più importante $(a s ̌ a d d u)$ del suo ricordare ciò che gli ha detto a voce, poiché l'ispirazione non fornisce se non il puro significato, e quindi è come il testo esplicito (nasss): non c'è bisogno di interpretazione $\left(t^{2} \tilde{w} \bar{l} l\right)$ riguardo ad essa, in quanto essa è ciò che è stato determinato per lui, mentre la conversazione riguardo al discorso è inferiore a questo grado, essendo vincolata dai termini (alfāz). Con la conversazione non senti se non dei termini, ed il termine è soggetto all'interpretazione e talvolta essa corrisponde a ciò che vuole dire il Maestro con quel termine nella conversazione e talvolta non corrisponde, a differenza dell'ispirazione.

Nell'ispirazione vi è la determinazione ( $t a$ ysinn) della cosa, e quindi egli ricorda quella cosa determinata, mentre nella conversazione non è in grado di ricordare l'interpretazione, poiché non sa se in ciò ha colto nel segno o ha sbagliato. Quindi ciò che egli ricorda della conversazione è il termine stesso in modo specifico, in modo da esporlo al Maestro perché gli spieghi uno dei suoi significati, quando non si tratta di una enunciazione testuale esplicita riguardo all'argomento.

Quanto al suo detto: “e non si infastidisca (lā yanza'ağu $)$ per la numerosità delle soste e dell'andare e venire (taraddud) alla porta del Maestro, ogni volta che può”, sappi che con l'espressione lā yanza'ağu vuole dire "non si indispettisca e non si stufi", poiché l'aspirante all'istruzione iniziatica non si reca alla porta del Maestro se non per ordine del Maestro, ed il suo detto: "ogni volta che può", vuol dire "se non lo ostacola una malattia che non gli consente [47] di alzarsi". Oppure ha detto: "ogni volta che può", intendendo ogni volta che può [farlo] contrastando la sua anima, quando egli prova la riluttanza da parte di essa, e va da sé che egli è in grado di contrastarla e di conformarsi all'ordine del suo Maestro, a meno che Allah lo abbandoni, il che è rigettato, e quindi non ne parliamo.

Riguardo a questa raccomandazione è riportato un racconto da parte di uno dei Maestri, e cioè che egli chiese all'aspirante di acquistare per lui al mercato un ago (ibra), ed egli portò un ago ed [il Maestro] glielo restituì dicendo: "Esso non è quello che voglio, portamene un altro", ed ogni volta che gli portava un ago gli spiegava che esso non era quello che voleva. Fece così con lui molte volte e l'aspirante si indispettì, senza essere consapevole del suo dispetto, e la sua anima interpretò ispirandogli: "Il Maestro è seccato perché tu non gli porti ciò che vuole, e se prendessi l'artigiano con i suoi arnesi e lo portassi dal Maestro affinché faccia per lui ciò che vuole conformemente al suo desiderio, quello solleverebbe il Maestro dalla sua seccatura nell'ottenere ciò che desidera" Allora l'aspirante disse questo all'artigiano, lo prese con i suoi arnesi e lo portò dal Maestro, e quando entrò da lui gli disse: "O mio signore, quest'artigiano l'ho portato con i suoi arnesi affinché faccia per il mio signore ciò che egli desidera e dia soddisfazione al suo proposito". Ed il Maestro gli disse: "La tua anima si è nascosta da te: tu ti sei indispettito per la numerosità delle volte in cui ti ho fatto tornare, sì che avresti dovuto portare ago dopo ago per la durata della tua vita finché non ti avessi detto: "Questo 
è ciò che voglio". Ma con il farti tornare non volevo altro che far uscire per te il tuo difetto; quanto a me qualsiasi ago avrebbe soddisfatto il mio bisogno. Guardati dall'essere indispettito per qualsiasi cosa ti venga ordinata, e questo non solo con il Maestro, ma sia un tuo tratto di carattere con [tutti] i servitori di Allah". Non ho visto nessuno, sia lode ad Allah, che abbia applicato così perfettamente questa stazione [48] quanto me: Allah mi ha dato potere in questo sulla mia anima tanto che mi divenne facile, in quanto non trovavo in ciò nessun fastidio, nei confronti del più basso e dell'elevato, del bambino, della donna e del servitore, e, a maggior ragione, dell'ordine del Maestro o di un grande uomo della gente di Allah, e non mi ha mai trattenuto da una cosa simile se non una malattia che impediva al corpo di muoversi e non ero quindi in grado di farla.

Poi ha detto: "Invero nella visione del Maestro vi è la vivificazione (ihy $\bar{a}$ ) del cuore dell'aspirante, un rimedio $\left(\check{s}_{i} f \bar{a}\right)$ per il suo petto $(s a d r)$, un andarsene della sua preoccupazione ed una quiete (sukūn) per la sua anima".

Quanto al suo detto: "la vivificazione del cuore dell'aspirante", è indispensabile per lui, in ogni visione in cui vede il suo Maestro, l'acquisizione di una scienza che non aveva, e con la scienza si vivificano i cuori, ed è indispensabile in ogni visione un vantaggio che gli viene dal Maestro per averlo visto, ed è quindi corretto che si dica al riguardo: "[ogni volta] che egli vede il Maestro", ed il meno [che si possa dire] di quello è che non vi è mai nell'esistenza una cosa che si ripeta $\left({ }^{184}\right)$, per la vastità $(i t t i s \bar{a})$ divina. Per questo Egli, quanto è Potente e Magnificente, ha detto di Se stesso che Egli "ogni giorno è all'opera" (Cor. LV-29), ed il più piccolo dei giorni è il singolo soffio dell'uomo, che è il tempo indivisibile (az-zaman al-fard) $\left.{ }^{185}\right)$, ed Allah nell'occuparsi di ogni parte del Mondo fa singolarmente una cosa che non è la stessa nell'altro tempo precedente, né in quello seguente, e questo è il significato del Suo detto riguardo a chi non sa quello da parte di Allah: "ma essi sono in dubbio per una nuova creazione" (Cor. L-15).

184) Nelle Futūhāt Ibn 'Arabī afferma spesso che non c'è ripetizione (takrār) nell'esistenza o nel Mondo [capitoli: 7 (I 126.20), 48 (I 266.9), 68 (I 342.19), 69 (I 479.13), 72 (I 721.22 e 735.15), 102 (II 185.27), 177 (II 302.19), 178 (II 392.13), 198 (II 47 1.32), 212 (II 500.1), 292 (II 657.14), 340 (III 159.4), 360 (III 288.16), 381 (III 510.28), 558 (IV 280.12) e 559 (IV 369.14)]

185) Nel Cap. 59 [I 292.16] Ibn 'Arabī precisa: "I giorni (ayyām) sono molti: ve ne sono di grandi e di piccoli, ed il più piccolo di essi è il tempo indivisibile, e su esso emerge "Ogni giorno Egli è all'opera" (Cor. LV-29). Il tempo indivisibile è stato chiamato giorno perché l'opera ha luogo in esso, ed esso è il più piccolo ed il più minuto dei tempi. Non c'è limite a cui si arresti il più grande di essi, e tra i due vi sono i giorni intermedi. Il primo di essi è il giorno convenzionalmente noto, che è diviso in ore, le ore sono divise in gradi [(darağ) di quattro minuti], i gradi sono divisi in minuti ( $(a q \bar{a} \vec{\imath} q$ ) e così via indefinitamente, secondo alcuni. Essi suddividono i minuti in secondi, e quando subentra il regime del numero il loro regime è il numero, ed il numero è indefinito, e la suddivisione in esso non ha fine". La dottrina del tempo indivisibile, o individuale, che coincide con l'istante della creazione, è esposta da Ibn 'Arabī in numerosi capitoli: 26 [I 189.26], 59 [I 292.16], 69 [I 479.33], 73, questione LXI [II 82.6], 90 [II 171.23], 123 [II 206.8], 192 [II 384.31], 198 [II 431.28, 446.3, II 454.19], 291 [II 654.1], 307 [III 30.23], 361 [III 295.12], 369 [III 360.27, 389.8, 395.32], 372 [III 452.25], 373 [III 460.2], 391 [III 550.4], 416 [IV 22.7], 526 [IV 169.19], 558 [IV 267.27] e 559 [IV 425.12]. Il termine "attimo", che secondo i filologi deriva dal greco á $о \mu о \varsigma$, senza parti, è sotto questo aspetto la traduzione letterale di zaman fard, ed è curioso notare che in tedesco atem corrisponda al soffio, nafas. 
È fermamente stabilito nella Scienza divina presso la gente di Allah che "Allah non Si manifesta (yatağallā) a due persone in un'unica forma, né due volte ad una persona in un'unica forma" ( $\left.{ }^{186}\right)$, ed è certo che Egli Si manifesta in continuazione, ed è quindi indispensabile la differenza delle forme, ed anche la differenza degli effetti su colui a cui Si manifesta. Egli Si manifesta a tutti, e chiunque non è consapevole di questo accrescimento [della scienza, conseguente alla Sua epifania] da se stesso, né dalla sua visione delle cose che gli sono esteriori [49], non è un conoscitore, né un uomo perfetto, e non è di coloro che sanno come stanno realmente le cose; e se ciò è come abbiamo menzionato, il vantaggio e l'accrescimento della scienza si verificano senza dubbio in ogni visione.

Quanto al suo detto:" un rimedio per il suo petto", il Maestro è identico al Corano, ed il significato di "identico al Corano" è che egli sintetizza ciò che Allah, sia Egli esaltato, ha ordinato della caratterizzazione (tahalluq) $\left.{ }^{187}\right)$ mediante il Corano, come ha detto Ā'iša, Allah sia soddisfatto di lei, riguardo all'Inviato di Allah, che Allah faccia scendere su di lui la Sua șalāt e la Pace, quando venne interrogata sui suoi tratti di carattere $(a h l \bar{a} q)$, e rispose: "I suoi tratti di carattere sono il Corano" $\left.{ }^{188}\right)$. Ed Allah ha detto riguardo al Corano che esso è "un rimedio per ciò che è nei petti" (Cor. X-57) "ed una Misericordia per coloro di voi che credono" (Cor.IX-61). Quando è autentica la fede dell'aspirante nel Maestro, la sua visione è un rimedio per ciò che è nel suo petto.

C'era presso di noi un uomo [(rağul) di Allah] a Fes, che si chiamava Abū l-'Abbās al-Ȟaššāb [il negoziante in legname] ${ }^{189}$ ), e venne da lui un uomo (insān) con un libro riguardante le fini realtà $($ raqū $q q)\left({ }^{190}\right)$ e gli disse: "O Abū l-'Abbās, voglio leggerti questo libro e [così] tu mi parlerai di esso".

186) Si tratta di una citazione, leggermente modificata, di un passo del Qūt al-qulūb di Abū Ṭālib al-Makkī, Dār Sāder, senza data, Vol. II, pag 86, [cfr. la traduzione di Richard Gramlich, Die Nahrung der Herzen, Franz Steiner Verlag, 1995, Vol. III, pag 16] "Egli non Si manifesta (yatağallä) con una Qualità (wasf) due volte e non Si manifesta (yazharu) in una [stessa] forma a due [persone]" Questa frase ricorre frequentemente nelle Futühăt [capitoli: 48 (I 266.10), ove viene attribuita ad Abū TTālib al-Makkī, 56 (I 285.29), 72 (I 679.8), 73, questione LV (II 77.27), 281 (II 616.3), 292 (II 657.13), 334 (III 127.32), 344 (III 178.23), 369 (III 384.30), 414 (IV 19.23), e 542 (IV 186.4)].

187) Il termine tahalluq, qui tradotto per semplicità come "caratterizzazione", indica l'assunzione dei Nomi divini come tratti di carattere (ahlāq), assunzione che costituisce un grado preliminare alla loro "realizzazione (tahaqquq)". Sull'argomento, che è troppo ampio per essere trattato in una nota, si può consultare l'introduzione di Pablo Beneito a Ibn al-'Arabī, El secreto de los Nombres de Dios, Editora Regional de Murcia, 1996, pag.XVIXVIII, e William Chittick, The Sufi Path of Knowledge, SUNY Press, 1989, pag. 21-22.

188) Hadīt riportato da Muslim, VI-139.

189) Ibn 'Arabī menziona questo Maestro nel Cap. 73 [II 21.13] ove afferma che era, alla sua epoca, uno di coloro che ricevevano le novelle divine (al-muhaddatūn), come 'Umar ibn al-Hatțāa all'epoca del Profeta.

190) Nel Cap. 15, Ibn 'Arabī riporta questa affermazione di un certo al-Kāsib [I 157.14]: "Invero Allah ha posto tutta la scienza nelle sfere ed ha fatto dell'uomo la sintesi delle fini realtà (raqa $\vec{\imath} q=$ corrispondenze) di tutto il mondo. Dall'uomo si estende una fine realtà verso ogni cosa del mondo, per mezzo di cui [si incanala] da quella cosa all'uomo ciò che Allah ha posto in quella cosa e che le ha affidato affinché la facesse pervenire a quell'uomo; e per mezzo di quella fine realtà l'uomo conoscitore muove quella cosa a sua volontà. Non c'è in effetti nulla nel mondo che non abbia un effetto sull'uomo e su cui l'uomo non abbia influenza" commentando 
Poi si mise a leggere ed il Maestro stava in silenzio, al che gli chiese: "Perché non mi parli di esso?", ed il Maestro gli rispose: "Leggimi!" e si alzò da lui. [L’uomo] andò a far visita ad Abū Madyan, il nostro Maestro ${ }^{191}$ ), e gli raccontò cosa era successo con al-Haššāb, ed egli gli disse: "Ti ha detto il vero! Cosa contiene il libro?", ed egli rispose: "Tutti i capitoli della Via, dalla rinuncia (zuhd), al combattimento spirituale (muğăhada), allo scrupolo, alla conoscenza ed altro”. Abū Madyan gli disse: "C'era un capitolo che non fosse uno stato per al-Ȟsašsāb?", ed egli rispose: "No! Tutto quello è l'attributo di al-Haššāb", al che gli disse: "La tua lettura di lui per mezzo del suo stato è più efficace del libro. Egli ha detto: leggimi! Se non sei capace di trarre profitto dal suo stato e dal suo attributo, come puoi trarre profitto dal suo discorso?". Ciò fa parte del rimedio per ciò che è nel suo petto.

Quanto al suo detto: "un andarsene della sua preoccupazione”, l'aspirante quando [50] è solo con la sua anima, immancabilmente gli si presentano dei propositi e la sua faccenda si disperde e si moltiplica la sua preoccupazione su cosa fare di ciò che gli è passato per la mente. Quando invece è di fronte al Maestro la sua preoccupazione se ne va ed egli resta ad osservare il Maestro per vedere ciò che gli ordina ed egli concentra la sua aspirazione su di quello: questo è l'andarsene della sua preoccupazione.

Quanto al suo detto: "ed una quiete per la sua anima" egli si riferisce a ciò che abbiamo menzionato della dispersione (tašattut) dei propositi che si presentano (hawātir in assenza della visione del Maestro, poiché all'aspirante arrivano le proiezioni dell'anima, di Satana, dell'Angelo e del Vero $\left({ }^{192}\right)$, mentre

poi che questo saggio aveva ottenuto lo svelamento e la conoscenza delle fini realtà e che esse sono simili ai raggi della luce. Nel Cap. 357 precisa inoltre [III 260.6]: "Sappi che non c'è forma nel mondo inferiore che non abbia un corrispondente nel mondo superiore. Le forme del mondo superiore preservano l'esistenza delle loro simili nel mondo inferiore [...] Tra i due mondi vi sono fini realtà che si estendono da ogni forma alla sua simile, sicché esse sono connesse e non disgiunte. L'ascesa e la discesa hanno luogo lungo queste fini realtà, che sono così scale ascendenti e discendenti. Talvolta esse sono chiamate interrelazioni (munāsabāt)". Va notato che Ibn 'Arabī parla anche di "fini realtà" sataniche [Cap. 310 (III 39.20)].

191) Ibn 'Arabī spesso denomina Abū Madyan come suo Maestro, ma non lo incontrò mai fisicamente: nella sua Risāla rūh al-quds, redatta alla Mecca nell'anno 600 dall'Egira, dunque dopo la morte di Abū Madyan, Ibn 'Arabī riferisce che mentre era a Siviglia ebbe un forte desiderio di incontrare Abū Madyan e poco dopo si presentò a lui Mūsā Abū 'Imrān aṣ-Șadrānī, uno dei sette Pilastri (awtāed), inviatogli da Abū Madyan per riferirgli alcune cose, tra cui il fatto che Allah non avrebbe permesso il loro incontro fisico in questo mondo [Ibn 'Arabī, Sufis of Andalusia, Allen \& Unwin, Londra, 1971, pag. 121]. L'episodio qui riportato da Abū l-'Abbās al-Hुaššāb si deve quindi riferire ad un'epoca anteriore, in cui a Fes si trovava Abū Madyan ma non Ibn 'Arabī.

192) Nel Cap. 55 [I 281.25], Ibn 'Arabī precisa: "I propositi che si presentano alla coscienza possono essere solo di quattro tipi: un proposito di origine dominicale (rabbāan $\overrightarrow{)}$, un proposito di origine angelica (malak $\vec{\imath}$, un proposito originante dalla nafs ed un proposito di origine satanica; non ce ne sono altri [...] Ora, se l'uomo non è consapevole dei suoi propositi e non sa distinguerli tanto da discriminare la proiezione $(i l q \bar{a})$ di Satana, anche se riguardasse una cosa buona, dalla proiezione dell'angelo e dell'anima e discernere tra di esse in modo corretto, allora [è bene] che non agisca, altrimenti non avrà mai successo". Nel Cap. 264 [II 563.32] dedicato appunto alla conoscenza dei propositi che si presentano, Ibn 'Arabī precisa che i hawätirir sono essenzialmente degli ambasciatori (sufar $\bar{a}$ ) che Allah invia al cuore del Suo servitore e che non hanno permanenza nel cuore del servitore se non per la durata del loro passaggio in lui. Allah li ha creati nella forma del messaggio per cui 
in presenza del Maestro egli si distoglie dal suo foro interiore e presta ascolto a ciò che gli ordina il suo Maestro, non avendo altro oggetto di contemplazione se non la forma del suo Maestro, e non gli resta alcun discorso dell'anima, né alcun proposito riguardo ad una cosa. Questo è il significato della quiete, che è il contrario del movimento nelle diverse direzioni che ha in assenza della visione del Maestro, a causa della dispersione dei propositi che abbiamo menzionato. Questo lo prova ogni uomo da se stesso nella riunione con gli uomini e nell'isolamento con se stesso: la persona quando è seduta con qualcuno si concentra con lui su ciò che gli riferisce il suo compagno, mentre quando resta da sola si moltiplicano per lui i propositi su diverse faccende. Questo riguardo alla gente comune e che dire dell'aspirante che non vede se non il suo Maestro, con una visione di amore e di convinzione?

Poi ha detto:'E quando il Maestro gli ordina una cosa esteriore, egli si affretta a farla ringraziando Allah, sia Egli esaltato, in quanto (kayfa) il Maestro lo ha onorato con quello", ove "kayfa" ha il significato di "haytu”", per il detto di Allah, sia Egli esaltato: "Obbedite ad Allah ed obbedite all'Inviato ed a coloro di voi che detengono il comando" (Cor. IV-59), ed il Maestro è tra coloro che detengono il comando, in quanto tu gli hai affidato la tua faccenda e ti sei posto sotto la sua giurisdizione e la sua obbedienza, e sei convinto che egli comunica (yuhbiru) da parte di Allah. In realtà [51] per noi, se l'aspirante è veridico nel suo rivolgersi (tawağğuh) verso Allah, quanto è Potente e Magnificente, e nel suo rivolgersi non cerca altro che Allah, Allah non lo dirige se non su un Maestro realizzato, dalla lingua sincera nella sua asserzione [di essere tale]. Se poi il Maestro non è in questa condizione, ma l'aspirante crede sinceramente che egli sia uno che comunica da parte di Allah e non ha esitazioni in ciò di cui è convinto, per la sua veridicità Allah, sia Egli esaltato, provvede a quel Maestro l'assistenza, la scienza ed il buon consiglio per ciò di cui questo aspirante ha bisogno e che egli non possedeva, né conosceva da se stesso, e solo per ciò che riguarda questa faccenda. Così questo preteso Maestro ottiene nel suo cuore la luce dell'assistenza, si risveglia dal sonno della noncuranza, e diventa corretto (yansalihu) in se stesso per il suo Signore, senza sapere che ciò viene da parte dell'aspirante e della sua veridicità - questo in quanto egli è assistito da parte di Allah - ed osserva in quella occasione la rettificazione del suo stato con Allah. E per mezzo della scienza che Allah gli ha donato, in cui si trova il bene (salāh $)$ di questo aspirante veridico, trae profitto il Maestro in se stesso e ne trae vantaggio l'aspirante veridico.

Se poi la consapevolezza di questo Maestro si rafforza, egli viene a sapere che l'influenza spirituale (baraka) della veridicità di questo aspirante è ricaduta su di lui ed è stato assistito per mezzo di essa, ed Allah gli ha fatto pervenire per mezzo di lui una Misericordia da parte Sua, e gli ha insegnato da parte Sua una scienza.

sono stati inviati e quindi ogni hătir è lui stesso il Suo messaggio: se questo messaggio arriva al cuore del servo senza incontrare ostacoli nel suo percorso allora si tratta di un hătir di origine dominicale, il cui contenuto è sempre inerente alla scienza ('ilm) e non all'agire; se invece viene intercettato dall'angelo custode del cuore, o dal demone che gli si contrappone o infine dalla nafs allora colui che lo intercetta, in virtù della facoltà di rappresentazione di cui è dotato, foggia una forma simile al hătir originale ed è infine questo hătir di secondo grado che viene presentato al cuore del servitore. è cosi che hanno origine gli altri tre tipi di hawätir, i quali a differenza di quelli di origine dominicale hanno sempre un contenuto inerente all'agire e non alla scienza. 
Questa stazione l'ho vista in modo contemplativo da parte di chi si manifestava nella forma della Maestria in Andalusia, e non era veramente un Maestro: quando lo incontrai era molto stimato dagli uomini, ed egli mi pose una questione che esulava dal suo stato ed io lo biasimai di fronte ai presenti con un risposta giusta e ciò apparve duro ai presenti poiché lo consideravano avido della stima. Poi, dopo questo fatto, uno che era al suo servizio ebbe fiducia in lui senza esitazione ed il Maestro fu assistito e riconobbe la sua mancanza e la falsità in cui si trovava [52] nello stato della sua pretesa [di essere Maestro] e divenne illustre nel paese per il riconoscimento [del suo errore] e fece marcia indietro da quella condizione in cui si trovava e divenne uno dei servitori eletti di Allah, e tutto ciò per l'influenza spirituale della veridicità di un aspirante che fu sincero nella sua convinzione al suo riguardo.

Allah ha sancito per Legge i due regimi (hukmayn) $\left({ }^{193}\right)$ ed ha ordinato alle coppie (zawğayn) di sottoporsi a questi due regimi. Chi impone a se stesso una persona come tutore (wall) è tenuto a sottostare al suo ordine, se gli ordina un atto di avvicinamento ad Allah noto nella Legge pura, o un atto che è lecito $(m u b a \bar{h})$ fare a colui a cui viene ordinato e che diventa obbligatorio (wāğib) per l'ordine di questo Maestro, ed il discepolo ottiene da parte del Vero la ricompensa di chi compie un atto obbligatorio e la dimora che gli spetta. In effetti la dimora del compiere le cose rese obbligatorie da parte del Vero è diversa dalla dimora degli atti supererogatori (nawāfil), e per quanto di obbligatorio vi è negli atti supererogatori $\left({ }^{194}\right)$ questi possiedono degli spiriti elevati presso Allah, poiché nel suo atto supererogatorio per ciò che vi è in esso di obbligatorio, egli si avvicina con ciò che è più caro ad Allah, sia Egli esaltato, in quanto Egli ha detto nella notificazione divina autentica: "Coloro che si avvicinano non si avvicinano con qualcosa che sia più caro a Me del compimento di ciò che ho imposto loro" ${ }^{195}$ ). Rientrano in questa notificazione gli obblighi di istituzione divina (farā $\nmid$ id) assoluta e gli obblighi di istituzione divina che sono inclusi negli atti supererogatori, e l'effetto degli obblighi di istituzione divina è noto a noi per mezzo del gusto spirituale, mentre l'effetto degli atti supererogatori è noto a noi per gusto spirituale e per ascolto, poiché la Legge ha esplicitato testualmente l'effetto degli

193) Dal contesto e dal riferimento alle coppie maschio-femmina [cfr. Cor LI-49: "Di ogni cosa abbiamo creato una coppia"] i due regimi sono verosimilmente quelli di attivo-passivo, superiore-inferiore, alto-basso. Nel Cap. 374 [III 462.12] Ibn 'Arabī precisa: "Egli ha creato lo Sgabello (kursì), e la Parola [unica] si divise in due ordini, sì che Egli potesse creare una coppia di ogni genere. Allora uno dei due sarà caratterizzato dall'elevatezza e l'altro dalla bassezza, uno dall'attività, l'altro dalla passività".

194) I riti supererogatori, come le raka $\bar{a} t$, i digiuni e le șadaqāt, si fondano comunque sui riti di istituzione divina e contengono pertanto elementi dei riti obbligatori. Nel Cap. 31 [I 203.9], Ibn 'Arabī precisa: "L'Inviato di Allah, che Allah faccia scendere su di lui la Sua salāt e la Pace, ha detto, riguardo a ciò che gli veniva comunicato da parte del suo Signore, che Allah ha detto: "Coloro che si avvicinano a Me non si avvicinano con qualcosa che sia più caro a Me del compimento di ciò che ho imposto loro" - questo è il fondamento (asl): il compimento dell'atto di istituzione divina - poi ha detto: "ed il servitore non cessa di avvicinarsi a Me con gli atti supererogatori", ed essi sono quelli che si fanno in più degli obblighi di istituzione divina, pur essendo dello stesso genere, tanto che questi ultimi sono il loro fondamento, come nel caso delle opere di bene supererogatorie che derivano dalla șalāt, dalla zakāt, dal digiuno, dal pellegrinaggio e dallo $\underline{d i k} r$ ”.

195) Hadīt quds̄̄ riportato da al-Buhārī, LXXXI-38, e da Ibn Ḥanbal. 
atti supererogatori ma non ha esplicitato testualmente l'effetto degli obblighi di istituzione divina, se non con il Suo detto: "più caro a Me". Egli ha posto quest'amore al di sopra dell'amore divino che risulta dagli atti supererogatori, ed ha menzionato riguardo all'amore divino che conferiscono gli atti supererogatori che Egli è le membra del Suo servitore e le sue facoltà $\left({ }^{196}\right)$, in occasione dello svolgimento delle loro funzioni per mezzo della Sua Ipseità (huwiyya), sia Egli esaltato, mentre non ha menzionato riguardo all'amore dell'obbligo di istituzione divina, che gli è più caro dell'atto supererogatorio, ciò che risulta dall'amore dell'obbligo di istituzione divina, ed esso non è dunque noto [53] se non per gusto spirituale, e fa parte dei segreti nascosti $\left({ }^{197}\right)$.

L'uomo, nel compimento dell'obbligo di istituzione divina è servitore per costrizione, e nell'atto supererogatorio è servitore per scelta, e per il conoscitore la sua conoscenza implica che nella sua

196) Si tratta del seguito dello stesso hadìt.

197) Nel Cap. 560 [IV 449.28] Ibn 'Arabī precisa: "Sappi che se sei assiduo nel compiere gli atti obbligatori (farā id ti avvicinerai ad Allah con la più amata delle cose che fanno avvicinare a Lui, e quando possiederai effettivamente questo attributo allora sarai l'udito del Vero e la Sua vista ed Egli non sente e non vede se non per mezzo di te. La Mano del Vero è la tua mano: "In verità coloro che prestano giuramento di fedeltà a te, prestano giuramento di fedeltà ad Allah. La Mano di Allah è sopra le loro mani!" (Cor. XLVIII-10), cioè le loro mani, in quanto esse sono la Mano di Allah, sono sopra le loro mani, in quanto esse sono le loro mani. Sono esse che prestano giuramento (mubāya'a) e l'Agente è Allah: quindi le loro mani sono la Mano di Allah e con le loro mani l'Altissimo presta giuramento di fedeltà ed essi sono coloro con cui viene prestato il giuramento (mubāyaûn). Tutte le "cause seconde" (asbāb), che hanno il potere di dare l'esistenza alle cose causate, sono la Mano di Allah. Questo è l'amore supremo, riguardo al quale non è stato trasmesso un testo chiaro come quello che ci è pervenuto per le opere supererogatorie: la perseveranza (mutäbara) nelle opere supererogatorie (nawäfil) ha come conseguenza necessaria un amore divino a cui si riferisce appunto il testo (nass) che afferma che il Vero è l'udito del servitore e la sua vista, mentre nel caso dell'amore dovuto al compimento delle opere obbligatorie le cose sono esattamente all'opposto. Quindi in ciò che è obbligatorio vi è la servitù ('ubudiyya) obbligatoria, che è quella originale, mentre nel ramo, cioè ciò che è supererogatorio, vi è la servitù volontaria (ihtiyârrî) ed in essa il Vero è il tuo udito e la tua vista. Si chiama supererogatorio (nafl) in quanto è in più, così come tu, per quanto concerne l'origine (asāla), sei in più nell'esistenza, poiché c'era Allah e tu non c'eri, poi tu ci fosti e si aggiunse la nuova (hädit $)$ esistenza: quindi tu sei supererogatorio rispetto all'esistenza del Vero. Ł̀ assolutamente necessaria per te l'opera chiamata supererogatoria, poiché in ciò è la tua origine, e non puoi fare a meno dell'opera chiamata obbligatoria, poiché in ciò è l'origine dell'esistenza, che consiste nell'esistenza del Vero. Nel compiere ciò che è obbligatorio tu appartieni a Lui e nel compiere ciò che è supererogatorio tu appartieni a te: ora, il Suo amore per te in quanto tu appartieni a Lui è più grande e più forte del Suo amore per te in quanto tu appartieni a te. ̇̀ stato riportato nella tradizione validamente trasmessa che Allah, sia Egli esaltato, ha detto: "Il Mio servitore non si avvicina a Me con qualcosa che Mi sia più gradito che il compimento di ciò che gli ho prescritto, ed il Mio servitore non cessa di avvicinarsi a Me con delle opere supererogatorie finché Io lo amo. E quando lo amo, Io sono il suo udito con il quale sente, la sua vista con la quale vede, la sua mano con la quale prende ed il suo piede con cui cammina. Se egli Mi rivolge una preghiera, certo Io la esaudisco. Se egli cerca rifugio presso di Me, Io glielo accordo. Nulla di ciò che faccio Mi fa tanto esitare quanto il ritirare l'anima del credente che detesta la morte; in effetti Mi ripugna di affliggerlo". Osserva ciò che produce l'amore di Allah e sii assiduo nel compiere ciò per cui ha luogo l'esistenza di questo amore divino. Un atto supererogatorio non è valido se non dopo quello obbligatorio e nello stesso atto supererogatorio vi sono aspetti obbligatori ed aspetti supererogatori: ora, ciò che di obbligatorio si trova in esso completa gli atti obbligatori". 
condizione di servitù non sia vincolato né da costrizione né da scelta, ma sia un servitore assoluto di Allah, nella cui servitù non affiora pensiero di costrizione né di scelta.

Quando il Maestro ordina una cosa all'aspirante, l'aspirante ringrazia Allah, sia Egli esaltato, per quello, in quanto il suo ordine è un riconoscerlo $(\operatorname{ta} \hat{r} \bar{y} f)$ da parte del Maestro, ed un annuncio che egli lo ha accettato come assoggettato (mukallaf) a lui ed al suo ordine. Il Maestro nel suo ordinare a quel aspirante non può fare a meno [di essere in una delle due situazioni seguenti]: o vede se stesso come colui che gli ordina ciò per cui l'aspirante gli ha dato mandato su se stesso, e ciò fa parte dell'incarico (tawliya) da parte dell'aspirante $\left({ }^{198}\right)$, ed il Maestro a questo pensiero è affranto in se stesso, poiché non è autonomo nel suo governo (walaya) su di lui, in quanto non lo governa se non per l'incarico da lui ricevuto, e non si tratta di un governo di costrizione (qahr).

Se il Maestro [invece] vede se stesso come nominato governatore da parte del Vero e non da parte dell'aspirante, in quanto Allah gli ha affidato questo governo su di lui, quando gli dà un ordine lo fa per una potenza ('izza) divina, e questa è ciò che viene chiamata l'efficacia dell'aspirazione (nufüd alhimma) $\left({ }^{199}\right)$ del Maestro riguardo all'aspirante nella sottomissione al suo ordine, e qui il Potere (quwrea) appartiene senza dubbio ad Allah, poiché il testimone (šähid) dello stato $\left({ }^{200}\right)$ lo attesta.

198) L'aspirante, come ha precisato Ibn 'Arabī all'inizio del libro, non è colui che "vuole l'iniziazione" ma colui che "vuole l'istruzione iniziatica", ed il Maestro non è considerato in quanto "trasmettitore" di una influenza spirituale, poiché tale ruolo potrebbe anche essere svolto da un muqaddam, ma colui che si prende carico dell'istruzione iniziatica dell'aspirante, istruzione indispensabile perché l'iniziazione da virtuale possa diventare effettiva. L'incarico di cui si tratta è sancito da un patto ('ahd o 'aqd), che coincide con la trasmissione dell'influenza spirituale, ma che comporta dei doveri reciproci, del Maestro nei confronti dell'aspirante e dell'aspirante nei confronti del Maestro. Se si trattasse solo dell'iniziazione virtuale non si giustificherebbe il mantenimento del nome di "aspirante", poiché in tal caso ciò a cui egli aspira è stato ottenuto ed invece che "aspirante" si dovrebbe chiamare "iniziato".

199) Questa espressione ricorre nel Cap. 361 [III 295.29] e nel Cap. 559 [IV 377.22 e 24].

200) Nel suo Kitāb mawāqi' an-nuğūm, a pag 83 dell'edizione di ‘Abd al-'Azīz Sulțān al-Manșūb, Il Cairo, 2016, Ibn 'Arabī precisa: "Sappi, figlio mio, che colui che fruisce di un'assistenza [(tarefî $q)$ divina] in una delle cose che sono richieste per la beatitudine e in altre, il testimone del suo stato attesta la veridicità della sua asserzione, oppure la smentisce. I testimoni degli stati sono di due tipi: un tipo che sussiste nell'essenza stessa di chi fa l'asserzione, ed un tipo che sussiste nell'essenza di un altro che è simile a lui nell'asserzione. Non vi è un terzo tipo. Quello che dipende da lui stesso è come il colore giallo della codardia ed il colore rosso della vergogna, ed il cessare di contrastare Allah nelle Sue decisioni e il sopportare le avversità da parte di chi asserisce di essere nella stazione della soddisfazione per il Decreto". Analogamente, nel Cap. 560 [IV 452.30] afferma: "Se trascuri di fare ciò che ti ho raccomandato non biasimare che te stesso, poiché se eri ignorante io ti ho fatto conoscere [ciò che ignoravi], se ti dimenticavi o trascuravi io ti ho avvertito ed ammonito, e se fossi credente certo l'avvertimento ti gioverebbe. Io mi sono conformato all'ordine di Allah, per quello che ti ho ricordato, ed il tuo trarre profitto dall'avvertimento è un testimone per te della fede. Allah, quanto è Potente e Magnificente, ha detto riguardo a tutti noi: "Ed avverti, poiché l'avvertimento giova ai credenti" (Cor. LI-55). Se dunque l'avvertimento non ti giova sospetta della fede della tua anima, poiché Allah dice il vero ed ha notificato che l'avvertimento giova ai credenti". 
E quando il Maestro accetta l'incarico dell'aspirante nei suoi confronti perché gli è stato assegnato da Allah, egli fa parte di coloro che sono dotati di comando e l'obbedienza a lui è obbligatoria, e questo Maestro è responsabile (mutālab) presso Allah in tutto ciò che ordina a chi rientra sotto la sua obbedienza $\left({ }^{201}\right)$.

Sennonché la differenza nel governo tra lui e tra i Re ed i sultani che detengono il comando è che l'ordine di questo Maestro, poiché dipende dalla sincerità dell'aspirante nel suo incarico, non viene mai disobbedito ed è assolutamente una misericordia nei suoi confronti. Il governo dei Re dipende invece da costrizione e paura e per quello la maggioranza non segue il suo ordine con l'accettazione dei loro cuori, [54] se non per ciò che le piace, non per ciò che le dispiace, e se gli obbedisce (imtatala) nella apparenza esteriore, in se stessa lo detesta per quello, a differenza dell'aspirante, ed il motivo di ciò nei confronti dei Re è la mancanza della scienza e della fede da parte dei sudditi, che li obbliga ad adottare [questo atteggiamento] ${ }^{(202}$ ), e questa è una faccenda nascosta alla maggior parte degli uomini.

Ed il Maestro ringrazia Allah come Lo ringrazia l'aspirante, e non è lieto (fārih $)$ nella sua gratitudine se non quando gli ordina con una lingua di verità e dà il dovuto alla bilancia stabilita per lui in ciò, ed allora è lieto per l'ordine che gli ha impartito in quanto esso soddisfa la bilancia, non in quanto ha dato un ordine ${ }^{(203)}$.

L'aspirante è lieto per l'ordine del suo Maestro quando vede la sollecitudine del Maestro verso di lui ed il fatto che egli lo ha accettato, e se la considerazione che gli provoca la letizia è il fatto che il Maestro ha accettato il suo incarico nei suoi confronti, quella è una leggerezza (rữna) dell'anima ed una letizia naturale, e dopo poco la sua letizia si trasformerà per lui in tristezza. La letizia dell'aspirante è ripartita in classi come è ripartita la letizia del Maestro, ed al Maestro si impone, quando sa che

201) Il Maestro non è però responsabile di ciò che fa l'aspirante dell'ordine che gli è stato impartito, come verrà precisato in seguito.

202) Non sono certo della traduzione del testo, che in tutti i manoscritti consultati recita: "wa sabab dālika $f \bar{\imath}$

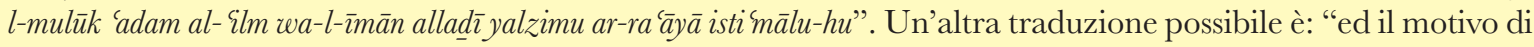
ciò nei confronti dei Re è la mancanza della scienza e della fede, la cui applicazione è necessaria per i sudditi".

203) Nel Cap. 304 [III 19.24] Ibn 'Arabī riporta un'altro motivo di ringraziamento del Maestro: "Tra le mancanze di adab nella Via di Allah, sia Egli esaltato, [...] vi è l’auto-esaltazione ('izza) dei Maestri nei confronti degli aspiranti che lo seguono, essendo questi dipendenti da loro per il loro insegnamento e per la loro eccellenza. Se il Maestro non rispetta il diritto della sua stazione, la dipendenza da lui dell'aspirante lo vela dalla sua propria dipendenza dal suo Signore nei suoi stati, ed allora egli contempla la sua indipendenza per Allah, e l'indipendenza per Allah comporta l'auto-esaltazione [o la potenza]. Il possessore realizzato di questa stazione, quando vede che gli aspiranti dipendono da lui per ciò che Allah gli ha dato, ringrazia invece Allah per questo, in quanto Allah ha reso i discepoli dipendenti da lui ed in questo modo ha rafforzato la sua dipendenza da Allah, sia Egli esaltato. Potrebbe infatti succedere che se essi non manifestano l'attributo della dipendenza (faqr) da lui egli dimentichi la sua dipendenza da Allah, sia Egli esaltato. Questo è lo stato del Maestro realizzato [...] Quindi l'aspirante è il Maestro del Maestro per il suo stato, ed il Maestro è il Maestro dell'aspirante per le sue parole ed il suo insegnamento". 
la letizia dell'aspirante e la sua gratitudine ad Allah dipendono dal fatto che il Maestro ha accettato il suo incarico e che per questo ha un potere su di lui, in quanto [l'aspirante] gli ha attribuito con il suo incarico la funzione di chi comanda $\left({ }^{204}\right)$, al Maestro [dicevo] si impone di non dargli ordini, bensì deve trascurarlo e allontanarlo da lui, affinché conosca se stesso e si senta povero, e riconosca che il grado del Maestro, come quello di Allah, è superiore al suo, e quando sa che egli ha questo orientamento ed è sincero in esso, allora gli ordina e gli proibisce $\left({ }^{205}\right)$.

Poi ha detto: "e si sforza di non tornare dal Maestro se non quando ha compiuto quell'ordine, e non torna velocemente scusandosi con il Maestro, e se quell'ordine è facile da eseguire torna dal Maestro rispettando l'adab".

Commento: egli dice "non torna velocemente" prima del compimento [55] di quell'ordine, e se lo completa velocemente torna dal Maestro velocemente, poiché tutta la sua aspirazione (himma) è connessa con ciò che il Maestro gli ha prescritto di compiere. E quanto al suo detto "scusandosi", sappi che la scusa è assolutamente abolita nella gente della Via di Allah, poiché la scusa è un indice categorico di una cattiva opinione di colui con cui ci si scusa $\left({ }^{206}\right)$, e la cattiva opinione è proibita per l'aspirante e per chiunque asserisca di far parte della gente della Via di Allah, poiché essi accettano le scuse dagli stranieri, non chiedono scusa e non accettano mai la richiesta di scusa gli uni con gli altri. Se uno della gente della Via realizza che scusandosi con un altro questi può trarre beneficio nella sua religione, e che può far cessare così ciò che nella sua anima porta alla censura nella sua fede, in quel caso è suo dovere chiedergli scusa, come insegnamento e come sollecitudine per lui, affinché cessi da lui ciò che è censurabile nella sua fede $\left({ }^{207}\right)$, ma se sa che l'altro accetterà la sua scusa esteriormente, restando interiormente nella sua cattiveria, allora non gli chieda scusa in alcun modo.

Poi ha detto: "e se gli ordina una seconda volta egli obbedisce", cioè si comporterà come ha fatto per il primo ordine, e se gli ordinasse mille volte o per tutta la sua vita, egli non cesserà di obbedire ai suoi ordini in successione, senza dispetto (dağar) né combattimento (muğăhada), ma considererà quello come parte della sollecitudine di Allah verso di lui, in quanto Allah, sia Egli esaltato, ha posto per lui questa mansione (manzila) nel cuore del Maestro. Invero l'ordine del Maestro all'aspirante non deriva da un suo bisogno di ciò che gli ordina, ma è un insegnamento per lui ed un profitto che il Maestro vede nei

204) Ibn 'Arabī si riferisce qui alla prima delle due situazioni in cui può trovarsi il Maestro.

205) Quindi, se dopo il patto iniziatico il Maestro non impartisce ordini all'aspirante, ciò vuol dire che l'aspirante non ha l'attitudine voluta nei confronti del Maestro, e questo è un ulteriore esempio di testimone dello stato.

206) La scusa presume una accusa da parte di colui con cui ci si scusa. Nel Corano è ingiunto due volte di non scusarsi (lā ta Yadirū) [IX-66 e 94], ancorché il discorso non sia rivolto ai credenti.

207) Analogamente, nel Cap. 560 [IV 480.] Ibn 'Arabī precisa: "Accetta la scusa da parte di chi si scusa con te, ma guardati dallo scusarti (itidārr), poiché ciò comporta una cattiva opinione da parte tua nei confronti di colui con cui ti scusi. Se sai che nel tuo scusarti con lui c'è un bene per lui ed una utilità nella sua religione, allora scusati con lui nel suo diritto, senza pensar male di lui, anzi ti si impone l'assolvimento di un suo diritto. Tra i diritti quello che ha più diritto è il diritto di Allah". 
suoi riguardi. E se l'aspirante ha avversione per quello, lo compia ed obbedisca al suo ordine contro voglia, e sarà così dedito al combattimento spirituale; in effetti, quando compie ciò che il Maestro gli ha ordinato combattendo, si aprirà per lui il sentiero (sabīl) [56] verso Allah, sia Egli esaltato, e procederà su di esso in quello. Il sentiero di Allah accresce il gusto spirituale $(\underline{\text { dawq }})\left({ }^{208}\right)$ e finché [l'aspirante] non prova il piacere (ladd $\underline{-} a)$ egli sa che non è sul sentiero di Allah cercato nella Via (tarīq); quando [invece] prova il godimento (iltid $\underline{a} \bar{a} \underline{d})$ nell'obbedienza - e l'obbedire all'ordine del Maestro è tra i più grandi atti di obbedienza - ed il godimento per la critica degli uomini nei suoi confronti, che normalmente è detestata per natura dalle anime ed è biasimata nell'uso comune, ma in cui questo aspirante prova piacere, allora egli sa che è nel sentiero specifico di Allah.

Ciò corrisponde al detto di Ibrāhīm ibn Adham $\left({ }^{209}\right)$ secondo cui l'uomo non è nella Via fintanto che la lode ed il biasimo non si equivalgono per lui, e questa è la prima delle porte della conoscenza di Allah, ed è una cosa che è molto facile (hayyin ǧidd ${ }^{a n)}$ da ottenere. Tra i Maestri che ho incontrato non ho visto chi lo abbia realizzato veramente se non Abū Ishạa ibn Ṭarīf $\left({ }^{210}\right)$, ad Algesiras $\left({ }^{211}\right)$; oltre a lui non l'ho visto [realizzato da alcuno] con la sobrietà (sahw), e quanto all'ebbrezza (sukr), che è chiamata follia d'amore (ğunūn), ho visto un gruppo che non si curava del biasimo. Quanto a quest'uomo, possessore di questa spiritualità, che ha fornito questa raccomandazione a colui che parla - Yūsuf ibn Ibrāhīm - cioè 'Alī al-Kurdī, non l'ho visto prendere piede (qadam) in questo [lo stato in cui lode e biasimo sono indifferenti] malgrado fosse di grande rango (kabīr al-qadr): partecipai

208) I manoscritti riportano yazìdu bi-l $\underline{d} a w q$, che letteralmente significa "aumenta con il gusto.

209) Celebre Șūfì del secondo secolo dall'Egira che abbandonò la sua funzione regale dopo avere ricevuto due volte la visita da parte del Hुiḍr. Cfr. Farīd ad-dīn al-'Aț̣ār, Parole di Süfì, Boringhieri, 1964, pagg. 161-187. Il detto in questione non è riportato nelle Futūhāt.

210) Nel Cap. 71 [I 617.2] Ibn 'Arabī precisa: "Questa è anche la posizione dottrinale del nostro Maestro Abū Ishāq [Ibrahīm ibn Aḥmad] ibn Ṭarīf, uno dei più grandi che abbia conosciuto. Un giorno mi trovavo nella casa di questo Maestro ad Algesiras, nell'anno 589. Stavo ascoltando ed egli mi diceva: "Fratello mio. Per Allah, nei miei confronti io considero gli altri solo come degli Intimi $(a w l i y \bar{a})$, fino all'ultimo di coloro che mi conoscono". Gli chiesi: "Cosa vuoi dire con ciò, Abū Ishāq?" ed egli rispose: "La gente che mi ha visto o che mi ha sentito o parla bene di me oppure dice l'opposto di quello. Chiunque parli bene di me e mi lodi, mi descrive con quello che è il suo attributo [proiettandolo su di me]; se non fosse che è degno ed è il ricettacolo di quell'attributo, non mi avrebbe descritto per mezzo di esso: secondo me costui è uno degli Intimi di Allah, sia Egli esaltato. Quanto a colui che parla male di me, anch'egli per me è un Intimo, a cui Allah ha fatto conoscere il mio stato. Egli è dotato di fisionomia ( firāsa) e svelamento (kašff), e vede per mezzo della Luce di Allah, sì che per me è un Intimo. Per questo, fratello mio, io vedo solo Intimi di Allah". Egli mi disse questo perché stavamo discutendo riguardo ad un uomo della gente di Ceuta che soleva contrastare questo Maestro, opponendosi a ciò che aveva appreso da lui. Questa [attitudine di ibn Țarîf] è più eccellente di colui che ha solo una buona opinione degli uomini. Egli faceva parte dei Maestri i cui soffi (anfās) rendono conto contro di loro, sì che essi sono puniti per le loro negligenze. Egli morì in conseguenza di un atto di trascuratezza che abbiamo menzionato ne La Perla Preziosa (ad-durra al-făhira), nella sezione dedicata a lui."

211 ) Il nome Algesiras viene dall'arabo al-ğazīra al-ḩadrā, l’isola verde, nome che venne attribuito dai conquistatori arabi nel 711 dell'era volgare, alla prima città che essi fondarono in Spagna, perché di fronte ad essa si trovava un isolotto verdeggiante, che poi venne inglobato nel porto. 
con lui ad una riunione ed accadde una cosa come questa da parte di una persona con lui [cioè una persona lo biasimò per qualcosa], ed egli si alterò contro di lui in modo totale, tanto che gli disse: "Se non fosse per la riverenza (hurma) per colui che è qui seduto ti farei vedere ciò che ti fa male!", e si alzò e procedette a combattere per se stesso riguardo a ciò per cui quell'uomo lo aveva messo in difficoltà $\left({ }^{212}\right)$.

Allah, sia Egli esaltato, dice riguardo a questa stazione spirituale: "E coloro che combattono in Noi, certo li guideremo sui Nostri sentieri" (Cor. XXIX-69) ed i sentieri non diventano chiari se non con questo combattimento, ed ha spiegato che colui che combatte non è guidato sui sentieri specifici di Allah [57] se non dopo la guerra ( ğiha $d)$ in Allah con la Sua vera guerra, e non combatte in Allah la Sua vera guerra se non l'eletto $($ muğtab $\bar{a})\left({ }^{213}\right)$.

212) 'Alī al-Kurdī, che da quanto è riportato venerava Ibn 'Arabī, non aveva realizzato lo stato in cui lode e biasimo sono indifferenti, e pertanto doveva ancora esercitare il combattimento spirituale.

213) Nel Cap. 76 [II 145.29] Ibn 'Arabī precisa: "Sappi, che Allah ti assista, che coloro che combattono sono la gente dello sforzo, della fatica e della sopportazione (mukäbada) ed essi sono di quattro categorie. La prima è rappresentata da coloro che combattono senza specificare per che cosa; a ciò corrisponde al Suo detto, sia Egli esaltato: "Allah ha preferito coloro che combattono a coloro che siedono [a casa, accordando loro] una ricompensa immensa" (Cor. IV-95). La seconda è rappresentata da coloro che combattono, con la specificazione "nel sentiero di Allah"; a ciò corrisponde il Suo detto: "Coloro che combattono nel sentiero di Allah" (Cor. IV-95) ed anche "e per una guerra nel Suo sentiero" (Cor. IX-24). La terza è rappresentata da coloro che combattono in Lui; a ciò corrisponde il Suo detto: "Quanto a coloro che combattono in Noi, certo li guideremo sui Nostri sentieri”" (Cor. XXIX-69), cioè spiegheremo loro affinché sappiano in chi combattono, ed essi o combattono in quella circostanza o non combattono. La quarta categoria è rappresentata da "coloro che combattono in Allah la Sua vera guerra" (cfr. Cor. XXII-78) ed il Vero li ha distinti da coloro che combattono in Allah senza questa specificazione, come coloro che "temono Allah con il timore che Gli è dovuto" (cfr. Cor. III-102) e "coloro che recitano il Libro con la recitazione che gli è dovuta" (cfr. Cor. II-121): questa è la quarta categoria"; poco oltre [II 148.2] aggiunge: "Quanto alla terza categoria [nel brano precedente era la quarta], essi sono coloro che combattono in Allah la Sua vera guerra, ove l'aggettivo "Sua" si riferisce ad Allah. In altri termini, essi sono caratterizzati dalla guerra, cioè sono nello stato della Sua guerra, per l'attributo del Vero, come abbiamo menzionato riguardo all'esitazione divina. Essi non vedono combattente al di fuori di Allah e questo perché la guerra ha luogo in Lui e nessuno sa come sia la guerra in Allah se non Allah. Quando essi fanno risalire ciò ad Allah, il che corrisponde al Suo detto: "la verità della Sua guerra", in cui Egli ha attribuito la guerra a Se stesso mediante l'aggiunta del pronome [" $h i$ ” in ǧih $h \bar{a} d i-h i]$, allora è Lui il combattente, non loro, anche se sono il ricettacolo della manifestazione degli effetti! Quindi essi sono i combattenti non combattenti [come nel versetto: "Non sei tu che hai scagliato quando hai scagliato, ma è Allah che ha scagliato" (Cor. VIII-17)] [...] La quarta categoria [nel brano precedente era la terza] è costituita da coloro di cui Allah ha detto: "e coloro che combatteranno in Noi, li guideremo sui Nostri sentieri" (Cor. XXIX-69), cioè coloro a cui diremo riguardo ad esse: "e non seguite i sentieri per non essere distolti dal Suo sentiero" (Cor. VI-153), cioè il sentiero in cui c'è per voi la felicità. In realtà tutti i sentieri sono verso di Lui, in quanto Allah è il punto di arrivo di ogni sentiero. "A Lui ritorna ogni cosa" (Cor. XI-123). [...] Poiché il motivo della guerra sono azioni che scaturiscono da coloro che ci è stato ordinato di uccidere e di combattere - e queste azioni sono le azioni di Allah - noi non combattiamo se non in Lui, non il nemico, poiché non sarebbe nemico se non fosse per esse. E quando noi combattiamo in Lui e ci diventa chiaro per il Suo detto - se combattiamo in Lui - che Egli ci guida sui Suoi sentieri, ciò ci indica i Suoi sentieri e noi entriamo in essi, allora non consideriamo di combattere un altro e chiediamo perdono ad Allah per ciò che ha luogo da parte nostra. Fa parte delle vie [di Allah] la 
La ragione di ciò $\left({ }^{214}\right)$ è la compresenza [nell'uomo (insān)] della sua umanità (bašariyya), come ha detto [il Profeta], su di lui la Pace: "Io sono un uomo (bašar) $\left({ }^{215}\right)$, mi incollerisco come si incollerisce l'uomo e sono soddisfatto come è soddisfatto l'uomo. Allähumma, colui contro cui ho imprecato cioè in occasione della collera umana - fa che quell'imprecazione su di lui diventi perdono per lui e soddisfazione (ridwān)" $\left({ }^{216}\right)$, ed Allah gli rispose a questo ordine $(a m r)\left({ }^{217}\right)$ universale e la sua richiesta di male divenne un bene per colui contro cui era stata formulata. Osserva quanto egli era conoscitore delle cose!

Come Egli disse, sia Egli esaltato: "Non è dato all'uomo (bašar) che Allah gli parli se non per rivelazione o dietro un velo" (Cor. XLII-51) e quale velo è più grande della sua umanità? $\left({ }^{218}\right)$ E se la persona

contemplazione che ciò che accade da parte nostra è Lui che lo fa accadere, non noi. E chiediamo perdono ad Allah, cioè chiediamo a Lui di non essere un ricettacolo per la manifestazione di un'opera in cui Egli descrive Se stesso come avverso ad essa, poiché è saldamente affermato che non c'è nell'esistenza altri che Allah. Non combatte in Lui se non Lui, ma se Egli non ci avesse guidato sui Suoi sentieri, noi non lo comprenderemmo".

214) Il riferimento è duplice: da un lato alla collera, come quella di 'Alī al-Kurdī quando venne criticato, e dall'altro al combattimento interiore.

215) In arabo, per indicare l'uomo in quanto genere (ğins), si usano i termini bašar o insān, entrambi impiegati indifferentemente per il maschile ed il femminile, mentre per indicare l'uomo in quanto maschio si usa il termine rağul. Dei due termini, bašar si riferisce soprattutto allo stato individuale umano, con i limiti che esso implica, mentre insān viene impiegato anche in riferimento agli stati sopra-individuali e non-manifestati dell'essere umano, nella sua completa universalizzazione: l'espressione Uomo universale corrisponde infatti all'arabo al-insān al-kāmil o al-insān al-kullī.

216) Hadīt riportato da Muslim, XLV-95, Abū Dāwud, XXXIX-10, e da Ibn Ḥanbal. Ibn 'Arabī cita questo hadīt nei capitoli 68 [I 350.23] ove precisa che la natura umana implica la collera e la soddisfazione, 73, questione CXIII [II 109.2] ove aggiunge che la collera e la soddisfazione fanno parte degli attributi dell'anima vitale [(hayawāniyya) o animale] nell'uomo, non dell'anima logica (nätiqa), 178 [II 340.28], 346 [III 191.17] e 366 [III 337.33].

217) Conformemente al versetto: "In verità Io sono vicino; Io rispondo all'appello di chi chiama, quando invoca Me" (Cor. II-186). Può stupire che la preghiera venga assimilata ad un ordine, ma in effetti spesso nelle preghiere il verbo è nella forma imperativa. Nel Cap. 457 [IV 72.5] Ibn 'Arabī fornisce alcuni esempi di preghiere prescritte nel Corano in cui Allah è soggetto all'ordine che Egli stesso ha imposto: "La seconda modalità dell'incombenza legale $(t a k l \bar{f} f)$ incondizionata (mutlaq) è il Suo includere in essa Se stesso insieme a noi, facendo sapere che Egli è Colui che è soggetto all'ordine e Colui che ordina, Colui che vieta e Colui che è soggetto al divieto. "Signor nostro, non punirci!" (Cor. II-286), "Signor nostro, non imporci" (Cor. II-286), "Signor nostro, non imporci ciò che non siamo in grado di fare" (Cor. II-286), e l'ordine "perdonaci" (Cor. II-286), "abbi Misericordia di noi" (Cor. II-286), "aiutaci" (Cor. II-250), questo da parte nostra per un ordine prescritto dalla Legge e la risposta da parte Sua, riportata nel Șah̄ih, è "l'ho fatto, l'ho fatto!"."

218) Nel Cap. 254 [II 554.4], Ibn 'Arabī precisa: "Egli ti ha reso identico alla Sua cortina (sitr) su di te, e se non ci fosse questa cortina non cercheresti l'accrescimento della scienza di Lui. Tu sei colui a cui viene parlato e proferito dietro la cortina della forma da cui Egli ti parla. Osserva la tua umanità: troverai che essa è identica alla tua cortina, dietro alla quale Egli ti parla, poiché Egli ha detto: "Non è dato all'uomo che Allah gli parli se non per rivelazione o dietro un velo (hiǧăb)" (Cor. XLII-51). Dunque Egli può parlarti da te, poiché tu sei il velo di te stesso a te (hiğăbu nafsi-ka 'an-ka) e la Sua cortina su di te, ed è impossibile che tu possa cessare di essere uomo, poiché tu sei uomo per la tua essenza, ed anche se potessi essere assente da te o estinguerti per uno stato 
viene sottratta alla sua umanità, il Vero le parla in modo specifico con il discorso cercato dalla gente di Allah $\left({ }^{219}\right)$, e per questo Allah, sia Egli esaltato, ha comunicato nel Corano l'ordine di quello [cioè di dire di essere un uomo] al Suo Profeta, su di lui la Pace, ed in diverse occasioni gli ordinò di dire: "Invero io sono un uomo come voi" (Cor. XVIII-110 e XLI-6). Questo per ergere l'argomento decisivo (huğğg) contro chi lo prendeva come un Signore, così come i cristiani consideravano il Messia ${ }^{(220)}$, e quindi egli dice loro: vi ho già detto diverse volte "Invero io sono un uomo", e non gli verrà detto nel Giorno della Resurrezione, come verrà detto a Gesù: "Hai forse detto agli uomini: prendete me e mia madre come degli Dei ad esclusione di Allah?” (Cor. V-116).

Ed Allah, sia Egli esaltato, ha detto riguardo a Muhammad in ciò che ha fatto scendere su di lui: "Dì: O gente del Libro, orsù ad una parola comune tra noi e voi. Noi non adoriamo se non Allah e non associamo nulla a Lui" (Cor. III-64), e forse essi hanno detto: "E così facciamo noi! Tu sei Allah?" ${ }^{(221)}$ ed Egli completò e chiarì dicendo: "e nessuno di noi prende un altro di noi come Signore ad esclusione di Allah" (Cor. III-64) ed ha associato se stesso a loro affinché avesse l'argomento decisivo [58] contro chi lo prendeva come Dio ed ha così trasmesso ciò che ha ricevuto da parte del suo Signore e nel Giorno della Resurrezione non sarà interrogato al riguardo.

spirituale che ha il sopravvento su di te, la tua umanità sussisterebbe come entità: la cortina è dunque abbassata e l'occhio non cade se non su di una cortina, poiché non cade se non su una forma!".

219) Nel Cap. 73, questione XLIV [II 7 1.5] Ibn 'Arabī precisa: "Se l'uomo viene meno alla sua umanità nella sua considerazione e realizza la contemplazione del suo spirito, Allah gli parla allo stesso modo in cui parla agli spiriti separati dalla materia", e nel Cap. 277 [II 601.33] aggiunge: "Ho sentito uno dei Maestri dire: "Finché egli resta nella sua umanità il Discorso a lui ha luogo dietro un velo, ma quando esce dalla sua umanità il velo viene sollevato". Questo Maestro era 'Abd al-'Azīz ibn Abī Bakr al-Mahdawī, noto come Ibn al-Karh. Gliel'ho sentito dire nella sua casa a Tunisi, Allah abbia Misericordia di lui, ed egli aveva colto nel segno, e nello stesso tempo sbagliava. Egli coglieva nel segno nell'affermare e stabilire fermamente il Discorso dietro al velo e che esso non può mai accompagnarsi alla contemplazione, ma sbagliava affermando che il velo può essere tolto, senza specificare. In effetti si può dire che il velo della sua umanità può essere tolto, ma senza dubbio dietro il velo della sua umanità vi è un altro velo: talora il velo dell'umanità viene tolto ed il Discorso da parte di Allah a questo servitore ha luogo allora dietro un altro velo, più elevato di esso".

220) Nel Cap. 71 [I 664.9] Ibn 'Arabī precisa: "Il Perfetto, che Allah faccia scendere su di lui la Sua șalāt e la Pace, disse: "Invero io sono un uomo come voi" (Cor. XVIII-110, XLI-6), per ordine di Allah. Gli venne detto: "Dì" ed egli disse: "Dì: io sono un uomo come voi". Da questo sappiamo che ciò è per ordine di Allah, poiché ci ha riferito l'ordine, così come ha riferito ciò che gli è stato ordinato. Questo discorso è il rimedio alla malattia che affligge chi adora Gesù, su di lui la Pace, tra coloro che fanno parte della sua comunità. Essi dicono: "Invero Allah è l’Unto, figlio di Maria", e manca loro una grande scienza, poiché dicono "figlio di Maria" e non se ne rendono conto".

221) Nel Cap. 37 [I 228.29] Ibn 'Arabī precisa: "Un gruppo della gente del Libro, tra coloro che prendevano come Signore $(r a b b)$ Gesù, dissero: "Invero Muhammad chiede a noi di adorarlo come adoriamo Gesù", ed Allah, sia Egli esaltato, fece scendere il versetto "Dì: O gente del Libro, orsù ad una parola comune tra noi e voi. Noi non adoriamo se non Allah e non associamo nulla a Lui" (Cor. III-64)". 
È necessario che l'aspirante esegua l'ordine del suo Maestro, che gli piaccia o non gli piaccia, rallegrandosi nel fare ciò che gli piace e combattendo se stesso [o: la sua anima] in ciò che detesta, poiché Allah, sia Egli esaltato, ha detto: "e ad Allah si prosterna chi è nei Cieli e sulla Terra, volente e nolente" (Cor. XIII-15) e quindi ha descritto la prosternazione a Lui come una cosa che può essere sgradevole ${ }^{222}$ ), cioè l'anima di chi si prosterna ha ripugnanza di ciò (tamağğ $\bar{u}-h u$ ) e malgrado questo Allah lo accetta, fino a che Allah lo guida sui sentieri in cui egli trova, al momento della loro contemplazione, il piacere per l'ordine di Allah.

Il Maestro è il rappresentante di Allah nei suoi riguardi e la forma [del rapporto] dell'aspirante con il Maestro è come la forma [del rapporto] di coloro che sono soggetti all'incombenza legale con Allah, e l'aspirante non è turbato per la sua avversione all'ordine del Maestro, ma si conforma ad esso combattendo, se non trova piacere in quello.

Poi ha detto: "e se questo aspirante vede che il Maestro compie una cosa e si propone che questo aspirante compia quella cosa con lui, prendendo esempio da questo Maestro, quel prendere esempio sia in presenza del Maestro, e se glielo vieta desiste". Con questo discorso, anche se impreciso nell'espressione, vuol dire che se il Maestro fa una cosa e non ha ordinato all'aspirante di fare quella cosa o di aiutarlo in quella, e l'aspirante vuole farla prendendo esempio dal suo Maestro, è indispensabile che sia in sua presenza, affinché l'aspirante veda se quell'atto è di quelli che caratterizzano specificamente il Maestro, e quindi gli è vietato, o se è tra quelli che sono comuni a tutti, e comunque non deve compiere quella cosa senza la presenza del Maestro.

Questa è la Via, di cui abbiamo completato [l'esposizione], affinché nulla di essa sia omesso, poiché costui che ha formulato la raccomandazione non intendeva questo con il suo discorso, se non il prendere esempio dal Maestro in ciò che egli dispone per lui in modo specifico. Egli ha detto: "e si propone che [l'aspirante] la compia con lui, e "con (máa)" implica la compagnia [59], ed ho precisato per lui l'espressione nel commento $[($ tarǧuma $)=$ traduzione $]$, ristabilendo le cose come sono, e per questo il Maestro ha completato la sua raccomandazione dicendo: "poi offre se stesso per quella azione e se il Maestro gli indica di farla, la fa, e se la vieta desiste".

Sappi che Allah, sia Egli esaltato, ha detto: "Voi avete nell'Inviato di Allah un bell'esempio" (Cor. XXXIII-21) e malgrado questo ci ha fatto sapere che egli è caratterizzato in modo esclusivo da certe cose che se noi le facessimo, perché egli le ha fatte, prendendolo come esempio, disubbidiremmo, come il matrimonio con la donna offertasi in dono, perché quello è specifico per lui ad esclusione dei credenti. Per questo è dovere dell'Inviato spiegare ciò agli uomini, poiché Allah, sia Egli esaltato, lo ha posto nella posizione di colui che va imitato, e se egli non avesse specificato e spiegato ciò che lo caratterizza, la guida sarebbe perdizione, e ti metteresti a fare ogni atto che egli, che Allah faccia scendere su di lui la Sua șalāt e la Pace, ha fatto, per il Suo detto: "Voi avete nell'Inviato di Allah un 
bell'esempio" (Cor. XXXIII-21); e quando ha vietato qualcosa di ciò che ha fatto noi ci atteniamo al suo divieto. Analogamente è per te al servizio del Maestro: noi sappiamo che egli non ci ordina se non ciò in cui vi è il bene (mașlaha) per noi, e così il suo divieto. Quando noi lo vediamo fare qualcosa accenniamo a lui di ciò con un gesto $(\bar{\imath} m \bar{a})$ o una allusione e se tace facciamo, poiché il suo silenzio è un segno della sua soddisfazione di noi in quell'atto $\left({ }^{223}\right)$, e se egli vede che ciò non è bene per noi, ci vieta [di farlo] e noi desistiamo.

Egli, su di lui la Pace, ha detto: "Prendete da me i vostri riti" $\left.{ }^{224}\right)$, ed ha detto: "Fate la salät come me la vedete fare" $\left({ }^{225}\right)$, ed ha vietato il digiuno ininterrotto (wișāl) pur praticandolo $\left({ }^{226}\right)$, e questo è un divieto di compassione, non il divieto di una cosa detestabile, né una proibizione (tahrīm), poiché egli continuò [a digiunare] con loro, poi spiegò per cosa si distingueva nel suo digiuno ininterrotto da quel gruppo di presenti, e diciamo "il gruppo dei presenti", poiché io ho fatto il digiuno ininterrotto ed un ristoratore (mut'am) mi ha dato da mangiare nel mio digiuno ininterrotto, ed un coppiere [60] mi ha dato da bere e mi sono trovato al mattino sazio e dissetato dal cibo che ho mangiato nel sogno, e per questo so che il Profeta, su di lui la Pace, non intendeva con il suo detto: "Io non sono nella vostra condizione" ${ }^{227}$ ) se non il gruppo dei presenti, e se avesse voluto dire la comunità io non avrei

223) Questo vale nel caso il Maestro abbia accettato di istruire l'aspirante, avendo questi la giusta attitudine nei suoi confronti, poiché in caso contrario il silenzio non equivale all'assenso.

224) Tali parole vennero profferite in occasione del pellegrinaggio d'addio ed il termine manāsik, che ricorre in Cor. II-128 e 200, si riferisce appunto ai riti del pellegrinaggio. Hadīt riportato da an-Nasāà̄ XXIV-220, e da Ibn Ḥanbal, III-318 e 366, e citato da Ibn 'Arabī nei capitoli 69 [I 518.22], 71 [I 637.16], 72 [I 668.8, 694.35, 697.1 e 31, 711.6], 88 [II 165.9], 161 [II 262.2] e 380 [III 502.5].

225) Hadīt riportato da al-Buhārī, X-18, LXXVIII-27, XCV-1, ad-Dārimī, II-42, e da Ibn Ḥanbal, V-53. Ibn 'Arabī lo cita nel Cap. 69 [I 412.6, 431.23, 433.6, 437.7 e 518.22], nel Cap. 73, questione CLIV [II 136.22], nel Cap. 88 [II 165.9], e nel Cap. 380 [III 502.5].

226) Nel mese di Ramadān, il Profeta proseguiva il digiuno fino all'alba, ma ad un gruppo di fedeli che voleva imitarlo vietò di farlo. Nel Cap. 71 [I 638.6] Ibn 'Arabī precisa: "Tra ciò che conferma la nostra affermazione che egli intendesse la misericordia verso gli uomini in quello [cioè nel divieto del digiuno ininterrotto] è anche quanto ha riferito Muslim da parte di Ā'iša, che ha detto: "Il Profeta, che Allah faccia scendere su di lui la Sua salāt e la Pace, vietò loro il digiuno ininterrotto per misericordia verso di loro. Essi dissero: Ma tu fai il digiuno ininterrotto! Ed egli rispose: Io non sono nella vostra condizione (inñ̄ lastu ka-hay'ati-kum); di notte il mio Signore mi nutre e mi dà da bere". Al gruppo a cui si rivolse si svelò in uno stato che essi non possedevano, senza far intendere con ciò che si trattasse di una sua prerogativa, ad esclusione della sua comunità"; e nel Cap. 311 [III 43.21] aggiunge: "[Il Profeta], su di lui la Pace, aveva vietato il digiuno ininterrotto, e gli venne detto: "Ma tu fai il digiuno ininterrotto!", al che egli, che Allah faccia scendere su di lui la Sua șalāt e la Pace, rispose: "Io non sono nella vostra condizione. Io passo la notte con un ristoratore che mi nutre ed un coppiere che mi versa da bere", ed in un'altra versione: "[Io passo la notte] mentre il mio Signore mi nutre e mi disseta". Nel gruppo delle persone a cui si rivolgeva non c'era al momento nessuno che avesse questa stazione spirituale, ed egli non ha detto: "Io non sono nella condizione degli [altri] uomini" [...] il nutrirsi aveva luogo nella Presenza dell'immaginazione, non nella Presenza del mondo sensibile".

227) Hadīt riportato da al-Buhārī, XXX-20, 48 e 50, Muslim, XIII-55 e 61, Ibn Māğah, e da Ibn Ḥanbal. 
visto questo stato e non lo avrei provato, ma l'ho provato e mi ha mostrato ciò che abbiamo detto $\left({ }^{228}\right)$.

Poiché l'Inviato di Allah è impeccabile ( $m a$ ș̣umm) nei suoi atti, il Vero ci ha ordinato di prendere esempio da lui, ed il Vero ha detto riguardo ai sapienti di questa comunità, quando essa [comunità] non sa: "Chiedete alla gente dello $\underline{d i k r}$, se non sapete" (Cor. XVI-43) e non ha detto "imitateli" e questo perché essi non sono impeccabili, in quanto dopo gli Inviati l'impeccabilità ('isma) è ignorata nelle comunità, e anche se in realtà Allah ha reso impeccabili alcuni dei Suoi servitori della comunità, non ci ha specificato chi siano, così come [invece] ha designato gli Inviati $\left.{ }^{229}\right)$.

Quando l'aspirante realizza che il Maestro non si muove né si ferma se non per un ordine divino, egli deve prenderlo come esempio, a meno che il Maestro non glielo vieti, e per quello non è concesso all'aspirante di fare qualcosa degli atti del Maestro se non in sua presenza, e se non dopo che si è offerto di fare quell'atto. Tutto ciò, beninteso, se vede il Maestro fare [qualcosa], ma se non vede nessun'atto da parte del Maestro egli non deve muoversi a compiere un'opera se non per l'ordine del suo Maestro.

Per quello questo Maestro ha detto a completamento di questa sua raccomandazione: "Poi, dopo di ciò, osserva l'atto del Maestro, i suoi movimenti ed il suo discorso, poiché gli atti e gli stati dei Maestri

228) Nel Cap. 71 [I 638.9] Ibn 'Arabī afferma: "In effetti, abbiamo provato noi stessi mediante il gusto spirituale questo stato, mentre facevamo il digiuno ininterrotto: passammo la notte senza rompere il digiuno e fummo nutriti ed abbeverati durante la notte del nostro digiuno ininterrotto. Al mattino eravamo pieni di forza e non provavamo alcun desiderio di mangiare. Si poteva persino sentire l'odore del cibo che ci aveva dato il nostro Signore. La gente si meravigliò del suo profumo delizioso e ci chiese: "Da dove proviene questo odore di cibo? Non abbiamo mai sentito nulla di simile!". Ad alcuni di loro comunicai il mio stato ad altri lo passai sotto silenzio. Se si fosse trattato di una prerogativa dell'Inviato di Allah, che Allah faccia scendere su di lui la Sua salät e la Pace, non avremmo ottenuto questo stato. Quindi facemmo validamente il digiuno ininterrotto e la rottura, assommando così per noi le due ricompense e le due gioie"; e un po' oltre [I 657.14] aggiunge: "Colui il cui stato spirituale nell'astenersi [dal mangiare] è che "il suo Signore lo nutre e lo abbevera" durante la notte, malgrado egli non mangi e non beva esteriormente, egli ha rotto [il digiuno] anche se sta digiunando. Questo l'ho gustato personalmente. Da ciò capisci che con il suo detto, che Allah faccia scendere su di lui la Sua șalāt e la Pace: "Io non sono nella vostra condizione: durante la notte il mio Signore mi nutre e mi abbevera", egli negava solo di essere simile al gruppo di coloro a cui si rivolgeva, che non possedevano questo stato spirituale, poiché se avesse voluto intendere tutta la comunità, io non avrei potuto gustarlo, ed invero l'ho provato per gusto spirituale, sia lode ad Allah!”.

229) Nel Cap. 72 [I 666.21] Ibn 'Arabī precisa: "Questa impeccabilità ('isma) che Allah ha loro accordato e della quale li ha investiti ha precisamente lo scopo di distinguerli dal resto dei credenti; un Profeta non conosce infatti che tre tipi di propositi: divini, angelici e psichici. La stessa cosa succede per alcuni Intimi che posseggono una porzione abbondante della Profezia, come Sulaymān ad-Dunbulī - che ho incontrato personalmente - che è tra coloro che hanno questo stato spirituale. Egli mi informò che da più di cinquanta anni non si presentava a lui un proposito detestabile, mentre la maggior parte degli Intimi ha questi propositi. Essi hanno in più [rispetto ai Profeti] il proposito satanico iracheno; in alcuni di loro il regime [di questo proposito] si manifesta esteriormente, ed essi sono [come] la maggioranza delle creature, in altri il proposito si presenta ma non ha alcun effetto esteriore, ed essi sono coloro che sono protetti (mahfüzūn) tra i Suoi Intimi”." 
sono tutti allusioni per chi li osserva; il suo discorso con gli uomini riguardo alla faccenda di quaggiù è un occultare il suo stato ed un rabbonire $($ tatyīb) il cuore di colui con cui parla". Sappi che ciò che ha detto non riguarda se non quello che il Maestro fa [61] in presenza della gente, non l'atto che compie quando è da solo. Può accadere di vederlo [questo atto] senza che il Maestro lo sappia, ma tu non devi guardare il Maestro senza informarlo della tua presenza ed una cosa simile non può succedere ad un aspirante se non in modo non intenzionale. Non è conveniente che l'uomo guardi di nascosto una delle creature di Allah, poiché colui che è visto di nascosto può detestare di essere visto durante quell'atto, come può non detestarlo, e non conviene all'uomo addentrarsi nella probabilità, perché è un pericolo.

Un uomo riuscì a vedere da uno spiraglio l'Inviato di Allah, che Allah faccia scendere su di lui la Sua salāt e la Pace, a casa sua mentre si pettinava, e l'Inviato di Allah, che Allah faccia scendere su di lui la Sua salāt e la Pace, era sul punto di cavargli l'occhio, e disse: "Il [chiedere] permesso è stato stabilito a causa della visione [cioè per evitare sguardi indiscreti]" $\left.{ }^{230}\right)$, ed egli, su di lui la Pace, ha detto: "Chi riesce a guardare nella casa di una gente senza il loro permesso, è lecito per loro cavargli l'occhio" ${ }^{(231)}$. Una cosa simile a questa non deve aver luogo da parte di un credente, ed a maggior ragione da parte di un aspirante con il suo Maestro $\left({ }^{232}\right)$ o con una delle creature di Allah, poiché Allah, sia Egli esaltato, ha detto: "e non spiate" (Cor. XLIX-12).

Quando il Maestro fa qualcosa in presenza della gente, e non è chiaro se quello riguarda specificamente lui, l'aspirante che prende esempio da lui può, se vuole, compiere il suo atto, ma in sua presenza e se non gli è stato vietato. L'omissione del divieto è un argomento a suo favore contro chi lo critica, ma malgrado questo si tratta di una cattiva condotta $(a d a b)$ da parte dell'aspirante, a meno che egli comprenda dall'evidenza dei fatti che il Maestro non ha fatto quello se non per essere preso ad esempio: allora è necessario che l'aspirante si affretti a compiere il suo ordine, [come] se lo avesse ordinato, e questo è come ciò che viene detto nel proverbio: "È te che intendo, ascoltami o vicina

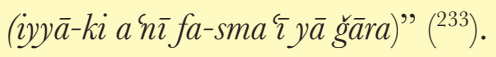

230) Hadīt riportato da al-Buhārī, LXXVII-75, LXXXVII-23, an-Nasā'ī, e da ad-Dārimī.

231) Hadīt riportato da Muslim, XXXVIII-43 e 44, Abū Dāwud, XL-127, an-Nasā'̄, ad-Dārimī, e da Ibn Hanbal.

232) La stessa raccomandazione è riportata nel Kitāb al-amr al-muhkam, a pag. 310 della traduzione di Asín Palacios già citata.

233) Un uomo, in epoca preislamica, si era innamorato della figlia del vicino, ma non sapeva come esprimerle il suo amore; un giorno si sedette nel cortile davanti alla sua tenda, sì che ella potesse sentire, e declamò dei versi indirizzandoli ad un'altra giovane, concludendo con la frase riportata da Ibn 'Arabī, frase che divenne proverbiale per gli arabi per indicare un discorso rivolto ad una persona ma mirato ad un'altra. Nelle Futühät, Ibn 'Arabī la cita, talora commentandola, nei capitoli 36 [I 223.17], 73, questione CLV [II 138.27], 154 [II 250.24], 178 [II 344.12], 198 [II 410.32], 345 [III 185.6], 359 [III 269.18] nel titolo stesso, e 527 [IV 171.4 ]. 
E questo è come il buon auspicio (al-fal al-hasan), come disse il Profeta [62], su di lui la Pace, all'uomo che venne da parte degli associatori (mušrikinn) riguardo alla pace di al-Hudaybiyya: "Come ti chiami?" e l'uomo rispose: "Sahl" ${ }^{234}$ ), ed egli disse: "La faccenda è facile (sahula-l-amr)" ${ }^{235}$ ) e così fu. E la pace fu sistemata secondo ciò che soddisfaceva Allah, ed una parte dei Compagni non ne fu soddisfatta ${ }^{(236)}$, ma l'obiettivo del credente è ciò che soddisfa Allah, non ciò che soddisfa lui.

Quanto al suo detto: "il suo discorso con gli uomini riguardo alla faccenda di quaggiù è un occultare il suo stato", egli ha sentenziato quello solo per il suo stato con Allah, sia Egli esaltato, specifico per lui, in quanto il suo discorso con gli uomini riguardo alla faccenda di quaggiù, di cui gli è lecito parlare, fa parte anch'esso del suo stato con Allah in quella circostanza specifica, ed egli quindi non si manifesta se non nel suo stato con Allah, in cui vi è l'occultamento di un altro suo stato con Allah. Se non ci fosse stata questa circostanza avrebbe manifestato un altro dei suoi stati con Allah, ed il giudizio (hukm) riguardo alle cose dipende dalle circostanze (mawātin), come egli, su di lui la Pace, disse vedendo Abū Duğāna pavoneggiarsi ed incedere fiero tra le due schiere, ed incedeva superbamente tenendo in mano la spada che gli aveva dato l'Inviato di Allah, che Allah faccia scendere su di lui la Sua salāt e la Pace, e che egli aveva preso con il suo diritto (haqq). E quando l'Inviato di Allah, che Allah faccia scendere su di lui la Sua salāt e la Pace, lo vide incedere con essa superbamente tra le due schiere, disse, che Allah faccia scendere su di lui la Sua șalāt e la Pace: "Questo portamento è inviso ad Allah ed al Suo Inviato se non in questa circostanza” $\left({ }^{237}\right)$ ed il giudizio dipende sempre dalle circostanze.

Quanto al suo detto: "ed un rabbonire il cuore di colui con cui parla", questo richiede una bilancia [cioè richiede misura], poiché l'Inviato di Allah, che Allah faccia scendere su di lui la Sua salāt e la Pace, venne rimproverato per una cosa simile; non è quindi opportuno che il Maestro faccia questo, a meno che non disponga di quella bilancia divina. Invero Allah, sia Egli esaltato, ha insegnato l'adab

234) Si tratta verosimilmente di un errore del copista, poiché secondo la tradizione il nome era Suhayl.

235) Hadīt riportato da al-Buhārī, LIV-15, e da Ibn Hanbal. L'episodio è citato anche nel Cap. 54 [I 281.5], ove Ibn 'Arabī precisa: "È così che fece l'Inviato di Allah, che Allah faccia scendere su di lui la Sua șalāt e la Pace, nella riconciliazione con gli associatori, quando essi gli impedirono di accedere alla Casa [la Ka'bah]. Venne un uomo degli associatori, il cui nome era Suhayl [derivato dalla radice sahula, essere facile] e l'Inviato di Allah, che Allah faccia scendere su di lui la Sua șalāt e la Pace, disse: "La faccenda è facile" prendendolo [il nome] come un buon auspicio $\left(f a^{\prime} l\right)$, ed avvenne come aveva auspicato l'Inviato di Allah, che Allah faccia scendere su di lui la Sua șalat e la Pace. La faccenda venne sistemata grazie a Suhayl".

236) Ibn 'Arabī ritornerà su questo argomento nelle pagine 88-89 del manoscritto.

237) In occasione della battaglia di Uhud, il Profeta brandì una spada e disse: "Chi prenderà questa spada con il suo diritto (haqq)?". Si fecero avanti prima 'Umar e poi az-Zubayr, ma la spada non venne loro concessa. Allora Abū Duğāna chiese: "Qual è il suo diritto, o Inviato di Allah?" ed egli rispose: "Che tu colpisca il nemico con essa fino a farla piegare!". Avendo Abū Duğāna detto che l'avrebbe presa con il suo diritto, essa gli venne data ed egli si mise a brandirla tra le schiere dei nemici. L'episodio è riportato da Ibn Ishāq nella sua Vita dell'Inviato di Allah, tradotta da A. Guillaume, a pag. 373. Cfr. anche lo hadịt riportato da Abū Dāwūd, XV-104. L'episodio è citato e commentato anche nei capitoli 69 [I 398.20 e 438.2], 70 [I 567.21], 463 [IV 79.22], 558 [IV 209.7] e 559 [IV 441.25]. 
all'Inviato di Allah, che Allah faccia scendere su di lui la Sua șalāt e la Pace, ed ha reso bello il suo $a d a b$, e non c'è $a d a b$ se non l'adab di Allah.

Riguardo ad una cosa simile è stato rivelato: "Egli si accigliò" (Cor. LXXX-1), poiché [il Profeta], che Allah faccia scendere su di lui la Sua salāt e la Pace, si era proposto di rabbonire coloro i cui cuori dovevano essere riconciliati (al-mu'allafat qulübu-hum) ${ }^{238}$ ), in modo che [63] essi si sottomettessero [o aderissero all'Islām], ed Allah lo rimproverò per quello, malgrado questo bel proposito profetico. Il Maestro deve osservare gli stati dei suoi compagni e mirare a rabbonire il cuore di chi è più vicino ad Allah, secondo quanto Allah ha testualmente stabilito, e sottrarsi con diplomazia (siyāsa) a chi è inferiore a questi. Riguardo a ciò è stato rivelato: "Sii paziente con coloro che invocano il loro Signore al mattino ed alla sera" (Cor. XVIII-28) ${ }^{239}$ ), e quando essi erano seduti con lui, che Allah faccia scendere su di lui la Sua șalāt e la Pace, egli non si alzava finché essi non si alzavano e se uno di loro metteva la sua mano nella mano dell'Inviato di Allah, che Allah faccia scendere su di lui la Sua salāt e la Pace, egli non la sfilava finché non era quella persona a sfilare [per prima] la sua mano. Si racconta che 'Umar ibn al-Hattāō, Allah sia soddisfatto di lui, poiché essi prolungavano la loro sessione con lui [il Profeta], indicò loro di alzarsi senza che l'Inviato di Allah, che Allah faccia scendere su di lui la Sua salāt e la Pace, se ne accorgesse, in quanto sapeva che egli, che Allah faccia scendere su di lui la Sua șalāt e la Pace, non si sarebbe alzato finché non si sarebbero alzati loro. E quando [il Profeta] li incontrava diceva loro: "Benvenuti coloro per i quali Allah mi ha rimproverato" $\left({ }^{240}\right)$.

238) L'espressione ricorre in Cor. IX-60, ed è riferita ad alcuni capi Qurayshiti con cui il Profeta si stava intrattenendo e che cercava di rabbonire con l'offerta di doni. In quel momento si presentò un cieco per parlargli ed il Profeta si accigliò e si distolse da lui; per questo Allah lo rimproverò con i primi versetti della Sūra LXXX, in quanto aveva preferito prestare attenzione a dei capi Qurayshiti piuttosto che ad un servitore che era più vicino ad Allah.

239) Nel Cap. 304 [III 18.22] Ibn 'Arabī spiega che: "la causa occasionale di questo versetto fu che i capi dei miscredenti tra gli associatori, come al-Aqrāe ibn Ḥābis ed altri, dissero: "Nulla ci impedisce di sederci con Muhammad se non il fatto che egli siede con questi schiavi”, riferendosi a Bilāl, Hubbāb ibn al-Aratt ed altri. Essi erano troppo orgogliosi per stare seduti insieme agli schiavi. L'Inviato di Allah, che Allah faccia scendere su di lui la Sua salāt e la Pace, desiderava ardentemente che costoro avessero fede, per cui ordinò a questi schiavi di non avvicinarsi a lui quando lo vedevano occupato con questi capi, finché non avesse finito con loro, o di abbandonare la riunione se questi capi gli facevano visita mentre essi erano con lui. Allora Allah fece discendere questo versetto per gelosia della stazione della servitù e della povertà, onde evitare che essa venisse disprezzata per l'attributo della potenza e della deificazione (ta'alluh) che si manifestava in una sede impropria. Dopo di ciò l'Inviato di Allah, che Allah faccia scendere su di lui la Sua șalät e la Pace, quando questi schiavi ed altri sedevano con lui, non si alzava finché non erano loro ad alzarsi per primi, anche se la seduta si prolungava, e soleva dire: "Allah mi ha ordinato di dominare la mia anima con loro". Quando la seduta con loro si prolungava, alcuni compagni, come Abū Bakr ed altri, facevano loro segno di alzarsi, di modo che l'Inviato di Allah, che Allah faccia scendere su di lui la Sua salāt e la Pace, potesse occuparsi di altre faccende. Questo deriva dalla gelosia di Allah per il Suo servitore povero e affranto, ed è uno degli indici più grandi della nobiltà della servitù e del dimorare in essa: questa è la stazione a cui noi chiamiamo gli uomini”.

240) Hadīt non recensito nelle raccolte canoniche, ma riportato da Ibn 'Arabī nel Cap. 77 [II 149.20], nel Cap. 351 [III 220.17] e nel Cap. 527 [IV 170.10]. 
Ma questo Maestro aveva in mente colui che ha detto: "Ascolta il discorso del tuo compagno, anche se ciò che apporta è insignificante (nazr), poiché ognuno ha in se stesso un valore [(qadr), o rango]" $\left({ }^{241}\right)$ e questa è una parola di saggezza che ha apportato la Profezia, che l'ha formulata per mezzo di ciò che Allah le ha fatto conoscere, e l'attenersi all'adab divino è preferibile.

Poi ha detto: "E se vedi il Maestro fare un atto in cui non è apparente l'aspetto dell'avvicinarsi con esso ad Allah, sia Egli esaltato, guardati dal respingere quello con il tuo cuore, poiché il Maestro non fa nulla se non per Allah, ma ciò ti è nascosto. Stai quindi all'erta da questo rifiuto (radd) ed implora umilmente il Maestro di far cessare questi cattivi propositi (hawātir) e di tramutarli nei propositi lodevoli [64], e così per ogni cosa che tu provi simile a questa”.

Egli ti dice: guardati dall'obiettare al tuo Maestro, sia esteriormente che interiormente, riguardo a ciò che tu sai che non è lecito, ed a maggior ragione riguardo a ciò che tu ignori. Racconterò ciò che ci è capitato a questo riguardo, dopo di che tornerò al discorso del Maestro in questa raccomandazione. Ero al servizio di un Maestro di grande rango (ğalīl al-qadr), erede spirituale di Gesù ('īssaw $)$ (242), ed egli mi parlò di una questione di cui sapevo che la verità era diversa: egli mi indicò una persona che l'Inviato di Allah, che Allah faccia scendere su di lui la Sua salāt e la Pace, aveva menzionato, ed uno si era levato affermando di essere quella persona, e pretendeva di esserla ma non era lui. Il Maestro disse: "Egli è quella [persona]!", ed io gli dissi: "O mio signore, non è lui, lui non è quella [persona]!" ed uscii da lui mentre il Maestro era molto alterato, e non feci molti passi allontanandomi da casa sua che mi trovai di fronte ad un uomo nella via che mi disse: "Rimettiti (sallim) a ciò che ha detto il Maestro, e non obiettare a lui!". Io ritornai subito dal Maestro per chiedergli perdono di ciò che era successo, e rimisi la mia anima a lui affinché mi punisse per ciò che avevo manifestato riguardo a ciò che pensava. Quando arrivai da lui egli mi precedette [nel parlare] e mi disse: "O Muhammad, come faccio, ogni volta che tu mi contesti riguardo ad una questione, a fare venire da te il Hiḍr per dirti: Rimettiti a ciò che ha detto il Maestro?", ed io accusai me stesso a lui ed egli non mi punì. Quando fu passato un certo tempo dopo quello, apparve al Maestro la mia veridicità in ciò che avevo detto su quella questione ed egli recedette dalla sua convinzione riguardo a quella persona ${ }^{(243)}$. Il Hiḍr mi

241) Nel Cap. 560 [IV 501.32] Ibn 'Arabī riporta una analoga raccomandazione: "Ascolta chi ti parla anche se è insignificante, poiché ognuno ha in se stesso un rango, e tu prendi in mano il suo cuore facendo così. Ciò è a tuo favore, non a tuo carico, poiché Allah ti ha ordinato di mostrarti amorevole verso gli uomini e questo fa parte dell'amore verso gli uomini".

242) Si trattava del Maestro Abū l-'Abbās al-'Uraybī, già citato. Nel Cap. 36 [I 223.20] Ibn 'Arabī precisa: "Il nostro Maestro Abū l-'Abbās al-'Uraybī, Allah abbia Misericordia di lui, fu cristico alla sua fine, mentre noi lo fummo ai nostri inizi, cioè la fine del nostro Maestro in questa Via fu cristica”, e nel Cap. 349 [III 208.26] aggiunge: "Il nostro Maestro Abū l-'Abbās al-'Uraybī era sul piede (qadam) di Gesù, su di lui la Pace".

243) Lo stesso episodio è riportato nel Cap. 25 [I 186.2], ove Ibn 'Arabī riferisce: "Sorse una questione tra me ed il nostro Maestro Abū l-'Abbās al-'Uraybī riguardo ad una persona di cui l'Inviato di Allah, che Allah faccia scendere su di lui la Sua șalät e la Pace, aveva annunciato la venuta. Il Maestro mi disse: "Si tratta del tale figlio del tale", nominandomi una persona che conoscevo per nome, ma che non avevo mai visto, mentre avevo visto 
insegnò la remissione (taslīm) alla gente di Allah, e talvolta il Maestro dice ciò che gli viene proiettato da parte di Allah e talvolta dice ciò che egli pensa da lui stesso $\left({ }^{244}\right)$, non ciò che gli ha fatto vedere Allah, ed è sufficiente a questo proposito [ricordare] lo hadīt autentico riguardante la fecondazione (ibarr) della palma, al divieto del Profeta, su di lui la Pace, di farlo, poi al suo recedere da ciò, [65] dicendo: "Voi ne sapete di più sulle faccende di questo vostro mondo" $\left({ }^{245}\right)$, ed anche lo hadīt dei

il suo cugino materno. Probabilmente ebbi dei dubbi al riguardo e non mi attenni ad accettarla, cioè la sua affermazione al riguardo, in quanto avevo una visione interiore (basîra) sulla faccenda [di quella persona] e non c'è dubbio che il Maestro recedette dalla sua opinione su di lui [lett.: ritirò la sua freccia ( $\mathrm{sahm}$ ) su di lui], ma fu interiormente risentito, ed io non mi accorsi di quello perché ero agli inizi. Me ne andai da lui per tornare a casa, ed ero sulla via quando mi venne incontro una persona che non conoscevo e mi salutò per primo, in modo amorevole e affettuoso, e mi disse: "Considera veridico (saddiq) il Maestro Abū l-'Abbās in ciò che ti ha detto riguardo ad un tale", e ci nominò la persona che aveva menzionato Abū l-'Abbās al-'Uraybì. Gli risposi di sì, sapendo ciò che voleva dire. Ritornai subito dal Maestro per fargli sapere ciò che era successo e mentre entravo da lui, egli mi disse: "O Abū 'Abd Allāh, c'è bisogno per te, quando ti menziono una questione che tu esiti ad accettare, che si intrometta il Hiḍr e ti dica 'Considera veridico un tale in ciò che ti ha detto'? E come può succederti questo per ogni questione che tu senti da parte mia e tu hai dei dubbi?". Io risposi: "La porta del pentimento è aperta!", ed egli mi disse: "Il pentimento è accettato". Seppi così che quell'uomo era il Hiḍr, e non ho dubbi, poiché interrogai il Maestro al riguardo: "Era lui?", ed egli rispose: "Sì, era il Huidrr"; e nel Cap. 366 [III 336.32], ove precisa: "Ho incontrato il Hुị̣r a Siviglia ed egli mi ha insegnato a rimettermi ai Maestri e a non contestarli. Quel giorno in effetti avevo contestato uno dei miei Maestri su una certa questione ed ero andato via da lui. Incontrai il Hiḍr nel quartiere di Qaws al-Ḥiniyya, ed egli mi disse: "Rimettiti a ciò che ha detto il Maestro" Io tornai subito dal Maestro e quando arrivai da lui, ancora prima che parlassi, egli mi disse: "O Muḥammad, c'è bisogno ogni volta che mi contesti che il Hiḍr ti raccomandi la remissione ai Maestri?". Gli chiesi allora: "Maestro, colui che mi ha fatto questa raccomandazione era dunque il Hiḍr?" Egli mi disse: "Si" ed io aggiunsi: "Lode ad Allah per questo insegnamento. Ciò non toglie che le cose stanno come ho detto io". Qualche tempo dopo andai dal Maestro e constatai che aveva receduto al mio punto di vista. Egli mi disse: "Io avevo torto e tu avevi ragione" $\mathrm{Al}$ che risposi: "Maestro, comprendo ora perché il Hiḍr mi ha soltanto raccomandato la remissione e non mi ha detto che tu avevi ragione su questa questione. Io non dovevo contestarti nella misura in cui non si trattava di norme giuridiche, sulle quali al contrario è vietato tacere". Fui riconoscente ad Allah per quello e fui contento per il Maestro a cui era diventata chiara la verità su quella questione".

244) Negli Aperçus sur l'initiation, a pag. 286 René Guénon precisa: «Dans ces conditions, bien entendu, l'interprète autorisé de la doctrine, en tant qu'il exerce sa fonction comme tel, ne peut jamais parler en son propre nom, mais uniquement au nom de la tradition qu'il représente alors et qu'il «incarne» en quelque sorte, et qui seule est réellement infaillible; [...] Si par ailleurs il lui arrive de parler en son propre nom, il n'est plus, par là même, dans l'exercice de sa fonction, et il ne fait alors qu'exprimer de simples opinions individuelles, en quoi il n'est plus aucunement infaillible, pas plus que ne le serait un autre individu quelconque; il ne jouit donc par lui-même d'aucun «privilège», car, dès que son individualité reparaît et s'affirme, il cesse immédiatement d'être le représentant de la tradition pour n'être plus qu'un homme ordinaire, qui, comme tout autre, vaut seulement, sous le rapport doctrinal, dans la mesure de la connaissance qu'il possède réellement en propre, et qui, en tout cas, ne peut prétendre imposer son autorité à qui que ce soit».

245) Hadit riportato da Muslim, XLIII-141, e da Ibn Ḥanbal, e citato da Ibn 'Arabī nel Cap. 12 [I 144.31 ] e nel Cap. 69 [I 523.4] delle Futūhät, e nel Cap. XXV dei Fusūss al-hikam.

Il Profeta aveva visto un gruppo di compagni che stavano praticando degli innesti nelle palme da datteri, per aumentarne i frutti, ed avendo affermato che era meglio non farlo, essi abbandonarono la pratica. Quando però i frutti diminuirono, il Profeta pronunciò la frase riportata, o, in un'altra versione [Muslim, XLIII-140] 
prigionieri $(u s \bar{a} r \bar{a})$ di Badr $\left.{ }^{246}\right)$, ed egli era l'Inviato di Allah, che Allah faccia scendere su di lui la Sua salāt e la Pace.

Non c'è dubbio che il Maestro [al-'Uraybī] non mi disse: "Invero Allah, sia Egli esaltato, mi ha informato", ma era più conveniente che io mi rimettessi alla sua affermazione e non obiettassi. Dopo di quello ho gustato personalmente questa stazione e fui oggetto di obiezione riguardo ad una cosa di cui avevamo accertato la verità, poiché su di essa mi basavo su una evidenza da parte del mio Signore.

È noto che il Maestro in questa Via [è tale] anche se non è impeccabile (mașūm), cioè la prova (dalñl) non dimostra la sua impeccabilità nei suoi movimenti né la sua non impeccabilità, poiché noi non sappiamo realmente ciò che egli è presso Allah, cioè se sia tra coloro che Allah ha protetto o non lo sia $\left.{ }^{247}\right)$. Già ti ho menzionato che talvolta dalla gente di Allah, cioè coloro che sono informati da Allah, scaturisce qualcosa che è in contrasto con ciò che è affermato nelle scuole dei dottori della Legge, per uno hadīt che è pervenuto in modo valido secondo il loro punto di vista, mentre il Maestro è stato avvertito nelle notificazioni ricevute che quella prova non vale nulla e che il Profeta, su di lui la Pace, non lo ha mai detto né proferito. Quel giudizio [di validità] presso i dottori della Legge si fonda su una prova debole e scadente e questa inconsistenza risulta evidente al Maestro secondo il modo abituale in cui viene informato, e può succedere, anzi si può affermare con certezza, che gli estranei dichiarino l'errore di questo [Maestro] dissenziente, mentre il suo disaccordo è l'ordine di Allah, sia Egli esaltato, e [dichiarino] che egli in questa questione non segue la Legge, mentre in realtà egli si conforma alla pura Legge ed egli ha la scienza, mentre nei dottori della Legge prevale un'opinione ed essi non hanno scienza di quello.

"Io sono un uomo (bašar): quando vi ordino qualcosa riguardo alla vostra religione (dīn) attenetevi a quello, e quando vi ordino qualcosa per opinione personale $(r a y)$, [ricordatevi che] io sono un uomo".

246) Hadīt riportato da Abū Dāwud, XV-120, e da Ibn Ḥanbal. A Badr erano stati fatti prigionieri 70 associatori ed il Profeta li liberò dietro riscatto, seguendo il suggerimento di Abū Bakr contro il giudizio di 'Umar che avrebbe voluto passarli a fil di spada. Il versetto Cor. VIII 67 diede ragione al giudizio di 'Umar. L'episodio è commentato nei capitoli 236 [II 536.13] e 247 [II 547.16] delle Futūhāt, e nel Cap. XXII dei Fusūss al-hikam.

247) Va ribadito che il termine 'isma non riguarda tanto l'infallibilità dottrinale, quanto l'impeccabilità nel dominio delle azioni: per Ibn 'Arabī la 'isma è un attributo proprio dei Profeti e degli Inviati [Cap. 69 (I 515.31)], ed è tecnicamente legata al fatto che essi non sono soggetti a propositi improvvisi di origine satanica [Cap. 72 (I 666.22)]; l'attributo equivalente degli Intimi (awliyā) è da lui denominato hifz [Cap. 69 (I 515.30)], ed essi sono invece soggetti a propositi satanici, ma sono protetti dal loro effetto. Nel Cap. 55 [I 283.6] Ibn 'Arabī precisa: "Iblīs venne da Gesù, su di lui la Pace, nelle sembianze, esteriormente sensibili, di un vecchio: per Satana infatti non c'è accesso all'intimo dei Profeti, su di loro la Pace, e quindi tutti i loro propositi (hawātir) sono o di origine dominicale, o angelica o provenienti dall'anima. Non c'è fortuna per Satana nel loro cuore. Quanto agli Intimi nella scienza di Allah che sono preservati, essi sono in questa situazione per quanto riguarda la protezione ('isma) da ciò che Satana getta [in loro], ma non per quanto riguarda la protezione dalla venuta di ciò in loro. Quindi l'Intimo che è sotto la Divina Provvidenza (al-mu Yanan bihi) è preservato in base ad un segno ('alāma) da parte di Allah riguardo a ciò che gli viene ispirato da Satana: la ragione di questa particolarità è che egli non è legiferante, mentre i Profeti lo sono ed è per questo che il loro intimo è reso inaccessibile [a Satana]". 
Il Maestro non chiama ad Allah se non secondo una visione interiore (bașira) avendo correttamente seguito $(i t t i b \bar{a})$ gli ordini della Legge dall'inizio $\left({ }^{248}\right)$, fino ad essere uno della gente dell'elezione, e l'Inviato ha riconosciuto ciò in una situazione simile, ed Allah ce lo ha notificato, poiché egli ha detto: invero "Io [66] chiamo ad Allah basandomi su una visione interiore, io e chi mi segue" (Cor. XII-108), ed ha quindi detto che in virtù del seguire l'uomo si basa nella sua faccenda su una visione interiore.

Non è opportuno che una persona stia al servizio di un Maestro nell’incertezza ( $5 a k k)$ riguardo a ciò a cui egli chiama e neppure deve servirlo perché lo considera impeccabile $\left({ }^{249}\right)$. Non è inoltre opportuno che imiti gli atti del Maestro per se stesso, a meno che il Maestro glielo ordini, né che prenda come esempio ciò che gli vede ordinare ad altri, poiché quell'ordine potrebbe non essere adatto a lui e per questo l'ha passato sotto silenzio. Il Maestro non è degno di sospetto (muttaham) nella sua raccomandazione (nush) alla gente comune, a maggior ragione nella sua raccomandazione agli aspiranti all'istruzione iniziatica.

Guardati dal farti passare per la mente di sollevare, anche solo interiormente, obiezioni a lui per un aspetto, anche se lo avessi visto fare ciò che ha fatto [di apparentemente disdicevole]. Un discepolo vide venire verso il suo Maestro una persona con una coppa in cui c'era del vino e gliela offrì, ed il Maestro ne bevve - ed il discepolo verificò de visu che si trattava di vino - poi dopo averne bevuto un po’ il Maestro la offrì al discepolo e quando il discepolo ne bevve constatò che si trattava di una bevanda più dolce del miele, ed il discepolo disse: "Mi pento di ciò che mi è venuto in mente!", ed il Maestro sorrise $\left({ }^{250}\right)$. Noi stessi abbiamo constatato molti episodi di questo genere: una volta giunsi

248) In Initiation et réalisation spirituelle, pag. 169-170, René Guénon afferma: "Quiconque se présente comme un instructeur spirituel sans se rattacher à une forme traditionnelle déterminée ou sans se conformer aux règles établies par celles-ci ne peut pas avoir véritablement la qualité qu'il s'attribue".

249) Il fatto che il Maestro possa non essere impeccabile non esclude la sua infallibilità nell'esercizio della sua funzione: Ibn 'Arabī ha riportato già due volte nel testo l'esempio di un Maestro che non avendo realizzato in proprio una certa scienza la riceve da Allah, in modo da poter istruire e guidare l'aspirante che ha sinceramente affidato a lui la sua istruzione iniziatica. A questo proposito è opportuno ricordare quanto scrisse René Guénon nelle pag. 285-286 di Aperçus sur l'initiation: "A ce point de vue, on peut dire ceci: le fait d'être investi régulièrement de certaines fonctions permet, à lui seul et sans autre condition, d'accomplir tels ou tels rites; de la même façon, le fait d'être investi régulièrement d'une fonction d'enseignement entraîne par lui-même la possibilité d'accomplir valablement cette fonction, et, pour cela, il doit nécessairement conférer l'infaillibilité dans les limites où cette fonction s'exercera; et la raison, au fond, en est la même dans l'un et l'autre cas. Cette raison, c'est, d'une part, que l'influence spirituelle est inhérente aux rites mêmes qui en sont le véhicule, et c'est aussi, d'autre part, que cette même influence spirituelle est également inhérente à la doctrine par là même que celle-ci est essentiellement «non-humaine»; c'est donc toujours elle, en définitive, qui agit à travers les individus, soit dans l'accomplissement des rites, soit dans l'enseignement de la doctrine, et c'est elle qui fait que ces individus, quoi qu'ils puissent être en eux-mêmes, peuvent exercer effectivement la fonction dont ils sont chargés". L'aspirante non deve servire o seguire il Maestro perché impeccabile o infallibile in se stesso, ma perché è per lui il rappresentante di Allah.

250) Lo stesso episodio è riportato nel Kitāb al-amr al-muhkam, a pag. 320 della traduzione di Asín Palacios già citata. 
ad una [fonte di] acqua dolce che non si riusciva a bere tutta d'un colpo e me la diede da bere con la sua mano una persona che mi era compagna, tre o più manciate, finché fui dissetato, ma quando poi ne presi con la mia mano non ero in grado di berla tanto era amara, e l'acqua era la stessa! Questa questione specifica non la conosce se non un profondo sapiente, cioè il cambiamento del cibo per quanto riguarda il sapore, o della bevanda, o del connubio (nikăh) per quanto riguarda la forma, tanto che colui che guarda vede una forma di cui non dubita che essa sia un certo tale presso di lui, ma non è che uno spirito che ha assunto una forma corporea, come Gabriele nella forma di Dihya $\left({ }^{251}\right)$, ed i Compagni non dubitavano che si trattasse di Dihya, mentre era Gabriele, e ne ho viste di cose simili.

Ricordati di questo capitolo, e rimettiti all'ordine di colui che lo detiene, ed occupati di ciò che [il Maestro] ti ha ordinato [67] e non di ciò che gli vedi fare, poiché quella è una perdita di tempo per l'aspirante: insomma, non passa tempo in cui egli non sia sotto un ordine da parte del Maestro, e quindi deve occupare se stesso in ciò che gli ha ordinato il Maestro, finché non lo esonera da quello.

Guardati dai cattivi propositi che si presentano a te riguardo ad una delle creature di Allah, chiunque sia questa creatura, buona o cattiva, poiché il Profeta, che Allah faccia scendere su di lui la Sua salāt e la Pace, ha detto: "Felicità $(t \bar{u} b \bar{a})$ a chi si occupa del suo difetto ('ayb) tralasciando i difetti degli [altri] uomini".

Il Maestro [Abū Ishạāq] Ibrāhīm ibn Ṭarîf $\left({ }^{252}\right)$ mi ha detto: "Figlio mio, io non vedo nel Mondo se non un Intimo (walt) di Allah nei miei confronti. Chi mi conosce non può fare a meno o di lodarmi per lo stato in cui mi trovo o di biasimarmi. Se egli mi loda io dico: "Questo Intimo non mi vede se non per mezzo della forma di ciò in cui lui si trova, e sia lode ad Allah che mi fa vedere uno dei Suoi Intimi"; se egli mi biasima io dico: "Questo è un uomo a cui Allah ha svelato il mio difetto, e non riceve lo svelamento se non un Intimo", oppure: "Questo è un uomo che mi offende con ciò che mi attribuisce, ma è un ammonitore (mudakkir) affinché io stia all'erta da questo attributo, e non dà il buon consiglio ai servitori di Allah se non un Intimo di Allah". Questa era la sua convinzione - Allah abbia Misericordia di lui - riguardo a tutte le creature, e tale deve essere l'attitudine dell'aspirante con gli uomini, ed a maggior ragione con il suo Maestro.

Poi ha detto: "e poni la massima attenzione al volto del Maestro ed ai suoi atti, ed ogni volta che si rivolge verso di te con il suo volto non allontanarti assolutamente da lui”, cioè quando sei in sua presenza, di fronte a lui, sia questa [68] la tua attitudine. Ed il completamento di ciò che ti ha qui raccomandato è che nei tuoi occhi vi sia uno sguardo di disposizione favorevole (tarahhum) [a lui] per remissione e non uno sguardo di sdegno (taharrud) verso di lui, poiché quello è lo sguardo di chi

251) Riferimento all'episodio in cui Gabriele si presentò al Profeta ed ai suoi Compagni sotto le sembianze di Dihya al-Kalbī per interrogarlo sull'Islām, sulla fede e sull'ihsān. Hadịt riportato da al-Buhāāī, II-37, Muslim, I-1, 5 e 7, at-Tirmidīi, e da Ibn Hanbal.

252) Questo Maestro è già stato citato a pag. 46 del manoscritto. 
odia (al-bagīed), mentre nello sguardo di chi ama vi è una disposizione favorevole e talora il suo occhio lacrima quando guarda chi ha in grande considerazione. Noi abbiamo constatato quello da parte di aspiranti che stavamo istruendo e li riconoscevamo nel loro sguardo verso il nostro volto.

E che nel tuo sguardo non vi sia ottusità (ğamūd) quando guardi il volto del Maestro, poiché ciò palesa stupidità (balāda) e avversione ('adāawa) nascosta, di cui non si accorge colui che la possiede finché non si manifesta da lui in seguito. Non si addice al Maestro di confidare in colui che guarda il suo volto in questo modo, ed il Maestro deve proteggere se stesso da uno come lui, o adoperarsi per allontanarlo da sé. Ciò che prevale in colui che guarda il suo Maestro con irritazione (ihtidād) e con ottusità è il fastidio (malal): egli non resiste con lui né se ne va, ed è soggetto a cattivi propositi, e la maggior parte delle volte chi ha questa considerazione si comporta con ipocrisia e non è riconoscente per nessuno dei suoi stati. Se l'aspirante è consapevole di ciò non deve rimanere con questo Maestro, poiché non può trarre alcun beneficio da lui finché non sussiste in lui la venerazione (hurma) del Maestro ${ }^{253}$ ).

Poi ha detto: "e instaura nella tua anima il timore riverenziale (hayba) $\left({ }^{254}\right)$ nei confronti del Maestro", questo se ne è capace, poiché è raro che ciò si attualizzi nel cuore se non per un dono da parte di Allah e per sollecitudine da parte Sua nei suoi confronti. Quanto all'instaurare (taqrīr) [il timore riverenziale] è inverosimile che una cosa simile possa essere stabilita nel cuore [da parte dell'aspirante], poiché ciò fa parte del Suo far essere $(\check{g} a q)$ e non è stabile se non ciò che fa parte del far essere di Allah $\left(^{255}\right)$; l'aspirante è cieco davanti al suo Maestro e non vede con lui altro che lui, ed Allah, sia Egli esaltato, non Si manifesta a lui se non nella sua forma [cioè la forma del Maestro], e se è in questo modo allora egli trae beneficio da lui.

253) La stessa considerazione è riportata nel Cap. 181 [II 365.24], dedicato alla venerazione verso i Maestri spirituali, che inizia con il verso [II 364.28]: "La venerazione del Maestro non è che la venerazione di Allah". Il termine hurma esprime l'attitudine verso ciò che è sacro ed inviolabile (haram), attitudine che può avere gradi diversi a seconda dell'oggetto della stessa: in italiano tali gradi sono espressi dai termini rispetto, riverenza e venerazione, che in arabo equivalgono tutti a hurma. Nel caso dell'attitudine dell'aspirante nei confronti del Maestro ho adottato la traduzione "venerazione", considerando sia l'espressione "Maestro Venerabile" usata nelle iniziazioni occidentali, sia quanto afferma René Guénon in Etudes sur l'Hindouisme, a pag. 9-10: "le sens principal de Bhagavat est celui de «glorieux» et de «vénérable» [...] En effet, Bhagavat est une épithète qui s'applique à tous les aspects divins, et aussi aux êtres qui sont considérés comme particulièrement dignes de vénération".

254) Nel Cap. 239, dedicato alla hayba, Ibn 'Arabī precisa [II 540.6]: "Invero la Bellezza (ğamāl) è temibile (mahūb) dovunque sia - poiché in essa appare evidente la Maestà (ğalāl) del Regno (mulk) [...] Sappi che il timore [o terrore] riverenziale è uno stato del cuore che è dato dall'effetto della epifania della Maestà della Bellezza divina nel cuore del servitore [...] ed è una immensità ('azama) che trova colui a cui Essa si manifesta nel suo cuore, e quando lo lascia essa porta via il suo stato ed il suo attributo, ma non fa cessare la sua entità". Questo è il senso tecnico del termine hayba per Ibn 'Arabī, che è diverso dal senso attribuito ad esso dall'estensore della raccomandazione, e ciò spiega il commento di Ibn 'Arabī, che fa intendere tra le righe che invece di timore reverenziale egli avrebbe dovuto parlare di venerazione.

255) Nel Cap. 341 [III 161.4] Ibn 'Arabī precisa che il termine ğa q, riferito ad Allah, ha il significato di ḩalq, creazione. 
Al-Qušayrī $\left({ }^{256}\right)$ ha riferito nella sua Epistola $\left({ }^{257}\right)$ che la venerazione del Maestro aveva abbandonato il cuore di un discepolo [69] ed [il Maestro] gli ordinò di allontanarsi da lui finché tale stato persisteva nella sua anima; egli si allontanò e quando la sua venerazione tornò per lui ad essere come era [in precedenza], ritornò dal Maestro e trasse beneficio da lui $\left.{ }^{258}\right)$.

Ad Allah appartengono uomini e donne che Egli ha connaturato secondo il puro bene, ed essi non vedono nessuno senza avere una buona opinione di lui, anzi a loro non si presenta [neppure] un cattivo proposito nei suoi riguardi: questi sono cuori che Allah ha avvicinato al puro bene ed essi traggono profitto da ogni essere. Chi prova quello da se stesso sia riconoscente ad Allah per ciò che gli ha donato!

Poi dopo il suo detto: "e instaura nella tua anima il timore riverenziale nei confronti del Maestro" ha aggiunto: "ed il timore (haref) di lui, poiché egli è colui che dispone (al-mutahakkim) della tua morte e della tua vita, della tua esistenziazione ( $\bar{\imath} \bar{g} \bar{a} d)$ e del tuo annientamento (ichām), per l'autorizzazione di Allah, sia Egli esaltato, Gloria a Lui”.

Quanto al suo detto: "ed il timore di lui" affinché egli non ti guardi con lo sguardo di esecrazione (maqt), e non avresti mai successo.

Quanto al suo detto: "egli è colui che dispone della tua morte e della tua vita", cioè egli è colui che dispone di te nello stato della tua morte e in quello della tua vita. In altre parole devi essere convinto riguardo a lui che Allah, sia Egli esaltato, Si manifesta a te nella sua forma, come ha detto Allah, sia Egli esaltato, riguardo all'Inviato: “Chi obbedisce all'Inviato, obbedisce ad Allah" (Cor. IV-80). Chiunque comunica, se non comunica da se stesso ma comunica da parte di un altro, si manifesta a te nella forma di quell'altro per ciò che comunica, e quindi quell'altro si manifesta a te nella sua forma, in quanto egli è il suo interprete, ed è lui che parla, non chi proferisce verbalmente la comunicazione.

256) Abū l-Qāsim 'Abd al-Karīm ibn Hawāzin al-Qušayrī, nacque nell'anno 376 dall'Egira a Ustuwā, nel Hurāsān, e morì a Naysābūr, ove trascorse la maggior parte della sua vita, nell'anno 465. Egli fu discepolo, per quanto riguarda il Tasawrenf, di Abū 'Alī al-Hasan ibn 'Alī ad-Daqqāq [m. 405 H/1015] di cui sposò la figlia Fāțima, e di as-Sulamī [m. 412 H/1021]. Oltre alla celebre Epistola (risāla) sul Tasawrouf, redatta nell'anno 437 dall'Egira, scrisse anche un Commento del Corano, intitolato Lată î̀ al-išārāt, ed un Commento ai Nomi più belli di Allah, intitolato Kïtāb at-tahbīr fì t-tadkì̄, di cui Faḩruddīn ar-Rāzī redasse un sunto.

257) La Risāla fu il primo trattato sull'esoterismo islamico che Ibn 'Arabī lesse, alcuni anni dopo essere entrato nella Via, con il commento orale dello Šayh Abū Ya'qūb al-Kūmī, discepolo di Abū Madyan. Nelle Futūhāt alQušayrī è citato 17 volte [Capitoli 35 (I 221.24), 69 (I 527.33), 71 (I 650.28), 73, questione CXXIV (II 117.8), 74 (II 143.20), 150 (II 245.16), 235 (II 537.27), 268 (II 569.15), 290 (II 649.30), 295 (II 679.1), 350 (III 213.20 e 216.2), 369 (III 372.22 e 396.25), 438 (IV 50.24), 555 (IV 194.32), e 559 (IV 368.17)], quasi sempre in relazione a ciò che egli riporta nella sua Epistola, salvo nel Cap. 290 ove è citato come autore di un Commento sui Nomi divini.

258) L'episodio è riportato da al-Qušayrī nella sua Epistola, a pag. 165 dell'edizione araba del Cairo del 1959 e a pag. 341 della traduzione di Alexander Knysh, "Al-Qushayrì's Epistole on Sufism", Garnet, 2007. Ibn 'Arabī lo riprenderà con più dettagli a pag. 127 del manoscritto. 
Colui che muore essendo sotto la giurisdizione $(h u k m)$ di un Maestro, Allah non Si manifesterà a lui nella Resurrezione se non nella forma di quel Maestro. Questo è stato da noi verificato per gusto spirituale e lo abbiamo visto noi stessi con il Vero. L'aspirante ha la ferma convinzione che egli [il Maestro] è una teofania divina, così come è convinto che è Allah colui che dice, tramite la lingua del Suo servitore che fa la salät,: "Allah ascolta chi Lo loda", per mezzo della notificazione autentica $\left.{ }^{259}\right)$, e a maggior ragione se ottiene lo svelamento. Questa è una questione molto profittevole per chi conosce, [70] e da qui egli riconosce il rango degli Inviati e chi è Colui che legifera (al-mušarri $)^{2}$ agli uomini.

Ibn Qasī $\left({ }^{260}\right)$, nel capitolo della visione divina nel Giorno della Resurrezione, ha fatto rilevare che Egli verrà visto con una visione muhammadiana in una forma muhammadiana $\left({ }^{261}\right)$ - riferendosi alla visione che si può avere in questa comunità - ed essa è la forma creaturale (halqiyya) più perfetta in cui Egli Si manifesta: questo è il significato di ciò che ha detto questo Maestro riguardo al disporre del Maestro della tua morte e della tua vita, e non ha detto: "del farti morire" né "del farti vivere".

259) Hadīt riportato da Muslim, IV-62 e 63, e da Ibn Hanbal, e citato da Ibn 'Arabī anche nel La niche des lumières, Éditions de l'œuvre, Parigi, 1983, pag. 60. In tale versione si legge "tramite la lingua del Suo Inviato, che Allah faccia scendere su di lui la Sua șalāt e la Pace", mentre nella versione citata da Ibn 'Arabī decine di volte nelle Futūhāt si legge: "tramite la lingua del Suo servitore" [Cap. 27 (I 192.32), Cap. 47 (I 257.20), Cap. 55 (I 282.30), Cap. 69 (I 395.14 e 15, 407.28, 416.1, 427.30.432.29, 433.17, 436.6, 454.27), ecc.].

260) Aḥmad ibn al-Ḥusayn Abū l-Qāsim, denominato Ibn Qasī, nativo dell'Algarve, oggi regione meridionale del Portogallo, oltre al ruolo di Maestro spirituale svolse, come altri Maestri della sua epoca [Ibn al-'Arīf e Ibn Barrağān], una attività "esteriore" di contrapposizione alla dinastia almoravide, tanto da essere considerato il Mahdī dai suoi seguaci; morì assassinato a Silves nell'anno 546 dall'Egira. Di lui è nota una sola opera, "Il libro della deposizione dei sandali (kitāb hal'an-na qayn)", che il figlio trasmise ad Ibn 'Arabī a Tunisi nell'anno 590 dall'Egira ed a cui Ibn 'Arabī stesso dedicò un commentario (sarh). Ibn Qasī è citato una ventina di volte nelle Futūhāt, con giudizi talora contrastanti, che nel commento alla sua opera assumono in alcuni punti tratti molto severi. Una revisione equilibrata dei giudizi di Ibn 'Arabī su questo Maestro si trova nel Cap. VIII di " $A s$ sandálias do Mestre" di Adalberto Alves, Esquilo, Lisbona, 2009.

261 ) Nell'edizione araba dell'opera curata da Muhammad al-Amrānī, pubblicata a Marrakesh nel 1997, a pag 299 si legge "[il Profeta, su di lui la Pace, nella notte dell'ascensione] vide con una visione muhammadiana una forma muhammadiana" e nel commento di Ibn 'Arabī, edito a Marrakesh dallo stesso curatore nel 2013 sulla base dei più antichi manoscritti, a pag. 206 si legge: "la sua [del Profeta] visione in questa dimora è una visione muhammadiana in una forma muhammadiana, e la visione nell'aldilà sarà una visione adamica in una forma adamica". Nel Cap. 482 [IV 129.10] Ibn 'Arabī precisa: "Già abbiamo spiegato [nel Cap. 397 (III 560.20)] che la visione più grande è una visione muhammadiana in una forma muhammadiana, e questo è ciò che sosteneva l'Imām Abū l-Qāsim ibn Qasī nel suo Libro della deposizione dei sandali, che ci è stato trasmesso da suo figlio a Tunisi nell'anno 590". D'altra parte nel Cap. 480 [IV 116.32] egli afferma che anche nel Giorno della Resurrezione vi saranno coloro che vedranno il loro Signore con una visione muhammadiana, a differenza del Paradiso in cui la visione sarà adamica. Ibn 'Arabī indica come esempio di questa visione divina muhammadiana in una forma muhammadiana il versetto: "Non sei tu che hai scagliato quando hai scagliato, ma è Allah che ha scagliato" (Cor. VIII-17) [Cap. 375 (III 471.1), Cap. 384 (III 525.11) delle Futūhāt, ed il Cap. XXII dei Fusūs al-hikam]. 
Poi ha detto: "della tua esistenziazione e del tuo annientamento", cioè [egli è colui che dispone] del darti l'esistenza di ciò che tu trovi e dell'annientare in te ciò che tu perdi, in quanto il Maestro si manifesta per mezzo dei Nomi di Allah e tra i Nomi di Allah, quanto è Potente e Magnificente,

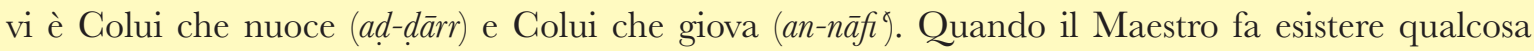
nell'aspirante, egli non fa esistere se non un bene, e quello è il Nome Colui che giova: "Ciò che ti capita di buono viene da Allah" (Cor. IV-79); e quando annienta in te un attributo che sussiste in te e che porterebbe alla tua rovina, egli fa cessare in te il male, a meno che non scaturisca da te qualcosa che rende necessario che ti sia sottratto il bene in cui ti trovi, come fece uno dei Maestri nel sottrarre gli stati spirituali all'aspirante, considerando quello un giovamento per lui, per l'ostentazione (zahw) che egli vedeva in lui di quella elargizione (minha), ed egli gli sottrasse quello stato in questo mondo, lo conservò per lui per l'aldilà e glielo rese [nell'aldilà].

Questo successe al Maestro Ardašīr ${ }^{(262)}$, Allah abbia Misericordia di lui, nei confronti di un suo aspirante, come mi ha riferito 'Abd Allāh Badr [al-Habašī] $\left({ }^{263}\right)$ da parte del suo Maestro e compagno Makkī al-Wāsiṭī ${ }^{(264)}$, ed egli era tra i più grandi della gente della proiezione $\left(i l q \bar{a}^{\prime}\right)$ e dell'incontro (liq $\bar{a})$, Allah sia soddisfatto di lui.

262) Questo Maestro è menzionato nel Cap. 37 [I 227.13]: Nell'edizione critica di 'Uțān Yahyā [1985] il nome è trascritto Azdašīr, mentre nell'edizione di ‘Abd al-'Azīz Sulțān al-Manșūb [2010], basata sullo stesso manoscritto autografo, il nome è trascritto Ardašĩr. Si tratta di un nome sassanide, che corrisponde al nostro Artaserse.

263) 'Abd Allāh Badr al-Habaš̄ era uno schiavo affrancato di origine abissina che ebbe il privilegio di essere compagno inseparabile di Ibn 'Arabī per ben 23 anni, dall'anno 595 dall'Egira fino all'anno 618, allorquando morì a Malatya. Nel prologo delle Futūhāt [I 10.17] Ibn 'Arabī precisa: "Ho scritto questa Epistola [al-Futūhāt al-makkiyya], unica nel suo genere, che il Vero ha fatto esistere come amuleto per dissipare l'ignoranza, per lui ['Abd al-'Azìz al-Mahdawī] e per ogni compagno puro ed ogni realizzato Șūfì, e per il nostro caro amico, il nostro puro fratello, nostro figlio dilettevole, 'Abd Allāh Badr, l'Abissino, al-Yamanī, servo affrancato di Abū l-Ganā’im ibn Abū l-Futūh al-Harrān̄̄”. Altri riferimenti ad al-Ḥabaš̄i si trovano nei capitoli 29 [I 198.3], 35 [I 221.26], 73, questione XIII [II 49.28], 380 [III 502.3], e 560 [IV 505.15].

264) Nel Cap. 37, dedicato ai Poli cristici ed ai loro segreti, Ibn ‘Arabī precisa [I 227.6]: "Quando essi vogliono conferire uno degli stati spirituali che essi posseggono e che sono sotto il loro dominio, perché vedono in questa persona la predisposizione $(i s t i c d \bar{a} d$ ) a riceverlo, o per svelamento o per notificazione divina, essi toccano quella persona, o la abbracciano, o la baciano, o le danno una delle loro vesti, o le dicono: "Distendi la tua veste", poi prendono per lui una manciata di ciò che vogliono conferirgli - e chi è presente vede che essi prendono una manciata nell'aria - e la mettono nella sua veste, nella misura di quanto è stato definito loro dalle manciate. Poi gli dicono: "Stringi tutti i capi del tuo vestito al tuo petto", o "Avvolgiti con esso", nella misura dello stato spirituale che essi desiderano donargli. E qualsiasi cosa essi facciano di ciò, quello stato pervade all'istante quella persona designata, che è voluta per quello, senza indugio. Noi abbiamo visto ciò in uno dei nostri Maestri: egli andava dal più adatto tra il volgo e mi diceva: "Questa persona ha una predisposizione spirituale", poi si avvicinava a lui e quando lo toccava o lo batteva con il suo petto sul suo dorso, con il proposito di donargli ciò che voleva, quello stato si diffondeva immediatamente in lui, ed egli usciva da quello in cui si trovava e si consacrava al suo Signore. Possedeva questo stato anche Makkī al-Wāsițī, sepolto alla Mecca e discepolo di Ardašîr: quando lo prendeva lo stato spirituale, egli diceva a chi era presente: "Abbracciami", o chi era presente cercava di scoprire la sua faccenda e quando lo vedeva avvolto dal suo stato lo abbracciava, e quello stato si diffondeva in quella persona ed essa ne era rivestita". 
Quanto al suo detto: "per l'autorizzazione di Allah, sia Egli esaltato, [data] a lui in tutto quello", esso fa parte del suo aver appreso l'adab, come Allah, sia Egli esaltato, ha reso noto a Gesù, su di lui la Pace, menzionando il Suo favore (imtinān) verso di lui, col dire: "Ricorda il Mio favore su di te [...] quando ti ho aiutato con lo Spirito di Santità" e menzionò la creazione dell'uccello, la rivivificazione del morto, l'insufflazione dello spirito, e la guarigione del cieco e del lebbroso, e disse: tutto questo "per la Mia autorizzazione" (Cor. V-110) ed in un altro versetto: "per l'autorizzazione di Allah" (Cor. III-49) [71]. Questo fa parte del suo adab nel [fare] la sua raccomandazione.

Poi ha detto: "E quando vedi che il Maestro ordina ad un altro di fare ciò che tu avevi fatto di fronte a lui, o che il Maestro dice una cosa ed un altro dei presenti gli ribatte su quello ed egli rivede la sua affermazione, o che uno che si è ribellato ('a $\bar{a} s$ ) con una disobbedienza si presenta da lui ed egli [il Maestro] gli proibisce [quella disobbedienza] in modo mite, prega [Allah] per lui, e glielo ripete più volte, aggiungendo: "Questo per il Decreto ( qad $\bar{a}$ ') di Allah e per la Sua misura (qadar)" - tutto ciò per la sua saggezza - devi apprendere da questo l'adab ed assumere i suoi tratti di carattere per quanto ti è possibile".

Diciamo che talvolta il Maestro si trova in un momento che esige da lui che egli si rivolga al gruppo parlando ad uno [di loro], per un ordine che gli è venuto in mente [di impartire] nel suo rivolgersi a quell'uno, ma ciò che è voluto è [rivolgersi a] il gruppo, come [succedeva con] le sentenze (qadāa ā) riguardo ai casi individuali quando il Legislatore voleva [estenderle a] la comunità, ed il suo giudizio sull'uno era il suo giudizio sulla totalità. Il Maestro dà l'ordine a quell'altro e tu devi compiere quell'atto, che è stato ordinato a quell'altro, di fronte al Maestro, e se egli intendeva [includere] anche te in quello allora non ti dice nulla riguardo a ciò, se invece non intendeva anche te allora te lo vieta in quel momento [in cui te lo vede fare] $\left.{ }^{265}\right)$. Oppure tu stai compiendo un atto e vedi che il Maestro lo ordina ad un altro, non dicendoti niente al riguardo: in questo caso tu non devi farlo e devi astenerti da esso in modo tale che il Maestro veda che tu ti astieni da esso, e se il Maestro non ti dice niente tu sai che l'intenzione del Maestro per te è che tu non lo faccia. Se invece non tace e lo ordina anche a te, oppure sceglie te per quello, nel primo caso devi continuare nel tuo atto, nel secondo caso non agire, a meno che tu non veda che colui a cui esso è stato ordinato, e che è altri che te, ribatte al Maestro per essere stato escluso da quell'atto ed il Maestro non gli dice nulla, allora tu fallo e non essere ingannato [72] dal silenzio del Maestro. Quanto al caso in cui ha scelto te e quell'altro si è già messo sollecitamente a fare ciò che il Maestro gli ha ordinato, non agire, malgrado ti abbia scelto e quell'altro abbia accettato [di compierlo].

Se vedi quell'altro a cui è stato ordinato quell'atto ribattere al Maestro su ciò che ha detto e [affermare] che è meglio non farlo, ed il Maestro rivede ciò che ha detto, tu non devi recedere ma devi affrettarti

265) Nel caso qui descritto si tratta di un atto che l'aspirante aveva già compiuto in presenza del Maestro e per il quale aveva evidentemente ricevuto la sua approvazione, poiché in caso contrario non si metterebbe a ripeterlo quando viene ordinato ad un altro. 
a fare quell'atto dinanzi agli occhi del Maestro: se il recedere $(r u g ̌ \breve{u})$ del Maestro alle parole dell'altro è un recedere di accettazione allora ti vieterà quell'atto, se invece non ti dice nulla e non te lo vieta, sappi che il suo recedere alle parole di quell'altro è una astuzia (makr) da parte del Maestro nei suoi confronti. Infatti i Maestri hanno una astuzia divina che essi esercitano con i discepoli quando vedono da parte dell'aspirante il segno ('alāma) della mancanza di successo [(falāh), o: progresso] nella loro risposta ai Maestri, o nel loro sollevare delle obiezioni, o nel loro trovare giusto ciò che essi dicono piuttosto che ciò che dice il Maestro.

Non c'è disobbedienza più grave per l'uomo, dopo l'associazione, del suicidio $\left.{ }^{266}\right)$. Al-Qušayrī, Allah abbia Misericordia di lui, ha riferito che uno dei Maestri ordinò al suo discepolo di accendere il forno, ed egli lo fece, poi andò dal Maestro e lo informò mentre il Maestro era impegnato in una riunione, ed egli insistette nel farglielo sapere, tanto che fece incollerire ed irritare il Maestro, sì che questi, nella sua irritazione, gli disse: "Gettati in esso [nel forno]!". Egli obbedì all'ordine del Maestro e si gettò in esso, poi il Maestro si ricordò di lui e disse: "Prendetelo, poiché egli ha fatto con me un patto di ascolto ed obbedienza, volente o nolente". Essi si affrettarono verso di lui e lo trovarono nel forno, grondante di sudore come chi è nel hammām, ed il forno era al massimo del calore; lo portarono dal Maestro che si rallegrò di lui e disse: "Così è il servizio (hidma) della gente di Allah, coloro che parlano da parte di Allah" $\left.{ }^{267}\right)$. Essi sono così, come ha detto l'Inviato di Allah, che Allah faccia scendere su di lui la Sua șalāt e la Pace, al suo Signore: "O Signore, io sono un uomo (bašar), mi incollerisco come si incollerisce l'uomo [73] e sono soddisfatto come è soddisfatto l'uomo. Allāhumma, per colui contro cui ho imprecato - cioè nel momento della sua collera - fa che quella imprecazione su di lui diventi misericordia, perdono e soddisfazione (ridwān)" (268) ed Allah fece così con lui, poiché un giorno egli aveva imprecato contro una piccola bambina che lo aveva irritato, ed ella ebbe paura della sua imprecazione, al che le disse: "Non aver paura di me! Ho pregato Allah", e menzionò questa notificazione, e la sua richiesta del male divenne un bene nei confronti di colui contro cui l'aveva formulata.

Il Maestro voleva mostrare a chi era presso di lui come egli prendesse esempio in ciò dall'Inviato di Allah, che Allah faccia scendere su di lui la Sua salāt e la Pace, e come si conformasse all'adab e

266) Questa frase si ricollega al testo che la precede in quanto l'obbedienza al Maestro va mantenuta anche se ciò che viene ordinato può comportare la morte dell'aspirante, come nell'esempio riportato subito dopo. Ibn 'Arabī ribadisce la gravità del suicidio nel Cap. 368 [III 360.6] e nel Cap. 398 [III 563.14], ove precisa: "Il rispetto (hurma) dell'uomo per se stesso è più importante presso Allah del rispetto per gli altri, in quanto non sono prossimi [a lui come la sua anima]: chi uccide se stesso commette una colpa più grave di chi uccide un altro, e la sua elemosina (sadaqa) fatta a se stesso ha una ricompensa più grande dell'elemosina fatta ad un altro".

267) L'episodio è riportato nel capitolo della Epistola dedicato alla volontà (irāda), ove è precisato che il Maestro era Abū Sulaymān ad-Dārānī, morto nell'anno 215 dall'Egira, ed il discepolo Aḥmad ibn Abū l-Ḥawārī [AlQushayri's Epistle on Sufism, Garnet, 2007, pag. 215].

268) Hadīt riportato da Muslim, XLV-95, Abū Dāwud, XXXIX-10, e da Ibn Ḥanbal. 
qual'è il risultato dell'obbedienza dell'aspirante nei confronti del Maestro $\left({ }^{269}\right)$. Ciò che è necessario per l'aspirante è che consideri la parola proferita dal suo Maestro come la parola proferita dal Vero, in tutto ciò che dice, di bene e di male, secondo consuetudine e secondo Legge, e questo è molto raro negli aspiranti. Per lo più, coloro che accettano ciò, quando lo accettano senza obiettare, lo fanno con riluttanza da parte loro; è indubbio che essi saranno puniti per l'obiezione, e anche se la verità fosse dalla loro parte in quello, tuttavia l'obbedienza al Maestro è prioritaria per l'aspirante in ogni caso.

Un giorno un Maestro mi fece un discorso in cui c'era una grande nefandezza (fuhš) [e mi disse]: "Comunicalo agli altri della gente comune!". La comunicazione di ciò era una disobbedienza (ma siyya), secondo la Legge fermamente stabilita per noi, ma io mi mostrai rispettoso dell'adab nell'attenermi al suo ordine alla presenza (mahdar) del gruppo. Il Maestro mi chiese: "E tu farai quello?"; gli risposi: “Certo, per Allah!”, ed egli disse: "E sai che quella è una disobbedienza per la Legge?”, ed io risposi: "Si!", ed egli disse: "E come lo farai, sapendo che è una disubbidienza per la Legge? Con riluttanza o con animo lieto?", ed io gli risposi: "Con animo lieto!". Egli disse: "Come mai ciò?", ed io gli risposi: "In quanto noi non abbiamo appreso la Legge direttamente dal Legislatore, ma l'abbiamo appresa indirettamente da Lui, come ha detto Abū Yazìd: "Voi prendete la vostra scienza morto da morto, e noi prendiamo la nostra scienza dal Vivente che [74] non muore”. Il tuo discorso è per me la Legge che avvicina ad Allah, sia Egli esaltato, poiché per me tu sei uno di quelli che parlano da parte di Allah, non delle passioni della loro anima, ed apprendere da te è più saldo e valido del mio apprendere dalle parole dei sapienti della Legge". Egli disse: "Allah ti benedica: siediti e non fare quello! Io non volevo se non far vedere al gruppo la tua sincerità nel servizio e la tua venerazione [per il Maestro], e così è stato, sia lodato Allah! Figlio mio, quello che ti ho ordinato è una disubbidienza anche per me, e non te lo avrei comunque lasciato fare, ma ti ho messo alla prova in modo da sapere, come Egli, sia Egli esaltato, ha detto esplicitamente nel Suo Libro, malgrado la Sua Scienza: "Noi vi metteremo alla prova, in modo da sapere" (Cor. XLVII-31)".

Quanto al suo detto, Allah sia soddisfatto di lui: "o che uno che si è ribellato con una disobbedienza si presenta da lui ed egli gli proibisce [quella disobbedienza] in modo mite", quello è da parte sua un conformarsi a ciò che Allah ordinò a Mosè ed Aronne, quando li inviò dal Faraone, dicendo loro: "e parlategli in modo mite: forse egli si ricorderà o avrà paura" (Cor. XX-44).

Non c'è disobbedienza più grave della associazione (šrik), e malgrado questo Egli ha ordinato loro la mitezza $\left(l_{\bar{n}} n\right)\left({ }^{270}\right)$ in ciò che essi invocavano, poiché "Allah ama la gentilezza $($ rifq $)$ in ogni faccenda"

269) La collera del Maestro non arrecò danno all'aspirante, così come la collera del Profeta non arrecò danno alla bambina.

270) Nel Cap. 375 [III 472.15], Ibn 'Arabī spiega che il termine līn indica "l'abbassare le ali [(hafḍ al-ğanāh) cioè essere condiscendenti], la delicatezza (mudārā), e la diplomazia (siyāsa)". Nella lingua araba "hurūf al-līn" sono le consonanti "deboli". È curioso notare che l'italiano "lène" o "lèno", di etimologia incerta, significa debole, lieve, soave ed in linguistica è usato per le consonanti che sono pronunciate con minore tensione articolatoria rispetto alle corrispondenti forti. 
$\left.{ }^{271}\right)$, usando nella notificazione l'espressione "ogni [faccenda]". Questa è una delle faccende in cui è opportuna la gentilezza, poiché ciò fa parte del fare bene (ihsānn), e le anime sono ricettive a ciò che viene dal benefattore (muhsin), essendo inclini per natura ad amare chi fa loro del bene, e l'amore implica l'accettazione. E ognuno desiste [se trattato] con la gentilezza e le buone parole, e non desiste in assenza della gentilezza, quando colui che vieta tratta con severità e durezza nel suo divieto, poiché le anime detestano di essere sopraffatte e di essere contestate. Ciò soprattutto in questa specifica comunità, poiché Allah, sia Egli esaltato, non ha inviato Muhammad, il suo [della comunità] Inviato, se non come Misericordia, tanto che quando egli, che Allah faccia scendere su di lui la Sua șalāt e la Pace, pregò contro [le tribù de] i Ríl, i Dukwān e gli 'Ușayya tra i politeisti nel qunūt $\left({ }^{272}\right)$, Allah gli rivelò il divieto di pregare contro di loro e gli disse: "Non ti abbiamo inviato se non come Misericordia [75] per i Mondi" (Cor. XXI-107) ${ }^{273}$ ), "e a te spetta solo la trasmissione" (Cor. XLII-48), "E tu avverti, poiché sei solo un ammonitore, non hai potere su di loro!" (Cor. LXXXVIII-21 e 22), cioè non hai dominio [(lasta) bi mutassalit $]$.

Per tale motivo questo Maestro proibiva con mitezza a colui a cui proibiva, ed invocava per lui la riuscita (tawfìq), come fece al-Ǧunayd ${ }^{(274)}$ quando con i suoi compagni incontrò della gente riunita a commettere una disobbedienza, ed i suoi compagni si incollerirono e dissero al Maestro. "Invoca [Allah] contro costoro!" e al-Ǧunayd disse: "Allāhumma, come li hai riuniti nella disobbedienza a Te, così riuniscili nella obbedienza a Te".

27 1) Hadīt riportato da al-Buhārī, LXXXVIII-35, LXXIX-22, LXXX-59, LXXXVIII-4, Muslim, XXXIX-10, XLV-47, Abū Dāwud, XL-10, at-Tirmid̄ī, Ibn Māğah, ad-Dārimī, Mālik, e da Ibn Ḥanbal. Ibn 'Arabī lo cita nel Cap. 72 [I 744.12] e nel Cap. 404 [IV 6.5].

272) L'infinito qunüt ha come significato primario quello di obbedienza, ma indica anche la stazione eretta. La preghiera del qunüt (du ( $\bar{a}^{\prime}$ al-qunüt) è una recitazione che va fatta durante la salät, preferibilmente quando si è in piedi.

273) Nell'anno 4 dall'Egira le tre tribù citate trucidarono a Bi’’ Ma'ūna 70 Ansār che su loro richiesta erano stati inviati dal Profeta per insegnare l'Islām. Secondo gli ahādīt riportati da al-Buhāāī, LVI-9 e 19, LXIV-28, e Muslim, V-294, 297, 299, 303, 307 e 308, il Profeta maledisse per trenta giorni consecutivi, durante la preghiera del qunūt del fağr, queste tre tribù, finché, come spiega Ibn 'Arabī, Allah non gli rivelò tramite lo Spirito fedele: "O Muhammad, invero Allah ti fa sapere che non ti ha inviato come colui che oltraggia (sabbāb), né come colui che maledice ( $l a$ "' $\bar{a} n)$, ma ti ha suscitato come Misericordia"; poi gli rivelò il versetto "Non ti abbiamo inviato se non come Misericordia per i Mondi". Questo episodio è riportato e commentato da Ibn 'Arabī nei capitoli: 34 [I 215.14], 73, questione CL [II 127.7], 198 [II 411.33], 369 [III 398.20], 382 [III 519.12], 400 [III 568.1], 436 [IV 48.30] e 520 [IV 163.11]. La correlazione tra l'episodio e la rivelazione del versetto non è riportata né nelle raccolte canoniche di hadīt, né nei commenti del Corano.

274) Abū l-Qāsim al-Ǧunayd ibn Muhammad al-Ḩazzāz al-Qawārīrī al-Nihāwandī fu uno dei più celebri Maestri del Tasawrouf: trascorse tutta la sua vita a Bagdād, ove morì nell'anno 297 dall'Egira, all'età di 76 anni. Al-Ǧunayd è citato una trentina di volte nelle Futūhăt, ove Ibn 'Arabī lo definisce "il signore del gruppo (sayyid at-tā'ifa)" [Cap. 275 (III 591.31) e Cap. 297 (III 684.29)]. Ciò che è rimasto del suo insegnamento scritto è stato tradotto da Roger Deladrière in Enseignement spirituel, Sindbad, Paris, 1983. 
Osserva quanto è bello questo e ciò che ha fatto conseguire: la preghiera di al-Ğunayd arrivò a questo gruppo ed essi accorsero a lui e si pentirono grazie a lui, e questo è il risultato del fare bene (ihsān) nell'invocazione ad Allah. Ed anche se noi non siamo soddisfatti di ciò che è decretato (maqd̦), poiché Allah "non gradisce per i Suoi servitori l'ingratitudine (kufr)" (Cor. XXXIX-7) [malgrado essa sia stata decretata], tuttavia è nostro dovere, ed è obbligatorio, essere soddisfatti del Decreto di Allah e della Sua misura (qadar), poiché il Decreto non è identico a ciò che è decretato, pur non essendo in contraddizione, per chi ha appreso la scienza $\left({ }^{275}\right)$.

Sappi che non c'è cosa più spiacevole $\left(a s^{\prime} a b\right)$ in questa Via, né più grave come perdita e privazione, del criticare i Maestri e del replicare a loro in ciò che dicono; quando vedete l'estraneo (ağnabî), per non parlare dell'aspirante, replicare ai Maestri con ciò che è stabilito nella sua scienza, sappiate che egli è un infelice (mahrūm) che non avrà mai successo, e nulla uscirà da lui [di buono] finché persisterà in tale mancanza. Il minimo che costoro possano fare è di considerare questo Maestro alla guisa del giurisprudente (muğtahid) quando esercita la sua giurisprudenza e formula un giudizio: chi confuta il giurisprudente nel suo giudizio riguardo a lui manca di $a d a b$ nei confronti del Legislatore e rifiuta ciò che il Legislatore ha attestato come Suo giudizio nei confronti di quel giurisprudente $\left({ }^{276}\right)$; e chi rifiuta una legge deliberata disobbedisce ad Allah ed al Suo Inviato in ciò che ha stabilito. E anche se un dottore della Legge ( $f a q \bar{\imath} h$ ) non sostiene quello [che ha affermato il giurisprudente] ed Allah non lo ha asservito a ciò, è sì proibito per lui mettere ciò in atto, ma non la sua accettazione [di quel giudizio] da parte del giurisprudente; ciò accade spesso, tra i dottori della Legge, agli imitatori ignoranti degli Imām che vennero prima: essi mescolano l'imitazione pedissequa (taqlīd) [76] con la critica (wuqū') verso i giurisprudenti e l'affermazione del loro errore (tahtīt), ma non ne hanno diritto.

Poi ha detto: "E se vedi che una delle faccende di questo mondo si svolge in presenza del Maestro e sei convinto riguardo a quella che essa non è secondo l'aspetto di ciò che è ben fatto (mașlaha),

275) Nel Cap. 538 [IV 182.11, Ibn 'Arabī precisa: "A lui, su di lui la Pace, ed ai credenti, è stata ordinata la rettitudine (istiqāma), ma il regime (hukm) appartiene alla Scienza, non al Comando (amr), ed Allah non è ingiusto con i servitori. Egli, sia Egli esaltato, non ha Scienza se non di ciò che Gli apportano gli oggetti della scienza, e la Scienza segue il suo oggetto, e non si manifesta nell'esistenza se non ciò che implica l'oggetto della scienza, "e ad Allah appartiene l'argomento decisivo" (Cor. VI-149): chi non conosce la realtà in questo modo non ha alcuna nozione di come stanno le cose. L'uomo ignora ciò che avverrà da lui prima che avvenga, e quando accade da parte sua ciò che accade, non accade se non per la Scienza di Allah riguardo ad esso, ed Egli non ha Scienza se non di ciò che è implicito nell'oggetto della scienza. È quindi valido il Suo detto: "ed Egli non gradisce per i Suoi servitori l'ingratitudine" (Cor. XXXIX-7); il gradimento (rid̄a) è volontà (irāda) [tra i significati dell'arabo rida $\bar{a}$ vi è anche desiderio, volere], e non c'è contraddizione tra il Comando [prescrittivo, non quello creativo] e la Volontà, ma soltanto tra il Comando e ciò che apporta la Scienza che segue il suo oggetto". Questo argomento è sviluppato anche nelle pagine 7 e 8 del manoscritto, riguardo al segreto del destino.

276) Ibn 'Arabī afferma più volte [capitoli: 14 (I 151.7), 36 (I 224.35), 68 (I 355.21), 69 (I 392.14, 449.1 7, 499.28, 522.29, 523.2, 545.30), 73, questione XXV (II 58.17), questione LVII (II 79.13), 88 (II 163.1 e 165.27), 156 (II 255.2), 171 (II 288.13), 198 (II 477.23), ecc.] che Allah ha stabilito la validità del giudizio del giurisprudente, anche se sbaglia. 
devi comprendere da quello $\left({ }^{277}\right)$ che non è necessario che l'uomo intraprenda le faccende di questo mondo secondo l'aspetto della giustezza (sadād) e dell'esattezza (ihkām), bensì che respinga uno stato $\left(d a f^{c} h \bar{a} l^{i n}\right)\left({ }^{278}\right)$ giorno per giorno; poi offriti tu stesso di fare quella [faccenda] e se ti permette di farla bene, [va bene] altrimenti hai compreso lo scopo. In tutto ciò sii di fronte al Maestro come se fossi di fronte a colui che quando vede un [tuo] fallo (zalla) ti taglia la testa, anzi peggio, poiché ci rimetti questo mondo e l'altro, Allah ci protegga (al- $i y \bar{a} \underline{d}$ bi-llāhi), e preserva te stesso e ricorri al Maestro riguardo a tutto ciò. Dopo di ciò devi sforzarti di rabbonire il cuore di ogni aspirante verso il Maestro, devi rispettarlo e riverirlo con il massimo rispetto e riverenza, e devi trattarlo con riguardo (ikrām), poiché il riguardo verso l'aspirante è per via del Maestro, e per l'ossequio di uno hai riguardo a cento. E se sei in grado di fare la munificenza $(m u ' \bar{a} s \bar{a})$, guardati dall'essere corto al riguardo, verso chiunque tu puoi, e specialmente verso gli aspiranti, e che il dare ciò che è necessario $\left(s a h \bar{a}^{\prime}\right)$ e l'abnegazione

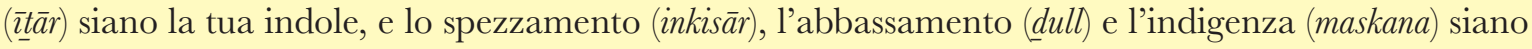
costantemente la tua natura, o aspirante, e così la tristezza (huzn) e sii saldo (šadīd) in tutto ciò che ti ho menzionato, dotato di forte fermezza (qawiyyu l-cazm) in tutto quello. Sappi che ogni volta che il cuore del Maestro è con te, nessuno può assolutamente farti del male, e se il cuore del Maestro ti abbandona, Allah ci protegga, diventerai [77] tra gli uomini come colui che è bandito (matrūd) da un posto ad un altro, cerchiamo rifugio in Allah da quello. Sappi che quando il cuore del Maestro è con te, anche se la gente del Cielo e della Terra si mettesse insieme per farti del male, non vi riuscirebbe, poiché ogni volta che il cuore del Maestro è con te, Allah è con te".

Commento. Quanto al suo detto riguardo a "ciò che si svolge delle faccende di questo mondo di fronte al Maestro", fino al suo detto "il respingere uno stato giorno per giorno", devi sapere innanzitutto che questo Maestro è incapace di spiegare ciò che trova (yağid) [inaspettatamente nel suo cuore] $\left.{ }^{279}\right)$, e che gli iniziati (al-qawm) hanno menzionato, riguardo all'apertura spirituale (futūh)

277) Come verrà spiegato nel commento, "quello" si riferisce al silenzio del Maestro di fronte all'avvenimento che si è svolto di fronte a lui.

278) Il termine $d a f^{\prime}$, infinito del verbo dafáa, è usato nelle Futūhăt nel senso di respingere, allontanare qualcosa di negativo, come l'offesa $(a \underline{d} \bar{a})$, la costrizione (darūra), il dolore (alam), mentre il termine $h \bar{a} l$ indica lo stato del momento, e nel linguaggio tecnico uno stato spirituale non stabilizzato. Ma nel Cap. 192, dedicato allo stato spirituale, né altrove nelle Futūhăt, non è mai questione di respingere lo stato spirituale, per cui il senso da attribuire al termine hăl in questa frase è quello di uno stato non spirituale, bensì psichico, che a differenza del precedente può anche essere negativo o dannoso. Nel Corano ricorre due volte l'ingiunzione: "Respingi il male con ciò che è più bello (ahsan)" [XXIII-96 e XLI-34] e nel Cap. 354 [III 246.25] Ibn 'Arabī afferma: "Tra le scienze di questa dimora spirituale vi è la scienza dell'opporsi ai nemici e del fronteggiare le passioni con le passioni. In effetti, se la ragione non respinge la passione con la passione non raggiunge il suo scopo, poiché l'anima è abituata ad apprendere solo dalla sua passione. Quando la ragione conosce l'arte del governo ed è abile a foggiare le forme, fa apparire all'anima la forma di ciò che essa [ragione] cerca come oggetto della sua stessa passione, e l'anima lo accoglie con ardore, ed in questo modo la ragione ha il sopravvento".

279) Nel Cap. 236 [II 537.1] Ibn 'Arabī precisa che il wağd, termine derivato dal verbo wağada, trovare, indica per gli iniziati (at-tâtifa): "ciò che il cuore incontra improvvisamente degli stati spirituali che estinguono per lui la presenza di sé e quella degli altri; per essi talvolta indica il frutto della tristezza nel cuore. Il Maestro (ustāe 
in senso tecnico, una apertura nel modo di esprimersi ( $i b \overline{a r a})\left({ }^{280}\right)$. Non tutti coloro che hanno degli stati spirituali inaspettati sono capaci di trasmettere e non tutti coloro che sono capaci di trasmettere riescono ad esprimere bene quello, per ciò che è possibile comunicare, poiché per ciò che non è possibile comunicare, come le scienze dei gusti spirituali, ciò è precluso per se stesso.

Questo Maestro ti ha detto nella sua raccomandazione, riguardo a ciò che avviene delle faccende di questo mondo in presenza del Maestro ed al silenzio del Maestro riguardo a quello ( $\left.{ }^{281}\right)$, di non pensare, quando ha luogo una cosa simile, che in ciò non vi sia un beneficio (mașlaha), bensì [di pensare] che in ciò vi è un beneficio che il Maestro conosce e che gli altri ignorano. Questo non è necessario: talvolta accadono delle faccende di questo mondo in cui non vi è un beneficio, né in senso ordinario né in senso tradizionale, secondo l'apparenza esteriore, ed Allah ha in ciò un segreto; talvolta vi è in quello una prova divina per chi è presente con il Maestro e per gli altri, poiché Egli, sia esaltato, è colui che ha detto: "Noi vi metteremo alla prova, in modo da sapere" (Cor. XLVII-31), e non ha menzionato con cosa; e talvolta vi è nel gruppo dei presenti qualcuno che ha una pretesa e viene messo alla prova per vedere come si comporta in quella circostanza.

Quanto al detto di questo trasmettitore: "Devi comprendere da quello che le faccende di questo mondo non è necessario - egli dice che non è obbligatorio - che l'uomo le compia secondo la giustezza [78] e l'esattezza" e dice che talvolta ['aspirante] respinge per mezzo di esse lo stato del momento. Non c'è dubbio che egli si riferisce ad una giustezza specifica, poiché il respingere lo stato del momento fa parte della giustezza più bella $\left({ }^{282}\right)$, ma per chi non ha uno stato che viene respinto

ha detto - e nell'insieme è giusto - che il wağd è uno stato spirituale ( $h \bar{a} l)$ e gli stati spirituali sono dei doni, non delle acquisizioni".

280) Nel Cap. 216 [II 505.12] Ibn 'Arabī precisa che per gli iniziati vi sono tre tipi di apertura spirituale: il primo è l'apertura nel modo di esprimersi esteriormente, il secondo è l'apertura della dolcezza (halāwa) interiore, il terzo è l'apertura dello svelamento (mukā̌safa). Aggiunge poi che "in sintesi, ogni cosa che ti arriva senza uno sforzo [per ottenerla], né una mira (istišra $\bar{f}$ ), né una ricerca, è una apertura, sia essa esteriore o interiore. Per colui che prova una apertura vi è un segno indicatore, che consiste nella assenza di apprendimento dall'apertura dell'altro o dalle conclusioni del pensiero $(f i k r)$, e tra le condizioni che definiscono l'apertura vi è la non concomitanza del pensiero e l'indipendenza dal pensiero". Poco oltre [II 506.2] Ibn 'Arabī precisa che "l'apertura nel modo di esprimersi è propria solo del muhammadiano perfetto tra gli iniziati, anche se fosse erede di un altro Profeta. La stazione più forte che ottiene il possessore di questa apertura è la veridicità (sidq) in tutti i suoi discorsi, movimenti e soste [...] Chi ha questa apertura non è in grado di concepire in se stesso un discorso, di ordinarlo mentalmente e quindi di formularlo, ma il momento in cui lo proferisce è il momento stesso in cui concepisce le parole con cui esprime ciò che ha in se stesso [...] Nella mia vita non ho visto in alcun uomo di Allah che ho incontrato traccia di questa apertura; è possibile che vi siano uomini che hanno questa apertura e che non li abbia incontrati, ma sono certo e sicuro che io sono uno di loro".

281) Nel testo della raccomandazione non si fa riferimento al silenzio del Maestro, né al commento verbale di uno dei presenti, che è citato alla fine della pag. 81 del manoscritto. Probabilmente entrambi i manoscritti sono lacunosi su questa raccomandazione.

282) La prima giustezza si riferisce al modo in cui si svolge una delle faccende di questo mondo, la seconda al fatto che tramite ciò che avviene l'aspirante riesce a respingere uno stato che andava respinto. Ma se in quel momento l'aspirante non ha un simile stato il beneficio viene meno, come è spiegato subito dopo. 
da ciò che ha luogo non si tratta per lui di giustezza, mentre lo è per colui il cui stato del momento viene respinto da ciò che ha luogo. Poi, se esamini il punto di vista del Legislatore riguardo a ciò che accade, se la Legge lo loda allora è senza dubbio la giustezza, poiché non è necessario che tutte le faccende di questo mondo siano biasimate, come è stato tramandato nella notificazione dal significato autentico: "Questo mondo (ad-dunyā) è la cavalcatura (matiyya) del credente, su di essa egli raggiunge il bene e con essa si sottrae al male. Quando uno di voi dice: "Allah ha maledetto questo mondo", questo mondo dice: "Allah ha maledetto il più ribelle di noi al suo Signore“" ${ }^{(283)}$. Qatāda $\left({ }^{284}\right)$ ha detto: "Nessuno rende giustizia a questo mondo: esso è biasimato per la cattiva azione che l'iniquo compie in esso e non è lodato per la bella azione che il pio compie in esso" $\left({ }^{285}\right)$.

Se quello che accade fa parte di ciò che la Legge ha biasimato, è la lingua del Vero che lo ha biasimato e tu non hai da formulare alcun giudizio su ciò, bensì il giudizio spetta alla Legge, ed il massimo che puoi fare è dire: "Perché il Maestro ha taciuto riguardo a una cosa simile?".

Sappi che è stato ordinato di rettificare [(tagy $\bar{\imath} r)$, letteralmente modificare] le cose riprovevoli (munkarāt) nella misura del possibile, e se il momento esige di rettificare con la mano, sappi che la fede [o fiducia $(\bar{\imath} m \bar{a} n)]$ nel sovrano (sultān) e nei governatori $(w u l \bar{a})$ è forte $\left({ }^{286}\right)$; e se non è possibile farlo con la mano ed [il credente] è al sicuro per se stesso quando le rettifica con la lingua, [lo fa verbalmente] ed egli è in una situazione intermedia per quella forza riguardo ai governatori, cioè la fede, e non per

283) Hadīt non recensito nelle raccolte canoniche. Ibn 'Arabī lo riporta nel Cap. 126 [II 210.8], nel Cap. 560 [IV 542.10], e nel libro Muhādarat al-abrār [RG 493], Dār Sāder, Beirut, Vol. I, pag. 261, e pag. 191 dell'edizione litografica del Cairo del 1888.

284) Qatāda ibn Di‘āma ibn Qatāda as-Sadūsī, appartenente alla generazione successiva a quella del Profeta, fu allievo di Ḥasan al-Basrī e di Ibn Sirīn. Cieco dalla nascita, divenne proverbiale per la sua prodigiosa memoria e le sue conoscenze in materia di esegesi coranica e di hadīt.

285 ) Questo detto è riportato anche in Muhāẹarat al-abrār, Vol. II, pag. 277 e nel Cap. 126 [II 210.4], ove Ibn 'Arabī precisa: "Qatāda ha detto: "Nessuno rende giustizia a questo mondo: esso è biasimato per la cattiva azione di chi fa il male in esso, ma non è lodato per la buona azione di chi fa il bene in esso". Se per la sua essenza esso desse la turpitudine (qubh) ed il male come sarebbe possibile che vi siano in esso Profeti inviati e servitori pii? Allah gli ha attribuito l'obbedienza dicendo: "Invero la sua parte alta e quella bassa dicono entrambe: veniamo obbedienti" (Cor. XLI-11) ed ha detto anche: "e la Terra, la erediteranno i Miei servitori pii" (Cor. XXI-105). Ora, chi è pio non eredita se non la ricchezza che va bene, di cui gli è lecito disporre in quanto è un servitore pio. Ed il Vero non ha detto che tutti i servitori la erediteranno. Ciò sta ad indicare che la sua eredità è un'acquisizione onesta e per questo la ereditano i servitori pii di Allah. L'Inviato di Allah, che Allah faccia scendere su di lui la Sua șalāt e la Pace, ha detto: "Quando uno di voi dice: "Allah ha maledetto questo mondo", questo mondo dice: "Allah ha maledetto il più ribelle di noi al suo Signore", cioè un figlio irrispettoso verso di lui. Mentre egli lo ha maledetto dichiarando il suo nome, questo mondo, per il suo affetto verso i suoi figli, non può maledire suo figlio. Infatti ha detto: "Allah ha maledetto il più disubbidiente di noi al suo Signore" e non è stato in grado di chiamarlo con il suo nome. Questa è la compassione e la pietà della madre per il suo figlio! Meravigliamoci di noi".

286) Come verrà chiarito nel seguito del testo, si tratta di cose riprovevoli perpetrate pubblicamente da coloro che detengono il potere, o con il loro consenso. 
quella debolezza; e se non è al sicuro per se stesso quando [le] rettifica con la lingua, le rettifica con il suo cuore, poiché è un credente, e quello è il massimo della debolezza della fede nel sovrano e nei governatori, non nei confronti [della fede] di costui che rettifica con il suo cuore $\left({ }^{287}\right)$.

Invero Allah gli ha imposto il diritto della sua anima come il più grande dei diritti per lui, tanto [79] che ha detto al suo riguardo: "Invero chi si uccide, Allah gli vieterà il Paradiso" (288), ed ha detto riguardo all'uccisione di altri: "Se non viene punito per quello allora la sua faccenda riguarda Allah: se vuole lo perdona e se vuole lo punisce" ${ }^{289}$ ), e non ha sentenziato al suo riguardo ciò che ha sentenziato riguardo al suicida. Colui che fa torto a se stesso commette un atto più grave di chi fa torto agli altri.

Quando la fede nel sovrano è al massimo della debolezza, in quanto colui che rettifica, se rettifica con la lingua o con la mano, non si sente al sicuro dalla persecuzione del sovrano e dalla sua uccisione a causa di quello, egli è libero di scegliere tra il rettificare e il non rettificare: se rettifica pur sapendo che verrà ucciso egli fa torto a se stesso (nafsa-hu) e se non rettifica fa torto per se stesso (li-nafsi-hi), ed egli è tra gli eletti a cui Allah ha lasciato in eredità il Suo Libro $\left({ }^{290}\right)$.

287 ) Riferimento al hadīt riportato da Muslim, I-78, Abū Dāwud, II-232, XXXVI-17, an-Nasā'̄î, Ibn Māğah, e da Ibn Hanbal, secondo il quale "Il primo ad introdurre la predica (hutba) prima della șalāt nel giorno della Festa fu Marwān. Un uomo si alzò e disse: "La salāt non viene prima della predica?" e Marwān rispose: "Ciò che si faceva è stato abbandonato!". Abū Sa īd [al-Hudrī] commentò: "Quest'uomo ha fatto il suo dovere; ho sentito l'Inviato di Allah, che Allah faccia scendere su di lui la Sua șalāt e la Pace, dire: "Chi di voi vede una cosa riprovevole la rettifichi con la sua mano, e se non è in grado [di farlo con la sua mano] lo faccia con la sua lingua, e se non è in grado [neppure di fare quello] lo faccia con il suo cuore, e quello è il più debole (ad'af) nella fede". Il testo di Ibn 'Arabī mette in evidenza che la debolezza in questione non riguarda la fede del credente, ma la sua fiducia in coloro che detengono il potere. Analogamente, nel Cap. 213 [II 501.14], commentando questo hadīt, precisa che "il più debole nella fede" riguarda il momento (zamān), non l'anima di colui che è alterato $($ gay $\bar{u} r)$ per la cosa riprovevole.

288 ) Hadīt non recensito nelle raccolte canoniche. Ibn 'Arabī riporta una affermazione simile anche nei capitoli 69 [I 534.24], 147 [II 234.28] e 375 [III 473.21].

289 ) Hadīt riportato da Muslim, XXIX-41. Ibn 'Arabī lo cita nel Cap. 147 [II 234.27].

290 ) Riferimento al versetto 32 della Sūra XXXV, in cui tra gli eletti sono inclusi coloro che fanno torto per se stessi, o per le loro anime. Nel Cap. 73, questione CLIV [II 136.21] Ibn 'Arabī precisa: "Egli, sia Egli esaltato, ha detto: "Poi abbiamo dato in eredità il Libro a coloro che abbiamo eletto tra i Nostri servitori" (Cor. XXXV-32), e l'eletto è l'Intimo (wall); poi ha aggiunto riguardo agli eletti: "di essi fa parte chi fa torto per la sua anima" (Cor. ibidem), negandole il suo diritto a causa sua; cioè il diritto che tu hai, o anima mia, su di me in questo mondo lo posticipiamo per te nell'aldilà. Affrettati qui alla fatica ed allo sforzo, attieniti alle decisioni severe ed evita l'inclinazione alle facilitazioni, e tutto ciò [queste ultime] è tuo diritto. Egli quindi fa torto a se stesso per se stesso, a causa della sua anima, e per questo Egli ha detto riguardo a coloro che ha eletto: "di essi fa parte chi fa torto per la sua anima", cioè a causa della sua anima per renderla felice [nell'aldilà], e non fa torto ad essa se non per essa". 
Un simile rettificatore ha bisogno di conoscere la forza della sua anima ed il rango di essa. Una cosa simile l'ha detta Abū Sulaymān ad-Dārānī (291): "Io ho visto la cosa riprovevole e sapevo che rettificandola sarei stato ucciso, e, per Allah, non ho paura della morte, ma ho desistito perché non ero al sicuro che nella mia anima non subentrasse il farsi bella di quello al momento della morte, in quanto sarei stato ucciso per aver rettificato la cosa riprovevole, e la faccenda non era chiara per me, per il difetto della mia anima, per cui ho desistito". Così gli iniziati fanno il conto con le loro anime.

E se quella faccenda che è avvenuta in presenza del Maestro fa parte delle faccende di questo mondo che per la Legge non hanno che il regime giuridico della liceità, il Maestro, anzi la gente della Via in modo unanime, considerano che non ci sia tempo per loro di occuparsi di ciò che è lecito, ma solo di ciò che è obbligatorio e raccomandato, e se non c'è ciò che comporta obbligatorietà o raccomandazione, allora il minimo della presenza (hudūr) del credente riguardo a quella cosa lecita è di aver presente la fede che si tratta di una cosa lecita, e ciò è obbligatorio per lui, cioè la fede nella sua liceità, e in quel momento lo stato del Maestro, o [80] di chiunque della gente della Via, è la considerazione dell'obbligatorietà della fede nella sua liceità, e quindi egli ha presente una cosa obbligatoria.

Poi [devi sapere che] il Maestro realizzato non distingue, tra tutti gli Atti di Allah che avvengono in questo mondo, ciò che riguarda questo mondo da ciò che riguarda l'aldilà, per la sua contemplazione di Colui che dispone nel divenire [del Mondo], e quindi egli considera nel suo giudizio ( $h u k m)$ di quell'accadimento da parte di Allah il momento ed il gruppo in cui ha luogo, ed esso può riguardare l'insieme o uno dei due. È indispensabile la scienza della correlazione (munāsaba) tra ciò che si manifesta ed avviene ed il tempo ed il gruppo, oppure uno dei due, ed egli sa che quella correlazione comporta l'accadimento di quella faccenda, e quindi considera in quella occasione quale sia il giudizio di Allah prescritto per la faccenda correlata, insieme alla sua contemplazione che essa viene da parte di Allah e per la disposizione di Allah - ciò non è nascosto a lui, né alla gente di Allah - e quando sa il regime di quella cosa correlata si comporta conformemente alla sua scienza di esso: se la scienza comporta che egli parli al riguardo con un divieto o altro, egli parla, e se comporta per lui il silenzio tace. Invero, il grande procede secondo la scienza che ha delle cose, come ha detto uno dei signori [della Via]: "Il magnanimo $(s a h \breve{\imath})$ non è colui che spende della sua ricchezza, bensì è magnanimo colui che spende di se stesso secondo la scienza" $\left.{ }^{292}\right)$, cioè che fa che la scienza abbia l'autorità (hukm) su di lui.

291) Lo šayh Abū Sulaymān ad-Dārānī, originario di Dārā, un paese vicino a Damasco, morì nell'anno 215 dall'Egira. Nelle Futūhāt il suo nome ricorre solo nel Cap. 45 [I 251.28]. L'aneddoto qui citato è riportato da Abū Țālib al-Makkī, Qūt al-qulūb, Vol. II, pag. 137, da al- Gazālī, Ihyā' ulūmi-d-dìn, Vol. I, pag. 123, ed anche da Farīduddīn al-'Aț̣ār, nell'originale persiano di Tadkirat al-awliya $\bar{a}$, nella sezione dedicata a questo Šayh, ma non nella versione uigur su cui si sono basate le traduzioni francese, Le mémorial des Saints, ed italiana, Parole di Süfì.

292) La stessa frase, che in Muhādarat al-abrār, Vol. II, pag. 284 è attribuita a Ibn al-'Arîf, è riportata nel Cap. 477 [IV 113.35], preceduta dalle seguenti considerazioni: "Ciò che è prioritario per il servitore a cui Allah ha imposto ed affidato il governo $(t a d b \bar{r} r)$ della sua anima [o: di se stesso] è che egli sappia e, quando egli sa, che la sua scienza lo metta in opera, in modo che egli sia conforme alla sua scienza, e non che egli metta in opera 
Se tu dici: "A questo possessore delle soste (mawāqif) è stato detto nella sosta della scienza: non obbedire all'ordine della scienza!" ${ }^{293}$ ), noi rispondiamo: "Hai detto il vero, egli non è obbediente all'ordine della scienza, bensì è obbediente al sapiente che gli ha ordinato, poiché la scienza non ordina, ma l'ordine appartiene al sapiente ed egli è obbediente al sapiente che gli ordina". Quando l'uomo ordina a se stesso per il suo essere sapiente, dotato di scienza, è lecito nell'espressione dire che la scienza gliel'ha ordinato - ed è così che stanno le cose - così come Egli, sia Gloria a Lui e sia Egli esaltato, ha detto: "Gli sguardi [81] non Lo percepiscono" (Gor. VI-103), informando della Sua realtà essenziale, ma la verità è che colui che Lo percepisce è chi guarda con lo sguardo, non lo sguardo. ${ }^{294}$ Analogamente la scienza non ordina, ma è il sapiente che ordina per essa, poiché non ordina se non sa, e non tutti coloro che sanno ordinano, ed i signori [della Via] dicono: "Invero il Ṣūfì è figlio del suo istante" ${ }^{295}$ )

Quindi il Maestro non tace riguardo a ciò che succede se non in base ad una visione interiore, ed il suo silenzio è una chiamata $\left(d u^{(} \bar{a}\right)$ ad Allah, e la gente di Allah che segue la Sua guida non chiama ad Allah se non in base ad una visione interiore, come è stato notificato testualmente $\left({ }^{296}\right)$.

Talvolta la chiamata avviene per mezzo della lingua, talvolta avviene con il silenzio e l'omissione della disapprovazione (nakīr), ed è saldamente stabilito dal giudizio della Legge che l'omissione della disapprovazione da parte del Profeta, su di lui la Pace, quando avveniva una cosa in sua presenza, era

la sua scienza. Infatti, se egli mette in opera la sua scienza è la sua scienza ad essere conforme a lui, poiché talvolta egli agisce in base ad essa e talvolta la tralascia, cioè non agisce in base ad essa [...]. Se invece è la scienza a metterlo in opera ed a disporre di lui, ed egli viene fatto agire ed è utilizzato dalla scienza, essa per forza lo governa in modo corretto, ed egli ottempera cosi ai diritti di coloro che li posseggono”. Nel Cap. 560 [IV 460.13] Ibn 'Arabī precisa inoltre: "Invero il generoso la cui generosità (sahā ) è perfetta è colui che dona generosamente se stesso in base alla scienza, conformandosi in ciò a quello che Allah gli ha prescritto: egli sa, agisce di conseguenza ed insegna a chi non sa".

293) Ibn 'Arabī si riferisce a Muhammad ibn 'Abd al-Ǧabbār an-Niffarī, autore del "Libro delle soste (kitāb almawāqif)". An-Niffarī visse nella prima metà del IV secolo dell'Egira, conducendo una vita errante nei deserti, ignorato dagli uomini, e, secondo lo storico Ḥăğğḡi Hualīfa, morì in un villaggio dell'Egitto nell'anno 354. Il Libro delle soste è stato pubblicato e tradotto in inglese da A.J. Arberry nel 1935. La frase citata si trova all'inizio della sosta XXXV, ed è riportata da Ibn 'Arabī nel Cap. 5 [I 115.13] e nel Cap. 69 [I 392.35].

294) Questa precisazione è riportata anche nel Cap. 211 [II 499.5] e nel Cap. 558 [IV 301.22].

295) Questo detto, di cui non è noto l'autore, è riportato nei capitoli 68 [I 373.3], 69 [I 462.8], 71 [I 647.27], ove Ibn 'Arabī precisa: "I signori della gente di Allah hanno detto che l'autorità spetta al momento (al-hukm li-lwaqt) e che l'uomo, o il Șūfí, è figlio del suo momento - né passato né futuro hanno potere su di lui - sennonché l'uomo non sa che egli è figlio del suo momento, malgrado il potere del momento su di lui, mentre il Șūfì sa che è governato dal suo momento, così come realmente è. Per questo abbiamo detto: il Șûfí è figlio del suo momento, per la sua consapevolezza di quello e per la sua scienza di possedere il segno della Profezia (atar annubuwrwa), in ciò che il suo momento gli comanda. Non tutti gli uomini lo sanno, malgrado sia realmente cosi”, e 377 [III 485.11].

296) Riferimento al versetto 108 della Sūra di Giuseppe (XII): "Dì: questo è il mio sentiero. Io chiamo ad Allah in base ad una visione interiore, io e chi mi segue". 
un argomento probante (huğğa) in quanto egli l'aveva vista ed aveva taciuto di essa e non aveva detto nulla al riguardo, ed il suo silenzio indicava la liceità di quella cosa in quel momento. Quindi il suo silenzio equivaleva a un giudizio sulla questione, come il suo silenzio in sua presenza quando venne mangiata la lucertola $(d a b b)$ alla sua tavola - e la mangiarono Ḩālid ibn al-Walīd $\left({ }^{297}\right)$ ed altri - ed egli non disse che ciò era vietato né che era lecito, ma stette in silenzio $\left({ }^{298}\right)$ ed il suo silenzio indicò la liceità di mangiare [la carne di lucertola], e questa è una espressione intelligibile per mezzo della lingua dello stato (lisān al-ḥăl). Il Maestro perfetto comunica con il suo silenzio così come comunica con il suo discorso, allo stesso modo.

Colui che ha tradotto [in parole] lo stato del Maestro, a mo' di commento, ha detto che si comprende da quello [cioè dal silenzio del Maestro] che non è necessario che le faccende di questo mondo si svolgano secondo la giustezza, bensì [che è necessario] respingere uno stato giorno dopo giorno - quello è il suo limite massimo (mablag) - e che lo stato del Maestro testimonia che egli vuole dire che se le cose fossero andate diversamente sarebbe stato meglio, ma il tempo (zamān) ha deciso, e noi abbiamo già spiegato che il giudizio riguardo a quello spetta ad Allah, per ciò che comporta il momento, e costui ha menzionato [solo] uno degli aspetti della questione.

Quanto al suo detto: "poi offriti tu stesso di fare quella [faccenda]", cioè se ciò che è accaduto fa parte delle cose che si fanno, oppure parlane anche tu come ha parlato l'altro, poiché il regime [82] del Maestro con l'aspirante che è suo discepolo (tilmīd) non è come il regime del Maestro con un altro aspirante che non è suo discepolo, né è come il regime del Maestro con chi non è affatto aspirante. Il regime del Maestro con il suo aspirante è che dica ciò che è bene per lui, sia che taccia al momento dell'atto - il silenzio è nel significato come un discorso da parte sua per questo aspirante, perché egli sa ciò che egli comprende da esso, e se il suo aspirante fa parte degli ottusi, in quanto non comprende dal Maestro per mezzo del tacere, allora è obbligatorio per il Maestro parlare all'aspirante quando egli propone se stesso per quello - sia per mezzo di un ordine [esplicito] riguardo a ciò, o per mezzo del divieto di ciò, ed allora tu devi comportarti conformemente a ciò che il Maestro ti ha detto.

Quanto al suo detto: "In tutto ciò sii di fronte al Maestro come se fossi di fronte a colui che quando vede un [tuo] fallo ti taglia la testa, anzi peggio", egli vuol dire che devi stare in guardia dal Maestro come stai in guardia da chi vuole il tuo danno, poiché quando ti proponi per un certo atto senza un ordine del Maestro commetti un fallo, ed è noto della Via che il Maestro quando non punisce l'aspirante per il suo fallo è sleale con lui ed è sleale con Allah in ciò, in quanto è suo dovere punirlo e non tollerare ciò: egli [l'aspirante] non è diventato suo compagno e non è entrato sotto la sua

297) Huālid ibn al-Walīd ibn al-Mugīra al-Mahzūmī, dopo aver combattuto i musulmani nella battaglia di Uhud, si convertì all'Islām e diresse con successo molte campagne nei primi anni delle conquiste arabe, tanto da essere denominato la spada (sayf) di Allah. Morì nell'anno 21 dall'Egira.

298) Hadīt riportato da al-Buhārī, LXX-16, XCVI-24, Muslim, XXXIV-40, Abū Dāwud, XXVI-27, atTirmidīī, XXIII-3, Ibn Māğah, e da Ibn Ḥanbal. 
giurisdizione se non perché vengano applicate le regole imposte a lui dalla via verso Allah $\left({ }^{299}\right)$.

Non vedi come si è espresso l'Inviato di Allah, che Allah faccia scendere su di lui la Sua salāt e la Pace: "Chi ci rivela il suo errore (safha) [noi applicheremo a lui la pena]" $\left({ }^{300}\right)$, cioè colui di cui veniamo a sapere che ha fatto un atto che implica per lui l'applicazione della pena, noi la applichiamo. Al punto che quando venne informato riguardo ad una sentenza individuale nei confronti della donna che aveva violato il suo pegno - ella si era fatta prestare un gioiello e poi aveva negato ciò, ed era tra le nobili della sua gente - per cui le doveva essere tagliata la mano, e gli venne chiesto di lasciarla [impunita] [83] per la sua nobiltà, egli, che Allah faccia scendere su di lui la Sua șalāt e la Pace, disse: "Se fosse che Fāṭima figlia di Muḥammad - cioè di lui stesso - avesse rubato, le taglierei la mano" ${ }^{\left({ }^{01}\right)}$. Allah ha lodato coloro "che non hanno paura del biasimo di chi rimprovera" (Cor. V-54), cioè [che agiscono] dal lato di Allah e nell'osservanza del Suo diritto $\left.{ }^{(302}\right)$.

Quanto al suo detto: "e preserva te stesso e ricorri al Maestro riguardo a tutto quello", egli dice: se sai da te stesso che fai parte degli ottusi, in quanto non comprendi dalla concatenazione delle circostanze ( qarā’in al-ahwāl) ciò che il Maestro vuole da te, poiché il Maestro conosce la tua situazione, ma talvolta è occupato con Allah in un momento che lo distoglie da te, e quindi non ha presente ciò in cui tu e gli altri vi trovate, allora informa il Maestro del tuo stato, affinché ti tratti nel modo in cui vi è il tuo beneficio e sia portato con te a dire ciò che vuole che tu faccia o non faccia, e non rimetterti alla concatenazione delle circostanze, poiché tu non sei uno di quelli [che le capiscono].

Quanto al suo detto: "Poi, dopo quello, devi sforzarti di rabbonire il cuore di ogni aspirante verso il Maestro", per ciò che ha detto Allah, sia Egli esaltato, nei confronti dei Compagni dell'Inviato di Allah, che Allah faccia scendere su di lui la Sua salāt e la Pace ${ }^{(303)}$. Essi sono per lui, su di lui la Pace, a guisa degli aspiranti all'istruzione iniziatica per il Maestro, ed il Maestro è un erede, ed è come l'Inviato per essi, poiché fa parte di coloro che detengono il comando su colui che gli ha dato autorità su se stesso. Quindi è necessaria l'obbedienza a lui, come è necessaria l'obbedienza nell'insieme ad Allah ed al Suo Inviato, e non c'è possibilità di disputare con lui, né di controbattergli, né di interpretare in sua presenza. Ciò che il Profeta, che Allah faccia scendere su di lui la Sua șalāt e la Pace, esigeva dai Compagni riguardo alla fede in Allah ed in ciò che egli stesso apportava, lo esige

299) Le stesse considerazioni sono riportate nel Kitāb al-amr al-muhkam, a pag. 304 della traduzione di Asín Palacios già citata.

300) Hadīt riportato da Mālik, XLI-12. Nella traduzione di R. Tottoli è riportato a pag. 636.

301) Hadīt riportato da al-Buhārī, LXII-18, Muslim, XXIX-11, at-Tirmid̄ī, an-Nasā'̄̄, e da Ibn Ḥanbal.

302) Nel Cap. 370 [III 413.4] Ibn 'Arabī precisa: "Per questo ha detto: "e che non hanno paura del biasimo di chi rimprovera" (Cor. V-54): il diritto di Allah ha più diritto ad essere rispettato del diritto della creatura, quando essi [diritti] si riuniscono, poiché la creatura non ha diritto se non per la creazione di Allah. Se in un certo momento sono imposti entrambi i diritti, il servitore assistito (muwaffaq) [da Allah] comincia a soddisfare il diritto di Allah, che Gli spetta, poi si mette ad osservare il diritto della creatura, che Allah gli ha imposto".

303) La frase si riferisce ai versetti che verranno citati nel seguito del commento. 
il Maestro dai discepoli: la fede in ciò che egli comunica loro da Allah. Ed essi [i Compagni], Allah sia soddisfatto di loro, sono tra di loro come Allah, sia Egli esaltato, ha notificato, dicendo che essi sono: "misericordiosi tra di loro" (Cor. XLVIII-29), cioè gli uni hanno misericordia degli altri, "[e] desiderano da parte di Allah grazia e soddisfazione" (Cor. ibidem). Dotati [84] di compunzione (hušuc) e calma (sakina), essi stanno di fronte ad Allah, sia Egli esaltato, di fronte al Maestro, e gli uni di fronte agli altri, come è stato detto riguardo alle loro riunioni:

[immobili] come coloro che hanno un uccello sulla loro testa $\left({ }^{304}\right)$, non per timore di un torto, ma per timore reverenziale (hawf iğlāl) $\left.{ }^{305}\right)$

Non c'è persona di loro che non rispetti il suo compagno per il suo timore riverenziale (hayba) verso il suo Maestro, e lo riverisca per la venerazione verso il suo Maestro, e non lo scusi per un fallo, e se esso accade da lui per negligenza o interpretazione egli glielo fa notare, affinché receda da quella interpretazione, oppure menziona riguardo a quello un aspetto in cui vi è per lui un avvicinamento ad Allah, sia Egli esaltato, ed ha così luogo il vantaggio $(f \bar{a} \imath \dot{d} a)$ tra i due. E non c'è un aspirante tra questi che non vigili sugli stati del suo compagno per mezzo della sua presenza (hudūr) e della sua vigilanza (murāqaba) sulla sua anima nei suoi propositi improvvisi [quando sono espressi], poiché ad essi è stato ordinato di raccomandarsi a vicenda il vero, di raccomandarsi a vicenda la pazienza e di raccomandarsi a vicenda la clemenza $\left.{ }^{306}\right)$, ed essi sono i Compagni della destra $\left({ }^{307}\right)$, e per ciò questo Maestro ha fatto questa raccomandazione.

Ed ha detto: "devi rispettarlo e riverirlo con il massimo rispetto", cioè gli aspiranti del suo Maestro, e secondo me è necessario che si comporti così con tutti i servitori di Allah, poiché egli non sa quando [ad uno di loro] sopraggiunge la Misericordia di Allah ed è d'improvviso iscritto nell'`Illiyyūn ( $\left.{ }^{308}\right)$. Quindi fa parte dell'adab con Allah il rispetto verso i servitori di Allah, e [l'aspirante] non osserva la loro disobbedienza, che accade a loro di commettere, ma biasima le disobbedienze, non il disobbediente.

Quanto al suo detto, Allah sia soddisfatto di lui: "e devi trattarlo con riguardo (ikrām), poiché il riguardo verso l'aspirante è per via del Maestro e per l'ossequio di uno hai riguardo a mille", egli

304) Con questa espressione viene descritta l'attitudine dei Compagni di fronte al Profeta in uno hadīt riportato da al-Buhārī, LVI-37, Abū Dāwud, XXVII-1 e XXXIX-24, an-Nasā̄ī, Ibn Māğah, e da Ibn Ḥanbal. I lessicografi arabi spiegano questa espressione con il fatto che i cammelli, quando un corvo si pone sulla loro testa per nutrirsi degli insetti che ne infestano il pelo, restano immobili per evitare che volino via.

305) Gli stessi versi, sempre in riferimento al timore riverenziale (hayba), sono riportati da Ibn 'Arabi nei capitoli 8 [I 130.11], 73 [II 12.31], 73, questione CIX [II 105.17], 558 [IV 241.22] e 559 [IV 393.19] delle Futūhāt, e nel Kitāb al-amr al-muhkam, a pag. 319 della traduzione di Asín Palacios già citata.

306) Cfr. Cor. XC-17.

307) Cfr. Cor. XG-18.

308) Questo termine ricorre in Cor. LXXXIII-18, ove è precisato che si tratta del Libro ove sono iscritti i pii (abrār). 
dice che poiché il Maestro nei riguardi degli aspiranti prende il posto del Vero nei riguardi dei Suoi servitori, è necessario che essi si amino gli uni gli altri in Allah, cioè a causa di Allah, in quanto essi sono servitori di un solo signore e sono figli, per religione $(d \bar{\imath} n)$, di un solo padre, poiché Allah, sia Egli esaltato, ha detto: "La comunità (milla) di vostro padre Abramo" (Cor. XXII-78), chiamandolo padre dei musulmani, e riguardo ai credenti ha detto: "Invero i credenti sono fratelli" (Cor. XLIX-10) [85] e non c'è dubbio che i figli del padre sono fratelli gli uni degli altri, e quando c'è la fratellanza c'è la compassione (šafaqa) e la misericordia, e quando c'è la compassione e la misericordia c'è il buon consiglio (nașịha) ( $\left.{ }^{309}\right)$, e per questo l'Inviato di Allah, che Allah faccia scendere su di lui la Sua șalāt e la Pace, ha detto: "La religione $(d \bar{\imath} n)$ è il buon consiglio". Chiesero: "A chi, o Inviato di Allah?". Ed egli rispose: "Ad Allah, al Suo Inviato, agli Imām dei musulmani e alla loro gente" ${ }^{(310)}$. Non c'è dubbio che tutti i servitori di Allah sono sottomessi ad Allah, ma in modi diversi. Non vedi che gli associatori affermano riguardo ai loro Dei che essi li adorano solo perché li avvicinino ad Allah? $\left({ }^{311}\right)$ Essi quindi sottomettono loro stessi ad Allah, sia Egli esaltato, in un modo che non è gradito da Allah, ed è quindi necessario dare loro il buon consiglio affinché abbandonino quella via per seguire la via che la Legge ha prescritto loro. Non vedi quanto è bello l'insegnamento di Allah, sia Egli esaltato, ai Suoi servitori associatori nell'avvertirli del loro errore con il Suo detto, sia Egli esaltato: "Adorate ciò che voi avete fabbricato?" (Cor. XXXVII-95) ed il Suo detto: "Forse che chi crea è come colui che non crea?" (Cor. XVI-17), ed il Suo detto: "Dì: nominateli" (Cor. XIII-33)? E non è possibile che ci sia nella gentilezza nei loro confronti da parte di chi ha potere su di loro, nella cortesia (talattuf), nella bellezza del richiamo ad Allah, sia Egli esaltato, e nell'insegnamento, qualcosa di più bello di questa amabilità (lutf) divina nei loro confronti. E così si addice che si comporti la gente di Allah quanto alla misericordia con i servitori di Allah in modo incondizionato, ed a maggior ragione con coloro che sono credenti e con coloro di essi che si raggruppano al servizio di un sapiente in Allah.

309) Sul significato del termine "nașịha" si può consultare la prefazione alla traduzione del trattato dello Šayh at-Tādilī, La vie traditionnelle c'est la sincérité, Éditions Traditionnelles, Parigi, 1971. Dato il contesto ho adottato in questa traduzione il significato di "buon consiglio" e di "consigliare il bene", conforme al senso che hanno i termini derivati dalla stessa radice nella Sūra VII [versetti: 21, 62, 68, 79, 93], ove più frequentemente ricorrono nel Corano.

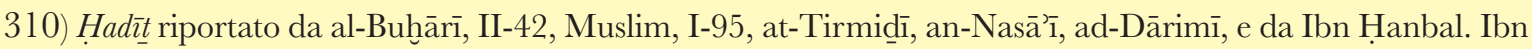
'Arabī riporta per esteso questo hadīt nel Cap. 560 [IV 468.27 e 547.6] e lo cita nei capitoli 71 [I 658.1], 76 [II 145.4], 290 [II 650.9] e 374 [III 467.23]. Nel Cap. 71 precisa anche che Allah gli ha ordinato più volte, senza intermediari, di dare il buon consiglio ai suoi servitori. A questo hadīt egli dedica un lungo commento nel Cap. 560 [IV 468.27 a 470.24], ove precisa: "Sappi che il "nișahh" è il filo, il "minsaha" è l'ago, il "nạsih" è il sarto ed il sarto è colui che mette insieme le parti del tessuto finché diventano una camicia o quello che sia, ed egli fa buon uso di esso mettendone insieme le parti, e non le mette insieme se non con la sua abilità nel cucire (nushh). Il "nāsih" nella religione di Allah è colui che ricongiunge i servitori di Allah con ciò in cui sta la loro felicità presso Allah, e che ricongiunge Allah con le Sue creature, il che corrisponde alla sua affermazione: "Il buon consiglio nei confronti di Allah"”

31 1) Cfr. Cor. XXXIX-3. Ho preferito tradurre mušrikūn come associatori e non come politeisti, perché il primo termine implica l'adorazione di altri Dei insieme ad Allah, mentre il secondo implica solo l'adorazione di molti Dei. 
Allah, sia Egli esaltato, dirà nel Giorno della Resurrezione: "Dove sono coloro che si amano gli uni gli altri per la Mia Maestà? Oggi farò loro ombra con la Mia ombra, in un giorno in cui non c'è altra ombra che la Mia" ( ${ }^{312}$ ), ed ha parlato dell'obbligo del Suo Amore per gente come loro, dicendo nella tradizione autentica: "Il Mio Amore è dovuto per coloro che si amano gli uni gli altri in Me, per coloro che danno generosamente gli uni agli altri in Me, e per coloro che siedono gli uni accanto agli altri in Me" ( $\left.{ }^{313}\right)$, ed ha imposto a Se stesso l'Amore per costoro e chi riceve l'Amore di Allah da Allah per via dell'obbligatorietà ha un rango più elevato di chi lo riceve per via del Favore (imtinān), poiché riunisce due Misericordie da parte di Allah $\left({ }^{314}\right)$, in quanto [86] per la Misericordia del Favore ama in Allah chi lo ama e per via di ciò che gli conferisce questa Misericordia di Favore è obbligatorio l'Amore di Allah per lui, e quindi riunisce le due Misericordie, ed ogni amante ama in Allah chi lo ama.

Egli ha attirato la tua attenzione su una cosa che ho gustato personalmente e che è raro trovare, e cioè che quando sei compagno di una persona o la ami in Allah e succede che questa persona ti detesti, o per una passione della sua anima ed un cattivo proposito che sussistono in lei e che ti rendono detestabile alla sua anima, oppure perché la coglie un sospetto riguardo a te che suscita l'avversione verso di te in Allah per ciò che le conferisce quel sospetto, tu devi restare nel tuo amore per lei in Allah e trattarla come fanno coloro che si amano vicendevolmente in Allah, e non considerare ciò che le è capitato riguardo a te, e sii tu il clemente con lei per la sua avversione. Se ti comporti in questo modo dai alla stazione ciò che le spetta $\left({ }^{315}\right)$; abbi quindi molta cura in una cosa simile e non avrà effetto

312) Hadīt riportato da Muslim, XLV-38, at-Tirmid̄ī, XXXIV-53, ad-Dārimī, Mālik, e da Ibn Ḥanbal. Ibn 'Arabī lo cita anche nel Cap. 560 [IV 534.34] e ne "La niche des lumières", pag. 34.

313) Hadīt riportato da Mālik, LI-16, e da Ibn Hanbal. Ibn 'Arabī lo cita anche nel Cap. 73 [II 21.11], nel Cap. 178 [II 344.5], nel Cap. 560 [IV 535.31] e ne "La niche des lumières", pag. 116.

314) Nel Cap. 392 [III 550.32] Ibn 'Arabī precisa: "Egli è Misericordioso (rahmān) per le due Misericordie: la generale ('āmma) che è la Misericordia del Favore, ed Egli è Clemente (rahīm) per la Misericordia specifica (hāssa), che è [quella] obbligatoria a cui si riferisce il Suo detto: "Ed Io la prescriverò per coloro che sono timorati" (Cor. VII-156) ed il Suo detto: "Il vostro Signore ha prescritto a Se stesso la Misericordia" (Cor. VI-54). Quanto alla Misericordia del Favore, Allah ha misericordia di colui che Egli assiste nell'opera buona che impone a Lui la Misericordia obbligatoria, e per mezzo di essa [Misericordia del Favore] il peccatore e la gente del Fuoco infernale ottengono la cessazione del castigo, anche se la loro situazione e la loro dimora è la Gehenna". Analoghe considerazioni si trovano nel Cap. 338 [III 147.34] e nel Cap. 558 [IV 200.6].

315) Nel Cap. 560 [IV 498.27] Ibn 'Arabī riporta: "Nell'anno 590, a Tlemsen, ho visto in sogno l'Inviato di Allah, che Allah faccia scendere su di lui la Sua salāt e la Pace; mi era giunta notizia che un uomo detestava lo Šayh Abū Madyan, che era uno dei più grandi conoscitori ('ârifün) ed io ero convinto di ciò per scienza certa, e provai avversione per quella persona in quanto detestava lo Šayh Abū Madyan. L'Inviato di Allah, che Allah faccia scendere su di lui la Sua șalät e la Pace, mi disse: "Perché detesti quell'uomo?", ed io gli risposi che era per la sua avversione nei confronti di Abū Madyan. Allora mi disse: "Non ama forse Allah e me?", ed io gli risposi: "Certamente, o Inviato di Allah, egli ama Allah, sia Egli esaltato, ed ama te". Allora mi disse: "Perché lo detesti per la sua avversione verso Abū Madyan e non lo ami invece per il suo amore nei confronti di Allah e del Suo Inviato?". Allora gli dissi: "O Inviato di Allah, fino a questo momento, per Allah, ho sbagliato e sono stato noncurante: ora io mi pento ed egli è per me la più amata delle persone ed invero tu hai messo in guardia ed hai 
sul tuo amore per lei in Allah ciò che è accaduto in lei dell'avversione verso di te in Allah secondo quanto ella pensa. Tu non hai visto di lei ciò che le ha determinato l'avversione per te in Allah, sii quindi cortese nel ristabilire il suo cuore verso di te, per una misericordia verso di lei, senza che se ne renda conto.

Poi questo Maestro ha detto: "e se sei in grado di fare la munificenza ( $m u$ 'āsāh), guardati dall'essere corto in quello, verso chiunque tu puoi, e specialmente verso gli aspiranti, e che il dare ciò che è necessario

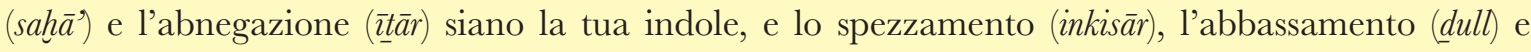
l'indigenza (maskana) siano costantemente la tua natura, o aspirante". Questa è una raccomandazione da parte sua ai suoi fratelli tra gli aspiranti e tra gli altri credenti affinché abbiano questa attitudine, e ciò corrisponde al Suo detto, sia Egli esaltato: "coloro che danno generosamente gli uni agli altri in Me". Guardati dall'astenerti dal dare quando potresti farlo, e che il tuo dare sia in proporzione al bisogno, ed in questo consiste il dare ciò che è necessario $\left(s a h \bar{a}^{9}\right)\left({ }^{316}\right)$. Quanto all'abnegazione (ītār) essa consiste nel dare ciò di cui tu pensi di avere bisogno nel futuro, malgrado sia superfluo per te [87] al momento $\left.{ }^{317}\right)$, e per questo Egli, sia Egli esaltato, ha detto: "ed essi prediligono [lui] a loro stessi anche

consigliato il bene: Allah preghi su di te". Quando mi svegliai presi con me un vestito molto caro ed una somma da elargire di cui non ricordo l'ammontare, montai a cavallo ed arrivato a casa sua lo informai di ciò che era accaduto. Egli si mise a piangere ed accettò il mio regalo, e prese il sogno come un ammonimento da parte di Allah, sia Egli esaltato, e svanì dalla sua anima la sua avversione verso Abū Madyan e lo amò. Volli conoscere la ragione della sua avversione verso Abū Madyan, malgrado dicesse che Abū Madyan era un uomo pio, e gliela chiesi. Egli mi rispose: "Ero con lui a Biğāya e gli vennero portate delle vittime della Festa del sacrificio, ed egli le divise tra i suoi compagni e non me ne diede neanche un pezzo: questo è il motivo della mia avversione per lui e della mia caduta".

316) Nel Cap. 70 [ [ 585.18] Ibn 'Arabī precisa: "Sappi che la ricchezza ammette i [diversi] modi del dare, i quali sono otto e ad ognuno corrisponde un nome. Essi sono: la beneficenza (in 'ām), il dono (hiba), l'elemosina (sadaqa), la generosità [che segue la richiesta] (karam), l'offerta (hadiyya), la generosità [che precede la richiesta] $(\underline{g} \bar{u} d)$, il dare ciò di cui c'è bisogno $\left(s a h \bar{a}^{\prime}\right)$ e l'abnegazione $(\bar{\imath} t \overline{a r})$ : l'uomo dà in tutti e otto i modi, mentre il Vero, sia Egli esaltato, dà in sette di essi, facendo eccezione dell'ultimo". Nel Cap. 95 [II 179.16] aggiunge: "È stato riportato nello hadīt di Abū Bakr an-Naqqāš, riguardo ai luoghi di sosta della Resurrezione, il Nome "Colui che dà nella misura del necessario (as-sahñ "), hadīi che è stato citato in questo libro nel capitolo dedicato al Paradiso [Cap. 65]. Quanto al dare proprio di questo tipo di generosità, esso è il dare nella misura del necessario e questo è il dare della saggezza (hikma) e deriva dal Suo Nome "il Saggio". Da parte del Vero questa generosità è quella a cui si riferisce il detto di Mosè: "Il nostro Signore è Colui che dà ad ogni cosa la sua creazione" (Cor. XX-50); "Ogni cosa è presso di Lui secondo una misura" (Cor. XIII-8); "Se Allah largheggiasse nella provvista ai Suoi servitori, essi insolentirebbero sulla Terra, ma Egli [ne fa] scendere nella misura che Egli vuole" (Cor. XLII-27); "E non la facciamo scendere se non con una misura nota" (Cor. XV-21). Quanto a questa generosità da parte del servitore, essa consiste nel suo dare ciò che è dovuto a chi ne ha diritto, e nella sua equità. "La sua anima ha un diritto su di lui, la sua famiglia ha un diritto su di lui, il suo occhio ha un diritto su di lui, e la sua gola ha un diritto su di lui" (hadīt)". A questo aspetto della generosità è dedicato anche una sezione del Cap. 558 [IV 263.22].

317) Nel Cap. 95 [II 179.21] Ibn 'Arabī precisa: "Quanto all'abnegazione [o altruismo], il Vero non ha un Attributo che le corrisponda se non per un aspetto remoto, e menzionarla è una mancanza di adab, anzi essa non è una realtà essenziale ed abbandonarla è preferibile. Essa non è sostenuta se non da coloro che non 
se li portasse in ristrettezza (hașạsa)" (Cor. LIX-9). Questa è l'indicazione nell'ipotesi in cui abbia luogo la ristrettezza, ma se la ristrettezza c'è in egual modo [in entrambe le parti], allora il diritto (haqq) della tua anima su di te è predominante per Allah, e lo stesso per il [diritto del] più vicino (aqrab), cioè il più vicino per condizione ( $h \bar{a} l)$ come la moglie, per lignaggio (nasab) come il figlio, per dimora come il vicino di casa e per attribuzione (nisba) come lo schiavo (mamlük). Questa è l'istruzione (tarbiya) data dal Vero, sia Egli esaltato, tramite la lingua del Suo Inviato, che Allah faccia scendere su di lui la Sua șalāt e la Pace, riguardo all'osservanza dei diritti in proposito $\left({ }^{318}\right)$. Chiunque [nel dare] trasgredisce ciò che il Vero gli ha imposto riguardo all'osservanza dei diritti, la sua è una munificenza (mu'assâ) di desiderio e di interesse personale, non [fatta] per Allah. Chi fa la beneficenza stia all'erta da questo equivoco (uglüta), ed al riguardo non c'è bisogno di interpretazione ( $\left.t a^{\prime} w \bar{\imath} t\right)$, poiché inevitabilmente egli vedrà il risultato (gibb) di ciò che ha fatto, e questo [stare all'erta] non è possibile se non a chi teme Allah nei suoi stati e nelle sue disposizioni.

Poi il suo detto riguardo allo spezzamento (inkisār), all'abbassamento (dull) ed alla indigenza (maskana) ti mostra molti insegnamenti utili, poiché colui che dà prova sempre nella sua anima un senso di superiorità ('izza) rispetto a colui a cui dà, e questa è la cosa più nociva che possa capitare al servitore. Quindi [colui che dà] deve adoperarsi per far arrivare ciò che dà a chi lo riceve senza sapere, da parte sua, che egli ha dato qualcosa [di suo] al ricevente.

Gli espedienti (hiyal) per quello sono molti e noi li abbiamo usati spesso. La scienza di Allah che aiuta colui che dà è che egli dica a se stesso: "Se ciò che hai scelto e dato in munificenza ad un altro fosse il tuo sostentamento (rizq), a te destinato, non avresti potuto togliertelo né darlo, e se non ti appartiene, nella valutazione di Allah e nella Sua spartizione delle cose, allora sai che ciò è un deposito (amāna) che detieni e ti è stato ordinato di rendere il deposito al suo legittimo possessore. Ciò che hai dato non ti appartiene, ed invero hai dato ciò che Allah ti ha affidato per lui, e se hai una ricompensa (ağr), essa non è che [88] la ricompensa dell'aver reso il deposito. Non pensare quindi con questo di avere una superiorità (maziyya) né una eccellenza su di lui per ciò che gli fai avere, poiché ciò che gli fai avere, secondo la scienza autentica, non è che il suo, non il tuo". Questo è un rimedio efficace: se lo adotti non penserai di avere una eccellenza su qualcuno.

Se colui che prende da te è come te riguardo a questa considerazione, allora non preoccuparti del tuo farglielo avere, sia in segreto che pubblicamente. Se egli invece non ha questo grado, tu sai per certo che la sua anima altèra è affranta quando egli prende da te, e ritiene che tu abbia una eccellenza su di lui: fai in modo dunque di fargli avere quello da parte tua senza che egli provi spezzamento per ciò,

hanno scienza tra la gente della locuzione teopatica (šath). Diciamo dunque che talora l'abnegazione è il dare di un bisognoso (muhtăğ) ad un [altro] bisognoso, talora è il dare per la ristrettezza (hasạasa) [altrui] malgrado la ristrettezza [propria] o la supposizione della ristrettezza".

318) Riferimento ad uno hadīt riportato da al-Buhārī, XIX-20, XXX-51, 54 e 55, LXVII-89, LXXXVIII-84 e 86, Muslim, XIII-182 e 187, Abū Dāwud, V-27, XIV-56, che inizia con l'affermazione: "Invero la tua anima ha un diritto su di te", a cui segue l'elenco, con diverse varianti, degli altri esseri che hanno diritto su di noi. 
né abbassamento in quello, e gli aspetti sono molteplici $\left({ }^{319}\right)$.

Quanto al suo detto: "e così la tristezza (huzn)", egli dice: la tristezza sia costantemente il tuo carattere distintivo $\left({ }_{s i}{ }^{c} \bar{a} r\right)$. Essa consiste nel tuo considerare ciò che ti è sfuggito $\left({ }^{320}\right)$ e tu [devi] riparare ciò che ti è sfuggito; essa, cioè la tristezza, è come una compensazione (diya) ${ }^{321}$ ) nascosta, poiché la tristezza è connessa con ciò che ti è sfuggito. Tu la ottieni [la riparazione] per mezzo della tristezza, così come la ottieni per mezzo dell'intenzione (niyya), e non c'è via ad essa, cioè di ottenerla, se non tramite una di queste due cose, la tristezza e l'intenzione.

Quanto al suo detto: "e sii saldo (šadīd) in tutto ciò che [ti] ho menzionato, dotato di forte fermezza in tutto quello", sappi che Allah, sia Egli esaltato, ha dato ordine al Suo servitore, dicendo: "Ed abbi pazienza come ebbero pazienza i dotati di fermezza ('azm) tra gli Inviati“ (Cor. XLVI-35) ( ${ }^{322}$ ), ed i dotati di fermezza sono i più saldi nella religione di Allah, come Abū Bakr nella sua fede riguardo

319) Nel Cap. 70 [I 579.24] Ibn 'Arabī precisa: "Sappi che fare la șadaqa di nascosto è un requisito per l'ottenimento della elevata stazione spirituale con cui Allah ha caratterizzato i sette Sostituti $(a b d \bar{a} l)$. La forma del farla di nascosto ha diversi aspetti. Uno di essi è che colui a cui tu hai fatto l'elemosina non ti conosca, e tu gliela faccia pervenire con circospezione in qualsiasi aspetto sia, poiché gli aspetti sono molti. Uno di essi è quello di fargli sapere come prende [la șadaqa], cioè che egli la prende da Allah, non da te, sì che egli non ti attribuisca alcun merito nei suoi confronti per ciò che gli hai dato, e non gli si imponga, di fronte a te, alcuna traccia di umiltà o indigenza: egli consegue così una scienza magnificente di Colui che gli ha elargito. Tu quindi resti nascosto alla sua vista al momento in cui gli dai, avendolo inoltre convinto che egli non prende se non ciò che gli appartiene. Ciò fa parte del nascondere la sadaqa. Un'altra modalità è quella di nascondere che si tratta di una sadaqa, e colui che riceve la sadaqa non è noto a chi la fa. Quando dunque la prende l'esattore incaricato dal Sultano, la prende da te con forza e coercizione, e quando essa arriva nelle mani del Sultano, che è il depositario di essa di fronte ad Allah, il Sultano la dà alle otto [categorie] di proprietari [finali]. Ed i proprietari la prendono con amor proprio e non con umiltà, poiché quello è un loro diritto di fronte a questo depositario. Quindi chi prende non sa, nel suo riceverla, chi sia il proprietario [iniziale] di quel bene. Quindi non c'è favore né onore da parte del ricco proprietario del bene verso questo povero, ed egli non sa neppure se veramente gli è arrivato il suo stesso bene. Anche questo fa parte del tener nascosta la sadaqa, in quanto colui che fa l'elemosina non sa a chi l'ha fatta, e colui che prende l'elemosina non sa chi l'ha data. Nel tener nascosto non c'è grado superiore a questo".

320) Nel Cap. 104, dedicato alla tristezza, Ibn 'Arabī precisa [II 186.28]: "Il termine tristezza (huzn) è derivato da al-hazn, che è il terreno aspro e duro, e la rudezza (huzūna) nell'uomo è la rudezza dei suoi tratti di carattere. La tristezza non riguarda se non ciò che è trascorso [o: sfuggito], e ciò che è trascorso e passato non ritorna; ritorna però il simile [nella forma] e quando ritorna ricorda se stesso a colui in cui è sussistito il suo simile che è passato e trascorso, e questo ricordo provoca tristezza nel cuore del servitore, soprattutto in chi cerca di rispettare gli attimi (anfās), il che è difficile da conseguire se non per la gente della contemplazione diretta tra gli iniziati. L'immensità del possibile non consente l'ottenimento di tutta la faccenda, per cui è inevitabile che qualcosa sfugga, e quindi è inevitabile la tristezza".

321) Il termine diy $\bar{a}$, nel linguaggio giuridico, è il prezzo del sangue, cioè la compensazione pecuniaria dovuta alla famiglia della vittima, da parte di chi ha commesso involontariamente un omicidio.

322) Secondo uno hadīt riportato nel Kitāa al-kẩ $\bar{\imath}$ di al-Kulaynī, gli Inviati dotati di fermezza furono Noè, Abramo, Mosè, Gesù e Muhammad. 
alla pace di al-Hudaybiyya ${ }^{323}$ ). Allah non aveva messo alla prova (ihtabara) la fede dei credenti più di quanto avesse messo alla prova lui riguardo a quella pace, al punto che in quel giorno la fede di 'Umar fu scossa, a dispetto della sua saldezza (salāba) nella sua religione - e da quel giorno noi sappiamo che la sua saldezza era naturale (tabī iyya) ${ }^{\left({ }^{324}\right)}$ - poi credette e impiegò la sua saldezza nella sua fede. Quando la sua fede fu turbata da questa persona specifica $\left({ }^{325}\right)$ la saldezza era rimasta in lui come prima [cioè basata sulla natura], ed egli disse [al Profeta, su di lui la Pace]: "Concediamo il disonore [89] nella nostra religione? Non siamo noi nel vero ed essi nel falso?” $\left.{ }^{326}\right)$.

Se non fosse che Allah fu gentile con lui tramite Abū Bakr in ciò che egli gli rammentò, dicendo le stesse cose che [aveva detto] l'Inviato di Allah, che Allah faccia scendere su di lui la Sua șalāt e la Pace [non avrebbe creduto e si sarebbe comportato come gli altri Compagni] ( $\left.{ }^{327}\right)$. Quanto ai Compagni essi erano sul punto di morire di rabbia quando in quella [occasione] ordinò loro di uscire dal loro stato di sacralizzazione (ihrām) $\left.{ }^{328}\right)$, mentre Abū Bakr non era provato, per la saldezza della sua fede, per la sua forza e per il suo dominio sulla sua natura.

Considera il Suo detto, sia Egli esaltato: "No, per il tuo Signore, essi non crederanno finché non ti avranno costituito giudice delle loro discordie ed allora non troveranno nelle loro anime alcuna difficoltà ad accettare la tua decisione e si sottometteranno fiduciosi” (Cor. IV-65). L'Inviato di Allah, che Allah faccia scendere su di lui la Sua salāt e la Pace, decretò ciò che decretò nella pace di al-Hudaybiyya, poi fissò il testo in quella riunione e disse: "E per Allah, essi non chiederanno

323) Al-Hudaybiyya è un piccolo villaggio situato ad un giorno di marcia a nord della Mecca, fuori dal territorio sacro (harām); in questo luogo, il sesto giorno di $\underline{D} \bar{u}$ l-Qa'da dell'anno 6 dall'Egira, il Profeta sottoscrisse un trattato con i Qurayshiti, le cui principali disposizioni erano le seguenti: nell'immediato i musulmani dovevano ritirarsi senza entrare nel territorio sacro, ma l'anno seguente la Mecca sarebbe stata evacuata per tre giorni per permettere ai musulmani di compiere la 'umra; per 10 anni vigeva l'armistizio tra le due parti; il Profeta doveva rinviare alla Mecca tutti i Qurayshiti che erano venuti da lui senza l'autorizzazione del loro protettore; fatta eccezione per i Quraysh, ogni individuo era libero di unirsi ad una delle due parti. I musulmani, che erano venuti con l'intenzione di compiere la 'umra, furono molto delusi da questo trattato, che ritennero troppo favorevole ai Quraysh, ma a sostegno delle decisioni del Profeta, vennero rivelati i primi versetti della Sūra XLVIII, che definivano il trattato come una "chiara vittoria" concessa da Allah. Tra i più turbati nella fede fu 'Umar, mentre Abū Bakr non ebbe alcun dubbio sulle decisioni prese dal Profeta.

324) Ibn 'Arabì distingue qui la saldezza nella religione che trae origine dalla natura, come la saldezza di 'Umar, da quella che trae origine dalla fede, come la saldezza di Abū Bakr.

325) Il riferimento può essere a Suhayl, che dettò le condizioni dei Quraysh nel trattato, o a suo figlio Abū Ğandal, che convertitosi all'Islām contro il volere del padre si era rifugiato dai musulmani, ma che in base alla terza delle clausole citate del trattato dovette essere restituito ai Quraysh.

326) Hadīt riportato da al-Buhārī, LIV-15, LVIII-18, Muslim, XXXII-94, e da Ibn Ḥanbal.

327) I manoscritti risultano qui incompleti, poiché non è indicata la conseguenza dell'ipotesi.

328) Il Profeta ordinò ai Compagni di radersi la testa, segno della fine della 'umra, ma nessuno gli obbedì finché egli stesso non dette l'esempio radendosi la testa. 
una condizione (hutta) in cui vi sia la soddisfazione di Allah senza che io non la conceda loro" $\left({ }^{329}\right)$. Da questa [affermazione] riguardo al suo accoglimento (iğăba) [delle richieste dei Quraysh], che i Compagni disconoscevano, sappiamo che esse facevano parte di ciò di cui Allah era soddisfatto, e non c'era nessuno di loro che non trovasse difficoltà per ciò che egli aveva decretato nel suo accoglimento, ad eccezione di Abū Bakr il confessore (siddīq): non c'è dubbio che la sua fede compensava la fede di tutta la comunità ed egli prevaleva su di loro per essa.

Per la lode di Allah, mi è stata data questa fede nell'Inviato e nei suoi eredi, Allah sia soddisfatto di loro, propria di Abū Bakr il confessore, tanto che io non sostengo la loro impeccabilità ('isma) se non in ciò che essi trasmettono da parte di Allah, e anche se essi commettessero tutte le disobbedienze ed i peccati gravi (kabā'ir), nulla di quello sminuirebbe la mia fede in loro $\left.{ }^{(330}\right)$. E anche se sapessi che i peccati che essi commettono sono peccati gravi presso Allah, e che essi li hanno commessi sapendo che lo sono, ciò non diminuirebbe per me e nel mio cuore la mia fede in loro del peso di un atomo, né di più di quello, sia lode ad Allah per ciò. E se essi sono protetti da una cosa simile, ciò spetta ad Allah.

Questa è una questione in cui vi sono molte distinzioni [da fare] e la sua spiegazione è lunga, poiché il credente non va al di là, in questo caso, di ciò che comporta la prova [90] razionale, e la prova razionale non comporta riguardo a costoro se non l'impeccabilità dalla menzogna riguardo alla trasmissione specifica da parte di Allah: al di fuori di ciò, tutto il resto è possibile che accada da parte loro, a meno che essi non affermino testualmente quello [cioè l’impeccabilità al di fuori della trasmissione] per mezzo di una rivelazione da parte di Allah a loro, poiché essi non sanno ciò che c'è nella Scienza di Allah al loro riguardo.

È così che deve essere la fede e per questo il Profeta, che Allah faccia scendere su di lui la Sua salāt e la Pace, disse ai suoi Compagni riguardo al suo divieto di fecondare la palma: "Ciò che vi comunico da parte di Allah, prendetelo [come vero], per il resto voi ne sapete di più sulle faccende di questo vostro mondo" $\left({ }^{331}\right)$.

Se sei sagace e dotato di attenzione, allora sai già ciò che l'Inviato di Allah, che Allah faccia scendere su di lui la Sua salāt e la Pace, ha voluto dire in questa notificazione, e sai ciò a cui ho alluso in quanto ho menzionato.

329) Hadīt non recensito nelle raccolte canoniche. Una versione leggermente diversa si trova in A. Guillaume, "The Life of Muhammad" [traduzione della Sīra di Ibn Ishāq], Oxford University Press 1970, a pag. 501.

330) A pagina 36 e 60 del manoscritto Ibn 'Arabī ha affermato l'impeccabilità dei Profeti, ma ha anche precisato che dopo Muhammad, il sigillo della Profezia, tale impeccabilità non è più garantita ai loro eredi spirituali, ed è di questi che egli sta parlando.

331) Hadīt riportato da Muslim, XLIII-141, e da Ibn Hanbal. La prima parte richiama il versetto Cor. LIX-7, la seconda è citata nel Cap. 12 [I 144.31] e nel Cap. 69 [I 523.4] delle Futūhāt e nel Cap. XXV dei Fusūssal-ḥikam. 
Quanto al suo detto: "Sappi che ogni volta che il cuore del Maestro è con te, nessuno può assolutamente farti del male, e se il cuore del Maestro ti abbandona, Allah ci protegga, diventi abietto (hasīs) tra gli uomini come colui che è bandito (matrūd) da un posto ad un altro, Allah ci protegga", il significato della sua espressione "sappi (ta lam)" è "asserisci (taqtac)" e "afferma con certezza (tağzim)", così come colui che sa la cosa la asserisce con decisione, e ciò fa parte della sua indicazione riguardo alla aspirazione (himma), in quanto egli sa che le aspirazioni delle anime hanno effetto sui corpi del mondo ${ }^{(332)}$. Questa è una questione molto importante, su cui egli ha posto l'attenzione per gusto spirituale da parte sua, e per questo ha asserito con decisione, e se non avesse gustato [ciò che affermava] non avrebbe asserito. Egli ha parlato quindi per il suo stato spirituale ed ha parlato anche per come la realtà è in se stessa.

Quanto al suo detto: “diventi abietto tra gli uomini”, per gli uomini egli intende i tuoi simili tra gli aspiranti e la gente della Via, e l'abiezione con cui ti ha caratterizzato presso di loro significa che tu non hai valore ( $q a d r$ ) nei loro cuori ed hai perso la loro stima, e chi perde la stima della gente di Allah ha perso la stima di Allah (saqata min 'ayni-Llāhi). Guardati dunque dal contrastare la gente di Allah!

Abū Yazīd stava mangiando del cibo e disse ad uno degli aspiranti: "Mangia con noi!", e l'aspirante rispose: "Sto digiunando!" ( $\left.{ }^{333}\right)$, ed Abū Yazīd disse: "Mangia con noi ed avrai la ricompensa del tuo giorno [di digiuno]!", ed egli rispose: "Sto digiunando!", al che Abū Yazīd disse: "Mangia [91] ed avrai la ricompensa di dieci giorni!", ed egli ribadì: "Sto digiunando!". Abū Yazīd disse allora al gruppo: "Lasciatelo perdere!". Egli perse la stima di Allah perché per questo atto aveva perso la stima di Abū Yazīd, ed aveva gettato via con lui la Via di Allah. Dopo quell'episodio si vide quella persona, che era ormai un vecchio attempato, affrontare le ragazze in strada e toccarle (yagmizu) ${ }^{(334)}$.

Quanto a me, andai a trovare il nostro maestro Abū al-Ḥusayn Yahyā ibn as-Ṣā'ig $\left.{ }^{335}\right)$ a Ceuta; egli stava mangiando del cibo ed io stavo male, e mangiare quel cibo avrebbe aumentato quel malessere, ed inoltre stavo digiunando. Egli mi disse: "Mangia con noi!" ed io gli menzionai il mio digiuno ed il mio malessere e che mangiare quel cibo avrebbe aumentato il malessere, ed egli riprese a dire: "Mangia con noi!", ed io risposi: "Dopo averti fatto sapere [del mio stato], giacché ti sono dovuti

332) Come già riportato, nel Cap. 229 [II 526.26] Ibn 'Arabī precisa: "Quanto alla himma della volontà essa è l'inizio della veridicità (sidq) dell'aspirante ed è una himma concentrata a cui nulla resiste: questa himma si trova molto in un gruppo chiamato in Africa gli 'Azābiyya, che per mezzo di essa uccidono coloro che vogliono. L'anima, quando si concentra, ha un'influenza sui corpi del mondo e sulle sue condizioni a cui nulla può contrapporsi".

333) Poiché il Maestro non digiunava, non si trattava di un digiuno obbligatorio, bensì di un digiuno supererogatorio o di compensazione.

334) L'episodio è riportato da al-Qušayrī nella sua Risāla, pag. 341 della traduzione di Alexander Knysh.

335) Questo Maestro è citato nel Cap. 560 [IV 489.20] ed a lui è dedicata anche una breve notizia nella Epistola dello Spirito di Santità (risāla rūh al-quds); cfr. Ibn 'Arabī, Sufis of Andalusia, Allen \& Unwin, Londra, 1971, pag. 136. 
l'ascolto e l'obbedienza". Mangiai ed il malessere scomparve immediatamente al primo boccone, e vidi che quello dipendeva dalla baraka del mio ascolto e della mia obbedienza al Maestro e dalla mia considerazione del Maestro con magnificazione $\left(\mathrm{ta}^{\mathrm{Z}} z \bar{\imath} \mathrm{m}\right)$ e riverenza. E così di tutti i Maestri che incontrai e degli aspiranti sinceri nessuno mi disconobbe, e non ho mai servito un Maestro senza che egli fosse al mio servizio per qualcosa che egli non possedeva, che Allah gli fece conoscere grazie a me $\left.{ }^{336}\right)$. Così era il mio stato con i Maestri, e non ho visto motivo per ciò se non la mia obbedienza, il mio prestar fede (tas $\bar{\imath} q)$ a tutto ciò che essi avevano realizzato, la mia accettazione (tastīm) di ciò che essi apportavano e dello stato in cui si trovavano, e la mia astensione ( $\underline{d} a b b)$ dal controbattere loro. Vidi in sogno, ed Allah è più Sapiente, l'Inviato di Allah, che Allah faccia scendere su di lui la Sua salāt e la Pace, o uno degli impeccabili, che mi disse: "Sai come hai fatto ad ottenere ciò che hai ottenuto da Allah?"; io gli risposi di no ed egli disse: "Per la tua venerazione di chi afferma di far parte della gente di Allah, indipendentemente dal fatto che ciò che afferma sia vero o meno, ed Allah lo ha tenuto in considerazione per te e lo ha elogiato da parte tua, e ti ha dato ciò che tu sai". Da quel momento spero che [92] Allah, sia Egli esaltato, mi faccia erede del Suo Profeta $\left.{ }^{(337}\right)$ in ciò che gli ha elargito generosamente nella Sūra: "Noi ti abbiamo accordato una chiara apertura affinché Allah ti perdoni il tuo peccato di prima e di poi" ( ${ }^{338}$ ) (Cor. XLVIII-1 e 2) fino al suo detto: "e al crepuscolo" (Cor. XLVIII-9), anzi, fino al versetto: “costui riceverà una ricompensa immensa" (Cor. XLVIII-10) (339).

336) Ad esempio, nel Cap. 71 [I 616.20], Ibn 'Arabī ricorda il "Maestro Abū Ya'qūb Yūsuf ibn Yaḩlaf alKūmī. Egli fu l'unico dei miei Maestri che mi abbia inculcato la disciplina iniziatica (riyāda); egli mi ha aiutato nella disciplina iniziatica ed io l'ho aiutato nei suoi stati enstatici (mawāğg̀d). Per me egli era sia istruttore spirituale (ustād $)$ che discepolo ed io ero lo stesso per lui; la gente si stupiva e nessuno capiva la ragione di ciò. Questo successe nell'anno 586 [dall'Egira]; l'apertura spirituale ( $f$ ath $)$ nel mio caso aveva preceduto la disciplina iniziatica, e questa è una stazione spirituale di pericolo (hatar). Allah mi fece ottenere la disciplina tramite quel Maestro, che Allah lo ricompensi da parte mia con tutto il bene".

337) All'epoca in cui scrisse queste righe erano già passati trent'anni da quando Ibn 'Arabī aveva ricevuto l'investitura come erede del Profeta [cfr. Claude Addas, Ibn 'Arabĩ ou la quête du soufre rouge, Gallimard, 1989, pag. 238-242], per cui la speranza riguarda in particolare l'eredità contenuta nei primi dieci versetti della Sūra della Vittoria.

338) Nel Cap. 560 [IV 491.32] Ibn 'Arabī precisa: "Il perdono non ha altra connessione che con il fatto che Egli ti protegga dal peccato o ti protegga dal suo castigo. Allah, Gloria a Lui, ha detto al Suo Profeta, Allah faccia scendere su di lui la Sua șalāt e la Pace: "Affinché Allah ti perdoni i tuoi peccati passati e futuri" (Cor. XLVIII-2): quindi per ciò che è passato non sarai punito e per ciò che è futuro esso non ti colpirà. Questa è una notificazione da parte di Allah dell'impeccabilità del Profeta, Allah faccia scendere su di lui la Sua salāt e la Pace" e nel Cap. 73, questione CLV [II 138.22] aggiunge che proprio per questa sua impeccabilità egli non può essere soggetto a perdono e che il discorso, anche se rivolto a lui, è in realtà indirizzato alla sua comunità, che si estende da tutti gli uomini da Adamo fino a lui [i peccati "passati"] a tutti gli uomini da lui fino al Giorno della Resurrezione [i peccati "futuri”].

339) La Sūra della Vittoria o dell'Apertura (fath) è costituita da 560 parole; 560 erano gli anni trascorsi dall'Egira al momento in cui nacque Ibn 'Arabī e 560 sono i capitoli della sua opera maggiore, intitolata in alcuni manoscritti "Kitāb al-fath al-makk $\vec{\imath}$ ". Vi è certamente una stretta relazione tra Ibn 'Arabī e questa Sūra, i cui primi dieci versetti contengono riferimenti al patto iniziatico, alla Pace spirituale (sakinna), all'impeccabilità ('isma) ed alla apertura spirituale. 
E non ho visto nessuno che abbia ottenuto questo, né qualcosa di prossimo ad esso, se non il nostro compagno Sulaymān ad-Dunbulī; lo incontrai più volte a Damasco ed egli mi disse: "Fratello mio, da 50 anni Allah non mi suscita un proposito (hātir) di male, né me lo suggerisce la mia anima” ${ }^{340}$ ). Questa è tra le cose più strabilianti che abbia sentito, poiché la protezione (hifz) [divina] non implica se non la preservazione dalla manifestazione esteriore [del male], anche se l'anima lo suggerisce, mentre questo è molto di più, in quanto Allah ha preservato la sua anima dalla proiezione (ilq $\left.\bar{a}^{\prime}\right)$ di Satana in lui $\left({ }^{341}\right)$. Le cose biasimevoli, riprovevoli e vietate vengono dalla proiezione di Satana, il loro opposto dalla proiezione dell'Angelo, le cose lecite dalla proiezione dell'anima in se stessa, e se essa ordina il male ciò deriva dalla proiezione di Satana in essa e non da se stessa ${ }^{342}$ ), e l'apertura (fath) nelle conoscenze per gusto spirituale viene da Allah, e queste quattro [classi di propositi (hawätir) o di proiezioni], a cui non se ne aggiunge una quinta, ciascuno le trova [o prova (yağidu)] da se stesso.

Quanto al suo detto: "e sappi che quando il cuore del tuo Maestro è con te, anche se la gente del Cielo e della Terra si mettessero insieme per farti del male, non vi riuscirebbero, poiché ogni volta che il cuore del Maestro è con te, Allah è con te", questo richiama la tua attenzione sullo stato spirituale del

340) Ibn 'Arabī incontrò Salmān o Sulaymān ad-Dunbulī, di origine probabilmente curda in quanto Dunbulī o Dumbulì è il nome di una tribù curda del Daylām, quando ormai risiedeva a Damasco, e quindi non lo ha menzionato nell'Epistola dello Spirito di Santità, in cui riporta aneddoti riguardanti i Maestri da lui conosciuti in Occidente. Nel Cap. 560 [IV 491.34] racconta infatti: "Sulaymān ad-Dunbulī - un servitore pio, per ciò che ho visto, che piangeva molto e che aveva familiarità (uns) con Allah - mentre ero seduto con lui nella Moschea [degli Umayyadi] di Damasco, nella loggia (maqșüra) di ad-Dawla'ī presso la zāuriza di 'A'iša, e stavamo parlando insieme, mi disse: "Fratello mio, per Allah, da più di 50 anni la mia anima non ha mai pensato ad una disobbedienza: sia lode ad Allah per questo!". Nel Cap. 422 [IV 35.3] Ibn 'Arabī precisa inoltre: "Non è nel potere dell'uomo impedire l'accesso al suo cuore ai propositi improvvisi (hawātir), e quando il Vero fa sì che non gli si presenti alcun proposito cattivo quegli è colui che è impeccabile [...] Ho visto chi aveva questo attributo nella persona di Sulaymān ad-Dunbulī, Allah abbia Misericordia di lui; egli era sul passo (qadam) di Abū Yazīd al-Bistāmī"; l'espressione "Allah abbia Misericordia di lui" si usa per i defunti, per cui ad-Dunbulī dovette morire prima del completamento, nell'anno 629 dall'Egira, della prima redazione delle Futūhāt. Egli è inoltre menzionato nei Cap. 397 [III 560.27], 444 [IV 58.6] e 449 [IV 64.11].

341) Questo tipo di preservazione o impeccabilità ('isma) è propria dei Profeti e degli Inviati, mentre la protezione (hifz) è caratteristica degli Intimi (awliyā'). Nel Cap. 72 [I 666.20], Ibn 'Arabī precisa: "Secondo questa forma quadrangolare $\left(m u r a b b a^{c}\right)$ sono costituiti i cuori dei credenti, ad esclusione degli Inviati e dei Profeti impeccabili. Questa impeccabilità ('ișma) che Allah ha loro accordato e della quale li ha investiti ha precisamente lo scopo di distinguerli dal resto dei credenti; un Profeta non conosce infatti che tre tipi di propositi: divini, angelici e psichici. La stessa cosa succede per alcuni Intimi che posseggono una porzione abbondante della Profezia, come Sulaymān ad-Dunbulī - che ho incontrato personalmente - che è tra coloro che hanno questo stato spirituale. Egli mi informò che da più di cinquanta anni non si presentava a lui un proposito detestabile, mentre la maggior parte degli Intimi ha questi propositi. Essi hanno in più [rispetto ai Profeti] il proposito satanico iracheno; in alcuni di loro il regime [di questo proposito] si manifesta esteriormente, ed essi sono [come] la maggioranza delle creature, in altri il proposito si presenta ma non ha alcun effetto esteriore, ed essi sono coloro che sono protetti (mahfüzūn) tra i Suoi Intimi”.

342) Ibn 'Arabī ritornerà su questo tema a pag. 232 del manoscritto, commentando il versetto: "Certo l'anima ordina il male" (Cor. XII-53). 
Maestro e sulla sua protezione nei tuoi confronti, poiché i cuori dei Maestri, Allah sia soddisfatto di loro, non sono con te se non per l'ordine di Allah: essi infatti sono dotati di una autorizzazione (idn) divina e per questo egli ha detto "Allah è con te", e vi sono notificazioni divine autentiche, trasmesse tramite la lingua dell'Inviato di Allah, che Allah faccia scendere su di lui la Sua șalāt e la Pace, che corroborano ciò $\left.{ }^{343}\right)$.

Poi ha detto: "ed ogni fermo proposito ('azm) che ti venga, o una immaginazione (haya $\bar{l}$ ) che ti si presenti, soppesalo con la bilancia della Legge: se trovi che esso è conforme alle norme della Legge [93] e degli stati degli aspiranti, si tratta di una ispirazione (ilhām), accoglilo dunque con accettazione; se invece contrasta con esse supplica il Maestro di farlo cessare".

Questa raccomandazione riguarda la gente di Allah, non l'aspirante all'istruzione iniziatica, poiché l'aspirante all'istruzione iniziatica non possiede la bilancia della Legge, e quindi quello riguarda il Maestro che lo istruisce; e se egli è un aspirante all'istruzione iniziatica, è suo dovere presentare il suo proposito o la sua immaginazione specificamente al Maestro, ed il Maestro la considererà in base a ciò che egli sa da parte di Allah al riguardo.

Quanto al suo detto nei confronti di chi è solo con se stesso, senza il Maestro, riguardo a ciò che egli si propone fermamente o ad una immaginazione che gli si presenta, egli non intende con la bilancia della Legge il fatto che egli sappia quale è il giudizio della Legge riguardo a ciò, poiché non di tutto ciò che gli accade egli sa quale è il giudizio della Legge al riguardo, soprattutto quel genere di persone, poiché il loro essere occupati con Allah impedisce loro di studiare le notificazioni ed i giudizi profetici, e di queste non apprendono se non ciò con cui Allah li asservisce (táabbada) nelle loro manifestazioni esteriori e specialmente nell'apparenza della loro interiorità (zāhir bawātini-him).

Questo Maestro intendeva qui con la bilancia solo ciò che voleva dire al-Ğunayd con il suo detto: "Questa nostra scienza è costruita (mušayyad) con il Libro e con la Sunna" (344), ed il suo significato è

343) Nel Cap. 206 [II 486.32] Ibn 'Arabī afferma: "Invero Allah ha con alcuni dei Suoi servitori una compagnia (ma iyya) specifica, come la Sua compagnia con Mosè ed Aronne nel Suo detto: "Invero Io sono con voi, ascolto e vedo!" (Cor. XX-46), e questa fu una buona novella per loro due, affinché non avessero paura [...] Da qui conosci il rango di Muhammad, che Allah faccia scendere su di lui la Sua salät e la Pace, e la sua elevatezza rispetto al grado degli altri Inviati. Invero Allah ha riferito di Muhammad, che Allah faccia scendere su di lui la Sua salät e la Pace, quando il confessore [Abū Bakr] si trovava in uno stato di paura per lui e per se stesso: "e disse al suo compagno", rassicurandolo e rallegrandolo, "mentre essi erano nella grotta" [cfr. Cor. IX-40], che era il rifugio di Allah per loro, "non essere triste. Invero Allah è con noi!". Il Profeta, che Allah faccia scendere su di lui la Sua salāt e la Pace, in questa notificazione ha preso il posto del Vero nella Sua compagnia con Mosè ed Aronne, e ne ha fatto le veci”. D'altra parte Ibn 'Arabī ripete decine di volte nelle Futūhāt l'affermazione: "Egli è con noi ovunque noi siamo (huwa ma'a-nā aynama kunnā)" ed il versetto: "Egli è con voi ovunque voi siate" (Cor. LVII-4).

344) Questa frase, riportata da al-Qušayrī nella sezione della sua Epistola dedicata ad al-Ğunayd, è citata e commentata da Ibn 'Arabī nei capitoli 69 [I 404.14], 71 [I 607.25 e 35, 631.19], 88 [II 162.26], 301 [III 8.14], 314 [III 56.1], 558 [IV 262.13] e 559 [IV 419.33] delle Futūhät. Nel Cap. 71 [I 607.32] egli precisa: "Ciò che 
che la scienza che essi trovano nel loro intimo, il proposito fermo, eccetera, sono solo la conseguenza dell'agire in conformità al Libro ed alla Sunna. Il motivo di ciò è che queste realtà sono dischiuse alle anime da parte degli spiriti superiori, chiamati dalla Legge "Angeli" e dagli antichi "Intelletti attivi" ${ }^{(345)}$, che arrivano con queste realtà sulle anime quando esse abbandonano i desideri della natura, si liberano dalla loro prigionia, si purificano per mezzo dell'esercizio e del combattimento spirituale e levigano la loro superficie specchiante, sì che tutto quello che è nel mondo viene inciso (yantaqišu) in esse per mezzo di ciò ${ }^{346}$ ), ed esse parlano delle cose nascoste e sanno come stanno le cose, sia che queste anime siano legate ad una Legge specifica per mezzo della fede in essa o che non lo siano. È la loro purezza $(s a f \bar{a})$ [94] che conferisce quello, cioè conferisce il loro raggiungimento (luhūq) del principio da cui procedono, ed esse non comunicano se non ciò che conferisce la loro stazione e la loro dimora spirituale.

Al-Ǧunayd ha detto: "A ciò che otteniamo, noi e la gente di Allah, non siamo arrivati per la via degli antichi, cioè per mezzo della speculazione razionale sul principio della natura (hilqa) delle anime e su ciò per cui esse appaiono (ahallat), ma abbiamo operato secondo ciò che ci ha detto il Legislatore, abbiamo avuto fede in Lui ed abbiamo appreso da Lui il nostro modo di procedere (sulük)". E se succede che vi sia una comunanza nell'apertura e nel risultato, coloro che hanno il gusto spirituale trovano una differenza evidente tra i due conseguimenti (idrākayn); inoltre la gente di Allah, che opera in base alla fede, ottiene da Allah una proiezione spirituale (ilq $\bar{a}$ ) specifica, che non ottiene mai chi non segue la via della fede, ed anche per questo si differenziano le due classi $\left({ }^{347}\right)$.

comprendo dalle parole di al-Ǧunayd, per la mia conoscenza della Via, è che egli voleva che si distinguesse tra ciò che viene dato a chi si dedica ai ritiri, al combattimento ed agli esercizi spirituali, al di fuori della via prescritta dalla Legge ma seguendo ciò che le anime ottengono per via dell'intelligenza ('aql), e ciò che si manifesta a coloro che seguono la via prescritta dalla Legge con i ritiri e gli esercizi spirituali. Il percorso iniziatico (sulük) di questi ultimi, secondo la via divina prescritta, fa vedere loro che quanto si manifesta loro viene da Allah come carisma (karäma) per loro. Questo è il significato del detto di al-Gunayd: "Questa nostra scienza è vincolata (muqayyad) al Libro ed alla Sunna", e secondo un'altra recensione "costruita (mušayyad)", cioè è conseguenza di un'opera divina prescritta, al fine di distinguere tra essa e tra ciò che si manifesta a coloro che sono dotati di intelligenza, i compagni delle norme sapienziali (an-nawāmīs al-hikmiyya). L'oggetto della conoscenza è unico, la via è differente ed il possessore del gusto spirituale distingue tra le due cose". Nella versione qui riportata della frase di al-Ǧunayd è presente la variante mušayyad, mentre nelle citazioni delle Futūhāt, come pure nel seguito di questo testo si trova muqayyad.

345) L'espressione "Intelletto attivo" risale al De Anima di Aristotele, ed è stata ripresa nel mondo islamico da Avicenna e da Averroé.

346) Analogo passaggio si trova nel Cap. 344 [III 177.10] ove viene precisato che nelle anime di coloro che seguono una via speculativa sapienziale viene inciso solo quella parte del Mondo che è retta dalla Natura, mentre nelle anime di coloro che seguono una Legge rivelata viene incisa anche la parte al di sopra della Natura.

347) Nel Cap. 88 [II 162.21] Ibn 'Arabī precisa: "Poiché chi non ha fede nelle Leggi rivelate può condividere con noi gli esercizi spirituali, il combattimento spirituale e la purificazione dell'anima dal regime della Natura, può aver luogo per lui una congiunzione con gli Spiriti puri e purificatori, e questa congiunzione può produrre in lui ciò che produce nei credenti che tra di noi mettono in pratica le Leggi rivelate, sì che ha luogo una 
Questo è ciò che vuol dire questo Maestro con la sua frase: "soppesalo con la bilancia della Legge", cioè esso è conseguenza di un'opera prescritta dalla Legge, non di un atto speculativo sapienziale, e per questo lo ha rafforzato con la frase seguente: "[se trovi che esso è conforme] alle norme della Legge e degli stati degli aspiranti”, cioè soppesalo con la bilancia della gente della Via. E questo è quanto ha detto al-Ğunayd: "Questa nostra scienza è vincolata (muqayyad) al Libro ed alla Sunna", cioè essa non ci arriva se non a seguito dell'operare secondo il Libro di Allah e la Sunna del Suo Inviato.

Quanto al suo detto: "si tratta di una ispirazione", in quanto alle anime si presenta [anche] ciò che assomiglia all’ispirazione, cioè la suggestione (waswasa), riguardo a cui Allah ha detto: “... suggerisce (yuwaswisu) ai cuori degli uomini” (Cor. CXIV-5). Chi non conosce la differenza tra le due cose si immagina che la suggestione sia una ispirazione, ma noi ti abbiamo già spiegato ciò che caratterizza ciascun proposito improvviso (hätir): impegnati dunque per essa [ispirazione] e non ti preoccupare. Vi è però qui una sottigliezza, e cioè ogni volta che ti si presenta un proposito di un atto o di una astensione in cui vi è un avvicinamento (qurba) ad Allah, sia Egli esaltato, non allontanarti mai da esso per un altro atto meritorio finché non lo hai completato, ma dedicati a quello. Stai in guardia perché in ciò vi è un veleno mortale [95] da parte dell'avversario di Allah: se egli non è in grado con te di far accadere una disobbedienza manifestamente detestabile, introduce nella tua stazione spirituale il difetto (naqs) e si accontenta di questo, cioè che tu sia manchevole nella quota (hazz) [che ti è stata assegnata]. Se tu hai fortuna e ti si presenta il proposito di un'opera di avvicinamento e tu sei risoluto e ti impegni con Allah di farla, egli ti fa vedere ciò che è meglio di quella affinché tu ti distolga da essa, sì da far parte di coloro che infrangono il patto di Allah dopo averlo contratto.

Quando ti capita una cosa del genere, sappi che è una proiezione satanica, e per questo ti abbiamo detto: se hai preso un impegno ('aqd) con Allah di fare un digiuno o altro e chi è più grande (akbar) di te ti ordina qualcosa che è incompatibile con il tuo impegno, esponi a costui l'impegno che hai preso e se dopo di ciò ti ordina di recedere da esso per eseguire il suo ordine, lascialo da parte e fai ciò che ti ha ordinato senza contraddirlo, poiché è lui che dovrà rispondere di ciò presso Allah, non tu; e se ti ordina di continuare nel tuo impegno, mantieni il tuo impegno e non scioglierlo.

somiglianza ed una condivisione in ciò che abbiamo menzionato riguardo alla maggioranza degli uomini. Parliamo delle scienze che vengono conferite mediante svelamento per gli esercizi spirituali e mediante l'aiuto degli Spiriti superiori, ed in queste anime virtuose viene inciso tutto ciò che c'è nel Mondo ed esse parlano delle realtà nascoste. Al-Ǧunayd ha detto: "Questa nostra scienza, anche se vi è una condivisione in essa tra noi e coloro che ricorrono all'intelligenza, ha un fondamento diverso, poiché i nostri esercizi spirituali, i nostri combattimenti spirituali e le nostre opere, che ci conferiscono queste scienze e gli effetti che si manifestano in noi, si basano sul nostro mettere in pratica il Libro e la Sunna". Questo è il significato della sua frase: "Questa nostra scienza è vincolata al Libro ed alla Sunna", e nel Giorno della Resurrezione noi ci distingueremo da loro per questa misura. Essi non hanno gusto nelle cose divine, poiché l'effusione per loro è spirituale, mentre per noi è spirituale e divina". Una esemplificazione del diverso percorso spirituale degli uomini che appartengono a queste due classi si può trovare nel Cap. 167, dedicato all'alchimia della felicità. 
La nostra dottrina è che chi ha contratto un impegno con Allah non lo debba sciogliere finché non lo ha portato a termine, poiché se le anime si abituano a sciogliere il patto con Allah si affrancano dal patto della Legge e si uniscono a "coloro che più sono in perdita per le [loro] opere, coloro il cui sforzo nella vita di questo mondo è stato sviato mentre essi pensavano di avere agito bene" (Cor. XVIII-103 e 104)

Non ho conosciuto alcun aspirante a cui abbia ordinato di fare una cosa mentre aveva preso un impegno con Allah, sia Egli esaltato, che era in contrasto con quell'ordine e che me lo abbia comunicato, senza che io gli abbia ordinato di persistere nel suo impegno precedente, anche per mio ordine; quando poi il suo tempo era trascorso e finito, allora egli faceva ciò che gli avevo ordinato, se persistevo in quell'ordine. Facevo così a guisa di buon consiglio per lui e di preservazione per me stesso dal dover rendere conto ad Allah, sia Egli esaltato, riguardo [96] a ciò [cioè dell'aver fatto disattendere un impegno precedente], poiché sarebbe inevitabile.

Poi ha anche detto: "Sforzati di nascondere le qualità che nel tuo stato di ignoranza giovanile (sabwa) mostravi agli uomini riguardo alle disposizioni lodevoli ed alle belle opere, e [sforzati] di mostrare ciò che nascondevi agli uomini per timore di essi e per vergogna nei loro confronti, e conserva il tuo segreto (sirr) per quanto ti è possibile. Se ti si presenta un'ispirazione improvvisa (wärid) da parte del Maestro riguardo alla visita della tomba di uno dei Maestri, affrettati a farlo, poiché si tratta di un proposito improvviso (hätir) legalmente valido, una ispirazione (ilhām) da parte del Maestro per te. E quando sei arrivato alla tomba, se ti viene ispirato di fare ciò che fanno coloro che ritornano pentiti [ad Allah $(a t-t \bar{a} \hat{i} b \bar{u} n)$ ], cioè il distacco (hurūğ dall'anima, da questo mondo, dalla tua volontà propria, dal Paradiso, dall'insieme del Malakūt, e di vendere il tutto per amore di Allah, fallo, poiché si tratta di un proposito lodevole; tuttavia rimetti al Maestro l'accesso $(d u h \bar{u} l)\left({ }^{348}\right)$ a tutto quello che hai venduto e se egli ti autorizza ad accedervi, accedivi e sarai in tutto ciò in prestito ('âriya)".

Questa raccomandazione non riguarda se non colui tra gli aspiranti che non ha rapporto con un Maestro e che è in relazione solo con i fratelli, poiché l'aspirante all'istruzione iniziatica non si muove, non si ferma e non mostra se non per l'ordine del suo Maestro ed il suo Maestro non gli ordina se non ciò in cui vi è il bene (maslaha) per lui.

Abū Madyan, questo Maestro dei Maestri, Allah sia soddisfatto di lui, soleva dire ai suoi compagni: "Mostrate la rottura del corso abituale (harq al- $\left.{ }^{c} \bar{a} \bar{a} t\right)\left({ }^{349}\right)$ conseguente ai vostri atti di obbedienza, e rendeteli noti, così come in [97] quest'epoca i disobbedienti fanno mostra degli atti di disobbedienza,

348) Il termine duhūl ha un significato opposto a quello del termine hurūğ, che significa letteralmente "uscita", e che abbiamo tradotto qui con "distacco".

349) Tale espressione, a cui è dedicato il Cap. 186 delle Futūhăt, indica fenomeni straordinari come il camminare sull'acqua o il librarsi nell'aria, fenomeni che non sono da considerare sovrannaturali, poiché, come verrà spiegato nel seguito del testo, essi rientrano nelle possibilità della Natura, anche se non nel corso abituale delle cose. 
e fate sì che la Parola di Allah sia superiore $\left({ }^{350}\right)$ e non estinguete la Luce di Allah con l'occultamento $($ ihf $\bar{a})\left({ }^{351}\right)$ "Invocherete altri che Allah, se siete sinceri?" (Cor. VI-40)" ( $\left.{ }^{352}\right)$.

C'erano due libri che non venivano mai letti sotto la sua guida, Allah sia soddisfatto di lui ( $\left.{ }^{353}\right)$ : il libro dell'ostentazione $(r i y \bar{a}){ }^{(354)}$ ed il libro dell'audizione $(\operatorname{sam} \bar{a})\left({ }^{355}\right)$, ed egli soleva dire del libro dell'ostentazione che esso generava l'ostentazione e che l'essere meticolosi in essa la consolidava nel cuore di colui che agisce. [Egli diceva:] "Non c'è agente se non Allah, poiché Allah, sia Egli esaltato, ha detto: "Ed Allah ha creato voi e ciò che voi fate" (Cor. XXXVII-96), e perché ostenti, visto che l'opera non ti appartiene? Mostratevi dunque al volgo e riferite i carismi (karāmāt $)\left({ }^{356}\right)$ che Allah vi ha conferito interiormente ed esteriormente: nel fare così sarete tra coloro che obbediscono all'ordine di Allah, poiché quello [i carismi] fa parte dei più grandi favori accordati al servitore, ed Allah ha detto: "Quanto al favore del tuo Signore, riferiscilo!” (Cor. XCIII-11), ed egli, che Allah faccia scendere su

350) Cfr. Cor. IX-40.

351) Cfr. Cor. IX-32 e LXI-8.

352) Analogamente, nel Cap. 73 [II 11.31] Ibn 'Arabī afferma: "Il nostro Maestro Abū Madyan, Allah abbia Misericordia di lui, soleva dire ai suoi compagni: "Rendete nota agli uomini la vostra conformità [all'ordine divino] così come gli uomini rendono nota la loro difformità e rendete noto ciò che Allah vi ha conferito dei favori esteriori, cioè la rottura del corso abituale, e di quelli interiori, cioè le conoscenze, in quanto Allah ha detto: "Quanto al favore del tuo Signore, riferiscilo" (Cor. XCIII-11) ed [il Profeta], su di lui la Pace ha detto: "Riferire i favori è ringraziare" e diceva, con la lingua della gente di questa stazione spirituale: "Invocherete altri che Allah, se siete sinceri?" (Cor. VI-40)", e nel Cap. 70 [I 590.15] aggiunge: "Il nostro Maestro [Abū Madyan] soleva dire ai suoi compagni: "Rendete nota l'obbedienza ad Allah affinché la parola di Allah sia la più elevata, così come quelli rendono pubbliche le disobbedienze, le ribellioni e le manifestazioni delle cose riprovevoli, e non hanno vergogna verso Allah"”."

353) Abū Madyan soleva far leggere e memorizzare ai suoi discepoli l'Ihyyà 'ulüm ad-dīn di al-Gazālī [Vincent J. Cornell "The way of Abu Madyan" cit., pag. 4-5], che comprende quaranta libri, due dei quali riguardano rispettivamente le regole dell'audizione spirituale [XVIII] ed il biasimo della fama e dell'ostentazione [XXVIII].

354) Il termine riya à è l'infinito della terza forma del verbo $r a$ 'a, vedere, forma che ricorre nel versetto 142 della Sūra IV: "Gli ipocriti cercano di ingannare Allah, ma è Allah che li sta ingannando. Quando si alzano per la salāt si alzano di malavoglia e solo per farsi vedere dalla gente, e non invocano Allah se non poco", e nel versetto 6 della Sūra CVII. Il termine riy $\bar{a}$ ' può avere i significati opposti di dissimulazione ed ostentazione, poiché, si tratti di astensione o di azione, l'individuo con essa non ha purezza di intenzione (ihlās). Nel Cap. 177 [II 315.22] Ibn 'Arabī precisa: "Tra le malattie dell'azione vi è anche il tralasciare l'opera a causa della gente e questa è la dissimulazione (riy $\left.\bar{a}^{\prime}\right)$ secondo la moltitudine. Quanto all'opera compiuta a causa della gente, quella è associazione (šrik), non ostentazione, secondo i signori della Gente di Allah, ed il suo rimedio è "Ed Allah ha creato voi e ciò che voi fate" (Cor. XXXVII-96) ed altri versetti simili".

355) Nel linguaggio tecnico del Tasawwuf il termine sama $\bar{a}^{`}$ si riferisce all'ascolto delle sessioni di canto rituale. Non è dato sapere quali fossero le ragioni per cui Abū Madyan escludeva la lettura di questo libro, tanto più che in una sua opera egli si esprime favorevolmente sull'ascolto delle sessioni di canto rituale [Vincent J. Cornell "The way of Abü Madyan" cit., pag. 80].

356) Nel Cap. 40 [I 236.24] Ibn 'Arabī afferma che vi sono "tre tipi di rottura del corso abituale [degli eventi]:

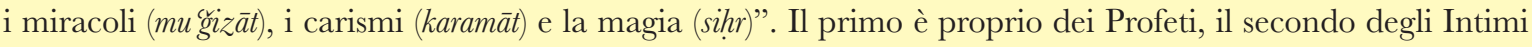
(awliy $\bar{a}^{\prime}$ ) e dei pii $(s \vec{a} l i h \bar{u} n)$ ed il terzo della maggioranza degli uomini. 
di lui la Sua salāt e la Pace, ha detto: "Riferire i favori è ringraziare" ${ }^{(357)}$. E poiché il volgo riferisce il contrario di quello, opponetevi a loro ed informateli che tutto ciò che essi sperimentano (yataqallabūn) sono favori da parte di Allah, sia Egli esaltato: se si tratta di sfortune ( $r a z \bar{a} y \bar{a})$ esse sono una via verso le ricompense che risulteranno a loro, e quindi sono una via verso favori sicuri, e se non sono sfortune si tratta di favori anticipati ed è necessario il ringraziamento per essi, poiché Allah, sia Egli esaltato, ha detto: "Se voi ringrazierete, Noi vi faremo accrescere" (Cor. XIV-7) (358)".

Ad ogni modo mostrare la religione $(d \bar{\imath} n)$ è superiore al nasconderla, ed Allah non ha prescritto la salāt in comune nelle moschee, l'appello dai minareti ed il pellegrinaggio, in cui ha ordinato di alzare la voce [ $(i h l \bar{a} l)$ per dire labbayka], se non per rendere manifesta la religione ed elevare la Parola di Allah, sia Egli esaltato.

E fai bene [lett: fai belle (hassin)] tutte queste opere, quando le compi, per due ragioni: la prima è l'ordine che ti ha impartito Allah di fare bene le tue opere $\left({ }^{359}\right)$; la seconda è che ti prenda come esempio chi ti vede tra coloro che non sanno, o si desti il noncurante [98] che sa, e si ricordi. E sii allo stesso modo in tutti i tuoi atti di adorazione, sia in privato che in pubblico: questa Via (tarīqa) è la Via dei più grandi ed al di sotto di essa sta questa raccomandazione fatta da questo Maestro. Senza dubbio questo aspetto si trova anche nella via $(\operatorname{tar} \bar{q})$ degli aspiranti dei Malāmiyya $\left({ }^{360}\right)$, che non è in contrasto con ciò che abbiamo indicato; infatti gli aspiranti dei Malāmiyya agiscono contrastando i propositi delle anime, come affermano testualmente nei loro libri, in cui è detto: "è necessario che gli aspiranti dei Malāmiyya combattano le loro anime contrastandole". Quindi essi dormono nel momento in cui desiderano non dormire e stanno svegli nel momento in cui desiderano dormire, digiunano quando desiderano mangiare e mangiano quando desiderano digiunare, stanno in compagnia solo di colui di cui detestano la compagnia e non frequentano colui con cui desiderano stare; se trovano piacere nel digiuno (sawm) lo tralasciano e se trovano piacere nella rottura (fitr) la tralasciano, si affrettano a soddisfare il bisogno di colui che detestano e ritardano il bisogno di colui che amano, finché Allah apre l'occhio della loro visione interiore ed essi vedono la realtà come è in se stessa ed agiscono da quel momento in conformità a ciò che viene proiettato in loro e che ricevono da Allah.

357) Hadīt non recensito nelle raccolte canoniche. Ibn 'Arabī lo riporta nei capitoli 73 [II 11.33], 120 [II 202.31], 471 [IV 104.9], 558 [IV 256.16] e 559 [IV 351.27].

358) Questo versetto verrà commentato da Ibn 'Arabī a pag 282 del manoscritto.

359) Nel Cap. 560 [IV 486.1] Ibn 'Arabī afferma: "Quando compi un’opera prescritta dalla Legge, falla bene, poiché chi compie bene la sua opera ottiene la sua aspettativa. Fare bene (ihsān) consiste nel compiere l'opera come Allah ti ha prescritto di compierla e nel vedere Allah, sia Egli esaltato, nel momento in cui la compi. Invero l'Inviato di Allah, che Allah faccia scendere su di lui la Sua șalāt e la Pace, ha spiegato il fare bene nel modo che abbiamo ora menzionato, dicendo: "Fare bene consiste nell'adorare Allah come se tu Lo vedessi"."

360) Sui Malāmiyya o Malāmatiyya si possono consultare i capitoli XXVIII e XXIX di Initiation et réalisation spirituelle di René Guénon, l'Epistola dei Malāmatiyya di as-Sulamī, tradotta da Roger Deladrière nel 1991 con il titolo "La lucidité implacable", ed in arabo lo studio di Abū l-'Alā 'Afîfí "Al-malāmatiyya, ass-sūfyyya wa ahl alfuturwa", pubblicato al Cairo nel 1945. Si noti che Ibn 'Arabī non sta qui descrivendo la stazione spirituale dei Malāmiyya, bensì il metodo adottato per gli aspiranti a tale stazione. 
Quanto alla Via che ha indicato questo Maestro nella sua raccomandazione, essa è la via di alMuhāsibī ( $\left.{ }^{361}\right)$ e dei suoi simili, ma è una via in cui vi è lontananza (bucd $)$ [da Allah], ma la morte è vicina, ed è indispensabile che [l'aspirante] passi da questa disposizione a ciò che abbiamo detto ${ }^{362}$ ).

361) Abū 'Abd Allāh al-Ḥārit ibn Asad al-Muhāsibī nacque a Basra nell'anno 165 dall'Egira ma trascorse la maggior parte della sua vita a Bagdād, ove morì nell'anno 243. Il suo soprannome al-muhāsib̄ significa "colui che rende conto delle proprie azioni" ed è indicativo del suo metodo di purificazione dell'anima, basato soprattutto sull'esame di coscienza.

Ibn 'Arabī lo cita nei capitoli 43 [I 244.34] "Sappi che Abū 'Abd Allāh al-Ḥārit ibn Asad al-Muhāaisibī faceva parte della moltitudine di coloro che posseggono questa stazione spirituale [dello scrupolo $(w a r a)$ ], mentre Abū Yazīd al-Bistāmī e, nella nostra epoca, il nostro Maestro Abū Madyan, facevano parte della sua élite (hāssa)", 53 [I 278.18], 70 [I 590.15] "Quanto a ciò che dice la maggioranza della gente di questa via, come Abū Hāmid [al-Gazālī], al-Muhāsibī ed i loro simili tra la maggioranza, riguardo all'ostentazione $(r i y \bar{a})$ ed alla ricerca della sincerità (ihlās), invero quello è il discorso del Vero per mezzo della lingua della maggioranza affinché si diffonda tra gli uomini, ma non è la lingua di chi non vede se non Allah", 73, q. XIX [II 53.12], 177 [II 298.29] "Al-Muhāsibī ha ricordato che la conoscenza (márifa) è la scienza ('ilm) di quattro cose: Allah, l'anima, questo mondo e Satana" e [II 299.30] "La conoscenza consiste nella scienza di sette cose e questa è la via che percorre l'élite dei servitori di Allah: la prima è la scienza delle realtà essenziali (haqü $q$ q), cioè la scienza dei Nomi divini; la seconda è la scienza dell'epifania (tağallî̀) del Vero nelle cose; la terza è la scienza del discorso del Vero rivolto ai Suoi servitori sottoposti al vincolo legale [proferito] tramite la lingua delle leggi tradizionali; la quarta è la scienza della perfezione e del difetto nell'esistenza; la quinta è la scienza dell'uomo stesso per quanto attiene alle sue realtà essenziali; la sesta è la scienza dell’immaginazione (hay $\bar{a} l$ e del suo mondo congiunto (muttasil) e disgiunto (munfasil); la settima è la scienza delle malattie e dei loro rimedi. Chi conosce queste sette questioni ottiene ciò che si chiama conoscenza, e ciò è compreso in quanto hanno detto al-Muhāsibī ed altri riguardo alla conoscenza", e 309 [III 34.33].

362) Nel Cap. 309, dedicato ai Malāmiyya, Ibn 'Arabī precisa [III 34.28]: "Sappi che gli Uomini (riǧăl) di Allah sono di tre categorie, non ce n'è una quarta. Vi sono Uomini che sono dominati dalla rinuncia (zuhd), dalla devozione costante (tabattul) e dalle opere pure, tutte lodevoli. Essi purificano i loro intimi da ogni atto biasimevole che è stato biasimato dal Legislatore, tuttavia non vedono nulla al di là delle opere che compiono: essi non hanno conoscenza degli stati e delle stazioni, né posseggono le scienze donate da Allah, né i segreti, né gli svelamenti, né le cose che altri realizzano. Essi sono chiamati gli adoratori ('ubbād) [...] se uno di loro dovesse dedicarsi alla lettura, il suo libro sarebbe il kitāb ar-ri āya di al-Muhāsibī, o altri libri simili [...]

La seconda categoria è superiore alla prima: essi vedono che tutti gli atti appartengono ad Allah e che essi non posseggono alcun atto [...] Essi sono simili agli adoratori in serietà, sforzo, scrupolo, rinuncia, affidamento (tawakkul), ecc., ma oltre a ciò essi vedono qualcosa al di là della situazione degli adoratori, cioè stati, stazioni, scienze, segreti, svelamenti e doni carismatici $(k a r a \bar{m} \bar{a} t)$. Quindi essi attaccano le loro aspirazioni all'acquisizione di queste cose ed una volta che hanno ottenuto qualcosa di esse, essi lo manifestano tra la gente comune come doni carismatici, poiché non vedono altro che Allah. Essi sono la gente del carattere (huluq) e della cavalleria spirituale (futuwrwa) e questa categoria è chiamata dei "Süfì" (sūfiyya). Rispetto al terzo gruppo, essi sono la gente della frivolezza ( ru ūna) ed i possessori di anime (nufüs) [mentre i Malāmiyya non hanno più anima] [...]

La terza categoria è costituita da Uomini che non aggiungono nulla alle cinque salät obbligatorie ed ai riti supererogatori (rawätib). Essi non si distinguono dai credenti che osservano le obbligazioni divine per qualche condizione in più per la quale possano essere riconosciuti. Essi camminano nei mercati, parlano con la gente [...] I Malāmiyya non si distinguono dalle altre creature di Allah e per questo sono sconosciuti. Il loro stato è lo stato della gente comune". Il metodo propugnato da al-Muhāsibī e da 'Alī al-Kurdī è quello della prima categoria degli Uomini di Allah, ed Ibn 'Arabī suggerisce qui all'aspirante di non sprecare il suo tempo in esso, poiché la vita è breve, e di cercare piuttosto un Maestro che lo guidi ad avvicinarsi ad Allah ed alla apertura spirituale. 
Apprenda dunque ciò che abbiamo detto come preparazione teorica, e va bene tutto, ma quanto abbiamo detto è meglio e più vicino all'apertura spirituale.

Il Maestro Abū Madyan soleva dire: "Un eccellente sincero (sādiq) non viene se non da un eccellente

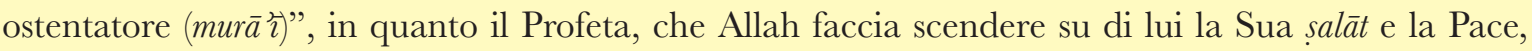
diceva: "Il bene è abitudine".

Quando le anime si abituano a compiere il bene esteriormente, anche se uno lo facesse per ostentazione [cioè per essere visto], se [99] questo ostentatore si pente, il suo pentimento è come l'elisir, tramuta l'essenza delle sue opere precedenti $\left({ }^{363}\right)$; quindi egli torna pentito sul bene che si è manifestato in precedenza e tutto ciò viene accettato e gli viene accordata la sua ricompensa, ed è come se egli non avesse cessato di fare il bene. Questo è il suo profitto, e sarà facile per lui fare il bene insieme al pentimento perché era abituato a farlo nello stato della [sua] ostentazione.

Questo Maestro [che ha redatto la raccomandazione] non aveva timore se non dell'ostentazione $(r i y \bar{a}$ ) e della vanagloria ('uğb) che subentra nell'anima quando viene lodata per gli attributi lodevoli che si manifestano in essa, ed essa accresce nell'opera su una base che non è eccellente, poiché non c'è dubbio che la sua base [in se stessa] è eccellente, ma [il difetto] è la sua ignoranza e la sua indigenza nella scienza, e se mettesse in opera la scienza sarebbe conforme a ciò che noi abbiamo menzionato riguardo a questa questione $\left.{ }^{364}\right)$.

Tra ciò che conferma quanto abbiamo detto vi è ciò che si racconta di al-Ğunayd; un uomo starnutì nella sala di riunione di al-Ǧunayd e disse: "La lode spetta ad Allah", ed al-Ǧunayd gli disse: "Completa la [tua frase] e dì: [La lode spetta ad Allah], il Signore dei Mondi”. L’uomo rispose: "O mio signore, chi è il Mondo tanto da essere menzionato insieme ad Allah?", ed al-Ğunayd disse: "Adesso dillo, fratello mio, poiché quando il transitorio (muhdat) si congiunge all'eterno non ne resta traccia” ${ }^{365}$ ). Costui aveva

363) Nel Cap. 333 [III 123.24] Ibn 'Arabī precisa: "L'opera non è un'adorazione ('ibāda), poiché l'opera è una forma e l'adorazione è il suo spirito. L'adorazione viene accettata da Allah in ogni caso, sia essa accompagnata da un'opera o non lo sia, mentre l'opera senza adorazione non è mai accettata per quanto riguarda colui che si è proposto di compierla, che è l'anima soggetta all'incombenza legale. Ma in quanto l'opera scaturisce dalle membra o da una di esse specificamente, quel membro viene ricompensato per essa, e l'opera viene accettata per colui da cui si manifesta, ma nulla di essa ricade sull'anima che l'ha ordinata alle membra, se l'opera è formalmente buona, come la salāt dell'ostentatore e dell'ipocrita, e così per tutte le opere buone che si manifestano grazie alle sue membra e per le quali l'anima non si propone un'adorazione". Quindi, se l'ostentatore si pente, la ricompensa delle sue opere ricade anche sulla sua anima.

364) Come spiegherà nel seguito del testo, il rimedio all'ostentazione non è l'esame di coscienza, ma la scienza che non c'è Agente se non Allah.

365) Nel Cap. 5 [I 103.29] Ibn 'Arabī precisa: "Uno dei signori [della Via], avendo sentito dire ad uno che aveva starnutito "La lode spetta ad Allah", gli disse: "Completa ciò come ha detto Allah [aggiungendo]: il Signore dei Mondi". Colui che aveva starnutito disse: "O mio signore, chi è il Mondo tanto da essere menzionato con Allah?", ed egli rispose: "Adesso dillo, fratello mio, poiché quando il transitorio si congiunge all'eterno non ne resta traccia". Questa è la stazione spirituale del congiungimento (wusla) e lo stato spirituale di sconvolgimento 
estinto il Mondo accanto ad Allah ed al-Ǧunayd gli aveva dato ragione in quello, poiché sapeva che era la verità, e [lo] aveva giustificato ('allala).

E costui che ostenta la sua opera, a chi la ostenta, non essendoci che Allah? E quale "sua" opera ostenta se Colui che agisce è Allah, come è Lui che dice tramite la lingua del Suo servitore: "Allah ascolta chi Lo loda", e così per tutte le Sue opere [attuate] mediante il Suo servitore?

Quanto al suo detto: "E conserva il tuo segreto per quanto ti è possibile", egli intende con la sua conservazione ciò che è necessario fare per osservare il suo diritto (haqq), che ti è imposto di rispettare. Se si tratta di un segreto che è necessario palesare, allora il suo diritto è di essere palesato nella sua sede appropriata, e se si tratta di un segreto che è necessario tenere nascosto allora il suo diritto è di restare nascosto. Egli non ha specificato quale segreto intendesse e quindi prendi la sua raccomandazione in senso generale, poiché egli non ti ha ordinato [100] se non in modo specifico di conservarlo, e la sua conservazione non è altro che ciò che ti ho menzionato.

Esso non si chiama segreto se non prima della sua conoscenza (ițilia $\vec{a}^{c}$ ed il segreto è ciò che c’è tra te ed Allah, sia Egli esaltato, senza che un Angelo o una creatura lo conoscano, ma non è mai del tutto così, e non fa differenza se lo conosce uno che non sia Allah o tanti. Abbiamo detto che non è mai del tutto così perché si tratta di una cosa che c'è e che ti è capitata nella dimora di questo mondo, e non c'è cosa che sia in questa dimora che non sia nota alla Penna (qalam) ed alla Tavola (lawh) ed a coloro che sono occupati su di essa. Dov'è dunque la cosa che solo tu possiedi ad esclusione di una delle creature di Allah? Essa non si trova e questo Maestro non intendeva con la conservazione del segreto se non ciò che ti abbiamo menzionato del tuo accordargli il suo diritto, in modo specifico.

Quanto al suo detto: "Se ti si presenta una ispirazione improvvisa da parte del Maestro riguardo alla visita della tomba di uno dei Maestri", egli dice: "e tu sai, quando ti arriva, che il Maestro vuole quello da te", e non c'è differenza tra ciò e la sua comunicazione verbale a te dell'ordine, poiché tu ti basi su una evidenza da parte sua. "Affrettati a farlo", come ti affretti quando ti dà l'ordine esteriormente, poiché egli si manifesta in te interiormente, così come si manifesta esteriormente con la parola.

In questa Via ciascuno ha bisogno di un segno rivelatore ('alāma), tra lui ed il suo Signore, in ciò che apprende dal suo Signore, cioè per la via che il suo Signore ha lodato, in quanto tutto viene da Lui, sennonché Egli, sia esaltato, ha suddiviso la modalità in cui ciò avviene, facendo sì che fosse per il tramite di un'anima, di un Angelo, di un demone, o senza tramite [cioè diretta].

L'aspirante ha bisogno di un criterio $(f \bar{a} r i q)$ [per riconoscere la modalità], ed il segno rivelatore è molteplice, e ne avevo parlato. Abū Yazīd, Allah, sia Egli esaltato, abbia Misericordia di lui, non prendeva nulla dal Vero se non con quattro testimoni, Muhammad, Abramo, Mosè e Gesù, nella 
luce, con lui, di “Non c'è Dio se non Allah". Quanto a noi, abbiamo un segno rivelatore che ci è proprio, che non è questo; ed ogni persona ha un segno rivelatore tra lui ed Allah che conferma per lui ciò che la Profezia conferma per il Profeta, [cioè] che egli è un Profeta in se stesso $\left.{ }^{366}\right)$.

Quando [101] l'aspirante trova questa ispirazione da parte del Maestro, in quanto il segno rivelatore stabilito per lui gli dà testimonianza che quello è da parte del Maestro, ciò non avviene mai senza che il Maestro lo sappia, e se egli la trova ed il Maestro non lo sa, egli si immagina che essa venga dal Maestro, e quindi la faccenda è confusa per lui e quella non è una ispirazione da parte del Maestro, a meno che non sia voluta per il Maestro. Comprendi dunque.

Quando trovi quella ispirazione agisci riguardo ad essa conformemente a ciò che la sua realtà comporta, senza restrizioni; quanto a ciò che ti ha raccomandato di fare quando trovi quella [ispirazione], ed egli si riferiva ad una ispirazione specifica cioè alla visita della tomba di un Maestro, segui la sua raccomandazione, poiché essa è profittevole in questa sede. Noi ti abbiamo fatto notare ciò che comporta l'ispirazione in senso generale, ed il nostro discorso si applica ad ogni ispirazione da parte del Maestro o di altri.

Quanto al suo detto: "di vendere il tutto per amore di Allah" egli ti indica il distacco dalla tua anima, poiché è la tua anima che cerca il tutto, e questo è un discorso facile. Abū Yazīd diceva riguardo al credente, e quindi a maggior ragione riguardo all'aspirante: "Il credente non ha anima!" (367); egli venne interrogato al riguardo e per risposta recitò: "Invero Allah ha comperato dai credenti le loro anime e le loro ricchezze" (Cor. IX-111) e quindi il credente non ha anima né ricchezza, perché le ha vendute ad Allah, che le ha comperate da lui in virtù della procura (wakāla) da parte dell'anima logica (an-nafs an-nātiqa) ${ }^{368}$ ). L'anima di cui ha luogo la vendita e l'acquisto è l'anima animale (an-

366) Ibn ‘Arabī accenna a questo argomento nel Cap. 283 [II 622.26 e 624.1].

367) Questa frase, senza però essere riferita ad Abū Yazīd, è riportata nel Cap. 73 [II 38.28], nel Cap. 76 [II 147.20] e nel Cap. 375 [III 471.20 e 21], ove Ibn 'Arabī precisa: "Poiché [Egli] ha detto che ti ha fatto sulla [Sua] forma, sappi che è inevitabile che tu asserisca [di avere] il dominio (mulk), poiché tu sei fatto sulla [forma] di Lui, ed Egli è il possessore del Dominio. Non c'è dominio più vicino per te [di quello] della tua anima ed è lei che asserisce il dominio, in quanto è sulla forma di Chi ha il Dominio. Egli Si è rivolto ad essa in quanto è credente, per il Suo Nome il Credente, ed ha comperato dal credente la sua anima, così che il credente non ha anima come gli altri esseri viventi. Non resta così nessuno che asserisca il dominio ed il Regno diventa "di Allah, l'Unico, il Dominatore" (Cor. XL-16), e cessa la comunanza. Quindi il credente non ha anima e non ha pretesa al dominio ed ogni credente che asserisce un dominio reale non è credente, in quanto il credente è colui che ha venduto la sua anima e non resta in lui nessuno che asserisca, poiché era la sua anima ad avere la pretesa, in quanto fatta sulla forma di Colui che ha asserito il Dominio, cioè Allah, sia Egli esaltato. Fratello mio, tieni a freno la tua anima da una asserzione che ti spoglierebbe della fede e guardati dal difendere la tua anima che ti apparteneva, e se decidi di difenderla, allora fallo avendo ben presente e sapendo che essa è l'anima del Vero, non la tua anima".

368) L'anima logica, ove logica ha il significato greco del termine, cioè "parlante", costituisce la differenza specifica tra l'uomo e gli altri animali [Cap. 68 [I 331.33)] e per questo è assimilata alla ragione ("aql) [Cap. 71 (I 641.8)], anche se nel Cap. 177 [II 319.13] Ibn 'Arabī sembra distinguerla da essa: "Allah, sia Egli esaltato, ha 
nafs al-hayawāniyya), sede degli appetiti e dei desideri, ed Egli l'ha comperata dal credente per mezzo della procura dell'anima logica e l'ha ripagata con il Paradiso "in cui vi è ciò che le anime desiderano e di cui gli sguardi si dilettano" (Cor. XLIII-71) e l'anima animale è dotata del desiderio. L'anima logica ottiene il Paradiso, [102] che è il prezzo (taman) [dell'anima animale], e lo conserva presso di sé per quest'anima animale, e quando nel Giorno della Resuscitazione (yawm al-ba $\underline{\text { }}$ ) Allah farà dono all'anima logica di questa anima animale, restituendogliela, essa manterrà il suo prezzo, su cui il Vero non recederà, e l'anima logica lo donerà a questa anima animale, poiché essa è sede dei desideri ed il Paradiso è la dimora dei desideri.

Così aveva fatto l'Inviato di Allah, che Allah faccia scendere su di lui la Sua șalāt e la Pace, con Ǧābir ibn 'Abd Allāh. Mentre era in viaggio con lui, egli, che Allah faccia scendere su di lui la Sua șalāt e la Pace, comperò da lui il cammello che egli montava, e Ğābir pose come condizione all'Inviato di Allah, che Allah faccia scendere su di lui la Sua salāt e la Pace, di poterlo montare fino a Medina e la condizione venne accettata. Quando arrivò a Medina calcolò per lui, che Allah faccia scendere su di lui la Sua salāt e la Pace, il prezzo del cammello e quando lo ebbe incassato egli, [che Allah faccia scendere su di lui la Sua salāt e la Pace], gli regalò lo stesso cammello, sì che egli ottenne insieme il prezzo e la restituzione del cammello $\left.{ }^{(369}\right)$.

Allo stesso modo agisce Allah con il credente, cioè con la sua anima logica $\left({ }^{370}\right)$, quando compera da

creato la facoltà chiamata ragione e l'ha posta nell'anima logica per contrastare con essa il desiderio naturale". Nel Cap. 148 [II 239.24] egli afferma: "Sappi che la modalità sottile dell'uomo, che governa il suo corpo, ha una faccia (wağh) rivolta verso la Luce pura, che è suo padre, ed una faccia rivolta verso la Natura, che è la tenebra pura e che è sua madre. Per questo l'anima logica è a mezzo tra la luce e le tenebre e la causa del suo stare in mezzo come posizione è il suo ruolo di regittore (mudabbir), come l'Anima universale che sta tra l'Intelletto e la Hyle universale, che è una sostanza tenebrosa mentre l'Intelletto è Luce pura. Quest'anima logica è come il barzah tra la luce e le tenebre: essa accorda ad ogni cosa il suo diritto (haqq) e quando una delle due parti prevale su di lei, essa sta dalla parte di chi prevale, ma se non ha inclinazione verso nessuna delle due parti accoglie le cose secondo equilibrio ed equanimità e decide per il vero", e nel Cap. 358 [III 262.34] aggiunge: "Sappi che l'anima logica è felice in questo e nell'altro mondo, non c'è quota per lei nell'infelicità in quanto essa non fa parte del mondo dell'infelicità. Allah le ha fatto montare questo veicolo corporeo designato come l'anima animale e questa è per l'anima logica come l'animale che essa cavalca [...] le è impossibile opporsi [all'Ordine divino] poiché essa fa parte del Mondo della preservazione che è quello degli spiriti puri [...] essa è stata insufflata [nell'uomo] a partire dallo Spirito di Allah [...] essa non può disobbedire". L'esposizione più ampia delle differenze tra l'anima logica, quella animale e quella vegetativa si trova nel capitolo 353 delle Futūhāt, parzialmente tradotto da William Chittick in The Self-Disclosure of God, SUNY Press 1998, pag. 343-344; inoltre su questo tema si può consultare lo studio di Miguel Asín Palacios, La psicologia segun Mohidin Abenarabi, in Actes du XIV Congrès International des orientalistes, t. 3, E. Leroux, 1906, pag. 79-191.

369) L'episodio è riferito da Muslim, XXII-115, al-Buhārī, XXXIV-33, LI-23, at-Tirmid̄ī, XII-30, XLVI-52, e da Ibn Hanbal. Ibn 'Arabī lo riporta nel Cap. 558 [IV 271.31].

370) Nel Cap. 76 [II 147.15], Ibn 'Arabì precisa: "Le anime che Allah ha acquistato in questo versetto sono le anime animali, che Egli ha comprato dalle anime logiche credenti. Quindi le anime logiche dei credenti sono i venditori, che possedevano queste anime animali che il Vero ha comperato da loro, poiché ad esse tocca l'uccisione [cioè sono mortali]. Queste anime [animali] non sono la sede della fede, poiché sono le anime logiche 
lui l'anima animale in cambio del Paradiso: Egli gli conferisce il Paradiso e gli rende l'anima, per mezzo della resuscitazione in essa, fino al Giorno della Resurrezione, anzi [gliela rende] al momento stesso della Sua riscossione di essa, che è il martirio (šahāda), poiché il martirio, cioè l'uccisione nel sentiero di Allah, è un trasferimento dalla mano di chi vende alla mano di chi compera senza che vi sia una morte. Infatti colui che viene ucciso nel sentiero di Allah non è morto, e legalmente non si dice che è morto, poiché in realtà non è morto: al momento del trasferimento dell'anima animale Allah la restituisce all'anima logica, come il Profeta, su di lui la Pace, restituì il cammello a Ğābir al momento del suo arrivo, ed insieme gli pagò anche il prezzo. Allah ha descritto quello con il Suo detto, sia Egli esaltato: "Non considerate coloro che vengono uccisi nel sentiero di Allah come morti, bensì come vivi presso il loro Signore, ed essi sono nutriti” (Cor. III-169), ed [il Profeta], su di lui la Pace, ha detto riguardo agli spiriti dei martiri: "essi [sono nei gozzi di uccelli verdi che] si nutrono dei frutti del Paradiso" $\left.{ }^{371}\right)$, cioè mangiano, e ciò non riguarda se non coloro che vengono uccisi [103] nel sentiero di Allah, e non c'è dunque nessuno che entri in Paradiso a pronta cassa (bi-n-naqd) se non specificamente costoro.

Quanto al suo detto: “tuttavia rimetti al Maestro l'accesso a tutto quello che hai venduto e se egli ti autorizza ad accedervi, accedivi e sarai in tutto ciò in prestito", egli si rivolge a un aspirante che segue l'istruzione iniziatica di un Maestro e che è sotto il suo controllo; se gli si presenta un proposito simile a questo, la regola che deve seguire è quella che egli ha menzionato, cioè di esporgli il proposito che gli si è presentato riguardo all'ordine di vendere, cioè la vendita del tutto. Il Maestro non glielo ordina se non in considerazione del momento (waqt) e di ciò che è profittevole per lui - altro che questo non è possibile - e ciò perché [l'aspirante] si trova in un momento [particolare]; in un altro stato spirituale non gli ordina la vendita, bensì richiama la sua attenzione sulla identità del Vero nelle cose, e non c’è vendita né acquisto, perché il proprietario non compera ciò che egli [già] possiede.

Poi ha detto: "E se possiedi una ricchezza o una posizione (mansib), o hai una moglie o un figlio, tutto quello appartiene al Maestro: se vuole lo fa restare in tuo possesso, e se vuole lo toglie al tuo possesso per darlo a chi vuole". Dice questo colui che dispone (mutahakkim) di te, per tutto ciò che Allah trova giusto per te; affida dunque la tua faccenda a lui e guardati dall'opporti a lui riguardo a come egli dispone di ciò che è in tuo possesso, poiché egli, Allah sia soddisfatto di lui, non ti fa nulla se non per un vantaggio che torna a te. Egli non è uno di cui si possa dubitare (gayru muttaham), in quanto è erede dell'Inviato di Allah, che Allah faccia scendere su di lui la Sua șalāt e la Pace, nella considerazione delle cose che sono profittevoli per te, e non considera quelle cose da se stesso, bensì osserva ciò che Allah gli proietta riguardo alla tua faccenda, secondo la via nota che c'è tra loro ed Allah. Essi non

ad essere qualificate dalla fede e da esse il Vero ha comperato le anime dei corpi, dicendo: "Ha acquistato dai credenti", che sono le anime logiche qualificate dalla fede, "le loro anime", che sono i loro veicoli sensibili ed esse sono quelle che escono con loro per l'uccisione e per la guerra. Il credente non ha anima!".

37 1) Hadīt riportato da Abū Dāwud, XV-25, at-Tirmid̄ī, XX-13, e da Ibn Ḥanbal. Ibn 'Arabī lo cita nel Cap. 558 [IV 235.1]. 
si attengono alla considerazione razionale, né alla riflessione ed all'esame individuale, poiché questi talvolta sono in accordo e talvolta sono in contrasto [con il giudizio di Allah]. Poiché il fondamento è il Suo detto, sia Egli esaltato: "Ed il giudizio spetta ad Allah, l'Elevato, il Grande" (Cor. XL-12), gli iniziati non trovano giusto di ergersi a giudici in una cosa se non con il giudizio di Allah [104], noto tra di loro. Gli Intimi hanno una via da cui apprendono ciò che Allah fa accadere tramite loro, e quell'apprendimento (talaqq $\vec{\imath})$ si chiama ispirazione (ilhām) e comprensione (fahm) di [quello che vuole] Allah, e nel caso degli Inviati si chiama rivelazione (wahy), discesa (tanzīl) e legge (šar): l'Inviato ha le due cose, mentre l'erede ne ha una sola di esse, ed è quella che abbiamo menzionato ${ }^{372}$ ).

Il fondamento della via riguardo alla faccenda della moglie in modo specifico, prescindendo da ciò che è stato menzionato, è che quando l'aspirante si reca dal Maestro ed ha una moglie, egli non attua una separazione tra lui e lei, e se viene e non ha moglie, egli non lo fa sposare ma lo accetta nella condizione in cui si presenta, e fa il patto iniziatico con lui mentre è in questa condizione, ed analogamente per tutto ciò che [l'aspirante] possiede, in conformità a ciò che abbiamo menzionato. Questo è il fondamento della via, e se il Maestro intraprende un combattimento spirituale riguardo a quello [che l'aspirante possiede], diversamente da ciò che concede la gente della via, non lo fa se non per un ordine divino in cui vi è un vantaggio per quell'aspirante.

Ciò su cui è d'accordo la gente di Allah, sia Egli esaltato, riguardo all'istruzione iniziatica dell'aspirante, è che il Maestro apporta all'aspirante ciò che contrasta la sua volontà, la sua passione ed il suo interesse [individuale]: questo è il fondamento dell'istruzione iniziatica. Se [l'aspirante] arriva, all'inizio della sua faccenda, sottomesso, senza alcun interesse (garad) riguardo ad una cosa ad esclusione di un'altra, costui ha percorso già un grande tratto della via, in cui molti degli uomini si perdono, ed allora il Maestro ha con lui un atteggiamento diverso, che non è l'atteggiamento che ha verso colui in cui resta un residuo di ciò che possiede o di cui dispone come ricchezza, posizione, moglie e figlio.

L'opposizione al Maestro non consiste in ciò che la lingua dell'aspirante proferisce - quello è a guisa del parlare di miscredenza nei confronti di chi crede nell'Inviato - bensì l'opposizione da parte sua è ciò che si presenta alla sua anima senza che egli lo esprima, ed egli deve cancellare ciò dalla sua anima, se aspira a ciò che si propone, e non deve menzionare una cosa simile al Maestro, poiché la cancellazione di quello [105] spetta all'aspirante, non al Maestro, in quanto Allah, sia Egli esaltato, ha detto al riguardo: "Invero tu non guidi chi ti piace, [è Allah che guida chi vuole]" (Cor. XXVIII-56) ${ }^{(373)}$ e "Non spetta a te la loro guida" (Cor. II-272) $\left.{ }^{374}\right)$.

372) Cioè l'erede ha l'apprendimento, ma non la facoltà di legiferare.

373) Questo versetto venne rivelato quando il Profeta chiese a suo zio Abū Ṭālib di recitare in punto di morte la testimonianza di fede ed egli rifiutò.

374) Nel Cap. 379 [III 498.11] Ibn 'Arabī precisa: "Sappi che la guida (hidāya) è un effetto divino nel Suo detto: "Colui che Allah svia non ha guida" (Cor. VII-186) ed un effetto dell'essere contingente (kawn) nel Suo detto: "Ogni gente ha una guida" (Cor. XIII-7), ed il significato di questo [versetto] si riconduce al primo, poiché la guida esistente non è che un Inviato da parte di Allah ed egli è uno che trasmette, non uno che guida, 
Ed egli non deve trasgredire il suo rango con il Maestro, né con l'Inviato, e ciò che spetta ad Allah spetta ad Allah, e ciò che spetta all'Inviato ed all'erede spetta all'Inviato ed all'erede. Quando l'aspirante trova l'opposizione nella sua anima e non la cancella, e non si rivolge alla sua anima con biasimo dicendole: "Questo è come trafiggere $(t a n)$ la tua fede in ciò che ti proponi"; e se malgrado ciò l'opposizione che sussiste in lui resta e lui non la fa cessare, egli è un ipocrita (munāfiq), e nel linguaggio degli iniziati ciò denota che egli non è sincero nella via, e chi non è sincero nella via non arriva mai a nulla. E se è ignorante e menziona quell'opposizione al Maestro, egli è come colui che manifesta la miscredenza all'Inviato, ed è obbligatorio per il Maestro far sì che egli si penta di quello, oppure farlo uscire dalla sua casa e dai suoi compagni, se non si pente, così come è obbligatorio per l'Inviato, quando ha una spada, di proporre all'apostata (murtadd) il pentimento, che è la sottomissione (islām), e se egli non si sottomette viene ucciso, il che equivale alla sua espulsione dalla sua famiglia e dalla sua discendenza [spirituale] per mezzo dell'uccisione. Il Maestro non è responsabile della cessazione dell'opposizione, né complessivamente del successo dell'aspirante, poiché a lui spetta solo l'istruzione di coloro che sono sinceri con lui e che si affidano a lui, cioè coloro che affidano a lui le loro redini così che egli li conduca laddove vede un vantaggio per loro, come il proprietario dei cammelli cerca per essi il pascolo ubertoso.

Poi ha detto: "e così anche per la faccenda dell'aldilà, affidala al Maestro: se vuole ti ordina [di andare] verso il Fuoco, oppure verso il Paradiso". Egli vuol dire che, in se stessa, la faccenda si suddivide in due classi, sia in questo che nell'altro mondo: ciò che non piace (makrūh) e ciò che piace $(m a h b u \bar{u} b)$. Ciò che non piace è duro per le anime, ed esso è il Fuoco, ovunque esso sia, mentre ciò che piace è facile per l'anima, ed esso è il Paradiso, ovunque esso sia. Allah, sia Egli esaltato [106], ha circondato il Fuoco con i desideri (šahawāt) ed ha circondato il Paradiso con le avversità (makārih) $\left.{ }^{375}\right)$, cioè le cose il cui avvenimento è penoso per le anime; quindi l'interno del Paradiso è diventato l'esterno del Fuoco e l'interno del Fuoco è diventato l'esterno del Paradiso. Chi segue la via dei desideri avrà come destinazione il Fuoco, mentre chi segue le avversità e domina la sua anima in esse avrà come destinazione il Paradiso. Per questo quell'uomo che incontrai a Mossul e che faceva parte

nel senso che non ha successo, bensì una guida nel senso di colui che spiega [la via]. Egli, sia Egli esaltato, ha detto riguardo all'evidenza (bayān) che essi hanno ed all'esposizione (tibyān) che Allah ha imposto loro: "affinché spiegassi agli uomini ciò che è stato rivelato per loro" (Cor. XVI-44) ed ha detto riguardo alla guida che è il successo (tarefiq ): "Non spetta a te la loro guida" (Cor. II-272), cioè non spetta a te di riuscire a far loro accettare ciò con cui ti ho inviato e che ti ho ordinato di esporre, "ma Allah guida", cioè dà successo, "chi vuole" (Cor. ibidem), ed Egli conosce bene chi sono i ben guidati, cioè coloro che accettano l'Assistenza [divina], e ciò dipende dalla complessione specifica con cui ha dato loro l'esistenza. Queste guide sono le guide della spiegazione, non le guide che ottengono il successo: alla Guida, che è Allah, spetta la spiegazione ed il successo, mentre alla guida che è la creatura non compete se non specificamente la spiegazione”.

375) Riferimento ad uno hadīt riportato da Muslim, LI-1, Abū Dāwud, XXXIX-22, at-Tirmid̄̄ī, XXXVI-21, an-Nasā'̀̄, XLVII-3, ad-Dārimī, XX-117, e da Ibn Ḥanbal. Ibn 'Arabī lo riporta nel Cap. 559 [IV 385.19]. 
della gente dello svelamento della nuova Mossul $\left.{ }^{376}\right)$ vide Ma ${ }^{c}$ rūf al-Karhī $\left.{ }^{377}\right)$ nel mezzo del Fuoco e ciò lo sgomentò finché non ci incontrò, non avendo trovato nessuno che gli spiegasse la cosa. Gli dissi: "Se avessi accesso a lui lo vedresti nel Paradiso! Quel Fuoco che hai visto sono le avversità che egli ha affrontato nei giorni del suo combattimento spirituale e che lo hanno condotto al Paradiso. Come lo hai visto?", ed egli rispose: "L'ho visto sano, non in preda alle fiamme, malgrado il Fuoco fosse intorno a lui". Gli dissi: "Egli vuole dirti: "Chi vuole ottenere la mia stazione spirituale deve passare attraverso queste avversità’”" ed egli si liberò dal suo sgomento $\left({ }^{378}\right)$.

Devi poi sapere che la faccenda è pazienza $(s a b r)$ e ringraziamento $(\check{s} u k r)$, favore $(n i m a)$ e prova $(b a l \bar{a})$ : la prova richiede la pazienza ed il favore richiede il ringraziamento in questo mondo.

Questo Maestro ha detto: "e così anche per la faccenda dell'aldilà", cioè in questo mondo, "affidala al Maestro"; se egli ti ordina [di andare] verso il Paradiso, cioè ti fa prendere la via delle cose agevoli e del conseguimento degli obiettivi dell'anima è per il vantaggio che vede in ciò per l'aspirante. Le complessioni degli uomini sono diverse, ed egli sa che la complessione di quell'aspirante specifico non trae beneficio se non con i favori, e che egli fa parte di coloro che ringraziano. Se egli venisse sottoposto alla prova ed alle avversità fuggirebbe e diventerebbe miscredente, e l'obiettivo è invece la sua salvezza dai pericoli, ed in qualsiasi modo ciò si ottenga il Maestro gli fa prendere quella strada, e questo è l'ordine del Maestro a quell'aspirante [di andare] verso il Paradiso. Analogamente se egli vede nella sua complessione che il favore lo guasta e lo annette alla gente della baldanza e della vanità, e che la povertà e la prova [107] sono benefiche per lui e lo conducono verso Allah, sia Egli esaltato, e quindi il Maestro sa che egli fa parte dei pazienti, allora lo mette alla prova con ciò in cui egli sarà paziente, e che non sono altro che le avversità, e lo istruisce per mezzo di esse, ed egli arriva con ciò alla felicità ed avrà la ricompensa dei pazienti, così come l'altro avrà la ricompensa dei riconoscenti, e questo è il significato in questo contesto dell'ordine del Maestro [di andare] verso il Fuoco.

Quanto all'ipotesi che egli gli ordini [di andare] verso il Paradiso per mezzo dei desideri e dei favori, malgrado sappia che ciò lo guasterebbe, ciò non è dato, e lo stesso vale per l'ipotesi contraria. Questo Maestro non intende dire con queste parole che egli gli ordini le disobbedienze che conducono al

376) Mentre Mossul si trova sulla riva occidentale del Tigri, di fronte all'antica Ninive, la città chiamata Hadītat al-Mawesil, o semplicemente al-Hadīta, si trova sulla riva orientale del Tigri.

377) Abū Maḥfūz ibn Fīrūz Márūf al-Karḩī, nato in una famiglia di Sabei di Bagdād, si convertì all'Islām grazie all'Imām sciita 'Alī ibn Mūsā ar-Riḍā e divenne uno dei Șūfĩ più venerati a Bagdād, ove morì nell'anno 200 dall'Egira. Fu Maestro di Sarī as-Saqațī.

378) L'uomo che ebbe questa visione è citato nelle Futūhāt come uno dei due contemporanei di Ibn 'Arabī che avevano realizzato la stazione spirituale dell'Immensità e che egli ebbe modo di conoscere personalmente. Mentre Ibn 'Arabī era a Mossul, l’Imām Nağmuddīn Muhammad ibn Abī Bakr ibn Š S̄àī al-Mawṣilī, che era stato informato della situazione di quell'uomo, fece sì che i due si incontrassero: Ibn 'Arabī gli chiarì il significato della sua visione e poi lo prese come compagno nelle sue peregrinazioni. Cfr. i capitoli 351 [III 225.16], 463 [IV 83.31], 558 [IV 241.13] e 559 [IV 385.20]. 
Fuoco infernale, cioè [di soddisfare] i desideri riprovevoli, né gli atti di obbedienza eccessivi che lo indurrebbero alla negligenza nel compierli, bensì egli, Allah sia soddisfatto di lui, ha una bilancia in questo, che egli conosce.

Quanto al senso esteriore del suo detto riguardo al Paradiso ed al Fuoco, poiché entrambi si riferiscono a quaggiù, è che egli considera ciascuno dei due per ciò da cui è circondato secondo la notificazione profetica e divina; e tutte le anime non hanno una sola complessione, ed il Maestro è il miglior conoscitore di ciò che è vantaggioso [per l'aspirante], e la fede, come ha detto, su di lui la Pace, è: "metà pazienza e metà ringraziamento" $\left({ }^{379}\right)$. Il ringraziamento esige i favori e le cose che danno piacere, e la pazienza esige le avversità e le difficoltà, e la pazienza e il ringraziamento sono due stati che hanno come dimora questo mondo, ed Allah ama i riconoscenti come ama i pazienti: "Dì: chi ha proibito l'ornamento di Allah che Egli ha scelto per i Suoi servitori e le buone cose del sostentamento? Dì: esse sono per i credenti nella vita di questo mondo ed ancor più nel Giorno della Resurrezione" (Cor. VII-32). Questa persona verrà trasferita da un Paradiso ad un Paradiso: renda dunque lode ad Allah e Lo ringrazi per quello. Ti ho così spiegato il proposito di questo Maestro con queste sue parole: il Maestro e l'Inviato, in quanto incaricati di guidare, non ordinano a nessuno qualcosa il cui punto di arrivo sia il Fuoco: questo non è possibile!

Poi ha detto: "Insomma, se raggiungi questa meta [108] sii con il tuo Maestro come se egli fosse colui che ti fa sortire all'esistenza, ti fa morire e ti fa vivere, ti fa del male e ti è di giovamento in ciò, ti abbandona e ti onora, ti spezza e ti rimette a posto, ti rende potente e ti umilia, per l'autorizzazione di Allah, quanto è Potente e Magnificente".

Commento. Egli dice: "Insomma, se raggiungi questa meta", rimettendoti alle decisioni del Maestro al tuo riguardo, è necessario che tu sappia che è Allah, sia Egli esaltato, che dispone di te, poiché, quando l'aspirante è sincero nella compagnia del Maestro, Allah non fa accadere per mano del Maestro se non ciò in cui vi è la salvezza e la felicità di quell'aspirante, e talvolta questo accade mediante ciò che fa piacere alla sua esteriorità e talvolta mediante ciò che dispiace ad essa, come egli ha menzionato.

Egli ti dice di non considerare il Maestro nella sua forma esteriore, per mezzo della quale è simile a te, bensì devi considerare che il Vero Si manifesta a te nella forma di questo Maestro, così come Si manifesta nella forma dell'Inviato, e chi obbedisce all'Inviato invero obbedisce ad Allah. Se guardi il Maestro con quest'occhio sai che non è altri che Allah, sia Egli esaltato, a decidere di te, e la forma del Maestro è uno strumento con cui Allah ti fa fare ciò che ti ordina la lingua di questo Maestro.

Quanto alla sua annotazione sul farti sortire all'esistenza dalla non-esistenza, egli vuol dire la tua uscita dal male puro al bene puro, che è l'esistenza; in uno degli accadimenti spirituali (waq $\bar{a} \imath^{\natural}$ ) parte della fede e la fede è metà pazienza e metà ringraziamento". 
l'Inviato del Vero mi disse da parte di Allah: "Sappiate che il male è nella non-esistenza ed il bene è nell'esistenza!" $\left.{ }^{380}\right)$.

Ma quando sei qualificato dall'esistenza è necessario che in quello stato tu sia con Allah come eri nello stato della tua non-esistenza, cioè che tu non ti opponga a Lui in ciò che Egli fa a te. Allora Egli ti vivificherà con la scienza e ti farà morire all'ignoranza, e farà per te una luce con cui camminerai nelle tenebre del tuo essere contingente $($ kazen $)\left({ }^{381}\right)$, sì che lascerai in eredità da parte tua a te [stesso] (taqifu min-ka 'alay-ka) ciò che ti iscrive tra i vivi che saranno nutriti, e saprai che Egli ti ha fatto morire all'opposto dello stato in cui sei. Allo stesso modo Egli "ti fa del male" con ciò [109] che ti ordina di ciò che non soddisfa il tuo interesse [individuale] e che la tua anima detesta. Invero tu hai fatto con lui un patto di ascolto e di obbedienza, sia in ciò che piace che in ciò che non piace; e "ti è di giovamento", per mezzo di ciò che trovi a seguito di questo danno, così come il malato trova sgradevole il medicamento al momento in cui lo beve, ma ad esso consegue salute e benessere.

Ed il suo detto: "ti abbandona", in quanto egli ti lascia nella situazione in cui chiedi aiuto per ciò che ti capita di quanto non ti è gradito delle vicissitudini del tempo, per il beneficio che vi vede per te; ed il suo detto: "ti onora", venendoti incontro con l'aiuto in un altro momento, conformemente allo stato, ed il suo onorare ( $\operatorname{tas} r \bar{y} f)$ è un onorare ed il suo abbandonare (hidlān) è un onorare per chi capisce; ed il suo detto: "ti spezza", cioè frustra la tua opinione di lui quando cerchi il suo aiuto e la sua assistenza nel respingere le avversità [ed egli non te li da]; ed il suo detto: "ti rimette a posto", togliendoti la cortina della cecità, sì che tu vedi il beneficio che ottieni da quella frattura (inkisār) che ti spezza, soprattutto se nella tua contemplazione vedi che la riparazione è [da parte] di Allah, poiché Allah, sia Egli esaltato, è presso ('inda) coloro che hanno i cuori infranti ( ${ }^{382}$ ), ed apprendi per via della

380) Su questo accadimento spirituale si può consultare la nota che si riferisce alla fine della pagina 15 del manoscritto. Va precisato che per Ibn 'Arabī vi sono due tipi di non-esistenza ('adam): la non-esistenza dell'impossibilità (muhāl) e quella della possibilità (imkān), e solo la prima può essere denominata come il male. Nel Cap. 559 [IV 370.33] egli afferma: "Solo chi ignora la realtà sostiene che la non-esistenza è il male, poiché quella non-esistenza in cui non c'è entità e di cui ciò che è caratterizzato da essa non ammette l'essere, non è altro che l'impossibilità e solo quella non-esistenza è il male puro sotto ogni aspetto. Quanto alla non-esistenza che implica le entità, quella è la non-esistenza della possibilità".

381) Riferimento al versetto: "E chi è morto e lo abbiamo vivificato e abbiamo fatto per lui una luce con cui cammina tra gli uomini, è forse simile a colui che è nelle tenebre da cui non esce?” (Cor. VI-122).

382) Hadīt non recensito nelle raccolte canoniche. Nel Cap. 471 [IV 103.25] Ibn 'Arabī afferma: "Nel compimento di quanto è obbligatorio non vi è profumo di Signoria, in virtù della quale [il servitore] se vuole compie e se vuole non compie una certa opera, come è il caso dell'opera supererogatoria. In ciò che è obbligatorio egli è senza dubbio un servitore forzato, costretto (mağbūr), e lo coglie lo spezzamento (inkisār), nella sua anima, per la potenza ('izza) che è in lui per il fatto che è lui a dare ad Allah la scienza di sé. Allah tuttavia ripara (yağburu) il suo esser spezzato con il Suo detto: "presso di Me la Parola non muta" (Cor. L-29): con questa frase Egli elimina dalla sua anima il "se vuole [fa] e se vuole [non fa]", e non gli lascia se non la stessa cosa che Egli vuole, e non la scelta in quello. Quando il servitore ascolta simili parole, la frattura (kasr) viene riparata (inğabara) [...] Svanisce quindi l'esser spezzato in cui si trovava, e ciò corrisponde al Suo detto, sia Egli esaltato, quando dice, nella notificazione in cui parla di Sé: "lo sono presso coloro che hanno i cuori infranti per causa 
riparazione la vicinità ('indiyya) ${ }^{(383)}$ connessa con quella frattura, e te ne rallegri e sai che il Maestro in quella frattura non voleva per te se non ciò in cui vi è la felicità e la buona novella per te.

Ed il suo detto: "ti umilia" per ciò che ti fa conoscere della tua servitù ('ubüdiyya); ed il suo detto: "ti rende potente" facendoti sapere che Allah, quanto alla Sua Ipseità (huwiyya) è l'insieme delle tue facoltà ed Egli Si manifesta nell'esistenza per la tua essenza, e poiché Egli ha la Potenza tu diventi potente, come ha detto Allah: "La Potenza appartiene al Allah, al Suo Inviato" per Allah, "ed ai credenti" (Cor. LXIII-8) per Allah e per l'Inviato; ed il suo detto: "per l'autorizzazione di Allah", cioè tutto questo per l'autorizzazione di Allah, sia Egli esaltato, al Maestro riguardo al suo disporre di te, secondo questi aspetti opposti.

Poi ha detto: "Se egli raggiunge il grado del Maestro, Allah assoggetta a lui i Cieli e la Terra", richiamando l'attenzione sulla stazione spirituale [110] della Maestria (šayhüha); non che essa sia il massimo grado, poiché la quota dell'eredità della Profezia che spetta al rango chiamato Maestro

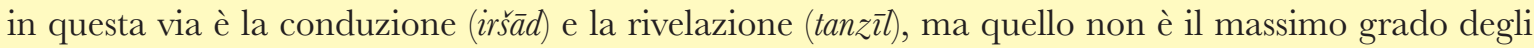
Inviati, che le salāt di Allah scendano su di loro. Per questo Egli antepone alcuni di loro ad altri, come ha detto, sia Egli esaltato: "di quegli Inviati abbiamo anteposto alcuni di loro ad altri” (Cor. II-253), ed ha detto: "ed invero abbiamo anteposto alcuni Profeti ad altri” (Cor. XVII-55), malgrado l'uguaglianza nella Missione e nella Profezia. In quanto Inviati essi sono una realtà (haqīqa) sola, e la differenza gerarchica ha luogo per un'altra faccenda, così come gli uomini hanno in comune la definizione di uomo in quanto tale e si differenziano in grado gli uni dagli altri per ciò che si aggiunge alla caratteristica di essere uomo. Il rango del Maestro è il rango degli Inviati nella conduzione ed il rango del medico tra i sapienti della Natura, anche se il medico non ha raggiunto il massimo grado nella scienza della Natura e non ne conosce se non ciò che regola il corpo degli animali o dell'uomo, se si arresta a questo, e se ne sa di più è gerarchicamente superiore agli altri medici, ma per una faccenda che non è connessa con la medicina $\left.{ }^{384}\right)$.

Mia", il ché significa: "lo ho spezzato i loro cuori con ciò che ho imposto loro, con cui li ho fatti entrare nella costrizione e li ho fatti scendere dalla roccaforte della loro potenza"."; e nel Cap. 558 [IV 281.14] aggiunge: "Tu sei l'ala fratturata, poiché Egli ti ha creato sulla Sua Forma poi ti ha fratturato con ciò che ti ha imposto per Legge, facendoti diventare soggetto ad ordine ed a proibizione. Poi ti ha riparato da questa frattura con ciò che ti ha tolto [di responsabilità] dicendo: "Ed Allah ha creato voi e ciò che voi fate" (Cor. XXXVII-96), poi ti ha fratturato con la ricompensa, poiché Egli non fa insieme a te se non ciò che sa, e non sa se non da te. Colui che è fratturato di nuovo non è altro che questo, ed egli è colui che è fratturato dopo una riparazione e la riparazione non ha luogo se non per una frattura, ed il principio è l'assenza di frattura, cioè l'integrità (sihha a), e non è altro che la Forma [divina]".

383) Il termine 'indiyya deriva dalla particella 'inda, che significa presso, vicino a. La vicinità di cui si tratta è quella menzionata nel hadīt qudsì: "lo sono presso coloro che hanno i cuori infranti per causa Mia".

384) Nel Cap. 181 [II 365.5] Ibn 'Arabī precisa: "Tra i sapienti per Allah [i Maestri] sono a guisa del medico rispetto a colui che ha la scienza della Natura; il medico non conosce la Natura se non in quanto essa governa specificamente il corpo umano, mentre colui che ha la scienza della Natura la conosce in modo incondizionato, anche se non è un medico". 
Quanto al suo detto: "Allah assoggetta a lui i Cieli e la Terra", si tratta del suo disporre (tahakkum) degli spiriti degli aspiranti e dei loro corpi, per mezzo degli esercizi e dei combattimenti spirituali, ed è in base a questo che essi [gli aspiranti] fanno un patto con lui, "e chi di loro [lo] infrange (nakata) lo infrange solo a proprio danno" (Cor. XLVIII-10). Non spetta al Maestro revocare il patto (bay'a) dell'aspirante se egli glielo chiede, ma gli dirà: "Se recedi da ciò che hai pattuito con me ne risponderai tu; quanto a me è impossibile che ti revochi il tuo patto, poiché mi è stato ordinato da Allah di darti il buon consiglio (nașîha), così come all'Inviato è stato ordinato di trasmettere".

Un uomo andò dall'Inviato di Allah, che Allah faccia scendere su di lui la Sua șalāt e la Pace, e gli disse: "Revocami il mio patto!", e l'Inviato di Allah, che Allah faccia scendere su di lui la Sua șalāt e la Pace, rifiutò e disse: "Non lo farò e se tu ti ritirerai, ti ritirerai con miscredenza!" ${ }^{(385)}$. Egli non lo fece e quell'uomo si tirò indietro, e la tradizione è nota [111].

Quanto all'assoggettamento (tashīr), Allah, sia Egli esaltato, ha detto: "Egli ha assoggettato a voi ciò che è nei Cieli e ciò che è sulla Terra, tutto da parte Sua“" (Cor. XLV-13), e l'assoggettamento della cosa nei tuoi riguardi consiste solo nel [suo] conferirti ciò che è in suo potere di quanto Allah le ha affidato nei tuoi confronti, non si tratta di un assoggettamento proprio $(\underline{d} \bar{a} t \bar{\imath})$.

Abū Ṭālib al Makkī ( $\left.{ }^{386}\right)$ ha detto riguardo alle sfere celesti (aflāk) che esse ruotano per i soffi (li anfās) del Mondo $\left.{ }^{387}\right)$ ed il significato di quanto ha detto è che il motivo della loro rivoluzione (dawrān) e dei

385) La prima parte del hadīt è riportata da al-Buhārī, XCIII-45 e 47, XCVI-16, Muslim, XV-489, at-Tirmid̄ī, XLVI-67, Mālik, XLV-4 e da an-Nasā'̄i, XXXIX-22, mentre la seconda parte, cioè la risposta, non è recensita nelle raccolte canoniche, ed è sostituita da un commento diverso.

386) Della vita dello Šayh Abū Ṭālib Muhammad ibn 'Alī al-Ḥārit̄ī al-Makkī non ci sono pervenuti molti dettagli: cresciuto alla Mecca, si trasferì prima a Basra e poi a Bagdād, ove morì nell'anno 386 dall'Egira. Egli è noto soprattutto per il suo "Libro del nutrimento dei cuori (Kitāb qūt al-qulüb)", di cui è disponibile una traduzione in lingua tedesca a cura di Richard Gramlich: Die Nahrung der Herzen, 4 volumi, Franz Steiner Verlag, Stoccarda, 1992-1995. Al-Gazālī, nel redigere l'Ihya ', si ispirò ampiamente a quest'opera, talvolta copiandone letteralmente il testo. Al-Makkī è citato una ventina di volte nelle Futūhăt, nei capitoli: 2 [I 58.14 e 87.8, 10, 11, 12, 15, 18], 14 [I 184.18], 48 [I 266.9], 53 [I 277.30], 67 [I 326.31], 69 [I 441.17], 71 [I 602.34], 73 [II 7.25, 39.27, e 129.18], 178 [II 355.8], 312 [III 48.16], 378 [III 488.12] e 558 [IV 208.28].

387) L'unico punto del Kitāb qūt al-qulūb in cui sia questione di soffi e di sfere celesti è il seguente brano della decima sezione [pag. 26 dell'edizione Dār Sāder, Beirut, senza data], ove Abū Ṭālib precisa: "Uno dei conoscitori ha detto qualcosa di ancor più stupefacente e sottile riguardo al Potere di Allah, quanto è Potente e Magnificente, ed alla Sua opera nascosta. Egli ha menzionato che la notte ed il giorno sono 24 ore, che l'ora è [fatta di] 12 minuti, che ogni minuto è 12 ša ira e che ogni ša ira è 24 soffi [(anfäs), attimi]. I soffi si manifestano

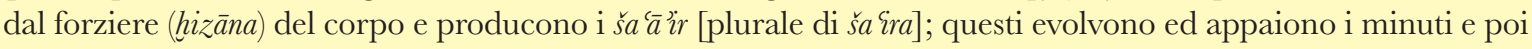
le ore; le ore si mettono in moto e fanno girare le sfere celesti (aflak); le sfere celesti ruotano e fanno espandere la notte ed il giorno nell'atmosfera e nelle regioni della Terra; quando la notte ed il giorno si espandono, fanno ruotare il Cielo negli orizzonti e ciò che era previsto si coagula [cioè si realizza] in modo dettagliato. Quando la sensibilità (ihsās) svanisce ed i soffi cessano, le sfere celesti si disgiungono (infakkat) e con esse le stelle si disperdono ed il Cielo si fende, e le dimore vengono demolite ed appare la dimora della persistenza (qarār) [...] Gloria al Sottile, il Saggio. Egli fa girare quelle sfere grossolane per mezzo di questi soffi sottili, così come cela 
loro movimenti è che esse conferiscono la respirazione (tanaffus) in chi respira, poiché esse ne sono garanti, e quando è finito ciò che è deposto in esse di questo dare, e non resta nel Mondo nessuno che respiri, poiché non resta per esse un soffio da conferire, il Mondo perisce, il Cielo si fende, gli esseri viventi muoiono e l'edificio ('umrān) viene trasferito nella dimora dell'aldilà ( $\left.{ }^{388}\right)$.

E questo fa parte dell'assoggettamento dei Cieli e della Terra, poiché Allah, sia Egli esaltato, ha reso la Terra piana $\left.{ }^{389}\right)$ ed ha stabilito in essa i suoi nutrimenti $\left({ }^{390}\right)$ in ciò che fa uscire da essa, e del suo [della Terra] assoggettamento specifico, come il suo ripiegamento (tayy) nei confronti di alcuni uomini $\left({ }^{391}\right)$ e come il suo far sortire qualcosa prima del suo tempo abituale, secondo il corso abituale della Natura, non secondo la Natura, poiché noi non abbiamo conoscenza della Natura se non nella misura di ciò che essa ci conferisce da se stessa, e anche ciò che ci è arrivato da essa prima del suo

la sfera grossolana con il velo dello spazio $\left(f a d \bar{a}^{\prime}\right)$ sottile. La Sfera suprema non cela il Cielo, mentre lo spazio tenue cela la Sfera, poiché Egli, Gloria a Lui, sia Egli esaltato, volle farci vedere il Cielo e volle che fosse nascosta a noi la Sfera: quindi non vediamo se non ciò che Egli ci fa vedere. È il servitore che ne è la causa (sabab) ed il motore, ma non se ne accorge. Il suo fulcro (madār) sono i suoi soffi, i suoi soffi sono le sue ore, le sue ore sono la [durata della ] sua vita, la durata della sua vita è il suo termine (ağal) ed il suo termine è il suo aldilà; ma egli è noncurante in questo suo mondo mentre gioca con ciò che gli piace. Se osservi il Cielo vedi che esso produce i soffi, se osservi i soffi vedi che essi fanno girare le sfere celesti e se osservi ciò che sta al di sopra di tutto ciò diventi cieco riguardo a tutto il resto".

È curioso notare che il termine "attimo", che ha assunto nella lingua italiana una connotazione esclusivamente temporale, deriva dal germanico "atem", che significa "soffio", come l'arabo "nafas".

Ibn 'Arabī tratta questo aspetto dottrinale nel Cap. 2 [I 87.14] in riferimento alla sfera da cui traggono esistenza le vocali, precisando che "si tratta di un segreto stupefacente, tra i più grandi segreti divini, ed Abū Ṭālib ha fatto allusione ad esso nel suo Libro del nutrimento [dei cuori]", e ne accenna nei capitoli 67 [1 326.30] ove afferma che la sfera ruota per mezzo dei soffi (bi anfās) del Mondo, 69 [I 441.17] e 178 [II 355.8] ove afferma che la sfera ruota per mezzo dei soffi dell'uomo. Cfr. anche il Kitäb nushat al-haqq, pagg. 267 e 272 del primo volume delle Rasā ỉl ibn 'Arabī curata da Sa'īd 'Abd al-Fattāh, Beirut, 2001.

388) Nel Kitāb nushat al-haqq, a pag 272 dell'edizione citata, Ibn 'Arabī precisa: "Sappi che l'affermazione del Sûfí che la sfera celeste ruota per i soffi del Mondo, si riferisce al Mondo che respira, cioè il motivo della sua rivoluzione è l'esistenza dei soffi, cioè in occasione della sua rivoluzione Allah genera i soffi. Quando non resta in essa movimento che conferisca un soffio in chi respira essa non dà vita, e quando non dà vita la vita si è allontanata da essa, e quando la vita si allontana da essa non le resta alcuna brama (šawq), e quando non le resta alcuna brama non fa più alcun movimento, e quando non ha più alcun movimento la sfera celeste si spezza e scompare tutto il Mondo elementare. Abū Țālib [al-Makkī] ha menzionato questa questione, ma non l'ha spiegata, nel capitolo dedicato ai momenti temporali $(a w q \bar{a} t)$. Questo è uno dei sensi per cui si dice che la sfera celeste ruota per i soffi del Mondo. Un altro senso è che quando la sfera celeste ruota essa conferisce un inizio agli esseri prodotti (muwalladât), nel principio della sua rivoluzione, ed il numero delle sue rivoluzioni è per il numero dei soffi che esistono negli esseri prodotti; essa quindi ruota per il loro numero e quando sono finiti l'ordine (nizām) è distrutto e l'edificio ('imara) viene trasferito nell'aldilà'.

389) Cfr. Cor. LXVII-15.

390) Cfr. Cor. XLI-10.

391) L'espressione tayy al-ardi indica il ripiegamento della Terra, che accorciandosi consente di percorrere distanze più lunghe nello stesso tempo in cui ordinariamente si percorrono distanze brevi. Ibn 'Arabī accenna a questo carisma nel Cap. 184 [II 369.14 e 34]. 
tempo fa parte di essa: essa ci ha conferito ciò per l'autorizzazione del suo Signore, e se non fosse nel suo potere dare quello non vedremmo nulla di ciò, mentre noi lo vediamo.

Racconto. Muḥammad ibn 'Abd al-Karīm, il probo ('adl) ( $\left.{ }^{392}\right)$, ci ha riferito nella città di Fes che Abū l-Ḥasan ibn Harāzim ( $\left.{ }^{393}\right)$, Allah abbia Misericordia di lui, gli disse: "Quando ero piccolo, [vi fu un periodo in cui] la pioggia venne negata agli uomini. Sul monte Zarhūn ${ }^{394}$ ) viveva un uomo noto per la [sua] pietà (salāh), e mio padre si recò da lui portandomi con sé.

Quando arrivammo da lui aveva in mano una lastra di ferro che teneva sul fuoco per riscaldarla, al fine di cuocere su di essa del pane per sé. Mio padre gli raccontò della cessazione della pioggia e gli chiese di pregare affinché piovesse. L'uomo disse: "L'aumento dei prezzi [112] non dipende dalla cessazione della pioggia e la terra non si copre di vegetazione perché la pioggia scende su di essa. Se Allah volesse far crescere una spiga su questo ferro che sta sul fuoco la farebbe crescere!". Ibn Harāzim disse: "Vidi crescere la spiga sulla lastra di ferro che era sul fuoco, la prendemmo, la

392) Si tratta dello Šayh Abū 'Abd Allāh Muhammad ibn al-Qāsim ibn 'Abd ar-Raḥmān ibn 'Abd alKarīm at-Tamīmī al-Fāsī, che Ibn 'Arabī incontrò a più riprese nei suoi soggiorni a Fes e da cui ricevette un'investitura spirituale (hirqa) nell'anno 593 dall'Egira, come riportò nel suo Kitāb nasab al-hirqa, a pag 35 dell'edizione pubblicata da Dār al-Qubba az-Zarqā', Marrakesh, 2000. Originario di Fes, at-Tamīmī, dopo aver fatto il Pellegrinaggio alla Mecca e viaggiato per una quindicina di anni in paesi "orientali", apprendendo la scienza delle tradizioni profetiche e nel contempo ricollegandosi al Tasawrouf, si stabilì definitivamente a Fes, ove fu discepolo anche di Abū Madyan, e dove morì nell'anno 603 dall'Egira. Scrisse una ventina di opere tra cui una agiografica dedicata agli Intimi (awliy $\bar{a})$ della città di Fes e dei suoi dintorni, di cui è stata pubblicata nel 2002 a Tetouan una edizione incompleta, contenente 115 notizie biografiche [Kitāb al-mustafäd fì manäqib al-ubbād bi-madīna fās wa mā yalī-hā min al-bilād, a cura del Dr. Muḥammad aš-Šarīf].

Ibn 'Arabī lo cita tre volte nel Cap. 560, datando anche le diverse occasioni: [IV 503.23] "Questo aneddoto, insieme ad altri episodi, è stato riportato dal nostro Maestro Abū 'Abd Allāh Muhammad ibn Qāsim ibn 'Abdur-Raḥmān ibn 'Abd al-Karīm at-Tamīmī al-Fāsī, Imām della Moschea al-Azhar, nel quartiere di 'Ayn alhayl della città di Fes, in un suo libro intitolato "Il profitto nella menzione degli adoratori pii" o "nella menzione degli adoratori nella città di Fes e nel territorio circostante" Abbiamo ascoltato questo libro dalla sua viva voce, penso, nell'anno 593"; [IV 541.22]: "Di ciò fa parte quello che ci ha riferito Abū 'Abd Allāh Muhammad ibn Qāsim ibn 'Abdur-Raḥmān ibn 'Abd al-Karīm at-Tamīmī nella moschea al-Azhar, sita nel quartiere di al-Hayl nella città di Fes, nell'anno 591, dalla sua viva voce, mentre lo ascoltavo"; e [IV 549.25]: "Ho sentito Muḥammad ibn Qāsim ibn 'Abdur-Rahmān ibn 'Abd al-Karīm at-Tamīmī al-Fāsī, il probo, nella città di Fes, credo nell'anno 594 dire [...]”. Inoltre lo nomina nel Cap. 42 [I 244.17], e nel Kitāb muhādarat al-abrār, Vol. I, pag. 12, dichiarando che at-Tamīmī gli aveva trasmesso il suo Kitäb al-lum'a, dedicato alle mogli del Profeta ed ai suoi sette figli.

393) Abū l-Ḥasan 'Alī ibn Ismāềil ibn Muḥammad ibn 'Abd Allāh ibn Ḥarāzim, o ibn Ḥirzihim, originario di Fez, apprese gli insegnamenti di al-Gazālī dallo zio paterno Abū Muhammad Șāliḥ ibn Ḥirzihim, che conobbe direttamente al-Gazālī nel corso dei suoi viaggi In Oriente; a sua volta Abū l-Ḥasan trasmise questi insegnamenti al giovane Abū Madyan. Morì a Fes nell'anno 559 dall'Egira. Cfrr. Ibn al-Zayyāt at-Tādilī, Regards sur le temps des Soufis, Editions Unesco, 1994, pagg. 129-133, e V.J. Cornell, Realm of the Saint, University of Texas Press, 1998, pagg. 24-26. Non è mai citato nelle Futühăt.

394) Piccolo monte situato a 60 chilometri da Fes, sulle cui pendici venne ritrovato nel 1318 il corpo di Mulay Idrīs I e fondata l'omonima città santa. 
sgranammo e la mangiammo". Il Maestro disse: "Ti ho fatto solo un esempio e non è escluso che esso faccia parte di ciò che Allah autorizza alla Natura di conferire: la sua realtà è ignota e le forze che essa comporta sono ancora più ignote". Disse ibn Harāzim: "Tornammo alla città di Fes, senza che piovesse, ed Allah proiettò nei cuori la sazietà e la soddisfazione, sì che arrivò la prosperità ed il benessere e venne tolto il rincaro dei prezzi ed il bene si moltiplicò nel territorio, tanto che gli uomini non videro un anno più prospero di quello, malgrado la cessazione della pioggia e la siccità (mahl), confermando la veridicità di quanto aveva detto quell'uomo pio".

Quanto all'uomo perfetto (ar-rağul al-kāmil) che si manifesta nel Mondo con la forma del Vero, affinché Lo conosca tutto il Mondo $\left.{ }^{395}\right)$ ad eccezione di alcuni degli uomini e dei ğinn (at-taqalān) ${ }^{(396)}$, non c'è dubbio che i Cieli e la Terra e chi si trova in essi, ad eccezione di alcuni degli uomini e dei ğinn, sono assoggettati a lui $\left.{ }^{397}\right)$, così come i Cieli e la Terra e chi si trova in essi lo glorificano. Quando essi videro la forma divina [dell'uomo perfetto] dalla loro glorificazione venne il loro stesso assoggettamento a

395) Riferimento allo hadīt qudsī, non recensito nelle raccolte canoniche: "Ero un tesoro nascosto ed amai di essere conosciuto: Allora ho creato le creature al fine di essere conosciuto da esse". Nel Cap. 358 [III 266.27] Ibn 'Arabī afferma: "Allah, sia Egli glorificato, volle essere conosciuto, come abbiamo affermato, per mezzo della conoscenza contingente (häditita) affinché fossero resi perfetti i gradi della conoscenza e l'esistenza venisse resa perfetta con l'esistenza contingente. Poiché una cosa non può essere conosciuta se non da se stessa o da un suo simile era necessario che l'essere contingente a cui Allah ha dato l'esistenza perché Lo conoscesse fosse sulla forma di Colui che gli ha dato l'esistenza, in modo da essere il Suo simile. L'Uomo Universale è una realtà essenziale unica".

396) L'espressione "at-taqalān", che ricorre in Cor. LV-31, significa letteralmente "i due dotati di peso" ed è attribuita tradizionalmente ai ğinn ed agli uomini. Nel Cap. 43 [I 247.20] Ibn 'Arabī afferma: "Poiché la maggior parte degli uomini e dei ğinn (at-taqalān) ignora queste scienze, per questo non conoscono i gradi di questi iniziati, e non li lodano e non si interessano di loro. Per questo Egli, sia esaltato, ha reso noto che ogni cosa nel mondo si prosterna ad Allah, sia Egli esaltato, senza distinzione, ad eccezione degli uomini, dicendo: "Non vedi che si prosterna ad Allah chi è nei Cieli e chi è sulla Terra, il Sole, la Luna, le stelle, le montagne, gli alberi e gli animali", senza distinzione, "e molti degli uomini?" (Cor. XXII-18), distinguendo negli uomini gruppi diversi"; e nel Cap. 177 [II 305.12] aggiunge: "Sappi, che Allah ti assista, che ad eccezione degli uomini e dei ğinn (at-taqalān) tutto ciò che è altro che Allah ha conoscenza di Allah, riceve una rivelazione da parte Sua e sa Chi Si manifesta a lui. Ciò è innato per essi ed essi sono tutti beati. Per questo Egli, sia esaltato, ha detto: "Non vedi che si prosterna ad Allah chi è nei Cieli e chi è sulla Terra?", facendo una affermazione generale. Poi ha distinto per spiegare agli uomini ciò che è disceso su di loro ed ha detto: "il Sole, la Luna, le stelle, le montagne, gli alberi, gli animali e molti degli uomini" (Cor. XXII-18). Ciò corrisponde al Suo detto: "Salvo coloro che credono e che compiono buone opera, e pochi non sono" (Cor. XXXVIII-24), cioè non sono pochi e quindi sono molti, come nella Sua frase "e molti degli uomini" (Cor. XXII-18). Poi ha detto: "e molti meritano il castigo" (Cor. XXII-18)".

397) Nel Cap. 198 [II 469.2] Ibn 'Arabī precisa: "Sappi che tutti i gradi sono in origine divini e le loro proprietà si manifestano nell'esistenza contingente. Il rango divino più elevato si è manifestato nell'Uomo Universale ed il rango più elevato è l'indipendenza da ogni cosa, e questo rango non si addice se non ad Allah, quanto alla Sua Essenza. Il rango più elevato nel Mondo è l'indipendenza per mezzo di ogni cosa, e se preferisci puoi dire la povertà verso ogni cosa: questo è il rango dell’Uomo Universale. Ogni cosa è stata creata per lui ed a causa sua ed è assoggettata a lui, in quanto Allah sapeva del suo bisogno di essa, per cui egli non ha alcuna indipendenza da essa". 
lui, poiché l'uomo, anche se è secondo la forma divina, non si allontana dalla realtà essenziale della dipendenza (iftiquar) ed è per questa realtà essenziale che ha luogo l'assoggettamento a lui.

"I sette Cieli, la Terra e chi è in essi Lo glorificano" cioè Allah, sia Egli esaltato, "e non c’è cosa che non glorifichi con la Sua lode" (Cor. XVII-44), cioè afferma la Sua trascendenza dalla dipendenza, e questo è il significato della glorificazione in questo versetto $\left({ }^{398}\right)$; e nei confronti di quest'Uomo Universale (al-insān al-kāmil) la glorificazione diventa assoggettamento, per la forza della dipendenza verso Allah, sia Egli esaltato, che si vede in lui.

E nella misura in cui sussiste nell'uomo la convinzione di non aver bisogno di Allah per via delle cause seconde $(a s b \bar{a} b)$, per la noncuranza che lo coglie, in quella misura è impedito l'assoggettamento del Mondo a lui, ed egli si affanna ad ottenere qualcosa con la sua anima e con il suo corpo. Con questo [113] ti ho chiarito ciò a cui alludeva quest'uomo nel suo riportare da parte del Maestro: "invero Allah assoggetta a lui i Cieli e la Terra".

Poi ha detto: "Custodisci la tua faccenda in tutto ciò, e se sei in presenza di qualcuno, o se sei pregato di venire ad un invito $(d a w a)$, mangia, e se stavi digiunando non mostrare che stai digiunando, e se mangi di meno è meglio".

Commento. Questa raccomandazione non è possibile che riguardi un aspirante alla presenza di un Maestro, poiché egli si conforma al Maestro, e quindi questa è una raccomandazione soltanto per colui che è con la sua anima e la governa. Ciò che lo ha spinto ad una simile affermazione è la sua paura che egli ['aspirante] si faccia bello di fronte al prossimo per l'atto di adorazione che sta compiendo; egli ha ritenuto che colui che digiuna in un atto di obbedienza volontario (tatawrer $)$ comanda se stesso, ed ha ritenuto che la rottura [del digiuno] sia preferibile per lui, senza far sapere del suo digiuno, e più fedele (ahlas) al suo atto. Questa è la situazione di costui che ha fatto la raccomandazione, ed egli ha parlato in base a se stesso. Quanto a ciò che è corretto e sancito è che egli non rompa, continuando il digiuno, e preghi (yad u) ${ }^{(399}$ ) per colui che ha fatto l'invito, mettendo così insieme la notificazione (habar) ed un'altra cosa che gli è richiesta. La notificazione in oggetto è il suo detto, su di lui la Pace: "Se uno di voi è invitato ad un banchetto risponda" ${ }^{400}$ ), quindi la risposta è obbligatoria per te, "e se non sta digiunando mangi, mentre se sta digiunando continui" $\left.{ }^{401}\right)$, cioè preghi per colui che offre il nutrimento.

398) Nel Cap. 393 [III 555.14] Ibn 'Arabī afferma: "Allah è indipendente dai Mondi e l’indipendenza è un attributo di trascendenza, e secondo noi la lode più grande nei riguardi del Vero è il Suo detto, sia Egli esaltato: "Non c’è cosa simile a Lui" (Cor. XLII-11) [...] Ed il Vero, sia Egli glorificato, non ha lodato Se stesso con qualcosa di più grande della negazione del simile, e non c'è simile a Lui, sia Egli glorificato. Per questo Egli ha detto del Mondo in quanto dotato di parola: "e non c'è cosa che non glorifichi con la Sua lode" (Cor. XVII-44) e la glorificazione è una affermazione di trascendenza".

399) Dicendo: "Allah ti benedica (bāraka Allahu fì ka)!]".

400) Hanbal.

401) Hadīt riportato da Abū Dāwud, XXVI-2, come tradizione separata dalla precedente. 
Quanto al suo ordine di mangiare e all'attenersi ad esso secondo l'aspetto che egli ha menzionato, è che quando l'uomo intraprende un atto di adorazione egli stringe e rispetta il suo patto con Allah e non lo rompe finché non lo ha portato a termine, e se lo rompe fa parte [114] di coloro che rompono il patto di Allah dopo averlo contratto; ed Allah ha anche detto: "O voi che credete, obbedite ad Allah ed obbedite all'Inviato e non vanificate le vostre opere" (Cor. XLVII-33): per questo alcuni sapienti ritengono che se [colui che digiuna] rompe sia tenuto a recuperare, ed al riguardo è pervenuta una notificazione $\left.{ }^{402}\right)$.

È quindi indispensabile per chi sta digiunando seguire la raccomandazione, da parte di questo Maestro, di mangiare; e questa persona [il Maestro] deve sostenere [l'obbligo] del recupero, e quindi [l'aspirante] è tenuto ad esso per Legge. Ora, se egli è tenuto ad esso per Legge e nel suo primo digiuno compie un atto di obbedienza volontaria, avendo la ricompensa di chi compie un atto di obbedienza volontaria [se lo completa], nel recuperare compie un atto obbligatorio, avendo così la ricompensa di chi compie un atto obbligatorio ed essa è più completa, e quindi egli si proponga questo, ovviamente se rompe il digiuno. Ma il primo [comportamento] è preferibile, cioè che non rompa il digiuno.

I Maestri, Allah sia soddisfatto di loro, dicono ciò che esigono i loro stati spirituali nei loro momenti, caratteristica che è specifica di essi a differenza dei perfetti tra di loro, poiché questi dicono ciò che esige il momento nei confronti di chi ascolta, non nei confronti di chi parla.

Quanto al suo detto: "e se mangi di meno è meglio", questo lo esige la via degli iniziati, cioè il mangiare poco, poiché in ciò sta la purezza dell'anima, la prestanza delle membra, la durevolezza della salute e l'assenza degli eccessi ${ }^{403}$. Egli, su di lui la Pace, ha detto: "Al figlio di Adamo bastano alcuni bocconi per tener dritta la sua spina dorsale" ( $\left.{ }^{404}\right)$; il limite ( hadd) nel mangiare per ogni uomo è che egli prenda del cibo nella misura di quanto egli sa che non lo renderà troppo debole per compiere ciò in cui Allah ha reso obbligatorio per lui il movimento corporeo, come fare la salāt, esercitare un mestiere, e sforzarsi di acquisire il sostentamento per la famiglia: questo e niente altro.

402) Nel Cap. 71 , nella sezione dedicata alla rottura del digiuno di obbedienza volontaria [I 634.1] Ibn 'Arabī afferma: "Uno di loro [dottori della Legge] ha riferito il consenso sul fatto che colui che inizia il digiuno per obbedienza volontaria e poi lo rompe per un motivo giustificato non è tenuto a recuperare. Vi è divergenza se egli lo interrompe deliberatamente, senza un motivo valido: c'è chi sostiene che sia tenuto al recupero e chi sostiene che non sia tenuto ad esso", ma non riporta alcuna notificazione.

403) Ibn 'Arabī ribadisce l'importanza della fame (ğu') nella via iniziatica nel Cap. 53 [I 278.11] e nel trattato intitolato Hilyat al-abdāl, tradotto da Stephen Hirtenstein con il titolo "The four pillars of spiritual transformation", Anqa Publishing, 2008.

404) Hadīt riportato da Ibn Māğah, XXIX-50. Ibn ‘Arabī lo riporta nei capitoli 71 [I 660.18], 106 [II 188.14], 333 [III 125.13] e 397 [III 560.13]. 
Quanto al suo detto: "Custodisci la tua faccenda in tutto ciò", egli vuol dire: custodisci la tua faccenda con Allah, cioè mira all'avvicinamento ad Allah in tutti i tuoi movimenti [115] e le tue soste, persino in ciò che è lecito $(m u b \bar{a} h)$ e che non comporta alcuna ricompensa né pena. Chi si trova in questa condizione verrà ricompensato per ciò, in quanto egli compie ciò che è lecito sapendo che è lecito - e la convinzione di ciò è obbligatoria per lui - ed il suo aver presente questa convinzione nel momento in cui compie ciò che è lecito fa sì che sarà ricompensato con la ricompensa di ciò che è obbligatorio, malgrado egli agisca a suo arbitrio in ciò che gli è lecito fare.

Poi ha detto: "È necessario per te, o aspirante, sforzarti di soddisfare i bisogni dei musulmani, farti prendere da compassione (riqqa), considerare te stesso il più insignificante degli uomini ed il più povero di essi nei confronti di Allah, sia Egli esaltato. E comincia con la gente della tua casa, per quanto ti è possibile, preferendo loro a te stesso; anteponi il loro bisogno al tuo bisogno al massimo della tua capacità, ed anteponi gli interessi del tuo Maestro al tuo interesse, se egli gradisce da parte tua lo sforzo in questo; e preferisci lui a te stesso, al punto da preferire la sua permanenza alla permanenza di te stesso, e moltiplica l'abbassarti e l'essere umile di fronte a lui, al punto che se potessi diventare la terra su cui cammina lo faresti“.

Quanto alla sua affermazione di "sforzarti di soddisfare i bisogni dei musulmani", con questo egli intende dire di anteporre nel tuo sforzo i bisogni dei musulmani, cioè, quando ti capita un bisogno indispensabile per un musulmano e per uno che non è musulmano, devi anteporre il bisogno dei musulmani, così come Allah ha preferito lui [il musulmano] dandogli la Sua assistenza nel conferirgli l'Islām ed escludendo altri da esso. Allah ha stabilito dei gradi riguardo a ciò che è necessario anteporre, [gradi] che ha precisato, come il vicino (ğâr) più prossimo al vicino più lontano, e come la moglie al figlio, che è un pezzo del fegato $(k i b d)\left({ }^{405}\right)$.

Invero ciò che è voluto dagli iniziati è che si sforzino di soddisfare i bisogni delle creature in senso assoluto, assumendo in ciò i tratti di carattere di Allah, sia Egli esaltato, [116] poiché Allah, sia Egli esaltato, è ogni giorno occupato a creare [le creature], dalla prima all'ultima, chi di esse entra nell'esistenza e chi non vi entra, poiché ciò che è connesso all'occupazione è il dare l'esistenza a ciò che è non-esistente, e questo compete ad Allah, sia Egli esaltato.

Occuparsi a soddisfare i bisogni delle creature è la più perfetta caratterizzazione (tahalluq) possibile per il servitore, poiché egli si sforza di dare esistenza a ciò che non esiste, in quanto chi ha un bisogno non possiede ciò di cui ha bisogno e questo servitore si sforza di dare esistenza a ciò presso di lui.

Non hai considerato che la prostituta, quando vide un cane con la lingua penzolante per la sete, si tolse una scarpa, la riempì con l'acqua del pozzo e diede da bere al cane, ed Allah la ringraziò

405) L'affermazione che il figlio è un pezzo del fegato ricorre nei capitoli 70 [I 583.29], ove è precisato che è tratta da una poesia della Hamāsa [di Abū Tammām], in cui è recitato: "invero i nostri figli tra di noi * sono i nostri fegati che camminano sulla Terra", e 559 [IV 363.35 e 394.13]. 
per il suo gesto e la perdonò per avere abbeverato un cane? ${ }^{406}$ ) Cosa avrebbe fatto [Allah] se si fosse trattato di un uomo? E cosa avrebbe fatto se si fosse trattato di un musulmano? Ed Allah ha detto: "Ci occuperemo di voi, o uomini e ğinn" (Cor. LV-31). Egli non ha altra occupazione che il Mondo, poiché non ha affaccendamenti se non con ciò che è altro che Lui, ed Egli è colui che dà continuamente l'esistenza, ed a lui appartiene il Dominio (malaküt) di ogni cosa.

Se tu ti sforzi di soddisfare i bisogni delle creature sei a questa stregua, dotato di un Attributo divino, e chi è qualificato da un Attributo divino ed è ornato da esso, quell'Attributo lo fa arrivare al suo [dell'Attributo] rango ed alla sua dimora rispetto ad Allah.

Quanto alla sua affermazione di "farti prendere da compassione", il Profeta, su di lui la Pace, ha detto: "per [il bene fatto ad] ogni animale [lett. : fegato (kibd) umido] assetato dall'arsura, vi sarà una ricompensa!" ${ }^{407}$; ; e ciò che ha portato questa prostituta ad abbeverare questo cane assetato non era che compassione e pietà insorta nel suo cuore per lui, ed Allah la ringraziò per il suo gesto e la perdonò per quello. Quanto a ciò che l'ha indotta alla compassione che è insorta in lei, non ne valuta l’importanza se non Allah, sia Egli esaltato.

Mi riferì al-Hasan, l'illustre insegnante di Malatiya, discendente di Salmān al-Fārisī, che il governatore di Buhāāā stava passeggiando quando vide un cane rognoso in un giorno molto freddo; venne preso da compassione per lui ed ordinò ad una delle sue guardie di portare il cane in casa, lo trattò con gentilezza e lo onorò, fece accendere per lui un fuoco e lo mise in un posto [117] in cui potesse scaldarsi, e gli diede da mangiare e bere. Ed egli vide, in ciò che vede colui che è addormentato, che veniva acclamato per ciò, malgrado fosse ingiusto nel suo governo: "O tale, eri un cane e ti abbiamo perdonato (wahabnā) per un cane!". Dopo tre giorni [il governatore] morì ed ebbe un mausoleo [o funerale $($ mašhad $)$ ] immenso simile a quelli delle persone note alla gente per la [loro] integrità, ed Allah pose per lui nelle anime degli uomini il consenso ed il bell'apprezzamento, così come egli si era dedicato a quel cane, e questo fu il frutto di quella compassione da cui fu caratterizzato $\left.{ }^{408}\right)$.

Quanto alla sua affermazione di "considerare te stesso il più insignificante degli uomini ed il più povero di essi nei confronti di Allah, sia Egli esaltato", egli allude con la sua raccomandazione

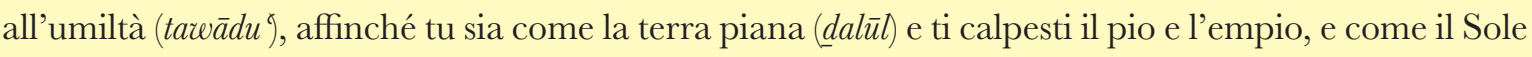

406) Hadīt riportato da al-Buhārī, LX-54, Muslim, XXXIX-154 e 155, e da ibn Ḥanbal. Ibn 'Arabī lo cita nel Cap. 170 [II 287.29] e nel Cap. 560 [IV 464.27].

407) Hadīt riportato da al-Buhārī, XLII-9, XLVI-23, LXXVIII-27, Muslim, XXXIX-123, Abū Dāwud, XV44, Mālik, XLIX-23, e da Ibn Ḥanbal. Ibn 'Arabī lo riporta nei capitoli 69 [I 424.19], ove precisa che il fegato è la dimora $(d \bar{a} r)$ del sangue, 170 [II 287.29], 371 [III 436.3], e 560 [IV 464.27 e 484.25], ove afferma: "È tuo dovere aver compassione (šafaqa) dei servitori di Allah in modo generale, anzi di ogni essere vivente poiché in ogni essere vivente [lett: fegato umido] vi è una ricompensa presso Allah, sia Egli esaltato".

408) Questo racconto è riportato testualmente nel Cap. 560 [IV 464.29] ed accennato nel Cap. 170 [II 287.30]. È riportato anche nel Kităb al-amr al-muhkam, a pag. 342 della traduzione di Asín Palacios già citata. 
che, malgrado la sua elevatezza e la sua purezza, getta i suoi raggi sui letamai e sull'immondizia e non esime se stesso da quello. Allo stesso modo è necessario che si comporti il credente con le creature, senza considerare la loro condizione attuale per quanto attiene all'obbedienza ed alla disobbedienza, alla miscredenza ed alla fede, e le loro meschinità non gli devono precludere quello, poiché Allah non fa sapere a questo servitore in modo specifico come ciascuno andrà a finire.

Per questo al-Qušayrī, quando menzionò [nella sua Epistola] i Maestri spirituali, riferì che uno dei signori $(s \bar{a} d \bar{a} t)$ disse: "Chi ritiene di essere migliore del Faraone è un orgoglioso" $\left.{ }^{409}\right)$.

Il servitore deve considerare se stesso assoggettato a tutte le creature per l'assoggettamento di Allah, ed in quanto è assoggettato a tutte le creature di Allah deve ritenere, riguardo a se stesso, di essere la creatura più insignificante in valore, poiché la misura di chi è assoggettato è stabilita in base a colui a cui è assoggettato ed egli è assoggettato alla creatura più insignificante in valore e quindi egli è ancora più insignificante di essa.

Allah, sia Egli esaltato, ha detto: "Noi abbiamo elevato in grado gli uni sugli altri affinché gli uni prendessero gli altri come servi” (Cor. XLIII-32) ed ha quindi assoggettato il più elevato al più basso, in ciò a cui [il più basso] lo ha assoggettato $\left({ }^{410}\right)$. Poni mente a questa questione, poiché [118] essa è

409) Si trattava di Abū Șālị Ḥamdūn ibn Aḥmad ibn 'Umāra al-Qassār, morto nell'anno 271 dall’Egira, e la frase citata è riportata a pag 20 dell'edizione del Cairo del 1959. Ibn 'Arabī la riporta anche nel Cap. 69 [I 527.33]. L'espressione "signori" viene usata da Ibn 'Arabī per indicare i Malāmiyya [Cap. 309 (III 36.33)], e questo era il caso dello Šayh Hạdūn, come afferma nel Cap. 309 [III 34.10].

410) Nel Cap. 153 [II 249.7] Ibn 'Arabī precisa: "Essi [gli uomini] sono assoggettati (musahharūn) gli uni agli altri, il più alto al più basso ed il più basso al più alto, e chi è intelligente non può negarlo, perché è quello che succede. Il rango più elevato è quello del Re ed il Re è assoggettato agli interessi dei sudditi e del volgo, ed i sudditi ed il volgo sono assoggettati al Re. L'assoggettamento (tash $\bar{r} r)$ del Re da parte dei sudditi non dipende dall'ordine dei sudditi, ma da ciò che comporta l'interesse [pubblico] per lui stesso, ed i sudditi ne traggono profitto di conseguenza e non perché essi si propongono quel profitto che ricade su di loro per l'assoggettamento. L'assoggettamento dei sudditi ha due aspetti: il primo aspetto essi lo condividono con il Re in quanto essi non sono indotti ad assoggettarsi se non per la ricerca del vantaggio che ne ricade su di loro, così come fa il Re. Il secondo assoggettamento consiste nella loro accettazione dell'ordine del Re nella difficoltà e nella facilità, volenti o nolenti, ed in questo si distinguono dall'assoggettamento dei Re, ed essi sono sempre umili (adillāa) e non alzano mai la testa, malgrado il bisogno dei Re di loro", e nel Cap. 198 [II 465.12] aggiunge: "Egli, sia Egli esaltato, ha detto: "ed ha assoggettato a voi ciò che è nei Cieli e ciò che è nella Terra, tutto da parte Sua" (Cor. XLV-13) e gli animali rientrano in quello. E questo è il regime (hukm) del Nome "Colui che umilia (al-mudill)" nel Mondo per mezzo dell'assoggettamento, al punto che tra coloro a cui [il Mondo] è assoggettato Allah ha fatto sì che gli uni fossero assoggettati agli altri [...] ed ha stabilito come causa dell'assoggettamento degli uni agli altri, malgrado il Mondo sia assoggettato a noi, l'innalzamento di alcuni di noi sugli altri nel grado di cui ha bisogno colui che è assoggettato. Egli, sia Egli esaltato, ha detto: "Noi abbiamo elevato in grado gli uni sugli altri affinché gli uni prendessero gli altri come servi" (Cor. XLIII-32) [...] Sappi che l'assoggettamento talora ha luogo per abbassamento e talora per provvedere a ciò di cui colui che è assoggettato ha bisogno nel momento, e questa è la differenza tra i due assoggettamenti, per ciò che comporta la realtà essenziale di chi è assoggettato e di colui a cui è assoggettato. Il servitore, che è l'uomo, è assoggettato al suo cavallo ed al suo animale da soma: egli si occupa di lui nel suo abbeveramento, nel suo foraggio, e nel controllo delle sue 
molto proficua nell'ambito della conoscenza, e sul fatto che il volgo ed i sudditi assoggettano il loro sovrano riguardo ai loro bisogni, malgrado l'elevatezza del rango della autorità e dell'Imāmato.

Quanto al suo detto: "ed il più povero di essi nei confronti di Allah, sia Egli esaltato", poiché tutte le creature sono povere nei confronti di Allah, sia Egli esaltato, a meno che esse non siano colte da stati psichici accidentali ('awārid nafsiyya) dipendenti dai profumi della Potenza ('izza) divina, nella misura di quanto hanno ottenuto della Forma divina su cui sono state create. Ogni uomo prova nella sua anima dei momenti di potenza e di elevatezza, senza conoscerne il motivo, e ciò non dipende se non in modo particolare dal suo essere secondo la Forma divina. Non passa momento in cui non sia caratterizzato da un Nome divino ed il rango divino nella Forma non è dato da altro che da questi Nomi, ed il sapiente ('âlim) è distolto dalla sua ricchezza per Allah a causa della sua povertà verso Allah e ciò è preferibile per lui, ed egli [colui che fa la raccomandazione] gli ha indicato ciò che è preferibile e più doveroso.

Allah, sia Egli esaltato, ha detto: "O uomini, voi siete i poveri verso Allah ed Allah è il Ricco, il Lodato" (Cor. XXXV-15), e questo servitore è tra le creature più povere verso Allah, cioè quelle che meno contemplano la loro ricchezza per Allah e la loro potenza per Allah, a cui si riferisce il Suo detto: "La Potenza appartiene ad Allah, al Suo Inviato ed ai credenti" (Cor. LXIII-8), nobilitandolo in quello. La sua povertà è identica alla sua indipendenza dal Mondo, e quindi il suo essere correlato e qualificato con la povertà, che è la radice primaria, è preferibile per lui del suo essere qualificato e correlato con la ricchezza per Allah, che è il ramo secondario, e bisogna basarsi sulle realtà essenziali e primarie e non sugli accidenti occasionali e secondari. Sappi ciò.

Quanto al suo detto: "E comincia con la gente della tua casa, per quanto ti è possibile, preferendo loro a te stesso", sappi che Allah, sia Egli esaltato, in ciò che ha legiferato ha già classificato per te ed elencato chi ha la precedenza, e ciò corrisponde alla sua affermazione "per quanto ti è possibile",

condizioni per ciò che attiene alla sua integrità, alla sua salute ed alla sua vita. Ed esso è assoggettato a lui, per via dell'abbassamento $(i \underline{d} l \bar{l} l)$, per portare i suoi carichi, per fungere da cavalcatura e per essere da lui utilizzato in ciò che gli serve. Analogamente è nella specie umana, per l'innalzamento in gradi tra di loro e per mezzo del grado l'uno assoggetta l'altro. Il grado del Re comporta che egli assoggetti i suoi sudditi in ciò che egli vuole, per via dell'abbassamento, per soddisfare i suoi interessi che lo rendono bisognoso di quello; ed il grado dei sudditi e della plebe comporta l'asservimento del Re nella loro protezione, nella loro difesa, nel combattere i loro nemici, nel giudicare riguardo alle dispute che intervengono tra di loro e nella ricerca dei diritti. Questo è un asservimento di sostegno (qiyām), non un asservimento per abbassamento". Analogamente, nel capitolo XXIV dei Fusuus al-hikam egli afferma: "L'assoggettamento ha luogo a causa dei gradi (darağăt) ed è di due tipi: un assoggettamento che è voluto da parte di colui che assoggetta, costringendo nel suo assoggettare la persona che è assoggettata, come l'assoggettamento dello schiavo da parte del padrone, anche se egli è suo simile nell'umanità, e come l'assoggettamento dei sudditi da parte del sovrano, ed anche se essi sono simili a lui egli li assoggetta per mezzo del grado. L'altro tipo è un assoggettamento per mezzo dello stato ( $h \bar{a} l$ ), come l'assoggettamento del Re da parte dei sudditi, in quanto egli si prende carico delle loro faccende, difendendoli, proteggendoli, combattendo chi li aggredisce e conservando i loro beni e le loro persone. Tutto ciò è un assoggettamento per mezzo dello stato da parte dei sudditi, che assoggettano in quello il loro Re". 
poiché vi sono circostanze riguardo alle quali il Vero ti ha detto con la lingua della Legge: "Anteponi te stesso!" $\left.{ }^{411}\right)$ [119], ed in quel momento non hai possibilità [di scelta] per ciò che la Legge ti ha imposto. La tua possibilità sussiste quando hai libertà di scelta, ed allora anteponi ciò che è preferibile e sarai così qualificato dall'abnegazione $(\underline{i} \underline{t} \bar{a} r)$. Se poi i bisogni si equivalgono in tutto, anteponi colui a cui la Legge ha dato la preminenza, poiché ciò è quanto vi sia di più obbligatorio, poi colui che viene dopo fino ad arrivare all'ultimo nell'obbligatorietà e nella preferenza, in quanto tralasciando ciò che è obbligatorio l'uomo è disobbediente, e tralasciando ciò che è più obbligatorio è privo di fortuna ed abietto nell'aspirazione.

Osservate il suo detto, su di lui la Pace: "Ciò che vi ho proibito evitatelo", in modo assoluto, "e ciò che vi ho ordinato fate di esso ciò che potete" $\left({ }^{412}\right)$ stabilendo la possibilità riguardo all'ordine, ed ordinando di conformarsi al divieto in modo assoluto. Egli ha vietato la salāt supererogatoria dopo l'așr ed ha ordinato di salutare la moschea quando vi si entra, quindi quando il sapiente entra nella moschea dopo l' 'aśr ciò che è preferibile per lui è che non faccia una șalāt, per il divieto menzionato che Egli ha ordinato di ottemperare senza condizioni, ed in ciò egli si conforma anche all'ordine di Allah, sia Egli esaltato, poiché Egli ha detto in esso: "fate di esso ciò che potete". Ed egli [il sapiente] dice: "O mio Signore, il Tuo divieto non mi ha lasciato possibilità di fare la șalāt all’ingresso nella moschea", e ciò è più meritevole ${ }^{413}$ ). Questo è l'insegnamento della sua affermazione: "per quanto ti è possibile" e "al massimo della tua capacità".

Il sapiente è tale in virtù della scienza e fa procedere i suoi stati (ahweāl) riguardo a se stesso secondo la giustezza (sadād), e quando l'uomo procede riguardo agli stati di un altro invero sta procedendo riguardo agli stati di se stesso, poiché il suo sforzo è assolutamente solo a suo favore se è per il bene, ed

41 1) Nel Cap. 69 [I 543.7] Ibn 'Arabī precisa: "Quando l’uomo esce per dispensare la sua elemosina (sadaqa), il primo bisognoso che incontra è se stesso, prima di ogni altro bisognoso, ed egli elargisce l'elemosina solo ai bisognosi. Se egli passa oltre il primo bisognoso [cioè se stesso], lo fa per la sua passione, non per Allah, poiché Allah gli ha detto: "Comincia con te stesso (ibda' bi-nafsi-ka)" [hadīt riportato da Muslim, XII-41]; la sua anima è il primo che incontra della gente del bisogno".

412) Hadīt riportato da al-Buhārī, XCVI-2, Muslim, XV-412, XLIII-130, an-Nasā'ī, XXIV-1, Ibn Māğah, Introduzione-1, e da Ibn Ḥanbal. Ibn 'Arabī lo cita nei capitoli 69 [I 508.13], 72 [I 737.18], 88 [II 163.33], e 560 [IV 479.1], ove afferma: "il Profeta, che Allah faccia scendere su di lui la Sua șalāt e la Pace, ha detto: "Ciò che vi ho proibito evitatelo" ed ha parlato in modo assoluto senza porre condizioni, mentre a proposito dell'ordine ha detto: "e ciò che vi ho ordinato fate di esso ciò che potete" e ciò fa parte della misericordia del Profeta, che Allah faccia scendere su di lui la Sua șalāt e la Pace, verso la sua comunità".

413) Le stesse considerazioni sono riportate nel Cap. 69 [I 508.9] nella sezione dedicata alle due raka'at di saluto della moschea. All'inizio di tale sezione Ibn 'Arabī afferma: "Vi è divergenza tra i sapienti della Legge riguardo alle due raka'at per l'ingresso alla moschea: c'è chi sostiene che esse siano Sunna e chi sostiene che sono obbligatorie. Ciò che ritengo al riguardo e che sostengo è che queste due raka'at non sono obbligatorie per chi entra nella moschea a meno che non intenda sedersi in essa; se sosta in essa senza sedersi o se passa in essa senza sedersi, secondo me è libero di scegliere: se vuole le fa e se vuole non le fa e nessuno gli può dire qualcosa. Compie invece un peccato se le trascura sedendosi e non facendo le due raka át, a meno che non entri nel momento in cui è vietato fare salāt o non sia in stato di purità legale". 
a suo scapito se è per il male. Allah, sia Egli esaltato, ha detto: "Chi opera bene lo fa a suo vantaggio e chi opera male lo fa a proprio danno" (Cor. XLI-46), ed ha detto: "All'uomo non appartiene se non ciò in cui si sarà sforzato ed il suo sforzo sarà considerato" (Cor. LIII-39 e 40). Quindi il suo rango sarà in proporzione al grado del suo sforzo ed al grado [120] di colui per cui si è sforzato; è quello ciò che verrà fatto emergere dalla vera Legge, che è la Bilancia posta nella Terra, con la quale commerciano coloro che la adoperano.

Quanto al suo detto: "ed anteponi gli interessi del tuo Maestro al tuo interesse, se egli gradisce da parte tua lo sforzo in questo", il Profeta, su di lui la Pace, ha detto: "Un servitore non avrà fede finché io non sarò per lui più caro della sua famiglia, della sua ricchezza, della sua progenie e di tutti gli uomini insieme" $\left({ }^{414}\right)$, ed il servitore fa parte dell'insieme degli uomini, ed è quindi indispensabile che l'Inviato sia più caro a lui della sua stessa anima, malgrado egli non lo ami se non a causa di se stesso. Egli infatti lo ama per se stesso, poiché il frutto di quell'amore ricade solo su lui stesso, mentre nulla di esso ricade su colui che è amato, a meno che in quel momento non rimuova da lui ciò che lo danneggia. E tra gli interessi a cui fa riferimento è che [l'aspirante] si alzi per difendere il suo onore [del Maestro] e che si sforzi di rimuovere da lui il pregiudizio: stai attento a tutto questo e lo sperimenterai da te stesso.

Per questo ha detto: "e preferisci lui a te stesso", poiché difendere il tuo Maestro è come difendere il rango in cui Allah lo ha fatto stare, ed Allah ha elogiato questo rango e lo ha magnificato, in quanto lo ha posto come Sua luogotenenza (hilāfa) nei confronti di colui verso cui lo ha nominato luogotenente. "Chi magnifica i segni (ša čär) di Allah, essa [magnificazione] fa parte della pietà dei cuori” (Cor. XXII-32) e quale segno è più grande dei ranghi di coloro che chiamano ad Allah e che Lo indicano? "Chi magnifica le cose sacre (hurumāt) di Allah ciò è meglio per lui presso il suo Signore" (Cor. XXII30) $\left.{ }^{415}\right)$ e quale cosa sacra è più grande della sacralità di coloro che chiamano ad Allah e che Lo indicano? Ed essi sono gli Inviati e gli Eredi, chiamati Maestri.

414) Hadīt riportato da al-Buhārī, II-8, LXXXIII-3, Muslim, I-69 e 70, an-Nasā̄̄, Ibn Māğah, e da Ibn Ḥanbal. 415) Nel Cap. 475 [IV 109.17 e 26] Ibn 'Arabī precisa: "I segni di Allah sono le Sue indicazioni (a qām) e le Sue indicazioni ci indicano come arrivare a Lui [...] ed ogni segno è una indicazione (dalı̄l) di Allah riguardo ad una cosa specifica che Egli vuole e che ha chiarito per la gente della comprensione tra i Suoi servitori“, e nel Cap. 69 [I 399.1] aggiunge: "Quanto al Suo detto, sia Egli esaltato: "e chi magnifica le cose sacre di Allah, ciò è meglio (hayr) per lui presso il suo Signore!” (Cor. XXII-30), cioè meglio per lui rispetto a chi magnifica i segni di Allah, poiché attribuiamo all'espressione "hayr" un significato comparativo, per distinguere tra la magnificazione dei segni e la magnificazione delle cose sacre di Allah, in quanto la sacralità (hurma) di Allah è essenziale. Egli quindi esige la magnificazione per la Sua Essenza, a differenza delle cause seconde magnificate. Per chi osserva l'indicazione (dalīl) essa non è ricercata per se stessa, ma egli se ne allontana e la lascia per andare a ciò che è indicato. Per questo il Mondo è una indicazione di Allah, in quanto noi passiamo da esso a Lui, sia Egli esaltato, e non si addice che noi prendiamo il Vero come una indicazione del Mondo e che passiamo da Lui al Mondo. Ciò non è ammissibile! Quanto è sublime il discorso della Profezia, quando ha detto: "Chi conosce se stesso conosce il suo Signore!", ed Egli, sia Egli esaltato, ha detto: "Non hanno considerato..?!" (Cor. LXXXVIII-17) ed ha enumerato le cose create affinché fossero prese come indicazioni di Lui, non perché ci si arrestasse ad esse. Questa è la differenza tra le cose sacre di Allah ed i segni di Allah". 
$\mathrm{Al}$ punto che questo Maestro ha detto nella sua raccomandazione: "Prediligi la sua permanenza alla permanenza della tua anima se sei capace di farlo, e se egli lo accetta da parte tua in una circostanza (mawtin) fallo", cioè sii pronto a sacrificare te stesso [o: la tua anima], poiché l'essere timorati (taqwā) $\left({ }^{416}\right)$ è il lignaggio (nasab) di Allah $\left({ }^{417}\right)$, ed il timorato $\left(\right.$ muttaq $\vec{\imath}\left({ }^{418}\right)$ è colui che pone se stesso come scudo

416) Il termine arabo taqwā, che pur ricorre 17 volte nel Corano, è uno di quelli che non è facile tradurre correttamente nelle lingue occidentali con una sola parola o con una semplice espressione, perché in esso sono riuniti più concetti che nelle lingue occidentali sono espressi con termini diversi. I due significati principali contenuti nel termine taqwā sono il timore (hawef) e il proteggersi (hidr) da ciò che si teme [Ibn 'Arabī, Kitāb $\bar{\imath} \bar{g} \bar{a} z$ al-bayān, in Raḥma min ar-rahmmān, a cura di Maḥmūd al-Gurāb, Damasco, 1989, pag. 48], protezione che non si attua con una semplice "vigilanza" ma mediante uno scudo protettivo (wiqāya), cioè qualcosa che si frappone tra colui che teme e ciò che è temuto [Futūhăt, Cap. 84 (II 157.19)]. Le due traduzioni più frequenti di taqwā sono "timore di Dio" e "pietà", quest'ultima intesa non come "compassione" ma come la virtù di chi è pio, cioè di chi si attiene scrupolosamente alle prescrizioni ed interdizioni della Legge tradizionale, proteggendosi così dal castigo e dalla collera divine. Entrambe le traduzioni esprimono correttamente un aspetto della taqwā, quando essa ha come oggetto Allah, ma quando il suo oggetto è altro, come il velo (sitr), il Fuoco infernale (nār) o le pene legali ( $h u d \bar{u} d)$ di questo mondo, alla taqwā dei quali Ibn 'Arabī dedica tre capitoli distinti delle Futūhăt [85-87], non è più possibile utilizzare tali espressioni. Ho adottato pertanto, per la taqwā riferita ad Allah, la traduzione "essere timorati", perché in italiano, a differenza del "timoroso", il "timorato" è colui che mette in pratica il suo timore facendo scudo con i riti e con l'osservanza delle norme. Una descrizione delle caratteristiche del timorato si trova, secondo il commento di Ibn 'Arabī [Kitāb ǐğāz al-bayān, cit., pagg. 48-61], nei versetti 3-6 della Sūra II.

417) Ibn 'Arabī si riferisce qui ad un hadīt qudsī, non citato nelle raccolte canoniche, ma riportato da Abū Ṭālib al-Makkī nel suo "Kitāb qūt al-qulūb" [edizione di Bulāq, 1306 H, Vol. I, pag. 205]: "Quando Allah avrà riunito i primi e gli ultimi per l'appuntamento di un giorno noto, li chiamerà con una voce che sentirà il più lontano di loro come il più vicino, e dirà: "O uomini, vi ho dato ascolto da quando vi ho creato fino a questo giorno, oggi ascoltate voi Me! Sono le vostre opere che ricadono su di voi. O uomini, Io ho stabilito un lignaggio (nasab) e voi avete stabilito un lignaggio, ed avete posto in basso il Mio lignaggio ed innalzato il vostro. Io ho detto: "Il più nobile di voi presso Allah è colui tra voi che è più timorato" (Cor. XLIX-13), ma voi avete voluto ad ogni costo "un tale figlio di un tale è più ricco di un tale". Oggi ho deposto il vostro lignaggio ed ho innalzato il Mio lignaggio. Dove sono i timorati (muttaqūn)?”. Per costoro verrà innalzato uno stendardo (hiwe $\bar{a})$ ed essi seguiranno il loro stendardo fino alle loro dimore, ed Egli li farà entrare in Paradiso senza rendiconto". Nelle Futūhat, il brano relativo al lignaggio è riportato nei seguenti capitoli: 272 [II 582.17], 368 [III 359.34], 386 [III 531.24], 454 [IV 69.2], 558 [IV 237.33] e 559 [IV 415.25], mentre nei Fusüs al-ḩikam è riportato nel Cap. X, pag. 117 dell'edizione di 'Abd al-'Azīz Sulțān al-Manșūb. Il termine nasab è spesso tradotto come "ascendenza genealogica", ma in questo contesto ho preferito "lignaggio", per contrapporre la nobiltà di sangue a quella conseguente all'essere timorati.

418) Il termine muttaq $\bar{\imath}$ è il participio attivo del verbo ittaqā, di cui taqwā, secondo alcuni grammatici arabi, è un infinito irregolare. Ibn 'Arabī distingue in certi punti della sua opera due tipi di taqwāa, uno specifico (hăsss) e l'altro generale ('āmm) [Cap. 386 (III 531.30) e Kitāb i ĭğa al-bayān, in Rahma min ar-rahmāan, a cura di Maḥmūd al-Gurāb, Damasco, 1989, pag. 294]: la prima è quella prescritta dalla Legge con le numerose ingiunzioni "siate timorati (ittaqū)" riportate nel Corano, mentre la seconda è conosciuta solo dagli iniziati, malgrado essa caratterizzi tutte le creature. Nella prima l'uomo protegge se stesso facendosi scudo con i riti o con Allah, nella seconda l'uomo, consapevolmente se lo ha realizzato, e le creature, inconsapevolmente, proteggono Allah facendo scudo con se stessi ed addossandosi gli attributi biasimevoli, conformemente al versetto: "Ogni bene che ti coglie viene da Allah ed ogni male che ti coglie viene da te stesso" (Cor. IV-79). Commentando lo hadīt riportato nella nota precedente, Ibn 'Arabī precisa [Cap. 386 (III 531.24)]: "Egli, sia Egli esaltato, ha riferito 
(wiqāaya) per Allah, con cui Egli Si ripara dai dardi di tutto ciò che Gli è attribuito e che Gli viene lanciato [121] degli attributi biasimevoli, e quindi il servitore diventa uno scudo (mağann) contro di essi $\left.{ }^{419}\right)$, prendendoli su se stesso, sì che essi non arrivano al Vero.

Allah, sia Egli esaltato, ha caratterizzato Se stesso col fatto di venire offeso $\left(^{420}\right)$ e Si è denominato "Colui che ha molta pazienza $(s a b \bar{u} r)$ " per quello $\left.{ }^{421}\right)$, malgrado in una circostanza simile a questa il

di Sé nella tradizione autentica: "Oggi ho deposto il vostro lignaggio", poiché esso è qualcosa di accidentale, non un fondamento (asl), in quanto ci siamo divisi [in tribù o genti] e non siamo riuniti, e talvolta l'uno non conosce l'altro. Il nostro [rapporto di] lignaggio che abbiamo tra di noi non è un fondamento, perché se fosse tale non ammetterebbe gli accidenti e non sarebbe possibile la negazione. Poi ha detto: "ed ho innalzato il Mio lignaggio", poiché non ci allontaniamo mai da esso, né siamo separati da esso, né ci separiamo, né esso ci viene meno. E come potrebbe cessare nei confronti di Colui che ci tiene in pugno e che è con noi dovunque noi siamo [...]? Poi ha detto: "Dove sono i timorati?" e noi ci presenteremo a Lui tutti insieme, poiché non c’è nessuno di noi che non Lo prenda come scudo nell'allontanare le disgrazie da se stesso, e ciò corrisponde al Suo detto: "E quando sul mare vi tocca una calamità quelli che invocate al di fuori di Lui si perdono" (Cor. XVII-67), e non c'è nessuno di noi che non sia per Lui uno scudo nell'allontanare ciò che si dice riguardo a Lui essere male $(s \bar{u}$ ), e noi siamo come lo scudo (mağann) per Lui, ed i dardi dei mali colpiscono noi, ed ogni cosa biasimevole è attribuita a noi, a prezzo del Suo riscatto, e quindi è corretto dire che tutti gli uomini sono timorati. Ma vi è un essere timorati $(t a q w \bar{a})$ specifico ed un essere timorati generale, che le Leggi tradizionali hanno distinto ed ai quali abbiamo accennato. Chi sa ciò che abbiamo detto applica l'essere timorati nel senso generale a tutte le creature, e chi si arresta all'essere timorati che è noto agli uomini specifica". Ibn 'Arabī fa qui riferimento al tipo generale di taqwā.

419) Nel Cap. 350 [III 211.14] Ibn 'Arabī precisa: "Talvolta si tratta di cortine (h̆ğ̌ub) intelligibili con cui la persona allontana l'offesa $(a d \bar{a})$ da colui che è generoso con lui, come una persona da cui scaturisce nei confronti di un'altra qualcosa che quella detesta, in quanto non confacente alla sua natura e non corrispondente al suo obiettivo, ed a ciò segue il biasimo (damm) per ciò che è scaturito da lui nei riguardi di quell'altra persona. Ed una [terza] persona si mette a fare da scudo a lui con se stessa, affinché i dardi di quel biasimo raggiungano lei stessa, ed instaura nell'anima di colui che biasima che è lei la causa che ha determinato quello e che quella offesa era tutta da parte sua, affinché colui che biasima quella cosa si convinca che essa veniva da parte di questa persona, in qualsiasi modo le sia possibile arrivare a ciò. Il biasimo viene così collegato a lei [terza persona] che si frappone tra lui [colui che biasima] e la persona a cui colui che biasima aveva attribuito l'offesa, e protegge così il suo onore con se stessa. Allo stesso modo noi addossiamo a noi stessi quelle opere brutte che non corrispondono agli obiettivi e che non sono confacenti alla natura, malgrado la nostra scienza che tutto viene da Allah, ma poiché con esse è correlata la lingua del biasimo, noi riscattiamo con noi stessi ciò che viene attribuito al Vero di quello, per adab con Allah; quanto a ciò che c'è di buono e di bello [nelle opere] noi ci togliamo di mezzo e lo attribuiamo ad Allah, affinché sia Lui ad essere lodato, per adab con Allah, e perché è veramente così, poiché ciò appartiene senza dubbio a Lui, malgrado il profumo di condivisione (ištirāk) che si trova nella notificazione divina nel Suo detto: "Ed Allah ha creato voi e ciò che voi fate" (Cor. XXXVIII-96), ed il Suo detto: "Ciò che di bene ti arriva viene da Allah, e ciò che di male ti arriva viene da te stesso" (Cor. IV-79), ed ha detto: "Dì: tutto viene da parte di Allah" (Cor. IV-78), attribuendo l'opera una volta a noi ed una volta a Lui, e per questo abbiamo parlato al riguardo di profumo di condivisione".

\section{0) Cfr. Cor. XXXIII-57.}

421) Riferimento allo hadīt: "Non c'è nessuno più paziente di Allah per l'offesa che sente", riportato da alBuhārī, LXXVIII-7 1, XCVII-3, Muslim, L-49 e 50, e da Ibn Ḥanbal, IV-395, 401 e 405, e che sarà citato da Ibn 'Arabī nel seguito del testo. 
servitore credente sacrifichi se stesso al suo Signore. Ed il Maestro è il Califfo di Allah per lui ed egli quindi, riguardo a ciò che offende il suo Maestro, fa ciò che fa nei confronti del suo Signore: questo è obbligatorio per lui nei confronti di chiunque abbia simile rango, indipendentemente che il Maestro non ci sia perché morto, o sia esistente, o si tratti di colui su cui si basa il suo Maestro, o di uno dei Maestri che hanno il rango dell'Imāmato, del Califfato e della stazione spirituale (maqām).

Quanto alla sua affermazione riguardo a colui che si trova di fronte ad un Maestro e sotto la sua giurisdizione "che moltiplichi l'abbassarsi (tadallul) $\left({ }^{422}\right)$ di fronte a lui", ciò vuol dire che egli non dispone di se stesso se non in ciò che il suo Maestro dispone per lui, e con ciò si guadagna il cuore del Maestro, e quando il suo cuore è con lui il profitto è immenso.

La vicinanza (qurb) dei Maestri agli aspiranti che sono di fronte a loro è la vicinanza del Vero ai credenti che cercano la vicinanza ad Allah, ed essa è la vicinanza raddoppiata, poiché la vicinanza del Vero al credente, quando egli si avvicina a Lui con ciò che Egli gli ha ordinato di fare per avvicinarsi a Lui $\left({ }^{423}\right)$, è due volte la vicinanza del credente a Lui, ed è doppia per un segreto nascosto che è vietato svelare $\left.{ }^{424}\right)$, a cui accenneremo.

La vicinanza ad Allah avviene per mezzo dell'indipendenza (gina $\bar{a}$ per Allah e per mezzo della dipendenza (faqr) verso Allah ${ }^{425}$, e non è possibile per l'essere contingente mettere insieme nello

422) Il verbo tadallala significa farsi umili, bassi. Nelle Futūhāt Ibn 'Arabī riporta 16 volte un colloquio tra Abū Yazīd al-Bistāmī ed Allah in cui Abū Yazīd Gli chiese come potesse avvicinarsi a Lui ed Egli gli rispose: "Con ciò che non Mi appartiene: la bassezza [umiltà, abbassamento (dilla)] e l'aver bisogno [indigenza, dipendenza (iftiquarr)]", ed il tema della vicinanza ad Allah è appunto quello che sarà sviluppato nel seguito del testo.

423) Ibn 'Arabī, nel Cap. 260 dedicato alla conoscenza della vicinanza, distingue tra la vicinanza ottenuta mediante gli atti obbligatori di istituzione divina (qurb al farā ìd) e la vicinanza ottenuta mediante gli atti di obbedienza supererogatori (qurb an-nawāfil). Riguardo a quest'ultima egli cita uno hadīt riportato da al-Buhārī, LXXXI-38, e da Ibn Hanbal: "Il Mio servitore non si avvicina a Me con qualcosa che Mi sia più caro (ahabbu) di ciò che gli ho imposto come obbligo, ed il Mio servitore non cessa di avvicinarsi a Me con le opere supererogatorie finché Io lo amo, e quando lo amo sono il suo udito con cui egli sente, la sua vista con cui egli vede, la sua mano con cui egli afferra ed il suo piede con cui egli cammina". Riguardo ai frutti della prima afferma invece che il servitore diventa il Suo udito, la Sua vista, la Sua volontà; da quanto precisa nel testo, "quando egli si avvicina a Lui con ciò che Egli gli ha ordinato di fare per avvicinarsi a Lui" il raddoppio della vicinanza riguarda il primo tipo di avvicinamento.

Su questi due tipi di vicinanza si può consultare lo studio di Mohammed Rustom "Ibn Arabi on Proximity and Distance: Chapters 260 and 261 of the Futuhat", accessibile online http://www.mohammedrustom.com/wpcontent/uploads/2013/05/Ibn-Arabi-on-Proximity-and-Distance-JMIAS-41-2007.pdf.

424) Nel Cap. 260 [II 560.5] Ibn 'Arabī precisa: "La vicinanza del Vero è di due specie: la prima è una vicinanza di misericordia, di propensione, di lasciar correre, di perdono e di carità; la seconda è una vicinanza che non è possibile svelare".

425) I termini gina a e faqr significano letteralmente ricchezza e povertà, cioè il non avere o l'avere bisogno, e quindi, in senso traslato, indipendenza e dipendenza. René Guénon, nel suo articolo su "El-faqru" [Aperçus sur l'ésotérisme islamique et le Taoïsme, pag. 44] ha precisato: "L'être contingent peut être défini comme celui qui n'a pas en lui-même sa raison suffisante; un tel être, par conséquent, n’est rien par lui-même, et rien de ce 
stesso momento le due vicinanze, poiché egli ha un solo oggetto di contemplazione (mašhad). Se la sua contemplazione diretta (šuhüd) è l'indipendenza per Allah, in quel momento la sua contemplazione non può essere la dipendenza verso Allah, e se la sua contemplazione è la dipendenza verso Allah, non è possibile che l'indipendenza per Allah sia contemplata da lui, anche se entrambe le cose [122] sono attributi [possibili] per lui, ma questo attributo ['indipendenza per Allah] non è coscientemente presente (mustahdara) per lui, e questo è il doppio della vicinanza di Allah a questo servitore, poiché Egli è il Ricco, il Lodato $\left.{ }^{426}\right)$, e la Sua vicinanza al servitore è una indipendenza da lui ed egli viene così favorito con la vicinanza da parte Sua ${ }^{(427)}$.

Vi sono cose la cui esistenza non è possibile da Allah se non per mezzo di essa [vicinanza], che è come uno strumento per l'artigiano: quando Egli Si manifesta, da parte del servitore, con un atto divino, ciò implica che quell'atto da parte sua non avviene se non per la vicinanza del Vero a lui, e questa vicinanza è quella che raddoppia la prima vicinanza e diventa il doppio della vicinanza del servitore a Lui. Per questo Egli ha detto: "Chi si avvicina a Me di una spanna (šibr), Mi avvicino a lui di un cubito

qu'il est ne lui appartient en propre. Tel est le cas de l'être humain, en tant qu'individu, ainsi que de tous les êtres manifestés, en quelque état que ce soit, car, quelle que soit la différence entre les degrés de l'Existence universelle, elle est toujours nulle au regard du Principe. Ces êtres, humains ou autres, sont donc, en tout ce qu'ils sont, dans une dépendance complète vis-à-vis du Principe, «hors duquel il n'y a rien, absolument rien qui existe»; c'est dans la conscience de cette dépendance que consiste proprement ce que plusieurs traditions désignent comme la «pauvreté spirituelle». En même temps, pour l'être qui est parvenu à cette conscience, celle-ci a pour conséquence immédiate le détachement à l'égard de toutes les choses manifestées, car il sait dès lors que ces choses aussi ne sont rien, que leur importance est rigoureusement nulle par rapport à la Réalité absolue. $[\ldots]$ et l'on peut dès lors comprendre ce que sont les «riches» $[\ldots]$ : ce sont les êtres attachés à la multiplicité, et qui, par suite, sont incapables de s'élever de la connaissance distinctive à la connaissance unifiée. Cet attachement, en effet, est directement contraire au détachement dont il a été question plus haut, comme la richesse est contraire à la pauvreté".

426) "O uomini, voi siete bisognosi (fuqarā) di Allah ed Allah è il Ricco, il Lodato" (Cor. XXXV-15).

427) Per Ibn 'Arabī la condizione normale dell'uomo è la dipendenza, non l'indipendenza. Nel Cap. 304 [III 19.15] precisa: "La gente della nostra Via ha trascurato questa via: [i sostenitori di essa] ritengono che l'indipendenza per Allah, sia Egli esaltato, faccia parte dei gradi più grandi, e questo li vela dal realizzare il richiamo alla dipendenza da Allah, che è il loro vero attributo. Essi pongono questo attributo nell'indipendenza per Allah, in modo implicito, per il loro amore verso l'indipendenza, che è un'uscita dal loro attributo. L'Uomo è colui che conosce la sua misura e realizza il suo attributo senza uscire dalla sua sede, e che mantiene su se stesso la veste di onore del suo Signore, [cioè] il suo soprannome ed il suo nome con i quali Egli lo ha soprannominato e nominato, dicendo: "Voi siete bisognosi di Allah ed Allah è il Ricco, il Lodato" (Cor. XXXV15)", e nel Cap. 162 [II.263.34] aggiunge: "Colui che è indipendente per Allah è dipendente da Lui, ma l'attribuzione dell'espressione "essere dipendenti da Allah" è più degna di quella di essere indipendenti, in quanto l'indipendenza è un attributo essenziale che abolisce la relazione tra l'Essenza del Vero e la manifestazione, mentre la richiesta $(t a l a b)$ implicita nella condizione di dipendenza presuppone una relazione. [...] Allah, sia Egli esaltato, ci ha posto tra coloro che sono bisognosi di Lui per mezzo di Lui: invero la dipendenza da Lui per mezzo di Lui (al-faqr ilayhi bihi) è identica all'indipendenza (gina $\bar{a})$, in quanto Egli è l'Indipendente e tu sei dipendente per mezzo di Lui, quindi per mezzo di Lui sei indipendente dai mondi”. 
$\left.(\operatorname{dir} \bar{a})^{\prime}{ }^{428}\right)$, ed il cubito equivale a due spanne di colui che ha quella spanna, "e chi si avvicina a Me di un cubito, Mi avvicino a lui di un braccio $(b \bar{a})$ " ed il braccio equivale a due cubiti di colui che ha quel cubito, "e chi viene a Me di corsa, Io vengo da lui a passo spedito (harūla)" ed il passo spedito è il doppio della corsa di colui che ha quella corsa $\left({ }^{429}\right)$. Egli ha così menzionato la moltiplicazione per mezzo dei due equivalenti, e ciò è identico alla vicinanza che abbiamo citato della ricchezza e della povertà, se comprendi, ed Allah è il Ricco, il Lodato.

Questa questione comporterebbe una lunga spiegazione, ma questa misura è sufficiente e bastante per coloro che comprendono le allusioni, ed Allah è Colui che assicura il successo.

Poi ha detto: "Se egli ti respinge, o ti sgrida, o ti strapazza, o ti schiaffeggia, o ti picchia, tu aumenta in tenerezza (riqqa) verso di lui ed in umiltà, ed ogni volta che egli ripete quello su di te, abbi verso di lui ancora più amore, abbassamento, tenerezza e spezzamento (inkisār) di fronte a lui, poiché egli mira al tuo perfezionamento ed alla tua istruzione, e ti mette alla prova con quello, e fa tutto ciò come beneficio per te, che il Maestro sa e che tu ignori”.

Quanto al suo detto: "Se egli ti respinge", nel suo respingerti vi sono due possibilità: o ti specifica una direzione verso cui andare [123] o non la specifica. Se nel respingere ti indica una direzione verso cui andare, vai verso quella direzione, seguendo il suo ordine, e non abbandonarla finché egli non è soddisfatto di te; se non te la indica non smettere di stare dietro la [sua] porta notte e giorno, se non nei momenti in cui hai bisogno di fare l'abluzione per la salät, e prendila come una moschea finché egli non è soddisfatto di te e ti fa avvicinare, oppure muori in quella condizione.

Al-Qušayrī ha riferito che un Maestro ordinò ad un aspirante di uscire da casa sua respingendolo, e quando egli si allontanò camminando a ritroso, ottemperando all'ordine del Maestro, il Maestro lo fece chiamare e gli chiese: "Cosa ti è venuto in mente di fare?", e l'aspirante rispose: "Ho pensato di scavarmi una fossa davanti alla porta della tua casa e di entrarvi finché sarei morto o tu fossi soddisfatto di me", ed il Maestro disse: "Uno simile a te è adatto al servizio dei Maestri", e lo fece approssimare ed avvicinare e lo antepose al gruppo [dei suoi compagni] $\left.{ }^{430}\right)$.

428) Hadīt qudsī riportato da al-Buhārī, XCVII-50, Muslim, XLVIII-2, 3, 20-22, Ibn Māğah, XXXIII-58, atTirmidīi, XLV-131, e da Ibn Hanbal. Ibn 'Arabī lo cita nei capitoli 27 [I 192.4], 69 [I 534.28], 73 [II 27.18, 31.8, 34.11, q. XII (49.6), e q. LXV (II 84.6)], 178 [II 340.13 e 360.28], 260 [II 559.6], 274 [II 589.31], 306 [III 28.7] e 560 [IV 446.34].

429) Il sistema metrico decimale è stato introdotto in Occidente alla fine del XVIII secolo, mentre in tutte le civiltà tradizionali le misure di lunghezza erano basate sulle misure e proporzioni del corpo umano. Ibn 'Arabî non si riferisce qui a misure fisse, come il cubito Reale, ma alle misure di un individuo qualsiasi, definendo peraltro il "braccio" come il doppio del "cubito", mentre in genere il braccio [brasse in francese e fathom in inglese] è inteso come la distanza tra le estremità delle dita quando le braccia sono distese, e corrisponde così a quattro cubiti, ed a due braccia.

430) Il Maestro in questione era Abū Ḥafs al-Ḥaddād ed il discepolo era Abū 'Uțmān Sac̄ìd ibn Ismāểl al-Ḥīrī. L’episodio è riportato da al Qušayrī nella notizia biografica dedicata al discepolo, a pag. 21 dell'edizione araba 
Capitò al nostro Maestro 'Alī ibn 'Abd Allāh ibn Ğāmi', come egli stesso mi riferì nel giorno in cui mi investì del mantello (hirqa) con cui il Hiḍr di persona lo aveva investito in presenza di Qadīb alBān ${ }^{431}$ ), dicendomi: "Ero al servizio di 'Alī al-Mutawakkil, che era uno degli Uomini perfetti, Allah sia soddisfatto di lui. 'Alī si incollerì un giorno per una cosa che aveva visto e mi fece allontanare dalla sua stanza, aprì la porta, mi schiaffeggiò e mi fece uscire. Io avevo un piede a terra e l'altro su un gradino che era fuori dalla porta, ed il Maestro si separò da me mentre ero in quella condizione, chiudendomi la porta in faccia e rientrando nella sua dimora. Io restai in quella condizione, in cui il Maestro mi aveva lasciato, per giorni, notte e dì, senza spostare il mio piede che era su quel gradino né l'altro che era sulla terra, se non nei momenti delle salāt, a causa della șalāt, e dopo aver fatto la șalāt ritornavo alla mia condizione, e quando dormivo, dormivo in quella condizione, senza spostarmi da essa. Dopo alcuni giorni il Maestro chiese di me ad uno dei suoi compagni, dicendo: "Cosa fa [124] 'Alī?", e gli venne risposto: "Egli è nella condizione in cui lo hai lasciato ed in cui il tuo sguardo lo ha abbandonato". Venne detto [da altri]: "Come dici?", ed egli rispose: "Egli è come ho detto al mio signore”. Il Maestro allora aprì la porta, uscì lui stesso verso di me, mi abbracciò, mi baciò tra gli occhi e mi fece entrare nella sua dimora, ed io non smisi di godere del suo favore fino a che mor’”.

L'allontanamento (tard) da parte dei Maestri non è una espulsione ( ${ }^{432}$ ), bensì un'educazione, e l'aspirante non deve disperare, in quell'allontanamento, della misericordia del Maestro, poiché essa è la Misericordia di Allah verso di lui, anche se morisse nella sua condizione di allontanamento.

Non è infatti costume dei Maestri che chiamano ad Allah di allontanare uno dalla porta di Allah, poiché da parte loro si tratta solo di educazione ( $a d a b)$ nei confronti dell'aspirante; e quando il suo allontanarlo dipende dal fatto che il Maestro sa che non ha niente da offrirgli, allora glielo fa sapere e gli dice: "tu non fai per me e da parte mia non c'è niente per te: non affannarti [con me], e guarda altrove", oppure gli indica un altro Maestro che egli sa avere qualcosa per lui. E se sa che da lui [l'altro Maestro] non arriva nulla di ciò che l'aspirante cerca, e che egli non ha buon nome tra la gente dell'elezione, non glielo fa sapere $\left({ }^{433}\right)$, poiché si tratterebbe di una delle cose più nocive (adarr) nella

del Cairo del 1959 e a pag. 45 della traduzione di Alexander Knysh, "Al-Qushayrìs Epistole on Sufism”, Garnet, 2007.

431) L'episodio è riportato nel Cap. 25 [I 187.1] e nella sua Risāla rūh al quds, a pag. 178 della traduzione di Ralph Austin, "Soufis of Andalusia", Allen \& Unwin, 1971.

432) In arabo il termine qui tradotto come espulsione è lo stesso che viene usato per indicare l'allontanamento. Il senso della frase è che l'allontanamento, anche se si configura come espulsione, non è irreversibile e se l'aspirante reagisce nel modo dovuto può essere riammesso alla presenza del Maestro, come negli esempi riportati da Ibn 'Arabī. Nel Kitāb al-amr al-muhkam, a pag. 306 e 312 della traduzione di Asín Palacios già citata, nella parte dedicata ai doveri del Maestro, Ibn 'Arabī riporta invece due situazioni in cui il Maestro deve allontanare l'aspirante.

433) Vale a dire che se un Maestro sa di non aver nulla da offrire ad un certo aspirante, ma conosce un altro Maestro che invece può guidarlo, allontana l'aspirante dicendogli di non avere nulla per lui e lo indirizza all'altro Maestro; ma se non conosce un Maestro valido non lo allontana e non gli fa sapere di non avere nulla per lui, ma lo tratta come un estraneo. 
Via presso Allah, ma è gentile con l'aspirante e lo tratta come si trattano gli estranei che cercano la vista del Maestro per la baraka, non per l'istruzione iniziatica ${ }^{(434)}$.

Il Maestro non gli ordina né gli vieta nulla, né si muove nei suoi confronti con il moto che ha con gli aspiranti che sono presso di lui, e se l'aspirante è sagace sa che nulla di ciò che cerca verrà da lui; malgrado ciò egli deve assolvere il suo impegno di servizio e di venerazione verso il Maestro, e non tralasciare il suo servizio, né mancare alle regole di buona creanza verso di lui, come succedeva prima di quello $\left.{ }^{435}\right)$. E quando questo aspirante coglie un desiderio del Maestro riguardo ad una cosa che è in grado di soddisfare, egli lo fa di sua iniziativa, senza che il Maestro glielo ordini, poiché il Maestro non gli darà mai ordini, per principio, anche se desse ordini [125] agli estranei, in quanto a costui non darà mai ordini affinché non capiti nella sua anima il pensiero di trovarsi nelle stesse condizioni dei suoi compagni.

Ogni volta che il Maestro rimprovera l'aspirante o lo strapazza, o lo picchia, o lo schiaffeggia, sappi che egli è bene accetto presso il Maestro, e se così non fosse non eserciterebbe la sua funzione su di lui.

I Maestri non esercitano una simile funzione nei confronti dell'aspirante, sulla sua pelle (bašra) o sulla sua ricchezza, se lo considerano un estraneo, ma il Maestro si comporta così con lui solo perché sa che da lui sortirà ciò che egli vuole e che la sua predisposizione $(i s t i c d \bar{a} d)\left({ }^{436}\right)$ ammette, e questo è una buona novella, da parte del Maestro all'aspirante, che egli avrà successo.

In Initiation et réalisation spirituelle, Editions Traditionnelles, Parigi, 1964, a pag. 191, René Guénon precisa: "C'est pourquoi l'ambition d'un vrai Guru, si l'on peut dire, doit être surtout de mettre son disciple en état de se passer de lui le plus tôt possible, [...] en l'adressant, quand il ne peut plus le conduire plus loin, à un autre Guru ayant une compétence plus étendue que la sienne propre" ed aggiunge in nota: "Il doit être bien entendu que ce changement ne peut jamais s'opérer régulièrement et légitimement qu'avec l'autorisation du premier Guru, et même sur son initiative, car c'est lui seul, et non pas le disciple, qui peut apprécier si son rôle est terminé vis-àvis de celui-ci, et aussi si tel autre Guru est réellement capable de le mener plus loin qu'il ne le pouvait lui-même. Ajoutons qu'un tel changement peut aussi avoir parfois une raison toute différente, et être dû seulement à ce que le Guru constate que le disciple, du fait de certaines particularités de sa nature individuelle, peut être guidé plus efficacement par quelqu'un d'autre".

434) L'espressione "cercano la vista del Maestro per la baraka" non si riferisce alla ricerca del ricollegamento iniziatico tramite la trasmissione della baraka o il patto, ma più semplicemente di una partecipazione "esteriore" all'influenza spirituale del Maestro. Un caso che Ibn 'Arabī non ha esaminato in questo testo, ma che nei nostri tempi è tutt'altro che raro, è quello dell'aspirante che mira al ricollegamento iniziatico ma non all'istruzione iniziatica: in questo caso il Maestro non eserciterà la funzione di istruttore nei confronti di questo aspirante, ma si limiterà, se sussistono le qualificazioni nel candidato, ad esercitare un ruolo di trasmettitore dell'influenza spirituale. Ibn 'Arabī accenna alla frequentazione dei Maestri per la baraka nel Cap. 181 [II 366.17].

435) Cioè prima che l'aspirante sagace si renda conto dal comportamento del Maestro che egli non è in grado di guidarlo.

436) La predisposizione, che Ibn 'Arabī assimila alla preparazione (tahayyu) [Cap. 198 (II 401.4 e 426.35), e Cap. 369 (III 406.3)] è strettamente connessa alle possibilità che l'essere porta in sé e che appaiono delle potenzialità per l'individuo finché non le ha realizzate o attualizzate. 
Il Maestro non si muove sulla pelle dell'aspirante, né sulla sua ricchezza, con un gesto che potrebbe essere perseguito dalla Legge o ritenuto colpevole se a causa di esso [l'aspirante] lo convocasse davanti alla Legge, e così è anche per l'estraneo. Questo non avviene mai da parte del Maestro che è un vero Maestro, ma una cosa simile accade con i falsi Maestri, ma essi non sono Maestri e non fanno parte della gente della Via; il Maestro quindi non ha moti con cui egli possa fornire un argomento contro di lui presso la Legge.

Ed un simile trattamento nei confronti dell'aspirante è un chiaro segno, per la gente di Allah, della felicità di questo aspirante, e d'altra parte esso non è un'iniziativa del Maestro bensì una punizione dovuta per un errore che l'aspirante ha commesso esteriormente o interiormente.

In questa via non è permesso al Maestro di avere indulgenza per gli errori degli aspiranti, quando Allah glieli fa conoscere $\left.{ }^{437}\right)$, ed ogni Maestro che non punisca l'aspirante per il suo errore interiore o esteriore manca verso di lui nell'istruzione iniziatica $\left.{ }^{438}\right)$. L'Inviato di Allah, che Allah faccia scendere su di lui la Sua salät e la Pace, ha detto: "Chi ci rivela un errore (saftha), noi applicheremo a lui la pena" $\left({ }^{439}\right)$ cioè riguardo ai crimini per i quali si applicano le pene. Il giudizio di questi Maestri riguardo agli atti interiori è il giudizio degli Inviati riguardo agli atti esteriori, poiché il rango degli Inviati implica gli atti esteriori ad esclusione di quelli interiori [126] sì che essi accettano gli ipocriti così come accettano i credenti, in quanto essi sono venuti da parte di Allah per tutta la loro comunità in modo generale.

Per i Maestri non è così: essi non vanno dagli uomini né sono inviati ad essi, bensì sono gli uomini che vanno dai Maestri e cercano da essi la purificazione del loro lato interiore e l'apprendimento dei difetti delle loro anime, e fanno un patto con essi perché esercitino il governo su di loro, quando essi vedono in ciò il beneficio per loro, esteriormente ed interiormente. È dovere dei Maestri punire per gli errori interiori, così come è dovere degli Inviati e dei giudici punire per gli errori esteriori, ed è loro proibito di essere indulgenti per essi, quando il crimine esige l'applicazione della pena a colui che lo ha commesso.

Quanto alla sua affermazione: "E se il Maestro si comporta così con te, sii ancora più tenero con lui", intende qui per tenerezza (riqqa) l'amore (mahabba), cioè amalo di più in quanto non è tollerante con te. Allo stesso modo anche i fratelli in Allah ed i compagni in Allah non sono indulgenti gli uni con gli altri in Allah.

437) Non è necessario quindi che l'aspirante renda noto il suo errore.

438) Una analoga affermazione è riportata nel Kitāb al-amr al-muhkam, a pag. 304 della traduzione di Asín Palacios già citata. Se l'aspirante è consapevole di un errore che ha taciuto al suo Maestro e vede che il Maestro non lo punisce, prima di pensare che il Maestro ha mancato verso di lui dovrebbe chiedersi se non è lui a mancare nella sua attitudine verso il Maestro, poiché se non cerca veramente l'istruzione iniziatica il Maestro non è tenuto a punirlo, a meno che l'errore non venga palesato.

439) Hadīt già riportato a pag. 82 del manoscritto, ove è trattata la stessa questione. 
La gente di Allah dice: "I Sūfi non smettono di andar bene fintanto che si criticano l'un l'altro, e quando sono d'accordo non c'è bene tra di loro" $\left({ }^{440}\right)$, cioè tra di loro non c'è alcuna piaggeria (mudāhana), anzi essi sono esenti da essa $\left({ }^{441}\right)$, ed il fratello non accetta da parte di suo fratello se non ciò che sa essere accettato da Allah, e gli confuta ciò che sa che gli viene confutato da Allah, e lo tratta riguardo al diritto di Allah in tutti i modi in cui Allah gli ha ordinato di trattarlo, e quanto a ciò che spetta di diritto a lui stesso [e non ad Allah], egli è indulgente per quello, perdona, ripara e rende bello, e così è per la gente di Allah $\left.{ }^{442}\right)$. E come si comportano i Maestri?

La differenza tra il Maestro con l'aspirante ed il fratello con il suo fratello in Allah è che il fratello è indulgente con l'errore di suo fratello nei suoi confronti, mentre il Maestro non è indulgente con l'errore dell'aspirante nei suoi confronti, perché il diritto (haqq) del Maestro è il diritto di Allah, e non c'è modo di annullare il diritto di Allah, come il giudizio esteriore previsto dalla Legge nei confronti di chi commette adulterio o di chi ruba. Anche se costui si pentisse di fronte [127] al giudice, dopo che la sua faccenda è arrivata al giudice, ed avesse restituito tutta la ricchezza che ha rubato, ciò non lo salverebbe, ed il giudice non gli toglierebbe la pena del taglio della mano, né la fustigazione di chi commette adulterio senza essere stato sposato, né la lapidazione se si tratta di qualcuno che è già stato sposato (tayyib) $\left.{ }^{443}\right)$.

I diritti di Allah non possono essere cancellati dai giudici e quando ci sarà il Giorno della Resurrezione non resterà Giudice se non Allah, ed allora spetterà ad Allah, nei confronti del colpevole, di annullare il Suo diritto o di punirlo per esso.

E poiché i diritti dei Maestri sugli aspiranti sono i diritti di Allah, per questo motivo non è lecito ai Maestri di cancellarli, ed essi non possono essere indulgenti per gli errori che commettono gli aspiranti nei loro confronti, anche se fosse uno di quelli per cui è lecito essere indulgenti nel caso della maggioranza.

La venerazione (hurma) dei Maestri è obbligatoria per gli aspiranti, e non può aver luogo da parte di essi un errore nei confronti del Maestro se non insieme alla perdita della venerazione, e quando la venerazione cade dal cuore dell'aspirante egli non trae più alcun vantaggio da quel Maestro, ed il Maestro è tenuto ad allontanarlo da sé finché la venerazione non gli ritorna, e quando la venerazione del Maestro rientra nel suo cuore allora egli torna al suo servizio. Egli [il Maestro] non lo punisce

440) Questo detto è riportato da al-Qušayrī nella sua Epistola, nel capitolo dedicato al Tasarereuf ed è attribuito a Ruwaym al-Bagdādī. Ibn 'Arabī non lo cita nelle sue Futūhạt.

441) Analoga affermazione si trova nel Cap. 235 [II 536.2].

442) La stessa raccomandazione è riportata nel Kitāb al-amr al-muhkam, a pag. 326 della traduzione di Asín Palacios già citata.

443) Conformemente ad uno hadīît riportato da Muslim, XXIX-12 a 14, Abū Dāwud, XXXVII-23, at-Tirmid̄ī, XV-8, Ibn Māğah, XX-7, ad-Dārimī, XIII-19, e da Ibn Ḥanbal. 
mai se non con l'allontanamento da lui, ed ogni volta che non lo allontana, manca ad Allah in ciò, e l'aspirante crede di poggiarsi su qualcosa ma non poggia su nulla. E se si trattiene dall'allontanarlo dalla sua casa, il minimo che possa fare è di scansarlo e di non rivolgersi a lui, sì che egli sappia che si è attirato ciò che una simile attitudine comporta per lui da parte del Maestro.

Al-Qušayrī ha riferito che una persona era al servizio di un Maestro e vide da parte sua qualcosa che lo sminuì ai suoi occhi $\left({ }^{444}\right)$, e cioè che egli faceva la pasta, essendo un fornaio privo di schiavi. Quando il Maestro venne a saperlo lo allontanò da sé, dicendo: "Non stare in mia compagnia, poiché la venerazione per cui trai beneficio da me ti è venuta meno, e quando questo stato finirà per te allora troverai di nuovo beneficio", e si separò da lui. E quando quello [stato] finì per lui, ritornò dal Maestro e trasse beneficio da lui $\left({ }^{445}\right)$.

La venerazione dei Maestri è la venerazione di Allah ${ }^{446}$, poiché essi sono i rappresentanti di Allah su di loro e per loro, e la contentezza dell'aspirante [128] quando il Maestro lo colpisce o lo strapazza e più grande della sua contentezza per il suo mostrarsi favorevole (iqbāl) verso di lui, poiché il suo colpirlo non ha bisogno di una bilancia, mentre il suo mostrarsi favorevole ha bisogno di una bilancia. Invero il mostrarsi favorevole all'aspirante da parte del Maestro può essere per il vantaggio che l'aspirante trova in quello, in quanto egli sa come sono fatte le anime: vi è un'anima che non prospera se non per la ricchezza ed un'anima che non prospera se non per la povertà, la ristrettezza e la vita dura, e se diventasse ricca sarebbe presuntuosa ed ingrata; vi è un'anima che non prospera se non per l'abbassamento (dilla) e l'umiliazione (hawān) ed un'anima che non prospera se non per la considerazione ed il mostrarsi favorevole. Talvolta l'anima di questo aspirante a cui il Maestro si mostra favorevole non prospera se non per il mostrarsi favorevole, ed allora è indispensabile per il Maestro che si mostri favorevole, poiché egli non lo tratta se non con ciò in cui vi è profitto per l'aspirante, è ciò è doveroso per il Maestro. Talvolta il mostrarsi favorevole all'aspirante da parte del Maestro è una astuzia $(m a k r)$ da parte di Allah con lui ed una lusinga, come abbiamo menzionato, ed il suo mostrarsi favorevole equivale alla lontananza. Per questo egli ha bisogno della bilancia, e già l'abbiamo spiegata in ciò che precede, e cioè che egli sappia in che termini i Maestri si mostrano favorevoli agli estranei ed alla gente comune ed in che termini si mostrano favorevoli agli aspiranti, e quando vede che il mostrarsi favorevole del Maestro assume la forma del suo mostrarsi favorevole agli estranei, egli non è contento per quello e sa di essere respinto. Se egli non vede verso di sé il suo mostrarsi favorevole alla gente comune, è ben contento e sa che è a posto per quanto riguarda la volontà $(i r \bar{a} d a)$ : sappi questo.

444) La persona aveva visto che il Maestro si copriva il capo con un velo per proteggersi dal calore del forno e pensò che se fosse stato veramente un Intimo di Allah non avrebbe avuto bisogno del velo per proteggersi.

445) L'episodio è riportato da al-Qušayrī nella sua Epistola, a pag. 165 dell'edizione araba del Cairo del 1959 e a pag. 341 della traduzione di Alexander Knysh, "Al-Qushayr’’s Epistole on Sufism", Garnet, 2007.

446) Questa affermazione costituisce i versi iniziali della poesia introduttiva al Cap. 181, dedicato alla venerazione dei Maestri spirituali [II 348.28]. 
L'aspirante ha bisogno di questa bilancia e di essere attento in essa, ed è dovere del Maestro, quando vede che l'aspirante ce la fa da solo ed ottiene il grado (martaba) tanto da eguagliarlo o superarlo, comportarsi con lui, se lo eguaglia, secondo l'adab dei pari, e se lo supera, adeguare il suo comportamento al grado per cui egli è superiore a lui. I nostri Maestri hanno fatto così con noi, sedendosi di fronte a noi.

L'adab invero dipende [129] dal grado: sappilo! Ci è stato fatto sapere che l'Inviato, che Allah faccia scendere su di lui la Sua șalāt e la Pace, era uguale a noi nell'umanità, ma Allah ci ha ordinato di onorarlo e di venerarlo, e questo non è dovuto se non al grado in cui Allah lo ha fatto stare, non a lui stesso. Lo stesso vale per il Sultano, e così pure per gli Intimi di Allah: per il grado gli uomini sono superiori gli uni agli altri, e non dimenticarti di tener presente una cosa simile nel tuo pensiero, ed Allah è Colui che dà il successo, non c'è Signore se non Lui.

Poi ha detto: "O aspirante, accettalo se sei un amante veridico (sādiq) ed un aspirante puro, e quando ti capita qualcosa [di male] nella tua vita in questo mondo o nella tua vita tradizionale (dīn), ed Allah ci protegga dalla sventura nella faccenda della vita tradizionale, rivolgiti al tuo Maestro, al Maestro del tuo Maestro ed ai fratelli del Maestro, e chiedi aiuto (tawassal) $\left({ }^{447}\right)$ ad Allah per mezzo di loro, poiché lo sguardo del Maestro, sia egli vivente o morto, non si stacca mai da te, in quanto Allah, Gloria a Lui, gli ha affidato la tua istruzione iniziatica, e quindi il suo sguardo non si stacca da te. Sii certo di ciò. Ed anche per questo rivolgiti agli aspiranti del Maestro, i tuoi fratelli, poiché essi si rivolgono al Maestro nei tuoi riguardi e chiedono aiuto [per te] ad Allah tramite il Maestro. E le intenzioni (himam) sono efficaci. Poi non essere affrettato nella tua faccenda, poiché colui che ha fretta è prossimo alla rovina".

447) Il verbo tawassala è strettamente correlato al termine wasīla, che ricorre due volte nel Corano, V-35 e XVII-57. Letteralmente il tawassul, infinito del verbo tawassala, significa usare un tramite per avvicinarsi a qualcosa o qualcuno, e quindi, in senso traslato, cercare una intercessione (šafáa $a)$ o una mediazione. Sul tema del tawassul sono stati versati nella storia dell'Islām fiumi di inchiostro per affermare o negare la sua liceità, in particolare nel caso della intercessione degli Intimi $(a w l i y \bar{a})$. Ibn 'Arabī usa raramente questo termine nelle Futūhāt, ove ricorre solo due volte, nel Cap. 73, questione XCIII [II 97.24], e nel Cap. 533 [IV 177.17] ove egli precisa: "Quando il servitore si stabilisce in questo ${ }^{i} i k r$ [il capitolo è dedicato alla conoscenza dello stato spirituale del Polo la cui dimora è (il versetto) "e se i Miei servitori ti chiedono al Mio riguardo: In verità Io sono vicino; Io rispondo all'invocazione di chi invoca, quando invoca Me: che essi dunque rispondano a Me" (Cor. II-186)], la prima cosa che ne risulta per lui è la rinuncia (zuhd) riguardo a ciò che è altro che Allah ed egli quindi cessa di cercare la vicinanza a Lui per mezzo di altro, poiché l' "uso di un tramite per avvicinarsi (tawassul)" corrisponde alla ricerca della vicinanza da parte Sua ed Allah, sia Egli esaltato, ci ha riferito che Egli è vicino e quindi non c'è vantaggio in questa ricerca, poiché la Sua notifica è veridica. Poi ci ha comunicato che Egli risponde alla richiesta di coloro che chiedono, e ciò è la notificazione che Egli detiene il Dominio (malaküt) su tutte le cose, ed ha comunicato che Egli risponde affinché colui che chiede faccia attenzione e vigili su ciò che chiede, poiché la risposta è inevitabile e talvolta il servitore chiede ciò che non è bene per lui, per ignoranza di ciò che è benefico (masălihh)". Poiché nella raccomandazione si fa specificamente riferimento alla necessità di un aiuto di Allah per una situazione in cui l'aspirante si trova e per la quale egli cerca l'intercessione di coloro che sono più vicini ad Allah, ho preferito tradurre il verbo tawassala con "chiedere aiuto [ad Allah tramite altri]" piuttosto che con "cercare la vicinanza [ad Allah]". 
Quanto al suo detto: "O aspirante", con la particella del vocativo, [è] per la sua lontananza al momento da ciò a cui [il Maestro] lo chiama, e se ciò che gli raccomanda è già in lui, allora [è] per la persistenza in ciò e per la saldezza $(t a b \bar{a} t)$. La chiamata $(n i d \bar{a})$ può avvenire da un luogo vicino, come nel caso appena descritto, in cui il Maestro lo chiama da vicino, o può avvenire da un luogo lontano $\left({ }^{448}\right)$, cioè nel caso in cui ['aspirante] è privo di ciò che gli ha raccomandato. Quanto alla chiamata che viene dall'uomo a se stesso si tratta del chiamante $(d \bar{a} \hat{\imath})\left({ }^{449}\right)$ che [130] chiama al bene dal suo segreto (sirr) e dal suo interno, ed esso riunisce la vicinanza e la lontananza: in realtà se lo chiama per il bene da se stesso a se stesso è meglio [della chiamata del Maestro], ed è una chiamata vicina, e se in quella chiamata gli ordina di compiere delle cose che non sta facendo al momento si tratta di una chiamata da un luogo lontano, poiché viene dalla sede (mawtin) a cui lo chiama $\left.{ }^{450}\right)$.

Così è per ogni chiamata che ha luogo nel Corano o nel discorso degli uomini, e per questo uno dei Maestri $\left.{ }^{451}\right)$, commentando l'indicazione allusiva (išâra) ha specificato che essa è una chiamata in capo alla lontananza ${ }^{452}$ ), poiché talvolta si tratta di una chiamata in capo alla vicinanza, quando

448) La chiamata da un luogo vicino è menzionata in Cor. L-41, mentre la chiamata da un luogo lontano è menzionata in Cor. XLI-44.

449) Il termine $d \bar{a} \tau$, letteralmente colui che chiama o che convoca, ricorre quattro volte nel Corano: XX-108, XXXIII-46, e XLVI-31 e 32. Nel Cap. 73, q. CLIII [II 132.11] Ibn 'Arabī spiega: "Se chiedi cos'è il freno ( $z \bar{a}$ ğ $i r)$, noi diciamo che esso è l'ammonitore $(w \bar{a} \xi z)$ del Vero nel cuore del credente, ed esso è colui che chiama $(d \bar{a} \hat{\imath}) "$

450) La vicinanza e la lontananza non si riferiscono qui a colui che chiama ma a ciò a cui l'aspirante viene chiamato.

451) Si tratta dello Šayh Abū l-'Abbās ibn al-'Arīf as-Sinhāḡī, autore dei Mahāsin al-maǧălis, pubblicati e tradotti in spagnolo da Miguel Asín Palacios [edizione francese, ed. Paul Geuthner, 1933], che oltre a fornire dei dati biografici di Ibn al-'Arîf, ha anche tradotto la maggior parte dei passi delle Futūhāt in cui l'autore o la sua opera sono citati [i passi che gli sono sfuggiti, o che ha omesso, si trovano nei capitoli 5 (I 112.29), 71 (I 577.4 ), 74 (II 143.18), 172 (II 290.31), 178 (II 325.2), 378 (III 488.19) e 559 (IV 411.16)]. Malgrado Ibn al-'Arīf sia morto 24 anni prima della nascita di Ibn 'Arabī, nell'anno 536 dall'Egira, quest'ultimo lo definisce più volte come suo Maestro.

452) La frase si trova a pag. 29 della traduzione di Asín Palacios. Ibn 'Arabī la cita nove volte nelle Futūhāt; nel Cap. 54 [I 279.2] precisa: "Sappi che per la Gente della Via di Allah l’indicazione allusiva (išăra) fa riconoscere la lontananza (bu'd), oppure la presenza $(h u d \bar{u} r)$ dell'altro $(a l$-gayr). Uno dei Maestri ha detto nei "Mahāsin al-mağălis" che: "L'indicazione allusiva è una chiamata in capo alla lontananza e un palesarsi (bawh) della infermità ('illa) stessa", intendendo con ciò che essa è una dichiarazione netta dell'occorrenza della malattia (marad), in quanto l'infermità è una malattia, e ciò corrisponde alla nostra affermazione "la presenza dell'altro". Qui ['autore] non intendeva con [il termine] 'illa la causa occasionale (sabab), né la causa efficiente, come la definiscono i raziocinanti ('uqalā) tra la gente della speculazione. La forma della malattia nell'indicazione allusiva è che a colui che allude (al-mušrir) è nascosto il Volto del Vero in quell'“altro", e se ad uno è nascosto il Volto del Vero nelle cose vuol dire che l'asserzione individuale $(d a \Leftarrow \bar{a})$ si è impossessata di lui, e l'asserzione individuale è identica alla malattia. È fermamente stabilito per i realizzati che non c'è nell'esistenza se non Allah, ed anche se noi siamo esistenti, la nostra esistenza è [solo] per Lui, e colui che esiste per altro è [in realtà] nel regime della non-esistenza ('adam)". Nel Cap. 215 [II 504.24] aggiunge: "Ogni indicazione allusiva che sorge nella comprensione non è contenuta [esteriormente] nell'espressione ('ibāra) [che la indica, come nel caso del dito 
ha luogo da una persona al suo vicino, nel caso vi sia un terzo a cui colui che allude non vuol far conoscere ciò a cui allude.

Ed il suo detto: "accetta tutto quello", cioè quanto ha raccomandato, e se già [l'aspirante] si trova in esso, allora il suo senso è: "sii saldo in ciò e persisti", mentre se non si trova in esso il suo senso è quello che ha espresso [letteralmente].

Quanto all'affermazione successiva riguardo alla sua condizione (̌́art) nell'accettare: "se sei un amante sincero", indica "colui che è voluto (murād)" ("53), "o un aspirante puro", indica "colui che vuole (murīd)".

La prima cosa che Allah procura a colui che è voluto è l'amore e così egli diventa un amante (muhibb) e gode di tutto ciò a cui il suo Amato lo chiama, se è sincero nel suo amore per Lui.

"O un aspirante puro", ed egli [cioè colui che vuole] è colui che trova l'impedimento (man') e si fa carico di ciò a cui è chiamato con il suo combattimento ed il suo sforzo interiori, poiché è difficile per lui. Per questo nella stipula del patto di ascolto ed obbedienza all'Imām vi è la clausola: "in ciò che piace ed in ciò che non piace", cioè in ciò che le anime trovano gradevole e che sono ben disposte a fare quando l'Imām glielo ordina, $\mathrm{o}$ in ciò che le anime respingono e che è pesante per esse e che

che indica la Luna]. Sappi che la gente di Allah ha definito l'indicazione allusiva una chiamata in capo alla lontananza e un palesarsi della infermità stessa. Ma nella classificazione delle indicazioni allusive è necessario fare una distinzione. L'indicazione allusiva che è una chiamata in capo alla lontananza è il trasferimento di ciò che l'espressione non trasmette, come l'indicazione gestuale per colui a cui non arriva il suono, a causa della lontananza di chi parla, ma che è dotato di vista e gli viene così indicato in modo allusivo ciò che si vuole da lui ed egli capisce. Questo è il significato del loro detto: "una chiamata in capo alla lontananza". E tutte quelle scienze che un'espressione non contiene sono come colui a cui non arriva il suono essendo lontano da colui che allude, ma non lontano da ciò che è voluto da lui; quindi l'indicazione allusiva gli fa comprendere ciò che fa comprendere il discorso o ciò che trasmette il suono [...] Quando poi non c'è lontananza allora è un palesarsi dell'infermità stessa: il sordo è vicino a colui che parla ma la sua vicinanza non è di alcun vantaggio, poiché il suono non gli arriva per l'infermità della sordità; quindi [Egli/egli] indica in modo allusivo malgrado la vicinanza, come: "il Vero dice tramite la lingua del Suo servitore: Allah ascolta chi Lo loda", e questo è il massimo della vicinanza insieme all'esistenza dell'infermità ed alla sua manifestazione". Gli altri riferimenti alla frase si trovano nei capitoli 2 [I 63.2], 72 [I 697.32], 210 [II 498.6], 360 [III 278.20], 364 [III 316.27] e 559 [IV 336.26].

453) Nel Cap. 73, q. CLIII [II 134.11] Ibn 'Arabī precisa: "Se chiedi chi è colui che è voluto (murād) e chi è colui che vuole (murīd) rispondiamo che chi è voluto è colui che è stato attirato (mağdūb) via dalla sua volontà, congiuntamente alla preparazione della faccenda per lui, sì che oltrepassa tutti i limiti (rusūm) e le stazioni spirituali senza sforzo. Quanto a chi vuole è colui che ha rinunciato (mutağğarrid) alla sua volontà. Abū Hāmid [al-Gazālī] ha detto: egli è colui a cui spettano i Nomi e che è entrato a far parte del gruppo di coloro che si concentrano su Allah per mezzo del Nome. Quanto a noi, applichiamo l'espressione "colui che vuole" a due persone per due stati [diversi]: il primo è colui che percorre la via con sforzo e difficoltà e che non è distolto dalla sua via da quella difficoltà; il secondo è colui la cui volontà è efficace nelle cose, e costui è colui che realizza (mutahaqqiq) per mezzo della volontà, non colui che è voluto". Queste definizioni sono ulteriormente sviluppate nei capitoli 227 e 228, rispettivamente dedicati allo stato spirituale di chi è voluto ed a quello di chi vuole. 
detestano, ma che malgrado l'avversione fanno. Ed Allah ha detto: "e ad Allah si prosterna chi è nei Cieli e sulla Terra, volente e nolente" (Cor. XIII-15), sia riguardo a ciò che c'è per Lui (fī mā kāna lahu), sia Egli esaltato, e questo, senza divergenza [di opinioni], è volente, sia [riguardo] a ciò che c'è a causa Sua (mā kāna min ağali-hi), e di questo vi è chi è volente e chi è [131] nolente $\left.{ }^{454}\right)$.

Colui che vuole è spinto a fare ciò che detesta o per desiderio (rugba) o per timore $(r a h b a)\left({ }^{455}\right)$, di questo o dell'altro mondo - e quando lo compie magnificando l'ordine, si tratta di un amante conoscitore [cioè di colui che è voluto] - poiché [altrimenti] egli, se non temesse e non sperasse, non si affretterebbe a fare ciò che gli è difficile.

Quanto alla magnificazione $\left(t a^{\prime} z \bar{\imath} m\right)$ essa è al di fuori del timore e della speranza, e ciò corrisponde al detto del Profeta, su di lui la Pace, riguardo a Șuhayb, quando lo lodò: "Che eccellente servitore è Șuhayb: anche se non temesse Allah non Gli disobbedirebbe" $\left.{ }^{456}\right)$, e ciò equivale a quanto abbiamo indicato dell'atto difficile [compiuto] per la magnificazione che l'uomo prova nella sua anima nei confronti di Chi glielo ha ordinato, malgrado l'eliminazione della paura di Lui, per un certo aspetto, e della speranza in ciò che è presso di Lui $\left.{ }^{457}\right)$.

Quanto al suo detto: "Quando ti capita qualcosa nella tua vita in questo mondo o nella tua vita tradizionale, rivolgiti al tuo Maestro, al Maestro del tuo Maestro ed ai fratelli del Maestro, e

454) Nel Cap. 69 [I 510.3] Ibn 'Arabī precisa: "Questa è la prosternazione della Sūra del Tuono, laddove Egli, sia esaltato, dice: "E ad Allah si prosterna chi è nei Cieli e sulla Terra, volente e nolente, e le loro ombre al mattino ed alla sera" Cor. XIII-15). Le ombre degli spiriti sono i loro corpi [non grossolani]. Allah, sia Egli esaltato, ha così comunicato che "si prosterna a Lui chi è nei Cieli", ed essi sono coloro che sono elevati, "e chi è sulla Terra", ed essi sono coloro che sono bassi, cioè il mondo dei corpi che sussistono su una costituzione elementare, "volente", per gli spiriti quanto alla loro scienza ed alla loro stazione, e per i corpi quanto alle loro essenze ed alle loro entità, "e nolente", negli spiriti quanto alle loro essenze e nei corpi quanto al loro ruolo di comando ed alla loro preminenza sui loro simili". Nel manoscritto non è chiaro il significato della distinzione tra ciò che è per Lui e ciò che è a causa Sua: essa potrebbe riferirsi a ciò che è creato direttamente dal Comando divino e ciò che è creato in occasione delle cause seconde, o per mezzo di strumenti.

455) Nel Cap. 73, q. CLIII [II 131.25] Ibn 'Arabī precisa: "Se chiedi cos'è il timore rispondiamo: il timore dell'esteriore per l'attuazione della minaccia ed il timore dell'interiore per il cambiamento (taqallub) della scienza, ed un timore per l'attuazione di una cosa precedente, ma dopo la precedenza del desiderio. E se chiedi cos'è il desiderio, rispondiamo: il desiderio dell'anima riguarda la ricompensa, il desiderio del cuore riguarda la realtà essenziale (haqīqa) ed il desiderio del segreto riguarda il Vero, ed esso è la stazione della stabilità (tamkīn)". Due espressioni simili (ragaban wa rahaban) ricorrono associate in Cor. XXI-90.

456) Hadīt non recensito nelle raccolte canoniche. Ibn 'Arabī lo cita nel Cap. 344 [III 179.3], ove spiega che: "la causa del suo essere protetto dall'esistenza della disobbedienza era il suo timore (hawef), e se non ci fosse stato il timore glielo avrebbe impedito il pudore $(h a y \bar{a})$ di fronte ad Allah che venisse pronunciata per lui la parola "peccato (danb)" nei confronti di chicchessia, anche se non fosse un peccato nei Suoi confronti", e nel Cap. 369 [III 402.10].

457) Le due tipologie qui riportate, quella di colui che supera le difficoltà per timore o speranza e quella di colui che le supera per magnificazione di Colui che gli ordina di superarle, corrispondono alla distinzione di colui che vuole e di colui che è voluto. 
chiedi aiuto ad Allah, quanto è Potente e Magnificente, per mezzo di loro riguardo a quello", esso corrisponde alla affermazione di Abū Yazīd al-Bistāmī, o di un altro dei grandi Maestri, che profferì un giorno ad uno dei suoi aspiranti: "Se hai bisogno di Allah, scongiuraLo (aqsim 'alayhi) per mezzo di me" $\left.{ }^{458}\right)$. [Egli disse] ciò perché sapeva che quel suo aspirante era convinto che il suo Maestro, avesse questa posizione (makāna) presso Allah, cosa di cui non era convinto di altri che lui. Ed il Maestro sapeva che le aspirazioni (himam) e la veridicità (sidq) nelle cose, quando sono forti, sono efficaci, indipendentemente dal fatto che colui a cui è chiesto sia nella posizione in cui colui che gli chiede è convinto che sia, o che sia più in basso, poiché è inevitabile la risposta per l'effetto che comportano la veridicità e l'efficacia (nufūd) delle aspirazioni.

Per questo la magia (sihr $)$ che le donne mettono in opera nelle faccende fa ciò che non è di giovamento per la maggior parte degli uomini, e questo non avviene se non per il loro aver appreso [la magia] con l'accettazione $(q a b \bar{u} l)$ e per il loro prestar fede che questo avverrà, inevitabilmente; e l'atto si manifesta per la loro veridicità, la loro aspirazione, la loro fermezza e la loro decisione, non per l'opera ( ${ }^{459}$ ).

Già abbiamo stabilito come debba essere la convinzione dell'aspirante sincero nei confronti del Maestro [132], e quindi la sua veridicità lo solleva da ciò che gli è capitato, quando chiede aiuto [ad Allah] per mezzo di coloro che ha menzionato [nella sua raccomandazione] riguardo alla cosa che gli è capitata. Talvolta questo dipende da entrambi i fattori, cioè dalla sua aspirazione e dalla posizione del Maestro, ed è come se vi fossero più intercessori riguardo ad un'unica cosa: Colui presso cui si intercede accetta l'intercessione di ciascuno riguardo ad essa, come se intercedesse da solo. Talvolta poi, oltre alla aspirazione, capita che colui che chiede aiuto [a Lui] per quello nella sua menzione del suo Signore durante la sua preghiera invochi un Nome che comporta per la sua efficacia specifica (hăssiyya) la risposta a ciò che chiede, senza che se ne accorga.

Quanto al suo detto riguardo al Maestro: "che sia vivente o morto, il Maestro non stacca il suo sguardo da te", egli vuol dire che l'aspirazione dei Profeti riguardo a coloro a cui sono stati inviati è che essi siano guidati per loro tramite, e quindi il loro sguardo su di essi non cessa (460). Così è per gli Eredi, cioè i Maestri: essi non staccano il loro sguardo dagli aspiranti che sono sotto la loro

458) Questa frase, pronunciata da Márūf al-Karhī a as-Sarī as-Saqatị, è riportata da al-Qušayrī nella sua Epistola, a pag. 10 dell'edizione araba del Cairo del 1959 e a pag. 22 della traduzione di Alexander Knysh, " $A l-$ Qushayrī's Epistole on Sufism", Garnet, 2007.

459) Nel Cap. 385 [III 528.11] Ibn 'Arabī precisa: "Non vedi l'efficacia delle aspirazioni (himam) delle donne nella magia $(s i h r)$, che è nota per essere efficace in colui che ne è oggetto (mashür)? Se non fosse che disprezzano chi è oggetto della magia e decidono con le loro aspirazioni che ciò che fanno, a parole o atti, avrà effetto su colui che è oggetto della magia, non sarebbe efficace, ma è senza dubbio efficace. Chi non ha questa aspirazione nella potenza di quell'atto e magnifica [cioè non disprezza] colui che vuole ammaliare tra gli uomini, mediante l'efficacia in lui di quell'opera o di quella parola, se la compie o la proferisce non sarà di alcuna efficacia. Per questo abbiamo detto [nel titolo del capitolo]: "Chi è disprezzato (huqqira) è sopraffatto (guliba)"”.

460) Si tratta di una chiara confutazione dell'affermazione di quei dottori della Legge che negano la possibilità di intercessione da parte dei Profeti o degli Intimi quando questi sono morti. 
istruzione, ed essi [aspiranti] sono per loro come la comunità per l'Inviato, quella credente, a cui il suo Inviato ha parlato rivolgendosi direttamente ed essi hanno appreso [il discorso] per scienza, non per la prevalenza di una [buona] opinione (galaba zann), così come lo apprende la persona da colui che riporta ciò che ha detto il Maestro $\left.{ }^{461}\right)$. Il discorso diretto non equivale alla trasmissione indiretta (naql), poiché esso fornisce la scienza ed egli [il Maestro] agisce in base ad una visione interiore (bașīa) $\left({ }^{462}\right)$.

Per questo i successori dell'Inviato, che hanno appreso [direttamente] da lui, o, quando è morto, per mezzo dello svelamento, o da quegli spiriti puri da cui ha appreso quell'Inviato, o da Allah - ed Egli è l'origine a cui si risale - coloro che hanno così appreso chiamano ad Allah in base ad una visione interiore, cioè ad una scienza che implica la vista ('ayn). Ciò è dato dal seguire quanto [l'Inviato] gli ha detto direttamente o che gli è stato riportato in un modo che rende valida quella trasmissione, e quindi [colui che segue] lo ha appreso con l'accettazione ( $y a$ h $h u d u$ - $h u$ bi-l-qabūl) ed afferma con certezza in base ad essa (yaqta u bi-hi), ed anche questi è tra i suoi successori. Ciò corrisponde al Suo detto: "Io chiamo ad Allah in base ad una visione interiore e [cosi] coloro che mi seguono" (Cor. XII-108) (463).

Quanto al suo detto: "Ed anche per questo rivolgiti", cioè riguardo a quella faccenda che ti è accaduta, "agli aspiranti [133] del Maestro, i tuoi fratelli, poiché essi si rivolgono al Maestro nei tuoi riguardi e chiedono aiuto [per te] ad Allah", con ciò egli vuol dire più cose. Tra di esse è che tu sia convinto, riguardo agli aspiranti tuoi fratelli, che essi sono sinceri, ed elimini dalla tua anima il sospetto (tuhma) che ti viene in mente nei loro confronti, affinché tu non ritenga di avere alcuna superiorità (maziyya) su di loro, e chieda loro aiuto per ciò che desideri, poiché Allah, sia Egli esaltato, ha detto: "aiutatevi l'un l'altro nella pietà e nel timor di Dio" (Cor. V-2). Quando l'uomo ha questa attitudine verso i suoi prossimi, non sussiste nella sua anima alcun disprezzo per loro, né manchevolezza (naqs) e questo è un Paradiso anticipato per lui, “come fratelli seduti su troni uno di fronte all'altro” (Cor. XV-47).

Tra esse vi è anche il fatto che talvolta tra gli aspiranti vi è chi è più elevato di lui presso Allah, sia Egli esaltato, o presso il Maestro, in quanto la Sua accettazione di quell'aspirante è più rapida della Sua accettazione di chi ha avuto la sventura, ed Allah, sia Egli esaltato, quando ascolta riguardo a lui la

461) Nel Cap. 14 [I 150.24] Ibn 'Arabī precisa: “Quando lo ascolta dallo Spirito proiettore, l'Intimo è simile al Compagno che lo ha sentito dalla bocca dell'Inviato di Allah, che Allah faccia scendere su di lui la Sua salāt e la Pace, avendone così una scienza in cui non vi è alcun dubbio, a differenza di chi segue (tābic), che gli dà il proprio assenso per via della prevalenza della [buona] opinione (galabat az-zann), rimuovendo il sospetto (tuhma) che interviene nei confronti della veridicità (sidq)".

462) Ne L’homme et son devenir selon le Vêdanta, Editions Traditionnelles, 1974, pag. 15, René Guénon precisa: 'La vue est prise comme symbole de la connaissance, dont elle est l'instrument principal dans l'ordre sensible; et ce symbolisme est transporté jusque dans l'ordre intellectuel pur, où la connaissance est comparée à une «vue intérieure», ainsi que l'indique l'emploi de mots comme celui d'«intuition» par exemple".

463) L'espressione "coloro che mi seguono" non è riferita ai credenti ma a "coloro che chiamano ad Allah in base ad una visione interiore", che nel Cap. 268 [II 569.18] Ibn 'Arabī identifica con la "verità della certezza (haqq al-yaqīn). 
richiesta di questo aspirante approssimato a Lui, soddisfa la sua necessità riguardo a lui ed anche di più, poiché Allah per mezzo del suo compagno gli mostra sollecitudine e lo preserva a causa sua per ciò che resta della sua vita.

Tra esse vi è anche il fatto che nella Scienza di Allah sia stabilito che quel bisogno non sarà soddisfatto se non per mezzo di questo insieme [di richiedenti], o per la richiesta di una sola persona di loro, e non sarà se non ciò che la Scienza ha già stabilito, e quindi gli ha raccomandato ciò perché sapeva che la risposta sarebbe stata di questo genere $(q a b \bar{\imath} l)$, e non ha lasciato alcuna delle possibilità senza indicare in essa ciò in cui è il bene per lui, in quanto [gli] ha raccomandato in modo generale un gruppo di persone a lui sconosciute.

E quanto alla sua affermazione a questa persona: "poi non essere precipitoso nella tua faccenda, poiché chi ha fretta è prossimo alla rovina", essa si riferisce al suo detto, su di lui la Pace: "Invero Allah risponde al servitore, a meno che il servitore non dica: Egli non mi risponde!” $\left({ }^{464}\right)$ e questo è il significato della rovina, poiché se egli dice: "Egli non mi risponde", Allah non gli risponderà dopo di quello. Ciò perché ha mancato di $a d a b$ ed ha accusato Allah di menzogna riguardo al Suo detto: "Io rispondo [134] alla invocazione di chi invoca quando invoca Me” (Cor. II-186).

È necessario che vi sia la risposta e spiegherò la sua sede, il suo limite (hadd) e resterà [da spiegare] come avviene l'esaudimento di ciò che [il servitore] ha chiesto in essa. Quanto al Suo detto: "Io rispondo alla invocazione di chi invoca quando invoca Me", è necessario che colui che prega, quando prega Lui, Lo invochi con uno dei Suoi Nomi. Dirà ad esempio: "O Allah!" o uno dei Nomi o qualcosa del Discorso (kalām) [divino], con la lingua o con il cuore, cioè il discorso dell'anima, ed è inevitabile che Allah gli dica: "EccoMi $\left(\right.$ labbayka)" $\left.{ }^{465}\right)$, cioè "in risposta a te", chiunque Lo invochi e

464) Hadīt non recensito nelle raccolte canoniche. Ibn 'Arabī lo cita nel Cap. 71 [I 629.34], e nel Cap. 560 [IV 498.14], ove precisa: "Quando preghi Allah non giudicare lenta la risposta e non dire: "Allah non mi risponde!", poiché Egli è il Veridico ed ha detto: "Io rispondo all'invocazione di chi invoca quando invoca Me!" (Cor. II186). Egli ti ha già risposto se l'orecchio della tua fede fosse aperto e Lo avresti sentito, altrimenti sospetta della tua fede. Se hai pregato per un peccato $(\underline{i} \underline{\underline{t}} \mathrm{~m})$ o per la rottura di un legame di sangue sappi che nel caso di una simile preghiera Allah non risponde a colui che l'ha fatta. Egli, sia Egli esaltato, ci ha prescritto nella Legge cosa chiedere nella preghiera e l'esempio ora fatto è l'eccesso nella preghiera. Certo Allah esaudisce il servitore finché il servo che prega per ciò che è lecito chiedere non dice: "Egli non mi esaudisce", poiché se dice quello smentisce Allah nel Suo detto: "Io rispondo all'invocazione di chi invoca quando invoca Me!" e chi accusa di menzogna non è credente ed è sotto la stessa maledizione (wayl) di coloro che smentiscono, a meno che si penta.

465) Si tratta della formula che il pellegrino deve pronunciare ripetutamente dopo la sacralizzazione (ihrām) per il pellegrinaggio (hağğ). L'espressione significa letteralmente "In duplice risposta (labbay) a te ( $k a)$ "; la desinenza in "ay", che è del duale, può significare "duplice", "due volte", ma nel Lisān al 'Arab è proposto anche il significato "dopo aver già [risposto]" e "spesso, più volte". Nel Cap. 533 [IV 177.23] Ibn 'Arabī precisa: "Riguardo a questo $\underline{d i k r}$ [cioè il versetto Cor. II-186] vi è una condizione che spiegherò, per via della nostra constatazione che per la maggior parte degli uomini ciò che chiedono al loro Signore non viene esaudito. Sappi che Allah ha notificato che Egli risponde all'invocazione di chi invoca quando invoca Lui, e la sua invocazione a Lui non è altro, quando Lo chiama con uno dei Suoi Nomi, che il suo dire: "O Allah", oppure "O Signore", o "O mio 
per qualunque cosa Lo invochi, ed è necessaria questa risposta, cioè: "Ho ascoltato la tua invocazione riguardo a ciò che vuoi o a ciò che hai chiesto in essa"; e dopo questa invocazione [con un Nome] il servitore menziona quale è il bisogno che chiede [di soddisfare] in essa.

Non c'è dubbio che la Scienza di Allah riguardo alle misure, ai tempi ed ai modi non muta, e se nella Scienza di Allah era già stabilita la Sua accettazione e la Sua risposta a ciò per cui Lo ha invocato, ciò avverrà in un tempo vicino o lontano, o dipenderà da uno stato specifico di colui che ha pregato, o da un'altra faccenda: ciò è necessario. E la risposta sarà rapida o lenta in base a quando ciò avrà luogo, come è stato riferito nella storia di Mosè, nel Suo detto, sia Egli esaltato: "Ho già risposto alla vostra richiesta" (Cor. X-89), e tra la sua preghiera riguardo ad essa e la manifestazione di ciò che aveva chiesto ed il suo accadimento trascorsero 40 anni, ed egli aspettò per quello ciò che era stabilito nella Scienza come tempo o come condizione, o per entrambi $\left.{ }^{466}\right)$.

E se nella Scienza di Allah è stabilito che ciò che è richiesto non abbia luogo, è necessario che prenda il suo posto la riparazione (takfîr) di qualche errore commesso [dal servitore]: se ciò gli venisse svelato egli preferirebbe quello alla soddisfazione del suo bisogno e vedrebbe che ciò è meglio e che Allah è stato accomodante con lui e [lo] ha aiutato, compensandolo con questo in cambio di ciò che ha chiesto $\left.{ }^{467}\right)$. Oppure [come risposta] fa salire [il servitore] a dei gradi a cui non sarebbe arrivato se Egli avesse esaudito il suo bisogno riguardo a ciò che ha chiesto in essa, ed anche [in questo caso] se [135] Allah gli svelasse ciò egli sceglierebbe questi gradi piuttosto che il soddisfacimento del suo bisogno. In ogni caso Egli non frustra mai la sua richiesta del bene, a meno che egli non dica: "Egli non mi risponde", e se dice : "Egli non mi risponde" non otterrà nulla di tutto questo, poiché la sua opera è la sua affermazione "Egli non mi risponde" ed il Profeta, su di lui la Pace, ha detto: "Esse

Signore", o "O Tu che sei dotato della Magnificenza e della Generosità", ecc. L'invocazione è una chiamata $(n i d \bar{a})$ ed è un restare in attesa (ta'ayya) di Allah. E l'esaudimento di questa misura (qadr) - che è l'appello (da\&a) e per questo si chiama "chi invoca $(d \bar{a} \hat{\imath})$ " - è che il Vero gli risponda (yulabbi-hi $)$ dicendo: "EccoMi (labbayka)", e questo è inevitabile da parte di Allah nei confronti di ogni richiedente. Poi, ciò che viene dopo questa chiamata è al di fuori della invocazione; quindi la risposta [divina] ha luogo, come Egli ha detto. Dopo la chiamata [il servitore] comunica quel bisogno che ha in mente riguardo a ciò che vuole, ma in questo dikr non è inclusa la Sua risposta riguardo a ciò che ha chiesto e per cui Lo ha invocato, ed Egli, se vuole, soddisfa il suo bisogno, e se vuole non lo fa'. Ibn 'Arabī distingue quindi nella preghiera l'invocazione, o l'appello, dalla richiesta (su'āl): la prima è sempre esaudita, la seconda non necessariamente.

466) Il riferimento è ai 40 anni trascorsi dagli Ebrei nel deserto prima di raggiungere la terra promessa. Cfr. Cor. V-26.

467) Nel Cap. 533 [IV 177.28] già citato Ibn 'Arabī aggiunge: "E per questo non tutto ciò che è richiesto in essa [preghiera] viene esaudito da Allah per il Suo servitore, e questo è un [atto di] Misericordia nei suoi confronti, poiché talvolta egli chiede ciò in cui non vi è del bene per lui, e se Egli avesse assicurato la risposta anche per quello, ciò accadrebbe e sarebbe per lui la rovina nella sua religione e nel suo aldilà, e forse anche in questo mondo, senza che egli se ne accorga. Fa quindi parte della Sua Generosità il non aver assicurato la risposta a ciò che gli viene chiesto, ed ha soltanto garantito la risposta all'invocazione, in modo specifico, come abbiamo spiegato. E questo è il massimo della Generosità da parte del Signore (sayyid) nei confronti del Suo servitore". 
non sono altro che le vostre opere che vi vengono rese" $\left.{ }^{468}\right)$, e qui non c'è opera se non la sua cattiva opinione del suo Signore.

Questo è ciò che egli voleva dire [nella sua raccomandazione] ed è la rovina, come disse Allah a degli uomini che ritenevano che Allah non sapesse molto di ciò che essi facevano, dicendo loro: "Quell'opinione che vi siete fatti del vostro Signore vi ha fatto perire ed ormai fate parte di coloro che sono rovinati" (Cor. XLI-23), chiediamo ad Allah, sia Egli esaltato, che ci protegga da una cosa simile.

Poi ha detto: "Non insistere mai con il tuo Maestro su una faccenda che ti riguarda, poiché egli sa meglio di te dove sta il bene per te, e non dirgli nulla con la tua lingua e non parlare direttamente con lui di ciò, ma se c'è nella tua anima qualcosa su cui vuoi consultare (turăği $u$ ) il Maestro, menzionagliela in ciò che c’è tra te e la tua anima, poiché a lui nulla è nascosto del tuo stato".

Quanto al suo detto: "Non insistere mai con il tuo Maestro su una faccenda", quando lo interroghi, "poiché egli conosce meglio di te ciò che è bene nei tuoi riguardi", ciò che egli dice è come quello che successe al giovane che si gettò nel forno acceso, a causa della sua insistenza con il Maestro, e di cui abbiamo già riportato il racconto, e se non fosse stato per il sopravvento per lui della Provvidenza, per ciò che aveva chiesto al Maestro prima di quello, sarebbe bruciato ed avrebbe fatto parte della gente del Fuoco infernale $\left.{ }^{469}\right)$.

Uno dei compagni che l'Inviato di Allah, che Allah faccia scendere su di lui la Sua salāt e la Pace, aveva messo a capo di un reggimento di persone, si presentò loro, accese un fuoco e disse loro [136]: "L'Inviato di Allah, che Allah faccia scendere su di lui la Sua salāt e la Pace, non vi ha forse ordinato di ascoltarmi e di obbedirmi?", ed essi risposero: "Certamente!", ed egli disse loro: "Gettatevi in questo fuoco", ed essi gli risposero: "Noi abbiamo abbracciato l'Islām per salvarci dal Fuoco, e, per Allah, non ascolteremo". Quando ciò venne comunicato all'Inviato di Allah, che Allah faccia scendere su di lui la Sua șalāt e la Pace, egli disse: "Se si fossero gettati nel fuoco non ne sarebbero usciti" ${ }^{470}$. Ed egli, su di lui la Pace, ha detto: "Coloro che vennero prima di voi furono rovinati dall'abbondanza delle loro domande e dalla loro divergenza (ihtiliāf) con i loro Profeti”" (471). Ed Allah, sia Egli esaltato,

468) Si tratta di un brano dello hadīt quds̄̄ riportato in una nota alla traduzione della pag. 120. Ibn 'Arabī cita questo brano 10 volte nelle Futūhāt, nei capitoli 22 [I 175.20 e 177.28], 64 [I 316.8], 68 [I 345.9], 276 [II 598.5], 362 [III 307.11], 429 [IV 42.20], 558 [IV 235.25], 559 [IV 347.24] e 560 [IV 526.4].

469) L'episodio è riportato a pag. 72 del manoscritto ed esemplificava un caso estremo di obbedienza al Maestro. Qui però Ibn 'Arabī precisa che se l'aspirante fosse morto per quel gesto suicida, ancorché attuato per obbedienza al Maestro, sarebbe finito all'Inferno.

470) Hadīt riportato da Muslim, XXXIII-40, an-Nasā̄ì, XXXIX-34, e da Ibn Ḥanbal. La conclusione, qui non riportata, è che l'obbedienza è obbligatoria solo in ciò che è bene fare.

$471)$ "L'Inviato di Allah, che Allah faccia scendere su di lui la Sua șalāt e la Pace, si rivolse a noi e disse: "O uomini, Allah ha reso obbligatorio per voi il pellegrinaggio: fate dunque il pellegrinaggio". Un uomo chiese: "Tutti gli anni, o Inviato di Allah?", ed egli tacque finché l'uomo formulò la domanda per la terza volta. 
ha detto: "O voi che credete, non chiedete di cose che se vi fossero manifeste vi farebbero del male" (Cor. V-101), ed i Compagni hanno detto: "Ci è stato vietato di interrogare l'Inviato di Allah, che Allah faccia scendere su di lui la Sua salāt e la Pace" $\left({ }^{472}\right)$, cioè di nostra iniziativa, e come potremmo insistere nella domanda per avere la risposta? Il silenzio di colui che è interrogato è una risposta, per chi è intelligente, soprattutto nel caso dei Maestri, gli Eredi dei Profeti, poiché essi conoscono meglio di te le opportunità ed i momenti del discorso. Guardati dal porre al Maestro la domanda di chi cerca la risposta e di ripeterla con lui, bensì esponigli solo ciò che ti capita nella tua anima, nel tuo proposito e nel sogno che hai visto, e quando hai finito e vedi che il Maestro tace con te, non aggiungere nulla e dedicati alla tua occupazione $\left.{ }^{473}\right)$.

Questo è l'adab profittevole, poiché se il Maestro avesse saputo che risponderti sarebbe stato un bene per te lo avrebbe fatto, e quindi il suo silenzio coincide con ciò che è vantaggioso per te in quel momento.

Quanto al suo detto: "e non dirgli nulla con la tua lingua e non parlare direttamente con lui di ciò", questa è il modo per insegnare il raggiungimento [dello scopo] mediante l’influenza delle aspirazioni (himam) degli aspiranti sui Maestri e gli altri e la loro veridicità in questo, poiché quando l'aspirante è sincero muove il Maestro con la sua veridicità, e questo è noto nella [137] Via.

Avevo un compagno che era al servizio di un Maestro, di cui anche noi eravamo al servizio, ed il Maestro era assente. Questo fratello venne da me e mi chiese a proposito di una cosa che gli era successa nella lettura del Corano, ed io lo strapazzai e gli dissi: "Che differenza c'è tra te ed il volgo? Se hai questa attitudine tu prendi la scienza dagli uomini! Abū Yazīd non ha forse detto: "Voi prendete la vostra scienza morto da morto, e noi prendiamo la nostra scienza dal Vivente che non muore."? Perché non sei sincero con il tuo Signore e non ti affidi a lui in questa questione, sì da apprendere la risposta per gusto spirituale da Allah direttamente? Per Allah, se il Maestro fosse presente l'avresti indotto ad insegnarti l'adab. Non vedi che il Maestro, Allah sia soddisfatto di lui, non ci rimanda se

[Allora] l'Inviato di Allah, che Allah faccia scendere su di lui la Sua șalāt e la Pace, disse: "Se vi dicessi di si sarebbe obbligatorio e non ne sareste capaci!", poi aggiunse: "Lasciatemi stare finché vi lascio [fare]. Coloro che vennero prima di voi furono rovinati dall'abbondanza delle loro domande e dalla loro divergenza con i loro Profeti. Quando vi ordino qualcosa, fate di essa ciò che siete capaci, e quando vi vieto qualcosa astenetevi da essa". Hadīt riportato da Muslim, XV-412, at-Tirmid̄ī, XXXIX-17, an-Nasā̄ī, XXIV-1, Ibn Māğah, Introduzione-1, e da Ibn Ḥanbal. Ibn 'Arabī lo riporta integralmente nel Cap. 72 [I 737.18].

472) Nel suo Kitāb at-tadbīrāt al-ilāhiyya fì ișlāh al-mamlakat al-insāniyya [pag 114 dell'edizione di Nyberg e pag. 82 dell'edizione curata da 'Abd al-'Azīz Sultān al-Mansūb] Ibn 'Arabī precisa: "I Compagni, Allah sia soddisfatto di loro, erano soliti interrogarlo riguardo a delle cose finché questo non venne loro vietato nel Suo detto,sia Egli esaltato: "O voi che credete, non chiedete di cose che se vi fossero manifeste vi farebbero del male" (Cor. V-101), ed i Compagni dissero: "Ci è stato vietato di interrogare l'Inviato di Allah, che Allah faccia scendere su di lui la Sua șalāt e la Pace".

473) Una analoga affermazione è riportata nel Kitāb al-amr al-muhkam, a pag. 315 della traduzione di Asín Palacios già citata. 
non ad Allah riguardo ad ogni scienza che ci si presenta?". L'aspirante disse: "Hai detto il vero!", si pentì e si allontanò da me. Il giorno dopo venne da me, mi baciò sulla testa, e disse: "Che Allah ti ricompensi da parte mia, o eccellente compagno e generoso fratello. Di notte mi sono appartato con Allah su quella questione, ed Egli ha insufflato nella mia mente (raw $w^{c}$ la risposta ad essa, che è così e così", menzionando la risposta, che era giusta e completa, ed io gli dissi: "Non è forse più bello così?”, ed egli rispose: “Certamente!”. Malgrado questo non passai sotto silenzio l'episodio quando il Maestro fu presente, ma glielo raccontai ed egli disse: "È eccellente ciò che hai fatto!", ed il Maestro per quello ruppe i rapporti con lui per un periodo.

Quanto al suo detto: “Ma se c’è nella tua anima qualcosa per cui vuoi rivolgerti al Maestro, menzionagliela in ciò che c'è tra te e la tua anima, poiché a lui nulla è nascosto di quella scienza”, sappi innanzitutto che quando l'aspirante ha fiducia (saddaqa) nel Maestro, Allah pone per lui nella sua anima un'immagine (mitāll) del Maestro; questa immagine è ciò che egli contempla e che predomina in lui tanto che dice: "Questo è il Maestro!", e non dice: "è come se fosse lui (ka-anna-hu huwa)", [138] ma dice: "è proprio lui (huwa huwa)", e così essa è proprio lui. Egli menziona quindi quella questione al Maestro immaginato (mutawahham) ${ }^{\left({ }^{47}\right.}$ ), che esiste e che è presente nella sua immaginazione (hayāl), così come il credente che fa la salāt colloquia nella sua qibla con Allah. Se Allah fa sapere al Maestro

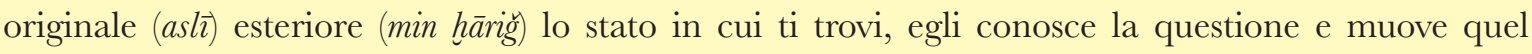
Maestro immaginato che tu contempli fornendoti la risposta a quella questione. Invero quel Maestro che è in te stesso sta al Maestro esteriore come l'ombra alla persona, ed è quindi l'ombra del tuo Maestro: attaccati quindi a lui $\left.{ }^{475}\right)$. Ciò che lo produce presso di te non è altro che la luce della tua veridicità $(s i d q)$, ed essa lo estende nella tua natura per mezzo della luce divina che è in te da parte Sua per la fede nel tuo Maestro, e ciò succede spesso agli aspiranti veridici.

Questo tipo di risposta è più profittevole per l'aspirante della risposta che egli riceve da Allah [direttamente] senza l'intermediario di questo Maestro immaginato, poiché l'Epifania (tağallı) del Vero nei Maestri è più grande della Sua Epifania nell'aspirante. Come nel caso dell'aspirante che

474) Dalla stessa radice trilittera, wh $\mathrm{m}$, derivano due verbi, wahama e wahima: il primo significa pensare, immaginare, il secondo significa sbagliarsi, fare una congettura errata. Mentre l'infinito/sostantivo wahm ha anche una connotazione negativa, il participio passivo mutawahham è qui usato come sinonimo di mutahayyal, immaginato. Nel Cap. 311 [III 78.23] Ibn 'Arabī afferma, ad esempio: "Il barzah è la stazione immaginata (mutawahham) che non ha esistenza se non nell'immaginazione $(w a h m)$ tra il Mondo della manifestazione visibile (šahāda) e l'invisibile (gayb)". L'espressione "Maestro immaginato" non ricorre nel testo delle raccomandazioni ed è quindi parte del lessico proprio di Ibn 'Arabī, anche se a mia conoscenza non si trova in alcuna delle altre sue opere, e certamente non nelle Futūhăt.

475) La natura "interiore" di questo Maestro immaginato non deve indurre a pensare che si tratti di ciò che nella tradizione indù si chiama il "Guru interiore", di cui il Maestro esteriore non è che l'ombra o il prolungamento. Il Maestro immaginato, come precisa Ibn 'Arabī, è l'ombra del Maestro esteriore, ed è pertanto assimilabile, pur essendo di natura interiore, a ciò che la tradizione indù definisce un upaguru. Su questa questione si può consultare il capitolo XX, "Guru et upaguru", in Initiation et réalisation spirituelle di René Guénon, Editions Traditionnelles, Parigi, 1964. 
riteneva di poter fare a meno di Abū Yazīd essendogli sufficiente Allah, quando il conoscitore, buon consigliere, gli disse: "Che tu veda Abū Yazīd una volta è meglio per te che vedere Allah mille volte!", perché sapeva che Allah, sia Egli esaltato, non Si manifesta a ciascuno se non in proporzione alla purezza del suo specchio e della sua forma (řakl), e sapeva che lo specchio di Abū Yazīd era più perfetto, e così fu. E quando quell'aspirante lo vide morì di terrore reverenziale, e quando fu seppellito venne riferita la sua vicenda ad Abū Yazīd, che disse: "Egli Lo vedeva secondo la sua misura ed ora Lo ha visto in noi secondo la nostra misura, non ha resistito ed è morto" $\left.{ }^{476}\right)$.

L'Inviato, che Allah faccia scendere su di lui la Sua șalāt e la Pace, apprendeva la rivelazione da Allah nello specchio di Gabriele, il suo Maestro, e ciò corrisponde al Suo detto, sia Egli esaltato: "È disceso con esso lo Spirito fedele sul tuo cuore" (Cor. XXVI-193 e 194) ed al Suo detto: "Spetta a Noi raccoglierla e recitarla e quando Noi la recitiamo" (Cor. LXXV-18 e 19) [139] ed ha attribuito la recitazione a Lui, sia Egli esaltato, così come dice tramite la lingua del Suo servitore che fa la salāt: "Allah ascolta chi Lo loda" $\left.{ }^{477}\right)$, "E non sei tu che hai gettato quando hai gettato, ma è Allah che ha gettato" (Cor. VIII-17). Analogamente non sei tu che hai recitato quando hai recitato, ma è Allah che ha recitato, e l'Inviato di Allah, che Allah faccia scendere su di lui la Sua șalāt e la Pace, ha ascoltato la recitazione da Gabriele, ma colui che recitava era Allah, poiché ha detto: "Quando Noi la recitiamo", attribuendo la recitazione a Lui, sia Egli esaltato. In questo modo l'Epifania del Vero nei Maestri per gli aspiranti è più completa nell'apprendimento da Lui rispetto alla Sua Epifania all'aspirante da solo in quanto tale.

Quanto al suo detto: "e chiedi aiuto (tawassal) al Maestro" ${ }^{478}$ ), egli vuol dire quel Maestro immaginato che la tua veridicità ha generato, e per questo ha aggiunto: "in ciò che è tra te e la tua anima". Poi ti ha detto, riguardo al tuo chiedere aiuto a lui, di farlo "tramite Allah, poi tramite Muhammad, che Allah faccia scendere su di lui la Sua șalāt e la Pace, poi tramite gli Angeli ed i Profeti, poi tramite il suo Maestro $\left.{ }^{479}\right)$, poi tramite il pio $(s \bar{a} l i h)\left({ }^{480}\right)$ tra i servitori di Allah".

476) Lo stesso episodio era già stato riportato a pag. 31 del manoscritto.

477) Hadīt riportato da Muslim, IV-62 e 63, e da Ibn Ḥanbal. Cfr. l’ultima nota alla pag. 69 del manoscritto.

478) Nel testo prima riportato della raccomandazione non si trova questa frase, ma si legge: "Ma se c'è nella tua anima qualcosa per cui vuoi rivolgerti al Maestro, menzionala al Maestro".

479) Dal commento che seguirà si comprende che questa espressione non si riferisce al Maestro del suo Maestro, bensì al Maestro esteriore.

480) Sălih è uno di quei termini che è difficile tradurre correttamente nelle lingue occidentali con una sola parola, poiché in arabo implica i significati di colui che è buono, giusto, retto, integro, virtuoso, devoto ecc. Nel Corano i pii sono citati al quarto rango di coloro su cui scende il Favore di Allah, dopo i Profeti, i confessori ed i martiri [[IV-69] ed è riportato che essi erediteranno la Terra [XXI-105]. Nel Cap. 73 [II 26.5] Ibn 'Arabī definisce i pii come "coloro nella cui integrità (salăh) non entra una falla (halal) in un certo momento", e nel Cap. 381 [III 509.23] come "coloro a cui non accade mai una disobbedienza, né grande, né piccola". 
Egli dice: chiedi aiuto a quel Maestro che è nella tua immaginazione, che è l'ombra del tuo Maestro esteriore, tramite Allah, cioè poni Allah mediatore tra te e lui in ciò che cerchi da lui. Poi, avendo precisato che Allah, sia Egli esaltato, Si manifesta secondo la misura di ciascun gruppo, e quindi tutta la faccenda si riconduce a Lui e tutte le credenze ('aqāid) riguardo a Lui sono valide ${ }^{481}$ ), stando così le cose quando egli chiede aiuto [al Maestro] tramite Allah, lo fa tramite l'Allah che è nella scienza che ha di Lui Muhammad, che Allah faccia scendere su di lui la Sua șalāt e la Pace, in quanto egli è la persona perfetta di questa specie umana.

Poi tramite gli Angeli, in quanto Egli Si è manifestato in essi mediante il Suo Nome la Luce, e per mezzo della luce si manifestano le cose agli sguardi ed alla vista interiore. Egli intende qui per gli Angeli gli Spiriti creati dai soffi $\left({ }^{482}\right)$ di Muhammad, che Allah faccia scendere su di lui la Sua salāt e la Pace, e per questo ha fatto precedere Muhammad, su di lui la Pace, a loro nella menzione. Se avesse voluto parlare degli esseri elevati $\left(a l-{ }^{c} \bar{l} l \bar{\imath} n\right)$ tra gli Angeli perdutamente innamorati, li avrebbe anteposti a Muhammad, che Allah faccia scendere su di lui la Sua șalāt e la Pace: così [sarebbe] se questo [140] Maestro fosse tra coloro che sostengono ciò. Invece è tra coloro che sostengono l'eccellenza del perfetto di questa specie umana rispetto all'Angelo - e non c'è essere più perfetto di Muhammad, che Allah faccia scendere su di lui la Sua salāt e la Pace, in questa specie umana - e per questo lo ha anteposto agli Angeli. Nel caso di questo Maestro è preferibile intendere il suo discorso secondo il primo aspetto, poiché è necessario che l'uomo intenda il discorso del suo compagno secondo il più completo degli aspetti, in modo da rendergli il suo diritto, e se quello [l'uomo] è così [cioè lo intende] allora gli apre gli occhi (ayqaza-hu), e se è al di sotto di quello allora dà alla stazione il suo diritto nell'alludere ad essa, e questa via è preferibile.

Poi, dopo gli Angeli, tramite i Profeti ed essi sono coloro che posseggono la scienza di Allah nel Suo detto: "Allah testimonia che non c'è Dio se non Lui, e [testimoniano anche] gli Angeli e coloro che

481) Conformemente alla prima parte del hadīt: "Io sono secondo l'opinione che il Mio servitore ha di Me: abbia quindi una buona opinione di Me!". Nel Cap. 69 [I 405.27] Ibn 'Arabī precisa: "Il Vero è secondo il credo di tutti coloro che hanno un credo, dopo il loro sforzo di giurisprudenza (i⿱ğtihād). Egli, sia esaltato, ha detto: "e chi invoca insieme ad Allah un altro Dio, per il quale non ha alcuna prova" (Cor. XXIII-117) [poiché se avesse una prova, fosse anche sbagliata, il suo credo sarebbe valido]. Comprendi dunque! Così come Egli è secondo l'opinione che il Suo servitore ha di Lui [...] Ed Allah ha detto: "Ed il tuo Signore ha decretato che voi non adoriate se non Lui" (Cor. XVII-23), cioè Egli ha giudicato (hakama). Ed è a causa Sua che la divinità è adorata e lo scopo dell'adorazione di chiunque adori non è se non Allah, e non c'è cosa che sia adorata per se stessa se non Allah".

482) Nel Cap. 155 [II 254.8] Ibn 'Arabī precisa: "La Profezia è diffusa in ogni essere [non solo tra gli uomini] [...] ma il nome di Profeta o di Inviato non si applica ad alcuno di essi se non agli Angeli, in modo speciale agli Inviati tra di loro, che vengono chiamati Angeli. Ogni spirito che non porta un messaggio è [solo] uno spirito e non si dice di lui che è un Angelo se non in senso figurato, come gli spiriti che sono creati dai soffi dei credenti che menzionano Allah. Allah crea dai loro soffi degli spiriti che chiedono perdono per chi ha pronunciato quella menzione ( $\underline{d i k r}$ ), fino al Giorno della Resurrezione. Lo stesso vale [per gli spiriti creati] da tutte le loro azioni lodevoli, in cui vi sono i loro soffi". Altri riferimenti agli Angeli creati dai soffi si trovano nei capitoli 7 [I 123.3], 157 [II 256.10], 198 [II 466.18], 369 [III 361.10] e 558 [IV 219.12]. 
posseggono la scienza" (Cor. III-18), ed Egli ha anteposto gli Angeli e ci ha fatto sapere, dicendo "coloro che posseggono la scienza" tra di noi, che gli Angeli sono tutti possessori della scienza di Allah, mentre riguardo a noi ha specificato i possessori della scienza [e non ha detto gli uomini]. Con questa espressione Egli intende la gente dello svelamento (kašf) e della teofania (tağall $\vec{\imath}$ ), e coloro che hanno le prove speculative razionali, non intende coloro che seguono ciecamente, poiché anche se essi incontrano la scienza, non sono sapienti. Chiunque abbia una considerazione (nazar) di Allah ha scienza di Allah, anche se un altro sapiente diverge da lui in quello, poiché la realtà in se stessa è troppo vasta per essere vincolata ad una persona ad esclusione di un'altra. Analogamente coloro che hanno scienza di Allah per mezzo della teofania sono nella stessa condizione della speculazione razionale riguardo alla scienza di Allah, poiché l'epifania del Vero ad ognuno che ha una teofania è diversa dalla Sua epifania ad un altro, essendo la realtà troppo vasta per quello, e tutti hanno scienza di Allah. Per questo chi è buon consigliere di se stesso deve studiare ogni affermazione (maqāla) di chi ha considerazione di Allah per conoscerla, poiché essa è una delle forme del Vero, ed egli deve sapere quindi ciò che hanno apportato i Profeti riguardo ad Allah e credere (ya qaqidu) in quello. Chi si comporta in questo modo (șâhib hâd $\underline{a} \bar{a} l$-amr) vedrà il Vero in ogni credenza (mu qaqad) $\left({ }^{483}\right)$, e questa è la considerazione perfetta e la stazione universale: non è concepibile da parte di uno come lui che disconosca il Vero, quando Si manifesterà nella sede del disconoscimento (maztin al-inkār), e se tace [141] di quello, il suo silenzio dipende da una conoscenza di Allah, e la sede e lo stato comportano per lui il silenzio $\left.{ }^{484}\right)$.

483) Questo argomento è stato ampiamente trattato da William Chittick, nel capitolo XIX di The Sufi Path of Knowledge, SUNY Press, 1989, e da Henry Corbin in L'imagination créatrice dans le soufisme d'Ibn 'Arabī, Flammarion, 1958, pagg. 145-148. Nel Cap. 165 [II 268.18] Ibn 'Arabī precisa: "Questa [la stazione della realizzazione $(\operatorname{tah} q \bar{\imath} q)]$ è una stazione rara, tanto che poche volte vedrai uno che la gusta, a meno che si tratti di colui che ha questa stazione. Il segno di riconoscimento del possessore di questa stazione è che per lui, in tutto ciò che è chiamato errore nell'esistenza vi è un aspetto verso il Vero, [aspetto] che egli conosce e che fa conoscere a chi glielo chiede se sa che lo accetterà da lui: questo è il segno di riconoscimento. Egli è colui che vede il suo Signore in ogni credo, in ogni punto di vista ed in ogni forma".

484) L'espressione "sede del disconoscimento" ricorre anche nei capitoli 329 [III 107.29], 463 [IV 85.28] e 475 [IV 110.11] e si riferisce ad uno hadịt riportato da al-Buhārī, LXXXI-38, che Ibn 'Arabī riassume così nel Cap. 64 [I 314.1] "Qui vi è una enorme descrizione dettagliata di cui sarebbe lungo parlare, poiché si tratta di una stazione immensa. Diremo solo che Allah si manifesterà in quel giorno [il Giorno della Resurrezione] e dirà: "Che ogni comunità segua ciò che adorava" finché non resterà che questa comunità [muhammadiana] con i suoi ipocriti. Ed il Vero Si manifesterà loro nella forma più vicina a quella con cui Si era manifestato loro prima di quel [Giorno] e dirà "Io sono il vostro Signore" ed essi diranno "Ci rifugiamo in Allah da te! Noi aspetteremo finché verrà il nostro Signore" Ed Egli, sia Egli esaltato, dirà loro: "C'è tra voi e lui un segno con cui Lo riconoscerete?" Essi risponderanno "Si" ed Egli Si tramuterà nella forma in cui essi Lo riconoscono per quel segno ed essi diranno "Tu sei il nostro Signore"”. In quella sede Allah Si manifesterà volutamente in una forma che non verrà riconosciuta dalla maggioranza degli uomini, ma i conoscitori di Allah Lo riconosceranno anche in quella forma, poiché essi "sono coloro che Lo riconoscono nella teofania del disconoscimento e che Lo contemplano in ogni credo" [Cap. 210 (II 498.14)]; mentre la maggioranza degli uomini dirà: "Mi rifugio in Allah....", essi taceranno. Altri riferimenti al silenzio dei conoscitori si trovano nei capitoli 279 [II 609.35] e 379 [III 496.14]. 
Ed egli [l'aspirante] chiede aiuto a quel Maestro immaginato anche tramite il suo Maestro esteriore, come ha menzionato [nella raccomandazione]: questo Maestro immaginato, che è l'ombra del Maestro esteriore, trae la sua materia $(m \bar{a} d d a)$ da questo Maestro esteriore ma l'aspirante non vede lui se non da questo Maestro immaginato, che l'aspirante lo sappia o non lo sappia.

Poi chiede aiuto a quel Maestro che è presso di lui anche tramite il pio tra i servitori di Allah, e con il pio si riferisce alla stazione alla quale i Profeti hanno chiesto di essere ammessi, con il Suo detto: "E ammettimi, per la Tua Misericordia, tra i Tuoi servitori pii”' (Cor. XXVII-19) ed Allah l'ha attestata per alcuni dei Profeti, come Gesù, il figlio di Maria, ed altri, come è menzionato nel Corano. $\left({ }^{485}\right)$

Poi, colui che ha fatto questa raccomandazione, Allah sia soddisfatto di lui, dopo questo cercare la mediazione di coloro che ha menzionato, ha detto: "Osserva la tua anima, e se trovi presso di te un desiderio ardente (šawq) del Maestro", intendendo che desideri ardentemente il Maestro esteriore, il che non avviene, malgrado la contemplazione di lui nel suo interno, se non a chi sa che quello che c'è di lui nel suo interno è la sua immagine e la sua ombra, non lui stesso. Quest'aspirante quindi desidera ardentemente il Maestro esteriore finché diventa per lui come la sua ombra, che è il Maestro immaginato, e questo è il punto di appoggio (sanad) più vicino.

Quando apprende dal Maestro immaginato dice: "L’ombra del mio Maestro mi ha riferito da parte del mio Maestro", e quando apprende dal Maestro esteriore, al momento dell’incontro, o comprendendo da lui per come egli lo guarda, o perché il Maestro gli rivolge direttamente la parola, egli dice: "Il mio Maestro mi ha riferito".

Poi ha detto dopo quello: "e se prova un impulso a fermarsi di fronte a lui", ove l'impulso che lo spinge proviene da quel Maestro immaginato, ed esso è a guisa del chiamante $(d \bar{a} \hat{\imath})$ del Vero che [142] c’è nel cuore di ogni credente ${ }^{\left({ }^{486}\right)}$. Quando Egli vuole che [il credente] si penta, Allah gli fa sentire quel chiamante, ed invero il chiamante non cessa mai di chiamare al pentimento, ma nelle orecchie vi è sordità, e quando cessa quella sordità dell'orecchio di chi è chiamato, egli sente e risponde, e si affretta a fare ciò a cui è chiamato. Analogamente si affretta quest'aspirante quando prova l'impulso, poiché esso è il proposito (hătir) [ispirato] dal Maestro esteriore, ed il Maestro immaginato è il suo interprete e l'impulso è la lingua dell'interprete. Sappi ciò! E per questo ha detto: "si affretta a [fare] ciò". E sappi che è il proposito del Maestro che ti ha inquietato, quindi non opporti.

Poi ha detto: "Se uno ti dice che il Maestro ti cerca o ti ha menzionato e non trovi quell'impulso ( $b \bar{a} \underline{i} \underline{t})$ confermato in te, non affrettarti dal Maestro", in base a quello [che ti viene detto], senza che ciò sia nel tuo cuore. Questo ti incita a cercare di essere sempre presente con il Maestro nel tuo cuore, al

485) L'attestazione è riportata per Abramo in Cor. II-130, per Zaccaria, Giovanni, Gesù ed Elia in Cor. VI-85, per Isacco e Giacobbe in Cor. XXI-72 e per Isacco in Cor. XXXVII-112.

486) Cfr. l’inizio della pag. 130 del manoscritto. 
punto che la presenza diventi per te un'abitudine, e troverai lo stesso con Allah quando avrai perduto il Maestro, o quando farai da solo senza di lui, anche se è inevitabile che resti un residuo (baqiyya) di colui che è venuto prima (mutaqaddim) e che è stato preso come modello in colui che viene dopo (muta'ahhirir) e che segue il modello, ciò è inevitabile. Ciò è simile al Suo detto, sia Egli esaltato, quando menzionò i Profeti a Muḥammad, che Allah faccia scendere su di lui la Sua salāt e la Pace, e gli disse: "Costoro sono quelli che Allah ha guidato, prendi dunque come modello la loro guida" (Cor. VI-90), anche se lui è il signore della comunità profetica e anche se nella vita essi lo avessero seguito, per il solo fatto della loro precedenza temporale e che la via è unica, colui che viene dopo segue senza dubbio l'esempio di chi viene prima $\left.{ }^{487}\right)$.

Allah, sia Egli esaltato, ha detto: "Egli vi ha prescritto della religione ciò che ha raccomandato a Noè, e quello che abbiamo rivelato a te" (Cor. XLII-13), e quello è ciò che lo contraddistingue rispetto alla comunità [profetica], "e ciò che abbiamo raccomandato ad Abramo, a Mosè ed a Gesù, cioè che pratichiate la religione e non vi dividiate in essa" (Cor. ibidem), ed ha apportato la raccomandazione di praticare la religione e di abbandonare [143] il contrasto e di essere uniti in essa, ed è necessario che chi viene dopo prenda come esempio chi venne prima nel tempo, riguardo a ciò in cui ha luogo la condivisione. "E quello che abbiamo rivelato a te" (Cor. XLII-13) è ciò che caratterizza anche il Maestro erede, o l'aspirante quando fa da solo ed è fuori dall'influenza ( $t a{ }^{\prime} t \bar{\imath} r$ ) del Maestro su di lui, avendolo eguagliato o avendo realizzato più di lui.

L'aspirante deve osservare, riguardo a ciò che gli viene detto da fuori, ciò che trova nel suo cuore, perché esso è per lui come il libro (mushaf) in cui il Vero gli recita ciò che vuole da lui ( $\left.{ }^{488}\right)$, e l'aspirante

487) Nel Cap. 73, questione CXLIV [II 125.2] Ibn 'Arabī precisa: "Ogni Legge con cui essi [i Profeti] sono stati inviati fa parte della sua Legge, su di lui la Pace, per quanto attiene al Suo nome "l'Interiore", poiché egli era Profeta quando Adamo era ancora tra l'acqua e l'argilla [mentre la sua manifestazione corporea attiene al Suo Nome "l'Esteriore"]. Quanto al Suo detto, sia Egli esaltato, a lui: "Costoro sono quelli che Allah ha guidato, prendi dunque come modello la loro guida" (Cor. VI-90), non ha detto "prendili come modello", poiché la loro guida è la tua guida che è penetrata dentro di loro dalla tua realtà essenziale. Quindi il significato di questo versetto per quanto attiene alla scienza è: "Se segui l'esempio della loro guida segui l'esempio della tua guida, poiché tu hai la primità (awwaliyya) interiormente e l'ultimità esteriormente e la primità nell'ultimità esteriormente ed interiormente"”, e nel Cap. 463 [IV 77.14] aggiunge: "Egli ha detto: "Segui ciò che ti è stato rivelato dal tuo Signore" (Cor. VI-106) [...] Io ti ho creato come uno che va seguito, non come uno che segue. Per questo quando menzionò i Profeti gli disse: "prendi dunque come modello la loro guida" (Cor. VI-90) non loro, e la loro guida non è altro che la Legge di Allah".

488) Nel Cap. 559 [IV 412.25] Ibn 'Arabī afferma: "Abū Yazīd ha detto: "Il mio cuore mi ha riferito da parte del mio Signore" ed è da Lui che ha appreso". Nel Cap. 2 aveva però precisato [I 57.31]: "Vi è una grande differenza tra un autore che dice: "Un tale, Allah abbia Misericordia di lui, mi ha riferito riguardo a un tale, Allah abbia Misericordia di lui" ed uno che dice: "Il mio cuore mi ha riferito riguardo al mio Signore". E se già quest'ultimo è più elevato in rango, vi è tuttavia una grande differenza tra lui e chi dice: "Il mio Signore mi ha riferito riguardo al mio Signore", cioè "Il mio Signore mi ha riferito di Se stesso". In ciò vi è una sottile allusione: il primo è il Signore oggetto della credenza (al-mu qaqad), il secondo è il Signore che non è soggetto a limitazioni”. 
non deve fare affidamento se non in ciò che trova nel suo cuore, non in ciò che sente con il suo orecchio.

È stato tramandato nella notificazione ciò che conferma questo, ed è una notificazione convalidata per via dello svelamento: "Consulta il tuo cuore, anche se i giuristi (muftūn) ti hanno dato un responso legale" $\left({ }^{489}\right)$ ed a questo riguardo, nel capitolo dello scrupolo, ha aggiunto con ciò che è autentico per entrambe le vie $\left.{ }^{490}\right)$ : "Lascia ciò che ti ispira dei dubbi per ciò che non ti ispira dubbi" $\left({ }^{491}\right)$. Tutto ciò è una indicazione da parte del Legislatore a colui che è soggetto all'incombenza legale affinché esamini il suo cuore in ogni questione e veda in esso le tracce del suo Signore, sia Egli esaltato.

Poi ha detto: "Invero Allah ha dato potere al Maestro sul tuo cuore, e se volesse che tu fossi presente di fronte a lui ti attirerebbe a lui". Quanto alla sua affermazione sul potere assegnato al Maestro sul suo cuore, è che all'inizio l'aspirante non è venuto dal Maestro se non per dargli autorità su se stesso, e non ha potere sul suo cuore altri che lui, per ciò che [l'aspirante] crede fermamente (íaqada) riguardo a lui. Per questo è punito quando lo contraria in qualcosa a cui il Maestro lo ha chiamato o che [il Maestro] ha attuato mentre l'aspirante era testimone di quello. Nel credo dell'aspirante [è implicito che] il Maestro agisce in lui con la sua aspirazione (himma) senza dover ricorrere ad una espressione verbale, bensì la sua espressione è interiore, con il linguaggio dell'ignoto (lisān al-gayb), e ciò è indispensabile.

489) Hadīt non recensito nelle raccolte canoniche. Nel Cap. 43 [I 246.8] Ibn 'Arabī precisa: "Osserva quanto è bella la frase che colui che ha ricevuto le Parole sintetiche, che Allah faccia scendere su di lui la Sua salät e la Pace, ha detto riguardo a questa stazione spirituale, spiegando come devono comportarsi coloro che vi si trovano: "Lascia ciò che ti suscita dei dubbi ed attieniti a ciò che non lascia dubbi", ed ha aggiunto: "Consulta il tuo cuore, anche se i giuristi ti hanno dato un responso [di liceità]". Egli ha in questo modo ingiunto loro di rimettersi ai loro cuori, sapendo che in essi c'è un segreto di Allah di cui sono venuti in possesso mediante l'acquisizione di questa stazione spirituale [dello scrupolo (wara $)$ ]. Nei cuori invero vi è una protezione ('isma) divina, di cui è cosciente solo la gente della vigilanza (murăqaba), e ciò costituisce un rifugio (sitr) per loro. In effetti se questi iniziati, di cui è risaputa la ricerca (baht $)$ e l'osservazione minuziosa ( $t a f t \bar{s} \tilde{s})$, interrogano gli uomini od i sapienti, che vengono interpellati in questo caso, in merito ad una questione di questo genere [cioè inerente allo scrupolo], è inevitabile che venga attribuita e riconosciuta loro la "devozione pura [ad Allah]" (ad-dīn alhālis), come successe fra altri a Bišr al-Hāfí, che fu uno dei Poli di questa stazione spirituale e che fu noto per questo fatto, per il quale fu irreprensibile (salima la-hu). Si racconta che una sorella di Bišr al-Hāẫ interrogò Aḥmad ibn Hanbal, uno degli Imām della tradizione, riguardo al lavoro di filatura che aveva compiuto alla luce delle torce della ronda notturna che passava davanti alla sua casa mentre era sulla sua terrazza: per questa domanda fu palese che ella apparteneva alla gente dello scrupolo, ma se avesse applicato lo hadīt "Chiedi consiglio al tuo cuore...", avrebbe compreso che la sua domanda dipendeva dal dubbio insorto nel suo cuore ed avrebbe interrotto quel lavoro di filatura, oppure non avrebbe più filato dopo di ciò, rinunciandovi". Questo hadīt è citato anche nei capitoli 88 [II 166.2], 347 [III 196.35], 411 [IV 16.7], 438 [IV 50.15] e 560 [IV 472.10 ].

490) Cioè la via dello svelamento e la via della trasmissione orale.

491 ) Hadīt riportato da al-Buhārī, XXXIV-3, at-Tirmid̄ī, XXXV-60, ad-Dārimī, XVIII-2, e da Ibn Ḥanbal, III-153. Ibn 'Arabī lo cita nei capitoli 43 [I 246.9], 51 [I 273.10], 88 [II 166.1], 91 [II 175.16], 411 [IV 16.7], e 560 [IV 472.9] 
Si tratta dell'orientamento (tawağğgh) della volontà da parte del Maestro verso ciò che egli vuole da lui, e questa è la definizione del suo ordine all'aspirante [144] ed è indispensabile il discorso dell'anima, cioè un ordine intelligibile che si aggiunge alla volontà $\left({ }^{492}\right)$. L'orientamento della volontà verso ciò che è voluto è un regime (hukm) aggiuntivo alla volontà stessa, che viene indicato con la parola e con l'ordine, e ciò corrisponde al Suo detto, sia Egli esaltato: "Invero il Nostro Ordine $\left({ }^{493}\right)$ ad una cosa quando la vogliamo è di dirle Sii ed essa è" (Cor. XVI-40), e non si è accontentato della Volontà, tanto che ha riportato la Parola (qawl) a mo' di Ordine, e se è così dal Lato divino - anzi le realtà essenziali non comportano che quello - a maggior ragione è così per la creatura. E la sua causa mediata (sabab) è la connessione dell'aspirazione dell'aspirante (himmat al-murīd) con il Maestro, ed il Maestro è più vicino a lui della sua stessa anima e non è altro che il Maestro che si trova nel suo proposito (hătir). Tra l'aspirante, cioè il cuore dell'aspirante, ed il Maestro si estende una fine realtà (raqĩqa) ${ }^{494}$ ) ed essa è una corda (habl) che lo collega [al Maestro]; per mezzo di quella fine realtà egli lo attira, e per mezzo di essa l'aspirante è attirato a lui, ed essa è simile alla corda di Allah a cui Allah ci ha ordinato di attaccarci $\left({ }^{495}\right)$.

492) Nel Cap. 73, questione XLI [II 68.23] Ibn 'Arabī precisa: "Il più grande dei suoi [dell'investitura divina] effetti (ta'tîrăt) è l'azione esercitata con la himma (al-fil bi-l-himma) in quanto l'anima è parlante (nätiqa), non mediante il linguaggio ed il suono ordinario articolato nel discorso verbale, in quanto la himma senza la parola profferita dall'anima nel modo che le si addice, anche se non è simile alla parola profferita dalla lingua, non ha alcuna efficacia, sotto qualsiasi aspetto, secondo la maggioranza dei nostri compagni. Ciò che li ha indotti a questa affermazione è il regime di luogotenenza (niyāba) di Allah, che quando vuole una cosa, il che corrisponde in noi alla himma, le dice kun ed essa è, e questo corrisponde in noi alla parola o al discorso profferito nel modo che si addice a ciò a cui è attribuito [ ] Quanto a noi sosteniamo questo nella sua sede e ciò è corretto, sennonché l'Essenza [...] cerca il rango della Divinità con una ricerca essenziale non mediante una himma ed una parola, anzi la Sua himma e la Sua parola sono identiche alla Sua Essenza".

493) Nel Corano al posto di amr, Ordine, si trova qawl, Parola.

494) Questo termine arabo indica letteralmente qualcosa di fine, sottile, delicato; nel tradurlo ho evitato l'aggettivo "sottile" per non generare confusione con il significato che ha questo aggettivo nell'opera di Guénon. Sotto un certo aspetto tale termine equivale alle "corrispondenze" che, nella terminologia adottata da Guénon, esistono tra gradi diversi d'esistenza o tra stati diversi dell'essere. Nel Cap. 15, Ibn 'Arabī riporta questa affermazione di un certo al-Kāsib [I 157.14]: "Invero Allah ha posto tutta la scienza nelle sfere ed ha fatto dell'uomo la sintesi delle fini realtà ( $r a q \bar{a} i q=$ corrispondenze) di tutto il mondo. Dall'uomo si estende una fine realtà verso ogni cosa del mondo, per mezzo di cui [si incanala] da quella cosa all'uomo ciò che Allah ha posto in quella cosa e che le ha affidato affinché la facesse pervenire a quell'uomo; e per mezzo di quella fine realtà l'uomo conoscitore muove quella cosa a sua volontà. Non c'è in effetti nulla nel mondo che non abbia un effetto sull'uomo e su cui l'uomo non abbia influenza" commentando poi che questo saggio aveva ottenuto lo svelamento e la conoscenza delle fini realtà e che esse sono simili ai raggi della luce. Nel Cap. 357 precisa inoltre [III 260.6]: "Sappi che non c'è forma nel mondo inferiore che non abbia un corrispondente nel mondo superiore. Le forme del mondo superiore preservano l'esistenza delle loro simili nel mondo inferiore [...] Tra i due mondi vi sono fini realtà che si estendono da ogni forma alla sua simile, sicché esse sono connesse e non disgiunte. L'ascesa e la discesa hanno luogo lungo queste fini realtà, che sono così scale ascendenti e discendenti. Talvolta esse sono chiamate interrelazioni (munāsabāt)". Va notato che Ibn 'Arabī parla anche di "fini realtà" sataniche [Cap. 310 (III 39.20)].

495) Riferimento a Cor. III-103. Ibn 'Arabī precisa che la corda di Allah è "il mezzo che consente di arrivare 
Quanto al suo detto: "E sii certo di lui riguardo a ciò", egli ti avverte di essere sincero nella tua convinzione, riguardo al Maestro, che egli è capace di fare ciò che ti ha menzionato, e che è dotato di una aspirazione (himma) efficace su di te, cioè che Allah, sia Egli esaltato, ha stabilito questo per lui e per i suoi simili. Per questo ha aggiunto: "tutto ciò è per ordine di Allah", cioè [sii certo] che Allah, sia Egli esaltato, glielo ha ordinato, poiché il Maestro non fa nulla se non per ordine divino, così come l'aspirante all'istruzione iniziatica non fa nulla se non per ordine del Maestro ed in ciò impara ad apprendere da Allah. Se la persona non si muove se non per un ordine di Allah, secondo la via specifica riguardo al suo segreto e secondo la via prescritta dalla Legge riguardo al suo lato esteriore, la sua aspirazione è efficace ed il suo proposito funziona e ciò che si prefigge avviene necessariamente; se è negligente e si muove in una faccenda senza seguire un ordine divino, può cogliere nel giusto ma può anche sbagliare. Il Maestro, per lode di Allah, non si muove in tutto ciò per cui si muove se non per un ordine divino, a differenza dell'Inviato, che le salāt di Allah scendano su di lui [145]. Talvolta Allah lo [l'Inviato] fa muovere in una faccenda dal lato della sua anima e non avviene ciò che egli vuole, e talvolta non coglie nel giusto in una cosa che egli ordina in base a una considerazione individuale, e questo non dipende da una mancanza in lui, che Allah faccia scendere su di lui la Sua salāt e la Pace, bensì dal fatto che Allah lo ha posto come un modello da seguire per il debole e per il forte, ed ha fatto sì che tutti i suoi movimenti fossero un argomento (huğğa) per entrambe le parti, poiché Allah lo ha inviato come Misericordia per le Sue creature. Egli chiese che suo zio Abū Ṭālib fosse tra i ben guidati, senza avere realizzato la sua guida, ed Allah non esaudì per lui ciò che aveva chiesto, ma in cambio gli diede il bene che Egli volle, affinché il servitore, quando chiede una cosa determinata e non la ottiene, trovi nell'Inviato di Allah, che Allah faccia scendere su di lui la Sua salāt e la Pace, una consolazione per se stesso in quello. Poi Allah, sia Egli esaltato, assecondò il Suo Inviato, che Allah faccia scendere su di lui la Sua șalāt e la Pace, quando vietò ai suoi compagni di fare un innesto alla palma, di sua iniziativa e non per il consueto ordine di Allah, e la palma deperì ed egli si scusò per quello e disse: "Ciò che vi ordino o che vi proibisco da parte di Allah, prendetelo" ${ }^{\left({ }^{96}\right)}$; ed il debole, quando si trova in una simile situazione, trova un argomento nell'Inviato di Allah, che Allah faccia scendere su di lui la Sua șalāt e la Pace. Lo stesso vale per il suo giudizio, condiviso da Abū Bakr, riguardo ai prigionieri di Badr $\left.{ }^{497}\right)$, ed altre cose simili, ed il forte trova in lui un argomento ed il debole trova in lui un argomento. Ad eccezione dell'Inviato nessuno ha questa funzione (mansib), e se [il Maestro] non ha questa funzione nei confronti della comunità, il suo stato è che non si muove se non per ordine di Allah, ed ogni volta che si muove per un proposito personale lo comunica ai suoi compagni, affinché non decada dai loro cuori quando essi vedono ciò e non siano privati dal suo profitto. E quando egli li informa, essi sono a conoscenza di lui e non osservano attentamente

alla felicità" [Cap. 72 (I 744.10)], "la Legge rivelata" [Cap. 355 (III 249.25)] e "la via su cui Egli ti fa salire a Lui" [Cap. 463 (IV 85.18)].

496) L'episodio della palma è già stato citato alla fine della pag. 64 del manoscritto.

497) Ibn 'Arabī fa riferimento a questo episodio nei seguenti capitoli delle Futūhāt: 235 [II 536.13], 247 [II 547.15], 267 [II 568.24], 558 [IV 219.33], 560 [IV 469.20] e nel Cap. II dei Fusūs al-hikam, pag. 65 dell'edizione di 'Abd al-'Azīz Sulțān al-Manșūb. Questo episodio è stato già citato all'inizio della pag. 65 del manoscritto. 
l'accadimento di quella cosa, necessariamente, cioè quella in cui si muove il Maestro; si impone quindi al Maestro di spiegare agli aspiranti il suo moto personale in modo specifico. Quanto a ciò che egli passa in silenzio e di cui non rende edotti i suoi aspiranti, ciò deriva da un ordine divino.

Il Profeta [146] non è tenuto a quello, cioè [nel suo caso] l'informazione ai compagni non è data se non dopo l'accadimento, e la mansione (manzila) dell'Inviato è diversa dalla mansione del Maestro nei confronti della comunità, in quanto egli è la sede del prendere esempio (ta'ass $\overrightarrow{)}$ e dell'imitazione (iqtidā ), mentre il Maestro non è così né nei confronti della comunità né dei suoi compagni: sono loro che impongono a loro stessi di prendere esempio da lui, mentre l'Inviato ha imposto loro lui stesso di prendere esempio da lui, e questa non è una differenza che sia nascosta. Egli, che Allah faccia scendere su di lui la Sua șalāt e la Pace, ha detto: "Fate la șalāt come mi avete visto fare la șalāt" e "[Ap] prendete da me i vostri riti" ${ }^{498}$. Allah ha detto riguardo a ciò: "Invero nell'Inviato di Allah c'è per voi un bell'esempio per chi spera in Allah e nel Giorno Ultimo” (Cor. XXXIII-21).

Poi questo Maestro ha corroborato la sua affermazione riguardo al Maestro, cioè che tutto ciò non avviene se non per ordine di Allah, sia Egli esaltato, aggiungendo "e per la Sua Volontà (irāda)", intendendo senza dubbio riferirsi all'Ordine (amr) per mezzo di cui ha luogo la generazione (takwin), e non che egli [il Maestro] ordina e produce la cosa presso di sé, diventando un luogo (mahall) per gli avvenimenti (hawādit), ma le cose non stanno così.

Qui vi è un punto sottile su cui attiro la tua attenzione e cioè che al Vero appartiene la Manifestazione di Sè (tağallî̀) nelle forme ma Egli è governato dal regime della forma in cui Si manifesta, così come è governato nella gente comune quando Lo vede nel sogno in una certa forma, ed in qualsiasi forma Egli Si manifesti a colui che sogna, quella forma segue i suoi attributi inerenti (lawāzim) e ciò è innegabile. La percezione è unica per entrambe le parti, l'élite e la gente comune, sennonché l'élite contempla ciò da parte del Vero nella sua veglia nella sede (mawtin) in cui Lo contempla la gente comune, ma non nello stato $(h \bar{a} l)$ in cui Lo contempla la gente comune, poiché lo stato della gente comune in quello è il sonno, e la sede è unica.

Se le cose stanno così, può succedere che la forma sia di qualcuno la cui recettività agli avvenimenti la renda necessaria e quindi la cosa avviene presso di lui per la sua volontà in se stesso, se la forma comporta ciò per la sua realtà essenziale, e quindi il Vero Si manifesta in essa ed è inevitabile che sia governato [147] da essa. Comprendi ciò che ti ho menzionato, poiché è molto utile nella purificazione (tahlīs), in quanto il potere della immaginazione (wahm) è immenso e la sua profondità è insondabile $\left({ }^{499}\right)$.

498) Questi hadịt sono già stati riportati a pag. 59 del manoscritto.

499) Nel Cap. 381 [III 510.1] Ibn 'Arabī precisa: "In questa Presenza [della immaginazione] il Vero è con il servitore secondo tutto ciò che vuole il servitore [...] e per questo [nell'aldilà] ogni cosa è generata dal suo volere quando la desidera. Ed il Vero è a disposizione dell'uomo in questa Presenza in questo mondo, e del suo desiderio nell'aldilà, ma non in modo sensibile in questo mondo, così come il servitore, nel suo volere, 
Guardati da ciò che le intelligenze rifiutano per mezzo delle loro prove, poiché Allah è troppo vasto per essere vincolato dalla prova della ragione ad esclusione di altro, ma a Lui spetta ciò che la speculazione razionale dimostra ed altro; si tratta di ciò che è fatto risalire a Lui e che hanno apportato i Libri di Allah e tutti gli Inviati. Guardati dall'interpretare e dal ridurre questo a ciò che la ragione cerca con la sua argomentazione riguardo ad Allah, poiché è esiziale (muhlik).

Poi questo Maestro ha aggiunto: "e per il Suo Volere $(\operatorname{mašs} a)\left({ }^{500}\right)$ " ed il Volere da parte del Vero è uno dei regimi $(a h k a \bar{a} m)$ della Volontà ed è ciò che accresce l'esistenza, non ciò che la diminuisce, come il manifestare un'entità, non il suo annientamento $(i d \bar{a} m)\left({ }^{501}\right)$.

La Volontà riguarda la non-esistenza e l'esistenza mentre il Volere riguarda specificamente l'esistenza, e se questa viene annientata per mezzo del Volere ${ }^{(502}$ ) si tratta di un accrescimento di regime nella cosa esistente, cioè il suo ritorno alla non-esistenza da cui è venuta. Egli [il Maestro] ha tenuto in considerazione questo ed ha applicato ad esso il nome di Volere.

sottostà al Volere del Vero. Ed il Vero non ha altra occupazione che osservare il servitore per dare esistenza per lui a tutto ciò che egli vuole che esista in questa Presenza in questo mondo, e così pure nell'aldilà. Ed il servitore è subordinato al Vero nelle forme della Teofania, ed il Vero non Si manifesta a lui in una forma senza che Egli ne assuma il colore; quindi egli si tramuta nelle forme per il tramutarsi del Vero, ed il Vero si tramuta nell'esistenziazione per il tramutarsi del volere del servitore, in questo mondo specificamente in questa Presenza immaginativa, e nell'aldilà nel Paradiso in modo generale".

500) La distinzione tra Volontà (irāda) e Volere (maš̌̌̉ a) nella dottrina di Ibn 'Arabī non è di facile comprensione. Ad esempio, nel Cap. 312 [III 48.13] egli afferma: "La Volontà (irāda) non ha scelta (ihtityār), non c'è Libro né Sunna che lo abbia affermato, né ragione che lo abbia provato. Quella [la scelta] appartiene al Volere (maš̃ $a$ ): se Egli vuole è, e se vuole non è; il Profeta, su di lui la Pace, ha detto: "Ciò che Allah vuole $(s \bar{a} a)$ è, e ciò che non vuole non è", stabilendo una connessione della negazione e dell'affermazione con il Volere, e non è stato riportato: "ciò che non vuole (lam yurid) non è", ma è stato riportato: "Se volessimo (law aradnā) che fosse così sarebbe così", escludendo così la scelta. La Volontà è la connessione del Volere con ciò che è voluto (muräd), e ciò corrisponde al Suo detto: "Invero la Nostra Parola ad una cosa quando la vogliamo" (Cor. XVI-40); questa è la connessione del Volere [...] La scelta appartiene all'Essenza in quanto è Dio: se vuole fa e se vuole non fa; ed è l'esitazione (taraddud) divina riportata in una notificazione autentica". Nel Cap. 369 [III 375.3] afferma invece: "Il Volere è uno nella sua relazione [con le possibilità], non c'è scelta in esso", come aveva ribadito anche nel Cap. 368 [III 356.21].

Un utile chiarimento di questa distinzione si trova nel Cap. 294 del Kitāb al-mawāqif di 'Abd al-Qādir al-Ǧazāirin̄, tradotto da Michel Lagarde, "Le Livre des Haltes", E. J. Brill, 2001, Tomo II.

501) L'annientamento è qui considerato dal punto di vista della manifestazione in se stessa, ma da un altro punto di vista si tratta di un ritorno alla non-manifestazione, ed in questo senso l'annientamento del manifestato può essere attuato dal Volere, come viene affermato subito dopo. D’altra parte, nel Cap. 390 [III 548.3] Ibn 'Arabī precisa: "Ciò che è voluto non può che essere non-esistente e colui che vuole non può che essere esistente, e così per il potente e ciò che è potuto; quest'ultimo non può che essere non-esistente, e dopo che è stato esistenziato non ha annientatore (mu'dim) dopo la sua esistenza se non se stesso o la sottrazione della condizione (sart) della sua permanenza, cioè la permanenza dell'esistenza su di lui. Diversamente non può essere". Il possibile non cessa mai di sussistere nel suo stato di non-esistenza, essendo solo il supporto dell'esistenza di Allah.

502) Anche nel Cap. 559 [IV 368.24] Ibn 'Arabī afferma: “[...] per questo ha collegato l'annientamento con il Volere". 
Poi ha anche aggiunto: "e per il Suo Decreto $(q a d \bar{a})$ riguardo alle Sue creature”, cioè il Suo Giudizio $(h u k m)$ riguardo ad esse, poiché il Decreto è il Giudizio.

Poi ha detto: "e sforzati di tenere nascosto tutto questo in modo efficace" ed ha confermato nella raccomandazione quanto ha prima menzionato degli stati spirituali del Maestro. Egli dice che tutto ciò resti in te stesso, senza farlo sapere a nessun altro, affinché non derivi da lui il danno al tuo Maestro, e la perdita e la rovina non ricadano su coloro che negano questo riguardo allo stato spirituale del Maestro. La Via è misericordia, e la gentilezza (rifq) verso coloro che sono velati da una cosa simile è obbligatoria per ogni viandante $(s \bar{a} l i k)$. Il manifestare una cosa simile alla gente comune fa parte dell'eccesso (tagāl $\vec{\imath})$ nella religione e riguardo a questo è stato riportato il divieto da parte di Allah, sia Egli esaltato, nel Suo detto: "O gente del Libro", e tu fai parte della gente del Libro poiché sei della gente del Corano, "non eccedete nella vostra religione", poi ha aggiunto: "al di fuori del dovuto" (Cor. V-77) per colui che ritiene che ciò [148] non sia vero, cioè la gente comune, mentre per colui che lo considera vero [dirlo] non è un eccesso. Comprendi ciò.

Poi ha detto: "Se ti arriva una cosa che avevi sperato in Allah che ti fosse apportata per mezzo del tuo Maestro, non rivolgerti al Maestro riguardo ad essa". Egli ti dice di non occupare il tuo momento con la menzione del risultato, poiché perderesti il bene del momento, cioè "quello che arriva (wārid)" ( ${ }^{503}$ ) del momento e che è una delle opere (šu úun) in cui Allah è occupato nei riguardi dei Suoi servitori. Non c'è utilità a menzionare il risultato, a meno che la sua menzione non arrechi un accrescimento per essersi conformati ad un ordine divino, come il Suo detto: "Quanto al favore del tuo Signore riferiscilo" (Cor. XCIII-11), affinché l'altro senta e cerchi di ottenerlo, in quanto le anime hanno connaturato l'amore dei favori e dell'elargizione da parte di Colui che può farlo, e la sua menzione determina in coloro che ascoltano un ricorso (iltiǧa $\bar{a}$ ), un'aspirazione (himma), una ricerca ed una dipendenza da Allah nell'ottenere quello e altre cose simili.

503) Nel Cap. 265 [II 566.15] Ibn 'Arabī precisa: "Secondo gli iniziati (qawm) ed anche secondo noi, il "wārid" è ciò che arriva sul cuore da ogni Nome divino. Il discorso qui verte sul fatto che esso arriva non su ciò con cui arriva. Esso può apportare sobrietà od ebbrezza, contrazione o dilatazione, terrore o familiarità, e molte altre cose, ma si tratta sempre di wārid, sennonché gli iniziati nel loro linguaggio tecnico applicano questo nome ai propositi improvvisi (hawätir) lodevoli tra quelli che abbiamo menzionato. Devi sapere, fratello mio, che il wärid, in quanto tale, non è vincolato né dalla novità (hudūt), né dall'eternità, poiché Allah ha qualificato Se stesso, malgrado la Sua Eternità, con il venire (ityān): l'arrivo è un venire ed il wārid può avere diversi stati nel suo venire. Esso può arrivare d'improvviso, come l'irruzione (huğūm) e le sorprese (bawādih), o non d'improvviso ma piuttosto con la consapevolezza da parte di colui su cui arriva, mediante i segnali e la concatenazione delle circostanze che indicano l'arrivo di una determinata cosa, richiesta dalla predisposizione del ricettacolo. Ogni wārid divino porta solo beneficio e non c'è che un wärid divino, sia esso generato nel tempo $(k a w n \vec{\imath})$ o non generato nel tempo [cioè eterno]. Il beneficio che comporta ogni wārid è la scienza che viene ottenuta col suo arrivo da parte di colui su cui arriva, e non fa parte dei suoi requisiti il fatto che dia gioia o dolore, poiché ciò non fa parte del regime del wärid: il regime del wärid è la scienza che viene ottenuta, e ciò che va oltre a questo dipende da ciò che apporta, non da lui stesso". 
Per questo egli ha detto: "Non rivolgerti al tuo Maestro riguardo a ciò, poiché il Maestro è colui che ti porta ciò da parte di Allah e non c'è alcun vantaggio nel farglielo sapere, in quanto egli è più sapiente di te al riguardo", e non ti ha vietato di menzionarlo a chi tu sai che lo accetta ed ottiene per ciò una dimora (manzila) presso Allah.

Poi ha confermato la raccomandazione, dicendo: "e anche se quella cosa sperata è ritardata per te, non rivolgerti al tuo Maestro riguardo ad essa". Egli dice: se essa non ti arriva se non per via del tuo Maestro non c'è utilità nel rivolgerti a lui riguardo ad essa se tarda a venire, poiché così importuneresti il Maestro. Il Maestro non può trovarsi da parte di Allah se non in una delle due seguenti situazioni al riguardo: o Allah, sia Egli esaltato, gli ha già dato quello e non gli ha ordinato di trasmettertelo per un beneficio che c'è per te nel ritardare, poiché non si può dubitare del [comportamento del] Maestro riguardo all'aspirante, né riguardo all'insieme delle creature, e non c'è vantaggio nel rivolgerti [a lui], data la tua scienza che egli già sa ciò che è chiesto.

L'altra situazione è che Allah non abbia ancora conferito al Maestro quella cosa per dartela, perché tu insistessi rivolgendoti riguardo ad essa [149] al Maestro - ed egli ti ha proibito di insistere con il Maestro riguardo a qualcosa e di affrettare una cosa che Allah ha voluto ritardare - e questo per la tua ignoranza della predisposizione in cui ti trovi.

Qui non si tratta di impedimento, né di anticipazione, né di ritardo, bensì di un dono (wahb) assoluto e della ricezione $(q a b \bar{u})$ da parte nostra nella misura della predisposizione in cui ci troviamo in ogni attimo (nafas).

La ricezione non è ritardata se non per l'assenza di predisposizione. Abbi conoscenza dello stato in cui ti trovi ed avrai conoscenza di come stanno le cose, e non pensare male del tuo Maestro, poiché ciò equivale a pensar male del tuo Signore. Allah è secondo l'opinione che il Suo servitore ha di lui e se egli pensa di Lui che non gli risponde, dopo questo Egli non gli risponderà, poiché l'Inviato di Allah, che Allah faccia scendere su di lui la Sua șalāt e la Pace, ha detto: "Invero Allah risponde al servitore, a meno che il servitore non dica: Egli non mi risponde!".

Guardati dall'astuzia che Allah usa con te senza che tu te ne renda conto, soprattutto avendo saputo che per ogni cosa vi è una condizione (̌́art) perché essa si realizzi, che non è altro che la predisposizione che abbiamo menzionato.

Per questo, costui che parla ha completato il discorso dicendo nella sua raccomandazione: "Per ogni cosa vi sono delle condizioni, e vige la consuetudine di Allah di farla dipendere dalla riunione di queste condizioni”. L'uso dell'espressione "consuetudine ('a $d a)$ " è per adab verso Allah, poiché si tratta di una verità essenziale ma nella realtà in se stessa non c'è consuetudine, bensì essa in ogni attimo è un nuovo regime $(h u k m)$, di cui non si ha coscienza. I simili impediscono di comprendere quell'innovazione (tağdìd), come ha detto, sia Egli esaltato: "essi lo riceveranno simile" (Cor. II-25), 
e diranno che questo è quello. Per mezzo del gusto spirituale si conosce la distinzione (furqān) e tutta l'esistenza è nella distinzione stessa $\left.{ }^{504}\right)$ : la sintesi $\left(q u r^{3} \bar{a} n\right)\left({ }^{505}\right)$ per ciò che concerne la somiglianza delle forme e la distinzione per ciò che concerne i gusti spirituali, la sintesi è per la gente comune e la distinzione non è attualizzata se non dai timorati di Allah, sia Egli esaltato $\left.{ }^{506}\right)$.

Poi ha detto: "ma abbi presente quello nella tua mente e dirigi questo tuo pensiero verso il Maestro, come se tu chiedessi il suo esaudimento o la causa del suo ritardo" [150]

Questo Maestro ha raccomandato ciò perché sa che l'uomo è stato creato frettoloso $\left({ }^{507}\right)$ e che non ha pazienza, e quindi gli ha fornito una via per la sua fretta. È preferibile che non lo faccia, ma se lo fa, egli gli ha spiegato ciò che deve proporsi in quell'atto, tanto più che questo Maestro ed i musulmani hanno sentito il discorso di Abū Bakr al Profeta, che Allah faccia scendere su di lui la Sua șalāt e la Pace, nel giorno di Badr, quando l'Inviato di Allah, che Allah faccia scendere su di lui la Sua șalāt e la Pace, supplicò il suo Signore di venire in aiuto alla religione, poiché sapeva che il soccorso (nusra) in quel giorno era condizionato dalla sua supplica, e nessun altro lo sapeva.

504) Nel Cap. 223 [II 518.12] Ibn 'Arabī precisa: "Sappi che la radice di tutte le cose è la distinzione (tafriqa) che si manifestò inizialmente nei Nomi divini ed i loro regimi si distinsero per mezzo della distinzione dei loro significati", e poco oltre [II 519.4] aggiunge: "Quanto all'affermazione di chi dice: "La distinzione (farq) è l'affermazione della creazione" essa è simile a quanto detto in precedenza riguardo al significato della loro affermazione: "[La distinzione] è un'allusione alla creazione senza Vero". Sennonché tra le due vi è una differenza. Egli ha detto: "l'affermazione della creazione" e non ha detto "l'esistenza della creazione", poiché l'esistenza della creazione è identica all'esistenza del Vero. La creazione, quanto alla sua entità, è immutabile [o: fissa $(t a \bar{b} b i t)]$ e la sua immutabilità le appartiene dall'eternità; la sua qualificazione con l'esistenza è una faccenda nuova che le capita, e già ti abbiamo fatto sapere ciò che questa espressione significa. La sua affermazione: "l'affermazione della creazione", significa che nell'eternità ebbe luogo la distinzione tra Allah e la creazione; il Vero non è identico alle entità immutabili, a differenza dello stato in cui esse sono qualificate dall'esistenza, ed è Lui che è identico a ciò che è qualificato dall'esistenza, non esse".

505) I termini furqān e qur'ān sono anche due nomi del Libro sacro. Nel Cap. 90 [II 172.35] Ibn 'Arabī precisa: "Quanto alla Sua preferenza per il Corano tra i discorsi [divini], essa dipende dal fatto che al Corano appartiene l'attributo della sintesi (ğam ) e nella sintesi vi è l'essenza della distinzione (furqān), poiché la sintesi indica la molteplicità e la molteplicità è fatta di unità e queste sono l'essenza della divisione (iftirāq) nella sintesi stessa", e nel Cap. 325 [III 95.1] aggiunge: "Sappi poi che il Vero ha fatto scendere il Libro come Furqān nella Notte del Qadr, che era la notte di mezzo di Ša'bān, e lo ha fatto scendere come Qurāann nel mese di Ramad̄ān. Esso è stato fatto scendere per intero al Cielo più prossimo e da lì è disceso lungo un periodo di 23 anni, in modo distintivo, a pioggia di stelle (nuğüm), nella forma di versetti e Sure, sì che le mansioni (manāzil) potessero essere conosciute ed i gradi resi evidenti. A causa della sua discesa sulla Terra nel mese di Šacbân, esso viene letto [o recitato] come Furqān, mentre a causa della sua discesa nel mese di Ramaḍ̂n, viene letto come Qur'ān. Tra di noi vi sono coloro che lo leggono tramite Lui, nel qual caso è il Qur àn, e coloro che lo leggono tramite loro stessi, nel qual caso è il Furqān".

506) Cfr. Cor. VIII-29: "O voi che credete, se sarete timorati di Allah, Egli vi darà un discernimento (furqān)".

507) Cfr. Cor. XVII-11. 
Abū Bakr gli disse: "Ti è sufficiente, o Inviato di Allah, la tua supplica al tuo Signore, poiché Allah mantiene per te ciò che ti ha promesso" ( $\left.{ }^{508}\right)$, e l'Inviato di Allah, che Allah faccia scendere su di lui la Sua salāt e la Pace, non gli contestò la sua affermazione. È quindi lecito per noi domandare ad Allah, o al Maestro, di esaudire ciò che gli abbiamo chiesto, per ciò che sappiamo della Sua Grazia, e se non avviene sappiamo che vi è una causa che lo ritarda e noi vogliamo sapere la causa. Se la realtà essenziale di quella causa comporta che noi la sormontiamo, la sormontiamo, e se comporta il fermarsi presso di essa finché finisce ci fermiamo presso di essa. La causa si restringe a tempo, luogo e stato, non c'è altro che quello, e solo lo stato, tra queste condizioni, è noto ai conoscitori, poiché essi sono dotati di gusto spirituale e sanno se lo stato in cui si trovano non è compatibile con ciò che cercano, e se esso invece è compatibile allora sanno che l'ostacolo è il tempo o il luogo.

Poi ha detto: "Invero il tuo Maestro ti ha ispirato ciò e ti ha informato su queste condizioni per autorizzazione $(\underline{i d n})$ di Allah, sia Egli esaltato", cioè se Allah glielo ordina egli ti informa di ciò, e se non lo autorizza non ti parla. Sappi ciò!

Sennonché qui vi è una faccenda su cui attiro la tua attenzione e cioè che tu hai un Maestro esteriore e che la sua immagine (mitât) che è in te è parte di lui, per la tua unione (ittihâad) con lui e perché la tua essenza è imbevuta (uśribat) di lui; [151] quindi tu vedi il tuo Maestro esteriore nella sua immagine che è in te, come è stato riportato: "Adora Allah come se Lo vedessi”" (509) ove ti ha ordinato di rappresentarteLo davanti agli occhi nel tuo atto di adorazione di Lui.

Quanto al suo detto: "Invero il Maestro ti ha ispirato ciò e ti ha informato", se si tratta del Maestro che è fisicamente esteriore a te è indispensabile che il Maestro abbia conoscenza di questa ispirazione ed informazione affinché, se interrogato, dica le stesse cose che l'aspirante ha trovato in se stesso da parte del suo Maestro. Se [invece] il Maestro non ne è a conoscenza, allora l'ispirazione e l'informazione ha luogo in te solo da parte del Maestro immaginato, che abbiamo detto essere la sua immagine, e se non fosse che il Vero è Sapiente di ogni cosa diremmo di Lui la stessa cosa, sennonché la distinzione tra i due [il Maestro ed il Vero] è evidente $\left.{ }^{510}\right)$.

Il Maestro esteriore, anche se non ha scienza in modo specifico e distintivo di ciò che trova l'aspirante sa però ciò che esso comporta, e la sua aspirazione (himma) è connessa con tutto quello che la via conferisce di ciò in cui vi è la felicità di colui che la percorre. Il Dio che risulta dal credo del credente (itiqād al-mu taqid) ${ }^{511}$ ), [credo] che il cuore contiene, è Colui che ispira ed informa questo servitore

508) Hadīt riportato da Muslim, XXXII-58 e da at-Tirmidīī, XLIV ad Sūra VIII-3.

509) Hadīt già citato a pag. 33 del manoscritto.

510) Ibn 'Arabī stabilisce qui una corrispondenza tra il Maestro esteriore ed il Maestro immaginato con il Vero che tutto riunisce ed il Vero del credo del servitore, corrispondenza che verrà sviluppata nel seguito del testo.

511) Nel Cap. 523, dedicato alla conoscenza dello stato del Polo la cui dimora spirituale è [il versetto] "e quanto a chi teme la stazione del suo Signore" (Cor. LXXIX-40), Ibn 'Arabī precisa [IV 165.31]: "Sappi che 
che è assistito da Lui, ed il Vero che è connesso ad ogni credo è la sostanza ( $m \bar{a} d d a)$ di questa credenza (mu taqad) specifica che il cuore contiene ed è da Lui che apprende chi ha quel credo.

Ed Allah che [tutto] riunisce $(a l-g ̌ a m i q)$ ha scienza di ciò in modo dettagliato, ed il servitore dice di quello che ha trovato [o: realizzato] in modo specifico: "il Vero mi ha detto ed io Gli ho detto", come il possessore delle soste (mawāaif), delle sedi di contemplazione (mašāhid) e di altre realtà simili.

In realtà è su Lui che egli [il servitore o il credente] fa affidamento (yu'awwalu), sennonché qui il Maestro, per quanto riguarda il suo corpo, è esteriore a te, mentre il Vero che [tutto] riunisce $\left({ }^{512}\right)$ non è caratterizzato dall'entrare da te né dall'uscire da te, né dall'essere te, né dal non essere te, a differenza del regime della corporeità del Maestro, poiché egli è diverso da te e distinto da te [152], e ciò che è presso di te $(\{n d a-k a)$ non è presso di lui. Per quanto riguarda invece il Vero che [tutto] riunisce, tutto ciò che è presso di te è presso di Lui, e tutto ciò che è presso di Lui non è presso di te in modo dettagliato, anche se è presso di te in modo complessivo (muğmal) e si manifesta a te cosa dopo cosa, in questo e nell'altro mondo, senza mai finire $\left.{ }^{513}\right)$.

Quando ti informa e ti ispira il Maestro esteriore, che ha una scienza ed una visione interiore di ciò, è più profittevole e più completo nei tuoi riguardi, mentre quando ti informa e ti ispira il Maestro immaginato, sei tu che ispiri te stesso e tu sei la sede del dubbio (tuhma), talvolta cogli nel giusto e talvolta sbagli, e quindi hai bisogno di conoscere ciò che distingue i due Maestri. Nell'ispirazione che ti viene dal Maestro esteriore non hai bisogno di una bilancia, ma la accetti in modo remissivo, anche se non ne conosci il significato; nell'ispirazione che ti viene dal Maestro immaginato hai bisogno di una bilancia e quindi esiti ad accettarla finché la bilancia non depone a favore di essa, poiché egli [il Maestro immaginato] è te stesso, non è il Maestro che tu segui. Egli [il Maestro immaginato] in questo caso è come il Dio oggetto della credenza, poiché nell'ispirazione da parte del Dio oggetto della credenza hai bisogno della bilancia della Legge che è stata dettata per te e che è stata stabilita dal Dio che non è vincolato da un credo [(' $a q d)$, letteralmente nodo, contratto] ad esclusione di un altro e che è il Vero che [tutto] riunisce; quanto a quello che è l'oggetto della credenza, egli è il

ogni stazione di un signore (sayyid) presso un servitore che abbia un credo è conforme a ciò che il servitore ha prodotto in se stesso nel suo credo. Per questo Allah ha detto: "la stazione del suo Signore", attribuendola a Lui senza però darle un senso assoluto [come sarebbe se avesse detto: "del Signore"]; e non troverai mai questo Nome, "il Signore", se non correlato e condizionato, esso non è mai in forma assoluta nel Libro di Allah, poiché Egli è un Signore solo per la collocazione $\left(w a d^{d}\right)$ [relativamente a qualcosa]. Ed il Signore, quanto al suo significato - cioè questo Nome - è Colui che concede, nell'origine della Sua collocazione, di comprendere ogni credo di cui sia oggetto, e che Si manifesta con la Sua forma nell'anima del Suo credente. E se il conoscitore è veramente tale, non è vincolato da un credo ad esclusione di un altro e non disapprova il credo di uno riguardo al suo Signore ad esclusione di un altro, per il suo sostare presso la fonte che riunisce [tutte] le credenze".

512) Nelle Futūhāt questa espressione ricorre solo nel Cap. 559 [IV 437.4].

513) Le possibilità di un essere sono conosciute in modo dettagliato, nella loro permanente attualità, dal Principio, ma per l'essere manifestato sono possibilità che si attualizzano in modo successivo, pur essendo tutte contenute in lui in potenza. 
Vero [o: la Verità] creato per Lui (al-haqq al-mahlūq bi-hi) $\left.{ }^{514}\right)$, su cui si basano le creature nella Sua creazione, e l'ha creato il Vero che [tutto] riunisce per mezzo del Vero creato per Lui in lui, ed il Vero che [tutto] riunisce è Colui che è indipendente dai Mondi ed il Vero creato per Lui è dotato dei Nomi che gli esseri contingenti [o i modi di essere $(a k w \bar{a} n)$ ] esigono.

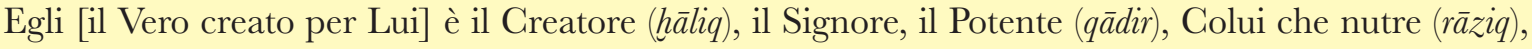
Colui che dà la vita, Colui che dà la morte, Colui che rende potenti (muizz), Colui che umilia (mudill), Colui che viene prima (muqaddim), Colui che viene dopo (mu'ahhir), il Primo, l'Ultimo, l'Esteriore, l'Interiore, così come il Vero che [tutto] riunisce è il Ricco (gan $\vec{\imath}$ ), il Santissimo (quddūs), Colui che ascolta, Colui che vede, Colui che sa, ed altri Nomi simili; Colui che ascolta, Colui che vede e Colui che sa sono [Nomi] condivisi tra il Vero che [tutto] riunisce e il Vero creato per Lui, che è il Vero della credenza, ed il Nome il Volente (murid $)$, il Potente ed altri simili a questi due [153] sono specifici del Vero della credenza: comprendi dunque! $\left({ }^{515}\right)$

514) Questa espressione, che ricorre una trentina di volte nelle Futūhāt, venne coniata da Abū l-Ḥakam 'Abd as-Salām ibn Barrağān, come Ibn 'Arabī stesso riferisce nel Cap. 73, questione XXXVIII [II 60.12]: "Abū l-Ḥakam 'Abd as-Salām ibn Barraǧān l'ha chiamata la Verità per cui ha luogo la creazione (al-haqq al-mahlūq $b i-h i$ ), poiché ha sentito Allah dire: "Non li abbiamo creati se non per la Verità" (Cor. XLIV-39), e "Non abbiamo creato i Cieli e la Terra, e ciò che sta tra di essi, se non per la Verità" (Cor. XV-85), e "e per la Verità lo abbiamo fatto discendere" (Cor. XVII-105)", e nel Cap. 320 [III 77.24]: “[...] la scienza della Verità per cui ha luogo la creazione, a cui ha alluso molte volte 'Abd as-Salām Abū l-Hakam Ibn Barrağān nei suoi scritti [...] Abū l-Ḥakam l'ha chiamata la Verità per cui ha luogo la creazione, traendo il nome dal Suo detto: "e non abbiamo creato i Cieli, la Terra e ciò che è tra essi se non per la Verità" (Cor. XV-85)". Ibn 'Arabī fornisce diverse spiegazioni di questa espressione, ed in questo caso il senso non è quello di "la Verità per cui ha luogo la creazione", bensì "il Vero creato per Lui". In effetti, nel Cap. 558 [IV 211.27] egli precisa: "Il tutto è creazione nella Nube che è il Soffio del Misericordioso, e che riceve le forme di tutto ciò che è altro che Allah. E ciò è detto [anche] riguardo alla creazione da parte del Vero di Se stesso, e tutte le intelligenze rifiutano ciò, per la loro mancanza di comprensione di quello, e non si accorgono che chiunque sostenga una formulazione riguardo ad Allah, raffigura nella sua anima una certa cosa di cui egli dice che "è Allah", e la adora, ed essa è Allah, non altro che Lui, e non l'ha creata in quel ricettacolo se non Allah: questo è il significato di quella notificazione. Le formulazioni dottrinali (maqūlāt) sono differenti per la diversità dei punti di vista con cui essi Lo considerano. Chiunque ha un punto di vista non adora e non crede se non in ciò a cui [Egli/egli] ha dato l'esistenza nel suo ricettacolo (mahall) e ciò che è esistenziato nel suo ricettacolo e nel suo cuore non è che una creatura (mahlüq), e non è che il Vero, ed è in quella forma, cioè in quella formulazione dottrinale, che Egli Si manifesta a lui anche se l'Essenza in quanto tale è Unica, tuttavia è così che egli Lo percepisce. E questo è il significato del detto di 'Ulaym al-Aswad quando batté con la sua mano la colonna (ustuwāna) ed essa divenne oro per chi vedeva. E quando colui che vide fu stupito di ciò, 'Ulaym gli disse: "O tale, in realtà le entità non cambiano, ma così la vedi [la colonna] per la tua realtà essenziale (haqiqqa) con il tuo Signore", alludendo alla manifestazione del Vero nella forma di ogni credo ad ogni credente. Questo è il Vero creato per Lui nell'anima di ogni possessore di un credo ('aqd), sia egli Angelo, Ǵinn o uomo, che segua pedissequamente o che abbia una considerazione [propria]".

515) Questa classificazione dei Nomi divini riferita al Vero creato nella credenza ed al Vero che tutto comprende non ha un corrispettivo nelle Futühăt, né in altre opere di Ibn 'Arabī, e differisce per molti aspetti dalla distinzione in Nomi dell'Essenza, Nomi degli Attributi e Nomi degli Atti che è riportata nel Libro della produzione dei cerchi, come pure dalla distinzione tra Attributi intrinseci ed Attributi di relazione che si trova nel Libro dell'eternità. 
Non conosce ciò che abbiamo detto se non chi conosce la distinzione tra i due Maestri, il Maestro esteriore e quello immaginato. Il Maestro esteriore, anche se non è identico all'aspirante, è tuttavia identico all'aspirante per un aspetto [il Maestro immaginato], ed egli fa parte del complesso (ğumla) dell'aspirante e l'aspirante è parte del complesso del Maestro, e [per questo aspetto] ciascuno dei due è identico all'altro; il Vero che [tutto] riunisce è nella creazione e la creazione non è in Lui, ed il Vero della credenza è nella creazione e la creazione è in Lui, come il Maestro esteriore ${ }^{(516)}$, e questo è ciò che distingue [il Maestro esteriore da quello immaginato]. Se sei timorato ti ho chiarito ciò, e se lo conosci nulla ti sarà oscuro, ed Allah guida noi e te.

Poi, questo legatario $(m \bar{u} s \bar{a})$, Yūsuf ibn Ibrāhīm, ha detto dopo di ciò in questa raccomandazione: "E se ti capita un turbamento (idtirāab) nel tuo stato e nella tua sensibilità (hiss), un'alterazione nella tua mente $(\underline{d} i h n)$, una debolezza nel tuo corpo ed una stanchezza (futūr) nei tuoi sensi, non essere inquieto per questo e fai affidamento ad Allah in tutto ciò, chiedendoGli la pazienza e la forza di sostenerlo per il Potere di Allah, sia Egli esaltato, per la Sua Volontà e per il Suo Volere, e non consultare verbalmente il tuo Maestro riguardo a questo o menzionarlo a voce di fronte a lui, bensì dirigi il tuo pensiero di esso verso il Maestro e chiedi a lui con il tuo cuore e chiedi aiuto tramite ciò che ti ho menzionato secondo le sue suddivisioni in ciò che precede, [tutto] ciò con il tuo cuore, ed evita che per la tua scelta scaturisca da te preoccupazione (qalaq) o inquietudine (dağar)".

Invero egli ti ha raccomandato ciò che ti ha raccomandato quando trovi nella tua anima ciò che ti ha menzionato, perché egli sa che talvolta la causa ( $s a b a b)$ di tutto questo dipende dalla natura $\left(t a b^{c}\right)$ e talvolta da una epifania divina senza che l'aspirante sappia che ciò deriva da una teofania, non sapendo Chi si manifesta a lui, come succederà nell'aldilà per alcune delle creature quando il Vero Si manifesterà loro ed esse non Lo riconosceranno, perché Lo hanno vincolato [ad una certa forma] $\left.{ }^{517}\right)$. E poiché sussiste questa possibilità riguardo alla causa di questi [154] stati passeggeri, egli ti ha detto di "non essere impaziente", finché non conosci la causa e quando la conosci allora comportati di conseguenza, in quanto per ogni causa vi è un comportamento (mu āmala) specifico, e quindi ti ha dato un buon consiglio.

Quanto al fatto di averti ordinato di chiedere e di cercare aiuto riguardo a ciò, non è per far cessare l'effetto, bensì perché diventi chiara per te la causa che determina questo effetto.

Quanto al suo detto: "un turbamento nel tuo stato" egli qui con lo stato vuole dire ciò che ti manca delle necessità di questo mondo, con il cui ottenimento saresti libero di occuparti con Allah. Si tratta di una debolezza di certezza che colpisce l'anima ed un turbamento naturale che non è possibile

516) Il "come" non si riferisce al Vero della credenza ma al Vero che [tutto] riunisce, poiché due pagine prima Ibn 'Arabī aveva affermato la corrispondenza tra il Maestro immaginato ed il Dio oggetto della credenza.

517) Ibn 'Arabī si riferisce qui alla "sede del disconoscimento", menzionata alla fine della pagina 140 del manoscritto 
respingere (daf) per l'effetto che ha sul corpo, poiché le sofferenze psichiche sono quelle che al credente è stato detto di respingere dalla sua anima, ed egli è in grado di farlo, ed a maggior ragione l'aspirante, a differenza delle sofferenze sensibili, poiché egli non è in grado di respingerle, come i dolori nelle membra e come la fame quando è eccessiva (afrata) e l'anima riprende a nutrirsi degli umori del suo corpo, in quanto la natura vuole il sostentamento del suo corpo $\left(^{518}\right)$.

Per questo l'Inviato di Allah, che Allah faccia scendere su di lui la Sua șalāt e la Pace, cercava rifugio in Allah dalla fame e diceva: "essa è un cattivo compagno di letto" ( $\left.{ }^{519}\right)$; l'uomo non è capace di

518) Analogamente, nel Cap. 198 [II 477.4] Ibn 'Arabī afferma: "L’uomo non è capace di rimuovere (raf) le sofferenze naturali sensibili quando arrivano, a differenza delle sofferenze psichiche che invece è in grado di rimuovere [...] I sensi sono più forti nel gusto dell'anima e la ragione di ciò è che il sensibile è secondo un'unica forma, non cambia, mentre il soffio (nafas) ammette la trasmutazione nelle forme: per questo non si riesce a rimuovere il regime della natura in presenza di sofferenze sensibili, data la loro immutabilità, mentre le sofferenze psichiche vengono rimosse per la velocità del loro mutamento nelle forme. Nessuno estingue le sofferenze naturali se non per qualcosa di forte che arriva (wärid) di divino o spirituale, che rimuove la sofferenza della natura quando si è instaurata in lui. Il motivo di quello che arriva può essere una faccenda sensibile o intelligibile, indifferentemente, come l'arrivo di una persona assente a cui si vuole bene. Il suo concentrarsi sulla gioia per l'arrivo di questa persona lo distoglie dalla sofferenza della fame e della sete che provava prima di vedere questa persona o di sentire i suoi passi. Questo è un motivo sensibile, quanto al motivo intelligibile esso è noto ai sapienti”, e nel Cap. 505 [IV 144.2] aggiunge: "[...] a differenza delle sofferenze psichiche; quando arrivano delle faccende che implicano per loro natura la sofferenza dell'anima talvolta uno dei servitori di Allah le riceve senza che esse abbiano alcun effetto esteriore su di lui. Quanto alle faccende che provocano una sofferenza sensibile, quando le percepisce è naturalmente turbato da esse, a meno che non lo distragga da esse una faccenda che gliene fa cessare la percezione".

519) Hadīt riportato da Abū Dāwud, VIII-32, Ibn Māğah, XXIX-53, e da an-Nasā'̄i, L-19 e 20. Ibn 'Arabī lo cita nei capitoli 69 [I 521.35], 107 [II 188.25 e 32], 292 [II 658.31], 305 [III 23.16], 559 [IV 352.4] e 560 [IV 553.2]. Questa affermazione non è in contrasto con l'uso metodico della fame nei primi stadi della via, sul quale si possono consultare i capitoli 106 e 107 delle Futūhät, tradotti da Eric Winkel, The Inter-actions, Fourneys 13-14, 2016, pag. 249-257, e The Four Pillars of Spiritual Transformation (Hilyat al-abdäl), tradotto da Stephen Hirtenstein, Anqa Publishing, 2008, pag. 35 e 46.

Nel Cap. 292 [II 658.24] Ibn 'Arabī precisa: "Non si può dire, ad esempio, che quando sei sazio puoi fare a meno di ricorrere alla fame, per ciò che concerne la sua realtà essenziale, in quanto la fame non è cercata da te per esimerti con essa dalla sazietà, bensì per ciò che la sua realtà essenziale ti conferisce quanto a purezza, tenerezza, gentilezza e realizzazione della servitù e della dipendenza: per questo la cerchi e non puoi fare a meno di essa. Se la sazietà ti conferisse ciò che ti conferisce la fame, di quelle che abbiamo menzionato, potresti fare a meno della fame, che non è cercata per se stessa, bensì soltanto per ciò che abbiamo menzionato, e se lo trovassimo nel suo opposto [cioè la sazietà] non avremmo bisogno di essa [...] Per questo l'Inviato di Allah, che Allah faccia scendere su di lui la Sua șalāt e la Pace, cercava rifugio dalla fame e diceva: "essa è un cattivo compagno di letto", poiché, anche se essa conferisce ciò che abbiamo menzionato, non è certo tuttavia che la dipendenza che si realizza sia nei riguardi di Allah, perché potrebbe anche essere verso altri che Allah. Per questo l'Inviato di Allah, che Allah faccia scendere su di lui la Sua salāt e la Pace, ha detto: "essa è un cattivo compagno di letto" per la gente comune, poiché i Maestri della Via dicono [invece]: "Se la fame si vendesse al mercato l'aspirante dovrebbe comprarla". Chi di loro considera le cose come ha fatto il Profeta, che Allah faccia scendere su di lui la Sua șalāt e la Pace, prende questa frase come uno dei sofismi della gente della Via [...] e questo è il mio punto di vista. La fame ha un limite ed una misura e questa è la fame vera, non la fame 
rimuovere le sofferenze sensibili, a differenza delle sofferenze psichiche: le sofferenze dell'anima dipendono da una debolezza della certezza e le sofferenze del corpo dalle malattie naturali che sono nelle membra e chi soffre per esse è lo spirito vitale (ar-rūh al-hayawān $\vec{\imath}$ ), mentre chi soffre per le sofferenze psichiche è l'anima logica (an-nafs an-nätiqa). Il turbamento che risulta all'anima logica per le sofferenze sensibili dipende dal fatto che lo spirito sensibile e vitale fa parte dell'insieme degli strumenti $(\bar{a} l \bar{a} t)$ di quest'anima logica, alla quale è stato ordinato di completare se stessa con questi strumenti, e quando [155] lo spirito vitale è impegnato dalle sofferenze che sente sussistere nelle membra, esso è distolto dall'assistere l'anima [logica] in ciò che le incombe legalmente, ed ha luogo per essa il turbamento che egli ha menzionato riguardo allo stato di questo aspirante, e per questo ha messo insieme il turbamento nello stato e la sensibilità.

Quanto al suo detto: “e un'alterazione nella tua mente”, si tratta di ciò che si verifica nello strumento del pensiero $(f i k r)$ per un accidente che capita al suo ricettacolo naturale. L'anima talvolta ha bisogno, per governare questo tempio [(haykal), cioè il corpo], che il pensiero sia esente da difettosità, e quando sopravviene al ricettacolo un deterioramento nella complessione per un accidente che gli capita, per una cattiva alimentazione o altro, lo strumento del pensiero, che è la mente, si altera rispetto all'anima, e ciò che è erroneo ( $f \bar{a} s i d)$ le appare con la forma della considerazione corretta, le fa credere che è valido ed essa lo mette in atto. Questo è il significato dell'alterazione, cioè le consegue altro che quello [che si aspetta], e quindi viene compromessa la funzione normale per l'anima di far prosperare l'opera di questo tempio. Le cause di tutto ciò sono diverse ed esse, nella loro differenza, hanno necessariamente un effetto nella complessione $\left({ }^{520}\right)$.

Quanto al suo detto: "e una debolezza nel tuo corpo", ciò dipende dalla forza in eccesso di uno degli umori (ahlāt) ( $\left.{ }^{521}\right)$ sugli altri, per difetto di resistenza (muqāwama) ad esso da parte di quelli restanti, in

immaginata, e la ricerca di rifugio profetica si riferiva solo alla fame vera, che porta l'uomo a disobbedire alla Legge ed a fare torto a se stesso, se è intenzionale. Per questo l'Inviato di Allah, che Allah faccia scendere su di lui la Sua șalāt e la Pace, non sopportava mai la fame se non vi era costretto"

520) Nel Cap. 68 [I 333.1] Ibn 'Arabī precisa: "Le scienze razionali, che si basano sul pensiero, sono pregiudicate dall'alterazione in quanto sono commisurate alla complessione di colui che pensa. Egli non prende in considerazione se non elementi sensibili presenti nell'immaginazione ed in questo modo stabilisce gli argomenti probanti di queste scienze. Le loro affermazioni sulla stessa cosa differiscono oppure lo stesso osservatore afferma cose diverse sulla stessa cosa in tempi diversi, per la differenza delle complessioni e della mescolanza degli umori al momento della loro concezione, sì che le loro affermazioni differiscono sulla stessa cosa, come pure sulle radici sulle quali costruiscono i loro rami".

521) Nel Cap. 7 [I 124.2] Ibn 'Arabī precisa: "In occasione di questa insufflazione in esso [il corpo di Adamo], per mezzo della sua propagazione nelle sue parti ebbe luogo il quaternario (arkân) degli umori, che sono la bile gialla $(s a f r a \vec{a})$, la bile nera (sawd $\vec{a})$, il sangue $($ dam $)$ e la flemma (balgam). La bile gialla proviene dall'elemento igneo, da cui Allah lo [l'uomo] creò, nel Suo detto, sia Egli esaltato: "dall'argilla asciutta, come il vasaio" (Cor. LV-14); la bile nera proviene dalla terra e corrisponde al Suo detto: "lo creò dalla terra" (Cor. XV-26); il sangue proviene dall'aria e corrisponde al Suo detto: "putrida" (Cor. XV-28) e la flemma dall'acqua con cui fu impastata la terra, per diventare argilla. Poi il Vero produsse in lui la facoltà appetitiva ( $g \breve{a} a \underline{d} i b a)$ per la quale gli animali sono attratti verso i cibi; poi la facoltà prensiva $(m \bar{a} s i k a)$, per cui gli animali prendono ciò di cui si 
quanto per l'anima la faccenda non si completa con giustezza se non con l'equilibrio degli umori. Quando uno di essi eccede sugli altri o uno di essi è in difetto rispetto agli altri c'è la debolezza del corpo $\left(^{522}\right)$, e l'anima che vuole compiere uno degli atti tradizionali a cui è assoggettata non ci riesce, perché il corpo è troppo debole per quello e l'anima resta impedita dal realizzare la sua volontà, in quanto non può ottenere il proprio effetto se non con la forza del corpo, che manca, e questa mancanza si chiama [156] debolezza.

Quanto al suo detto: "ed una stanchezza nei tuoi sensi”, essa si chiama tedio (malal) e per questo Allah ha reso numerosi i tipi di atti di obbedienza per chi è soggetto all’incombenza legale e ci ha ordinato di far riposare queste anime; per questo l'Inviato di Allah, che Allah faccia scendere su di lui la Sua șalāt e la Pace, alternava (yatahallalu) l'ammonimento ai suoi Compagni per timore che essi si tediassero ${ }^{523}$ ), poiché quando lo strumento viene usato troppo non migliora il lavoro dell'artigiano in ciò che egli compie solo con esso. L’intraprendere l'atto di adorazione di Allah con fervore (našāt) $\left({ }^{524}\right)$

nutrono; poi la facoltà digestiva (hädima), per mezzo della quale digeriscono i cibi; poi la facoltà escretiva $\left(\operatorname{da}_{\bar{a}}{ }^{\prime} a\right)$, per mezzo della quale essi eliminano le scorie per mezzo del sudore, l'alito, i peti, le feci e così via. Quanto alla diffusione dei vapori ed alla ripartizione del sangue nelle vene da parte del fegato ed a ciò che depura ogni parte degli animali, ciò avviene per mezzo della facoltà appetitiva, non di quella escretiva; la parte della facoltà escretiva riguarda, come abbiamo detto, solo le scorie e nient’altro"; nel Cap. 167 [II 275.24] aggiunge: "È da questo Cielo [Venere] che Allah ha ripartito nella costituzione corporea i quattro umori secondo l'ordinamento più bello"; nel Cap. 348 [III 198.7] stabilisce una corrispondenza tra i quattro umori e le quattro facoltà citate in precedenza, e poco dopo [III 205.5] afferma che "gli umori fanno parte degli Angeli di Allah".

522) Nel Cap. 15 [I 153.5] Ibn 'Arabī riporta un testo profetico ebraico in cui è affermato: "Poi, dopo questo [i quattro elementi e le quattro qualità naturali], ho creato nel corpo (ğasad) quattro altre specie, nessuna delle quali sussiste senza le altre, ed esse sono le due bili, il sangue e la flemma. Poi ho allocato la sede delle une [qualità naturali] nelle altre, ed ho stabilito che la sede della secchezza fosse la bile nera, la sede del calore la bile gialla, la sede dell'umidità il sangue e la sede della freddezza la flemma [...] Ogni corpo in cui questi umori sono equilibrati ha una salute perfetta e una costituzione bilanciata. Se uno di essi è in eccesso sugli altri e li domina subentra nel corpo la malattia, in proporzione all'eccesso; e se [un umore] è in difetto esso è troppo debole per resistere agli altri e la malattia subentra per il predominio degli altri su di esso e per la sua incapacità di resistere loro".

523) Riferimento ad uno hadīt riportato da al-Buhārī, III-12 e 13, Muslim, L-82 e 83, at-Tirmid̄ī, XLI-72, e da Ibn Hanbal. Nelle versioni canoniche si trova il verbo tahawwala, che ha il senso di ripetere frequentemente, mentre nel testo di Ibn 'Arabī si trova il verbo tahallala, che ha invece il senso di alternare, più congruo con il contesto della frase. La stessa affermazione è riportata nel Kitāb at-tadbirāt al ilāhiyya, a pag. 155 dell'edizione di Nyberg, ed a pag. 186 dell'edizione di 'Abd al-'Azīz Sulțān al-Manșūb.

524) Nel Cap. 560 [IV 499.19] Ibn 'Arabī afferma: “Quando ti alzi per l'atto di adorazione fallo con fervore e se sei svogliato lascia stare, salvo ciò che Allah ti ha prescritto di fare, e non adorare Allah con inerzia, poiché quello è poca considerazione per il Lato di Allah. Non essere di coloro che quando si alzano per la șalat si alzano svogliati [cfr. Cor. IV-141], e se fai la șalāt e uno ti guarda, nel fare bene la tua șalāt proponiti la sua istruzione, e dedica esclusivamente ad Allah il tuo atto di adorazione, poiché Egli non ha voluto che tu Lo adorassi se non con un culto sincero. Fai ciò che Allah ti ha ingiunto di fare, ciò è indispensabile, sia che tu sia svogliato, sia che tu sia fervido: in effetti ti ho ingiunto di lasciar perdere i riti supererogatori [in caso di svogliatezza]. Non adorare Allah con svogliatezza, ma dedicati ad un'altra azione supererogatoria, e non abbellire la tua șalät in pubblico ad esclusione di quando sei solo. Chi si comporta in questo modo, la sua azione denota una mancanza 
è il massimo della venerazione, e la voglia dell'anima in quello è preferibile al suo costringersi a farlo contro voglia. Quando vedi che la tua anima è stanca di un certo atto, orientala verso un altro atto di obbedienza in cui abbia fervore e voglia di esso: chi conosce questo ottiene il risultato senza sforzare la sua anima e senza fatica, e tutti i suoi atti rituali sono compiuti con lo zelo dell'atto rituale degli amanti. Ma la via a quello necessita di molta scienza dei tipi di avvicinamento [ad Allah], affinché si cambi da un atto di obbedienza ad un altro con fervore. Tra le peggiori disgrazie nella religione è che l'uomo abbia fervore nel soddisfare i suoi desideri naturali e sia svogliato nel compiere le faccende tradizionali, poiché ciò significa trascurare il suo Signore: questo è il caso di colui che fa bene la sua salāt quando è visto degli altri uomini e non la fa bene quando è da solo, come è riportato nella notificazione autentica ${ }^{(525)}$.

Chi conosce le vie di accesso di queste faccende non si affanna a respingerle e non si inquieta quando una di queste cose sussiste in lui finché non ne conosce la causa (sabab), e quando conosce la causa che ha determinato l'accadimento di una delle cose che egli ha menzionato [nella raccomandazione], o di tutte, allora la affronta come si deve.

Quanto al suo detto: "chiedendoGli la pazienza e la forza di sostenere ciò”, questo ti mostra che egli non intendeva se non le faccende naturali, non quelle tradizionali, poiché non si addice all'uomo di affrontare con la pazienza le faccende tradizionali quando gli capita [157] una faccenda che compromette qualcosa di esse, bensì egli si adopera, per via dell'obbligo che gli è imposto, a respingere quella [faccenda ed usa] la forza per contrastarla.

Il massimo della pazienza (ašadd aṣ-șabr)) è la pazienza [lontano] da ('an) Allah, che non ha luogo se non per avere contrastato l'ordine di Allah, poiché questa è la causa che determina l'allontanamento da Allah, e con ciò intendiamo significare l'allontanamento da ciò in cui vi è la felicità di questo servitore nella dimora dell'aldilà - questo per essere precisi ed equi - non la lontananza da Allah, poiché il ritorno (marği $)^{\prime}$ di tutti, beati e dannati, sarà verso Allah, ed Allah non smette di essere con loro in ogni stato.

Non vedi che aš-Šiblī $\left.{ }^{526}\right)$, quando il giovinetto gli disse: "Il massimo della pazienza è la pazienza di considerazione con cui offende il suo Signore: così è affermato". L'importanza del fervore nella Via, e quindi l'affermazione che la Via non è fatta per i "tiepidi", è ribadita anche nel Kitāb al-amr al-muhkam, a pag. 322 della traduzione di Asín Palacios già citata.

525) Riferimento ad uno hadīt trasmesso da Ibn Mas'ūd ma non recensito nelle raccolte canoniche. Ibn 'Arabī lo riporta nel Cap. 177 [II 315.19].

526) Abū Bakr Dulaf ibn Ğaḥdar aš-Šiblī, nacque a Sāmarrā’ nell'anno 247 dall'Egira e morì a Bagdād nel 334. Fu discepolo di al-Ğunayd ed amico, per un certo tempo, di al-Hallağ; non lasciò alcuna opera scritta ma le sue frasi, i suoi versi ed i suoi aneddoti sono stati tramandati da altri Sūfí. Ibn 'Arabī lo cita nei capitoli 2 [I 74.24], 5 [I 102.10], 44 [I 250.14], 69 [I 479.7], 72 [I 677.27 e 678.23], 73 [II 12.12], 124 [II 207.29], 150 [II 244.20 e 245.17], 174 [II 293.22], 178 [II 358.9], 232 [II 532.6], 247 [II 546.31], 297 [II 684.28], 423 [IV 36.6] e 560 [IV 545.23]. Su di lui si possono consultare: Richard Gramlich, Alte Vorbilder des Suftum Vol. I, 
[lontano] da Allah", svenne ( $\left.{ }^{527}\right)$ ? E non svenne se non per l'essersi immaginato la perdita della sorte della sua anima (faqd hazz nafsi-hi) [cioè l'allontanamento da ciò in cui vi è la felicità], ed Allah, sia Egli esaltato, prese qui il posto della sorte della sua anima, e ciò da parte dell'anima è un confondere (talbiss) se stessa riguardo alla scienza $\left.{ }^{528}\right)$.

A chi è veridico non sfugge una simile contemplazione e quindi è equo, e per questo, nell'interpretare la pazienza da Allah, abbiamo adottato una via diversa da ciò che afferma la maggioranza di loro al riguardo, al fine di essere equi e di non confondere noi stessi, ed abbiamo quindi detto che [la frase]: "la pazienza da Allah è il massimo della pazienza" sta ad indicare il nostro prendere la pazienza da Allah dal Suo Nome "Colui che ha molta pazienza (sabür)", poiché Egli ha descritto Se stesso con il fatto di venire offeso e Si è denominato "Colui che ha molta pazienza" ${ }^{529}$. Chi nella sua pazienza prende il posto del Vero nel Suo Nome "Colui che ha molta pazienza" prende direttamente la sua pazienza da Allah ed Egli è una fonte ( $m a$ h had ) molto nascosta e non tutti sanno come prendono la loro pazienza da Allah: per il sapiente in Allah si tratta di una cosa facile, ma tali conoscitori sono rari.

Harrassowitz Verlag, 1995, pag. 513-665, e Kenneth Avery, Shibli, State University of New York Press, 2014.

527) Ibn 'Arabī si riferisce ad un celebre episodio, riportato in molti trattati dell'esoterismo islamico, e riferito da al-Qušayrī, nel cap. 22 della sua Risāla, nei seguenti termini: "Un uomo venne da aš-Šiblī e gli chiese: Qual'è il massimo della pazienza per i pazienti?, al che egli rispose: La pazienza in Allah, quanto è Potente e Magnificente. L'uomo disse: No! Aš-Šiblī disse allora: La pazienza per Allah, sia Egli esaltato, ma l'uomo disse ancora: No! Aš-Šiblī disse allora: La pazienza con Allah, sia Egli esaltato, e l'uomo disse di nuovo: No! Aš-Šiblī chiese: Allora cosa?! e l'uomo rispose: La pazienza da Allah, quanto è Potente e Magnificente, al che aš-Šiblī gettò un grido, quasi che il suo spirito stesse per morire".

528) Nel Cap. 124 [II 207.5] Ibn 'Arabī precisa: "Sappi che la pazienza è di diversi tipi, in base alla diversità delle particelle (adawatt): la pazienza "in" ( $f \hat{\imath})$ Allah, quando si subisce un torto in Lui; la pazienza "con" (ma'a) Allah, cioè la visione di Colui che punisce nella punizione; la pazienza "verso" ('alä) Allah, cioè lo stato della sua assenza $(f a q d)$ per il suo Signore perché trova la sua esistenza non connessa con l'esistenza del suo Signore; la pazienza "per" (bi) Allah [cfr. Cor.XVI-127], quando il Vero è identico alla sua pazienza, così come Egli è il suo udito e la sua vista; la pazienza "da" ( $\mathrm{min}$ ) Allah, cioè lo stato in cui la forza e la potenza ti sono tolte, ed in cui non dici: "Non c'è forza né potenza se non per Allah", poiché [questo stato] verrebbe meno con il chiedere aiuto; e la pazienza "da" ('an) Allah. Questa è la più grande di esse come stazione ed è la pazienza che cessa con la morte e non si troverà nell'aldilà. Questa pazienza viene attribuita al suo possessore come il Nome as-Sabūr viene attribuito ad Allah e poiché questo [Nome] viene meno con la fine di questo mondo, così viene meno nel servitore con il suo allontanamento da questo mondo. Colui che tu abbandoni, si allontana da te! Costoro intendono la pazienza da ('an) Allah, così come tu dici: ho appreso questa scienza "da" ('an) un tale, e tu sei partecipe di essa come Lui [...] La pazienza "da" Allah, intesa in questo modo, è il più grande tipo di pazienza. Quanto alla pazienza "da Allah" secondo quanto si immagina la maggioranza, cioè la pazienza lontano da ('an) un tale, per la separazione da lui, questo non fa parte della natura della gente di Allah. Quando aš-Šiblī svenne per l'affermazione del giovane: "invero la pazienza da Allah è il massimo della pazienza", svenne per l'immensità della stazione a cui non arrivano se non i perfetti tra gli iniziati $(r i g ̌ a ̆ l l)$. Quando la pazienza balenò (lāha) a aš-Šiblī, dal discorso del giovane, ciò che arrivò (wārid) di essa fu più forte del ricettacolo di aš-Šiblī e per questo gli provocò lo svenimento. Tutto ciò che arriva che è più forte della forza del ricettacolo provoca in esso lo svenimento e la folgorazione $\left(s a^{c} a q\right)$. La gente di Allah non ha piede nella pazienza da Allah intesa come la intende la maggioranza".

529) Riferimento allo hadīt citato a pag. 121 del manoscritto. 
Il commento di ciò che resta del suo discorso in questa raccomandazione è già stato fatto in ciò che precede, e non rimane [da commentare] di questa sezione se non la sua frase conclusiva: "ed evita che per la tua scelta (ihtiy $\bar{a} r$ ) scaturisca da te preoccupazione o inquietudine". Non c'è dubbio che quando l'uomo sa di essere obbligato (mağbūr) nella sua scelta $\left.{ }^{530}\right)$ continua ininterrottamente a vivere nell'obbligatorietà, che sia [158] uno che sceglie o uno che non sceglie, ed a chi trascura ciò che abbiamo detto e distingue tra l'obbligatorietà e la scelta, cioè l'obbligatorietà nella scelta ${ }^{531}$ ), diciamo: "L'obbligatorietà della scelta non ti è nascosta come è nascosta ad alcuni uomini, e

530) L'affermazione che l'uomo è obbligato nella sua scelta ricorre una ventina di volte nelle Futühät, e non si riferisce al fatto che l'uomo sia obbligato a fare una scelta, né significa che egli sia costretto a fare qualcosa contro la sua volontà, concetto che in arabo è espresso dal termine $i k r a ̄ h$, bensì è strettamente connessa al segreto del Destino, a cui Ibn 'Arabī ha accennato alla fine della pag. 7 del manoscritto. Tutti gli atti dell'uomo, comprese le sue scelte, sono creati da Allah, che crea ciò che vuole, ma che non vuole se non ciò che sa, e ciò che sa dipende dal saputo, che non è altro che le possibilità immutabili dell'essere umano. La scelta dell'uomo è così determinata da Allah, che però non ha scelta nella Sua Volontà, essendo questa dipendente dalle possibilità dell'essere: l'uomo è quindi obbligato nella sua scelta, ma questo obbligo non deriva da qualcosa di esterno a lui, bensì dalla sua realtà più profonda. Nel Cap. 238 [II 539.13] Ibn 'Arabī afferma: "Essi sanno che il momento (waqt) conferisce quella faccenda e che Allah l'ha scelto per loro, poiché Egli è Colui che dice: "Ed il tuo Signore crea ciò che vuole", cioè determina il momento e dà l'esistenza, poi ha detto: "e sceglie" ed ha negato che essi abbiano la scelta, dicendo: "ed essi non hanno la scelta (mā kāna la-hum al-hiyāra)" (Cor. XXVIII-68), e secondo noi il " $m \bar{a}$ " in questo caso è un pronome [non una negazione] e sta per il complemento oggetto del Suo detto: "e sceglie", cioè [sceglie] ciò che è la scelta (al-hiyāra) per loro"; nel Cap. 73 [II 35.9] aggiunge: "La faccenda è come quella di chi è obbligato nella sua scelta e che quindi non viene elogiato per la scelta a meno che non gli venga contemporaneamente tolta la scienza della obbligatorietà in quella scelta, in quanto la libertà di scelta e l'obbligatorietà si contraddicono. A quel momento l'uomo sa cosa vuol dire la scelta e vede che non c'è nell'esistenza se non obbligatorietà (ğabr) senza costrizione (ikrăh), ed egli è obbligato (mağbūr), non costretto (mukrah)". [E per coerenza con questo passo che ho tradotto ğabr, che pure significa costrizione, come anche idtirār, con obbligatorietà, per distinguerlo da ikrāh]. Nel Cap. 312 [III 48.18] afferma: "La Volontà (iräda) non ha scelta, non c'è Libro né Sunna che lo abbia affermato, né ragione che lo abbia provato. Quella [la scelta] appartiene al Volere (mašš̀ a): se Egli vuole è, e se vuole non è; il Profeta, su di lui la Pace, ha detto: "Ciò che Allah vuole $(s ̌ a ̆ a)$ è, e ciò che non vuole non è", stabilendo una connessione della negazione e dell'affermazione con il Volere, e non è stato riportato: "ciò che non vuole (lam yurid) non è", ma è stato riportato: "Se volessimo (law aradnā) che fosse così sarebbe così", escludendo così la scelta [poiché law è una particella che nega la possibilità]. La Volontà è la connessione del Volere con ciò che è voluto (murād), e ciò corrisponde al Suo detto: "Invero la Nostra Parola ad una cosa quando la vogliamo" (Cor. XVI-40); questa è la connessione del Volere [...] Ciò che Egli ha decretato e di cui ha scienza non si modifica, né razionalmente, né secondo la Legge: "La Parola non cambia per Noi" (Cor. L-29) e per il profumo di obbligatorietà che vi è in essa ha continuato [dicendo]: "ed Io non sono ingiusto con i servitori" affinché uno non si immaginasse questo. Se il decreto dipende dalla Sua scienza di lui perché [il servitore] viene punito per ciò in cui è obbligato e non libero di scegliere?", e nel Cap. 411 [IV 16.16] conclude: "Se qualcuno potesse argomentare con Allah e dirGli: "La Tua Scienza aveva previsto al mio riguardo che sarei stato così: non punirmi dunque!", il Vero risponderebbe: "Ti ho forse conosciuto diversamente da quello che sei? Se tu fossi stato altro, non ti avrei forse conosciuto ugualmente?!”. È per questo che ha detto: "sì da sapere" [...] È la scienza che segue il suo oggetto, non il contrario: comprendi dunque, poiché si tratta di una questione sottile. [...] La scienza dipende dal suo oggetto, non è l'oggetto che dipende dalla scienza".

531) L'inciso esplicativo non è riferito a chi distingue l'obbligatorietà dalla scelta, ma a come stanno le cose in 
quando l'obbligatorietà della scelta è contemplata da te nell'atto, il tuo regime giuridico è quello di chi è obbligato e chi è obbligato non è punito né responsabile. Ma il sentiero per arrivare alla contemplazione di questa obbligatorietà nella scelta, che fa decadere la responsabilità, è difficile da raggiungere per gusto spirituale ${ }^{532}$. Guardati dall'essere ingannato dalla tua scienza di essere obbligato nella tua scelta, poiché essa non è utile a meno che non derivi da una contemplazione mediante il gusto spirituale e non da una consapevolezza mentale (istihdāar) - e ti ho già dato il buon consiglio - e non conoscerai il gusto spirituale in questo se non quando esso ti accompagnerà in tutti i tuoi comportamenti di libera scelta, ed allora in essi il tuo stato sarà quello di chi è obbligato e la cui costrizione $(i g g h b a \bar{r}$ ) è nota alla gente comune, e quando è così allora trarrai profitto dall'obbligatorietà nella scelta, poiché in questo caso la scelta prende il posto dell'atto a cui si è abitualmente costretti $\left({ }^{533}\right)$ ". Sappilo!

Poi ha detto: "e guardati dal palesare qualcosa di questo ad una delle Sue creature o che ciò sortisca da te a qualcuno per tua scelta. Abbi cura di ciò al massimo della tua capacità". Con l'espressione

realtà. Ibn 'Arabī ha appena affermato che l'uomo vive incessantemente nell'obbligatorietà, indipendentemente dal fatto che faccia delle scelte o non le faccia. Nel Cap. 69 [I 405.5] egli precisa: "La trasposizione simbolica della fissazione (tahdīd) della qibla è l'escludere il servitore dalla sua scelta (ihtiyār). La sua radice (asl) e la radice

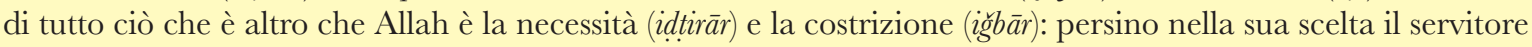
è obbligato. E sebbene Allah sia Agente e scelga, per via del Suo detto: "ed Egli sceglie" (Cor. XXVIII-68) e del Suo detto: "e se avessimo voluto" (Cor. VII-176), Egli non fa se non ciò che già sa, ed il cambiamento della Scienza è impossibile. Egli ha detto, sia Egli esaltato: "La Parola non cambia presso di Me ed Io non sono ingiusto con i servitori" (Cor. L-29), ed ha detto: "e ad Allah appartiene l'argomento decisivo" (Cor. VI149). Non ho visto nessuno che abbia compreso questo detto divino: il suo significato è estremamente chiaro e tuttavia per l'intensità della sua chiarezza è nascosto. Noi ne abbiamo parlato in questo libro e lo abbiamo spiegato: esso è il segreto del Destino. Chi comprende questa questione non si oppone ad Allah in nulla di ciò che Egli decreta e fa accadere ai Suoi servitori, in essi e da essi. Per questo ha detto: "Egli non sarà interrogato riguardo a ciò che fa, ma essi saranno interrogati!" Cor. XXI-23). Se tu fossi intelligente avresti capito da Allah: questo versetto ti sarebbe bastato per lo scopo", e nel Cap. 71 [I 624.1] aggiunge: "La sua realtà essenziale è la servitù ("ubüdiyya), ed egli non agisce a suo piacimento ma solo in regime di necessità e costrizione: la scelta è una prerogativa del Signore (sayyid), non del servitore. Il Signore ha posto il Suo servitore in una posizione di scelta per metterlo alla prova e verificare se resterà nella sua servitù o se opererà una scelta, comportandosi così come il suo Signore. In questo senso egli è obbligato nella sua scelta, poiché essa deriva dall'ordine del suo Signore; quindi egli non abbandona la sua servitù e non è simile al suo Signore $(r a b b)$ nella scelta che Allah gli ha imposto".

532) Nel Cap. 351 [III 229.31] Ibn 'Arabī riporta: "Poi gli disse: "Nel Mondo Allah ha un soggiogamento (qahr) nascosto, che non è conosciuto e con il quale li obbliga nella loro scelta, ed un soggiogamento palese nel quale essi non hanno scelta e che li governa. Gli Uomini di Allah osservano il soggiogamento nascosto poiché è riguardo ad esso che verranno interrogati da Allah e dovranno rispondere. Se tu contempli l'obbligatorietà nella tua scelta sei tra coloro che testimoniano l'obbligatorietà palese e questa contemplazione ti solleva dalla responsabilità, ma è raro colui che contempla ciò". Io ho visto pochi che avessero questo rango e stato, anzi ne ho visto uno solo, in Siria, e fui felice di incontrarlo".

533) E quindi solleva il servitore dalla sua responsabilità. Tale risultato non è però il frutto della conoscenza teorica del segreto del Destino, bensì della sua conoscenza effettiva, per mezzo della quale l'uomo sfugge al concatenamento causale delle azioni e reazioni concordanti. 
"di questo" egli allude a ciò che è stato menzionato precedentemente. La gente comune osserva la gente di questa Via, siano essi piccoli o grandi, per prenderli come esempio, e quando si manifesta da loro una di queste cose può succedere che uno debole di intendimento li imiti e dica: "Questo tale, un pio della gente di Allah, ha smesso di fare così o ha tralasciato delle opere", e se non fosse che egli vede che ciò non intacca la sua stazione, né il suo stato spirituale, né la via verso Allah, [159] non lo farebbe, né sarebbe caratterizzato da un tale comportamento; ma quest'uomo comune ('āmmî) tralascia quell'opera imitando quella persona ricollegata ad Allah, sia Egli esaltato, e ci rimette.

Per questo egli ti ha raccomandato di non palesare alcuna di queste cose che ti capitano ad una delle creature di Allah per tua scelta, e se uno della gente comune riesce a vederti in quello, senza che tu lo sappia e senza una scelta da parte tua riguardo a ciò, è affare di Allah, non tuo.

Non vedi che, nella nostra raccomandazione al Maestro $\left.{ }^{534}\right)$, [abbiamo detto che] egli non deve lasciare che l'aspirante lo osservi mentre è in ritiro spirituale (halwa), né mentre mangia, né mentre beve, né in alcuna di queste faccende naturali, poiché in tutto ciò il Maestro ha un comportamento divino derivante da un'esistenza divina realizzata? Di questo comportamento l'aspirante non conosce se non ciò che la gente comune fa abitualmente per il benessere umano naturale, e perciò il Maestro viene sminuito agli occhi di un siffatto aspirante, e quando [il Maestro] è sminuito viene meno il beneficio che si può trarre da lui. Tra le esortazioni di questo Maestro, nella sua istruzione iniziatica, vi è quella che un aspirante non osservi [il Maestro] in alcuna delle faccende naturali che la gente comune condivide con lui nella forma, poiché tra i due comportamenti vi è, per il gusto spirituale, una differenza di cui non hanno scienza se non i suoi compagni.

Gli ignoranti dissero: "Che Inviato è mai questo, che mangia il cibo e cammina nei mercati?" (Cor. XXV-7), disconoscendo a lui ciò che essi facevano, e per questo furono privati dal trarre beneficio da lui e non ebbero fede. Per questo il più delle volte egli diceva loro ciò che Allah gli aveva ordinato di dire: "Io sono soltanto un uomo come voi" (Cor. XVIII-110 e XLI-6), poi ha fatto rilevare la stazione spirituale che lo distingueva dalla gente comune nel modo di agire (tasarruf), malgrado la somiglianza nella forma, dicendo: "Io seguo solo ciò che mi è stato rivelato" (Cor. XLVI-9) dal mio Signore. L'uomo comune cammina e si comporta secondo il comune modo naturale, mentre il Profeta e l'Erede si comportano [esteriormente] nello stesso modo ma per la rivelazione divina, e questo è il gusto spirituale di cui abbiamo parlato. Il movimento è lo stesso ma il motivo è diverso e nascosto $\left.{ }^{535}\right)$ :

534) Ibn 'Arabī si riferisce al suo Kitāb al-amr al-muhkam, ove la raccomandazione che segue è testualmente riportata [pag. 310 della traduzione di Asín Palacios già citata].

535) In Initiation et réalisation spirituelle, Éditions Traditionnelles, 1964, René Guénon, parlando degli esseri che esercitano una missione divina, precisa [pag. 267]: "Non seulement ce caractère est évidemment inhérent à la fonction dont leur sacrifice est véritablement l'investiture; mais encore, car cela aussi est impliqué dans le sens original du mot «sacré», c'est là ce qui fait d'eux des êtres «mis à part», c'est-à-dire essentiellement différents à la fois du commun des êtres manifestés et de ceux qui, étant parvenus à la réalisation du «Soi», demeurent purement et simplement dans le non-manifesté. Leur action, même lorsqu'elle est extérieurement 
il Profeta e l'Erede lo conoscono da loro stessi, mentre l'uomo comune non lo conosce, [160] né da parte loro, né da se stesso. Colui di cui Allah vuole la privazione e la perdita nel suo commercio, lo mette a conoscenza, riguardo al Maestro, di un atto naturale senza che il Maestro lo voglia. Chi sa da se stesso che la gente comune lo osserva con occhio benevolo e devoto e prende come esempio ciò che egli fa, è meglio che si nasconda ad essa nel suo comportamento naturale, per buon consiglio (nașị̂a) riguardo ad essa, poiché ciò gli è stato ordinato da Allah nel suo detto, che Allah faccia scendere su di lui la Sua salāt e la Pace: "La religione $(d \bar{n} n)$ è il buon consiglio". Chiesero: "A chi, o Inviato di Allah?". Ed egli rispose: "Ad Allah, al Suo Inviato, agli Imām dei musulmani e alla loro gente" $\left.{ }^{536}\right)$, generalizzando, e del buon consiglio fa parte il nascondersi dalla gente comune da parte di questa persona per il motivo riportato. In questa circostanza non si dice che egli è un ipocrita, poiché l'ipocrisia $(r i y \bar{a})$ e la mancanza di ipocrisia, pur essendo identiche nella forma, si differenziano per l'intento (qasd), e poiché qui l'intento è bello Allah lo loda - e l'obiettivo non è altro che Allah ringrazi (yaškuru) per il tuo atto - e quando Egli ringrazia per il tuo atto non curarti di chi ti biasima o ti loda.

Poi ha detto: "E non essere attaccato ad una cosa che tu chiedi speranzoso ad Allah che faccia parte della tua quota (qism) presso Allah, poiché Allah, sia Egli esaltato, te l'accorderà per generosità (karam) da parte Sua, per gentilezza (lutf) e per benevolenza (ihsān) verso chi Egli vuole dei Suoi servitori. Conferma questo nei confronti della tua anima, sii fiducioso, e veglia nella menzione (dikr)". L'Inviato di Allah, che Allah faccia scendere su di lui la Sua șalāt e la Pace, ha riferito che Allah, quanto è Potente e Magnificente, ha detto: "Io sono secondo l'opinione che il Mio servitore ha di Me: abbia quindi una buona opinione di Me" ${ }^{537}$ ), ed Allah, sia Egli esaltato, ha detto: "Quell'opinione che vi siete fatti del vostro Signore vi ha fatto perire“" (Cor. XLI-23).

La loro opinione li ha fatti perire, mentre la buona opinione di Allah salva dalla perdita: se hai chiesto speranzoso ad Allah una cosa è inevitabile che avrai quella cosa o una simile, e non giudicare lento ciò, poiché presso Allah le cose sono stabilite per un certo momento, e quando il momento arriva si manifesta per te la cosa.

Quanto al suo detto: "e sii [in quello] fiducioso", cioè abbi fiducia (tiqa) di Allah poiché è inevitabile che otterrai ciò al cui ottenimento è attaccata la tua aspirazione (himma), oppure una cosa simile [161] o anche più grande di essa tra ciò che tu lodi e per cui gioisci.

Ed il suo detto: "e veglia" ti mette in guardia affinché tu non sia caratterizzato dalla noncuranza, e la veglia in questo caso è l'attesa di ciò per cui hai avuto una buona opinione del tuo Signore [pensando] che essa ti arriverà.

semblable à celle des êtres ordinaires, n'a en réalité avec elle aucun rapport allant plus loin que cette simple apparence extérieure; elle est, dans sa «vérité», nécessairement incompréhensible aux facultés individuelles, car elle procède directement de l'inexprimable".

536) Hadīt già riportato a pag. 85 del manoscritto.

537) Hadīt qudsī già riportato a pag. 34 del manoscritto. 
Ed il suo detto: "nella menzione", cioè il ritardo di quello ed il trovare lunga l'attesa non ti allontanino dall'opera, e la menzione è che tu lo menzioni con Allah in più momenti (ānat), poiché "Allah ama coloro che insistono nella preghiera $\left(d u^{c} \bar{a}\right) "\left({ }^{538}\right)$. Per questo, nel giorno di Badr, il Profeta, che Allah faccia scendere su di lui la Sua salāt e la Pace, moltiplicò la sua supplica al suo Signore riguardo al soccorso [divino], perché sapeva ciò, e poiché Abū Bakr non sapeva ciò che sapeva l'Inviato di Allah, che Allah faccia scendere su di lui la Sua șalāt e la Pace, gli disse: "Ti è sufficiente, o Inviato di Allah, la tua supplica al tuo Signore, poiché Allah, sia Egli esaltato, mantiene per te ciò che ti ha promesso" ${ }^{(539)}$. Se non fosse che Abū Bakr aveva sentito dall'Inviato di Allah, che Allah faccia scendere su di lui la Sua șalāt e la Pace, che Allah gli aveva fatto una promessa, non avrebbe menzionato quello né avrebbe emesso giudizi su Allah, ma Abū Bakr era ignaro di ciò che l'Inviato di Allah, che Allah faccia scendere su di lui la Sua salāt e la Pace, sapeva del suo Signore e che gli fece moltiplicare le sue suppliche al riguardo. Ed Abū Bakr non era più forte per certezza, né più dotato di scienza che l'Inviato di Allah, che Allah faccia scendere su di lui la Sua șalāt e la Pace, e ciò che indusse Abū Bakr a fare questo discorso non fu altro che la compassione per l'Inviato di Allah, che Allah faccia scendere su di lui la Sua șalāt e la Pace, per lo sforzo e per la implorazione che gli vide fare, al punto che tra le cose che disse al suo Signore vi fu: "Se questo gruppo sarà annientato non sarai più adorato dopo questo giorno" $\left({ }^{540}\right)$. Osserva quanti insegnamenti sono nascosti in questa notificazione per chi comprende e capisce la perfezione della scienza dell'Inviato di Allah, che Allah faccia scendere su di lui la Sua șalāt e la Pace, a quel riguardo.

Poi ha detto: "E sforzati, o aspirante, quando Egli ti fa seguire questo percorso (maslak), di non soffermarti su un impedimento che ti si presenta ed il primo che ti si presenta è una cosa da cui ti sei staccato e che hai venduto ad Allah, sia Egli esaltato" [162]. Sappi innanzitutto che per quanto concerne il discorso di quest'uomo, pur essendovi del disordine (tahbīt), l'intento è corretto, e se avesse autorizzato una correzione dei termini li avremmo corretti, ma è indispensabile che il nostro commento al suo discorso li precisi, affinché la loro comprensione sia corretta. In effetti non ti è permesso di fare di Allah un acquirente (muštar $)$, se non di quello di cui Egli stesso Si è dichiarato tale, senza andare oltre, e quello non è altro che la tua anima, se sei credente, poiché: "Allah ha comperato dai credenti le loro anime" (Cor. IX-111), per la loro asserzione riguardo al possesso di esse. Ed ha menzionato - ed Egli è il Veridico - che le ha comperate da loro, ed ha incluso nel Suo acquisto di esse la vendita [da parte dei credenti] con il Suo detto, sia Egli esaltato, riguardo alla loro vendita: "E tra gli uomini c'è chi vende $(y a s ̌ r \imath \imath) "$, cioè vende $\left(y a b \bar{\imath}^{\imath} u\right)\left({ }^{541}\right)$ "la sua anima cercando i favori di Allah" (Cor. II-207), ed essi non sono altro che i credenti, e questo versetto è il fratello dell'altro. Questo versetto indica la loro vendita, mentre l'altro indica l'acquisto da loro da parte del Vero, ed Egli ha

538) Hadīt non recensito nelle raccolte canoniche.

539) Hadīt già riportato a pag. 150 del manoscritto.

540) Hadīt riportato da Muslim, XXXII-58 e da at-Tirmid̄ī, XLIV ad Sūra VIII-3.

541) La precisazione si impone in quanto il verbo šarā può significare sia acquistare che vendere. 
spiegato qual'è la categoria [di uomini] che vende, cioè i credenti, e per questo ha detto: "E tra gli uomini”, e non: "Gli uomini", usando la particella partitiva [fra $(\mathrm{min})$ ]. In effetti per i sapienti tra gli uomini non è possibile vendere le loro anime ad Allah, perché essi sanno che Allah non cessa mai di possederle, per cui non le compera ai sapienti, bensì dispone [fin] dall'inizio delle anime dei sapienti, come fanno i proprietari, mentre dispone delle anime dei credenti successivamente all'acquisto [di esse] da loro. Tra il sapiente ed il credente vi è una enorme differenza: "Allah eleverà in grado coloro che credono di voi e coloro che hanno ricevuto la scienza" (Cor. LVIII-1 1); coloro che hanno ricevuto la scienza sono quelli che nelle faccende si basano su una visione interiore, mentre il credente è uno che segue ciecamente (muqallid) e che è sottomesso, quindi il credente è uno che segue (muttabi ${ }^{i}$ ), mentre il sapiente non è in questo modo. Il credente recede per il recedere di colui che egli segue, mentre il sapiente, se il suo compagno lo mettesse alla prova con una cosa che esige di recedere non recederebbe dalla sua scienza per il recedere del suo compagno, poiché sa che il suo recedere ed il metterglielo in mostra è una prova per la sua scienza, mentre il credente [163] non è così $\left({ }^{542}\right)$. Anche se Allah, sia Egli esaltato, ha connesso la proprietà (milk) con i Suoi servitori ${ }^{(543)}$, il sapiente accetta la connessione $(i d \bar{a} f a)$ ma non la proprietà, poiché la scienza gli impedisce di farlo, mentre il credente accetta sia la connessione che la proprietà, e per questo l'acquisto [da parte di Allah] ha

542) Nel Cap. 422 [IV 34.22] Ibn 'Arabī precisa: "Queste due categorie [coloro che credono e coloro che hanno una scienza speculativa del fatto che gli atti appartengono ad Allah] non arrivano al grado di colui che ha la contemplazione diretta, poiché egli ha in più di loro la visione. Egli contempla gli Atti del Vero in se stesso, così come lo speculativo ha scienza di essi e colui che segue ciecamente crede per la notificazione: ciascuno ha una stazione nota, ma coloro che sanno non sono uguali a coloro che non sanno. Se il Vero recedesse nella comunicazione dall'attribuire questi atti a Lui, sia Egli esaltato, e dichiarasse miscredente chi li attribuisce a Lui, sia Egli esaltato, il credente recederebbe per il recedere del Vero sia per credo che a parole, mentre il sapiente e colui che è dotato di contemplazione recederebbero solo a parole, ma non per convinzione, poiché non è possibile per chi ha una prova, se essa è solida, recedere da essa, né è possibile per chi è dotato di contemplazione" e nel Cap. 558 [IV 234.9] aggiunge: "Questa è l'adorazione di coloro che hanno scienza di Allah: essi affermano la trascendenza e contemplano l'immanenza e non si limitano a credere, poiché questo non deriva per loro da una notificazione (habar) ma si basa solo su una visione diretta. La porta della fede è la notificazione e colui che è velato crede nella parola di Colui che notifica, mentre colui che ha la contemplazione diretta vede la veridicità di Colui che notifica, e c'è una grande differenza tra chi vede e chi crede. Colui che vede non recede per l'abrogazione se non con il recedere di Colui che abroga, mentre chi crede recede per l'abrogazione ed è convinto che ciò che è stato abrogato sia miscredenza, dopo aver receduto da esso".

543) Nel Cap. 70 [I 580.21] Ibn 'Arabī precisa: "Allah dice al conoscitore: “Questa è la tua proprietà!” ed egli accetta questa da Lui per le regole di buona creanza. La scienza riguardo a ciò è che vi è una proprietà di spettanza (istihqa $q$ ), che è dovuta per chi ne è degno e per chi ha diritto ad essa; una proprietà di deposito ( essa. Tutte le cose sono proprietà di Allah per l'esistenza, ed esse appartengono al servitore conformemente allo stato. Ciò di cui non si può fare a meno nella realtà, di quello che arreca un beneficio all'anima, è una proprietà di spettanza per lui: per quanto riguarda il cibo e le bevande, si tratta di ciò di cui egli si nutre nel momento in cui si nutre di quanto ci si può nutrire, non di ciò che avanza e che fa uscire dai suoi due aditi e altrimenti. Per quanto riguarda gli indumenti si tratta di ciò che lo protegge dal caldo e dal freddo dell'aria. Tutto il resto è nelle sue mani come una proprietà di deposito per colui a cui va rimessa, anche ciò di cui egli si libera di quanto abbiamo menzionato". 
luogo dal credente, non dal sapiente. Ed Egli non ha comperato da loro se non specificamente le loro anime, poiché sa che tutto ciò che possiede lo schiavo (mamlūk) è subordinato ad essa [anima], e quando Egli la compera la segue tutto ciò che egli possiede, ed è come se comperasse il tutto. Il signore (sayyid) dispone del suo schiavo ('abd) e di ciò che il suo schiavo possiede, e quindi la proprietà dello schiavo è insicura (muzalzal). Tra gli uomini c'è chi considera che le cose hanno una spettanza e quindi le prende per la spettanza (istihqāq), non per la proprietà $\left({ }^{544}\right)$, e questo è ciò che esigono gli stati, così come dici: "la porta della casa", e la porta spetta alla casa ed essa le viene attribuita per una connessione di spettanza, non che la casa possieda la porta ${ }^{(545)}$. Così, in considerazione del Vero, sia Egli glorificato ed esaltato, tutte le cose spettano le une alle altre, ed il possessore è Allah in modo specifico, come il proprietario della casa è il proprietario della sua porta. Quindi noi non vendiamo al Vero se non ciò di cui Egli ci ha detto che lo compera e non aggiungiamo [altro] a quello.

Quanto alla sua menzione degli impedimenti ('awä $i q$ ), sappi che ogni attaccamento ('alāqa) è un impedimento, ma non tutti gli impedimenti sono degli attaccamenti. Gli attaccamenti sono ciò per cui tu hai una viva affezione e quell'attaccamento ti è di impedimento, per il tuo amore verso di esso, rispetto ad altro: non hai desiderio se non di ciò a cui sei attaccato e non aspiri a nulla al di là di quello. Quanto agli impedimenti essi sono più generali nell'ostacolare: tra gli impedimenti vi sono quelli a cui le anime sono attaccate, ed essi sono gli impedimenti interiori, e quelli a cui le anime non sono attaccate ed essi sono gli impedimenti (mawāni ${ }^{\Upsilon}$ esteriori, ai quali il Vero ti ha impedito di attaccarti.

Quanto a ciò di cui il Vero ti ha ordinato di occuparti e di gestire, come i parenti, i figli ed altri, essi non sono degli impedimenti, poiché il Vero, sia Egli esaltato, ha tracciato per te in essi una via

544) Nel Cap. 70 [I 587.12] Ibn 'Arabī precisa: "Per noi, dal punto di vista della realtà, colui che prende ha diritto, in quanto non prende se non per l'attributo della povertà e del bisogno, non per altro, quale che sia il modo di dare: una offerta, un dono o un'altra delle categorie del dare. Come il ricco mercante, possessore di migliaia [di dirham], attraversa i deserti, solca i mari, sopporta i pericoli, si allontana dalla famiglia e dai figli, ed espone se stesso e le sue ricchezze al rischio della perdita nei suoi viaggi: tutto per la ricerca di un dirham in più di quello che possiede! Su di lui ha potere l'attributo della povertà che lo rende cieco di fronte all'insorgere di queste paure e lo fa lasciare indifferente di fronte alle difficoltà, in quanto il potere di questo attributo nel servitore è forte. Chi considera le cose in questo modo, che è quello vero, vede che a chiunque dà una cosa e che la prende da lui, questi ne ha diritto, per la sua conoscenza dell'attributo per cui la prende da lui, a meno che non la prenda per esaudire una sua necessità, in quanto sarebbe danneggiato dal rifiutarlo, o per nascondere la sua stazione spirituale con il prendere".

545) Nel Cap. 358 [III 267.21] Ibn 'Arabī menziona tre tipi di connessione (idāfa), chiamata anche "stato costrutto" dai grammatici italiani della lingua araba: "connessione di proprietà (milk), di nobilitazione (tašrñf) e di spettanza (istihqāq). La connessione di proprietà è come "la ricchezza di Zayd", la connessione di nobilitazione è come "il servitore del Re" e la connessione di spettanza è come "la sella della cavalcatura" e "la porta della casa"”, e nel Cap. 348 [II 200.18] aggiunge: "E colui che non ha scienza dell'Esistenza nelle cose si immagina: "Tu hai una ricchezza e Lo hai preso come procuratore in ciò che è in tuo possesso, poiché la connessione delle ricchezze con te nel Suo detto "le vostre ricchezze" è una connessione di proprietà" e non sa che quella connessione è una connessione di spettanza come "la sella della cavalcatura" e "la porta della casa", non una connessione di proprietà". 
verso di Lui, e se tu la percorri arrivi al tuo obiettivo, [164] che è Allah, non la famiglia ed i figli. Non tutto ciò che è collegato a te ed in cui Egli ha tracciato una via verso di Lui, sia Egli esaltato, è un impedimento, sennonché il noncurante ( $g \bar{a} f i l$ lega il suo proposito ad una cosa determinata che è presso Allah, e non ad Allah, e quella cosa che è collegata con lui diventa un impedimento tra lui e ciò che è presso Allah ed a cui desidera ardentemente di arrivare, e se il suo obiettivo fosse Allah e non ciò che è presso Allah allora percorrerebbe la via che Allah ha tracciato in quella cosa che costui chiama impedimento, ed arriverebbe ad Allah. Ciò fa parte dell'ignoranza degli uomini riguardo a quello che cercano ed alla via su cui procedono, e sicuramente essi non cessano di essere nella confusione ( $\left.\operatorname{tašw} \bar{\imath}_{\zeta}\right)$, nella contrarietà e nelle malattie dell'anima, poiché la causa della malattia è l'obiettivo personale ( $\mathrm{garad}$ ) ${ }^{546}$ ) e chi non ha un obiettivo personale non ha malattia, intendo dire la malattia dell'anima.

Quanto al suo detto: "La prima cosa con cui ti si presenta questo basso mondo è nella forma di una bella donna, di una bellezza eccelsa, e per Allah, per Allah, non scrutarla!”, quest'uomo descrive invero il suo stato e può darsi che [il basso mondo] si sia presentato così a lui perché il Vero sapeva che gli piacevano le belle donne, ma la faccenda non è limitata a ciò che ha detto, bensì quando il Vero vuole mettere alla prova il Suo servitore osserva ciò a cui la sua anima è attaccata e ciò che gli è caro, e poi manifesta per lui questo basso mondo, ed ogni cosa con cui lo mette alla prova, nella forma di quello che gli è caro, per vedere se si fa prendere da quello e lo riceve o se lo spende riguardo ad Allah e se ne stacca.

Allah, sia Egli esaltato, ha detto: "Non raggiungerete la pietà (birr) finché non spenderete di ciò che vi è caro" (Cor. III-92); Ibn 'Umar ${ }^{547}$ ) amava lo zucchero e lo comperava con il denaro e faceva la sadaqa con esso e non con il denaro, con cui comperava lo zucchero, e diceva: "A me piace e non faccio la șadaqa se non con ciò che mi è caro" $\left.{ }^{548}\right)$.

546) Nel Cap. 318 [III 71.7] Ibn 'Arabī precisa: "Sappi che l'obiettivo personale (garad) è identico alla volontà (irāda), sennonché esso è una volontà per la quale l'anima nutre attaccamento e passione e che quindi è stabile. Essa viene chiamata così perché l'obiettivo è il bersaglio che gli arcieri erigono per la competizione, e poiché le frecce degli arcieri hanno di mira il bersaglio ed esso è stabile e non viene meno, la volontà che è fatta in questo modo viene chiamata obiettivo, per la sua stabilità nell'anima di colui in cui sussiste, dovuta al suo attaccamento a quella cosa. Egli non si cura degli strali verbali della gente indirizzati a lui per quello, indipendentemente che quell'obiettivo sia lodevole o biasimevole, ma la gente ha convenuto sul fatto che quando si dice che esso è un obiettivo personale, attribuendolo all'anima, è biasimevole, mentre quando è privo di questa attribuzione può essere lodevole o biasimevole. Per questo il Vero viene descritto come dotato di volontà e non si dice che Egli ha un obiettivo, poiché all'obiettivo è prevalentemente connesso il biasimo, essendo un accidente che si presenta all'anima".

547) 'Abd Allāh ibn 'Umar ibn al-Ḩaț̣āb, figlio del secondo Califfo, fu uno dei Compagni del Profeta e morì nell'anno 73 dall'Egira. Su di lui si può consultare l'articolo omonimo di Laura Veccia Vaglieri nella Encyclopédie de l'Islâm, seconda edizione, Vol. I, pag. 55-56. Ibn 'Arabī lo cita una quarantina di volte nelle Futūhăt, come fonte diretta di hadīt profetici.

548) Questo paragrafo è riportato in termini quasi identici nel Cap. 70 [I 573.1], ove Ibn 'Arabī aggiunge: "La 
La sua restrizione riguardo al [manifestarsi di] questo basso mondo nella forma di una donna è soltanto una limitazione dovuta alla situazione, quindi non respingerla, poiché la faccenda è come abbiamo detto. Invero Allah presenta [165] a questa gente il Suo Regno (mamlaka) in quanto essi hanno delle pretese riguardo a Lui e Lo cercano senza badare a ciò che Gli appartiene ${ }^{549}$. Ed Allah li mette alla prova con tutto ciò in cui prova piacere l'anima del cercatore, ed è quando gli presenta ciò che gli è caro che gli uomini si differenziano per grado: chi di loro è ignorante delle faccende non bada a ciò che arriva né a ciò che si presenta a lui, ed egli è sincero nella sua pretesa ma non diventerà mai un istruttore (murabbri) o un Maestro; colui che è accorto ed esperto, dotato di intendimento riguardo ad Allah, quando Allah lo mette alla prova presentandogli ciò che abbiamo menzionato lo riceve per $a d a b$ verso Allah senza farsi prendere da esso e conosce la fonte di quella forma e la sua provenienza, il perché è un velo e come può essere allontanato, avendone così una scienza completa - tutto questo nell'attimo (nafas) della teofania. Poi, dopo aver ottenuto la scienza di tutti questi dettagli, dice: "O mio Signore, non Ti ho cercato per questo, e Tu conosci la mia richiesta", ed Egli gli fa apparire in mostra il Suo Regno (mulk), cosa dopo cosa, ed egli accoglie tutte queste cose nel modo che abbiamo menzionato, senza soffermarsi su esse, avendo ottenuto la scienza che abbiamo menzionato, finché Egli non ha tralasciato per lui nulla di ciò che è esistente, e se egli non si è fermato allora Egli riconosce la veridicità della sua pretesa, ed egli viene fatto avvicinare e riceve in dono la contemplazione del Vero. A quel punto egli sa che Egli è identico a tutto ciò che gli ha mostrato mettendolo alla prova, e Lo riconosce in ogni cosa e Lo vede come la forma di ogni cosa, e da lui sortirà un vero Maestro per l'istruzione iniziatica $\left.{ }^{550}\right)$. E se fossimo nel tempo della Profezia legiferante il possessore di questo gusto spirituale sarebbe un Inviato, ma questa porta ormai è chiusa e non resta se non specificamente l'eredità (wirtr), che è una Legge nascosta di cui non è consapevole se non il suo possessore, ed il cui velo è l'eredità (wirāta): se tu dicessi che è un Inviato saresti miscredente, e se tu dicessi che è un Erede diresti il vero, ma l'entità è unica.

cosa che è più cara all'uomo è la sua anima, e se egli la spende nella via di Allah, ottiene per quello ciò che le equivale in peso. Chi esaurisce o consuma una cosa è debitore del suo valore ed il Vero ha chiesto a questo servitore di consumare l'anima, avendogli ordinato di spendere ciò che gli è caro. Ed essa non vale, presso di Lui, se non il Paradiso".

549) Nella sua Epistola delle luci (risālat al-anwār), edita in Mağmū'at rasā'il Ibn 'Arabī, Volume I, Dār al-mahağğa al-bayḍā', Beirut, 2000, Ibn 'Arabī afferma [pag. 274]: "Non attaccare la tua aspirazione (himma) ad altro che Lui, e se Egli ti offrisse tutto ciò che c'è nel Mondo prendilo con adab, non fermarti ad esso e continua nella tua ricerca, poiché Egli ti mette alla prova. Ogni volta che ti fermi ad una cosa Egli ti sfugge, mentre se Lo possiedi nulla ti sfuggirà. Una volta che questo ti è conosciuto sappi che Allah ti metterà alla prova con ciò che ti mostrerà [...] Poi Allah, sia Egli esaltato, ti mostrerà i gradi del Regno (mamlaka) come prova".

550) Nel suo Kitāb al-yā', edito in Mağmū'at rasā’il Ibn 'Arabī, Volume I, Dār al-mahağğa al-bayḍā', Beirut, 2000, Ibn 'Arabī afferma [pag. 469]: "Questo libro della $y \bar{a}$ ', che è il libro del Sé (huwa), lo abbiamo scritto per la gente delle allusioni esoteriche e delle realtà essenziali, coloro che riconoscono il Vero negli impedimenti e negli attaccamenti”. 
E l'affermazione di quest'uomo nella sua raccomandazione: "Guardati e poi guardati dal scrutarla, per Allah, per Allah" [166] è solo ignoranza da parte sua della faccenda, fiacchezza (hawar) nella natura e compassione verso la sua anima per la sua debolezza. Al contrario, il conoscitore o l'aspirante messo in guardia osserva lei, le sue bellezze, le sue curve e ciò di cui si orna, e fa apparire (yubrizu) per essa dalla sua anima ciò che le corrisponde e lo fa innamorare di lei, voglio dire quella cosa corrispondente (munāsib), poiché l'uomo è la somma del Mondo, ed Allah non manifesta una forma senza che presso di lui non vi sia ciò che quella forma cerca $\left.{ }^{551}\right)$. La faccenda continua così finché Egli non gli presenta [tutti] i generi del Mondo, e quando non resta in esso se non il segreto divino che non ammette se non il tutto, allora Egli solleva i veli e Si manifesta a lui ed egli Lo vede come il tutto, e guarda se stesso e vede se stesso parte dell'insieme del tutto. Egli Lo vede per mezzo di Lui [o del tutto], e dopo di ciò Egli non gli sfugge in alcuna forma, sia essa condizionata (muqayyad) o non condizionata $\left({ }^{552}\right)$, e questo servitore è condizionato nell'assenza di condizioni (itlāq) e libero da condizioni (mutlaq) in se stesso, come è la realtà in se stessa ${ }^{(553)}$. La scienza di Allah non comporta altro che questo, anzi non si può

551) Nel Cap. 477 [IV 112.22] Ibn 'Arabī precisa: "Allah, sia Egli esaltato, ha detto: "Ed ogni partito gioisce per ciò che possiede" (Cor. XXIII-53), ed il motivo della gioia è la corrispondenza (munāsaba). E poiché sappiamo che l'uomo è la somma di ciò che è presso Allah, sappiamo che non c'è cosa presso Allah che non abbia una relazione con lui e quindi l'uomo ha un corrispondente (munāsib) di essa. Il sapiente non getta via alcuna cosa dell'esistenza ma le fa apparire (yubrizu) solo ciò che di lui corrisponde ad essa, e non c'è stato che prevalga su di lui, anzi egli è con ogni stato per mezzo di ciò che gli corrisponde, così come Allah è con noi dovunque noi siamo. "La maggior parte degli uomini non sa" (Cor. XIII-21) ciò, anzi essi lo ignorano e non riescono a vederlo e per questo sono indotti a biasimare questo mondo e ciò che è in esso".

A colui che Lo cerca Allah mostra inizialmente che è presso di Lui ed allo stesso modo il servitore deve mostrare ciò che in lui corrisponde a quella cosa, senza però attaccarsi ad essa, poiché ciò che cerca è altro.

552) Nel Cap. 372 [III 449.26] Ibn ‘Arabī precisa: "Il Mondo è lo specchio del Vero ed i conoscitori non vedono in esso se non la Forma del Vero [...] Egli non ci ha creato se non perché Lo adorassimo e Lo conoscessimo e per questo non ci ha rinviato se non all'osservazione del Mondo, poiché ha posto in esso i segni e gli indicatori della scienza di Lui mediante la contemplazione e l'intelligenza. Quando osserviamo è Lui che osserviamo, quando ascoltiamo è da Lui, quando usiamo l'intelligenza è da Lui, quando riflettiamo è su di Lui, quando sappiamo è Lui e quando crediamo è in Lui. Egli è Colui che Si manifesta in ogni aspetto, che è ricercato in ogni segno, che è osservato da ogni occhio, che è adorato in ogni cosa adorata e che è perseguito [come obiettivo] nel mondo visibile ed in quello invisibile. Non c'è creatura a cui Egli sfugga nella sua natura primordiale ed innata", e nel Cap. 463 [IV 82.23] aggiunge: "Egli contempla il Suo amato in ogni cosa che contempla ed Egli non gli sfugge".

553) Nelle Futūhāt Ibn 'Arabī afferma spesso che l'assolutezza (itllāq) o assenza di condizioni è in se stessa un condizionamento (taquìd) e che affermare la trascendenza di Allah o la Sua immanenza equivale a condizionarLo, poiché in realtà Egli è al di là di tutte le distinzioni. Nel Cap. 143 [II 229.27] egli precisa: "L'assolutezza (al$i t l a \bar{q}$ ) è essa stessa un condizionamento, in quanto Egli Si distingue [per essa] dal condizionato o in quanto Egli penetra nelle cose condizionate - dillo come vuoi. Per il fatto stesso di distinguerSi è condizionato da ciò da cui Si distingue e quindi l'assolutezza è un condizionamento (al-itla $q$ taqvīd). Il massimo che si possa dire di Lui è che è ignorato, non conosciuto, ma in questo modo non sfugge al condizionamento poiché si distingue da ciò che è conosciuto. In ogni modo non c'è se non un condizionato ed in ciò che non c'è non c'è che un condizionato: la non esistenza è ciò che non c'è ed essa è distinta dall'esistenza come l'esistenza è distinta dalla non-esistenza, e non c'è quindi cosa conosciuta né ignorata che non sia distinta. Dunque il condizionamento detta legge e non resta che una gerarchia di condizionamenti, il più elevato dei quali è il condizionamento nell'assolutezza 
dire di Lui altro che questo: Egli è il velo, ciò che è velato e colui a cui è velato,

e non c'è se non Allah, soltanto Lui,

e tu, per mezzo di Lui, Lo vedrai nelle due situazioni. $\left.{ }^{554}\right)$

Quanto al suo detto: "poiché chi la osserva, ella lo uccide", ciò [accade] se egli ha avuto per gusto spirituale quello che ha detto, ed allora è perito, e se è uno che si è basato sull'analogia (qiy $\bar{a} s$ ) non c'è discorso con lui, e se non avesse detto ciò per gusto spirituale allora conoscerebbe la faccenda in cui si è trovato e non si guarderebbe da essa, e questo è ciò che è richiesto.

Egli, ed Allah è più Sapiente, non è se non uno che è velato e che non conosce la faccenda, in quanto dopo questo ha detto: "Allah mi protegga da quello" mostrando di non avere scienza della faccenda, poiché se avesse avuto scienza della faccenda in cui si trovava, nella sua richiesta di protezione avrebbe detto: "Allah mi protegga da Allah", come disse in questa stazione l'Inviato di Allah, che Allah faccia scendere su di lui la Sua șalāt e la Pace, dotato dello svelamento più completo: [167] "Io mi rifugio in Te da Te" ${ }^{555}$ ) in quanto il suo svelamento e la sua scienza erano ciò che abbiamo menzionato e

(taquìd fì itlāq)". Nel Cap. 369 [III 385.7] aggiunge: "Per via del nostro condizionamento (taqyīd) noi giudichiamo che Egli sia assoluto, ma la Realtà in se stessa non è qualificata né da condizionamento, né da assolutezza, bensì è una Esistenza che include tutto. Egli è identico alle cose, ma le cose non sono identiche a Lui: non c'è manifestazione di una cosa senza che la Sua Personalità sia identica a quella cosa. Colui la cui Esistenza è in questo modo, come può ammettere l'assolutezza o il condizionamento? Così Lo conoscono i conoscitori; chi afferma che Egli è assoluto non Lo conosce, e chi Lo dichiara condizionato è ignorante riguardo a Lui”; ed ancora, nel Cap. 420 [IV 28.27] afferma: "Allah, sia Egli esaltato, ha detto: "O gente di Yathrib, voi non avete più un luogo ove soggiornare: tornate dunque" (Cor. XXXIII-13). Colui che ha totalizzato le stazioni non ha più stazione ove andare, come è implicito in: "Colui che conosce se stesso conosce il suo Signore" e nel Suo detto: "Noi faremo loro vedere i Nostri segni sugli orizzonti" - cioè i segni che indicano queste stazioni sugli orizzonti - "e in loro stessi" (Cor. XLI-53). Poiché essi sono condizionati è inevitabile che condizionino Colui che è significato, anche se indicano la Sua assolutezza, poiché il Suo essere assoluto è un condizionamento, in quanto il condizionamento è distinzione (tamȳzz). La conoscenza che i conoscitori hanno di Lui, sia Egli esaltato, non deriva dalla visione dei segni esteriori ed interiori, poiché essi indicano ciò che è condizionato in un'assolutezza o un'assolutezza in ciò che è condizionato. I conoscitori Lo vedono come l'identità ('ayn) di ogni cosa".

Quanto al condizionamento nell'assenza di condizioni, nel Cap. 558 [IV 304.15] Ibn 'Arabī riporta il seguente esempio: "Il Vero ha descritto il Suo servitore Muhammad, che Allah faccia scendere su di lui la Sua salāt e la Pace, come compassionevole e clemente con i credenti [cfr. Cor. IX-128], e quindi lo ha condizionato con la fede ma non ha condizionato la fede e questo è un condizionamento in una assenza di condizionamento (taquìd fì l-itläq), poiché Egli ha detto riguardo alla fede che il suo possessore è credente nel vero e nel falso, e ciò corrisponde al Suo detto: "O voi che credete, credete in Allah e nel Suo Inviato" (Cor. IV-136) ed ha menzionato ciò che ha menzionato e li ha chiamati credenti, ed essi non sono credenti che nel falso, ed ha ordinato loro di credere in Allah, che è il Vero".

554) Questi versi non sono riportati nelle Futūhăt, anche se l'affermazione iniziale "e non c'è se non Allah" ricorre in otto versi.

555) Hadīt riportato da Muslim, IV-222, e da Abū Dāwud, II-148 e VIII-5. Ibn 'Arabī lo cita 25 volte nelle Futūhăt. 
quindi non trovò da chi proteggersi se non Lui, poiché Lo vide identico ad ogni cosa, e non trovò a chi chiedere protezione se non Lui. Osserva il suo insegnamento, che Allah faccia scendere su di lui la Sua salāt e la Pace, riguardo allo stato di colui che è velato, nel suo detto: "Mi rifugio nella Tua soddisfazione dalla Tua indignazione e nella Tua indulgenza dalla Tua punizione" (556), cercando rifugio da un Attributo in un Attributo e da un Atto in un Atto, e quando volle far conoscere come è realmente la faccenda, e cioè che Egli è identico alla soddisfazione ed alla indignazione, all’indulgenza ed alla punizione, disse: "Io mi rifugio in Te da Te" $\left.{ }^{557}\right)$. I sapienti in Allah si attengono a quest'ultima frase, mentre coloro che sono saldi nella scienza di Allah si attengono al tutto, e danno ad ogni sede ciò che le spetta, e questo è ciò che ci si deve proporre.

Quanto al suo detto: "Anzi, o aspirante, per Allah, per Allah, fuggi da questa forma", cioè la forma di questo basso mondo menzionata in precedenza.

Poi ha detto: "e pensa riguardo a te stesso che essa è una belva che ti divora, anzi ancora peggio, poiché la belva ti fa perdere la vita di questo mondo, mentre questa forma ti fa perdere la vita delle due dimore. Stai quindi in guardia da essa, poi prega per la liberazione (tahlīs) dal suo male, dal male dei demoni e dal male della tua anima". La sua esagerazione (mubālaga) in questa affermazione è per compassione nei tuoi riguardi secondo la misura della sua scienza, come ha detto, sia Egli esaltato: "Quello è il loro limite nella scienza" (Cor. LIII-30), e [la sua] non era una scienza. Questa raccomandazione nell'insieme è per la gente comune non per la gente della Via, né per gli aspiranti all'istruzione iniziatica, poiché l'aspirante all'istruzione iniziatica è diretto dal suo Maestro, che gli ordina di allontanarsi da quella forma o di accettarla - questo è ciò che non incombe a noi poiché la scienza apprende le faccende dalle forme degli stati e delle creature, cosa molto difficile da comprendere, che pochi tra i conoscitori conoscono.

556) Si tratta della parte iniziale dello hadīt riportato nella nota precedente. Ibn 'Arabī la cita nei capitoli 2 [I 76.34], 5 [I 108.22], 69 [I 421.11], 198 [II 401.19] e 560 [IV 553.4].

557) Nel Cap. 69 [I 421.10] Ibn 'Arabī afferma: "È stato riportano nella notificazione: "Mi rifugio nella Tua soddisfazione dalla Tua indignazione", cioè in ciò che Ti soddisfa da ciò che Ti indigna, e qui il servitore esula dal considerare la parte destinata alla sua anima per considerare la sacralità del suo Amato, e questo spetta ad Allah. Viene poi quello che riguarda la sua anima, e cioè il suo detto: "e nella Tua indulgenza dalla Tua punizione", e questo riguarda la sorte della sua anima. Quale dei due gradi è il più elevato? Su questo c'è da fare una osservazione. Chi considera ciò che implica la Maestà di Allah, in quanto nessuna possibilità la può raggiungere - cioè la realtà essenziale del possibile non può ricevere la magnificazione che si addice alla Maestà di Allah, e ciò è impossibile in realtà -vede che la ricerca di rifugio non è se non per la sorte della sua anima, dato che ricade su di lui. Chi invece considera il Suo detto: "se non perché Mi adorino» (Cor. LI-56), dice: "Non mi incombe del diritto del mio Signore se non ciò a cui arriva la mia forza, e io non opero se non per il mio Signore, e non per me stesso". Il Legislatore ha così stabilito le due formule di ricerca di rifugio per queste due persone. Quanto a colui che vede che la propria esistenza è l'esistenza del suo Signore, poiché in se stesso egli non ha esistenza, egli dice "Cerco rifugio in Te da Te", e questo è il terzo grado, e in questo grado è affermata l'entità del servitore". 
Questa raccomandazione è adatta [168] per gli adoratori e per gli asceti $(z u h h \bar{a} d)$, non per gli aspiranti e se egli li ha chiamati aspiranti [malgrado non lo siano] è perché essi desiderano percorrere la via della felicità delle loro cose esteriori, non la felicità delle loro cose interiori. La felicità delle cose interiori e dei cuori sta nel sapere prendere da queste forme mondane, sataniche e psichiche, poiché Allah, sia Egli esaltato, ha detto: "Noi sosteniamo tutti, sia questi che quelli, col dare del tuo Signore, ed il dare del tuo Signore non è precluso (mahzuur)" (Cor. XVII-20) $\left.{ }^{558}\right)$, cioè impedito (mamnū), e quindi non ha vietato (hağara) il Suo dare ed ha fatto avere il Suo sostentamento (imdād) ad entrambi i gruppi, affinché chi vuole sia felice. [Colui che ha realizzato la felicità delle cose interiori] sa come prendere da Allah da queste forme biasimate, come comportarsi con ciò che gli arriva e come innamorarsi di queste forme, sì da amarle intensamente, e quello perché sa da quale Presenza il Vero le elargisce, poiché il Suo dare non è impedito, e conosce la complessione di quella forma corporea non grossolana (șura ğasadiyya) $\left(^{559}\right)$ e distingue la sua complessione da quella della forma corporea

558) Nel Cap. 169 [II 286.8] Ibn 'Arabī afferma: "Ed Egli, sia esaltato, ha detto notificando: "Noi sosteniamo tutti, sia questi che quelli, col dare del tuo Signore" (Cor. XVII-20) menzionando ciò che è biasimato e ciò che è lodato", e nel Cap. 558 [IV 274.22] aggiunge: "“Noi sosteniamo tutti, sia questi", la gente del Paradiso, "che quelli", la gente del Fuoco infernale, "col dare del tuo Signore", malgrado la diversità di gusto, "ed il dare del tuo Signore non è precluso" (Cor. XVII-20), cioè impedito, ed il dare si estende a tutto. Noi sappiamo che il Suo dare è identico alla Misericordia che ha la preminenza e che comprende ogni cosa, sia sgradita o meno, sia collera od altro, e nel Mondo non c'è entità sussistente, né stato, che la Misericordia di Allah non pervada e non contenga".

559) Gism e ğasad sono due dei termini usati in arabo per indicare il corpo ed entrambi ricorrono nel Corano: ğasad in Cor. VII-148, XX-88, XXI-8 e XXXVIII-34, e ğism in Cor. II-247 e al plurale in Cor. LXIII-4. Ibn 'Arabī li usa spesso indifferentemente per indicare il corpo grossolano, come nei capitoli 15 [I 154.4], 16 [I 159.24], 21 [I 168.6], 68 [I 332.13 e 354.14] 69 [I 531.27 e 533.20], 71 [I 647.16], 73 [II 5.19], 167 [II 275.27] 198 [II 446.22] e 351 [III 223.25]. In altri punti invece li distingue attribuendo a ğasad un significato diverso da ğism: da un lato il ğasad è il ğism in cui è stato insufflato lo spirito, come nel Cap. 73, questione XL [II 67.28] ove afferma: "Tutto il Mondo è la differenziazione (tafșīl) di Adamo ed Adamo è il Libro sintetico ed egli è per il Mondo ciò che lo spirito è per il corpo (ğasad). Quindi l'Uomo è lo spirito del Mondo ed il Mondo è il corpo e nell'insieme tutto il Mondo è il macrouomo e l'Uomo è in esso. Se consideri il Mondo senza l'Uomo lo troverai come il corpo (ğism) proporzionato senza spirito, e la perfezione del Mondo per mezzo dell’Uomo è come la perfezione del corpo (ğasad) per mezzo dello spirito e l’Uomo è insufflato nel corpo (ğism) del Mondo". Nello stesso capitolo, alla questione CLIII [II 130.2] però afferma: "Se chiedi che cos'è il ğasad noi rispondiamo: ogni spirito o idea che si manifesta nella forma di un corpo (ğism) luminoso o elementare". E nel Cap. 346 [III 186.28] aggiunge: "In questa dimora ho compreso la differenza tra i corpi grossolani (ăgsām) ed i corpi non grossolani $(a g ̆ s s \bar{a} d)$ : i primi sono questi corpi conosciuti dalla gente comune, siano essi sottili [in senso fisico], diafani o spessi [cfr. Cap. 350 (III 214.17)], che si vedano o non si vedano, mentre i secondi sono quelli in cui appaiono gli spiriti durante la veglia e che assomigliano nella forma ai primi, come pure le forme che percepisce durante il sonno chi dorme e che sono simili ai primi per ciò che ne fornisce la sensazione, ma che in se stessi non sono corpi grossolani (ă̌sām)". Quest'ultima definizione di ğasad ha il suo fondamento nel Corano, come spiega Ibn 'Arabī nel Cap. 9 [I 133.12]: "Questa forma sensibile in cui si manifestano gli esseri spirituali si chiama ğasad e corrisponde al Suo detto: "e noi ponemmo sul suo trono un corpo (ğasad)" (Cor. XXXVIII-34), ed al Suo detto: "..noi non demmo loro un corpo (ğasad) che potesse fare a meno del nutrimento" (Cor. XXI-8). La differenza tra i ğinn e gli Angeli è che, pur avendo in comune la spiritualità, il nutrimento dei ǧinn è costituito dal cibo che apportano i corpi naturali, mentre per gli Angeli no. Per questo Allah ha menzionato nella storia 
grossolana (süra ğismiyya) ${ }^{(560}$ ), anche se tutto ciò fa parte del mondo della Natura, così come tutto ciò che apportano quelle forme corporee non grossolane e grossolane fa parte del sostentamento divino.

Non è opportuno rinviare ad Allah nulla di ciò che viene da Allah, anzi il conoscitore tra gli aspiranti sinceri sa come ricevere e quale $a d a b$ avere con Allah riguardo a quelle forme, e si comporta con il Vero con quell'adab: questo è lo stato in cui si trova la gente di Allah, ed essi hanno la lingua della lode assoluta ${ }^{561}$ ) che spetta ad Allah da parte dei Suoi servitori. Quanto agli altri, essi hanno una

degli ospiti di Abramo, l’Amico intimo: "Quando vide che le loro mani non si accostavano ad esso", cioè verso il vitello arrostito, ed essi non ne mangiarono, "egli li disconobbe" (Cor. XI-70) ed ebbe timore".

560) Nel Cap. 178 [II 333.26] Ibn 'Arabī precisa: "Sappi che quando lo Spirito riceve la forma naturale [ciò avviene] nei corpi non grossolani immaginali (al-ağsād al-mutahayyala), non nei corpi grossolani sensibili (al-ağsām al-mahsūsa) che normalmente si percepiscono; anche i corpi non grossolani immaginali si percepiscono come di norma ma non tutti coloro che li vedono li distinguono dai corpi realmente grossolani. Per questo i Compagni non riconobbero Gabriele quando discese nella forma di un arabo e non sapevano che quello era un corpo non grossolano immaginale, finché il Profeta, che Allah faccia scendere su di lui la Sua salāt e la Pace, non li informò dicendo loro: "Questo è Gabriele", mentre essi non avevano dubbio che si trattasse di un arabo. Analogamente accadde a Maria quando l'Angelo "prese per lei le sembianze di un bell'uomo" (Cor. XIX-17), poiché ella non aveva conoscenza del segno distintivo che permette di riconoscere gli Angeli quando assumono un corpo".

561) L'espressione "lode assoluta" ricorre nelle Futūhăt solo nel Cap. 467, dedicato al Polo la cui recitazione continua (hiğğìr) è al-hamdu li-llah, ove Ibn 'Arabī precisa [IV 96.15]: "La lode è l'elogio (tanä) di Allah ed è di due tipi: un elogio di Lui per ciò che Gli appartiene, come "Sia Egli glorificato", "Allah è il più grande" e "Non c'è Dio se non Allah", ed un elogio di Lui per ciò che viene da Lui, che è il ringraziamento per i favori ed i benefici che Egli dona. A Lui spettano le conclusioni poiché la lode non ritorna se non ad Allah, in quanto Egli è Colui che elogia tramite il servitore e Colui che viene elogiato, conformemente al suo detto, che Allah faccia scendere su di lui la Sua salät e la Pace: "Tu sei così come Tu elogi Te stesso". Egli è Colui per mezzo di cui il servitore Lo elogia, quindi l'elogio ritorna a Lui in quanto è Colui che elogia ed in quanto è Colui che è elogiato, e l'esito della lode spetta a Lui in entrambi i casi. Vi è poi un'altra suddivisione: la lode viene riportata da Allah in termini assoluti e condizionati, anche se è condizionata per lo stato, poiché non è possibile nell'esistenza l'assenza di condizionamento nella lode, in quanto è necessario che ci sia un motivo ( $b \bar{a} q \underline{t}-$ per essa e quel motivo è ciò che la condiziona, anche se essa non è condizionata nell'espressione, come il Suo ordine, sia Egli esaltato, nel Suo detto: "Dì: la lode spetta ad Allah" (Cor. XXVII-59), in cui non ha condizionato l'espressione. Quanto alla lode condizionata è indispensabile che essa sia condizionata da un attributo di Atto, come il Suo detto: "Sia lode ad Allah che ha creato i Cieli e la Terra" (Cor. VI-1), ed il Suo detto: "Sia lode ad Allah che ha fatto scendere il Libro sul Suo servitore" (Cor. XVIII-1) e: "Sia lode ad Allah che ha separato i Cieli" (Cor. XXXV-1), ma talvolta è condizionata da un attributo di trascendenza, come il Suo detto: "Sia lode ad Allah che non ha preso figli" (Cor. XVII-111)". Poco oltre [IV 97.11] aggiunge: "Per colui che pratica come recitazione continua la lode assoluta, in cui colui che recita non la condiziona con alcuno degli Attributi, anche se gli stati differiscono per lui [e gli stati dipendono dai Nomi, e quindi dagli Attributi], essi non sono il motivo di quella recitazione $(\underline{d} i k r)$, bensì è solo Lui [o: essa (lode)] il primo motivo per cui pronuncia in modo assoluto la recitazione: essa è un condizionamento in una assolutezza. Come risultato egli ottiene tutto ciò che conferisce ogni recitazione della lode ad Allah condizionata da uno degli Attributi estrinseci, o da un Nome o da un Attributo intrinseco, finché colui che fa questa recitazione non si sofferma su uno degli stati per la dolcezza che ricava da esso, poiché allora quel gustare la dolcezza lo condiziona, anche se egli formula la lode in modo assoluto. Dopo di ciò egli non ottiene come risultato se non ciò che corrisponde allo stato di cui ha gustato la dolcezza, poiché ha un attributo ed è conforme ad esso, cessando così per lui il primo regime. Fu detto ad Abū 
lingua di lode ed una lingua di biasimo (damm), ed essi sono gente condizionata da una Legge, da un obiettivo personale, da una convenienza di natura, o dalla considerazione di una perfezione e di una mancanza, e di tutti questi è più lodevole chi biasima e chi loda per mezzo della lingua di una Legge, in quanto è più puro, ma tuttavia è inferiore a colui che abbiamo menzionato della gente di Allah, la gente della lingua della lode assoluta, in cui non c'è biasimo. E come potrebbe essere biasimata una cosa che viene da Allah?

Per il conoscitore e per l'aspirante sincero è necessario conoscere il segreto del biasimo divino [169] delle cose, malgrado esse vengano da Lui $\left({ }^{562}\right)$, e chi le biasima tra i Nomi divini $\left({ }^{563}\right)$; e se è possibile

Yazīd: “Come stai stamattina?", al che egli rispose: "Non c’è mattino per noi, né sera; infatti il mattino e la sera appartengono a chi è condizionato dall'attributo. Io non ho attributi"”,

562) Nel Cap. 350 [III 211.19] Ibn 'Arabī precisa: "Allo stesso modo noi addossiamo a noi stessi quelle opere brutte che non corrispondono agli obiettivi e che non sono confacenti alla natura, malgrado la nostra scienza che tutto viene da Allah, ma poiché con esse è correlata la lingua del biasimo, noi riscattiamo con noi stessi ciò che viene attribuito al Vero di quello, per adab con Allah; quanto a ciò che c'è di buono e di bello [nelle opere] noi ci togliamo di mezzo ed lo attribuiamo ad Allah, affinché sia Lui ad essere lodato, per adab con Allah, e perché è veramente così, poiché ciò appartiene senza dubbio a Lui, malgrado il profumo di condivisione (ištirâk) che si trova nella notificazione divina nel Suo detto: "Ed Allah ha creato voi e ciò che voi fate" (Cor. XXXVIII-96), ed il Suo detto: "Ciò che di bene ti arriva viene da Allah, e ciò che di male ti arriva viene da te stesso" (Cor. IV-79), ed ha detto: "Dì: tutto viene da parte di Allah!” (Cor. IV-78), attribuendo l'opera una volta a noi ed una volta a Lui, e per questo abbiamo parlato al riguardo di profumo di condivisione. Egli, sia esaltato, ha detto: "a suo favore ciò che ha guadagnato ed a suo sfavore ciò che ha meritato" (Cor. II-286), ed ha detto: "Le ha ispirato la sua scelleratezza e la sua pietà" (Cor. XCI-7, 8) ed a Lui appartiene l'ispirazione in noi ed a noi il compiere ciò che ha ispirato, ed ha detto: "Noi sosteniamo tutti, sia questi che quelli, col dare del tuo Signore" (Cor. XVII-20) e ciò può essere il Suo dare l'ispirazione come il Suo creare l'opera, e questa è una questione in cui l'affermazione dell'Unità (tawhīd) non è mai pura, né dal lato dello svelamento, né dal lato della notificazione. La verità è che si tratta di una faccenda connessa tra Vero e creatura e non attribuibile esclusivamente ad uno dei due lati. La più elevata delle relazioni (nisab) divine è il fatto che il Vero, sia Egli esaltato, è l'esistenza stessa da cui traggono profitto le possibilità e non c'è dunque se non l'esistenza dell'entità del Vero, nient'altro. Le alterazioni (tagayyurāt) che si manifestano in questa entità sono i regimi (ahkām) delle entità delle possibilità: se non ci fosse l'entità [del Vero] non si manifesterebbe il regime, e se non ci fosse il possibile non si manifesterebbe l'alterazione e quindi negli atti è indispensabile sia il Vero che la creatura".

563) Nel Cap. 345 [III 183.6] Ibn 'Arabī precisa: "Malgrado l'esistenza dell'opposizione che comportano le realtà essenziali dei Nomi divini contrapposti non giunge ad essi, per la loro opposizione gli uni agli altri, una lingua di biasimo. Allo stesso modo all'opposizione che si manifesta in questa costituzione umana non giunge in conclusione un castigo ininterrotto, poiché l'origine la protegge da questo, ed essa è la Forma [divina su cui l'uomo è stato creato], che è costretta nella sua opposizione. L'opposizione è inevitabile per via della contrapposizione dei Nomi in colui che è stato creato sulla Sua forma: Colui che è benefico non è Golui che arreca danno, né Colui che dà è Colui che trattiene ed affinché la perfezione della forma sia possibile è necessaria la manifestazione di queste realtà essenziali in questa configurazione. L'obbediente si contrappone al disobbediente, l'associatore a colui che afferma l'Unità, e chi nega a chi afferma, tutto ciò per il sostegno dei Nomi divini. Ciò corrisponde al Suo detto: "Noi sosteniamo tutti, sia questi che quelli, col dare del tuo Signore" (Cor. XVII-20), cioè chi obbedisce e chi disobbedisce, la gente del bene e quella del male, "ed il dare del tuo Signore non è precluso" (Cor. ibidem), cioè impedito, poiché Egli dà mediante la Sua Essenza ed i luoghi di manifestazione, cioè i ricettacoli, ricevono in base alla loro predisposizione, che è l'effetto dei Nomi divini 
per esse un affrancamento dal biasimo alla lode, e diventino lodate dopo essere state biasimate, o no $\left({ }^{564}\right)$.

E se la ripartizione (taqsīm) [tra lode e biasimo] nella Presenza divina è possibile o no. E se è possibile, qual'è la sua causa? E se non è possibile, qual'è la sua causa?

in essi, e tra i Nomi divini ve ne sono di corrispondenti e di opposti. Quelli corrispondenti sono ad esempio il Clemente e Colui che perdona molto ed i loro simili, mentre quelli opposti sono ad esempio Colui che innalza e Colui che abbassa. Inevitabilmente la predisposizione di questo luogo di manifestazione sarà sotto il regime di uno di questi Nomi e il suo recepimento del regime divino sarà conforme ad esso, che sia corrispondente od opposto. E a chi si trova in questa situazione come può essere collegato un biasimo essenziale? Gli accidenti non sono immutabili mentre il bene è essenziale nell'uomo ed è il suo regime quello che resta. Il male è accidentale e quindi cessa, anche se dopo un po"”.

564) Nel Cap. 375 [III 472.23] Ibn 'Arabī afferma: "Non c'è nel Mondo realtà che sia biasimata in modo assoluto, né lodata in modo assoluto, perché gli aspetti ed i contesti condizionano ogni cosa. La radice (aș) è il condizionamento $(\operatorname{taqvi} d)$, non l'assolutezza, in quanto l'esistenza è necessariamente condizionata, e per questo l'indicazione dimostra che tutto ciò che entra nell'esistenza è condizionato", e nel suo Kitāb al-haqq, la cui traduzione è stata pubblicata nel numero 2 di El Azufre Rojo, 2015, pag. 137-161, precisa: "Sappi che la lode ed il biasimo connessi agli attributi non si riferiscono alle loro essenze, poiché se la proprietà $(\mathrm{hukm})$ [o il giudizio] del biasimo fosse riferita all'essenza dell'attributo non potrebbe mai succedere che esso sia oggetto di lode e viceversa se la proprietà della lode [fosse riferita all'essenza dell'attributo] non scorrerebbe mai la lingua del biasimo su di esso. L'attaccamento tenace $(\mathrm{bahl})$ riguardo alle ricchezze è biasimato [mentre l'attaccamento tenace per la tradizione $(d \bar{\imath} n)$ è lodato; la codardia (ğubn) verso il mondo (kawn) e la paura (hawef) di esso è biasimata] mentre la paura di Allah e di ciò che Egli ha ordinato di temere, in quanto lo ha ordinato è lodata; la bramosia (hirs) nell'accumulare la ricchezza e nel conservarla è biasimata, mentre la bramosia nella ricerca della scienza e delle conoscenze e nel conformarsi al massimo possibile a ciò a cui si addice conformarsi è lodata; l'invidia (hasad) riguardo all'ottenimento dei mezzi del benessere per usarli (isti $m \bar{a} l)$ è lodata mentre riguardo ad altro che quello è biasimata. [Il Profeta], su di lui la Pace, ha detto, nel Saḥ̄h: "L’invidia non può [legittimamente] riguardare che due persone", hadīt, e quindi ha attestato (qarrara) l'invidia dal punto di vista della Legge tradizionale. Il non credere $(k u f r)$ in ciò in cui è opportuno non credere è lodato, mentre la miscredenza nei confronti di Allah e dei suoi favori (níam) è biasimata. La fede $(i m \bar{a} n)$ in Allah, nei Suoi Angeli, nei Suoi Libri e nei Suoi Inviati è lodata, mentre la fede nella divinità degli astri (kawākib), dei Faraoni e di altri esseri contingenti (akwān) come al-Lāt, al-'Uzzah, Hubal, Manāt, Yagūt, Ya'ūq e Ba'l è biasimata. Analogamente per tutte le realtà (umūr) da cui l'umanità non può separarsi [44a] se non per mezzo della cessazione (zawāl) della loro realtà essenziale in questa sede (mawtin) del mondo di quaggiù (dunya $)$ e dell'incombenza legale (taklīf): la bramosia, l'avarizia, la codardia, l'invidia e la miscredenza non cessano mai per l'uomo e quindi su di lui scorre la lingua della lode e del biasimo per esse, conformemente al loro impiego (tasrīff). Chi dice all'uomo: "Non essere codardo e non essere avaro" è come se gli dicesse: "Vieni meno a questa tua costituzione naturale (naša), annientati e diventa un'altra natura, cioè non essere uomo", e questo non è nel potere dell'uomo, cioè che egli stesso produca un'altra costituzione naturale. "Invero l'uomo è stato creato avido, impaziente quando lo tocca il male e ritroso quando lo tocca il bene". (Cor. LXX-19 e 20). Egli non può quindi separarsi da ciò su cui è stato connaturato, e il Vero, sia Egli esaltato, ha determinato la sede [corretta] in cui esercitare questi attributi di relazione". La lode ed il biasimo non si applicano alle cose in se stesse, prodotte da Allah mediante il Suo comando creatore (al-amr at-takwiñ $)$, ma al modo in cui sono usate dall'uomo, in conformità o in difformità al Suo comando prescrittivo (al-amr at-taklīî̀). 
Chi conosce la ripartizione da parte di Allah della șalāt in due metà tra Lui ed il Suo servitore $\left({ }^{565}\right)$, sa ciò di cui stiamo parlando: Allah non ha ripartito tra Lui ed una delle Sue creature una cosa che Gli appartiene se non tra Lui e noi, perché questa costituzione naturale è stata creata sulla Forma divina ed è la sua ombra, ed Egli in questa ripartizione non esce da Se stesso, ma è come se Egli dicesse: "Ho ripartito la salāt tra Me per un certo aspetto e tra Me per un altro aspetto, ed Io ho un regime specifico sotto ogni aspetto in ogni aspetto, ed Io sono quei due aspetti, nient'altro che Me".

Questo è ciò che è raccomandato all'aspirante eletto, di cui si dice che fa parte della gente di Allah e della Sua élite, ed essi sono la gente del Corano, che riuniscono le realtà essenziali delle cose, e non c’è dunque forma che ti faccia perdere la vita, né quaggiù né nell'aldilà.

L'esagerazione di costui nel raccomandare questa cosa è dovuta ad uno dei due aspetti: o alla mancanza della sua scienza di come stanno le cose, o perché la maggioranza degli uomini non ha scienza di come stanno le cose, ed egli ha raccomandato ciò che è consuetudine tra coloro "che conoscono il lato esteriore della vita di quaggiù ma che sono noncuranti dell'aldilà" (Cor. XXX-7) e delle loro anime. Gli aspiranti sono lungi dall'abbracciare la carriera di costoro nel modo in cui essi vi si impegnano.

E il Mondo non è simile, malgrado il sostentamento (imdād) divino, se non a ciò che ha detto Allah, sia Egli esaltato: “... irrorati da una sola acqua, e Noi abbiamo reso più eccellenti gli uni sugli altri nel nutrirsi” (Cor. XIII-4) $\left.{ }^{566}\right)$. Gli uomini fanno parte dell'insieme degli alberi e delle piante, poiché Allah, sia Egli esaltato, ha detto riguardo alla loro composizione naturale: "ed Allah vi ha fatto crescere dalla Terra come delle piante" (Cor. LXXI-17), quindi siamo cresciuti come piante, poi dopo aver detto: "e Noi abbiamo reso più eccellenti gli uni sugli altri nel nutrirsi” (Cor. XIII-4) ha aggiunto: "In quello vi sono dei segni", cioè delle prove e delle evidenze [170], "per gente che

565) Riferimento ad uno hadīt quds̄̄ riportato da Muslim, IV-38 a 41, Abū Dāwud, II-132, at-Tỉrmid̄ī, XLIV1, Ibn Māğah, XXXIII-52, an-Nasā̄̄ê, XI-23 e da Ibn Ḥanbal, II-241, 285 e 460. Ibn 'Arabī lo cita una quarantina di volte nelle Futühät.

566) Nel Cap. 33 [I 209.13] Ibn 'Arabī afferma: "L'intenzione (niyya) è per l'insieme dei moti e delle soste di coloro che sono soggetti all'incombenza legale nelle opere l'equivalente dell'acqua per ciò che la Terra fa crescere. L'intenzione in se stessa è unica e si diversifica in base a ciò a cui è connessa, cioè l'oggetto dell'intenzione, ed è da quest'ultimo che dipende il risultato, non dall'intenzione stessa, la cui parte è solo quella di proporsi l'atto o di astenersi da esso. Il fatto che quell'atto sia bello o turpe, un bene o un male, non è l'effetto dell'intenzione, ma dipende soltanto da una faccenda accidentale che si presenta e che il Legislatore ha definito, imponendola a colui che è soggetto all'incombenza legale: sotto questo aspetto specifico l'intenzione non ha alcun effetto. Come l'acqua, la cui mansione è soltanto quella di scendere o scorrere sulla Terra, ed il fatto che la Terra sia morta e venga vivificata da essa o che la casa della povera vecchia venga distrutta dalla sua discesa non competono ad essa: il fiore dal buon profumo o maleodorante ed il frutto buono o cattivo escono per la cattiva complessione del terreno o per la sua bontà, o per la corruzione del seme o per la sua bontà. Egli, sia esaltato, ha detto: "irrorati da una sola acqua, e Noi abbiamo reso più eccellenti gli uni sugli altri nel nutrirsi" (Cor. XIII-4), poi ha aggiunto: "In quello vi sono dei segni per gente che comprende" (Cor. ibidem). In tutto ciò all'intenzione spetta solo il sostegno". 
comprende" (Cor. ibidem) ciò che vuole dire con quello, ed essi hanno scienza delle cose per come esse sono. Le forme degli stati sono come i frutti per questi alberi, ed in esse ha luogo la disparità dei cibi; quanto al Suo detto: "irrorate da una sola acqua" (Cor. XIII-4), non c’è divergenza riguardo al fatto che sia unica, poi ha detto: "ed abbiamo reso più eccellenti gli uni", cioè alcuni di questi alberi "sugli altri nel nutrirsi" (Cor. XIII-4), cioè di questa acqua che è il loro nutrimento e da cui dipende la loro vita, poiché Egli ha fatto dall'acqua ogni cosa vivente ${ }^{(567)}$. Quindi l'accettazione di alcuni di essi è superiore all'accettazione di altri, e la loro accettazione è identica al loro nutrirsi, ed essa è la misura con cui si nutrono di quell'acqua conformemente alla loro complessione ed alla loro realtà essenziale, ed essi la convertono nella loro natura e nel loro stato. E come si manifesta in essi la forma della dolcezza e dell'amarezza, e l'acqua è una e non è caratterizzata da nulla di ciò, così è con la lode ed il biasimo per gli stati che si manifestano sugli alberi degli uomini: l'assistenza (madad) divina è unica ed il biasimo e la lode sono connesse con essa da parte di essi [stati] ed il fondamento di tutto questo è quello di richiamare l'attenzione sul fatto che l'epifania del Vero è unica e che la diversità del Suo regime nella forma della Sua teofania è da ricondurre alle entità del Mondo che sono i supporti di manifestazione del Vero. Quindi l'esistenza nell'entità è Sua ed il regime in quella esistenza è del Mondo, e questa è la scienza di cui sussurrano i perfetti della gente di Allah, come gli Inviati e gli eredi, ed i Libri divini rivelati lo hanno trasmesso in ogni comunità e di ciò hanno parlato gli interpreti di Allah: "A Lui ritornerà tutta la faccenda" (Cor. XI-123), "Le faccende non torneranno forse ad Allah?” (Cor. XLII-53).

Se l'accettazione degli alberi nel nutrirsi con l'acqua è di gradi diversi, malgrado l'unità della sua realtà essenziale, è anche di grado diverso il cibo fornito dai frutti di questi alberi a chi li mangia, e quindi ne consegue l'eccellenza degli uni sugli altri nel nutrirsi di essi e da essi ed è così che devi comprendere le realtà delle cose.

Quanto alla sua preghiera di essere liberato dal male (šarr) delle forme di questo mondo, si tratta dell'essere liberato dall'attaccamento del pensiero (hātir) a questo mondo [171], poiché esso è destinato a separarsi dall'uomo, in quanto l'uomo è voluto per l'aldilà ed in questo mondo è solo un'ombra passeggera ed un accidente che si presenta, e quando egli si attacca con passione a ciò che lo abbandonerà è dura per lui la separazione ed alla morte soffrirà molto per la separazione delle cose con cui ha familiarizzato. Qui sopravviene un'altra ignoranza che sussiste in chi non fa parte della gente di Allah, e cioè in chi è in dubbio per una nuova creazione ${ }^{568}$ ); chi è testimone che il Mondo nella sua totalità, cioè la forma di ciò che appare, è rinnovato ad ogni attimo e che esso è il cambiamento del Vero nella Teofania, non soffrirà al momento della separazione da questo mondo con la morte poiché egli vede con i propri occhi il rinnovamento della creazione, e non c’è familiarità per chi non permane che un solo istante. La scienza di ciò è l'obiettivo più eccelso e più eccellente che si possa ottenere, ma nel nostro tempo non ho visto nessuno che si dedichi ad esso, per l'elevatezza

567) Riferimento a Cor. XXI-30.

568) Riferimento a Cor. L-15, versetto già riportato a pag 48 del manoscritto. 
della sua posizione (mansib) e per il segreto dell'inaccessibilità del mezzo (sirr izzat sababi-hi) [per ottenerla].

Quanto alla sua preghiera di essere liberato dal male dei demoni $\left.{ }^{569}\right)$, egli intende i demoni a cui appartengono i tocchi $\left(\right.$ lammāt) $\left({ }^{570}\right)$ nei cuori di coloro che sono soggetti all'incombenza legale tra gli uomini (bašar) in modo specifico ed in modo non specifico. Se tu fai una simile preghiera invero intendi il male della lontananza da ciò che è congiunto con la scienza della realtà per come essa è, in quanto il significato del termine "šaytân" è colui che è lontano dalla Misericordia di Allah stabilita nei fenomeni dell'uomo (al-muqarrara fĩ zawāhir al-bašar), poiché nella creazione dal fuoco senza fumo [cioè nella creazione dei ğinn] Satana è come il miscredente nella creazione umana naturale, ed essa [preghiera] è una richiesta di protezione ed una domanda di affrancamento da questa stazione [di lontananza].

Quanto alla tua preghiera di essere liberato dal male della tua anima, esso è dovuto solo alla sua ricettività, poiché talvolta l'anima, per la sua ignoranza, accetta da chi viene da essa, [e talvolta] non

569) Per Ibn 'Arabī i demoni non sono esseri distinti perché definiti da condizioni d'esistenza differenti da quelle che definiscono gli altri esseri, né perché dotati di caratteristiche specifiche come quelle che ad esempio definiscono la specie, bensì per il particolare orientamento da loro assunto. Quindi l'espressione coranica "demoni degli uomini e dei ǧinn" (Cor. VI-112) non è da intendere come "demoni che affliggono gli uomini ed i ğinn" bensì nel senso che tra gli uomini ed i ğinn vi sono dei demoni. Nel Cap. 55 [I 281.27] egli precisa:

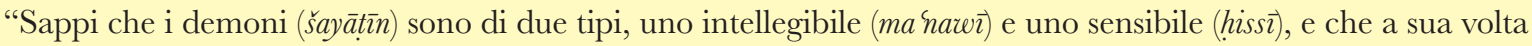
il tipo sensibile è suddiviso nel demone umano e nel demone dei ğinn. Allah, quanto è Potente e Magnificente, ha detto: "I demoni degli uomini e dei ğinn: gli uni ispirano inganno agli altri con l'abbellimento del discorso e se il tuo Signore avesse voluto non l'avrebbero fatto. Quindi abbandona loro e ciò che inventano" (Cor. VI112) definendoli quindi come la gente che inventa menzogne contro Allah; e fra questi due si genera (hadata) nell'uomo un demone intellegibile. Ciò vale a dire che i demoni degli uomini e dei ğinn, quando uno di loro getta nel cuore dell'uomo qualcosa con cui lo allontana da AIIah, talora vi getta qualcosa di specifico, cioè qualcosa che in se stesso è specificamente satanico, e talora vi getta qualcosa di generale e lo lascia. Ora, se si tratta di qualcosa di generale ciò gli apre in questo modo una via verso delle cose a cui né il demone dei ğinn né quello umano avrebbero pensato: in questo caso è l'anima che la approfondisce e che deduce da quegli argomenti dubbi delle cose che quando l'uomo le profferisce Iblīs impara da lui la trasgressione", e nel Cap. 383 [III 522.22] aggiunge: "E non si tratta del demonio dei ǧinn, ma intende il demonio degli uomini. Allah ha detto: "I demoni degli uomini e dei ginn" (Cor. VI-112), ed ha detto: "dal male di colui che sussurra e si ritrae * che sussurra nei petti degli uomini * tra i ğinn e gli uomini” (Cor. CXIV-4 a 6). I demoni umani hanno potere sia sull'esteriore che sull'interiore dell'uomo, mentre i demoni dei ğinn sono i sostituti dei demoni umani nell'interiore degli uomini. I demoni dei ğinn sono quelli che fanno penetrare le opinioni nei demoni umani, e governano il loro dominio (dawla $)$, spiegando loro nei dettagli i regimi che manifestano in esso".

570) Il termine lamma, che significa tocco, visita, ricorre in uno hadīt riportato da at-Tirmid̄ī, XLIV-Sūra II-35, secondo il quale Ibn Mas'ūd riferì che: "L'Inviato di Allah, che Allah faccia scendere su di lui la Sua salāt e la Pace, ha detto: Satana ha in proprio un tocco nell'uomo e l'Angelo ha in proprio un tocco. Il tocco di Satana pone in prospettiva il male e fa apparire la verità come una menzogna. Il tocco dell'Angelo pone in prospettiva il bene e fa apparire la verità come ciò che è vero. Chi prova quest'ultimo sappia che esso viene da Allah e lodi Allah, chi prova l'altro, cerchi rifugio in Allah da Satana”. Ibn 'Arabī lo cita nel Cap. 57 [I 286.17]. 
accetta da chi viene da essa $\left.{ }^{571}\right)$ : in realtà non c'è male o cattiveria che venga da essa se non per la sua ricettività verso ciò che viene dalla sede del male e della cattiveria, cioè propriamente $\mathrm{i}$ demoni dei ğinn. Quanto ai demoni degli uomini essi sono coloro che ricevono [172] dai demoni dei ğinn ciò che essi apportano loro dell'opposizione alla Legge e lo proiettano nei loro simili tra gli uomini. Allah li ha chiamati i demoni degli uomini, e per questo ha detto riguardo ai demoni degli uomini e dei ǧinn: "gli uni ispirano inganno agli altri con l'abbellimento del discorso" (Cor. VI-112); il demone dei ğinn ispira all'uomo ciò per cui egli diventa [un demone], se lo ascolta, e per cui [anche] egli viene descritto, conformemente a quanto si è proposto con ciò il demone dei ğinn, come demone, cioè lontano dalla sua beatitudine, non da Allah, anche se lo ignora.

La liberazione dal male è solo l'affrancamento dal lato esteriore della faccenda per coglierne il significato ed il segreto, e per questo nella lingua araba viene impiegato il termine "šarr", che talvolta indica l'essere manifesto $(z u h \bar{u} r)$, come ha detto Imru' al-Qays $\left({ }^{572}\right)$ nella sua poesia:

Se essi rendessero manifesto (yuširrūna) il mio assassinio $\left({ }^{573}\right)$,

di cui esistono due versioni, una con la sīn [yusirrūna], che è il nascondere, e l'altra con la šìn [yuširrūna], che è il rendere manifesto. Ed egli ha detto: "Se essi rendessero manifesto (yuširrūna)", cioè palesassero (yuzhirūna), con la šñn, ed il male non è chiamato così se non per il suo essere manifesto sul bene, poiché il bene è interiore ed il male è ciò che si manifesta all'uomo sapiente nel suo interiore o nel suo esteriore, e ciò che gli è nascosto di esso è il bene $\left({ }^{574}\right)$, poiché la scienza del sostentamento divino

571) Tutti i manoscritti che ho potuto consultare hanno il seguente testo, da me vocalizzato: fa qad taqbalu liğahli-hā min man qabala la-hā lā taqbalu min-hu, in cui sembra mancare un wa qad prima della negazione.

L'importanza del "chi" oltre che della "cosa" è spiegata dall'esempio riportato nel Cap. 55 [I 283.8]: "Disse dunque Iblis a Gesù, su di lui la Pace: «O Gesù, di: non c'è Dio se non Allah», ed avrebbe tratto soddisfazione da lui se egli avesse obbedito anche solo in questa misura al suo comando. Ma Gesù, su di lui la Pace, rispose: «Lo dico, ma non perché tu hai detto "non c’è Dio se non Allah!"» e Satana tornò indietro scacciato".

572) Celebre poeta arabo preislamico, morto una ventina d'anni prima della nascita del Profeta. Su di lui si può consultare l'articolo omonimo redatto da S. Boustany nella Encyclopédie de l'Islam, Vol. III, E.J. Brill, 1975, pag. 1205-1207. Ibn 'Arabī lo nomina otto volte nelle Futūhāt.

573) Il verso è riportato anche nel Cap. 369 [III 373.29].

574) Nel Cap. 369 [III 373.26] Ibn 'Arabī precisa: "Per questo [il Profeta], che Allah faccia scendere su di lui la Sua salät e la Pace, rivolgendosi in preghiera al suo Signore, sia Egli esaltato, ha detto: "Tutto il bene è nelle Tue mani, ed il male non Ti riguarda" [Muslim, VI-201], poiché esso è l'opposto del bene e dal bene non procede se non il bene. Il male non è altro che l'assenza del bene, e tutto il bene è esistenza e tutto il male è non-esistenza; esso è la manifestazione (zuhür) di ciò che in realtà non ha entità, poiché è un regime ed i regimi sono delle relazioni, ed abbiamo parlato al riguardo di "manifestazione" perché così è nella lingua araba. Imru' al-Qays ha detto: Se essi rendessero manifesto (yuširrūna) il mio assassinio, [usando il verbo šarra nel senso di manifestare]. Per questo Egli, sia esaltato, ha detto di Se stesso: "Egli conosce il segreto" - che è il nascondere ciò che ha un'entità - "e ciò che è più nascosto" (Cor. XX-7), che è il manifestare ciò che non ha entità sì che la gente si immagini che esso sia reale. Allah sa che esso non ha esistenza come entità nel suo stesso regime, e quindi "conosce il segreto e ciò che è più nascosto", cioè ciò che è più manifesto nell'occultamento di quanto lo sia il segreto". 
ignorato è un bene assoluto e si manifesta in una forma in base alla [sua] ricettività, e viene chiamato bene per un certo rapporto specifico e male per un altro rapporto specifico, e ciascuno parla in conformità a ciò che prevale in lui.

Noi non abbiamo preso la raccomandazione di costui come se fosse indirizzata ad una persona specifica, ma abbiamo esaminato le sue parole e la sua raccomandazione, e ciò che di esse è riferito all'aspirante all'istruzione iniziatica l'ho attribuito a lui, e ciò che di esse è riferito agli aspiranti in senso assoluto l'ho attribuito a loro, e ciò che è riferito agli adoratori e agli asceti che non rientrano in questa via specifica l'ho attribuito a loro, e ciò che di esse è riferito alla massa dei credenti l'ho anche [173] attribuito a loro, indipendentemente dal fatto che colui che ha dato la raccomandazione si proponesse ciò e lo sapesse o non si proponesse ciò e lo ignorasse.

Tu basati sulla forza della parola, su dove si manifesta il suo effetto e su chi ne è il destinatario: mangia gli ortaggi e non chiedere del terreno ove sono cresciuti $\left({ }^{575}\right)$, ciò ti sarà utile. Allah, sia Egli esaltato, talora fa dire cose sagge a chi non sa che si tratta di saggezza e non conosce il valore di ciò che Allah gli fa dire, affinché la ascolti chi la cerca, poiché essa è il sogno (dâlla) di ogni saggio $\left.{ }^{576}\right)$ ed egli la desidera e dovunque la trova la registra, e chi ne ha parlato non la conosce.

La saggezza è il sogno di ogni saggio e quando essa arriva a chi la conosce egli non la divulga a chi non la sa riconoscere, poiché l'Inviato di Allah, che Allah faccia scendere su di lui la Sua șalāt e la Pace, ha avvertito chi sa quello, cioè chi sa che essa è una saggezza che indica la felicità, dicendo: "Non date la saggezza a chi non ne è degno poiché le arrechereste danno", cioè essa andrebbe perduta con lui per la sua ignoranza della sua misura, poiché essa non è stata fissata se non perché venisse osservata, e la osserva chi sa che essa è saggezza, per questo è stata chiamata saggezza e non è stata chiamata scienza, ed è una scienza speciale; ed ha detto: "non impedite il suo accesso a chi ne è degno poiché arrechereste loro un danno" $\left({ }^{577}\right)$.

575) Detto proverbiale, riportato anche nel Kitāb muhādarat al-abrār, Dār Șāder, Vol. I, pag.399. Nella frase che lo precede nel manoscritto non è citato "chi" parla, che corrisponde al terreno ove sono cresciuti gli ortaggi.

576) Riferimento ad uno hadīt non recensito nelle raccolte canoniche.

577) Hadīt non recensito nelle raccolte canoniche. Ibn 'Arabī lo riporta nei capitoli 70 [I 557.20], ove afferma: "L'Inviato di Allah, che Allah faccia scendere su di lui la Sua salāt e la Pace, ha detto: "Non elargite la saggezza a chi non ne è degno perché fareste torto ad essa, e non astenetevi dall'elargirla a chi ne è degno perché fareste torto a lui”. Elargire la saggezza equivale a fare la zakāt su di essa, e c'è chi è degno di ricevere la saggezza così come c'è chi è degno di ricevere la zakāt. Se tu elargisci la saggezza a chi non ne è degno, credendo che lo sia, essa va persa, così come va persa questa ricchezza dopo averla versata, e non arriva al suo destinatario; e chi si comporta in questo modo è responsabile verso chi subisce la perdita, essendo stato negligente perché non si è accertato della conoscenza di colui presso cui questa saggezza è andata persa. Si impone dunque a lui di versarla un'altra volta a chi ne è degno, affinché cada nel posto giusto per essa”, 458 [IV-72.33], 502 [IV 140.1] e 560 [IV 542.26] 
Fa parte della saggezza il darla a chi ne è degno ed il non darla a chi non ha preparazione, ed egli, su di lui la Pace, ci ha ordinato di avere rispetto della scienza come abbiamo rispetto di chi è intelligente, ed ha imposto per le idee il regime che ha imposto per coloro che sono dotati di intelligenza, per la sua [del Profeta] scienza che ogni cosa vivente glorifica Allah, e la saggezza fa parte dell'insieme delle cose. È magnifico ciò su cui [il Profeta] ha attirato l'attenzione, poiché ha attirato l'attenzione su una scienza che la maggior parte degli uomini non riesce a vedere, ed il saggio è con le creature secondo la loro misura e chi è con esse secondo la loro misura esse sono secondo la sua misura, poiché egli è la loro somma (mağm $\bar{u})$, ed il saggio è colui che attribuisce agli uomini il loro posto. Ed Allah è Colui che dà il successo.

Poi ha detto: "Poi, dopo quello, ti si presenteranno delle cose che fanno parte dei resti (baqāya $)$ di questo mondo, oltre a ciò [174] che è stato menzionato prima, e guardati anche da esse". Abbiamo già premesso che quest'uomo descrive il suo stato e talvolta la faccenda accade come egli ha detto, e talvolta accade in altro modo; quanto alla sua raccomandazione di guardarsi da ciò, essa dipende dalla sua paura che egli venga velato per l'attaccamento a ciò che si manifesta a lui, e questo è dovuto alla sua ignoranza del volto (wağh) del Vero che c'è in ogni cosa $\left({ }^{578}\right)$ che si manifesta a lui: se sapesse che egli fa parte della gente del volto [divino] non gli avrebbe raccomandato di guardarsi.

578) Il termine wağh indica in arabo il volto, la faccia o l'aspetto. Nelle Futūhät Ibn 'Arabī afferma una ventina di volte che il volto di una cosa è la sua realtà essenziale (haqũqa), la sua essenza (dāt o 'ayn) e il suo essere (kawn), trasponendone così il significato al di sopra del dominio sensibile. L'espressione "volto del Vero" non ricorre nel Corano, ove però si trova più volte citato "il volto di Allah", come nel versetto: "ovunque vi volgiate là è il volto di Allah" (Cor. II-115), e "il Suo volto", come nel versetto: "Ogni cosa è peritura salvo il Suo/suo volto" (Cor. XXVIII-88), in cui, come precisa Ibn 'Arabī nel Cap. 559 [IV 417.18], il pronome arabo hu può essere riferito sia alla cosa che al Vero. A proposito della visione del volto del Vero in ogni cosa, nel Cap. 527 [IV 170.12] Ibn 'Arabī precisa: "Chi si dedica assiduamente a questo $\underline{d i k r}$ [quello di "coloro che invocano il loro Signore di mattina e di sera, cercando il Suo volto" (Cor. XVIII-28)] ottiene la conoscenza del volto del Vero in ogni cosa e non vede una cosa senza vedere in essa il volto del Vero. Invero essi [i Compagni a cui fa riferimento il versetto citato] invocavano il loro Signore di mattina [al tempo della colazione] e di sera [al tempo della cena], cioè nei [due] momenti in cui coloro che vengono nutriti ottengono il loro nutrimento, come Egli, sia esaltato, ha detto: "..ed in ciò essi hanno cibo per la mattina e per la sera" (Cor. XIX-62), il che corrisponde, presso gli arabi, a ciò che si beve al mattino $(s a b \bar{u} h)$ ed alla sera $(g a b \bar{u} q)$. Il nutrimento che costoro ricevevano al mattino ed alla sera era costituito da ciò che essi ottenevano della conoscenza del volto [del Vero], che era ciò che essi desideravano in quanto [nel versetto] Egli ha detto: "desiderando il Suo volto", cioè con la loro invocazione al mattino ed alla sera [essi desideravano] il volto del Vero, poiché sapevano che "ogni cosa è peritura salvo il Suo volto" (Cor. XXVIII-88) e quindi cercavano ciò che è permanente e lo preferivano a ciò che si estingue. Quando si manifestò (tağallā) loro il volto del Vero nelle cose [...] essi non distolsero i loro occhi da questo volto, né era loro possibile farlo in quanto esso, per se stesso, vincola (yuqayyidu) chiunque lo guarda", e nel Cap. 36 [I 223.23] aggiunge: "Allah ci ha conferito [...] [la visione] del volto del Vero in ogni cosa e dal nostro punto di vista non c'è per noi nel Mondo cosa esistente in cui non contempliamo l'essenza del Vero e la magnifichiamo per essa [essenza], e non rigettiamo nulla del Mondo esistente". 
Sappi che questo mondo è l'eccellente cavalcatura del credente conoscitore: su di essa consegue tutto il bene e con essa si salva da tutto il male $\left.{ }^{579}\right)$. Esso [mondo] fa parte dell'insieme delle cose con cui Allah mette alla prova i Suoi servitori che hanno delle pretese riguardo a Lui, e chi si attacca al volto del Vero in esso e che lo accetta nel modo che gli abbiamo spiegato, ottiene un grande successo (fawz), che è quello che riporta l'élite (hâsssa) di Allah; chi invece si attacca ad esso senza vedere quel volto c'è da temere per lui che venga abbandonato con esso $\left({ }^{580}\right)$, ed è questo ciò di cui aveva paura l'autore di questa raccomandazione. E lo stesso vale per tutta l'esistenza se essa si presentasse a te in questo e nell'altro mondo, sia ciò che è lodato di essa che ciò che è biasimato $\left({ }^{581}\right)$, e non c'è forma che si manifesti nel mondo sensibile, o in quello immaginato dalle due immaginazioni, quella congiunta e quella separata ${ }^{582}$ ), o in quello oggetto della scienza, senza che essa abbia uno spirito che è la vita di quella forma, e quello spirito viene indicato come il volto del Vero di essa $\left.{ }^{583}\right)$. Lo scopo non è altro che la scienza di quel volto in questo e nell'altro mondo, in modo sensibile, conoscitivo o immaginativo, e la raccomandazione di ciò è preferibile alla raccomandazione di guardarsi da quelle forme.

579) Riferimento ad uno hadīt già riportato a pag. 78 del manoscritto.

580) Questo argomento verrà più ampiamente sviluppato nelle pagine 273-275 del manoscritto.

581) Nel Cap. 92 [II 177.4] Ibn 'Arabī, parlando di colui che pratica lo scrupolo, avendone realizzato la stazione spirituale, afferma: "Questa pratica gli fa vedere il volto del Vero in ogni cosa e questa è la prospettiva trascendente $($ muttala $)$ : lo scrupolo si innalza e lo sguardo del suo possessore non si posa sulle cose ma soltanto sul volto del Vero in esse, da cui dipende la loro esistenza e per cui esse si manifestano. Di conseguenza il suo stato comporta l'abbandono dello scrupolo poiché non bisogna astenersi dalla visione del volto del Vero nelle cose, non essendo questa visione considerata come qualcosa di sconveniente. Invero il servitore non può allontanare da sé la teofania (tağallî) quando è reale, poiché egli è sotto il suo potere. Col che non voglio dire che chi abbandona lo scrupolo fruisca di ciò che è proibito o dubbio, dopo averlo riconosciuto come tale: nessuno dice questo! In effetti il possessore di questa stazione spirituale fruisce delle cose in conformità a ciò che prescrive la legislazione tradizionale e quindi non mangia se non cose lecite e non agisce se non in modi leciti. Il Vero fa cessare per lui l'indicazione [di ciò che è proibito o dubbio] con la visione del [Suo] volto, ed astenersi per scrupolo senza una indicazione equivale a pensare male degli uomini. La gente di Allah, e soprattutto coloro che contemplano il [Suo] volto, sono lungi dall'avere una cattiva opinione dei servitori di Allah".

582) Nel Cap. 177 [II 311.19] Ibn 'Arabīprecisa: "La differenza tra l'immaginazione congiunta e l'immaginazione separata è che quella congiunta scompare con la scomparsa di colui che immagina, mentre quella separata è una presenza autonoma, costantemente ricettiva verso idee e spiriti, a cui essa dà un corpo non grossolano per mezzo della sua proprietà speciale, nient'altro. L'immaginazione congiunta deriva da quella separata ed è di due tipi: la prima riceve l'esistenza da un atto [deliberato] di immaginazione (tahayyul), mentre la seconda non dipende da un atto di immaginazione. Le forme che vede in sogno chi dorme non sono prodotte da un atto [deliberato] di immaginazione, mentre riceve l'esistenza da un atto di immaginazione quello che l'uomo afferra nella sua anima di simile a ciò che ha percepito coi sensi o quello che è prodotto dalla facoltà rappresentativa in una forma che nel suo insieme i sensi non hanno afferrato, anche se le singole parti dell'insieme sono state necessariamente percepite dai sensi". Una analoga precisazione si trova nel Cap. 371 [III 442.4]. Sul tema dell'immaginazione si possono consultare le opere di William Chittick, The Suft Path of Knowledge, SUNY Press, 1989, Cap. VII, pag. 112-124, e di Henry Corbin, L'imagination créatrice dans le soufisme d'Ibn 'Arabi, Flammarion, 1958, in particolare le pagine 161-164.

583) Questa precisazione non si trova nelle Futūhāt. 
Non c’è cosa che non glorifichi con la lode del suo Signore, ma non tutti comprendono la sua glorificazione, e come potrebbe uno guardarsi da chi menziona Allah, essendo questa l'oggetto dell'imitazione e ciò che è prescritto? Ciò non può succedere se non per la cecità della vista interiore, e per questo Egli ha detto: "ma voi non comprendete la loro glorificazione" (Cor. XVII-44), e noi capiamo di non comprenderla e che non ci basta aver fede e credere [175] nella affermazione di Allah, veridica e continua, che quella cosa glorifica con la lode di Allah, sia Egli esaltato. Ma Allah, sia Egli esaltato, ha [anche] attestato l'equità e la purezza di quella cosa $\left({ }^{584}\right)$, e quindi il desiderio $(r a g b a)$ di essa è preferibile all'avversione per essa.

Allah siede con chi Lo menziona ${ }^{(55)}$ e tutto ciò che c'è nel Mondo, in questo e nell'altro mondo, Lo menziona e Lo glorifica e quindi Allah siede con lui, e chi siede con uno che menziona Allah siede con Allah, in quanto Egli, sia esaltato, siede con costui che [Lo] menziona. Dunque "non siate", dopo ciò che abbiamo menzionato riguardo a questa faccenda, "come colei che disfaceva il suo filato dopo averlo solidamente filato" (Cor. XVI-92).

In occasione della menzione di coloro che Lo menzionano con l'affermazione della trascendenza, che non giunge alla comprensione di tutti, Allah, sia Egli esaltato, non ha manifestato tra i Suoi Nomi se non "il Longanime (hatìm)" e "Colui che perdona molto (gafür)" ( $\left.{ }^{586}\right)$. Quest'ultimo in quanto

584) Nel Cap. 70 [I 559.30] Ibn 'Arabī precisa: "Queste membra soggette all'osservanza della Legge sono pure per il regime della loro origine, poiché sono secondo la natura primordiale (fitra); quella purezza e quella equità non le abbandonano mai. Non vedi che esse testimoniano nel Giorno della Resurrezione? E la loro testimonianza è accettata, a causa della loro purezza (zakât) originale e della loro equità. Il fondamento riguardo alle cose è l'equità, poiché esse procedono da un principio puro, mentre la ricusazione [della testimonianza] (ğurha) [cioè l'inaffidabilità o iniquità] è accidentale. Egli, sia esaltato ha detto: 'L'udito, la vista, il cuore, tutto ciò verrà interrogato riguardo a lui" (Cor. XVII-36); ed ha detto: "Il giorno in cui la loro lingua, le loro mani ed i loro piedi testimonieranno contro di loro" (Cor. XXIV-24); ed Egli, sia esaltato, ha detto: "Essi diranno alla loro pelle: "Perché testimoniate contro di noi'?" (Cor. XLI-21); ed ha detto: "Voi non potrete nascondervi sì che le vostre orecchie, i vostri occhi e la vostra pelle non possano testimoniare contro di voi" (Cor. XLI-22). Tutto ciò è un avvertimento da parte del Vero nei nostri riguardi: ogni parte di noi stessi è un testimone equo, puro ed accettato e quello è l'annuncio di un bene per noi. "Ma la maggior parte degli uomini non sanno" (Cor. XII-21) la forma di bene che esso contiene".

585) Riferimento ad uno hadīt non recensito nelle raccolte canoniche e che Ibn 'Arabī riporta nel Cap. 560 [IV 528.4]: "Mosé, su di lui la Pace, disse: "Qual'è [la situazione], Signore? Sei lontano, nel qual caso io Ti chiamo [a voce alta] o sei vicino, ed io Ti parlo?", ed Allah, sia Egli esaltato, gli rispose: "Io siedo (ğalīs) con chi Mi menziona, e chi Mi menziona Io sono con lui", ed egli aggiunse: "Qual'è l'opera che ami di più, Signore?" ed Egli rispose: "MenzionateMi molto in ogni condizione"”. Ne "La niche des lumières", Les Éditions de l'CEuvre, 1983, pag.76, Ibn 'Arabī precisa che questa tradizione risale a al-Maqburī e figura nel libro "I gradi dei pentiti" di Ismāêll ibn Ibrāhīm al-Harawī. L’affermazione: "Io siedo (ğalīs) con chi Mi menziona" è riportata nove volte nelle Futūhät: capitoli 47 [I 256.7], 69 [I 407.22 e I 511.13], 78 [II 151.33], 369 [III 378.29], 485 [IV 121.6], 559 [IV 441.15] e 560 [IV 461.33 e IV 528.4].

586) Si tratta dei due Nomi che sono citati alla fine del versetto XVII-44. 
Allah ha velato ${ }^{587}$ ) agli occhi ed alle orecchie di alcuni dei Suoi servitori $\left({ }^{588}\right)$ la percezione di quella glorificazione, ed il Longanime in quanto Egli ci ha menzionato che quello sta glorificando con la Sua lode e che noi non lo comprendiamo, e quindi non diamo il dovuto alla fede nella Parola di Allah riguardo a quello, e noi abbiamo offerto ad Allah le nostre anime come oblazione ed Egli ha caratterizzato Se stesso con la Longanimità in quello, e non ci ha punito in questo mondo ('áğila) e non sappiamo ciò che farà nell'aldilà, poiché la longanimità del Longanime consiste nella dilazione della punizione, non altro. Se punirà nel futuro, il Longanime soddisfa la sua longanimità, e se non punirà per quello il Suo servitore ciò dipende dal regime di un altro Nome, come "Colui che perdona molto", che Egli ha accostato a lui [il Longanime] ${ }^{(589)}$, ed altri simili. Quanto è perfetta la forma del Corano e quanto è meravigliosa per colui a cui Allah ha tolto il velo alla visione interiore e ha accordato la sua comprensione!

Non c'è al Mondo qualcuno che parli di una cosa senza che quel discorso non sia un commento al Corano, ma la maggioranza degli uomini non lo sa, poiché non c'è nulla che esuli dal Libro di Allah, e ciò corrisponde al Suo detto: "Non abbiamo trascurato nulla nel Libro" (Cor. VI-38).

Poi ha detto: "Poi, dopo quello, ti si presenteranno le forme dei tuoi stati [176] ed esse fanno parte delle tracce di questo mondo: in tutto quello stai in guardia e sii molto prudente". Qatāda, che era compagno del Profeta, che Allah faccia scendere su di lui la Sua salāt e la Pace, ed era dotato di intendimento, ha detto: "Nessuno rende giustizia a questo mondo: esso è biasimato per la cattiva azione che l'iniquo compie in esso e non è lodato per la bella azione che il pio compie in esso" $\left({ }^{590}\right)$. Fratello mio, sappi che se tu capissi che esso [questo mondo] è la sede della vicinanza (qurb) divina e delle opere di avvicinamento (al-qurab al- 'amaliyya) saresti senza indugio perdutamente innamorato di esso, e per questo esso è chiamato "il più prossimo $(d u n y \bar{a})$ ", cioè il vicino, ed esso è più vicino dell'altro [dell'aldilà], e lo stato $(h \bar{a} l)$ è lo stesso in entrambi [i mondi], e colui il cui stato è la vicinanza il suo attributo è il vicino, e lo scopo non è altro che quello.

Il massimo della venerazione da parte del servitore che onora il rango del suo Signore (sayyid) è quello di venerarLo nel velo e nell'invisibilità ( $g a y b a$ ), ed essa è più perfetta della venerazione nella contemplazione diretta, poiché nella contemplazione diretta egli è costretto per il timore reverenziale che comporta la stazione, mentre chi prova quello malgrado il velo e la cortina è più elevato nella stazione, più completo nella fede e più perfetto nello stato. E la sede di questo non è altro che questo

587) Il Nome gafür deriva da una radice che significa coprire, celare.

588) Nel Cap. 368 [III 255.25] Ibn 'Arabī precisa che "il pronome plurale voi in "voi non comprendete" si riferisce in modo specifico solo agli uomini e quindi tutte le creature adorano Allah ad eccezione di una parte degli uomini".

589) Nel Corano questi due Nomi sono accostati 5 volte: nei versetti II-225, III-155 e V-101 Colui che perdona molto precede il Longanime, mentre nei versetti XVII-44 e XXXV-41 il Longanime precede Colui che perdona molto.

590) Questa frase era già stata riportata a pag. 78 del manoscritto. 
mondo, in quanto esso implica per il suo nome la vicinanza da parte delle coscienze (sarāir $)$ e delle viste interiori, mentre l'aldilà implica la vicinanza per mezzo delle viste esteriori, e che dire del rango delle viste interiori rispetto alle viste esteriori? Le viste interiori afferrano la trascendenza e l'immanenza, le forme ed i significati, mentre le viste esteriori non afferrano altro che le forme e le tracce apparenti, malgrado il Vero sia la vista del servitore, ma egli non percepisce con la Sua vista se non la forma esteriore, poiché guarda per mezzo dello strumento, e colui che produce (sānic) l'opera con lo strumento è inferiore in rango a colui che la produce per mezzo dell'aspirazione (himma). Colui che produce è unico in entrambi i casi, e tra le due situazioni vi è nel rango una differenza che non si può nascondere, e lo strumento nelle viste interiori è più perfetto come realizzazione (wuğūd) che nelle viste esteriori, tant'è che Egli ha negato che le viste Lo colgano ma non ha negato di essere conosciuto, e ciò è la definizione delle viste interiori ( $\left.{ }^{591}\right)$. Anzi, ha ordinato dicendo: "Sappiate" (Cor. IX-3) [177] "e che sappiate" (Cor. XVI-12) e la percezione con le viste esteriori è stata menzionata solo riguardo allo stato seguente [l'aldilà] per la riunione (ğamc), e quella è l'eccellenza della riunione non l'eccellenza della percezione. Sappi dunque.

Questo fa parte della perfezione della riunione e dell'esistenza realizzata (al- ğam 'wa-l-wuğūd) ( $\left.{ }^{592}\right)$ e ciò nelle viste interiori è più grande di quanto lo sia nelle viste esteriori per ciò che le viste esteriori

591) Nel Cap. 421 [IV 30.5] Ibn 'Arabī afferma: "Allah, sia Egli esaltato ha detto: "Le viste non Lo percepiscono" (Cor. VI.103), ciò da parte di ogni occhio, che si tratti degli occhi del volto o degli occhi del cuore. I cuori percepiscono solo attraverso la vista (basar) e gli occhi del volto percepiscono solo attraverso la vista: laddove vi è la vista vi è la percezione. Nell'intelletto la vista è chiamata l'occhio della vista interiore [(basîra o: intuizione] mentre nel dominio apparente la vista è chiamata la vista dell'occhio. Nel dominio apparente l'occhio è la sede della vista, mentre nel dominio interiore la vista interiore è la sede di quell'occhio che è vista per l'occhio del volto. I nomi della vista sono differenti, ma essa non è diversa in se stessa. Come gli occhi non Lo vedono tramite la loro vista, così le visioni interiori non Lo vedono con i loro occhi. È stato riportato da parte dell'Inviato di Allah, che Allah faccia scendere su di lui la Sua salāt e la Pace, che: "Allah è velato agli intelletti così come è velato alle viste: il Pleroma Supremo [che fa parte del dominio spirituale] Lo cerca come voi stessi Lo cercate".".

592) Questa espressione ricorre una ventina di volte nelle Futūhăt, ma solo nel Cap. 463 [IV 81.34] è accompagnata da un commento esplicativo: "Quanto al quarto Polo, che è sul piede di Gesù, su di lui la Pace, la sua Sūra del Corano è "Dì: O voi che siete miscredenti” (CVIII) [...] Il suo [del quarto Polo] discorso riguarda la riunione e l'esistenza realizzata [...] Egli diceva che l'esistenza realizzata è l'esistenza del Vero e che la riunione è la riunione da parte del Vero degli Attributi dell'eternità (qidam) e della novità ( $h u d \bar{u} t)$, e questa è una scienza straordinaria (garīb) riguardo alla riunione; non ho visto nessuno della gente di Allah che sostenesse ciò a parte questo Polo, ed io ho incontrato questi Poli poiché Allah me li ha fatti vedere anche se avevano già lasciato questo mondo. Si tratta della scienza che hanno apportato le Legislazioni tradizionali riguardo al Vero e quindi sosteniamo che quella è la riunione. [...] L'essere nuovo [muhdat) o contingente] ha una pretesa individuale riguardo a quegli attributi che sono chiamati contingenti ed a causa della sua pretesa noi diciamo che è una riunione, ed altrimenti la faccenda sarebbe unica. Tutti essi sono attributi di eternità nell'eterno e contingenti nell'essere nuovo, per la loro manifestazione in lui, poiché non erano manifestati e sono venuti ad esistere presso colui che è qualificato da essi, come Egli ha detto: "Non arriva loro da parte del loro Signore un nuovo avvertimento" (Cor. XXI-2) ed esso non è altro che la Parola eterna di Allah e quindi noi riuniamo in Lui ciò che Gli appartiene malgrado la sua attribuzione a noi. Chi fa questo è detto essere dotato di riunione ed esistenza realizzata e ciò che è soggetto al regime delle possibilità è l'esistenza del Vero, nient'altro, e chi comprende la riunione in questo modo sa com'è realmente la faccenda". 
comportano di restrizione e limitazione, e se Allah ti presenta i tuoi stati come forme, come ha detto questo Maestro, si tratta degli effetti di questo mondo, cioè degli effetti della vicinanza divina.

Ed il suo detto: "in quello stai in guardia e sii molto prudente" è simile al detto di uno di loro: "Siediti sul tappeto (bisāt) e guardati dal dilatarti (inbisāt)" (593), e questo è quanto dice chi non ha gusto nelle realtà essenziali, anche se la sua intenzione non era che buona. La vicinanza eccessiva è un velo come la lontananza eccessiva ${ }^{(594)}$ e tu sai che Egli, sia esaltato, è più vicino all'uomo della sua vena giugulare ${ }^{(595)}$ e questa è la vicinanza della confusione (iltib $\bar{a} s$ ), che impedisce all'uomo di percepirLo,

593) Detto riportato da al-Qušayrī nella sua Risāla, a pag. 36 dell'edizione araba del Cairo del 1959, e a pag. 81 della traduzione di Alexander Knysh, "Al-Qushayrin’s Epistole on Sufism”, Garnet, 2007. Ibn 'Arabī lo riporta nei capitoli 39 [I 233.19], ove precisa: "Si racconta che un [conoscitore] abbia detto: "Resta seduto sul tappeto (bisatt)", cioè il tappeto rituale, "e guardati dal dilatarti (inbisât)", cioè stai attaccato a ciò che comporta la realtà essenziale della servitù in quanto essa è condizionata da cose [cioè atti ed astensioni] che il suo Signore ha definito a questo scopo. Se non ci fossero quelle cose certamente la sua stazione comporterebbe l'impudenza (idlăl), il vanto (fahr) e la fierezza (zahw), a causa della stazione di Colui di cui egli è servitore, e del Suo rango", 69 [I 397.12], 364 [II 316.6] e 559 [IV 363.8], ove afferma: "Quell'uomo che ha detto: "Siediti sul tappeto e guardati dal dilatarti" non aveva alcuna nozione di come stanno le cose e non ha mai presenziato un giorno sul tappeto del Vero, di fronte a Lui, per ottenere ciò che è presso di Lui. Ciò che è proprio del tappeto divino è il timore riverenziale (hayba): dov'è dunque l'attenzione? Esso non è la sede degli errori né della discesa delle infermità, e presso di esso non c'è impedimento né rimprovero, ma solo quiete e calma". Come si comprenderà dal seguito del testo, l'osservazione di Ibn 'Arabī non riguarda tanto il dilatarsi o il gonfiarsi del servitore, quanto lo stare in guardia da essi, che in questa condizione è fuori luogo. Va inoltre notata la differenza del commento riportato nel Cap. 39, che fa parte della sezione delle conoscenze, e quello del Cap. 559, che riguarda invece i segreti.

594) Nel Cap. 85 [II 159.12] Ibn 'Arabī precisa: "Osserva quanto sono sottili questi veli e quanto sono nascosti. Egli ha detto: "Noi siamo più vicini a lui della vena giugulare" (Cor. L-16) malgrado l'esistenza di questi veli che ci precludono la visione di Lui in questa vicinanza suprema, e noi per questi veli non vediamo alcuna entità, anzi essi stessi ci sono velati. Ed Egli, sia esaltato, ha detto: "Noi siamo più vicini a lui di voi, ma voi non vedete" (Cor. LVI-85). Sì, nostro Signore, noi non Ti vediamo e non vediamo i veli. Noi siamo dietro il velo dei veli, mentre Tu in rapporto a noi sei come la vena giugulare, o più vicino a noi di noi stessi, e questa vicinanza è la causa della mancanza di visione da parte nostra, che non può connettersi con Te. L'uomo non vede se stesso, e come potrebbe allora vedere Te, quando Tu sei più vicino a noi di noi stessi? L'estrema vicinanza è un velo, così come l'estrema lontananza è un velo", e nel Cap. 452 [IV 67.25] aggiunge: "Egli, sia esaltato, sa che l'eccessiva vicinanza è un velo immenso alla vicinanza ed ha detto che Egli è più vicino a noi della vena giugulare. Noi sappiamo della sua vicinanza ma i nostri sguardi non la vedono e così è per la vicinanza del Vero a noi: noi abbiamo fede nella Sua vicinanza, ma i nostri sguardi non Lo colgono".

595) Riferimento a Cor. L-16. 
per il detto dell'autore delle Soste (mawāqif), an-Niffarī $\left({ }^{596}\right)$ : "La vicinanza è un velo" $\left({ }^{597}\right)$, intendendo ciò che abbiamo menzionato, ma esso è un velo sulle viste esteriori, non sulle viste interiori, e se chi ha fatto questa raccomandazione avesse saputo che il credente per mezzo della vicinanza del Vero a lui non ha bisogno di stare in guardia, poiché la vicinanza è in se stessa una protezione, non avrebbe detto quello, anzi, in questa raccomandazione egli ti ha indicato la via per l'allontanamento da Allah. Infatti l'occupazione del servitore nello stare in guardia vuol dire occupare l'istante con la circospezione e quindi [il servitore] nel momento della circospezione è uno che perde, non uno che guadagna, ed il Vero non è oggetto della sua contemplazione poiché la circospezione lo vela da quello. Anche se egli è elevato in grado, ciò che noi abbiamo menzionato è più elevato, poiché per noi [la via] non è in discesa, anzi la faccenda in se stessa è elevata e più elevata, alta e più alta, e se costui che ha parlato avesse saputo che il Vero fa parte delle forme degli stati del servitore, anzi Egli è identico alle forme degli stati del servitore vicino ad Allah, [178] non gli avrebbe ordinato di guardarsi dal suo stato. D’altronde non è possibile guardarsi dagli stati riguardo alla loro occorrenza, in quanto uno stato non è tale se non per la sua occorrenza a colui per cui è uno stato, ed il guardarsi riguarda solo ciò che non è avvenuto e ci si guarda dalla sua occorrenza. Uno di loro ha detto:

Io sono in ansia per ciò da cui mi guardo,

e quando si risolve che ho a che fare con l'ansia?

E allo stesso modo io bramo ciò che cerco,

e quando è sparito che ho io a che fare con la brama? (598)

Sappi che gli stati delle creature non sono altro che gli effetti dei Nomi divini, ed è a loro che appartiene il regime, poiché non c'è stato se non per il regime e colui che stabilisce il regime (hākim) non è soggetto, nel suo stato di essere colui che stabilisce il regime, al regime che stabilisce ${ }^{599}$ ).

596) Nel manoscritto Yūsuf Aga 4860, in margine al testo è riportata la seguente annotazione: "[ll Libro del] le soste si trova nella biblioteca che aș-Ṣadr al-Qūnawī ha lasciato come fondo (waqf) per i suoi compagni. L'ho visto, l'ho preso e ci ho lavorato un po' in questi giorni. Lo ha scritto il faq̄̄r Muhammad Sirāğ Zādeh". La copia del Libro delle soste presente nel fondo Yūsuf Aga a Konya, attualmente catalogato col numero 5925 [cfr. Paul Nwiya, Trois ouvrages inédites de Mystiques musulmans, Dar el-Machreq, 1986, pag. 187], è stata scritta da Ismā̄îl ibn Sawdakīn, per cui la frase finale dell'annotazione si riferisce a chi ha scritto l'annotazione, non il Libro delle soste.

597) Non sono riuscito a trovare il testo citato nelle opere di an-Niffarī finora pubblicate da Arthur John Arberry e da Paul Nwiya.

598) Questi versi sono riportati anche nel Cap. 73, q. XXVII [II 59.24] e nel Cap. 103 [II 186.20], in cui Ibn 'Arabī commenta: "Questi due versi riuniscono l'abbandono della paura e della speranza per l'ottenimento di ciò di cui si teme l'accadimento e per la perdita di ciò di cui si spera l'ottenimento".

599) In questo contesto Ibn 'Arabī vuole sottolineare l’importanza degli stati del servitore, attribuendone l'origine ai Nomi divini, ma vi è un punto di vista ancora più profondo, strettamente correlato al segreto del destino. Nel Cap. 413 [IV 18.5] egli precisa: "Gli stati $(a h w a \bar{l} l)$ sono relazioni non-esistenti, ed essi necessitano l'esistenza dei regimi $(a h k \bar{a} m)$ da parte di coloro che stabiliscono il regime (al-hukkām) [cioè i Nomi divini] in ciò che è oggetto del regime $(a l-m a h k \bar{m} m b i-h i)$ e in colui che è soggetto ad esso $(a l-m a h k u ̄ m ~ ' a l a y-h i)$. Il possibile è ciò a cui è data la 
Questo Maestro in questa ed in altre sezioni non ha parlato se non con la lingua della gente comune, non con la lingua della conoscenza e dei conoscitori, ma si proponeva un bene ed ignorava la Via, ed Allah gli darà la ricompensa del suo proposito, anche se è stato privato del discernimento. Allo stesso modo il giurisprudente se sbaglia ha la ricompensa dello sforzo, e anche se il suo giudizio diventa operativo e viene applicato in una certa situazione ciò non dimostra che egli abbia colto quella determinata verità con cui Allah avrebbe giudicato l'evento: ratificare il giudizio è una cosa ed il giudizio da parte del Vero è un'altra cosa, e tra i due vi è una differenza che ben conosce il timorato.

Poi ha detto: "Poi ti si presenteranno dei quesiti prima della tua dirittura (istiqāma) sulla via (darb): non badare mai a nulla di quello". Quest'uomo descrive ciò che gli è capitato e ti dice: "Se ti capita la faccenda come è capitata a me comportati in essa come ho fatto io", e questo deriva dalla sua ristrettezza, poiché l'aspirante, quando il Vero Si manifesta a lui mettendolo alla prova o onorandolo, a seconda del suo stato, non è tenuto a comportarsi come si è comportato il Maestro, ma in ciò deve essere con Allah, sia Egli esaltato, conformemente alla sua stazione rispetto alla scienza di Allah, e talvolta è come lui e talvolta non lo è. Egli [il Maestro] non lo vincola necessariamente con il suo stato, né soprattutto con il suo comportamento e costui che ha fatto la raccomandazione non ha precisato i quesiti.

preponderanza (murağğah) nello stato della sua non-esistenza e della sua esistenza, e la preponderanza è l'effetto di Colui che dà la preponderanza in esso, e lo stato della preponderanza impone al possibile di chiedere, o di non chiedere, in conformità a ciò che esige il suo stato, in quanto noi non specifichiamo uno stato rispetto ad un altro. E per lo stato [il possibile] chiede e provoca la risposta in Colui che dà la preponderanza (murağǧih) e Colui che dà la preponderanza dà allo stato, nel Suo dare la preponderanza, ciò che ha reso necessario la richiesta che ha provocato la risposta in Colui che dà la preponderanza. Quindi Colui che dà la preponderanza non è necessitato se non da una richiesta, e non c'è richiesta se non da uno stato, e non c'è stato se non da una preponderanza, e non c'è preponderanza se non da uno che dà la preponderanza, e non c'è uno che dà la preponderanza se non perché c'è chi la ammette, ed esso è il possibile, ed il possibile è la radice della manifestazione di tutti questi regimi. Esso è colui che conferisce tutti i nomi, i regimi, e l'accettazione di colui che è soggetto al regime di quello, ed il nominato". E nei suoi Fusūs al-hikam, all'inizio del Cap. XIV, a pag. 137 dell'edizione di 'Abd al-'Azīz Sultān al-Manșūb, aggiunge: "Sappi che il Decreto $(q a d \vec{a})$ è il giudizio [(hukm), o il regime, o la decisione, o lo statuto] di Allah riguardo alle cose ed il giudizio di Allah riguardo alle cose è conforme alla Sua Scienza di esse e riguardo ad esse, e la Scienza di Allah riguardo alle cose è conforme a ciò che gli oggetti della scienza Gli conferiscono quanto a loro stessi. Il Destino (qadar) è la determinazione del momento (tawqit $)$ di ciò in cui le cose si trovano nella loro entità, senza alcuna aggiunta. Il Decreto quindi non giudica le cose se non per mezzo di esse e questo è il segreto stesso del Destino [...] Il giudice [(al-hăkim) o colui che stabilisce il regime] in realtà dipende dalla questione stessa riguardo a cui formula il giudizio per ciò che essa comporta nella sua essenza, e quindi ciò che è soggetto al giudizio, per ciò che è, ha un potere determinante sul [o: giudica il] giudice affinché lo giudichi in base a quello. Quindi ogni giudice è soggetto al giudizio da parte di ciò che giudica e di colui riguardo a cui formula il giudizio, quale che sia il giudice". Tenendo conto dei diversi significati del termine arabo hukm, si può notare la differenza tra quest'ultima affermazione e quella riportata nel manoscritto, differenza che non è una contraddizione ma solo la descrizione di come stanno le cose a livelli diversi di conoscenza. 
Abbiamo visto tra i servitori di Allah chi veniva onorato [179] prima della sua dirittura sulla via, come Ibrāhīm ibn Adham $\left({ }^{600}\right)$, quello delle due scodelle (sukurrağatayn) $\left({ }^{601}\right)$ e quello della locusta $(\check{g} a r a \bar{d})\left({ }^{602}\right)$, e nessuno di questi era in quel momento diritto sulla via. Così non è necessario che egli trascuri questi quesiti che gli vengono prima della sua dirittura, poiché nella Via la scienza è più efficace dell'opera, in quanto l'opera viene interrotta ed ha un limite a cui si ferma, mentre la scienza non si interrompe mai e non è concepibile che abbia un limite massimo a cui si arresti. La sua raccomandazione è di non badare a nulla di quei quesiti prima della sua dirittura sulla via, e per via vuol dire la Via (tarīq) verso Allah, che percorrono coloro che mirano ad Allah; essa è una via di ricerca della scienza e dell'opera in una sede specifica che è questo mondo, ed uno stato specifico che è l'assoggettamento all'incombenza legale, e talvolta quei quesiti fanno parte di ciò che la dirittura sulla via implica che vi si presti attenzione: [la sua raccomandazione] non ha quindi senso. Se egli avesse precisato i quesiti nella sua raccomandazione noi ci troveremmo riguardo ad essi in conformità a ciò che comportano quei quesiti e spiegheremmo ciò a cui prestare attenzione di essi e ciò a cui non prestare attenzione, benché nella Via non ci sia cosa a cui non prestare attenzione.

In effetti i grandi indicano agli aspiranti la modalità di apprendere da Allah in ogni cosa che Egli presenta loro, in quanto Egli è il Saggio, e non mostra una cosa ad uno dei Suoi servitori se non nel momento del suo bisogno di essa e chi la getta da parte non sa vedere il suo bisogno per il quale è venuta quella cosa che il Vero gli ha mostrato. L'aspirante sincero la prende come un rimedio per la malattia che c'è in lui, anzi sa che il Vero non glielo ha mostrato in questo mondo se non perché egli lo usi per far cessare una malattia che sussiste in lui, e se ignorava quella malattia ciò che si presenta a lui lo informa che c'è qualcosa che ha bisogno del suo uso e lo stimola a guardare in [180] se stesso e quando guarda lo trova necessariamente ed usa contro di esso quel rimedio.

Se egli non presta attenzione a ciò fa perdere alla sua anima un grande bene e si comporta male con Allah, poiché respinge di fronte a Lui ciò che Allah gli ha fatto arrivare; gli stati della persona esigono il corrispettivo ('iwad) da parte di Allah e quindi il Vero mostra ciò per via della richiesta dello stato e del momento e non bada al fatto che il suo possessore lo sappia o che lo ignori, poiché qui il mostrare è intrinseco essendo lo stato di questo servitore a determinarne la manifestazione. E se egli fosse

600) L'episodio di cui si tratta, in cui Ibrāhīm ibn Adham era stato richiamato dall'arcione della sua sella a risvegliarsi dalla sua noncuranza, come ricorda Ibn 'Arabī nei suo Kitāb mawāqi ‘ an-nuğūm, a pag. 137 dell'edizione di 'Abd al-'Azīz Sulțān al-Manșūb, è riportato nella Risāla di al-Qušayrī, a pag. 8 dell'edizione araba del Cairo del 1959, e a pag. 18 della traduzione di Alexander Knysh, "Al-Qushayri’s Epistole on Sufism", Garnet, 2007, e nel Tadkirat al-awliy $\bar{a}^{\prime}$ di Farīd ad-dīn al-'Aț̣ār, a pag. 163 della traduzione italiana intitolata Parole di Suf, Boringhieri, 1964.

601) L'episodio di cui si tratta è riportato per esteso da Ibn 'Arabī nel suo Al-kawkab ad-durrī fì manāqib D̄ $l$ l-Nūn al-Misrī, a pag. 65 dell'edizione di Sa'īd 'Abd al-Fattāh, Beirut, 2002, tradotto da Roger Deladrière in La vie merveilleuse de Dhû-l-Nûn l'Égyptien, Sindbad, 1988, pag. 64. Ibn 'Arabī lo cita anche nei suo Kitāb mawāqi' annuğǔm, a pag. 137 dell'edizione di 'Abd al-'Azīz Sulțān al-Manșūb, senza però menzionare Dū l-Nūn.

602) Non sono riuscito ad identificare la persona a cui Ibn 'Arabī fa riferimento. 
intelligente, come potrebbe non prestare attenzione alla cosa che il suo stato ha fatto manifestare? Questo sarebbe il colmo dell'ignoranza della faccenda.

Poi ha detto: "Poi, quando sei entrato nella via (darb) procedi in essa con adab, senza volgere lo sguardo a ciò che si presenta a te a destra ed a sinistra della via (tari $q)$, ma cammina in essa sulla rettitudine, senza mai scostarti, e sii in tutti questi stati inseparabile dallo $\underline{d i k}$, realizzandolo e facendo ricorso ad Allah, sia Egli esaltato, rivolgendoti al Suo volto generoso e sperando di ricevere da Lui ciò con cui Egli ti eleva in rango, così come eleva in rango i Suoi servitori pii. E non dimenticare come eri e le disobbedienze che sono scaturite da te, ma rammentati ciò in ogni sede a cui arrivi, affinché la tua anima diventi piccola per te e tu conosca il suo valore ed il valore di ciò con cui Allah ti ha favorito. Ed in tutto questo ricordati le tue disobbedienze, chiedendo perdono per il tuo peccato e riconoscendo lo stato di manchevolezza in cui ti trovi; e ricordati in ogni momento ciò che ti ho raccomandato e studia queste pagine, poiché vedrai in esse un aiuto, se Allah, sia Egli esaltato, vuole".

Quest'uomo non parla se non del suo stato e del suo gusto spirituale e si immagina che ciò che gli è richiesto da Allah è ciò che egli menziona, senza sapere che in realtà talvolta lo stato degli altri è simile al suo, ma talvolta non lo è. Egli sarà ricompensato specialmente per il proposito, non per l'aver colto nel segno, poiché non è concepibile che esista l'insieme di ciò che ha menzionato: l'anima non [181] ammette nel tempo indivisibile che un solo pensiero (hătiri) e non le è possibile mettere insieme la visione delle sue disobbedienze con la visione del favore di Allah su di essa, poiché ogni volta che è in una cosa con Allah non è in un'altra cosa. Questo è un argomento noto ed una scienza verificata. Quanto al suo ricordare in quella sede, che è la sede del pentimento (tawba) e dell'avanzare verso Allah, sia Egli esaltato, i suoi atti di disobbedienza, quella è sgarberia ( $\check{g} a f \vec{a})$ con Allah e mancanza di pudore.

Gli Imām hanno detto riguardo al pentimento che esso consiste nel dimenticare il tuo peccato, poiché nel pentimento sei in uno stato di purezza con Allah ed il ricordo del peccato nello stato della purezza è sgarberia $\left.{ }^{603}\right)$. Il motivo per cui questo Imām ha detto ciò è la risposta data da uno ad una persona che gli chiedeva cosa fosse il pentimento: "Esso sta nel non dimenticare il tuo peccato", analogamente

603) Nella Risāla di al-Qušayrī, a pag. 51 dell'edizione araba del Cairo del 1959, e a pag. 114-115 della traduzione di Alexander Knysh, "Al-Qushayrì's Epistole on Sufism", Garnet, 2007, è riferito il seguente episodio: "Al-Ğunayd ha detto: "Un giorno andai a trovare as-Sarī [as-Saqațī]. Vedendo che era inquieto gli chiesi che cosa avesse ed egli mi rispose: "È venuto un giovane che mi ha chiesto che cosa fosse il pentimento. Gli ho risposto che esso consiste nel non dimenticare il proprio peccato ed egli mi ha ribattuto dicendo: "No! Il pentimento consiste nel dimenticare il proprio peccato". Io [Gunayd] gli dissi allora: "Secondo il mio modo di vedere le cose stanno come ha detto quel giovane". Sarī mi chiese perché ed io continuai dicendo: "Per il fatto che quando ero nello stato di aver fatto una sgarberia Allah mi ha condotto allo stato della purezza, ed il ricordo della sgarberia nello stato della purezza è una sgarberia", ed egli tacque". Ho sentito Abū Hātim as-Siğistānī dire: "Ho sentito Abū Naṣr as-Sarrāğ aṣ-Ṣūfì dire: "Fu chiesto a Sahl ibn 'Abd Allāh [at-Tustarī] che cosa fosse il pentimento ed egli rispose: "Che tu non dimentichi il tuo peccato". Fu chiesto a al-Ğunayd che cosa fosse il pentimento ed egli rispose: "Che tu dimentichi il tuo peccato".". 
a quanto ha detto l'autore di questa raccomandazione. Quando questa risposta venne riportata all’Imām egli disse: "No! Anzi, il pentimento consiste nel dimenticare il tuo peccato" $\left.{ }^{604}\right)$.

Quanto alla sua affermazione relativamente al riconoscere lo stato di manchevolezza in cui egli si trova, questa è la frase di uno di loro che non aveva [colto] la realtà essenziale, e gli Imām commentarono questa risposta di colui che era stato interrogato $\left({ }^{605}\right)$ dicendo: "Invero questo Maestro ti ha ordinato il mero mazdeismo (mağusisyya). Perché non ti ha ordinato di compiere le opere contemplando Colui che le fa accadere e che le crea?”, come realmente è la faccenda $\left.{ }^{606}\right)$. In effetti, se essa ti viene svelata secondo il discorso di questo Maestro che ordina [di vedere] la manchevolezza la faccenda ti viene svelata per come non è ed essa diventa confusa per te, così come tu hai confuso te stesso inizialmente in essa, mentre se ti viene svelata secondo il discorso degli Imām tu vedi il Vero come vero e sei dotato di scienza.

Quanto al suo divieto: "Non volgere lo sguardo a ciò che si presenta a te a destra ed a sinistra della via”, ciò è bene per un aspetto, ma non è bene per un altro aspetto. Chi guarda alla sua destra ed alla sua sinistra non necessariamente deve camminare nella direzione in cui guarda, bensì può seguire un cammino diritto malgrado l'esistenza di questo volgere lo sguardo, anzi, gli viene meno molta scienza se non [182] volge lo sguardo, poiché se non volge lo sguardo non sa da cosa guardarsi. Se invece qui egli intendeva con il volgere lo sguardo (iltifät) il camminare verso ciò a cui volge lo sguardo a

604) Analogamente, nel Cap. 74 [II 140.23] Ibn 'Arabī afferma: “Tra i nostri compagni c'è chi ritiene di non poter avere rimorso se non richiamando alla coscienza il proprio peccato, che si frappone tra lui e ciò che gli è sfuggito dell'obbedienza all'ordine del suo Signore; ma “..il ricordo della sgarberia nello stato della purezza è una sgarberia", quindi è necessario che egli dimentichi il suo peccato, il che è il contrario di quanto sostiene il primo e cioè: "Il pentimento è che tu non dimentichi il tuo peccato".".

605) In tutti i manoscritti che ho potuto consultare si trova as-sẩ îl, che significa "colui che chiede", ma ciò non è coerente con l'episodio che viene qui riportato.

606) Nel Cap. 70 [I 590.14] Ibn 'Arabī afferma: "Quanto a ciò che dice la maggioranza della gente di questa via, come Abū Ḥāmid [al-Gazālī], al-Muhāsibī ed i loro simili tra la maggioranza, riguardo all’ipocrisia (riy $\bar{a})$ ed alla ricerca della sincerità (ihlās), invero quello è il discorso del Vero per mezzo della lingua della gente comune, affinché si diffonda tra gli uomini, ma non è la lingua di chi non vede se non Allah. Noi parliamo di ciò solo con la gente di Allah. Il nostro Maestro [Abū Madyan] soleva dire ai suoi compagni: "Rendete nota l'obbedienza ad Allah affinché la parola di Allah sia la più elevata [cfr. Cor. IX-40], così come quelli rendono pubbliche le disobbedienze, le ribellioni e le manifestazioni delle cose riprovevoli, e non hanno vergogna verso Allah". Uno dei signori [della via] disse ai compagni di un Maestro stimato: "Che cosa vi ha ordinato il vostro Maestro?", ed uno rispose: "Ci ha ordinato di sforzarci nelle opere e di vedere la manchevolezza in esse", ed egli ribatté: "Vi ha ordinato - per Allah - il mero mazdeismo. Perché non vi ha ordinato le opere e la visione di Colui che le fa accadere e che le crea?"’". Quest'ultimo aneddoto è riportato nella Risāla di al-Qušayrī, a pag. 34 dell'edizione araba del Cairo del 1959, e a pag. 78 della traduzione di Alexander Knysh, "Al-Qushayri’s Epistole on Sufism", Garnet, 2007: "Quando [Abū Bakr] al-Wasiṭ̄ arrivò a Nīsābūr chiese ai compagni di Abū 'Uțmān [al-Hīrīi]: "Che cosa vi ha ordinato il vostro Maestro?" ed essi risposero: "Di praticare gli atti di obbedienza e di vedere la [nostra] manchevolezza in essi". Egli disse allora: "Vi ha ordinato il mero mazdeismo. Perché non vi ha ordinato di assentarvi da essi per mezzo della visione di Colui che li crea e li fa accadere?". 
destra e sinistra allora va bene. Invero, il Profeta, che Allah faccia scendere su di lui la Sua salāt e la Pace, tracciò una linea diritta e tracciò ai lati della linea delle linee in questo modo $\left({ }^{607}\right)$, poi recitò il Suo detto: "Invero questa è la mia via (sirāt), che è diritta: seguitela dunque" (Cor. VI-153) ponendo il suo dito sulla linea diritta, "e non seguite i sentieri (subul)" (Cor. ibidem), indicando le linee che erano ai suoi lati "poiché vi allontanano" (Cor. ibidem), cioè le vie (turuq) "dal Suo sentiero" (Cor. ibidem), ponendo il suo dito sulla linea diritta; "questo è ciò che Egli vi ha raccomandato nella speranza che abbiate timore" (Cor. ibidem) di percorrere questi sentieri" (608).

Osserva quanto è più bello il suo detto: "e non seguite", e non ha detto: "non volgete lo sguardo", bensì è indispensabile volgere lo sguardo per conoscere la misura della via della salvezza, poiché chi non conosce la realtà essenziale di una cosa da cui deve guardarsi non si guarda da essa, ed egli [colui che segue l'indicazione coranica] volge lo sguardo ma non segue.

Egli non intendeva se non la Legge stessa che ha portato, poiché Allah, sia Egli esaltato, ci ha ordinato di aver fede in essa e di percorrerla, e ci ha ordinato di aver fede nei sentieri diversi da essa, ma non ci ha ordinato di percorrerli, ed i sentieri non sono altro che le Leggi precedenti. Come facciamo a non volgere lo sguardo verso ciò in cui ci ha ordinato di avere fede? E non è obbligatorio seguire tutto ciò in cui si ha fede, ma noi ci fermiamo a ciò che Egli, sia Egli esaltato, ha detto nel Suo Libro o tramite la lingua del Suo Inviato, e ciò che ci ha ordinato di fare lo facciamo e ciò che ci ha ordinato di omettere lo omettiamo, e non ci ha spiegato ciò che differenzia la loro via da quella specificamente diritta nota come la Legge di Muhammad se non perché ne avessimo scienza e noi non ne abbiamo scienza se non osservandola, non percorrendola.

607) Nel manoscritto, a fianco del testo, è tracciata una linea verticale affiancata ai due lati da tre tratti obliqui paralleli: /// $\square \backslash \backslash \backslash$. Nel Cap. 64 [I 315.18] la figura riportata nel manoscritto autografo è costituita da sette raggi che dipartono da una circonferenza, non tracciata, verso l'esterno.

608) Hadīt non recensito nelle raccolte canoniche. Nel Cap. 132 [II 217.8] Ibn 'Arabī afferma: "Per questo l'Inviato di Allah, che Allah faccia scendere su di lui la Sua șalāt e la Pace, disegnò una linea, poi tracciò ai due lati di quella linea alcune linee: la prima linea era la sua Legge e la sua via (minhāğ), con cui era stato inviato. Gli fu detto: "Dì alla tua comunità di percorrerla e di non discostarsi da essa". Le altre linee erano le leggi dei Profeti che lo avevano preceduto e le norme sapienziali stabilite [prima di lui]. Poi mise la sua mano sulla linea e recitò: "e invero questa è la mia via, che è diritta" (Cor. VI-153) attribuendola a se stesso e non dicendo che era la via di Allah, e caratterizzandola con la rettitudine. Egli non è entrato in particolari riguardo alla qualità delle altre linee, bensì ha taciuto su di esse; poi ha detto: "seguitela dunque" ove il pronome è riferito alla sua via, "e non seguite i sentieri” (Cor. ibidem), cioè le Leggi di coloro che lo avevano preceduto e le loro vie, in quanto esse non sono Leggi per loro; a meno che si trovi una regola di quelle nella mia Legge, nel qual caso seguitela perché è legge per noi, non perché era legge per loro, "sì che esse non vi disperdano dal Suo sentiero (sabīl)" (Cor. ibidem), cioè quelle Leggi vi allontanano dalla via che ha apportato Muhammad, che Allah faccia scendere su di lui la Sua șalät e la Pace, e non ha detto: "dalla via di Allah", poiché tutte sono la via di Allah, essendo Allah la loro meta. "Questo è ciò che Allah vi ha raccomandato, nella speranza che abbiate timore" (Cor. ibidem), cioè prendete quella via come protezione che vi impedisca di camminare su una via diversa". 
Quanto alla mia frase: "gli viene meno molta scienza se non volge lo sguardo", se tu non volgi lo sguardo non sai distinguere nella tua via ciò che è proprio della Legge muhammadiana da ciò che non le è proprio e che era legge per chi lo ha preceduto e che Muhammad, che Allah faccia scendere su di lui la Sua salāt e la Pace, ha confermato. Per quello tu dici di essere [183] Erede di Muhammad, che Allah faccia scendere su di lui la Sua șalāt e la Pace, in modo assoluto, ma non è così, poiché non sono Eredi di Muḥammad, su di lui la Pace, se non due uomini: il primo è colui che è suo erede in ciò che lo caratterizza di quanto non era legge per chi c'era prima di lui, il secondo uomo è colui che è suo Erede nel complesso di tutto quello in quanto è un tutto, non quanto ai suoi elementi distintivi ${ }^{(609)}$. E quando chi percorre la sua Via eredita da lui in una Legge che egli ha confermato, e che era legge per chi c'era prima di lui, se non volge lo sguardo non sa a quale Profeta appartiene, e questo Erede non è Erede se non di quel Profeta che aveva quella Legge, ed è ad esempio cristico, o mosaico o abramico (halīl $\vec{\imath})$, e dice invece di essere muhammadiano e si sbaglia senza dubbio in ciò $\left({ }^{610}\right)$. Talvolta si tratta dell'insieme dei sentieri e delle leggi sapienziali, che non hanno apportato gli Inviati ma che hanno inventato i saggi nei periodi di transizione nell'interesse dei servitori, e la Legge rivelata da Allah, sia Egli esaltato, ha confermato la loro regola, dicendo: "ed un monachesimo che essi hanno inventato, che Noi non abbiamo imposto loro" (Cor. LVII-27). Talvolta questi è erede di qualcosa di

609) Nel Cap. 36 [I 223.1] Ibn 'Arabī precisa: "Nessuno della gente di questa Via è chiamato muhammadiano se non due persone: o una persona che è contraddistinta dall'aver ereditato la scienza di una regola che non c'era nelle Leggi precedenti, e questa è chiamata muhammadiana, o una persona che ha riunito tutte le stazioni spirituali poi è uscito da esse per entrare nella non-stazione, come Abū Yazīd ed i suoi simili, ed anche questa è chiamata muhammadiana. $\mathrm{Al}$ di fuori di queste due persone tutti gli altri eredi sono ricollegati ad uno dei Profeti, e per questo è riportato nella notificazione che "I sapienti sono gli eredi dei Profeti" ed egli non ha detto "eredi di un Profeta specifico". Questo discorso riguarda i sapienti di questa comunità, ed in questo senso è stato anche riportato il suo detto, che Allah faccia scendere su di lui la Sua salāt e la Pace: "I sapienti di questa comunità sono i Profeti delle altre comunità", o in un'altra versione: "come i Profeti dei figli di Israele".

610) Nel Cap. 36 [I 222.24] Ibn 'Arabī precisa: "Sappi, che Allah ti assista, che poiché la Legge di Muhammad, che Allah faccia scendere su di lui la Sua salāt e la Pace, include tutte le Leggi precedenti, esse non hanno più giurisdizione in questo mondo se non per ciò che la Legge muhammadiana ha confermato, ratificandone così il carattere legale. E noi asserviamo noi stessi a queste regole perché Muhammad, che Allah faccia scendere su di lui la Sua șalāt e la Pace, le ha confermate e non perché quel Profeta le ha stabilite alla sua epoca. Oggi tutti coloro che sono vincolati all'incombenza legale, si tratti di uomini o di ğinn, sono muhammadiani, poiché oggi non c'è altra Legge divina se non questa Legge muhammadiana, e chi opera secondo essa non può fare a meno nel corso del suo lavoro [interiore] di incontrare, in ciò che gli si dischiude per esso nel suo cuore e nel suo percorso, una delle vie di uno dei Profeti precedenti inclusa in questa Legge [muhammadiana] e confermata dalla sua propria via, con i risultati che ne derivano. E quando egli ottiene una simile apertura viene denominato secondo il nome del Profeta di questa Legge [precedente] e si dice di lui che è cristico, mosaico, o abramico, per la realizzazione di ciò che lo contraddistingue tra le conoscenze e di ciò che gli si è manifestato della stazione rispetto all'insieme di ciò che è sotto l'egida della Legge di Muhammad, che Allah faccia scendere su di lui la Sua șalāt e la Pace. Questa relazione o questo lignaggio lo differenziano dagli altri solo affinché si sappia che egli non ha ereditato da Muhammad, che Allah faccia scendere su di lui la Sua șalāt e la Pace, se non ciò che avrebbe ereditato da Mosè o un altro dei Profeti, se questi fosse vivente ed egli lo seguisse. E poiché le loro Leggi sono precedenti a questa Legge abbiamo designato questo conoscitore come un erede, in quanto l'eredità spetta all'ultimo venuto". 
esse nella Legge di Muḥammad che è in accordo con ciò che ha stabilito e inventato questo saggio, ed allora questo erede è erede di quel saggio dalla Legge di Muḥammad, su di lui la Pace, ed egli distingue le Leggi divine dalle leggi del pensiero, e la regola non è mescolata per lui, ma è il lignaggio (nasab) che è mescolato per lui, ed egli non conosce il suo lignaggio e si guasta.

Se chi ha fatto questa raccomandazione avesse il dominio sulle stazioni, sui gradi e sulle dimore spirituali, la sua raccomandazione non sarebbe stata così; egli è un uomo che parla in base a se stesso ed alla sua contemplazione, non dal lato di come è la realtà, ma non tutti gli ascoltatori hanno la sua complessione ed il suo stato. Gli uomini si differenziano in ciò per rango così come si differenziano gli Inviati, ed Allah, sia Egli esaltato, ha stabilito per ogni Inviato una via ed un metodo $\left({ }^{611}\right)$, e quindi le Leggi non sono unanimi.

Analogamente gli ascoltatori non sono unanimi: non vedi come viene riportato uno stesso hadīt dall'Inviato, su di lui la Pace, e gli ascoltatori divergono nella sua interpretazione, e l'uno comprende [184] di esso ciò che non comprende l'altro, malgrado entrambi l'abbiano ascoltato? Come pure accade che i due ascoltatori si accordino su di esso se la loro comprensione è unica perché le loro complessioni sono simili: se non fosse così gli Imām non avrebbero divergenze sulla stessa Legge. E che dire della scuola giuridica di aššsāfí̄ rispetto alla scuola giuridica ḥanafita in ciò in cui divergono, malgrado il Legislatore sia lo stesso? Ed è inevitabile che se venisse presentata al Legislatore quella questione specifica su cui divergono Abū Hanīfa e aš-Šāfici il Legislatore sosterrebbe al riguardo la posizione di uno dei due Imām, oppure una terza posizione diversa da esse, poiché l'uno non prende come norma per se stesso la cosa ed il suo contrario riguardo allo stesso caso, ed anche se Egli ha ratificato la regola di ciascuno di loro $\left.{ }^{612}\right)$ ciascuno non prende come norma se non un'unica cosa specificamente. Comprendi ciò!

611) Riferimento a Cor. V-8.

612) Ibn 'Arabī afferma ripetutamente che il giudizio del giurisprudente è ratificato, anche se sbagliato, e riporta come esempio di giurisprudenza ciò che fece il Profeta durante la sua ascensione celeste. Nel Cap. 340 [III 155.26] egli afferma: "[Il Vero disse:] Non vedi come Muhammad, che Allah faccia scendere su di lui la Sua șalāt e la Pace, quando resi obbligatorie per lui e per la sua comunità 50 salāt, scese con esse e non disse nulla, né ribatté, e non disse: "Questo è tanto!". E quando scese da Mosè, su di lui la Pace, e questi gli disse: "Torna dal tuo Signore, forse Egli alleggerirà [il carico] alla tua comunità. Io per quello ho sopportato cose terribili da parte dei figli di Israele, e la tua comunità è incapace di sostenere un carico simile e sarà disgustata da esso", Muhammad, che Allah faccia scendere su di lui la Sua șalät e la Pace, restò disorientato. Il perfetto adab implicava il non controbattere, come aveva fatto, e la sua compassione per la sua comunità esigeva da lui l'alleggerimento per essa, affinché Allah non venisse adorato con dispetto, né con avversione, fastidio ed indolenza, ed egli rimase disorientato. [...] E si mise a cercare di capire se fosse più importante ciò che gli aveva detto Mosè, su di lui la Pace, o ciò che aveva osservato come adab con Allah. Allah in precedenza, menzionando l'insieme dei Profeti, su di loro la Pace, tra cui anche Mosè, su di lui la Pace, gli aveva detto: "Costoro sono coloro che Allah ha guidato: tu segui la loro guida" (Cor. VI-90), ed egli interpretò che questo era ciò che gli indicava della loro guida, e non capì al momento che Mosè, su di lui la Pace, quando era nello stato della Sua guida non chiese l'alleggerimento, e quella guida era ciò che era stato ordinato all'Inviato di Allah, che Allah faccia scendere su di lui la Sua șalāt e la Pace, di seguire. E questo sforzo di giurisprudenza lo indusse a ritornare da Allah per chiederGli un alleggerimento [del numero delle salāt] e non smise di andare e venire tra Allah, 
E poiché la faccenda è confusa per quelli che percorrono la Via senza volgere lo sguardo alla sua destra ed alla sua sinistra, ciascuno di loro afferma di essere muhammadiano, ma non è così, poiché non ha ereditato da Muhammad ciò che è proprio a lui solo, bensì ha ereditato solo ciò che ha condiviso e in cui ha seguito altri, come nel Suo detto: "Costoro sono quelli che Allah ha guidato, prendi quindi come modello la loro guida" (Cor. VI-90). Si tratta di ciò che egli ha confermato nella sua Legge della Legge di altri come opera, ed è obbligatorio avere fede in tutto ciò, sia che il compimento di quell'opera sia stato abrogato o non sia stato abrogato. Nell'eredità non si distingue, tra chi ha questo stato, una persona da un'altra e la faccenda è confusa, e quando il velo verrà tolto e [il servitore] vedrà la sua luce mista per la condivisione e quella di colui che è stato eletto pura dalla commistione, egli saprà allora da dove gli è arrivata [l'eredità], e nel Giorno della Resurrezione camminerà in una luce mista $\left.{ }^{(613}\right)$, mentre egli la credeva una luce pura, e gli apparirà da Allah ciò che egli non aveva considerato, e ciò per la sua mancanza di aver volto lo sguardo. Se avesse volto lo sguardo avrebbe visto le fini realtà (raq $\bar{a} \nmid q$ ) che si estendono dalla destra e dalla sinistra a ciò che corrisponde ad esse della via diritta, ed il viandante [185] avrebbe conosciuto ciò in cui ha luogo la condivisione, avrebbe visto nella sua via ciò di cui non c'è una fine realtà che lo collega con ciò che è alla sua destra ed alla sua sinistra, e avrebbe saputo che egli stava camminando in una via di elezione, e avrebbe visto da quale fonte di questi sentieri si estende la fine realtà che collega ciò in cui ha luogo la condivisione. Egli avrebbe contemplato l'origine ed essa avrebbe avuto un nome per lui, oppure gli sarebbe stata concessa la scienza di essa [origine] e l'avrebbe vista, se si trattava di un Profeta, o di un Inviato o di un saggio, e avrebbe detto: "Ho ereditato da un tale, l'Inviato, o il Profeta o il saggio, dalla Via di Muhammad, su di lui la Pace, riguardo al fare così e così", e avrebbe saputo ciò che è proprio di Muḥammad ad esclusione di ciò che egli ha condiviso.

sia Egli esaltato, e Mosè, su di lui la Pace, finché non disse ciò a cui lo condusse l'adab: "Mi vergogno di fronte al mio Signore", e la faccenda si concluse con l'alleggerimento ad un decimo, e discese con quello dalla sua comunità. E gli venne prescritto di legiferare per la sua comunità la giurisprudenza nei giudizi, nei quali vi è il bene (salāh $h$ del Mondo, in quanto egli, che Allah faccia scendere su di lui la Sua salāt e la Pace, per mezzo della giurisprudenza era tornato tra Allah e Mosè, su di lui la Pace, e la istituì per la sua comunità affinché essa diventasse familiare con quello che era occorso a lui e non si sentisse estranea". Inoltre Ibn 'Arabī cita spesso il seguente hadīt riportato da al-Buhāāī, XCVI-20 e 21, Muslim, XXX-15, Abū Dāwud, XXIII-2, an-Nasā̄ī', XLIX-3, Ibn Māğah, XIII-3, e da Ibn Ḥanbal: "Quando un giudice (hăkim) formula un giudizio, avendo fatto uno sforzo di giurisprudenza (iğtahada), ed è nel giusto, vi saranno due ricompense per lui; e se egli formula un giudizio, avendo fatto uno sforzo di giurisprudenza, ma sbaglia, vi sarà una [sola] ricompensa per lui”.

613) Riferimento a Cor. LVII-12 e LXVI-8. Nel Cap. 64 [I 316.3] Ibn 'Arabī precisa: "È stato riportato in una notificazione che "nel Giorno della Resurrezione il dorso (matn) del Sirāt apparirà agli sguardi in proporzione alla luce di coloro che passeranno su di esso, ed esso sarà stretto per gli uni e largo per gli altri". Questa notificazione conferma il Suo detto, sia Egli esaltato: "la loro luce correrà davanti ad essi ed alla loro destra" (Cor. LXVI-8) e la corsa è un marciare; non c'è dunque che il Sirāt [sia che appaia stretto, sia che appaia largo]. Egli ha detto "alla loro destra" perché il credente, nell'aldilà, non ha sinistra, come invece per la gente del Fuoco non c'è destra", e nel Cap. 73, questione XXXI [II 62.24], dopo aver affermato che la luce dell'esistenza con cui Allah ha rivestito ogni creatura sarà quella con cui camminerà nel Giorno della Resurrezione, aggiunge: "Il Giorno della Resurrezione è privo di illuminazione in sé e gli uomini correranno in esso solo grazie alle loro luci e nessuno potrà marciare in esso per mezzo della luce di un altro". 
Per questo ha detto: "I sapienti sono gli eredi dei Profeti" $\left({ }^{614}\right)$, e non ha detto gli eredi di un unico Profeta, poiché il nostro Profeta, su di lui la Pace, riunisce le Leggi che ci furono prima di lui ed è caratterizzato da una Legge specifica per lui. Quindi i suoi eredi tra i sapienti sono gli eredi dei Profeti, ed è opportuno che l'erede di ciò che è condiviso lo attribuisca al possessore di quella Legge tradizionale, anche se è muhammadiano, per non confondere.

Ed il minimo in questa questione è che anche se [l'erede] è subordinato (tā $\left.b \imath^{\prime}\right)$ a Muhammad, su di lui la Pace, per un aspetto, aspetto che è quello del suo insegnamento a lui [l'erede], poiché è da lui [il Profeta] che egli apprende, egli è uguale a lui per un altro aspetto, che è quello del suo seguire (iqtida $\overrightarrow{\text { ) }}$ l'esempio del primo, come lo ha seguito l'Inviato di Allah, che Allah faccia scendere su di lui la Sua salāt e la Pace, e questo è un onore per lui, così come è uguale a lui in ciò in cui è asservito di quanto condivide con lui, come la salāt, il digiuno, il pellegrinaggio, e ciò che ci ha detto di fare di quanto egli faceva. Ma noi siamo distinti da lui in ciò che caratterizza esclusivamente lui, su di lui la Pace, come il matrimonio per donazione da parte della sposa $\left.{ }^{615}\right)$ ed altro. Quindi noi siamo uguali a lui in una cosa ed egli si distingue da noi per un'altra cosa, ed egli ha l'eccellenza dell'insegnare a noi e noi non apprendiamo se non da lui, ma questo è un altro regime.

Come siamo tenuti a sapere ciò che lo caratterizza di quanto noi non condividiamo con lui, al fine di non cadere in ciò che è proibito, così siamo tenuti a conoscere da quale dei Profeti abbiamo ereditato nella Legge di Muhammad, che Allah faccia scendere su di lui la Sua salät e la Pace, al fine di non cadere nell'ignoranza, e cadere nell'ignoranza è peggio che cadere in ciò che è proibito, poiché la caduta in ciò che è proibito è inferiore alla caduta nell'ignoranza, anche se [186] l'ignoranza fa parte di ciò che è proibito, in quanto Allah ci ha ordinato di cercare la scienza con la riflessione e di chiedere ciò che non sappiamo a chi sa $\left.{ }^{616}\right)$.

Quanto al suo detto: "ricordati in ogni sede ciò che ti ho raccomandato", ciò non è possibile, poiché la sede ha senza dubbio giurisdizione su chiunque arrivi in essa; il Profeta, su di lui la Pace, in una circostanza dirà: "Alla larga $\left(s u h q^{a n}\right)$ ! Alla larga!” $\left({ }^{617}\right)$, ed in un'altra circostanza ha interceduto e si è accordato con il suo Signore riguardo alla sua comunità $\left({ }^{618}\right)$.

614) Hadīt riportato da al-Buhārīi, III-10, Abū Dāwud, XXIV-1, Ibn Māğah, Introduzione-17, ad-Dārimī, Introduzione-32, e da Ibn Hanbal, V-196.

615) Confrontare la traduzione della pag. 37 del manoscritto.

616) Riferimento a Cor. XVI-43 e XXI-7.

617) "Io vi precederò al Bacino (hawd); colui che vi arriverà berrà e chi avrà bevuto non avrà mai più sete. Arriveranno anche alcuni che conosco e che mi conoscono, ma essi verranno allontanati da me. [Io dirò:] Quella gente è dei miei! Verrà allora detto: non sai dunque ciò che hanno fatto dopo che tu non c'eri più?? Allora griderò: Alla larga! Alla larga coloro che hanno cambiato dopo di me!". Hadīt riportato da al-Buhāāī, LXXXI-53, XCII-1, Muslim, II-39, XLIII-26 e 29, LIII-17, Ibn Māğah, XXXVII-36, Mālik, II-28, e da Ibn Hanbal, II-300 e 408, III-28, V-333 e 339. Ibn 'Arabī lo cita nei capitoli 73, questione CL [II 127.9], 126 [II 211.21], 178 [II 340.35], 331 [III 118.22], 342 [III 166.35], 377 [III 485.13] e 438 [IV 51.28].

618) Riferimento ad uno hadịt riportato da al-Buhārī XCII-1, XCVII-36, Muslim, I-326, 327 e 346, at-Tirmid̄ī, 
Quanto al suo detto: "affinché la tua anima diventi piccola per te", non capisco a chi, della gente della Via, sia rivolto questo discorso. Se si tratta dell'aspirante pentito ciò non si applica, poiché il suo pentimento ed il suo ritorno (ināba) sminuiscono senza dubbio la sua anima presso di lui, e questo è contemplato da coloro che si pentono. Se si rivolge a colui che, tra la gente di Allah, è superiore all'aspirante, la sua scienza gli impedisce di magnificare la sua anima presso di lui, e se essa è magnificata presso il conoscitore, quella grandezza $(k u b r)$ non è da biasimare, poiché dipende dalla contemplazione che la sua realtà essenziale (haqīqa) è sulla forma del suo Produttore, e la grandezza $($ kibriy $\vec{a})$ spetta ad Allah non all'anima. Se in questo stato l'anima diventa piccola presso di lui, o se egli la sminuisce con la sua considerazione, egli sminuisce il Vero e getta la sua anima nell'oceano dell'ignoranza di se stessa e la fa uscire dalla sua conoscenza di sé, e chi esce dalla conoscenza di se stesso esce dalla conoscenza del suo Signore.

I sapienti vedono le loro anime dotate di grandezza ed immensità, mentre l'aspirante la vede piccola e bassa; se essa diventa piccola per il sapiente si tratta di una mancanza nei Suoi confronti ed egli non è un sapiente e quella piccolezza ricade sul suo Signore, e quindi egli ha un cattivo adab e merita necessariamente l'allontanamento (tard).

Se per l'aspirante la sua anima diventa grande non si tratta di un aspirante, ma egli fa parte della gente comune, ed il discorso di quest'uomo riguarda soltanto coloro che cercano la Via di Allah, ed il più piccolo di loro è colui che è denominato specificamente come aspirante. Da tutti i punti di vista il suo ordinare ciò che sminuisce per lui la sua anima è un discorso ridondante nei confronti dell'aspirante ed ignoranza da parte sua nei confronti del conoscitore, oppure noncuranza perché occupato nel suo stato.

Egli [Yūsuf ibn Ibrāhīm aš-Šāfic̄i], Allah sia soddisfatto di lui, mi disse di non aver registrato [187] nulla di questa raccomandazione per sua scelta, né per una visione, ma di aver trovato nella sua anima ciò che aveva menzionato e di averlo registrato così come lo aveva trovato; e che in quel momento ciò era per lui materia del suo compagno, 'Alī al-Kurdī, in cui credeva e da cui la materia si era infiltrata in lui in tutto ciò che trovava nella sua anima, indipendentemente che la faccenda fosse elevata o inferiore. Per questo, quando discussi con lui di ciò che era sortito da lui, capii che non sapeva ciò che comportava quanto aveva proferito, ed egli mi chiese di commentare quello che aveva registrato di ciò che era arrivato ed io gli risposi riguardo a quello.

Sappi che il nostro discorso riguardo a tutto ciò di cui parliamo, di nostra iniziativa o in risposta ad un quesito, è sempre riferito a ciò che comporta la stazione o lo stato spirituale e lo tratto come dovuto, senza contestare colui che ne parla e da cui è sortito. In effetti l'uomo non è fisso in una condizione, talvolta si innalza da essa e talvolta, in un altro momento, va al di sotto di essa, ed il discorso di chi è equo (munsif) riguarda solo gli stati, non gli uomini, e per questo essi [gli equi] sono esenti dalla 
maldicenza (gība). Chi comprende ciò che abbiamo detto e conosce il nostro intento non gioisce per una lode e non si rattrista per un biasimo, poiché non abbiamo accennato a lui in nulla di quello - ed egli è il miglior conoscitore di se stesso - soprattutto se fa parte della gente della visione interiore. E quindi non dice una cosa simile quando ascolta il mio discorso riguardo a ciò che egli ha apportato di uno stato basso, se questa persona non mi conosce ed ignora la mia stazione, poiché non mi sono riferito a lui in nulla di quello. Chi è equo consideri lo stato ed il nostro discorso riguardo ad esso: troverà che ho dato ad esso il suo diritto come il Vero ha dato [ad ogni cosa] la sua creazione ed ho preso Lui, sia Egli esaltato, come esempio quando ti ho spiegato il mio intento. Allah, sia Egli esaltato, ha detto: "Egli ha dato ad ogni cosa la sua creazione, poi ha guidato" (Cor. XX-50), cioè ha spiegato a coloro che ascoltano che Egli ha dato ad ogni cosa la sua creazione; così ho fatto io quando ho dato ad ogni stato e stazione spirituale ciò che è dovuto ed ho spiegato che ho dato ad ogni cosa che ha un diritto ciò che le spetta [188], ed Allah è Colui che asseconda con il Suo aiuto e che guida nel giusto.

Quanto al detto di quest'uomo che in questi stati da lui menzionati tu sia "inseparabile dallo dikr", la gente di Allah concorda sul fatto che ['aspirante] menzioni Allah, quanto è Potente e Magnificente, in essi, poiché ha bussato alla porta dei doni (minah) divini riguardo alla conoscenza di Allah, ma vieta la riflessione $(f i k r)$ in essi, e per questo i Süfi superano e si distinguono nel credo riguardo ad Allah dalla gente della speculazione. La considerazione riflessiva non dà della conoscenza di Allah se non specificamente gli aspetti di ciò su cui essa si basa e ciò che conferiscono gli effetti negli esseri contingenti delle relazioni indicate come gli Attributi, e niente altro $\left({ }^{619}\right)$. Lo $\underline{d i k r}$ dà la conoscenza della realtà per come essa è in se stessa, e di essa non si parla se non per similitudine (mitā $l$ ), ma Egli è superiore alla similitudine e ci ha vietato di fare delle similitudini per Allah $\left({ }^{620}\right)$, mentre è Lui che ha

619) Nel Cap. 144 [II 230.12] Ibn 'Arabī precisa: "La stazione della riflessione (tafakkur) non oltrepassa la considerazione di Dio, in quanto è Dio, e di ciò che si addice che esiga chi ha la qualità della Divinità: la magnificazione, la venerazione e la dipendenza essenziale nei Suoi confronti. Tutto ciò era la norma già prima dell'esistenza delle Leggi tradizionali, poi è venuta la Legge [...] ed ha ordinato di riflettere, anche se ciò è implicito nella natura dell'uomo, affinché fosse un atto di adorazione per il quale chi lo faceva venisse ricompensato. In effetti, quando la riflessione è un atto prescritto al servitore dalla Legge, essa gli dà dei risultati che non dà quando il servitore vi si dedica non in quanto essa è prescritta dalla Legge. La riflessione non ha autorità né dominio riguardo all'Essenza del Vero, né razionalmente, né secondo la Legge. La Legge ha vietato di riflettere sull'Essenza di Allah, ed è a questo che allude la Sua espressione: "Allah vi mette in guardia contro Se stesso" (Cor. III-28 e 30), cioè non riflettete sull'Essenza. La ragione di ciò è che manca la correlazione tra l'Essenza del Vero e l'essenza delle creature. [...] La riflessione è uno stato che non garantisce l'infallibilità: per questo è una stazione pericolosa. Colui che la possiede non sa se ha sbagliato o se è nel giusto, in quanto la riflessione ammette sia la giustezza che l'errore. Se il suo possessore vuole essere prevalentemente nel giusto riguardo alla scienza di Allah, allora deve approfondire tutti i versetti rivelati nel Corano che menzionano la riflessione e la considerazione (i qiba $\bar{r}$ ) e non oltrepassare mai ciò, a meno che non sia contenuto nel Libro o nella tradizione trasmessa da una serie ininterrotta di narratori".

620) Riferimento a Cor. XVI-74. Nel Cap. 69 [I 394.2] Ibn 'Arabī precisa: "Ed ha completato ciò dicendo: "Così Allah fa le similitudini" (Cor. XIII-17), poi ci ha vietato di farlo dicendo: "Non fate similitudini per Allah, poiché Allah sa, mentre voi non sapete" (Cor. XVI-74). Allah è un Nome che comprende tutti i Nomi divini ed include tutti i loro significati. Il fare similitudini può riguardare solo un Nome determinato, e quindi 
fatto delle similitudini per Se stesso, ed Egli dischiude a chi pratica lo $\underline{d i k r}$ riguardo a quella similitudine divina ciò che Egli dice con essa. L'estraneo si immagina che il Sūfĩ abbia fatto una similitudine per Allah, ma egli non lo ha fatto, avendo soltanto menzionato ciò che Allah gli ha dischiuso di Sé nella similitudine che il Vero ha fatto per Se stesso.

La gente di Allah non è conosciuta dalle creature, come Colui di cui essi sono la gente non è conosciuto da esse, ed il rango della gente di Allah non è mai compreso in questo mondo, poiché Allah non Si manifesta e non Si epifanizza alla gente di questo mondo, e come nell'aldilà si verificherà la Sua visione così è là che si manifesterà la gente di Allah e sarà verificato il loro grado e la loro mansione nella scienza di Allah.

Quanto al suo detto, dopo aver detto di essere "inseparabile dallo dikr": "realizzandolo", con la realizzazione (tahaqquq) di esso egli intende dire che il Vero sia la sua lingua in quello $\underline{d i k r}$, non lui, a differenza della caratterizzazione (tahalluq) con lo $\underline{d} i k r$, poiché la caratterizzazione con lo $\underline{d i k r}$ o con uno dei Suoi Nomi significa che in esso ci sei tu con te stesso al posto del Vero con Se stesso, mentre la realizzazione significa che in esso c'è il Vero, non tu, in quanto Egli è il tuo udito, la tua vista, la tua lingua, la tua mano, il tuo piede, nello stato della loro forza (batšs) [189] e del loro impegno (say), non altro. Per questo ti ha detto: "realizzandolo" avendo una visione interiore di Colui che menziona (dākir) per mezzo della tua lingua.

Lo strumento del produttore $\left(s \bar{a} n \imath^{i}\right)$ non ha più scienza del suo Produttore di quanta ne hai tu, ed il Vero ha fatto della tua lingua, delle tue facoltà e delle tue membra degli strumenti per Lui, per mezzo dei quali Egli fa ciò che si manifesta da essi del potere di disporre (tasarruf). Per questo li ha attribuiti a te, dicendo: "il tuo udito, la tua vista e la tua lingua", e non ha detto: "il Mio udito", né "la Mia vista", né "la Mia lingua", ed ha fatto della Sua Ipseità (huwiryya) l'entità [o: l’identità] di ciò che Lo menziona. Comprendi, se sei dotato di una essenza illuminata, e conosci "te (anta)" e conosci "Lui (huwa)": sii equo, poiché Egli, sia Egli esaltato, non viene meno (zāla) a te nella totalità né ti conferma nella totalità, ma ti conferisce ciò che sei tu e ti prende ciò che è Lui, e così sii tu fino a che avrai realizzato la realtà per come è.

Per ciò questo Maestro, dopo aver detto: "realizzandolo", ha aggiunto: "e facendo ricorso ad Allah, sia Egli esaltato" dandoti la tua giusta misura, affinché tu non ti inorgoglisca della realizzazione e dica "Io sono Lui", mentre "io" non sarà mai "Lui", né "tu", né [Egli] sarà mai "io", e ti ha stabilito

se facciamo similitudini per Allah, che è un Nome sintetico e universale, non conformiamo il simbolo a Chi dovrebbe essere simboleggiato da esso, in quanto il simbolo è specifico, mentre il simboleggiato è senza limiti, e senza dubbio incorriamo nell'ignoranza. Egli ci ha vietato di fare la similitudine in questo modo, a meno che non determiniamo un Nome particolare a cui si applica la similitudine, nel qual caso è lecito fare la similitudine per quel Nome particolare, come ha fatto Allah in questo versetto, dicendo: "è la luce dei Cieli e della Terra" (Cor. XXIV-35) e per questo Nome, cioè quello della luce correlata [ad un oggetto], ha fatto la similitudine della lampada" 
nel ricorrere $($ iltiǧ $\breve{a})\left({ }^{621}\right)$, come ha detto il Vero riguardo alla seconda metà della [Sūra] "L'aprente", quando ha diviso la salāt tra Sé ed il Suo servitore in due metà $\left({ }^{622}\right)$, metà di essa a Lui e metà di essa al Suo servitore. Questo è identico a ciò che abbiamo menzionato, e di essa vi è ciò che riguarda solo il Vero e di essa vi è ciò che riguarda solo il servitore, e di essa vi è ciò in cui ha luogo la condivisione $\left.{ }^{623}\right)$, e quindi si sa ciò che è di Allah in questa condivisione e che spetta solo a Lui, e ciò che è del servitore di questa condivisione e che spetta solo a lui, e le realtà essenziali si differenziano e le entità sono chiaramente distinte, ed una cosa simile non va trascurata, poiché Egli, quanto è Potente e Magnificente non l'ha trascurata.

Poi ha detto: "rivolgendoti al Suo volto generoso (karim)", poiché non è cercato se non il Generoso, ed Egli non è cercato se non per chiederGli ciò di cui il richiedente ha bisogno. Egli ha usato il Nome "il Generoso", perché il generoso è colui che dà al momento della richiesta, mentre il magnanime (乌̌awād) dà prima della richiesta, e per questo l'esistenza del Mondo dipende dalla Presenza della Magnanimità $(g ̆ u d d)\left({ }^{624}\right)$, poiché non è possibile la richiesta da parte di ciò che non è esistente [190],

621) Nel Cap. 558 [IV 295.3] Ibn 'Arabī precisa: "Questa Presenza [del Nome as-șamad] è la Presenza del fare ricorso (iltiǧ $\hat{a}^{\prime}$ ) e del cercare sostegno (istinâd) alla quale fa ricorso e nella quale cerca sostegno ogni "povero (faqīr)" per una faccenda o cosa, sapendo che quella cosa o faccenda di cui è bisognoso si trova in questa Presenza".

622) Riferimento ad uno hadīt qudsī già menzionato a pag. 169 del manoscritto. "Abū Hurayra disse di aver sentito l'Inviato di Allah, che Allah faccia scendere su di lui la Sua salāt e la Pace, affermare che Allah, sia Egli esaltato, ha detto: "Ho diviso la șalāt tra Me ed il Mio servitore, metà appartiene a Me e metà appartiene al Mio servitore ed il Mio servitore riceverà ciò che chiede". L'Inviato di Allah, che Allah faccia scendere su di lui la Sua salāt e la Pace, disse: "Quando il servitore dice "La lode ad Allah, il Signore dei Mondi", Allah dice "Il Mio servitore Mi ha lodato"; quando il servitore dice "Il Misericordioso, il Clemente", Allah dice "Il Mio servitore Mi ha glorificato"; quando il servitore dice "Il Re del Giorno del Giudizio", Allah dice "Il Mio servitore Mi ha lodato"; quando il servitore dice "È Te che adoriamo ed è a Te che chiediamo aiuto", Allah dice "questo versetto è condiviso tra Me ed il Mio servitore ed egli riceverà ciò che ha chiesto"; quando il servitore dice "Guidaci sul sentiero diritto, il sentiero di coloro su cui Tu effondi la Tua grazia, non di coloro su cui è la Tua collera, né di coloro che sono nell'errore", Allah dice "Questo appartiene al Mio servitore ed egli riceverà ciò che ha chiesto"'”.

623) Nel Cap. 69 [I 509.4] Ibn 'Arabī precisa: "L’Inviato di Allah, che Allah faccia scendere su di lui la Sua salât e la Pace, ha riferito nella notificazione fermamente stabilita che Allah, quanto è Potente e Magnificente, ha detto: "Ho diviso la salât tra Me ed il Mio servitore in due metà", menzionando nella suddivisione solo la recitazione della Fätiha, senza fare riferimento agli aspetti formali della posizione eretta, inclinata, prosternata e seduta. [...] Questo hadīt è per noi la prova dell'obbligatorietà, per colui che fa la salât, di recitare la Fätiha, e diciamo che colui che [la] recita fa la salât e parla in colloquio intimo con Allah, sia Egli esaltato, per mezzo degli Attributi che sono propri di Allah e per mezzo di quelli che sono propri del servitore [...] Vi sono dunque versetti [come i primi tre della Fätiha] che caratterizzano in proprio il Lato del Vero, ed essi appartengono specificamente ad Allah; vi sono versetti [come gli ultimi tre] che caratterizzano in proprio il lato del servitore, ed essi appartengono specificamente a lui; e vi sono versetti [come il quarto della Fätiha] in cui ha luogo la condivisione (ǐ̌tirâk), ed essi sono tra Allah ed il Suo servitore".

624) I termini wenğūd e ğŭd hanno le stesse lettere radicali poste in un ordine diverso, come precisa Ibn 'Arabī nel Cap. 95 [II 179.5]: "Dalla magnanimità [ $(g \check{g} \bar{u} d)$ il dare che precede la richiesta] deriva l'esistenza (wǔğud); il termine ğawd, che indica la pioggia abbondante, è un anagramma di wağada [esistere], come ğadaba e ğabada 
il liberale $(s a h \hat{\imath})$ è colui che dà nella misura del bisogno e non di più, l'abnegato ( $m u$ 'attir) è colui che dà ciò di cui lui ha bisogno nel momento o di cui si immagina di avere bisogno, il munificente (wāhib) è colui che dà per fare un favore, e colui che ricambia $(m u g ̆ a \bar{z} z \vec{\imath})$ è colui che dà per ringraziare $\left({ }^{625}\right)$. E poiché questa persona sta cercando [di realizzare] la sua faccenda egli ha chiesto che si rivolgesse al volto generoso del Vero e non ad altro, in conformità a ciò che gli conferisce il suo stato al momento.

Poi ti ha ingiunto di sperare da Lui ciò per cui sarai elevato in rango sopra ai figli del tuo genere, per differenziarti dal tuo simile per ciò con cui lo sovrasti, e qui c'è una faccenda che è necessario che noi chiariamo, e cioè che la fede comporta che tu desideri per il tuo fratello ciò che desideri per te stesso ${ }^{(626)}$; ora, se hai chiesto ciò per cui sarai più elevato del tuo fratello hai desiderato per te stesso ciò che non hai desiderato per il tuo fratello: questo intacca la tua fede o no?

Sappi che l'uomo o chiede una cosa simile per noncuranza o la chiede con consapevolezza: se è per noncuranza ciò non intacca la sua fede, poiché come egli dice "Perdona me ed i musulmani”, generalizzando, così chiede che il Vero lo elevi in grado così come eleva i Suoi servitori pii, e come ha chiesto di essere elevato su altri che lui così ha chiesto che altri fossero elevati su di lui. Se invece è con consapevolezza, il capo dei credenti, che è Muhammad, che Allah faccia scendere su di lui la Sua salāt e la Pace, ci ha richiesto di chiedere per lui ad Allah, quanto è Potente e Magnificente, che gli dia la Wasīla $\left({ }^{627}\right)$, che è una dimora nel Paradiso a cui non arriva se non una sola persona. Egli, su

[che significano entrambi attirare], e le lettere che compongono queste due parole hanno lo stesso significato anche se combinate in modo diverso. Alla magnanimità da parte del Vero verso le entità (afyan), che sono i supporti di manifestazione (mažăhir), è connessa la Sua manifestazione in esse, ed alla magnanimità da parte dei supporti di manifestazione verso Colui che Si manifesta è connesso ciò che essi elargiscono a Lui, per le loro predisposizioni essenziali, della lode con i Nomi Divini che essi Gli riconoscono. La magnanimità da parte del Vero è di benevolenza (imtinān) essenziale, mentre la magnanimità da parte delle entità è solo essenziale, non di benevolenza. Questa è la differenza tra le due magnanimità e questo è il senso della affermazione di coloro che dicono che la magnanimità consiste nel dare prima della richiesta".

625) Per tradurre questi sei termini arabi che indicano aspetti diversi del dare ho dovuto usare un po' arbitrariamente dei termini italiani che non corrispondono esattamente al significato di quelli arabi, poiché altrimenti avrei dovuto ricorrere a delle perifrasi, essendo la lingua italiana priva di singole parole equivalenti. Ai vari aspetti del dare è dedicato il Cap. 95 delle Futūhăt, e l'argomento è stato inoltre già affrontato alle pagine 86 e 87 del manoscritto.

626) Riferimento ad uno hadīt riportato da al-Buhārī, II-7, Muslim, I-71 e 72, at-Tirmid̄ī, XXXV-59, anNasā̄̄in, XLVII-19 e 33, Ibn Māğah, Introduzione-9, ad-Dārimī, XIX-5, e da Ibn Ḥanbal, I-89 e III-176. Ibn 'Arabī lo cita nei capitoli 150 [II 245.24], 178 [II 352.11] e 558 [IV 256.26].

627) Il termine wasila, che deriva da una radice verbale che significa cercare l'intimità o il favore di qualcuno, ricorre due volte nel Corano, V-35 e XVII-57, ed in entrambi al credente è ingiunto di cercarla. Nelle Futūhāt questo termine ricorre una ventina di volte ed è sempre utilizzato per indicare il nome di una dimora o grado paradisiaco, alla guisa di Eden o di Firdaws, per cui ho preferito non tradurlo. Nel Cap. 65 [I 319.13] Ibn 'Arabī precisa: "Quanto alla Wasila essa è il gradino più elevato del Paradiso dell'Eden, ed appartiene all'Inviato di Allah, che Allah faccia scendere su di lui la Sua salāt e la Pace. Egli la otterrà per la preghiera della sua comunità. Il Vero, Gloria a Lui, ha fatto ciò per una saggezza che ha tenuto celata. [...] Il Profeta, che Allah faccia scendere su di lui la Sua salāt e la Pace, ci ha ordinato, per ordine di Allah, di chiedere per lui la Wasîla 
di lui la pace, ha detto: "Spero di essere io" $\left({ }^{628}\right)$, e quindi ha chiesto ciò che lo eleverà in grado sopra tutte le creature, poiché sa che quella dimora non è ottenuta se non da uno, e se era consapevole in una cosa simile ha chiesto ciò che lo eleverà sopra gli altri. Ora, Allah, sia Egli esaltato, ha detto: "Certo nell'Inviato di Allah avete un bell'esempio" (Cor. XXXIII-21) ed ha detto, sia Egli esaltato: "Seguitemi dunque, Allah [191] vi amerà" (Cor. III-31), e questo fa parte di ciò in cui lo segui. Questa è una prima consapevolezza; la seconda consapevolezza è quando nella tua richiesta di questo genere il Vero, sia Egli esaltato, è la tua lingua con cui tu Gli chiedi, ed allora è Lui che chiede per mezzo della tua lingua, non tu.

Egli, nei Suoi Nomi, è secondo gradi simili, vicini, opposti e diversi, e poiché è per mezzo di questi regimi che la Ipseità divina Si è manifestata, a maggior ragione ciò vale per l'uomo, intendo dire questi rapporti gerarchici (mufădalāt). Dove sta Colui che perdona molto (gafür) rispetto a Colui che perdona ( $g \bar{a} f(r)$, rispetto a Colui che Si vendica (muntaqim), rispetto a Colui che crea (hallāq), rispetto all'Indulgente ('af $\bar{u})$, rispetto a Colui che è pronto a perdonare $(g a f f a \bar{r})$ ? Colui che perdona molto e

affinché egli entri in essa e la ottenga per la preghiera della sua comunità. Comprendi questa grazia immensa. Ciò fa parte del capitolo della gelosia divina, se tu capisci. [...] Tra questi gradi ve ne sono solo dodici che sono propri a questa comunità muhammadiana ad esclusione delle altre comunità, che non li condivideranno. Analogamente egli, che Allah faccia scendere su di lui la Sua șalāt e la Pace, sarà superiore agli altri Inviati nell'aldilà per la Wasila e per l'apertura della porta dell'intercessione, ed in questo mondo per sei cose che non furono concesse ad alcun Profeta prima di lui", e nel Cap. 73, questione XCIII [II 97.21] aggiunge: "La Wasĩla [...] è un grado nel Paradiso a cui non arriverà - o che non si addice se non a - un solo uomo. Egli, che Allah faccia scendere su di lui la Sua șalāt e la Pace, ha detto: "Spero di essere io, e chi chiederà per me la Wasīla avrà garantita l'intercessione". Se uno di noi chiedesse al suo Signore la Wasīla per se stesso non chiederebbe qualcosa a cui non ha diritto, poiché [l'espressione "un solo uomo"] potrebbe anche significare che non vi arriverà se non una persona che ha una specifica qualificazione. D'altra parte Allah ci ha detto: "Cercate la wasilla verso di Lui" (Cor. V-35), sennonché non ha detto "da Lui", e quindi è possibile che l'espressione wasīla si riferisca alla "ricerca di vicinanza o aiuto (tawassul)". Quella qualificazione o è ricevuta in dono o è acquisita e l'Inviato di Allah, che Allah faccia scendere su di lui la Sua salāt e la Pace, non l'ha specificata come non ha interdetto [la Wasīla] a qualcuno in particolare, né ha detto che essa si addice solo a chi è più eccellente presso Allah tra gli uomini - e noi sappiamo che egli è l'uomo più eccellente presso Allah per le sue testuali parole - e questa sarebbe una interdizione [per chi non ha quel rango]. E non ha neanche precisato, riguardo all'unicità di quella persona, se si tratta di un singolo individuo o di chi ha quella qualificazione, e se l'unicità riguardasse quella qualificazione ed essa fosse presente in mille persone, ciascuno di questi mille potrebbe accedere alla Wasīla, poiché tale qualificazione esige ciò. E poiché nulla di tutto ciò è venuto dal Legislatore ci è permesso di cercarla per noi stessi, ma ci trattiene da questo l'abnegazione [cioè il preferire il Profeta a noi stessi] e le buone maniere con Allah riguardo all'Inviato di Allah, che Allah faccia scendere su di lui la Sua șalät e la Pace, che ci ha guidato con la sua guida ed ha chiesto a noi di chiedere per lui ad Allah la Wasīla.

628) Riferimento al seguente hadīt riportato da Muslim, IV-11, Abū Dāwud, II-36, at-Tirmid̄ī, XLI-1, anNasā̄ì, VII-37, e da Ibn Ḥanbal, II-168 e III-83: “'Abd Allāh ibn 'Amr ibn al-'Ās ha riferito che l'Inviato di Allah, che Allah faccia scendere su di lui la Sua salāt e la Pace, ha detto: "Quando senti colui che fa l'appello (mu’addin) ripeti quello che dice, poi fai la șalāt su di me, poiché chiunque farà una șalāt su di me, Allah farà dieci salāt su di lui. Poi chiedi per me ad Allah la Wasīla, che è un grado nel Paradiso a cui potrà avere accesso solo uno dei servitori di Allah, ed io spero di essere quel servitore. Se qualcuno chiede che mi venga concessa la Wasīla avrà garantita la mia intercessione". 
Colui che è pronto a perdonare sono simili, ed essi sono vicini a Colui che perdona ed all'Indulgente, mentre sono opposti a Colui che Si vendica e diversi da Colui che crea ${ }^{629}$ ), e se la faccenda è come abbiamo menzionato allora l'uomo deve chiedere riguardo a ciò che è specifico e riguardo a ciò che è generale, e sono gli stati a determinare, poiché colui che chiede è sotto il regime dello stato, lo stato è sotto il regime del Nome divino ed il Nome divino è determinato dal ricettacolo, e la ricettività è data dalla predisposizione e la predisposizione esige per se stessa e colui che è predisposto chiede per essa, cioè per la predisposizione.

Se la faccenda non fosse così $\left({ }^{630}\right)$ sarebbe un circolo (dawr) $\left({ }^{631}\right)$, e se fosse un circolo avrebbe luogo l'arresto e non si manifesterebbe l'essere contingente, ma esso si manifesta e quindi non c'è circolo, e c'è un circolo per un altro aspetto, di cui non c'è bisogno [di parlare] $\left({ }^{632}\right)$.

Nel dare divino non c'è impedimento poiché esso è una effusione essenziale: non biasimare quindi se non te stesso e non lodare se non Allah, poiché l'impedimento dipende da te ed il dare da Lui. Per questo ti ho ordinato di biasimare te stesso e di lodare Allah: approfondisci questa sottigliezza, poiché molti tra coloro che sono ricollegati (muntaminn) ad Allah, quanto è Potente e Magnificente, non distinguono tra la lode ed il biasimo e li considerano uguali in relazione all'origine (așl), come Ibrāhīm

629) Nella Introduzione [I 33.33] Ibn 'Arabī afferma: "Quanto alle realtà essenziali degli Attributi, esse corrispondono ad ogni luogo di contemplazione in cui ti pone il Vero, da cui riesci a prendere conoscenza che Egli, Gloria Lui, è Sapiente, Potente, Volente, Vivente e [Possessore] di altri Nomi ed Attributi, diversi, opposti o simili"; nel Cap. 173 [II 292.23] aggiunge: "Anche se queste relazioni (nisab) sono molteplici, Colui che è nominato è Unico e Colui a cui sono attribuite queste relazioni è Unico, e la molteplicità in questo Unico non è concepibile se non in questo modo. Ogni Nome dunque si associa (šăaka) agli altri Nomi divini nell'indicare l'Essenza di Colui che è nominato, e questi Nomi non appartengono ad altri che a Colui che è denominato da essi. I Nomi divini sono per un aspetto sinonimi (mutarādifa), per un altro distinti (mutabāyina) e per un altro simili (muštabiha). I sinonimi sono ad esempio i Nomi al-'ālim, al-'́allām ed al-'alīm, e al-'azîm, al-ğabbār ed al-kabīr; i simili

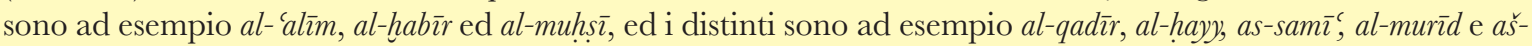
šakūr"; ed analogamente nel Cap. 466 [IV 95.4] afferma: "Le suddivisioni del Mondo e le sue parti sono simili, diverse ed opposte come i Nomi divini: al-'álim, al-'allām ed al-'alìm sono simili, ma Egli è anche Colui che reca danno $(d \bar{a} r r)$ e Colui che è benefico (năfi $)$ e questi sono [Nomi] opposti, ed Egli è il Potente ed il Saggio e questi sono [Nomi] diversi".

630) Cioè se non ci fosse la molteplicità delle predisposizioni, e quindi delle possibilità, non ci sarebbe la differenziazione dei Nomi divini e l'Ipseità non Si manifesterebbe per mezzo dei diversi regimi.

631) Cioè Allah Si manifesterebbe a Se stesso in Se stesso.

632) In effetti l'affermazione che la faccenda, o la realtà, è un circolo (al-amr dawr) ricorre più di una volta nelle Futūhāt: capitoli: 281 [II 614.34], 367 [III 352.12], 558 [IV 280.20], 559 [IV 329.25 e 405.7] e 560 [IV 470.25] ove Ibn 'Arabī afferma: "Sorveglia il tuo stato nel tempo che intercorre tra due salät. Ora, tu sei sempre tra due salât, poiché la faccenda è un circolo: il tempo che intercorre tra il mezzogiorno (zuhr) ed il pomeriggio ('asr) è un tempo tra due salāt, e così pure tra il pomeriggio ed il tramonto, e tra il tramonto e il cadere della notte ( $i s \bar{a}^{\prime}$ ") e tra il cadere della notte ed il mattino (subh) e tra il mattino ed il mezzogiorno, ed il circolo (dawr) ruota". Nel caso precedente si tratta di un circolo statico, come dimostra il riferimento all'arresto, mentre in questo caso si tratta di un circolo dinamico. 
ibn Adham $\left.{ }^{633}\right)$ ed altri, ma la faccenda non è così in realtà. Al dare del Vero non c'è impedimento e quindi il favore viene da Lui e l'impedimento da colui che riceve, e chi non [192] è predisposto a ricevere una determinata cosa, che egli desidera e cerca, dice: "Il Vero non mi dà ciò che ho chiesto", mentendo, poiché se fosse equo ciò che dovrebbe dire è: "Non sono nella predisposizione che implica per me il ricevere ciò che Gli ho chiesto". Per questo egli deve biasimare se stesso e lodare Allah, sia Egli esaltato, e non ricondurre queste due cose ad un'unica entità, poiché sarebbe privato del senno (sawāb) così come è stato privato del dare, ed avrebbe due perdite, e "quella è la perdita evidente" (Cor. XXII-11) e "non siamo Noi ad essere ingiusti con loro, ma sono loro ad essere ingiusti" (Cor. XLIII-76).

Poi ha detto: "Sappi che i Maestri, quando trapassano dal mondo di quaggiù, non lasciano i loro ragazzi (gilmān) ed i loro compagni, ma il loro sguardo (nazar) resta immutato: quando l'aspirante lo cerca lo trova immediatamente e sollecitamente". Egli, Allah abbia Misericordia di lui, vuol dire che quando i Maestri muoiono lasciano la loro aspirazione (himma) in connessione con i cuori di chi fa assegnamento su di loro, così come lasciano nella loro zāwiya, che essi hanno abitato, degli spiriti, derivanti dalle loro invocazioni e dai loro riti, che abitano quel luogo. Per questo chiunque entri nel luogo di un grande uomo nella tradizione che sia morto, prova entrando nella sua dimora compunzione, arrendevolezza e ritorno ad Allah, quanto è Potente e Magnificente, cose che non prova in un posto diverso. Se qualcuno entrava nella zāwiya di Abū Yazīd, dopo la sua morte, e faceva in essa qualcosa che era in disaccordo con ciò che comportava lo stato di Abū Yazìd, la sua veste veniva bruciata senza che vi fosse alcun fuoco nel posto, e costui diventava per loro [i Maestri] uno che era stato messo alla prova a Bistām $\left.{ }^{634}\right)$. Noi stessi abbiamo visto cose simili nei luoghi dei pii, poiché essi non sono morti e non sono spirati senza che la loro aspirazione restasse legata in modo generale al bene delle creature, ed in modo specifico ai loro discepoli ed ai loro compagni. [193]

Ti è stato già detto che l'aspirante ha nel suo cuore una immagine (mitāal) del suo Maestro, che è chiamata il Maestro immaginato, che è inseparabile da lui e che resta perennemente con lui. Che il Maestro sia trasferito nell'aldilà o che non sia trasferito, quel Maestro che sussiste nella sua immaginazione non cessa e non muore, e per questo ha detto: "il loro sguardo resta".

Quanto al suo detto: "quando l'aspirante lo cerca egli viene da lui immediatamente e sollecitamente", e come potrebbe essere altrimenti, dato che egli è più vicino a lui di lui stesso? Egli è identico a quell'immagine, che è indispensabile, e ciò è simile al suo detto, che Allah faccia scendere su di lui la Sua șalāt e la Pace, riguardo al Vero: "Adora Allah come se Lo vedessi, poiché anche se tu non Lo vedi Egli comunque vede te" $\left({ }^{635}\right)$ introducendoLo nella Presenza dell'immaginazione (hayāl) con il suo

633) Non ho trovato riferimenti a questa affermazione nelle Futūhāt.

634) Non ho trovato traccia di questo aneddoto né nelle altre opere note di Ibn 'Arabī, né in quelle di altri Maestri a lui anteriori.

635) Hadīt riportato da da al-Buhārī, II-37, Muslim, I-1, 5 e 7, Abū Dāwud, XXXIX-16, at-Tirmidīî, 
detto: "come se Lo vedessi", in cui ha usato il "come" della comparabilità (tašbīh) $\left.{ }^{636}\right)$. In altre parole immagina di star di fronte a Lui nel tuo atto di adorazione a Lui, come se Lo stessi guardando, cioè rappresentaLo davanti ai tuoi occhi, poiché la vista ('ayn) della tua immagine di Lui è la vista di Lui.

E per l'intento [dell'aspirante] egli viene "immediatamente e sollecitamente", poiché Allah, sia Egli esaltato, ha detto riguardo a quello: "Chi si avvicina a Me di una spanna, Io mi avvicino a lui di un braccio" ( ${ }^{637}$ ), cioè il Mio avvicinamento a lui è due volte più veloce del suo avvicinamento, finché ha detto: "e se viene da Me correndo Io vengo da lui a passo spedito"; questa è la quota della corsa e che dire di chi si affretta verso le cose buone? Il Vero sarà ancora più veloce di loro per quello che essi chiedono a Lui. I Maestri sono i rappresentanti di Allah ed i Suoi Califfi, ed è inevitabile che essi si manifestino alle creature per mezzo delle relazioni che ha il Vero e che Gli sono attribuite, e degli Attributi o dei Nomi; dì quello che preferisci di questi, ed i Nomi costituiscono la denominazione più corretta rispetto alle altre, poiché Allah, sia Egli esaltato, non ci ha specificato se non i Nomi, senza accennare all'espressione "gli Attributi", né "le relazioni (nisab)", espressioni che hanno introdotto i sapienti $\left.{ }^{638}\right)$. Non è opportuno, nell' adab, applicare al Vero se non le espressioni che Egli ha applicato

XXXVIII-4, an-Nasā̄̄ì, XLVI-5 e 6, Ibn Māğah, Introduzione-9, e da Ibn Hanbal, I-27, 51, 52 ecc. Si tratta della risposta del Profeta data a Gabriele che lo interrogava sull'Ihsān. Ibn 'Arabī lo cita una cinquantina di volte nelle Futūhāt.

636) Nel Cap. 36 [I 223.13] Ibn 'Arabī, dopo aver precisato che nella tradizione cristiana il culto delle immagini sensibili si fonda sulla apparizione in modo sensibile di Gabriele a Maria, afferma: "Quando venne la Legge di Muḥammad, che Allah faccia scendere su di lui la Sua salāt e la Pace, essa vietò le raffigurazioni sensibili, ma poiché egli, che Allah faccia scendere su di lui la Sua salāt e la Pace, abbracciava la realtà essenziale di Gesù e la Legge di questi era inclusa nella sua, ci ha prescritto di adorare Allah come se Lo vedessimo, introducendoLo così per noi nella immaginazione". Inoltre, nel Cap. 63 [I 304.14] precisa: "Il potere dell'immaginazione (sultān al-hayāl) è identico a "come se" e questo è il senso del detto dell'Inviato, che Allah faccia scendere su di lui la Sua salāt e la Pace: "Adora Allah come se lo vedessi!"”, e poco dopo aggiunge [I 306.7]: "Riguardo a questa Presenza [dell'immaginazione] il Profeta, che Allah faccia scendere su di lui la Sua salät e la Pace, ha detto: "Adora Allah come se lo vedessi" e "Allah è nella qibla di colui che fa la șalät". Cioè, immaginaLo nella tua qibla ed immagina di essere di fronte a Lui, in modo da prestare attenzione a Lui, avere vergogna di fronte a Lui ed osservare l'adab con Lui nella tua salät. Se non fai ciò non avrai rispettato l'adab. Se il Legislatore non avesse saputo che tu hai una realtà chiamata "immaginazione", che ha questa proprietà, non ti avrebbe detto: "come se tu Lo vedessi" [riferendosi alla] la tua vista sensibile. In effetti la dimostrazione razionale rifiuta il "come se", poiché dichiara, con i suoi argomenti, che la comparabilità è impossibile. Quanto alla vista, essa non percepisce che il muro. Comprendiamo così che il Legislatore si è rivolto a te affinché tu ti immagini di essere di fronte ad Allah nella tua qibla, verso la quale la Legge ti prescrive di rivolgerti. Nello stesso tempo Allah dice: "Ovunque vi volgiate, là è il volto di Allah" (Cor. II-115). Il volto (wağh) di una cosa è la sua realtà e la sua essenza: quindi l'immaginazione ha dato forma a ciò che, secondo la dimostrazione razionale, non può avere una forma o assumere delle forme".

637) Hadīt già citato a pag. 122 del manoscritto.

638) Nel Cap. 360 [III 289.4] Ibn 'Arabī precisa: "Riguardo alle realtà divine (al-ilähiyyāt) esse sono espresse nella lingua della Legge dai Nomi, negli intelletti sani (al- uqül as-salìma) dalle relazioni (nisab) e negli intelletti che hanno una prospettiva ristretta dagli Attributi", e nel Cap. 558 [IV 294.11] aggiunge: "Ciò che noi affermiamo sono le relazioni stesse, che la Legge esprime con i Nomi: non c'è Nome che non abbia un significato che non 
[194] a Se stesso, questa è la verità, anche se sappiamo che Egli è identico ad ogni cosa, come sappiamo che è conforme ad ogni cosa, come è già stato detto in precedenza.

Poi ha detto: "e se Allah ti assiste e sopporti ciò che ti arriva nella Via, sarai innalzato da questo mondo ('ālam) e sarai fatto arrivare al mondo dell'aldilà"; ciò che ha menzionato quest'uomo non è da prendere in senso letterale, se lo ha detto con conoscenza di causa e verità, e se ne ha parlato senza saperne il significato, ed egli conosce meglio se stesso, dobbiamo spiegare la forma del Vero in quello. L’uomo che percorre la via non sopporta le cose difficili che gli arrivano nel suo percorso se non è in un velo umano, ed Allah non gli parla se non dietro il velo dell'umanità, come Egli ha detto ${ }^{639}$ ). In realtà Allah è l'insieme delle sue facoltà e delle sue membra, e se egli sopporta dal Suo Nome, sia Egli esaltato, "Colui che sopporta molto $(s a b \bar{u} r)$ ", allora ha realizzato il Suo detto, sia Egli esaltato: "e la tua pazienza non è se non per Allah" (Cor. XVI-127).

La pazienza non è altro che avere fermezza (habs an-nafs) $\left({ }^{640}\right)$ nello stato con cui Allah lo mette alla prova, ed il significato del suo detto: "sarai innalzato da questo mondo" è che Allah ti svelerà che tu non sei tu, poiché nello stato della tua pazienza tu dici: "Io sono io", mentre il Vero dietro a questo velo dice: "No, anzi Io sono Io, e tu non ascolti"; e se tu non abbandonerai la tua sede Allah ti toglierà il velo del tuo "io" (anāniyya) per il Suo "Io" ( $\left.{ }^{641}\right)$, e contemplerai ciò che non contemplavi e ti immaginerai di essere trasferito in un altro mondo, ma non sei stato trasferito: Egli ti ha solo tolto un velo e tu vedrai ciò che prima non vedevi.

appartiene all'altro e quel significato è riferito all'Essenza del Vero, ed è chiamato Attributo dai teologi (ahl alkalām) speculativi ed è chiamato relazione dai realizzati (muhaqqiqūn)".

639) Riferimento a Cor. XLII-51.

640) Il verbo sabara ha in arabo molti significati: come verbo transitivo ha il senso di legare, incatenare, mettere i ceppi; come verbo intransitivo ha il senso di essere paziente, perseverare; con la preposizione 'alā significa sopportare, mentre con la preposizione 'an astenersi, rinunciare. Il verbo habasa significa ostruire, confinare, imprigionare, trattenere (con la preposizione 'an), mentre l'espressione habasa nafsa-hu 'alā significa dedicarsi interamente (a qualcosa), esercitare fermezza. L'espressione as-șabr habs an-nafs ricorre sette volte nelle Futühāt, ma a seconda del testo che segue indica significati diversi: trattenersi dal cibo durante il digiuno [Cap. 47 (I 258.18)], trattenersi dal fuggire di fronte al nemico [Cap. 69 (I 474.11 e 543.16), conformemente a Cor. II45], la perseveranza nella șalāt [Cap. 69 (I 542.25), conformemente a Cor. XX-32], trattenere l'anima dal lagnarsi con altri che Allah e dal fare affidamento su quell'altro [Cap. 124 (II 206.27) e Cap. 398 (III 564.13)], e dedicarsi interamente alle opere prescritte dalla Legge [Cap. 398 (III 564.13)].

641) Nel Cap. 362 [III 305.34] ] Ibn 'Arabī afferma "È stato riportato di uno dei conoscitori, ed io l'ho visto attribuire ad Abū Yazìd al-Bisțāmī, che in uno dei suoi gradi di contemplazione del Vero, in uno dei suoi stati spirituali, egli ha detto: "Il mio io è il Tuo Io"”, e nel Cap. 503 [IV 141.10] aggiunge: "Egli ci ha chiesto di dedicare solo a "Lui" [(la-hu), riferimento a Cor. XCVIII-5] il nostro atto di adorazione [o: rituale], poiché per mezzo di esso noi siamo servitori e non siamo servitori se non per la Sua Ipseità, quindi dedichiamo la servitù a Lui e ciò si effettua dicendo a Lui: "Tu sei Lui per il Tuo Io e Tu sei Lui nel mio io: non ci sei altro che Tu, e Tu sei denominato Signore e servitore"”." 
Questo Maestro ha espresso ciò con "un altro mondo", in quanto il Vero ha preso [195] il Mondo come Suo supporto di manifestazione, e la Teofania nei confronti di questo servitore è di varie specie, e quindi egli vede una forma che prima non vedeva, ed [il Maestro] ha espresso ciò con la trasmutazione nell'altra forma nel mondo dell'aldilà, malgrado avvenga nella sede di questo basso mondo.

Il Vero è governato dalle forme in cui Egli Si manifesta e ciò che è strettamente legato ad esse rende necessari gli Attributi estrinseci ed i Nomi $\left({ }^{642}\right)$. Se dici di essere stato trasferito, dici il vero perché questa forma non è quella forma, analogamente alla diversità degli stati per una stessa persona: colui che sta in piedi non è colui che è seduto, poiché lo stare in piedi non è lo stare seduti, e Zayd che sta in piedi non è Zayd che sta seduto, e per un aspetto l'entità è unica e per un altro aspetto non è unica; ed il Vero, anche se è Lui che Si manifesta nella prima forma, è identico a Sé nell'altra forma, ma una forma non è l'altra.

Questo Maestro ti ha ordinato nella sua raccomandazione la pazienza, che è l'avere fermezza in ciò che ti arriva affinché tu veda ciò che si dischiude a te in quello; se non hai pazienza sarai escluso dal beneficio della scienza di ciò che abbiamo menzionato e cadrai nell'ignoranza, da cui non c'è via d'uscita.

Poi ti ha raccomandato che: "il tuo Maestro non si assenti dal tuo proposito (hātirir)", cioè non trascurare la fine realtà (raqĩqa) che collega l'immagine del Maestro che è presso di te ed il Maestro stesso, sia egli vivente o morto: "Non siate come coloro che dimenticano Allah, ed Egli fa loro dimenticare loro stessi” (Cor. LIX-19) ${ }^{643}$ ), poiché chi dimentica Allah dimentica se stesso, avendo Allah notificato che Egli è le facoltà e le membra del servitore, e quindi chi dimentica Allah dimentica se stesso, cioè [ha notificato] che Allah, sia Egli esaltato, ha fatto loro dimenticare loro stessi nel loro dimenticare Allah, sia Egli esaltato. Quanto è sorprendente il discorso di Allah a colui che Egli ha predisposto e preferito.

642) L'affermazione che il governo, o il regime, sul Vero appartiene alle forme è apparentemente in contraddizione con il versetto 88 della Sura XXVIII, ove si legge: "Ogni cosa è peritura, salvo il Suo volto. A Lui appartiene il regime (la-hu l-hukm)", ma per Ibn 'Arabī il pronome "suo" nell'espressione "il suo volto" può riferirsi sia al Vero che alla cosa, e nel secondo caso anche il pronome "lui" si riferisce alla cosa e non al Vero. Ad esempio, nel Cap. 356 [III 255.22] egli afferma: "“"Ogni cosa è peritura" (Cor. XXVIII-88) per la forma, a causa delle trasmutazioni, "salvo il suo volto" (Cor. ibidem), ove il pronome "suo" si riferisce alla cosa e quindi la cosa è peritura quanto alla sua forma ed imperitura quanto al suo volto ed alla sua realtà essenziale, che non è altro che l'esistenza del Vero tramite la quale essa si è manifestata a se stessa. "Ad essa appartiene il regime" (Cor. ibidem), cioè il regime nel volto appartiene a quella cosa ed i regimi sono diversi per la diversità delle forme, "e ad essa sarete fatti ritornare" (Cor. ibidem), in quel regime, cioè a quella cosa sarà fatto ritornare il regime con cui essa ha governato il volto". Va precisato che il Vero che è governato dalle forme non è il Principio nella Sua Essenza, che è al di là di ogni distinzione, ma il Principio in quanto Dio e quindi in relazione al Mondo.

643) Ibn ‘Arabī commenta estesamente questo versetto nel Cap. 392 [III 552.23 a 553.12]. 
Quanto al suo detto: "poiché tu dipendi dal suo dare [a te] l'esistenza in questo mondo", egli dice che è lui che ti ha fatto nascere in questa forma [196] in cui tu sei, poiché è lui che ti ha spiegato cosa sei ed ha richiamato la tua attenzione su te stesso, in quanto eri noncurante di te. Per questo ha attribuito al Maestro il dare l'esistenza, affinché tu gli sia riconoscente per quello, ed Allah ti aggiunga da parte Sua un bene. Questa è la paternità dello stato spirituale, come nel genitore terreno vi è la paternità dei lombi; Allah ti ha ordinato di essere riconoscente ad Allah ed ai tuoi genitori $\left.{ }^{644}\right)$, e non ha distinto il genitore della tradizione $(d \bar{\imath} n)$ dal genitore dell'argilla $(t \bar{\imath} n)$, quindi sii riconoscente ad entrambi i tuoi genitori, poiché essi sono coloro che ti hanno dato l'esistenza. Il genitore dell'argilla ti ha dato l'esistenza nel mondo di quaggiù, ed il genitore della tradizione ti ha fatto conoscere e ti ha fatto vedere l'esistenza del Vero in te, ed è come se egli ti avesse dato l'esistenza come Vero, mentre da te stesso eri creatura. Osserva quanto è perfetta, completa e bella questa paternità del Maestro, e che la tua gratitudine verso il tuo Maestro sia più completa della tua gratitudine verso il tuo genitore usuale, poiché il tuo genitore usuale non si proponeva di darti l'esistenza ma è risultato [genitore] per il soddisfacimento della sua passione, e tu sei venuto come conseguenza, mentre la generazione del Maestro nei confronti dell'aspirante è voluta da lui, necessariamente, ed essa non è una conseguenza, né un caso, ma è in virtù del Maestro, ed il suo diritto è maggiore del diritto del genitore.

Per questo il diritto dell'Inviato su di noi è più grande del diritto dei due genitori, e la paternità della tradizione è più grande e più completa.

Poi ha detto nella sua raccomandazione: "Ricordati i tuoi stati da quando sei stato creato e ciò che è sortito da te, e considera ciò con cui Allah ti ha favorito, e magnifica quello nel tuo cuore". Egli ti raccomanda che ciò che si presenta (wārid) nel tuo istante sia il ricordo di ciò che è passato dei tuoi stati e dei loro cambiamenti, poiché tu sai che con quel ricordo riparerai ciò che si è rotto in ciò che è passato del tuo stato $\left({ }^{645}\right)$, e di considerare con la dovuta trasposizione (i $i$ i b $\bar{a} r$ ) come sei stato creato e

644) Riferimento a Cor. XXXI-14.

645) A pag. 88 del manoscritto Ibn 'Arabī ha precisato che la tristezza suscitata dal ricordo delle proprie mancanze equivale alla loro riparazione. Analogamente, nel Cap. 74 [II 140.19] precisa: "Il secondo pilastro del pentimento è il rimorso (nadam) per ciò che è passato, e per i dottori della legge esso è il pilastro principale, alla stessa maniera in cui il Profeta, che Allah faccia scendere su di lui la Sua șalät e la Pace, ha detto: "Il pellegrinaggio è 'Arafa", in quanto esso è il pilastro principale del pellegrinaggio. A questo proposito, riguardo ai penitenti, i discorsi sono molto differenti. La "mìm" di "nadam" (rimorso) è una mutazione della " $b \bar{a}$ ", come nelle parole "lāzim" e "lāzib" [che hanno lo stesso significato = necessario]; il rimorso, che si chiama "nadam" [traccia, segno], è la traccia (atar = segno) della sua tristezza (huzn) per ciò che è passato; il "rimpianto" (nadab = cicatrice) è la "cicatrice" (utrr) e la sua "bâ" è stata cambiata in "mīm" [nadab -> nadam] per indicare in modo particolare il segno [o la cicatrice] della tristezza. Quanto alla connessione del rimorso con le cose passate $(f a w \bar{a} t)$, tra i nostri compagni c'è chi ritiene che ciò sia un perdere l'istante $(w a q t)$, poiché ciò che è passato non ritorna. Altri, tra i nostri compagni, ritengono invece che ciò sia possedere l'istante e che ciò serva a riparare per lui ciò che è passato, appoggiandosi al Suo detto: "salvo coloro che si pentono, che credono e che agiscono bene: a costoro Allah tramuta le loro azioni malvagie in opere buone" (Cor. XXV-70)", e nel Cap. 259 [II 588.1] aggiunge: "Quando ciò che arriva (wärid) si presenta al cuore improvvisamente e gli apporta il dispiacere di aver mancato l'istante, esso è un avvertimento per chi ha trascurato il regime del suo istante su di lui e non 
ciò che è sortito da te, rimettendolo a posto; ed il significato della trasposizione [197] è che tu passi per mezzo della tua considerazione di questo a chi è Lui, finché Lo conosci, ed Egli non è che il Vero, non altro, poiché non c'è altro.

Ed il suo detto: "da quando sei stato creato", cioè da quando sei stato manifestato a te, poiché sei tu l'entità della forma in cui Egli Si è manifestato, e quindi sappi ciò che tu sei e ciò da cui sei governato (mahküm), in modo da sapere come stanno realmente le cose e venga a cessare per te l'incertezza (labs) che c'è agli occhi degli altri: da te non è sortito se non ciò che ti appartiene, e quindi non attribuire al Vero ciò che non Gli appartiene, poiché saresti tra gli ignoranti. Questa è una percezione difficile che esige molto $a d a b$, e sono rari coloro che hanno l'adab in ciò, poiché è un luogo in cui è facile fare passi falsi, e per questo l'autore della raccomandazione ha precisato, che lo sapesse o non lo sapesse, dicendo: "e considera ciò con cui Allah ti ha favorito, e magnificalo nel tuo cuore".

Ciò fa parte degli atti di culto di Allah e delle Sue cose sacre, ed egli [il Maestro] ti tiene occupato con la considerazione dei favori di Allah affinché tu non inciampi sulla realtà della faccenda e tralasci l'adab attribuendo ad Allah ciò che appartiene a te di quanto non è gradito né lodato. Egli ti ha dato questo rimedio a causa di questa malattia ed infermità, poiché ciò è esiziale e chi lo fa ha una malattia cronica. Ogni gruppo, eccetto questo gruppo che è lodato, sono tutti malati cronici a cui non giova nessun rimedio; questo gruppo ha un'integrità la cui complessione non ammette la malattia, mentre quella malattia cronica che affligge gli altri non trae giovamento da alcun rimedio.

Poi, dopo la sua conferma con parole che richiederebbero un lungo approfondimento, ha detto: "Stai attaccato alla porta con adab e non trasgredire mai alcuna delle regole di comportamento della Legge, poiché se infrangi una delle regole, tu o altri, la punizione è veloce; e stai attaccato all'anello (halqa) della porta, e pesa i tuoi movimenti con la bilancia della Legge". Egli ti dice, nella sua raccomandazione di stare attaccato alla porta ed al suo anello, [198] ciò che ha detto Allah, sia Egli esaltato: "Chi non crede nell'idolo prevaricatore $(t \overline{a g} \bar{u} t)$ ed ha fede in Allah si è attaccato al manico più saldo" (Cor. II-256) ed esso è l'anello della porta, che è la fede, mentre la porta è l'Islām ${ }^{(646)}$, e per mezzo della porta e del suo anello si realizza la felicità per il servitore. Egli ha specificato la fede in Allah e la miscredenza ( $k u f r)$ nell'idolo prevaricatore, poiché ha detto riguardo a della gente:

ha avuto $a d a b$ con ciò che gli è arrivato nel suo istante. Il Vero ha voluto avvertirlo per sollecitudine da parte Sua nei suoi confronti e gli ha inviato ciò che gli arriva come messaggero da parte di Allah, svelandogli che ha mancato il suo istante e che ha avuto un cattivo comportamento con Allah, ed egli prova rimorso per aver mancato l'istante e questo rimorso ristabilisce per lui il vantaggio che ha mancato nel suo istante, tanto che è come se non avesse mancato nulla. [...] questo è il vantaggio di ciò che colpisce improvvisamente (huğüm) e che ripara l'istante che ha mancato".

646) Nel capitolo dei segreti [559] Ibn 'Arabī dà un’altra spiegazione [IV 438.5]: "Il manico [della porta] ('urwa) è un cerchio in cui si suppongono due sezioni (qutrān) [cioè due semicerchi] separati da una linea immaginaria. Il manico più saldo sei tu e Lui quanto alle sue due sezioni. L'esistenza è spartita tra te e Lui, poiché è suddivisa tra Signore e servitore. Il Primordiale è il Signore ed il nuovo è il servitore e l'esistenza è ciò che ci riunisce. "Ho suddiviso la salāt in due metà tra Me ed il Mio servitore, sì che metà appartiene a Me e metà al Mio servitore"." 
"e coloro che hanno fede nel falso" (Cor. XXIX-52), chiamandoli credenti, come ha detto: "e non crede (yakfur) nell'idolo prevaricatore" (Cor. II-256), chiamandoli miscredenti, così come ha chiamato miscredente colui che non crede in Allah, e poiché ha luogo la condivisione nel nome ha specificato con un chiarimento per [evitare] l'insidia dell'espressione assoluta.

Sappi che le buone maniere $(\bar{a} d \bar{a} b)$ sono la somma del bene $\left.{ }^{(647}\right)$ e che la Legge è ciò che ha legiferato Allah e nella Legge vi è la somma del bene, poiché la via che porta a Lui non è conosciuta se non da Lui. Ad una creatura non è dato di giudicare ciò che avvicina ad Allah, se non i profumi dei caratteri nobili, poiché la forma divina comporta quello, e per questo inevitabilmente il credente che godrà del Paradiso coglierà i suoi frutti e così colui che resterà nel Fuoco infernale. La faccenda è come abbiamo detto e per questo egli ti ha ordinato le buone maniere [o: regole di comportamento] legali, affinché tu sia per mezzo di esse nella dimora chiamata Paradiso; quanto alla forma della pesatura tra il regime giuridico e le azioni di colui che è soggetto all'incombenza legale, la sua scienza dipende dalla scienza della Legge e la Legge è di due tipi. Una legge confermata che è in contrasto con una [altra] legge confermata, ed è ciò su cui vi è divergenza tra i giurisprudenti, ed una legge univoca, ed è ciò su cui essi concordano, e l'uomo accorto si premunisce e non smette mai di propendere verso

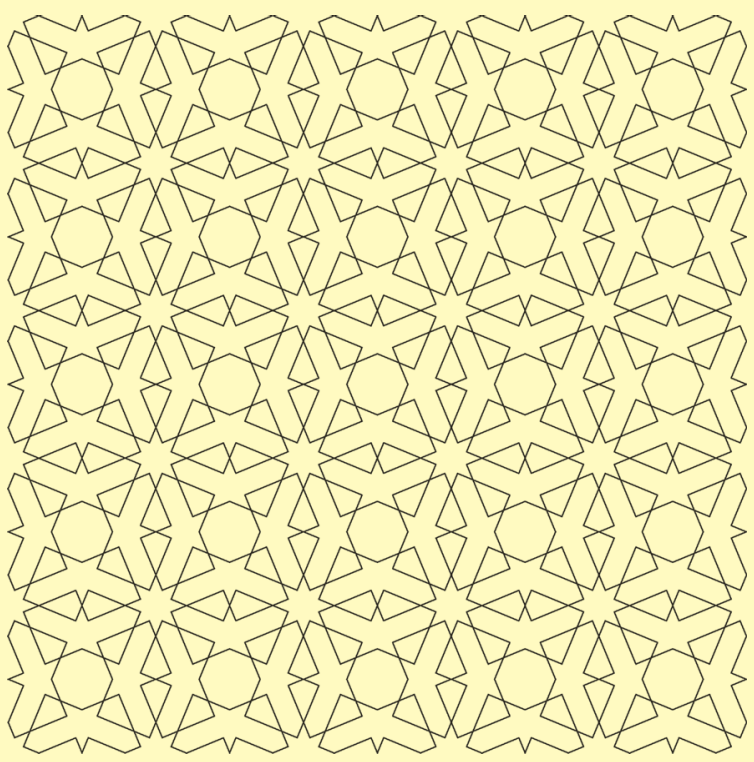

647) La stessa affermazione era già stata riportata a pag. 34 del manoscritto, ed essa ricorre anche nei capitoli 73, questione CLIV [II 138.2], 139 [II 226.15], 146 [II 233.26], 168 [II 284.29] ove Ibn 'Arabī afferma: "L'uomo di buone maniere $(a d \bar{\imath} b)$ è colui che assomma i tratti nobili di carattere e che conosce i tratti vili di carattere senza esserne caratterizzato. Egli assomma tutti i gradi delle scienze, sia quelle che sono lodate che quelle che sono biasimate, poiché agli occhi di una persona dotata di intelletto la scienza di una cosa è sempre meglio dell'ignoranza di essa. Quindi le buone maniere sono la somma del bene”, 288 [II 640.23], ove aggiunge: "La prima cosa che Allah ha ordinato al Suo servitore è la riunione (ğamc), che è l'adab, termine che deriva dal banchetto ( $m a^{\prime} d u b a$ ), cioè dal riunirsi per mangiare. Allo stesso modo il termine adab indica la somma di tutto il bene", e 559 [IV 365.33]. 
ciò su cui vi è il consenso $(i g ̆ m a \bar{a})\left({ }^{648}\right)$, come l'accorciamento nella șalāt per il viaggiatore $\left({ }^{649}\right)$, la rottura [del digiuno] per chi viaggia in Ramaḍān $\left({ }^{650}\right)$, l'ingresso alla Mecca, per chi non abbia una vittima da sacrificare (hady), per una visita ('umra) senza il pellegrinaggio ( $\left.{ }^{651}\right)$, l'astenersi dallo sposare la figlia

648) In senso stretto il "consenso", in quanto terzo fondamento della Legge, è il consenso dei Compagni dopo la morte del Profeta; nel Cap. 426 [IV 75.26] Ibn 'Arabī precisa: "I sapienti della Legge hanno fatto di essa ['analogia $(q i y \bar{a})$ ] un quarto fondamento [della Legge] così come hanno fatto del consenso un terzo fondamento, ed esso è il consenso della prima generazione. Essi dicono: loro non erano concordi su una faccenda a meno che non conoscessero necessariamente riguardo ad essa una affermazione esplicita a cui si rifacevano, che però non è giunta fino a noi, malgrado noi siamo certi della sua esistenza, poiché è impossibile che fossero d'accordo su un giudizio riguardo al quale non avessero una affermazione esplicita: la loro considerazione e la loro natura erano diverse ed era quindi inevitabile la divergenza e tuttavia erano concordi su una faccenda. Quindi è certo per noi che in quel giudizio essi si basassero su una affermazione esplicita dell'Inviato, che Allah faccia scendere su di lui la Sua șalāt e la Pace. E non c'è giudizio per consenso dopo il consenso della prima generazione", e nel Cap. 72 [I 726.32] aggiunge: "L'uso da parte dei dottori della Legge del termine consenso talvolta va al di là della sua definizione originaria per essere applicato ad altro: talvolta essi usano il termine consenso per indicare l'accordo di due scuole e talvolta per l'accordo delle quattro scuole, ma non si tratta del consenso che può essere preso come una indicazione, poiché il giudizio non si trova nel Libro né in una tradizione trasmessa da più fonti". Qui si tratta invece del consenso dei giurisprudenti, il cui giudizio, pur non equivalendo ad un fondamento della Legge, è comunque ratificato dal Legislatore per il caso specifico per cui è stato formulato, ma i cinque esempi di consenso che Ibn 'Arabī riporta nel seguito del manoscritto in realtà non sono tra quelli esenti da divergenze, come egli stesso afferma nelle Futühät Tutti i manoscritti che ho potuto consultare sono concordi sul testo, per cui o non ho capito ciò che vuole dire, oppure il testo è lacunoso.

649) Nel Cap. 69 [I 468.30] Ibn 'Arabī precisa: "Il viaggio ha come effetto l'accorciamento della șalāt, per giudizio concorde, ed il loro cumulo, con giudizi divergenti. Quanto all'accorciamento i sapienti della Legge sono concordi sulla permissibilità per chi viaggia di abbreviare la șalāt, ad eccezione di ' $\bar{A}$ '’šsa che sosteneva che l'accorciamento era permesso solo a chi aveva paura, per il Suo detto, quanto è Potente e Magnificente: "[Se voi viaggiate sulla Terra non c'è biasimo per voi se accorciate la vostra șalāt] se temete che i miscredenti vi possano attaccare" (Cor. IV-101)", ma poche righe dopo [I 469.11] afferma che per lui l'accorciamento della șalät per colui che viaggia è un obbligo (fard) .

650) Nel Cap. 71 [I 612.29] Ibn 'Arabī precisa: "Alcuni [dottori della Legge] sostengono che se essi [il malato ed il viaggiatore nel mese di Ramaḍān (riferimento a Cor. II-184 e 185)], digiunano, [il digiuno] è valido e sono autorizzati a farlo. Altri dicono che ciò non è ammesso per loro e che devono fare un numero di altri giorni [di digiuno compensatorio]. Io ritengo che se essi digiunano ciò non è lecito per loro e che devono digiunare per un altro numero di giorni; tuttavia distinguo tra il malato ed il viaggiatore, quando il digiuno viene fatto in queste condizioni nel mese di Ramaḍān. Per quanto riguarda il malato, il digiuno è supererogatorio per lui ed egli fa una opera pia che non è obbligatoria per lui: anche se egli la imponesse a se stesso, tuttavia non è obbligatoria per lui. Per quanto riguarda il viaggiatore, il suo digiuno mentre viaggia nel mese di Ramaḍān o in qualsiasi altro momento non è un'opera pia. Se non è un'opera pia, è come se non avesse fatto nulla - e questo è il caso più favorevole - oppure come chi fa l'opposto di una opera pia, ed il suo contrario è l'empietà, ma non è questo che sto dicendo. Io sto solo negando che egli sia impegnato in una opera pia nel compiere quell'atto in quella condizione. Ed Allah è più Sapiente".

651) Nel Cap. 72 [I 691.23] Ibn 'Arabī precisa: "La revoca (fash) consiste nel fatto che uno ha intenzione di fare il pellegrinaggio, ma non avendo una vittima da sacrificare tramuta la sua intenzione in quella di fare la visita ('umra), e compie la visita poi si desacralizza e quindi [quando ha trovato una vittima] intraprende il pellegrinaggio. Alcuni sostengono che ciò sia permesso, altri che sia obbligatorio ed altri ancora che non sia permesso: io sostengo che è obbligatorio", e nel Cap. 560 [IV 504.19] aggiunge: "Se hai intenzione di fare il pellegrinaggio ed hai una vittima da sacrificare entra in sacralizzazione (ihrām) per il pellegrinaggio, 
adottiva $(r a b i \bar{b} a)$ che non è stata allevata nella propria casa $\left.{ }^{652}\right)$, l'astenersi dal bere il succo lasciato fermentare $\left.(n a b \bar{\imath} \underline{d}){ }^{653}\right)$ [199] ed altre cose simili, e questa è la via degli obblighi severi ('azā'im) ( ${ }^{654}$ ). Ed egli ti ha ordinato di non dedicarti ad una interpretazione $\left(\operatorname{ta}^{2} w \bar{l} l\right)\left({ }^{655}\right)$ malgrado la tua capacità di

o riunisci il pellegrinaggio e la visita; se non hai una vittima entra in sacralizzazione per fare una visita e poi mettiti necessariamente a tuo agio [uscendo dallo stato di sacralizzazione, in attesa di riprenderlo per compiere il pellegrinaggio] $\left(\operatorname{tamattu}^{c}\right)$. Se fai così starai lontano dalle divergenze. Se sei ignorante e sei entrato in sacralizzazione per fare il pellegrinaggio e non hai con te una vittima, revoca [la tua intenzione] e trasformala in una visita: così ha ordinato ai suoi Compagni l'Inviato di Allah, che Allah faccia scendere su di lui la Sua salāt e la Pace, in occasione del Pellegrinaggio di addio, ordinando la revoca a chi non aveva una vittima".

652) Il divieto di sposare la figlia adottiva allevata nella propria casa è menzionato in Cor. IV-23; nel Cap. 289 [II 646.9] Ibn 'Arabī precisa che 'Alī riteneva lecito sposare la figlia adottiva non allevata nella propria casa perché il divieto si applicava solo se sussistevano entrambe le condizioni, cioè il rapporto sessuale con la madre e l'aver allevato la figlia adottiva. Questa questione è menzionata anche nei capitoli 57 [I 287.2] e 559 [IV 332.28].

653) Mentre sul divieto di bere il vino in questo mondo vi è accordo unanime, il succo fermentato di altri frutti, in particolare dei datteri, è ritenuto lecito dalla scuola giuridica di Abū Ḥanīfa, sia come bevanda che come liquido per l'abluzione rituale, ed Ibn 'Arabī lo cita come esempio, insieme a quello della figlia adottiva, della divergenza che vi è tra le scuole giuridiche o tra i giurisprudenti, nei capitoli 57 [I 287.1], ove afferma: "[...] come il bere il succo lasciato fermentare, tra chi lo ritiene lecito e chi lo proibisce, e lo sposare la figlia adottiva in cui non si riuniscono le due condizioni [che lo proibiscono]. Casi del genere sono frequenti nella Legge ed entrambe le scuole giuridiche sono legge confermata e valida, poiché derivano da uno sforzo di giurisprudenza, malgrado una delle due abbia sbagliato nel cogliere l'indicazione del Legislatore in base alla quale ha formulato il giudizio su quella questione [...] Talvolta uno dei due giurisprudenti coglie nel giusto, ma talvolta entrambi sbagliano", 177 [II 315.13], 289 [II 646.2], e 558 [IV 235.5], ove precisa: "Se il giudice è šāficita e gli viene condotto un hanafita che ha bevuto il succo lasciato fermentare, ritenendo ciò lecito, il giudice in quanto tale, ritenendo vietato il succo lasciato fermentare, gli commina la pena legale (hadd). Colui che ha bevuto, essendo hanafita ed avendo bevuto ciò che egli sa essere lecito, non decade dalla sua equità. Quanto a me, se fossi un giudice non punirei un hanafita per aver bevuto il succo lasciato fermentare, finché non si ubriaca, e se è ebbro allora lo punirei per essersi ubriacato con il succo lasciato fermentare [non per il fatto di averlo bevuto]". Nel Cap. 21 [I 171.4], riferendosi al ragionamento analogico afferma invece: "Quanto alla sua applicazione nelle questioni legali, se vuoi ad esempio sapere se il succo lasciato fermentare (nabîd) è vietato, usando questo metodo dici: "Tutto ciò che è inebriante è vietato, ed il succo lasciato fermentare è inebriante e quindi è vietato".".

654) Nel Cap. 73, questione IV [II 43.12] Ibn 'Arabī cita il seguente hadīt riportato da Ibn Ḥanbal, II-108: "Invero Allah ama che le Sue agevolazioni vengano compiute, così come ama che i Suoi obblighi severi vengano adempiuti". Il testo del manoscritto sembra indicare che l'aspirante deve attenersi alla norma più rigorosa e non all'agevolazione, e che gli esempi prima riportati riguardano le norme più rigorose.

655) Il termine tażūl ricorre 17 volte nel Corano, di cui ben 8 nella Sūra XII, dedicata al Profeta Giuseppe. Il suo senso è quello di "interpretazione", ma letteralmente esso significa ricondurre al principio o al senso originale, e questa è una delle attività proprie del giurisprudente, alla quale l'aspirante non deve dedicarsi, poiché seguirebbe una legge confermata e non una legge univoca. Nel Cap. 231 [II 531.23] Ibn 'Arabī afferma che: "non c'è nulla di più dannoso per il servitore dell'interpretare le cose", e nel Cap. 383 [III 522.33] aggiunge: "Il Profeta, che Allah faccia scendere su di lui la Sua salāt e la Pace, sapeva ciò che i Compagni non sapevano e per questo alcuni sapienti tralasciano l'interpretazione e non ne parlano, basandosi sul senso esteriore e lasciando la faccenda ad Allah, poiché Egli ha detto: "E non ne conosce l'interpretazione se non Allah" (Cor. III-7), e colui a cui Allah fa conoscere ciò che intendeva dire con il Suo detto lo sa per l'insegnamento di Allah e non per mezzo della sua considerazione razionale". 
fare una cosa simile, cioè non essere in un'opera prescritta dalla legge che un'altra legge ti confuta, mentre il Legislatore è unico, e più di questo buon consiglio da parte di quest'uomo riguardo ad una simile faccenda non è dato, ed Allah è più sapiente.

Poi ha detto: "e non badare alla purezza del tuo interiore con Allah, sia Egli esaltato, e alla disinvoltura (istirs $\bar{a} l)$ del tuo esteriore con gli uomini”, in ciò che è loro lecito; questa [nostra] specificazione è necessaria, poiché questo Maestro non l'ha fatta $\left.{ }^{656}\right)$, per fiducia da parte sua nella sollecitudine di Allah verso colui che è in questa situazione nella correzione del suo esteriore e del suo interiore. Ma questo Maestro ha trascurato il Suo detto, sia Egli esaltato: "Noi li condurremo gradualmente alla rovina (sa-nastadriğu-hum), senza che essi lo sappiano" (Cor. VII-182) ${ }^{657}$ ) ed il fatto che il Vero è con la persona nella misura in cui la persona è con Allah, sia Egli esaltato, cioè nella misura della sua scienza di Allah, poiché chi dà ad Allah dà nella misura di Allah presso di lui.

Per questo Abū Bakr si è staccato da tutto ciò che possedeva e non ha lasciato alla sua famiglia se non Allah ed il Suo Inviato $\left.{ }^{658}\right)$, cioè l'ascolto al Suo Inviato in ciò che gli ha ordinato, e se gli fosse stata restituita tutta la sua ricchezza l'avrebbe accettata malgrado se ne fosse staccato verso Allah. E per questo ha accostato l'Inviato ad Allah in ciò che ha lasciato alla sua famiglia, in quanto egli, che Allah faccia scendere su di lui la Sua salāt e la Pace, conosce meglio le necessità, come pure l'erede, che è il Maestro. Qualsiasi aspirante nasconda al Maestro qualcosa della sua ricchezza la perde da parte del Maestro nella misura di ciò che ha nascosto di essa, perché fa affidamento su ciò che ha nascosto e si basa su quello, sì che Allah lo affida a ciò e lo priva di molto [200] bene. Per questo Abū Bakr, il confessore, era superiore agli altri compagni, Allah, sia esaltato, sia soddisfatto di loro, anche se erano confessori.

Poi ha detto: "Sii uno che menziona Allah, sia Egli esaltato, e che Lo loda, e chiedi a Lui con cosa lodarLo, poiché Egli è Generoso, e recita la șalāt sull'Inviato di Allah, che Allah faccia scendere su di

656) Nel manoscritto la frase "in ciò che è loro lecito" sembra appartenere alla raccomandazione, ma ciò è in contraddizione con l'affermazione che il Maestro non ha fatto questa precisazione.

657) Il verbo istadrağa significa letteralmente far progredire per gradi e nel Cap. 39 [I 233.3] Ibn 'Arabī precisa che: "la progressione graduale (istidrăğ) ha luogo sia nel bene che nel male, sia nei beati che nei dannati", ma il versetto qui riportato riguarda solo i dannati. La degradazione progressiva è un aspetto dell'astuzia (makr) divina, "da cui è esente solo colui che Allah ha preservato richiamando la sua attenzione su questo pericolo" [Cap. 318 (III 69.8)].

658) 'Umar ibn al-Hुațāab ha detto: "L'Inviato di Allah, che Allah faccia scendere su di lui la Sua salät e la Pace, ci ordinò un giorno di fare una sadaqa, e quella corrispondeva ad una ricchezza che avevo. Dissi: "Oggi supererò Abū Bakr, se mai un giorno potrò superarlo!". Andai con metà dei miei averi e l'Inviato di Allah, che Allah faccia scendere su di lui la Sua salät e la Pace, mi chiese: "Cos'hai lasciato per la tua famiglia?" ed io risposi: "Lo stesso". Poi venne Abū Bakr con tutto ciò che possedeva ed alla domanda "Cos'hai lasciato per la tua famiglia?", rispose: "Ho lasciato loro Allah ed il Suo Inviato". Dissi allora: "Non riuscirò mai a superarti in nulla". Hadīt riportato da an-Nasā'̀ 1 XIV-26, XXIII-55, Abū Dāwud, IX-39, e da Ibn Ḥanbal. Ibn 'Arabī lo riporta nel Cap. 70 [I 581.3]. 
lui la Sua șalāt e la Pace". Quanto al suo detto: "e chiedi a Lui con cosa lodarLo", malgrado il Corano ci abbia insegnato come lodarLo, si tratta di un'incitazione a collegare la sua aspirazione (himma) con Allah, sia Egli esaltato, affinché egli riceva per svelamento, dalla Presenza da cui hanno appreso gli Inviati, ciò che essi hanno apportato della lode riguardo al Vero nei Libri e nei Fogli, ed egli ottenga la faccenda per svelamento e non per tradizione (naql), così da differenziarsi dai suoi simili ed essere designato tra i possessori della ispirazione rivelata per aver seguito ciò che gli ha imposto come legge l'Inviato, su di lui la Pace, e non una legge nuova per l'aggiunta o per l'abrogazione di una norma.

Per questo ha specificato dicendo: "[chiediGli] con cosa lodarLo" e non ha detto con ciò che tu prendi come regola per te stesso e per chi ti segue, poiché ciò non è dato, essendo la rivelazione legiferante conclusa $\left.{ }^{659}\right)$. Con ciò ha voluto che egli assaporasse il sapore dei Profeti in ciò di cui ci resta il gusto, e che abbiamo noi da non innalzare l'aspirazione (himma) per ottenere quello da Allah? Ciò che resta di quello sono i Nomi che risalgono a Lui, con cui Egli Si loda, o le notificazioni degli eventi degli esseri e di ciò che c'è, o delle regole che ha stabilito tramite la lingua della Legge $\left.{ }^{660}\right)$, affinché ci basiamo

659) Nel Cap. 14 [I 150.6] Ibn 'Arabī afferma: "Sappi, Allah ti assista, che è Profeta colui a cui l'Angelo porta la rivelazione da parte di Allah, quando questa rivelazione comporta una Legge ( šarī $\left.^{\prime} a\right)$ che riguarda solo lui, per mezzo della quale è asservito (táabbada) ad Allah, mentre se egli viene inviato (bu Ita $_{\text {) }}$ con questa Legge ad altri, allora è un Inviato $(r a s \bar{u})$. L'Angelo viene a lui secondo due modalità: o discende con questa Legge sul suo cuore, secondo una diversità di stati in questa discesa (tanazzul), oppure discende esteriormente con una forma corporea (ğasādiyya) e mette ciò con cui viene a lui alla portata del suo orecchio sì che egli lo sente, o alla portata della sua vista sì che egli lo vede, e ciò che acquisisce da quello sguardo equivale a ciò che acquisisce dall'udito; e così per le altre facoltà sensibili. Questa "porta" invero è stata chiusa con la venuta dell'Inviato di Allah, che Allah faccia scendere su di lui la Sua salāt e la Pace, e pertanto non è possibile che uno sia asservito ad Allah seguendo una legge che abroghi la legge muhammadiana".

Ibn 'Arabī distingue due tipi di Profezia: la Profezia generale ('āmma), che è propria di alcuni Intimi, quelli che sono eredi di un Profeta, e la Profezia legiferante, che a sua volta si suddivide in due classi: coloro che ricevono una Legge che riguarda solo loro e chi li vuole seguire, e questi sono i Profeti in senso stretto, e coloro che ricevono una Legge che riguarda anche gli altri, cioè gli Inviati. La Profezia legiferante è stata "sigillata" con la venuta di Muhammad, mentre la Profezia generale è tuttora accessibile ed è a questa che si riferisce il seguito del testo.

660) Nel Cap. 14 [I 150.13] Ibn 'Arabī afferma: "Quanto alla condizione dei Profeti degli Intimi in questa comunità, si tratta di coloro che il Vero innalza in una delle Sue teofanie e per i quali fa risorgere il luogo di manifestazione (mazhar) di Muhammad, che Allah faccia scendere su di lui la Sua salāt e la Pace, e quello di Gabriele, su di lui la Pace. Poi questo luogo di manifestazione spirituale [cioè Gabriele] fa loro sentire la proclamazione delle norme legali al luogo di manifestazione di Muhammad, che Allah faccia scendere su di lui la Sua șalāt e la Pace. Quando ha finito il suo discorso e lo spavento ha lasciato il cuore di questo Intimo, egli, avendo avuto questa contemplazione, comprende tutto ciò che quel discorso comporta quanto alle norme legali che sono state manifestate riguardo a questa comunità muhammadiana. Quest'Intimo quindi le riceve così come le ha ricevute il luogo di manifestazione muhammadiano, per il fatto di essere stato reso partecipe in questa "presenza" di ciò che è stato ordinato a quel luogo di manifestazione muhammadiano di trasmettere a questa comunità. Poi egli è ricondotto a se stesso e ricorda le parole con cui lo Spirito si è rivolto al luogo di manifestazione di Muhammad, che Allah faccia scendere su di lui la Sua șalāt e la Pace, e ne conosce quindi l'autenticità per una scienza certa, anzi per una visione certa; egli dunque riceve la norma di questo Profeta e si comporta conformemente ad essa "in base ad una prova evidente (bayyina) da parte del suo Signore" (Cor. XI-17)." 
su una visione interiore della nostra faccenda $\left({ }^{661}\right)$ nella chiamata a Lui.

E non tramandare da un uomo non indenne dalla congettura, dall'errore e dalla menzogna, poiché nel tramandare dagli Inviati ce ne sono molti come quello, e per questo appare la debolezza [201] nello hadīt, secondo i vari tipi di essa, e molti hadīt sono rigettati. Se tu invece lo apprendi dalla fonte da cui lo apprendono gli Inviati ti basi su una visione interiore, e per questo Allah, sia Egli esaltato, ha detto al Suo Profeta, su di lui la Pace, di dire riguardo a questa stazione: "Io chiamo ad Allah in base ad una visione interiore, io e chi mi segue" (Cor. XII-108), cioè a chi mi segue in ciò che ho legiferato, Allah, quanto è Potente e Magnificente, dà lo svelamento sì che egli veda la veridicità di ciò che ho apportato, come l'ho vista io, e tu quindi comunichi in base all'occhio della certezza $\left({ }^{662}\right)$.

$\grave{E}$ giunta una notificazione che lo svelamento ha convalidato, anche se essa non è solida dal punto di vista della trasmissione, in cui è riportato che l'Inviato di Allah, che Allah faccia scendere su di lui la Sua șalāt e la Pace, ha detto: "Se non ci fosse confusione (tamrīğ) nei vostri cuori ed aggiunta (tazayyud) nella vostra narrazione (hadīt), vedreste ciò che ho visto ed ascoltereste ciò che ho ascoltato" ( $\left.{ }^{663}\right)$. Egli

661) Nei manoscritti si trova "della mia faccenda (amrî)".

662) Nel Cap. 14 [I 150.19], nel seguito del brano riportato nella penultima nota, Ibn 'Arabī afferma: "Parecchi hadît deboli, ai quali si è desistito dal conformarsi per la debolezza della loro via di trasmissione, dovuta alla presenza di un inventore tra i suoi trasmettitori $(r u w \bar{a})$, sono in realtà autentici. In questo caso dunque colui che è ritenuto inventore $\left(w \bar{d} d i^{i}\right)$ non ha fatto che essere veridico nel trasmettere lo hadīt $\mathrm{e}$ non l'ha inventato; ma lo studioso di hadît lo respinge per mancanza di fiducia nella sua narrazione, se quel relatore è il solo a tramandarlo o comunque lo hadīt ruota intorno a lui per ciò che concerne la sua trasmissione. Se però fosse associata a lui a questo riguardo una persona degna di fede che lo avesse sentito insieme a lui, allora quello hadīt sarebbe stato accettato per via di questa persona degna di fede. Ora, quest'Intimo invero lo ha sentito direttamente dallo Spirito che lo proiettava sulla realtà essenziale di Muhammad, che Allah faccia scendere su di lui la Sua șalāt e la Pace, così come i Compagni del Profeta sentirono il colloquio di Gabriele, su di lui la Pace, con Muhammad, che Allah faccia scendere su di lui la Sua șalāt e la Pace, riguardo all'Islām, alla fede ed all'Iḥsān e la conferma da parte di Gabriele di quanto disse. Quando lo ascolta dallo Spirito proiettore, l'Intimo è simile al Compagno che lo ha sentito dalla bocca dell'Inviato di Allah, che Allah faccia scendere su di lui la Sua salāt e la Pace, avendone così una scienza in cui non vi è alcun dubbio, a differenza di chi segue, che gli dà il proprio assenso per via della prevalenza della [buona] opinione (galabat az-zann), rimuovendo il sospetto (tuhma) che interviene nei confronti della veridicità. Succede invece che uno hadīt , che per via dei suoi trasmettitori risulta autentico, sia giunto all'orecchio di quest'essere dotato di svelamento che ha visto quel luogo di manifestazione di cui parlavamo, e che avendo costui interrogato il Profeta, che Allah faccia scendere su di lui la Sua salät e la Pace, riguardo a questo hadīt, il Profeta non lo riconosca e dica: "Non ho mai detto ciò, né ho formulato giudizi in questo senso!". Egli in questo modo sa che quello hadīt è debole e desiste quindi dal conformarsi ad esso in base ad una evidenza da parte del suo Signore, anche se coloro che seguono la tradizione (ahl an-naql) si conformano ad esso per la validità della sua via di trasmissione: ma esso in realtà non è autentico".

663) Hadīt riportato da Ibn Ḥanbal, V-266. Ibn 'Arabī lo cita nei capitoli 12 [I 147.19], 302 [III 13.19] in cui afferma: "È stato riportato in uno hadīt profetico, che è autentico per la gente dello svelamento, anche se non è stata confermata la sua via [di trasmissione] da parte degli studiosi delle tradizioni, per via di un trasmettitore considerato debole, anche se aveva detto il vero. Egli ha riferito che l'Inviato di Allah, che Allah faccia scendere su di lui la Sua salāt e la Pace, ha detto: "su di lui la Pace, in uno hadīt autentico secondo lo svelamento, in cui ha affermato: "Se non ci fosse aggiunta nella vostra narrazione e confusione nei vostri cuori, vedreste ciò che ho 
allude al fatto di percepire le cose per gusto spirituale come le hanno percepite gli Inviati dei quali ci è stato ordinato di seguire la guida, affinché avvenga per noi da parte del Vero ciò che è avvenuto per loro, limitatamente a ciò che ci è concesso di quanto Egli ha fatto restare per noi di quello [dopo la venuta del Profeta], ed Egli ha escluso ciò [per la maggioranza degli uomini] con il Suo detto: "Essi hanno smentito la verità quando è giunta loro ed essi sono in uno stato confuso" (Cor. L-5) - e questa è la confusione che ha menzionato - ed altri [versetti] simili ad esso.

Quanto all'aggiunta nella narrazione è che l'uomo è portato per sua natura a divulgare (ifs $\bar{a}$ ) e per questo, nello svelamento, è al di sotto degli animali per la loro incapacità di parlare e per la capacità che c'è in lui di trasmettere ciò che egli vede e nel divulgarlo ${ }^{(64)}$; e poiché è noto che egli rivela gli venne nascosto ciò che il Vero voleva che non rivelasse, se non a coloro che mantengono il segreto tra i Suoi servitori, o per lo stato, come nel caso degli animali (bahä $\mathrm{im}$ ) e di chi non ha lo strumento per esprimersi correttamente, oppure a chi rispetta il pegno (amāna) $\left.{ }^{665}\right)$.

visto ed ascoltereste ciò che ho ascoltato". Allah, sia Egli esaltato, ha detto: “... affinché spieghiate agli uomini ciò che è stato loro rivelato" (Cor. XVI-44); non ci può essere qualcosa di più chiaro di questa spiegazione, ma dov'è colui che ha svuotato il suo ricettacolo per ricevere le tracce del suo Signore? Dov'è colui che trasmette ciò che ha ascoltato senza fare aggiunte? Costoro sono veramente rari", e 334 [III 131.14] ove aggiunge: "[Tra le scienze di questa dimora spirituale vi è] la scienza del motivo che impedisce che a noi avvenga da parte di Allah ciò che avvenne all'Inviato da parte Sua, ed esso è il suo detto, su di lui la Pace, in uno hadīt autentico secondo lo svelamento, in cui ha affermato: "Se non ci fosse aggiunta nella vostra narrazione e confusione nei vostri cuori, vedreste ciò che ho visto ed ascoltereste ciò che ho ascoltato". Questo chiarisce la via che porta alla stazione da cui egli ha visto ciò che ha visto e ascoltato ciò che ha ascoltato. C'è qualcuno a cui questo impedimento viene tolto ed arriva a questa stazione, o no? Noi diciamo di si, poiché Allah ci ha ordinato di spiegare agli uomini ciò che è stato loro rivelato, ed Egli non ha spiegato un impedimento alla salita ad un rango elevato se non perché fosse superato e non ha menzionato una dimora di vicinanza se non affinché fosse ottenuta, e chi si sforza trova e chi non riesce non ha che da biasimare se stesso".

La dimora spirituale a cui si riferisce il capitolo 344 corrisponde alla Sura L, in cui si trova il versetto che verrà riportato poche righe dopo nel testo, a conferma dell'impedimento citato nello hadīt.

664) Nel Cap. 560 [IV 549.34] Ibn 'Arabī riporta il seguente detto: "Tener nascosto il tuo segreto provoca la tua salvezza, divulgare il tuo segreto provoca il rammarico, e resistere a tener nascosto il segreto è più facile del rammarico per averlo divulgato".

665) Nel Cap. 348 [III 201.30] Ibn 'Arabī precisa: "Tutti coloro che non hanno la facoltà di trasmettere ciò che hanno visto hanno scienza di Chi Si manifesta a loro, e così pure chi ha la facoltà di trasmettere, ma è fedele $(a m \bar{\imath})$ [al suo pegno] e non parla se non per ordine divino, ha scienza di Chi Si manifesta a lui. A chi invece ha la facoltà di trasmettere, ma si sa che è uno che divulga ciò che ha visto e ciò che ha ascoltato e non è un fedele che aspetta l'ordine del possessore del pegno, a costui il Vero non fa sapere nella Sua teofania che è Lui, ed essi sono coloro che Lo disconoscono nella Sua teofania in questo e nell'altro mondo", e nel Cap. 378, dedicato alla dimora spirituale della comunità degli animali, aggiunge [III 491.22]: "Non c'è animale che non veda ciò e per questo Allah li ha resi incapaci di trasmetterci ciò che hanno visto ed essi sono fedeli per la forma del loro stato rispetto a noi. Allah non svela a nessuno della specie umana ciò che svela agli animali, a meno che non gli abbia dato il pegno, che consiste nel nascondere agli altri ciò che ha visto, se non per una rivelazione da parte di Allah di farlo conoscere. Allah non ha tolto alla visione ed all'udito della maggior parte degli uomini la comprensione dei suoni del soffiare dei venti e del mormorio delle acque e di tutto quello che produce suoni se non perché ciò restasse nascosto. Se colui che ha ricevuto lo svelamento divulga ciò vanifica la saggezza di ciò che è stato 
Non c'è dubbio che chi trasmette una cosa l'ha vista o l'ha sentita, e se la trasmette a senso talora la amplia e talora la riduce $\left({ }^{666}\right)$ e l'omissione [202] di qualcosa è [come] un'aggiunta nella notificazione di ciò che non c'era in essa $\left({ }^{667}\right)$. Se invece la trasmette alla lettera, come l'ha sentita nella sua lingua, che ne capisca il significato o non lo capisca, questi è colui che è indenne dall'aggiunta nella narrazione ed è raro, e questo raro è colui a cui viene svelato ciò che è stato svelato agli Inviati, ed egli quindi chiama ad Allah in base ad una visione interiore. Sennonché, per il suo pegno, egli non dice: "Mi è stato rivelato", ma dice: "È accaduto nel mio intimo (sirr)", o "Ho visto nell'accadimento", o "Il Vero Si è rivolto a me nel mio cuore dicendo così e così”, di ciò che gli è stato fatto contemplare dei fondamenti della Legge.

Simili signori vedono ciò che hanno visto gli Inviati ed ascoltano ciò che hanno ascoltato gli Inviati, ed essi sono quindi nella situazione dell'Inviato, su di lui la Pace, in ciò che è stato legiferato per lui ed in ciò a cui è stato asservito della Legge di chi c'era prima di lui, e sono pertanto eredi dell'Inviato in questa realtà essenziale. Una persona simile loda Allah con ciò che Allah gli ha insegnato dei Suoi Nomi, poiché non Lo loda, sia Egli esaltato, se non con i Suoi Nomi, e l'Inviato di Allah, che Allah faccia scendere su di lui la Sua șalāt e la Pace, ha alluso a ciò nel suo riepilogo dicendo: "Allāhumma, Ti chiedo con i Tuoi Nomi che hai tenuto per Te nella scienza del Tuo Invisibile, o che hai insegnato ad una delle Tue creature" $\left.{ }^{668}\right)$ ed ha usato una forma indeterminata senza specificare un genere, per la

istituito, a meno che non gli venga rivelato di svelarne una parte, nel qual caso è scusato per la divulgazione".

666) Nel Cap. 38 [I 229.22] Ibn 'Arabī precisa: "Colui che trasmette a senso ci trasmette solo la sua comprensione di quello hadīt profetico e chi trasmette la sua comprensione è solo messaggero di se stesso".

667) Nei manoscritti si legge: “e la riduzione della cosa è un'aggiunta nella notificazione di ciò che non c'era in essa".

668) Hadīt riportato da Ibn Hanbal, I-391 e 452. "Allähumma, Ti chiedo con ogni Nome con cui Ti sei denominato, o che hai insegnato ad una delle Tue creature, o che hai tenuto per Te nella scienza del Tuo Invisibile". Nel Cap. 69 [I 431.9] Ibn 'Arabī precisa: "I Nomi di Allah, come le possibilità, sono infiniti, ed ogni possibilità ha una specifica qualificazione, a cui corrisponde da parte di Allah un Nome specifico, e da quel Nome è specificata la qualificazione per cui essa si distingue dalle altre possibilità. Questa è una delle scienze più elevate della gente di Allah ed è menzionata in ciò che egli, che Allah faccia scendere su di lui la Sua salât e la Pace, ha detto nella sua preghiera: "Allăhumma, io chiedo a Te per mezzo di ogni Nome con cui Ti sei denominato, o che hai insegnato ad una delle Tue creature, o che hai tenuto per Te nella scienza del Tuo Invisibile".", e nel Cap. 560 [IV 454.21] aggiunge: "Non c'è dubbio che Allah non ama le entità del Mondo nello stato in cui il Mondo non esiste se non per il fatto che queste entità sono la sede della ricettività (infi $\bar{a} l$ ), e quando rivolge la sua attenzione (tawağğaha) su di esse con il Suo Nome "il Volente (murñd)" Egli dice loro: "Sii (kun)" ed esse sono. Si manifesta così la Sua autorità (mulk) su di esse nell'esistenza, e queste entità conferiscono ad Allah il Suo diritto (haqq) alla Sua Divinità (ulühiyya): Egli diventa così Dio ed esse Lo adorano mediante tutti i Nomi con il loro stesso stato, sia che conoscano quei Nomi, sia che non li conoscano, e non resta Nome ad Allah senza che il servo si situi in esso con la sua forma ed il suo stato, anche se non conosce l'effetto (natǐga) di quel Nome. A questo proposito l'Inviato di Allah, che Allah faccia scendere su di lui la Sua șalāt e la Pace, ha detto nella sua preghiera con i Nomi di Allah: "[Allāhumma, io chiedo a Te per mezzo di ogni Nome con cui Ti sei denominato,] o che hai tenuto per Te nella scienza del Tuo Invisibile, o che hai insegnato ad una delle Tue creature", riferendosi a uno dei Suoi Nomi, affinché essa [creatura] conoscesse la sua entità e la distinguesse 
sua scienza, su di lui la Pace, che Allah, sia Egli esaltato, talora caratterizza chi vuole dei Suoi servitori con uno dei Suoi Nomi - che Allah ci faccia essere di coloro che apprendono da Lui i Suoi Nomi per stato spirituale - ed esso [Nome] diventa un suo attributo, non una trasmissione (naql), nel qual caso egli non avrebbe di esso se non ciò che è sulla sua lingua.

Quando l'uomo loda Allah, con ciò con cui Lo loda dei Suoi Nomi, Lo menziona, ed Allah, sia Egli esaltato, ha detto: "MenzionateMi, Io vi menzionerò" (Cor. II-152), poiché Allah, sia Egli esaltato, Lo menzionerà con quegli stessi Nomi e quella lode ritornerà su di lui e Egli lo denominerà [203] con ciò con cui ha denominato Se stesso, ed Egli è veridico in ciò con cui menziona il Suo servitore. Quindi Egli non lo loda, rendendo quella lode a lui, fino a che il servitore non realizza, da parte di Allah, quei Nomi in se stesso e diventa identico ad essi, poiché è denominato da essi e quindi conferma Allah nella sua menzione di Lui con essi. Se venisse detto: "Va bene, Egli ha menzionato che menzionerà colui che Lo menziona, ma chi ha detto che lo menzionerà con ciò con cui Lo ha menzionato?" diremmo che la risposta ha due aspetti. Secondo un primo aspetto egli si rimette a noi, poiché si tratta di un'asserzione $(d a \Leftarrow \bar{a})$, cioè noi diciamo: "Così abbiamo trovato la faccenda nello svelamento e l'abbiamo ascoltata"; la seconda risposta è che consta che egli ha detto: "Esse non sono altro che le vostre opere che vi vengono rese" ${ }^{669}$ ) e quindi Egli fa tornare a noi la nostra stessa opera, e la nostra opera non è che la lode a Lui con questi Nomi specifici, e quando Egli li fa tornare a noi è la Sua stessa lode a noi per mezzo di essi.

Quanto alla sua raccomandazione di recitare la salāt $\left({ }^{670}\right)$ sul Suo Profeta e il Suo Inviato, che Allah

dalle altre per mezzo della scienza. In effetti molte cose sono nell'uomo mediante la forma e lo stato, e l'uomo non le conosce mentre Allah sa da lui [mediante la forma e lo stato] che quelle cose sono in lui".

Ibn 'Arabī riporta questo hadīt anche nei capitoli 48 [I 263.20], 69 [I 463.27], 71 [I 613.23], 73, questione XLII [II 69.32] e C [II 101.12], 282 [II 619.18], 294 [II 671.10], 358 [III 267.33], 365 [III 321.22], 388 [III 543.9] e 559 [IV 408.30].

669) Hadīt già riportato a pag. 135 del manoscritto.

670) Il termine șalāt ha diversi significati, come spiega Ibn 'Arabī nel Cap. 69 [I 386.22]: "La șalāt viene attribuita al Vero nel suo significato generale, il quale consiste nella Misericordia. Infatti Allah si è qualificato come il Clemente (rahīm) ed ha attribuito la Misericordia [anche] ai Suoi servitori, dicendo: "Io sono il più misericordioso dei misericordiosi!". E l'Inviato di Allah, che Allah faccia scendere su di lui la Sua salāt e la Pace, ha detto: "Certo Allah ha misericordia dei Suoi servitori misericordiosi". Ed [il Vero] ha detto: "Egli è Colui che fa la salāt (sallâ) su di voi" (Cor. XXXIII-43), qualificandoSi come Colui che fa la salāt, cioè "ha misericordia di voi", "facendovi uscire dalle tenebre alla luce" (Cor. ibidem), cioè dall'errata alla retta via e dall'infelicità alla felicità. La șalāt viene anche attribuita agli Angeli con il significato di misericordia, di preghiera e di richiesta di perdono per i credenti, come ha detto, sia Egli esaltato: "Egli è Colui che fa la salāt su di voi, e così i Suoi Angeli" (Cor. ibidem). [...] La șalät è stata poi attribuita all'uomo, con il significato di misericordia, di preghiera e di speciali atti istituiti dalla Legge, secondo quanto dirò. All'uomo competono quindi queste tre categorie di atti chiamati salāt. Egli, sia esaltato, ha detto, ordinando: "Osservate la șalāt" (Cor. II-43, ecc.). La salāt viene infine attribuita a tutto ciò che non è Allah, cioè all'insieme delle creature: Angeli, uomini, animali, vegetali e minerali, in conformità a quanto è stato imposto ad essi e a quanto è stato assegnato. Come ha detto, sia Egli esaltato: "Non vedi che glorifica Allah ciò che è nei Cieli e sulla Terra, e gli uccelli, stendenti le loro ali? Ognuno 
faccia scendere su di lui la Sua șalāt e la Pace, è stabilito che chi recita la salāt sull'Inviato di Allah, che Allah faccia scendere su di lui la Sua șalāt e la Pace, una volta Allah fa scendere su di lui la Sua salāt dieci volte $\left.{ }^{671}\right)$, poiché egli compie un'opera buona ed avrà [per ricompensa] dieci simili ad essa, fino a settecento volte ${ }^{672}$ ), in proporzione alla stazione da cui egli recita la șalāt su di lui, e chi implora il Profeta, che Allah faccia scendere su di lui la Sua șalät e la Pace, per una cosa, Allah, sia Egli esaltato, gli accorda il multiplo di quella cosa.

Se tu dici: "Egli supera per questo ciò che risulta al Profeta da parte sua con la șalät su di lui", rispondiamo che così è inevitabile, sennonché i ricettacoli non ricevono ciò che viene dal Vero se non in proporzione alle loro predisposizioni ed è noto che la predisposizione degli Inviati è più completa della nostra predisposizione, in quanto essi hanno ricevuto la rivelazione (wahy) legiferante e noi non l'abbiamo ricevuta, ed essi hanno ricevuto [anche] ciò che noi abbiamo ricevuto, quindi noi sappiamo che essi hanno una predisposizione che noi non abbiamo, e noi controbilanciamo [204] la singola cosa che essi hanno con mille di quelle che noi abbiamo, e che dire quindi di dieci? La generosità (ğ $\bar{u} d)$ divina è di ampiezza assoluta e non ci sono impedimenti, e la ricettività aumenta e diminuisce l'uno dall'altro.

Quando tu reciti la șalāt sul Profeta, su di lui la Pace $\left({ }^{673}\right)$,Allah, sia Egli esaltato, ha già fatto scendere la Sua salāt su di te con ciò con cui ha avuto misericordia di te, ma dalla tua stazione $\left({ }^{674}\right)$ : ora fa scendere la Sua șalāt su di te dalla stazione dell'Inviato su cui hai recitato la șalāt e la Sua șalāt, sia Egli esaltato, su di te, poiché è una ricompensa della tua șalāt sull'Inviato, è più completa della Sua salāt su di te quando non è una ricompensa. Per questo ti ha ordinato recitare la șalāt sul Profeta, che Allah faccia scendere su di lui la Sua salāt e la Pace, ed analogamente se includi in quella recitazione la sua famiglia, tutti i Profeti ed i servitori pii di Allah, come egli, su di lui la Pace, ha detto riguardo al tašahhud: "quando il servitore dice: "La Pace sia su di noi e sui servitori pii di Allah", [le sue parole]

conosce la sua șalāt e la sua glorificazione" (Cor. XXIV-41), ed ha così attribuito la șalāt ad ognuno". Quanto alla șalāt sul Profeta egli precisa [I 387.12]: "Quanto alla șalāt sull'Inviato di Allah, che Allah faccia scendere su di lui la Sua salāt e la Pace, essa rientra nella preghiera. Infatti l'Inviato di Allah, che Allah faccia scendere su di lui la Sua șalāt e la Pace, ci ha insegnato come fare la șalāt su di lui, cioè come pregare per lui. Egli ci ha ordinato di pregare che gli fossero accordati la wasilla e la stazione lodata".

671) Riferimento ad uno hadīt riportato da an-Nasā'̄i, XIII-48 e 55. Ibn 'Arabī lo riporta nel Cap. 560 [IV 472.24 e 535.30] e ne La niche des lumieres, Les Editions de l'Euvre, 1983, pag. 114.

672) Riferimento a Cor. II-261 e VI-160, e ad uno hadīt riportato da Muslim, XLVIII-22, an-Nasā̄̄è, XXII-42 e 82, Ibn Māğah, XXXIII-58, e da Ibn Hanbal, II-188, 214, 414 e 480.

673) Nel Cap. 69 [I 431.22] Ibn 'Arabī afferma che per lui la salāt sul Profeta deve obbligatoriamente essere inclusa nel tašahhud, e quindi recitata in occasione di ogni salāt.

674) Nel Cap. 69 [I 539.34] Ibn 'Arabī afferma: “Quando voi fate la salāt e menzionate Allah Egli fa scendere la Sua șalāt su di voi. Quindi la nostra șalāt e la nostra menzione di Lui, sia Egli glorificato, è tra due salāt da parte di Allah, sia Egli esaltato: Egli fa scendere la Sua șalāt su di noi, noi facciamo la șalāt a Lui ed Egli fa scendere la Sua șalāt su di noi”. 
raggiungono ogni servitore pio di Allah nel Cielo e sulla Terra" $\left.{ }^{675}\right)$ e non resta servitore pio che ascolti il tuo saluto che non ti renda [il saluto] e se non ha ascoltato, il Vero ti rende quello al posto suo, tanto che l'uomo, quando ha contemplato ciò, vorrebbe che Allah facesse le veci di tutti, per il bene che vedrebbe. Non conosce il valore di questo se non la gente del gusto spirituale, e fa parte della sollecitudine di Allah per questa comunità il fatto che Allah, sia Egli esaltato, si assuma personalmente l’incarico della șalāt di ricompensa su di essa.

Poi ha detto: "e Ti chiedo di accrescere quello" riferendosi alla scienza di Allah, poiché Allah, sia Egli esaltato non ha ordinato al Suo Profeta di chiedere l'accrescimento in una delle cose, né in un'opera, né in altro, se non della scienza, e gli ha detto: "Dì: o mio Signore, accrescimi in scienza" (Cor. XX114), e se ci fosse una categoria superiore alla scienza gli avrebbe ordinato di chiedere l'accrescimento di essa, e non ha detto [205]: "O mio Signore, accrescimi in opera", né "in stato", poiché l'opera è fatica (mašaqqa), soprattutto le opere naturali, e lo stato è una cosa accidentale e ciò che è accidentale non ha permanenza, mentre la scienza è un attributo divino di comprensione, e quindi ha chiesto l'accrescimento di esso per la sua elevatezza.

Sappi che il richiedere l'accrescimento della scienza si riferisce alla connessione non alla scienza, poiché se la scienza è un attributo è una e non ammette l'accrescimento, che riguarda solo l'oggetto della scienza, e ciò che è saputo non lo è se non per la connessione, ed ha nominato [nel versetto] la radice (așl), che è la scienza, perché non è scienza se non per la connessione. Tant'è che se supponessimo che essa non abbia connessione né con se stessa, né con un oggetto di scienza diverso da essa, non sarebbe assolutamente scienza, ma essa non cessa di essere connessa e non cessa di essere scienza. Poiché gli oggetti della scienza sono ordinati gerarchicamente e l'uno sovrasta l'altro e l'oggetto più elevato della scienza è la scienza di Allah, abbiamo stabilito che la richiesta dell'accrescimento riguarda la scienza, ma solo della scienza di Allah, non di altri, poiché le cose chiamate Mondo e trasposizione (iqibār) non sono conosciute se non per Allah. Noi non conosciamo ciò che c'è finché il Vero non Si manifesta in qualsiasi forma che noi percepiamo del Mondo, ed allora noi conosciamo del Mondo in misura di quello e conosciamo la relazione del Vero da quella forma che è per Lui un supporto di manifestazione, e per questo Egli Si manifesta in essa. Quindi la nostra scienza di Allah è identica alla nostra scienza del Mondo, ed in ogni Teofania siamo accresciuti di una scienza di Allah che non conoscevamo, e l'accrescimento è indispensabile, indipendentemente dal fatto che quello avvenga nelle forme ordinarie o in quelle straordinarie. E poiché la faccenda è come abbiamo affermato, noi chiediamo l'accrescimento in quanto Allah, sia Egli esaltato, ci ha ordinato l'accrescimento e compiamo un'azione obbligatoria che il Suo ordine ha reso obbligatoria per noi, e ci viene da parte del Vero la ricompensa dell'amore degli atti obbligatori, e la sua misura è immensa [206].

675) Had̄̄t riportato da al-Buhārī, X-148 e 150, LXXX-16, Muslim, IV-56, an-Nasā̄̄î, XIII-56, e da Ibn Māğah, V-24. Ibn 'Arabī lo cita nel Cap. 69 [I 508.25] e nel Cap. 72 [I 723.3]. 
Analogamente è indispensabile, per quanto riguarda gli ordini divini, che la gente di Allah, sia Egli esaltato, non li prenda se non come obbligo, non come raccomandazione (nadb) o licenza (ibāha), poiché essi sono gente di presenza (hudūr) o che cerca di essere presente (istihdūar) [cioè non noncuranti], e gli ordini impartiti verbalmente non prendono il posto degli ordini impartiti tramite l'intermediario. Allah, sia Egli esaltato, non ti ha ordinato se non perché ha dato la preponderanza al lato dell'accadimento di ciò che ti ha ordinato, quindi il minimo è conformarsi: sappi quello.

Se dici: "È evidente la preponderanza nell'ordine della raccomandazione, ma come può esservi preponderanza nell'ordine della liceità?", noi rispondiamo: se ti lascia la scelta nel lecito tra il fare ed il non fare, non fare, quello è il tuo stato nel momento, poiché non sei agente, e dai la preponderanza al fare sul non fare quando si manifesta un effetto del Suo ordine in te, allora compi del lecito ciò che è un atto, come il Suo detto, sia Egli esaltato: "E quando la șalāt è finita disperdetevi sulla Terra" (Cor. LXII-10). Se resti seduto nella moschea dopo la salāt del venerdì non aggiungi uno stato e non si manifesta in te un effetto che non c'era, e se ti alzi dal luogo di preghiera ove eri seduto nella moschea verso un altro luogo della moschea ti disperdi sulla Terra, poiché la moschea fa parte della Terra e si manifesta da te un atto che ti ha fatto uscire dal luogo ove hai fatto la salät; se lo hai fatto con questo proposito vieni ricompensato in ciò che è lecito, riguardo a cui i dottori della Legge hanno detto che è ciò che non comporta né ricompensa né punizione.

Lo stesso vale per le proibizioni; quanto a ciò che è vietato non c'è discorso, e quanto a ciò che è biasimato $(m a k r u \bar{h})$ la sua proibizione non è preponderante a meno che l'astenersi da esso sia meglio per il servitore. Quanto alla proibizione del lecito, in cui il fare è indifferente, ti abbiamo già fatto vedere la preponderanza del fare in una raccomandazione specifica $\left.{ }^{676}\right)$, quindi dai la preponderanza ad esso [il fare] in questa e simili situazioni, poiché riguardo ad esse non è stato riportato "se vuoi ... e se vuoi ..." (677) e quindi in questo caso l'ordine è preponderante [207] rispetto alla proibizione. Se invece riguardo al lecito è stato riportato "se vuoi ... e se vuoi ..." osserva: se l'ordine precede il volere della proibizione metti in atto l'ordine, e se precede la proibizione metti in atto la proibizione, poiché Allah, sia Egli esaltato, ha lodato coloro che si affrettano a compiere le opere buone e non ha dato la precedenza ad esso se non perché gli ha dato la preponderanza, quindi affrettati a fare ciò a cui ha dato la precedenza, come Egli Si è affrettato a dare la precedenza.

E quando arriva una [notificazione] simile a: "fai ciò che vuoi, poiché ti ho già perdonato" $\left.{ }^{678}\right)$,

676) Il tema del lecito è già stato affrontato alle pagine 79 e 115 del manoscritto.

677) Espressione che ricorre in alcuni hadīt, quali quelli riportati da Abū Dāwud, XL-92, at-Tirmid̄ī, XIV-1, an-Nasā̄̄î, XXII-56 e 57, Ibn Māğah, VII-10, Mālik, XXVIII-14, e da Ibn Ḥanbal, II-107.

678) Hadīt riportato da Muslim, XLIX-29, e da Ibn Ḥanbal, II-492. Ibn 'Arabī lo cita 14 volte nelle Futūhāt, usando sette volte l'imperativo if'al e sette volte l'imperativo imal. Nel Cap. 71 [I 622.3] precisa: "Sappi che vi sono servitori di Allah che sono informati da Allah riguardo agli atti di ribellione che Egli ha decretato per loro. Essi si affrettano a compiere questi atti per l'intensità del loro pudore di fronte ad Allah, sì che essi possano affrettarsi al pentimento e lasciarseli alle spalle, liberandosi così dall'oscurità della loro visione (šuhüd). 
per tutto ciò che tu fai di quanto ti era vietato fare non sarai punito per ciò in cui tu sei agente, ed ha applicato veramente a te il nome di agente, e se [invece] tralasci la șalāt sulla base di questa notificazione sei disobbediente, poiché non hai agito e verrai punito per quello, se Allah, sia Egli esaltato, vuole. Quanto all'opera a cui ti dedichi al posto della salāt, sia essa una cosa biasimata o altro, quell'opera è lecita per te e non sarai punito per essa, poiché Allah, sia Egli esaltato, te l'ha già perdonata. L'astenersi da ciò che è stato ordinato non è un'opera ed Egli non ha detto: “Astieniti da

Quando essi si pentono, vedono che il loro atto di ribellione si tramuta in una buona azione, conformemente a ciò che è. Un essere simile non viene intaccato nella sua dimora (manzila) presso Allah, poiché quando accade loro quello non si tratta di una violazione della sacralità (hurma) divina [cioè di una effettiva ribellione] ma di un adempimento del Decreto e del Destino al loro riguardo. Ciò corrisponde al Suo detto: "Affinché Allah ti perdoni i tuoi peccati passati e futuri" (Cor. XLVIII-2), secondo il quale il perdono precede l'evento del peccato. Questo versetto talvolta comporta che colui che è impeccabile (ma śum) sia protetto dai peccati $(\underline{d u n u} b)$ : essi lo cercano ma non lo raggiungono, sì che nessun peccato viene da lui commesso, poiché è protetto nei confronti di essi. Oppure egli è protetto nei confronti della punizione, così che essa non lo tocca: la punizione cerca la sede dei peccati ed Allah protegge chi vuole tra i Suoi servitori, per mezzo del Suo perdono, così che egli non subisce punizione né castigo. Il primo [dei due casi] è più completo (atamm): il perdono precede l'evento del peccato, si tratti di azione o astensione, sicché ha luogo solo una buona azione, che egli vede e che trova eccellente. Tra i servitori di Allah vi è poi chi fa in realtà solo ciò che è specificamente lecito per lui fare: questo è il caso più frequente riguardo alla Gente di Allah. È confermato nella Legge che Allah dice al servitore in una situazione particolare: "Fa ciò che vuoi, poiché ti ho già perdonato". Si tratta di ciò che è lecito (mubāh) e chi compie il lecito non viene punito da Allah per esso, e anche se esteriormente può apparire come ribellione agli occhi della gente comune, nel caso di questa persona per la Legge non si tratta di ribellione. In questo modo sono considerati presso Allah gli atti di ribellione della Gente della Casa. Il Profeta, che Allah faccia scendere su di lui la Sua șalāt e la Pace, ha detto riguardo alla gente di Badr: "Che ne sapete? Forse Allah informerà la gente di Badr e dirà: fate ciò che volete, poiché vi ho già perdonato". È detto nello hadīt confermato: "Il servitore commette un peccato e dice: O mio Signore, perdonami! Allah risponde: Il Mio servitore ha commesso un peccato e sa che ha un Signore che perdona il peccato e che punisce per il peccato. Poi egli ritorna a commettere un peccato finché, alla terza o quarta volta, Egli gli dice: Fa ciò che vuoi, poiché ti ho già perdonato". Quindi gli ha permesso tutto ciò che gli aveva proibito, tanto che egli non fa se non ciò che gli è lecito di fare, e presso Allah non si parla nel suo caso di peccato: anche se noi ignoriamo colui che ha questa caratteristica, questo è il suo regime presso Allah che noi dobbiamo riconoscere e quello non toglie nulla alla sua dimora presso Allah", e nel Cap. 74 [II 142.25] aggiunge: "A conferma di ciò che abbiamo affermato, e cioè che il pentimento è riconoscimento e richiesta ma non fermo proposito di non ricadere, si può riportare quanto è affermato nelle notificazioni $(a h b \bar{a} r)$ divine: è tradizione autentica che "il servitore che commette peccato sapendo che ha un Signore che perdona il peccato e che lo punisce", senza aggiungere altro, analogamente a quanto fece Adamo, "poi commette peccato sapendo che ha un Signore che perdona il peccato e che lo punisce", per tre o quattro volte, Allah gli dice: "Fai ciò che vuoi, poiché ti ho già perdonato". È quindi prescritto dalla legge (mašrǘ) che Allah tolga la punizione del peccato a chi è qualificato da questo attributo, in base a chi ritiene che il discorso, che non riguarda chi non è qualificato da questo attributo, si applichi [per legge]. Quanto al senso esteriore dello hadīt, Allah, per via di questo attributo, gli rende lecito ciò che gli aveva vietato, così come permette di nutrirsi della carne di un animale morto a chi è in stato di necessità, malgrado essa sia vietata per questo stesso individuo quando non vale per lui lo stato di necessità. Inoltre Egli ci ha spiegato che Allah informa alcuni dei Suoi servitori su ciò che essi faranno nel futuro: come possono dunque proporsi di non ricadere in ciò in cui sanno per certo di ricadere? Infine non ci è pervenuta alcuna tradizione che confermi che il fermo proposito riguardo al futuro faccia parte della definizione del pentimento: quindi il pentimento non è altro che ciò che abbiamo affermato a proposito della storia di Adamo, su di lui la Pace". 
[lett.: non fare] ciò che vuoi”, ed ogni opera è perdonata per te, ed Allah non ordina le turpitudini e per questo ti ha reso lecito ciò. Considera ciò su cui ho richiamato la tua attenzione, ne trarrai giovamento se Allah, sia Egli esaltato, vuole.

Poi ha detto: "Non dimenticare, o aspirante, il tuo Maestro ed i tuoi fratelli, poiché il tuo Maestro è il tuo capo $(r a$ 's $)$ ed i tuoi fratelli le tue ali'. Poiché la faccenda comporta l'ascesa, l'elevatezza e l'innalzamento ed Egli ha posto come sede di quello i Cieli, ha dotato gli Angeli di ali a causa della discesa, non a causa della salita, come ha dotato di ali i corpi naturali di quelli che sono denominati uccelli [208] per la salita, non per la discesa, poiché essi discendono naturalmente e verso un lato specifico di proposito, e per quel proposito utilizzano le ali con cui si librano, che sono come le gambe per chi non ha le ali ${ }^{\left({ }^{67}\right)}$. L'Angelo sale naturalmente, mentre per discendere ha bisogno delle ali; questi corpi umani sono elementari ed hanno bisogno come strumenti di ascesa delle ali per farsi aiutare da esse, ed Allah, sia Egli esaltato, ha detto: "Aiutatevi l'un l'altro nella pietà e nel timore di Dio" (Cor. V-2) e per quello egli ha posto i fratelli a guisa delle ali con cui il servitore si fa aiutare nelle opere di bene. Ed ha fatto del Maestro il capo della faccenda, poiché quando il capo è tagliato cessa il movimento del corpo; analogamente, se la guida spirituale (muř̌id) non è integra l'aspirante brancola nel buio, ed è quindi indispensabile qualcuno che indichi la via: i primi di essi sono gli Inviati, poi gli eredi nel rango più sotto. Poiché il capo è la sede di tutte le facoltà esso merita il nome di capo per il suo essere a capo di tutte le membra, e poiché il governo di questo corpo appartiene a queste facoltà che il capo riunisce ed il Maestro è colui che governa l'aspirante nell'insieme dei suoi comportamenti, quest'uomo lo ha posto a guisa del capo, ed i fratelli a guisa delle ali per l'aiuto reciproco.

679) Nel Cap. 314 [III 53.34] Ibn 'Arabī precisa: "Agli Angeli non è dato di acquisire, anzi essi sono creati nelle loro stazioni e non le oltrepassano [...] Le facoltà che hanno gli Angeli e che sono chiamate ali [...] in ogni Angelo non hanno facoltà di muoversi liberamente al di sopra della stazione del loro possessore, come invece avviene per l'uccello che si getta in basso e che si libra in alto. Gli Angeli discendono con le loro ali verso ciò che è sotto di loro, ma non hanno facoltà di salire con esse al di sopra della loro stazione, e quando scendono con esse dalla loro stazione verso ciò che è sotto di essa ritornano poi in alto verso la loro stazione e non la oltrepassano. Essi non sono stati provvisti di ali se non per la discesa, così come l'uccello non è stato provvisto di ali se non per la salita: quando scende lo fa per la sua natura e quando sale lo fa con le sue ali, al contrario dell'Angelo che quando scende lo fa con le sue ali e quando sale lo fa naturalmente. Quindi le ali degli Angeli sono fatte per scendere verso ciò che è al di sotto della loro stazione, e quelle dell'uccello per salire al di sopra della loro stazione", e nel Cap. 357 [III 261.18] aggiunge: "Le ali degli Angeli sono per la discesa, non per la salita, mentre le ali dei corpi elementari sono per la salita, non per la discesa. Gli Angeli si dirigono verso le Sfere da cui deriva la loro esistenza per mezzo della loro natura, su cui è fondata la forma dei loro corpi, e quando scendono verso la Terra lo fanno volando con le loro ali, mentre ritornano alle loro sfere per un movimento naturale [analogo alla caduta dei corpi elementari per la forza di gravità], anche se muovono le loro ali, al punto che se non le muovessero ritornerebbero comunque alla loro dimora ed alla loro stazione. L'uccello, dotato di un corpo elementare, muove le sue ali per salire e se smettesse di muoverle o le stendesse scenderebbe naturalmente verso la Terra, e non stende le ali nella discesa se non per bilanciarla, poiché se non lo facesse e si abbandonasse alla sua natura si farebbe male nella discesa per la forza del regime naturale; quindi il movimento delle sue ali nella discesa è un movimento di protezione". 
Ed il suo detto: "non dimenticare il tuo Maestro ed i tuoi fratelli" vuol dire [ne] i luoghi di sosta (mawāqif) del Vero; quando Egli lo fa sostare, in quella occasione egli menziona bene al suo Signore il suo Maestro ed i suoi fratelli, ed Allah, sia Egli esaltato, darà loro del bene in proporzione a ciò che si sono proposti, se il loro proposito è più elevato del luogo di sosta di questo aspirante, e se il luogo di sosta dell'aspirante è più elevato del loro proposito Allah, sia Egli esaltato, dà loro in proporzione al luogo di sosta dell'aspirante, anche se il loro proposito è inferiore a quello [209] e ciò per la magnanimità (karam) onnicomprensiva di Allah, poiché l'aspirante è nella bilancia del suo Maestro per ciò che è da lui e [per] il suo legame $(s a b a b)$.

Eravamo presenti ad una riunione del Maestro 'Abd al-'Azīz ibn al-Karh $\left({ }^{680}\right)$, mentre parlava della conoscenza, e gli uomini erano di fronte a lui, ed era presente alla sua riunione il suo Maestro Ğarrāh ${ }^{(681)}$, Allah abbia misericordia di tutti loro, ed il Maestro Ǧarrāḥ era contento di lui e di ciò che Allah, sia Egli esaltato, aveva dischiuso a lui. Poi volse la sua testa verso di me e verso l'assemblea e disse: "Questo 'Abd al-'Azīz con la sua mini-spiritualità (ruwayḥ̂na) - e la indicò al diminutivo - è nella mia bilancia", ed 'Abd al-'Azīz, Allah abbia misericordia di lui, quando lo sentì menzionare ciò fu radioso in viso e sorrise. E questo Maestro, Ğarrāh, Allah sia soddisfatto di lui, che era di elevata stazione spirituale, ignorata tra i suoi compagni, non manifestò mai al suo discepolo, il Maestro 'Abd al-'Azīz, un barlume del suo stato. Così mi disse ed io gli chiesi perché ed egli rispose: "Non lo sopporterebbe!”. Questo Maestro, Ğarrāḥ, era tornato pentito [ad Allah] in occasione di una sessione (mağlis) di Abū Madyan, Allah sia soddisfatto di entrambi, quando era a Tunisi ed avvenne di lui ciò che avvenne. Il Maestro Abū Madyan, a Biğāya, quando gli veniva menzionato Ğarrāḥ diceva: "Se avessi delle ali volerei con esse da Ǧarrāḥ", elogiandolo con il suo proposito di visitarlo malgrado fosse uno dei suoi aspiranti $\left({ }^{682}\right)$. Egli aveva imparato a memoria la Mudawwana di Saḥnūn $\left({ }^{683}\right)$ nella scuola giuridica di Mālik, Allah sia soddisfatto di lui, e si occupava di scienza giuridica (figh) prima del suo pentimento. Fu tra coloro che mettono in opera ('ummāl), [cioè] i fedeli, morì e fu sepolto a Marsā 'Īdūn ( ${ }^{684}$ ), presso una torre di guardia sul mare a dodici miglia da Tunisi, e quando il Maestro 'Abd al-'Azīz, suo discepolo, morì, ordinò ai suoi compagni di seppellirlo a fianco di lui, e mi è stato riferito che egli è

680) Si tratta dello Šayh 'Abd al-'Azīz al-Mahdawī al-Qurašī già menzionato nella introduzione. Il soprannome (laqab) Ibn al-Karh, "figlio della riluttanza", è citato nel Cap. 277 [II 601.34]. L'episodio ebbe luogo in occasione della prima visita di Ibn 'Arabī a Tunisi, nell'anno 590 dell'Egira, data la presenza dello Šayh Ğarrāh, che morì in quell'anno.

681) Si tratta dello Šayh Abū 'Abd Allāh Ibn Ḩāmis al-Kinānī, morto nell'anno 590 dall'Egira, noto anche come "il chirurgo" (al-ğarrăh), professione che esercitava a Tunisi. Ibn 'Arabī lo menziona nel Prologo [I 10.2] e nel Cap. 25 [I 186.16]. Su di lui si può consultare Claude Addas, Ibn 'Arabī ou La quête du Soufre Rouge, Gallimard, 1989, pag. 144-146.

682) Lo stesso aneddoto è riportato nel Muhtasar ad-durra al-făhira, pag. 468 del primo volume delle Rasā ỉl Ibn al-'Arabī, Ibn al-'Arabī Foundation, 2013, e pag. 141 di Sufis of Andalusia, George Allen \& Unwin, 1971.

683) Su questo celebre giurista di Kairouan e sul suo Codice (mudawrwana) si può consultare l'articolo omonimo di Mohamed Talbi nella Encyclopédie de l'Islam, E.J. Brill 1995, Vol. VIII, pag. 872-875.

684) Oggi si chiama La Marsa o Marsā al-'Abdūn. 
stato sepolto di fianco a lui nella rada (marsā) menzionata. Tra coloro che ho incontrato non ho mai visto [210] uno che osservasse più di lui la Sunna, se non ciò che ho sentito del Maestro al-Haddād ${ }^{(685)}$, nello Yemen, da parte del Maestro Rabīc ibn Mạ̣mūd al-Māridīnī al-Ḥațāāb ( $\left.{ }^{686}\right)$; egli mi riferì che a costui non arrivava mai una notifica da parte dell'Inviato di Allah, che Allah faccia scendere su di lui la Sua salāt e la Pace, che implicasse l'opera senza che egli non la mettesse in atto.

Poi disse nella sua raccomandazione: "Se partecipi ad una riunione non sederti se non nel posto più infimo che ci sia, ciò con abbassamento e spezzamento, ed abbi di loro molto timore e venerazione, per chi è piccolo e chi è grande tra loro, stando con loro a testa bassa ed avendo pudore (hay $\vec{a})$ ". Egli dice: considera te stesso come il più piccolo del gruppo, poiché tu conosci te stesso meglio di loro.

Uno di loro ha detto: "Questa via non si addice se non a coloro a cui Allah fa scopare il letame con i loro spiriti” $\left.{ }^{687}\right)$, poiché chi si umilia per Allah, Allah lo eleva.

Egli ha fatto una simile raccomandazione per il semplice fatto che Allah, sia Egli esaltato, non Si manifesta in un'unica forma a due persone $\left.{ }^{(688}\right)$, ed uno non sa se Allah Si è manifestato ad ognuno del gruppo in una forma che è più elevata della forma in cui il Vero Si è manifestato a lui. Se le cose stanno effettivamente così egli [ritenendosi il più piccolo del gruppo] ha dato alla stazione spirituale ciò che le spetta, se invece egli è in realtà più grande del gruppo in questa teofania, allora si tratta da parte sua di una discesa $(n u z \bar{u} l)$ verso di loro, poiché egli è conforme a ciò che si è manifestato a lui, ed Allah, sia Egli esaltato, ha attribuito a Se stesso la discesa dai Suoi servitori ogni notte verso il Cielo più basso ${ }^{(689)}$ : la Sua discesa per mezzo di questa teofania nella discesa di questo aspirante è

685) La stessa affermazione è riportata nel Cap. 380 [III 502.2].

686) Ibn 'Arabī lo menziona nel Cap. 16 [I 160.27], ove precisa: "Ogni Pilastro (watad) ha uno degli angoli (arkān) della Casa: quello che è sul cuore di Adamo, su di lui la Pace, ha l'angolo siriano, quello che è sul cuore di Abramo ha l'angolo iracheno, quello che è sul cuore di Gesù, su di lui la Pace, ha l'angolo yemenita e quello che è sul cuore di Muhammad, che Allah faccia scendere su di lui la Sua salāt e la Pace, ha l'angolo della Pietra nera, ed esso è il nostro, sia lode ad Allah. Nella nostra epoca uno degli angoli fu [di] Rabīi ibn Mahmūd alMāridīnī al-Ḥattāāb e quando egli morì un'altra persona prese il suo posto. Allah aveva informato di loro in uno svelamento lo Šayh̆ Abū 'Alī al-Hawwārī, prima che egli li conoscesse e realizzasse le loro forme, ed egli non morì finché non riconobbe tre di loro nel mondo sensibile: egli riconobbe Rabī` al-Māridīnī, riconobbe il secondo, che è un persiano, e riconobbe noi, e stette in nostra compagnia finché morì, nell'anno 599. Egli ci informò di questo e mi disse: "Non ho riconosciuto il quarto"; questi è un abissino", nel Cap. 380 [III 502.2$] \mathrm{e}$ nel Cap. 560 [IV 505.15]. Ibn Hağar al-'Asqalānī, nel suo Al-isāaba fì tamyīz aș-șahāba riferisce che morì nell'anno 602 dall'Egira a Gerusalemme.

687) La frase è riportata nella Risāla di al-Qušayrī, a pag. 140 dell'edizione araba del Cairo del 1959, e a pag. 292 della traduzione di Alexander Knysh, "Al-Qushayrīs Epistole on Sufism", Garnet, 2007.

688) Argomento già affrontato a pag. 48 del manoscritto.

689) Riferimento ad uno hadīt riportato da al-Buhāāī, XIX-14, LXXX-13, XCVII-35, Muslim, VI-168 a 170 , Abū Dāwud, XXXIX-19, at-Tirmidīi, II-211, VI-38, XLV-78, Ibn Māğah, V-191, ad-Dārimī, II-168, e da Ibn Hanbal, IV-16. Ibn 'Arabī lo cita una quarantina di volte nelle Futūhăt; nel Cap. 41 [I 237.33] afferma: "Allah, sia Egli esaltato, discende verso di loro [gli uomini] di notte al Cielo più basso, in cui non c'è velo celestiale tra 
più vicina come relazione nella discesa di quanto lo sia la Sua discesa, sia Egli esaltato, [211] verso il Cielo più basso $\left({ }^{690}\right)$.

Quanto alla sua raccomandazione riguardo al suo sedersi nel gruppo con abbassamento e spezzamento è affinché egli cerchi in questo modo la Potenza ('izza) di Allah e la Sua riparazione di ciò per cui è a pezzi, che non è altro che la sua asserzione di una condizione dominicale (rabbāniyya) nella sua condizione di servitù ('ubüdiyya), che è una breccia (talm) nella sua servitù. Ed Allah, sia Egli esaltato, ripara per lui quella frattura e chiude quella breccia e gli accorda la potenza che ha preparato per i credenti in virtù del suo abbassamento. Se invece non è a pezzi [lett.: fratturato] e la sua servitù non è sbrecciata ed il suo sedersi è il sedersi di coloro che sono spezzati senza una reale frattura, allora il suo stato spirituale è lo stato della manifestazione del Vero nella più bassa $(a d n \bar{a})$ delle forme: comprendilo.

Quanto alla sua raccomandazione di sedersi nel posto più abietto, che è quello in cui il gruppo si astiene dal sedersi, apprezzando un posto di rango, in quanto Allah, sia Egli esaltato, ha detto riguardo ad Idrīs: "E lo innalzammo in un posto elevato" (Cor. XIX-57), attribuendo al posto l'elevatezza sugli altri, questo Maestro dice: non smettere di testimoniare la tua servitù in questo gruppo, sedendoti nel posto dei servitori rispetto ai padroni, poiché Allah non ti ha manifestato la Sua Potenza se non in misura di ciò, né la Sua Signoria (rubübiyya) se non in misura della tua servitù, ed ogni volta che realizzi qualcosa Egli ti conferisce il suo contrario in proporzione ad essa $\left.{ }^{691}\right)$. E non distinguere nella magnificazione $\left(t a^{c} z \bar{\imath} m\right)$ tra chi di loro è piccolo per età e chi è grande, poiché il piccolo per età talora è grande per rango; è stato detto riguardo a Giovanni: "E gli accordammo il giudizio mentre era bambino" (Cor. XIX-12), ed egli era grande [nel rango] malgrado fosse piccolo [per l'età].

Quanto alla sua raccomandazione sulla necessità di avere pudore di fronte a tutti - e non ha parlato di qualcuno in particolare - sappi che egli voleva che questo aspirante non facesse distinzione e li mettesse insieme in base ad un'unica faccenda. Non c'è dubbio che un gruppo non si riunisce se non per una interrelazione (munāsaba) [212] ed è necessaria una cosa sola che li riunisca, che non sia esclusivamente presso uno di loro, quindi l'oggetto di contemplazione di questo aspirante è quella cosa unica che li riunisce ed è di essa che deve avere pudore, sì che questo aspirante non sia separato, e riceva con l'aiuto $(i m d \bar{a} d$ ) divino da quella faccenda unica ciò che non è dato a nessun altro del gruppo, né al gruppo stesso, a meno che il grado di contemplazione di un altro del gruppo sia il suo grado di contemplazione.

Lui e loro. La Sua discesa è una misericordia per loro ed Egli Si manifesta loro dal Cielo di questo mondo, come è stato riferito nella notificazione, e dice: "Mente chi pretende di amarMi e dorme durante la notte incurante di Me. Ogni amante non cerca forse di stare solo con il suo amato? Eccomi, Mi sono manifestato ai Miei servitori. C'è qualcuno che prega, che Io possa esaudire? C'è qualcuno che è pentito, che Io possa ristabilire nella Mia Grazia? C'è qualcuno che chiede perdono, che Io possa perdonare?"”.

690) Nel Cap. 2 [I 61.5] Ibn 'Arabī precisa che si tratta del Cielo di Adamo, cioè quello della Luna.

691) Come aveva affermato nella pagina precedente: "chi si umilia per Allah, Allah lo eleva". 
Poi ha detto: "Non parlare per primo ad uno di loro, ma se uno di loro ti fa un accenno rispondi al suo accenno con $a d a b$, e se uno di loro ti parla osserva l'adab rispondendogli in modo gentile, rotto nell'aspirazione (himma) e con la testa bassa", come se egli, Allah sia soddisfatto di lui, incitasse ad usare la diplomazia (siyāsa), a guadagnarsi i cuori ed a mostrarsi amabile verso gli uomini: quindi non essere tu a prendere l'iniziativa, ma che la richiesta venga da loro. Loro non prendono l'iniziativa se non per una accettazione nei tuoi riguardi, mentre se sei tu a prendere l'iniziativa imponi a loro la risposta e chi risponde lo fa talora amorevolmente e talora non amorevolmente, volentieri o malvolentieri, mentre se sei tu a rispondere sei aderente all'adab in relazione a ciò che ti è detto.

È come se egli in questa sezione, ed Allah è più sapiente, si riferisse all'ascolto $(s a m \bar{a})$ dal Vero, non da te stesso, ma da fuori, poiché questi sono gli stati spirituali di coloro che ascoltano dal Vero. Per questo ti ha raccomandato l'adab nel dare la risposta, e l'abbassamento e la quiete, in quanto colui che parla con te è il Vero per mezzo delle lingue dei Suoi servitori [213] e questa è un stazione tutta di prova, pochi se ne salvano; abbiamo dedicato ad essa un capitolo, cioè una sezione, del "Libro dei luoghi ove tramontano le stelle (mawāqi ‘ an-nuğumm)" ( ${ }^{692}$ ), che spiega come sfuggire alle insidie di questa stazione, congiuntamente alla sua realizzazione $\left({ }^{693}\right)$.

692) A pag. 261 dell'edizione di ‘Abd al-`Azīz al-Manșūb, Ibn ‘Arabī afferma: "L'ascolto dal Vero fa parte delle stazioni spirituali di coloro che percorrono la Via, ed essa è una dimora che dà un immenso profitto e fa parte delle dimore del cuore. Essa è connessa con la Presenza dell'ascolto, ma la sua sede propria è questa. In questa dimora è facile fare passi falsi per chi non l'ha veramente realizzata ed è privo di un Maestro che lo guidi: ai nostri tempi molti di coloro che entrano in questa stazione commettono dei passi falsi e cadono in un abisso di rovina. La spiegazione di ciò è che in questa nobile Via vi è una stazione nella quale l'aspirante ottiene come frutto l'ascolto dal Vero e non vede nessuno nell'esistenza che gli rivolga la parola se non Allah, sia Egli esaltato, ed egli quindi si conforma a tutto ciò che gli viene ordinato. Tra coloro che hanno realizzato questa stazione c'era Huyr il tessitore (nassăğ); quando ottenne il frutto di questo proposito, cioè di ottenere questa stazione e di attualizzarla, venne subito messo alla prova: egli incontrò un uomo che gli disse: "Tu sei il mio servitore ed il tuo nome è Hayr", ed egli ascoltò questo dal Vero, poi, dopo questo, l'uomo che lo aveva impiegato per anni nella tessitura gli disse: "Tu non sei il mio servitore ed il tuo nome non è Hayr"."

693) Nel seguito del testo riportato nella nota precedente Ibn 'Arabī aggiunge: "Se Allah vuole, ti spiegherò la modalità di realizzazione di questa stazione, affinché tu non faccia passi falsi in essa, con l'aiuto di Allah. Devi sapere, figlio mio, che se Allah ti accorda di arrivare a questa dimora, ed io sono con te, Allah ti risparmierà la Sua insidia (makr), e se io non sono con te Allah ti faciliterà, tramite la mia lingua, di liberarti dall'inganno di questa dimora. Questa dimora consiste nel fatto che l'uomo vuole non ascoltare assolutamente nulla da se stesso né di ciò che si presenta nel suo proposito, poiché tutto ciò deriva dalla sua passione, non essendo egli ancora realizzato nella Via, ed è quindi prigioniero della sua passione, anche se si sforza di operare bene. Non vedi che Dِū n-nūn [al-Mișrī] ha detto: "Ogni atto che non procede da un'influenza [esterna] è una passione dell'anima"? Effettivamente anche se ti caricassi sulle spalle le montagne inamovibili e sopportassi delle prove che nessun'altro ha mai sopportato non saresti in questa dimora, poiché in tutto ciò sei tu a disporre con la tua volontà e per la passione della tua anima, e questo non è gravoso per l'anima. Ciò che è molto gravoso e difficile per l'anima è solo sottomettersi ad altro che se stessa, poiché per sua natura essa è portata alla supremazia ed alla ricerca della preminenza, e quando viene posta in secondo ordine e diventa subordinata al dominio ed al potere di un altro, costretta a fare secondo la volontà dell'altro, adeguandosi a ciò che le viene ingiunto come ordine e divieto, tutto ciò diventa penoso e duro per essa, anche se in realtà è facile. Questa dimora di 
Abbiamo detto che egli intendeva riferirsi all'ascolto dal Vero in questo discorso per ciò con cui ha completato [la sua raccomandazione], dicendo: "e nessuno di loro ti fa cenno, quindi sei noncurante del Suo accenno". Allah, Allah, dunque ha affermato che sei così e se lo ha fatto allora l'attributo della noncuranza fa parte dell'insieme dei tuoi attributi, e se ti avesse posto in questa stazione, come

cui stiamo parlando è per l'anima come morire alla sua volontà, e tra le sue condizioni, come di altre dimore, vi è quella che solo chi ha un Maestro può praticarla ed entrare in essa, poiché il Maestro è il suo medico, in grado di curare le malattie che insorgono in coloro che percorrono la Via. [...] Sappi, figlio mio, che l'entrata in questa stazione, ed in qualsiasi altra stazione spirituale, non è altro che un patto ('aqd) che l'uomo contrae con Allah, sia Egli esaltato, ed a cui vincola se stesso: attieniti dunque ad esso e non infrangerlo, poiché saresti tra i perdenti, coloro che infrangono il patto di Allah dopo averlo contratto. Lo stato di coloro che entrano in questa stazione è di due tipi: c'è chi viene messo alla prova in essa e chi non viene messo alla prova. Colui che non viene messo alla prova in essa è preservato ed assistito dal suo stato, ed egli si immagina, per la sua esperienza (dawq), che è la realtà essenziale della stazione a conferire ciò e che nessuno viene mai messo alla prova in essa, negando quindi che tale prova esista. Questa è una mancanza da parte sua, tuttavia egli è veridico poiché è un süfì e non asserisce se non ciò che ha gustato e contemplato, e non parla se non del suo stato. Ed è così che ti risponde se lo interroghi sul suo negare la messa alla prova; bisogna allora dirgli: "Ciò che hai trovato è esatto, ma il giudizio che ne ricavi è senza dubbio un errore. Evitalo e correggilo, attenendoti a ciò che hai gustato e tacendo di ciò di cui non hai scienza, e rimettiti agli altri come loro si rimettono a te". Coloro che Allah mette invece alla prova sono di due categorie: coloro che vengono messi alla prova per sollecitudine, interessamento e benevolenza al fine di una elevazione nella stazione e di un accrescimento nella scienza, e coloro che vengono messi alla prova per essere rimandati alla più bassa delle dimore. La forma in cui uno viene messo alla prova in questa stazione è ad esempio che gli si presenti una giovane che gli ordina di avere rapporti con lei, o che gli ordina di bere una coppa di vino, o di uccidere un uomo o di commettere qualcosa che è proibito dalla Legge: se egli compie uno di questi atti disobbedisce, pecca e viene ricacciato verso la più bassa delle dimore, e se rifiuta di compierlo manca al suo patto con Allah, ed è quindi tra due fuochi. Se Allah vuole, spiegheremo riguardo a questa stazione come egli possa mantenere il patto con Allah, sia Egli esaltato, che ha contratto con Lui, senza intraprendere qualcosa di proibito e commetterla, salvaguardando così la stazione, e senza che essa venga ripartita per lui, sì che egli ascolta dal Vero riguardo ad una cosa e non ascolta riguardo ad un'altra, poiché la dimora non ammette questo, ma ascoltando da Lui in ogni cosa. A colui che obietta dicendo: "Questo postulante $(t a \bar{l} i b)$ ha impegnato con un patto la sua intenzione a conformarsi a ciò che gli dice il Vero, a meno che in quel discorso non gli venga ordinato di commettere una cosa proibita", si deve rispondere:"Non è come dici, egli ha soltanto impegnato la sua intenzione all'ascolto dal Vero, in modo assoluto senza restrizioni". E se egli chiede come ciò sia possibile noi rispondiamo che quando l'aspirante vuole mantenere il suo patto in questa stazione senza commettere un atto proibito se Allah lo mette alla prova, a colui che gli dice: "Bevi questo vino o compi adulterio con questa ragazza, poiché se non lo fai infrangi il tuo patto con Allah, sia Egli esaltato", deve rispondere: "Lungi da me! Anzi sono certo, per la mia stazione nell'ascolto dal Vero da fuori e non da dentro di me, che Allah, sia glorificato, si è rivolto a me e mi ha parlato tramite la lingua del Suo Profeta Muhammad, che Allah faccia scendere su di lui la Sua șalāt e la Pace, ordinandomi di non fare ciò che hai menzionato, e quando ho ascoltato questo discorso profetico ho detto: "Ho ascoltato ed obbedisco", facendo un patto di obbedienza con Allah. Ed io non ho smesso di realizzare questa mia stazione nell'ascolto dal Vero, poiché colui che ha parlato [cioè il Profeta] "non parla per passione" (Cor. LIII-3). Ma poiché ho realizzato questa stazione in questo ascolto e l'ho asserito, il Vero ha voluto mettermi alla prova per far conoscere alla mia anima il suo atteggiamento riguardo a ciò, e mi ha trovato, sia lode ad Allah, ossequiente a quel patto che avevo contratto quando avevo ascoltato da Lui. E questo discorso che diceva: "Bevi questo vino e fai ciò che ti è stato proibito di fare" l'ho sì ascoltato dal Vero ma si tratta di un ascolto di probandato da parte Sua nei miei riguardi" [...] Il süfi dunque in questa stazione ascolta e si conforma a ciò che ha ascoltato, ma solo nelle faccende che sono lecite, ed in questo modo si libera dalla passione della sua anima, attenendosi in quello all'ordine di un altro". 
ha posto l'altro, non ti avrebbe detto di non essere noncurante dell'accenno di Colui che ti fa accenno; questa è la condizione di colui che ascolta dal Vero, non c'è altra stazione che questa, cioè tra le stazioni della Via.

Quanto al suo ordine di essere rotto nell'aspirazione, di tenere la testa bassa e di rispondere in modo gentile, ciò corrobora quanto abbiamo menzionato riguardo all'intendimento di colui che ha fatto questo discorso, e cioè che egli intendesse riferirsi all'ascolto dal Vero, poiché l'aspirazione non è correlata se non con il Vero. Se essa arriva fino a questo non vi arriva senza che veda [colui che le parla] identico al Vero che è ricercato - poiché "dietro ad Allah non c’è bersaglio" (694) per una aspirazione - ed il suo essere a pezzi per la penetrazione (nufüd) [del Vero] in colui che le parla è identico al suo ritorno a Lui.

"E con la testa bassa" in questa stazione, per pudore verso la contemplazione, poiché egli vede che colui che gli parla e che gli chiede risposta da parte sua è il Vero in questo supporto epifanico (mağlā) creato.

"E [rispondendo] in modo gentile" dopo aver [taciuto per] prestare ascolto al Suo discorso in occasione della Sua richiesta, e ciò corrisponde al Suo detto: "Invero coloro che abbassano la loro voce presso l'Inviato di Allah" (Cor. XLIX-3), "Non alzate la vostra voce sopra la voce del Profeta e non rivolgetevi a lui nel modo in cui vi rivolgete tra di voi" (Cor. XLIX-2). Questo perché l'Inviato è il supporto epifanico [214] del Vero, ed egli è il Vero che parla ai Suoi servitori in questo supporto epifanico, ed il Discorso del Vero è tutto Corano, ed Egli ci ha ordinato di tacere durante la recitazione [del Corano] e di prestargli ascolto $\left.{ }^{695}\right)$, e se ci ha chiesto di rispondere a quello, noi rispondiamo nel modo più gentile e bello, come fecero i ğinn quando l'Inviato di Allah, che Allah faccia scendere su di lui la Sua șalāt e la Pace, fece loro ascoltare la Sūra del Misericordioso, ed ogni volta che diceva loro: "Dunque, quale dei benefici del vostro Signore dichiarate mendaci voi due [uomini e ǧinn]?” (Cor. LV-13), essi dicevano per risposta: "Nessuno dei Tuoi benefici, o nostro Signore, noi dichiariamo mendace”. Essi nella risposta non si rivolsero se non al Vero, travalicando l'Inviato, ed essi non lo ascoltarono se non dal Vero e non risposero se non al Vero, e per questo usarono la particella del discorso (harf al-hitāb) [Tuoi] nel loro detto: "dei Tuoi benefici”. E l'Inviato di Allah, che Allah faccia scendere su di lui la Sua șalāt e la Pace, fece il loro elogio quando risposero in quel modo e pose quello come un bell'esempio di ascolto, anteponendoli ai Compagni tra gli uomini, poiché erano inferiori a loro nell'ascolto $\left.{ }^{696}\right)$.

694) Hadīt già riportato a pag. 19 del manoscritto.

695) Riferimento a Cor. VII-204.

696) Ibn 'Arabī riporta questo episodio nel Cap. 73, questione CXI [II 106.10] ove precisa: "Il silenzio [dei Compagni] non era dovuto ad ignoranza del fatto che i benefici provenissero da Allah, né i ginn avevano più conoscenza di loro riguardo all'attribuzione dei benefici ad Allah, ma i ğinn rispettarono la perfezione della situazione esteriore dicendo: "Nessuno dei Tuoi benefici, o nostro Signore, noi dichiariamo mendace", come esigeva la circostanza [a domanda risposta], mentre i Compagni tra gli uomini non lo dissero quando veniva 
È noto che l'Inviato era colui che seguiva $(t \bar{a} l \vec{\imath})\left({ }^{697}\right)$, e chi recita il Corano è denominato "colui che segue $(t \bar{a} l \hat{\imath})$ ", in quanto segue il Vero in quello, poiché il discorso che recita colui che recita appartiene ad Allah, ed egli Lo segue $\left.{ }^{(698}\right)$. Colui che lo ascolta non lo ascolta se non da Lui e non lo attribuisce a colui che recita/segue, intendo dire quello che gli arriva del discorso, e colui che lo ascolta non lo ascolta se non da Allah, sia Egli esaltato $\left({ }^{699}\right)$, per mezzo del Suo udito, e dalle parole dell'Inviato per

recitato loro perché erano occupati ad acquisire la scienza, che essi non avevano, di ciò che l'Inviato di Allah, che Allah faccia scendere su di lui la Sua șalāt e la Pace, stava comunicando. Questa avidità (hirs) [di sapere] li distolse dal rispettare il momento di dire ciò che dissero i ğinn, per trarre profitto di ciò che il Profeta, che Allah faccia scendere su di lui la Sua șalat e la Pace, diceva riguardo alla scienza. Il loro desiderio di acquisire la scienza era più intenso di quello dei ğinn, ma i ğinn furono più capaci di loro a rispettare l'adab, rispondendo come richiedeva la circostanza. L'Inviato di Allah, che Allah faccia scendere su di lui la Sua șalāt e la Pace, li lodò per ciò in cui avevano mostrato un'eccellenza rispetto agli uomini,ma non lodò gli uomini per ciò in cui avevano mostrato un'eccellenza rispetto ai ğinn, e cioè per la loro avidità di un accrescimento nella scienza con il loro silenzio durante la recitazione, e soprattutto perché il Vero aveva detto loro: "Quando viene recitato il Corano, ascoltatelo attentamente ed in silenzio" (Cor. VII-204) e si trattava di una unica e stessa Sūra ed il discorso non era completo [poiché si trattava di un versetto di essa] e quindi essi tacquero finché non fu completo. I Compagni tra gli uomini riunirono dunque due eccellenze che l'Inviato di Allah, che Allah faccia scendere su di lui la Sua salät e la Pace, non ha menzionato, mentre ha menzionato l'eccellenza dei ğinn per ciò che essi avevano detto, che era espressione della servitù nella lingua dell'esteriore; ma essi erano servitori anche nella lingua dell'interiore ed avevano quindi riunito le due lingue nella loro risposta, mentre gli uomini tra i Compagni non lo avevano fatto al momento della recitazione, per la loro mancanza di questa lingua. L'Inviato di Allah, che Allah faccia scendere su di lui la Sua salät e la Pace, li rimproverò per insegnare loro ciò che esigevano le circostanze, cioè le circostanze in cui le lingue devono parlare, e per metterli in guardia affinché non sfuggisse loro in ciò il bene nell'opera. In quel momento essi erano intenti al bene nella scienza, ma la scienza non si oppone al regime dell'opera nella sua sede, poiché il regime dipende dalla sede, e [d'altra parte] l'opera non si oppone al regime della scienza nella sua sede. I ğinn sono estranei al dominio dell'esteriorità e si affrettano quindi a manifestarsi esteriormente per far sapere di aver preso piede in esso, poiché essi [per natura] sono nascosti e sono più prossimi all'interiore che all'esteriore, rispetto agli uomini; d'altra parte la recitazione avveniva con la lingua dell'esteriore. Gli uomini invece appartengono al grado dell'esteriore ed è la loro appartenenza alla sede dell'esteriore che li ha velati dal rispondere come hanno risposto i ğinn", e nel Cap. 300 [III 3.20] "Al rango elevato (šaraf) dei ğinn rispetto a noi è collegato il fatto che il Profeta, che Allah faccia scendere su di lui la Sua salāt e la Pace, allorquando recitò ai suoi compagni la Sūra del Misericordioso disse loro: "Invero l'ho recitata ai vostri fratelli tra i ğinn ed essi le hanno prestato miglior ascolto di voi", e menzionò lo hadīt in cui è detto: "Appena dissi loro: Quale dei benefici del vostro Signore dichiarate mendaci voi due? essi risposero: Nessuno dei Tuoi benefici, o nostro Signore, noi dichiariamo mendace!'”"

697) Il verbo talā in arabo significa sia seguire, imitare, che leggere, recitare.

698) Nel Cap. 47 [I 257.22] Ibn 'Arabī precisa: "Non si addice, a chi ha realizzato, di menzionare Allah se non con le formule rivelate nel Corano, di modo che nella sua menzione $(\underline{d} i k r)$ egli reciti/segua e riunisca la menzione e la recitazione in una sola espressione verbale, ottenendo così la ricompensa di coloro che recitano e quella di coloro che menzionano".

699) Nel Cap. 69 [I 395.14] Ibn 'Arabī afferma: "La stessa cosa vale per il Suo discorso, sia Egli esaltato, al Suo Profeta Muhammad, che Allah faccia scendere su di lui la Sua salāt e la Pace, riguardo all'arabo: "accordagli [asilo] affinché ascolti il discorso di Allah" (Cor. IX-6) ed egli non ascoltava se non i suoni e le lettere che uscivano dalla bocca del Profeta, che Allah faccia scendere su di lui la Sua șalāt e la Pace. Ed Allah ha detto: "Invero quello è il Mio discorso" e lo ha attributo a Se stesso ed il Vero è apparso nel mondo della realtà visibile nella forma di colui che recitava il Suo discorso". 
mezzo del suo orecchio, che è la sede dell'udito nel momento in cui colui che ascolta è velato dal fatto che Allah è il suo udito e la sua vista. E se fa parte della gente di quest'altra stazione allora colui che ascolta e colui che riferisce sono un'unica entità in due forme diverse, per due condizioni diverse $\left({ }^{700}\right)$, che esulano dal contesto a cui faceva allusione questo Maestro, Allah abbia misericordia di lui, nella sua raccomandazione, ed Allah è più sapiente.

Poi ha detto: [215] "E se nella riunione c'è chi è segnato a dito e vedi che il gruppo lo serve e si comporta con lui, di fronte a lui, secondo le regole dell'adab, sappi che egli è il tuo signore Muhammad, che Allah faccia scendere su di lui la Sua salāt e la Pace”. Questo richiama la tua attenzione sul fatto che gli spiriti indossano le vesti degli edifici [corporei] (hayākil), come mi riferì Awḥād ad-dīn Hāamid ibn Abī-l-Faḩr al-Kirmānī $\left({ }^{701}\right)$, Allah sia soddisfatto di lui.

Egli disse: "Ero al servizio di un Maestro, durante il mio ritorno dal pellegrinaggio, ed egli venne colpito da dissenteria, cioè da scariche intestinali. La sua sofferenza era penosa per me, e gli chiesi di lasciarmi parlare con il direttore dell'ospedale (bīmāristān) che si trovava sul cammino, ma egli me lo proibì. Quando però vide che la sua proibizione riguardo a quello era penosa per me, mi disse una notte: "Parti per l'ospedale che si trova sul cammino e portami una medicina". Io mi rallegrai e partii alla volta della sede dell'ospedale del signore di Sanğār $\left({ }^{702}\right)$. Una candela era accesa di fronte a lui nella sua tenda, e la sua comunità era in piedi davanti a lui al suo servizio; c'era un servitore che quando mi vide tra la folla si avvicinò a me, mi accolse e mi chiese di cosa avessi bisogno, e prima di allora non mi conosceva né ci eravamo mai incontrati. Egli appagò la mia necessità e mi portò il rimedio, ed io uscii con esso, contento, verso il Maestro. Egli uscì mettendosi al mio servizio ed io gli dissi di non farlo, per timore del Maestro, ed egli voleva ad ogni costo accompagnarmi per una parte della via, ma io rinunciai a lui ed egli tornò. Andai dal Maestro e gli raccontai la vicenda e tutto ciò che era successo, ed egli disse: "Hai detto il vero" e prese la medicina e non la usò; poi disse: "Ragazzo mio, non avevo bisogno di questa medicina, e ti ho ordinato di fare quello quando ho visto la pena che il tuo cuore provava per me, [216] ed ho avuto compassione per te. Ma quando ti ho mandato ho temuto per te che ti mandassero via, spezzandoti il cuore. Mi sono spogliato allora dal mio edificio [corporeo] ed ho indossato l'edificio [corporeo] di chi aveva il rimedio (sabīl), cioè quel servitore, ed ero io che ti ho accolto e che ho appagato la tua necessità, non lui, per confortare il tuo

700) La stessa affermazione si trova nel Cap. 369 [III 404.10].

701) Coetaneo di Ibn 'Arabī ma nativo di Kirmān, nell'attuale Iran, dopo aver viaggiato estesamente nel vicino oriente si trasferì a Bagdād ove morì nell'anno 635 dall'Egira. Ebbe migliaia di discepoli e l'unica opera scritta che rimane di lui sono le sue quartine persiane, tradotte da Bernard Weischer e Peter Lamborn Wilson in Heart's Witness, Imperial Iranian Academy of Philosophy, Teheran, 1978. Ibn 'Arabī lo incontrò a Qunya nell'anno 602 dall'Egira, come precisa lui stesso nel Kitāb al-amr al-muhkam [cfr. Asín Palacios, "El Islam Cristianizado", Editorial Plutarco, Madrid, 1931, pagg. 310] e quello fu l'inizio di una trentennale amicizia, tale che Ibn 'Arabī affidò ad Awhāe ad-dīn il compito di istruire suo figlio adottivo Șadruddīn al-Qūnawī. Su di lui si può consultare Claude Addas, Ibn 'Arabì ou La quête du Soufre Rouge, Gallimard, 1989, pag. 269-274.

702) La città di Sanğār dista circa 200 chilometri da Takrīt, luogo ove essi si trovavano. 
cuore. Se tu hai dei dubbi al riguardo, verifica la mia veridicità ritornando da lui senza che io rivesta la sua forma, ed osserva". Egli disse: "Mi presentai a lui il giorno successivo ed egli mi mandò via senza accogliermi, comportandosi con me all'opposto di ciò che avevo visto di lui il giorno prima. Ritornai dal Maestro e lo informai dell'avvenuto" $\left({ }^{703}\right)$.

Non c'è dubbio che gli eredi sono edifici [corporei] per la spiritualità del Profeta, che Allah faccia scendere su di lui la Sua șalāt e la Pace, ed egli è dunque Inviato per sempre, vivo e morto. Chi obbedisce al Maestro obbedisce all'Inviato, che è lo spirito del suo edificio [corporeo], e chi obbedisce all'Inviato invero obbedisce ad Allah, poiché egli è il Suo supporto epifanico e quindi l'Inviato è la sede della manifestazione del Vero.

Poi Egli cessa di essere (yafna $)$ l'Inviato con il Suo detto, sia Egli esaltato: "Chi obbedisce all'Inviato invero obbedisce ad Allah" (Cor. IV-80) e ciò che tu osservi nell'Inviato è Allah, sia Egli esaltato, e quindi scompare l'Inviato e resta il Vero $\left({ }^{704}\right)$. E come il Vero resta, testualmente, nella scomparsa dell'Inviato, così l'Inviato resta nella scomparsa del Maestro dalla tua vista interiore, e resta il Vero, poiché è Lui che parla dall'Inviato.

Egli ti ha quindi detto: "sappi che egli è il tuo signore Muḥammad, che Allah faccia scendere su di lui la Sua șalāt e la Pace" perché nel tuo procedere (sulūk) tu segui la sua Legge, la sua Sunna e la sua Via, e colui che in questa comunità è soggetto all'incombenza legale inevitabilmente, nel suo moto e nel suo restare immobile, ed in tutti i suoi stati, si trova in uno stato in cui vige uno dei regimi giuridici $(a h k \bar{a} m)$ della Legge ed il regime della Legge è vincolante per lui e non lo abbandona. Per

703) Lo stesso episodio è riportato nel Cap. 8 [I 127.25].

704) Nel Cap. 486 [IV 122.10] Ibn 'Arabī afferma: "Allah, sia Egli esaltato, ha detto: "Chi obbedisce all'Inviato, invero obbedisce ad Allah" (Cor. IV-80), poiché egli non parla se non da Allah, anzi non parla se non per mezzo di Allah, anzi non parla se non per Allah da parte Sua, poiché egli è la Sua forma. E non è stato tramandato: "Chi disobbedisce all'Inviato, invero disobbedisce ad Allah" come ha fatto per l'obbedienza, poiché l'obbedienza della creatura è intrinseca [o immediata, diretta], mentre la sua disobbedienza è per mezzo dell'intermediario [o mediata, indiretta]. Se Egli avesse posto qui l'Inviato allo stesso modo in cui lo ha posto riguardo l'obbedienza non sarebbe Dio, ma Egli è Dio e non viene disobbedito se non per un velo ed il velo non è altro che l'entità dell'Inviato. Noi oggi siamo più lontani dal disobbedire all'Inviato rispetto ai suoi Compagni ed a coloro che sono venuti dopo di loro fino a noi, poiché noi disobbediamo solo a coloro che detengono il comando su di noi nel nostro momento, cioè quelli di noi che hanno scienza di ciò che Allah ha ordinato e di ciò che ha proibito. Noi abbiamo quindi una punizione minore ed una ricompensa maggiore, poiché uno di noi ha la ricompensa di 50 volte per chi compie l'opera dei Compagni; egli, che Allah faccia scendere su di lui la Sua șalät e la Pace, ha infatti detto [ai suoi Compagni]: "Uno di loro che compia un'opera simile alle vostre avrà la ricompensa di 50 di esse" e poni attenzione al fatto che non ha detto "uno di voi".", e nel Cap. 558 [IV 255.23] aggiunge: "Egli ha assunto le vesti (talabbasa) dell'Inviato, ed ha detto: "Chi obbedisce all'Inviato, invero obbedisce ad Allah" (Cor. IV-80), confermando che egli non è venuto da Lui ( $m i n-h u)$ se non al posto Suo (illā $b i-h i)$ e non Lo ha lasciato. Le creature a cui è stato inviato non vedono se non l'Inviato, ed il suo lato esteriore è creatura (halq) mentre il suo lato interiore è Verità (haqq), come ha detto riguardo al patto: "Invero essi fanno il patto con Allah" (Cor. XLVIII-10)". 
questo ti ha detto: "sappi che egli è il tuo signore Muhammad, [217] che Allah faccia scendere su di lui la Sua șalāt e la Pace”, poiché il Maestro non viene segnalato se non per la realizzazione della sua osservanza $\left(i t t i b \bar{a}^{c}\right)$. E per questo, quando vediamo chi pretende in questa comunità di avere la stazione della chiamata ad Allah in base ad una visione interiore ed infrange una delle regole della Legge tradizionale, anche se si manifestasse in lui una di quelle rotture dell'ordinario che abbagliano gli intelletti e dicesse che quella è una regola di comportamento che lo caratterizza in proprio e che non vi bada, quello non è un Maestro né un realizzato, poiché i segreti di Allah, sia Egli esaltato, non sono affidati se non a colui che serba in sé le regole della Legge tradizionale.

Ma è un requisito indispensabile che permanga in lui la consapevolezza razionale dell'incombenza ('aql at-takliff), poiché se gli capita qualcosa che lo fa uscire dalla consapevolezza razionale dell'incombenza, allora lo si lascia al suo stato e non lo si prende come esempio $\left({ }^{705}\right)$, ed egli è beato. Nel momento in cui gli viene sottratta la consapevolezza razionale dell'incombenza egli è a guisa del Maestro quando muore, e come [al momento della morte] il suo spirito viene preso nello stato in cui si trova, così a costui che è preso da follia la sua ragione viene presa nello stato in cui si trova, e la sua beatitudine rimane come la beatitudine del morto, e la sua anima logica non ha governo sul suo edificio [corporeo] per il venir meno delle sue facoltà. Egli resta come gli animali governato dal suo spirito vitale e non viene criticato, perché Allah non lo ha assoggettato all'incombenza legale come non ha assoggettato i morti, anche se sono beati $\left({ }^{706}\right)$.

705) Analoghe considerazioni sono riportate nel Cap. 181 [II 366.1].

706) Nel Cap. 226 [II 522.22] Ibn 'Arabī afferma: "Solo colui di cui Allah è soddisfatto ottiene questa stazione [della conoscenza di Allah]: tra i segni distintivi di colui che la possiede è quello di accollarsi (mu ānaqa) le regole della buona creanza (adab), a meno che per questa contemplazione (mušăhada) non venga privato della ragione ('aql), nel qual caso, come per i folli [(bahālinl), termine che significa anche buffoni, giullari] e per i folli dotati di ragione ('uqalā' al-maǧăninn), non gli è richiesto di rispettare queste regole. Nel loro caso sopravviene improvvisamente una faccenda $(\mathrm{amr})$ divina che essi sono troppo deboli per sostenere e che fa quindi perdere loro la ragione; al cospetto di Allah è come se essi fossero morti in una condizione di contemplazione diretta $($ šuhüd), caratterizzati dalla rettitudine (istiqāma), e tuttavia continuassero ad esistere. Il loro modo d'essere è simile a quello dell'animale, che ottiene tutto ciò che la sua natura esige, quanto a bere e mangiare, all'accoppiamento ed ai modi di espressione ( $k a l \bar{a} m$ ), senza alcuna restrizione e senza alcuna rivendicazione (mutālaba) da parte di Allah e nello stesso tempo è caratterizzato da uno svelamento ( $k a s ̌ f)$. Agli animali in effetti viene svelata la vita del morto, che posto sul feretro emette un forte grido e dice, se è tra coloro che sono destinati al Paradiso: "Fatemi avanzare! Fatemi avanzare! (qaddimūn $\vec{\imath}$ ", mentre se è tra coloro che sono destinati all'Inferno dice: "Dove mi portano?"; essi sono quindi testimoni del castigo della tomba e vedono ciò che gli uomini ed i ğinn (at-taqalān) non vedono. Per questo diciamo che colui a cui Allah ha portato via la ragione nel corso della contemplazione è simile all'animale (hayawān); come quest'ultimo si può dire morto in base a ciò che per lui è morto, così quest'uomo folle (bahlül) si può dire morto per il fatto di essere stato privato della ragione: egli viene quindi annoverato tra i morti per aver perduto la ragione e tra i vivi per il persistere della sua natura $\left(t a b^{c}\right)$. Si tratta di esseri, questi, che fanno parte dei beati di cui Allah è soddisfatto, come Mas'ūd al-Habašī ed 'Alī al-Kurdī e tanti altri che abbiamo visto in questa condizione sia in Oriente che in Occidente: essi fanno parte dei servi di Allah ed Allah ci sia di aiuto per mezzo di loro in uno stato $(h \bar{a} l)$ simile. Se a colui che si trova in questo stato viene restituita la ragione, mentre vive in questo mondo, all'istante egli si mette ad osservare le regole tradizionali e se le accolla. Ma per gli iniziati colui che conserva la ragione è più perfetto e più elevato: fu chiesto al Maestro 
Comprendi ciò che ti abbiamo menzionato: ne sarai felice, poiché la maggior parte della gente della Via ignora questo stato, e che dire della massa dei dottori della Legge? Se essi fossero a conoscenza di ciò che abbiamo detto non sarebbero in grado di negarlo, e ciò che li vela è solo quello che essi vedono di lui dei suoi moti naturali, come mangiare, bere, accoppiarsi ecc., ed essi dicono che come egli si accoppia, mangia e beve, così [deve] fare la salāt, ed è la forma umana apparente che li inganna. Essi non sanno [218] che egli è un animale nella forma di un uomo, e che la sua anima logica è stata trasferita al barzah, come quella dei morti, anche se essa ha cura di questo edificio, e per via del sopraggiungere del termine stabilito, che è proprio dello spirito vitale in ogni animale, egli muore, poiché la morte appartiene all'animale [essere vivente], non all'uomo, se non in quanto è un animale. Comprendi, e credi ai folli (mağān̄̄n) della gente di Allah, ma non seguirne l'esempio, a differenza di quelli di loro che sono dotati di ragione $\left({ }^{707}\right)$.

Poi ha detto, dopo una preghiera che ha fatto per sé e per i musulmani: "E sappi che ciò è dovuto all'aspirazione del tuo maestro, del Maestro del tuo Maestro, dei fratelli del tuo Maestro e dei ragazzi del tuo Maestro". Egli dice: e sappi che il fatto che il Vero ti faccia vedere Muhammad, che Allah faccia scendere su di lui la Sua salāt $\mathrm{e}$ la Pace, in questa stazione è un segno della massima sollecitudine divina nei tuoi confronti, e ciò ha luogo per l'aspirazione (himma) di chi ha menzionato, se chi ha menzionato aveva una aspirazione correlata ad Allah nei riguardi dei tuoi simili. E sappi che il fatto che Allah, sia Egli glorificato ed esaltato, mostri Se stesso, sia Egli esaltato, a chi vuole dei Suoi servitori, non sta certo ad indicare l'elevatezza della sua stazione e del suo stato spirituale, poiché il Vero è nel credo ('aqd) di chiunque abbia un credo, sia esso piccolo o grande, ed Egli è diverso nelle

Abū as-Su'ūd ibn al-Šibl che cosa pensasse di quelli che, tra la gente di Allah, manifestano una apparente follia ed egli, Allah sia soddisfatto di lui, rispose: "Essi sono belli (mulăh), ma colui che è dotato di ragione è più bello (amlahu $)$ ", volendo così indicare che nei riguardi di colui che conserva la ragione la Provvidenza ('ināala è stata più completa".

707) Nel Cap. 44 [I 248.4] Ibn 'Arabī precisa: "Allah, sia Egli esaltato, ha detto: "e vedrai gli uomini ubriachi, mentre essi non sono ubriachi" (Cor. XXII-2); questo si riferisce ad una gente (qazm) di Allah la cui ragione, per lo stato in cui si trovano, è velata riguardo agli atti che il Vero, sia Egli esaltato, ha imposto loro nel Suo Libro [...] Essi non sapevano che Allah, sia Egli esaltato, il Vero, sopravviene d'improvviso a chi si ritira in segreto con Lui, obbedisce al Suo comando e prepara il suo cuore a ricevere la Sua luce; ed il Vero è venuto da loro improvvisamente, senza che essi se ne accorgessero o lo sapessero, non essendo predisposti per una realtà così straordinaria, ed ha portato via così la loro ragione. Ma Egli ha fatto sì che essi non cessassero di contemplare quella realtà che li ha colti di sorpresa, e quindi sono perdutamente innamorati di essa e vi scompaiono: nel mondo delle apparenze essi restano solo con il loro spirito animale, mangiando, bevendo e disponendo liberamente nelle loro necessità, con l'arbitrio dell'animale che riconosce istintivamente ciò che è vantaggioso per lui e ciò che non lo è, senza riflettervi [...] Costoro sono chiamati i folli dotati di ragione ('uqalàa'al-mağaññn), perché il motivo della loro follia non è una alterazione di temperamento dovuta ad una causa contingente come un cibo o la fame, bensì una manifestazione (tağall $\vec{x}$ ) divina nei loro cuori, una visita improvvisa del Vero che li ha colti di sorpresa ed ha fatto perdere loro la ragione. Quest'ultima invero resta segregata presso di Lui, beneficiando della Sua contemplazione ritirata nella Sua Presenza: essi quindi sono dotati di ragione, ma essendone privi in apparenza sono conosciuti esteriormente come dei folli, cioè come coloro che sono sottratti alla direzione della loro ragione". 
credenze $(i$ tiqāa $\bar{a} t)$ conformemente a ciò con cui sono connesse quelle credenze $\left({ }^{708}\right)$. Da quello non si riconosce l'elevato da chi è più elevato, né chi è impeccabile da chi non è impeccabile, poiché "Allah - sia Egli esaltato - è presso la lingua di chiunque parli”" ${ }^{709}$ ), cioè è con ciò che dice, e quindi è presso il credo di chiunque abbia un credo, e presso la più alta e la più elevata credenza. Ogni credenza in Allah, quanto è Potente e Magnificente, il suo possessore la prende da un Libro divino rivelato o dalle notificazioni dell'Inviato di Allah, che Allah faccia scendere su di lui la Sua salāt e la Pace, o da uno degli Inviati, e, al di sotto di queste, da ciò che indica la ragione, e tra i due [219] da ciò che concepisce formalmente l'immaginazione tra la ragione e le notificazioni. Non ci sono che queste tre categorie: o un Dio di cui un intelletto sano indica ciò che Gli può essere attribuito, o una Legge stabilita e fissata, o una immaginazione $(w a h m)\left({ }^{710}\right)$ che ha una concezione formale riguardo ad una

708) L'argomento è stato già affrontato a pag. 152 del manoscritto.

709) Hadīt non recensito nelle raccolte canoniche; Ibn 'Arabī lo riporta nei capitoli 182 [II 367.13] ove afferma: "Tra di noi c'è chi parla per Lui, come ha detto [il Profeta]: "Invero Allah ha detto tramite la lingua del Suo servitore "Allah ascolta chi Lo loda"”, ed il possessore di questa stazione parla sempre come [Suo] rappresentante, e tra di noi c'è chi pensa di parlare per se stesso, ma le cose non stanno così in realtà, poiché Allah è presso la lingua di chiunque parli, e come non c'è che Allah nell'esistenza, così non c'è chi parla, né chi ascolta, all'infuori di Allah", 500 [IV 137.6], ove aggiunge: "Sappi che [...] ogni opera ha una retribuzione, e la parola è un'opera, è quindi ha una retribuzione, poiché Allah è presso la lingua di chiunque parli, e dopo i propositi improvvisi non c'è opera più veloce di essa, cioè della lingua", 522 [IV 165.9], 544 [IV 187.19], ove precisa: "L'Inviato di Allah, che Allah faccia scendere su di lui la Sua șalāt e la Pace, ha detto: "Allah è presso la lingua di chiunque parli", senza specificare, bensì usando una forma indeterminata. Chiunque abbia una lingua è uno che parla ed egli quindi è presso Allah [...] Quando egli compie un'opera l'Angelo [custode] sa che ha compiuto una certa opera specifica, ma non la trascrive finché egli non ne parla, poiché i custodi sanno ciò che ha fatto il servitore, ma non gli registrano un'opera finché egli non ne parla, e quando ne parla la trascrivono [...] Il motivo di ciò è che essi non sono a conoscenza dell'intenzione del servitore in quell'atto [...] intenzione che è conosciuta solo da Allah e da colui che compie l'atto", 558 [IV 232.20 e 292.32], 559 [IV 362.34], in cui afferma: "Allah è presso la lingua di chiunque parli, ed è Lui Colui che parla. Sii attento quindi al Suo detto: "Io sono il suo udito con cui ascolta e la sua lingua con cui parla"”, e 560 [IV 450.12] in cui precisa: "È tuo dovere controllare ( $m u r \bar{a} \bar{a})$ le tue parole così come controlli le tue opere. Invero le tue parole fanno parte dell'insieme delle tue opere e per questo si dice: "Chi annovera le sue parole tra i suoi atti, parla poco". Sappi che Allah controlla le parole dei Suoi servitori, poiché Egli è presso la lingua di chiunque parli. Ciò che Allah ti ha proibito di dire, non dirlo anche se non ci credi, poiché Allah ti chiederà spiegazione di ciò. Ci è stato riferito che l'Angelo non registra a carico del servitore ciò che egli fa finché egli non ne parla. Egli, sia esaltato, ha detto: "Egli non proferisce parola senza che presso di lui non vi sia un osservatore" (Cor. L.18), cioè l'Angelo che conta a tuo carico le tue parole. Egli, sia esaltato, ha inoltre detto: "Su di voi vi sono dei custodi, nobili, che registrano e che sanno ciò che fate" (Cor. LXXXII-10 a 12) e le tue parole fanno parte dei tuoi atti", e [IV 459.15].

710) In arabo il termine wahm può significare sia congettura che immaginazione, ma Ibn 'Arabī lo usa prevalentemente nel secondo senso, distinguendolo peraltro spesso dal termine haya $\bar{l}$, che indica propriamente l'immaginazione riproduttiva, cioè la memoria delle immagini, attribuendole così un ruolo passivo o sostanziale, mentre il termine wahm indica l'immaginazione in un senso attivo, comparabile a quello del termine fantasia. Data la povertà del lessico italiano ho preferito tradurre entrambi i termini con immaginazione, accompagnandoli dal termine arabo. Nel Cap. 369 [III 364.29] Ibn 'Arabī precisa: "Egli ha fatto dell'immaginazione (hayāl) una presenza intermedia tra i due estremi del sensibile e dell'intelligibile, ed essa è il deposito dei dati [letteralmente: il tesoro (hizanna) delle imposte] che i sensi raccolgono, ed ha posto in essa una facoltà generatrice di forme 
prova speculativa o ad una notificazione, non c’è altro che questo.

L'anima è più soggetta al potere dell'immaginazione di quanto lo sia al potere della ragione, poiché l'immaginazione è più forte e più prossima in relazione a Lui della ragione; la sfera (maydān) dell’immaginazione è immensa ed il suo scorazzare (ğawalān) per le faccende è più libero dello scorazzare della ragione e la maggior parte delle notificazioni divine scorre meglio con l'immaginazione che con la ragione, in quanto esse includono nella chiamata ad Allah, quanto è Potente e Magnificente, il piccolo ed il grande, il sapiente e colui che segue ciecamente (muqallid). L'immaginazione ha il potere di disporre in tutti, nell'élite e nella massa, mentre la ragione non ha potere di disporre se non in un ristretto gruppo, malgrado il fatto che l'immaginazione è inseparabile dalle sedi del giudizio della ragione.

Non c’è dubbio che apprendere la scienza di Allah dalla Sua notificazione, sia Egli esaltato, è più degno di Lui rispetto alla scienza di Lui ottenuta per mezzo della speculazione razionale ${ }^{711}$ ), e di molto, poiché Egli, sia Egli esaltato, ha più scienza di Se stesso [di quanta ne possa avere la ragione]; la ragione non afferra ciò che ne afferra se non per mezzo di una similitudine immaginativa e di una deduzione analogica (qiyās) di ciò che è nascosto da ciò che è presente, poiché la realtà le è nascosta, mentre ciò su cui essa basa la sua deduzione le è visibile $[\ldots]\left({ }^{712}\right)$.

(quwrwa musawrira) sotto il regime della ragione e dell'immaginazione (wahm), e la ragione dispone di essa con il comando ed anche l'immaginazione dispone di essa con il comando. Ed in questa costituzione [umana] Egli ha reso forte il potere dell'immaginazione sulla ragione e non ha concesso alla facoltà della ragione di percepire realtà prive di substrato materiale [...] se non per mezzo di una concezione formale e questa concezione formale dipende dal regime dell'immaginazione, non dal suo. La sensazione (hiss) trasferisce all'immaginazione (haya $\bar{l}$ ) ciò che ha percepito e la facoltà generatrice di forme compone nell'immaginazione quello che vuole di ciò che non ha esistenza nel mondo sensibile come insieme, non quanto alle parti dell'insieme [che invece esistono]. Se la facoltà generatrice di forme lo ha concepito per ordine della ragione, tramite la facoltà della riflessione (fikr), ciò dipende dalla ricerca della scienza di una certa faccenda, e quella scienza è senza dubbio condizionata. Se invece ciò che ha concepito la facoltà generatrice di forme dipende dall'ordine dell'immaginazione (wahm), non in quanto la ragione ha disposto del regime dell'immaginazione, ma per l'immaginazione stessa, allora quella forma non persiste, poiché l'immaginazione è rapida a scomparire per la sua assenza di condizionamenti, a differenza della ragione, che è condizionata e incatenata da ciò su cui si fonda. E poiché ciò che prevale nelle creature è il regime delle immaginazioni, per il potere che l'immaginazione ha sulla ragione, in quanto Egli ha fatto sì che la ragione non accetti un significato che sa per certo non essere una materia, né in una materia, se non per mezzo di una concezione formale e questa concezione formale non è altro che la forma che è ordinata dall'immaginazione (wahm), la ragione è senza dubbio condizionata dall'immaginazione in ciò che essa sa per mezzo dell'osservazione. Quanto alla sua scienza necessaria (darūr $\vec{\imath})$ l'immaginazione non ha alcun potere su di essa".

$711)$ Nel Cap. 19 [I 166.7] Ibn 'Arabī precisa: "Le scienze possono essere elevate o modeste, a seconda del loro oggetto, per questo le aspirazioni (himam) sono correlate con le scienze nobili ed elevate [...] e la più elevata di queste per grado è la scienza di Allah. La più elevata delle vie per giungere alla scienza di Allah è la scienza delle Teofanie (tağalliyāt), e dopo di essa la scienza della speculazione (naz̧ar), al di sotto della quale non c'è scienza divina, ma solo credenze ("aqā id), per la generalità degli esseri, e non scienze".

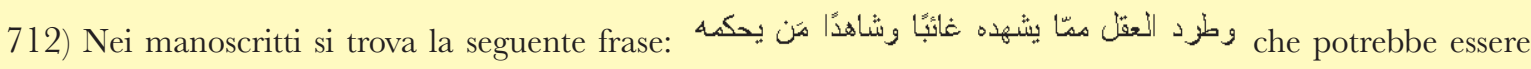


Se non fosse che la realtà è più vasta di questo, poiché la Vastità divina accetta tutto ciò che si dice di Lui, alcuni speculativi mancherebbero il colpo ed altri coglierebbero nel segno, [invece] tutti colgono nel segno in ciò che credono di Lui, tant'è vero che Allah, sia Egli esaltato, non Si manifesterà al Suo servitore ed egli non Lo riconoscerà se non nell'oggetto della sua credenza ed in ciò a cui è legato con [220] la sua anima con un credo di ragione, o di immaginazione, o di apprendimento di una notificazione divina. Tuttavia [in quest'ultimo caso] è necessaria un'immaginazione che dia forma a ciò che apporta questa notificazione, in modo da essere afferrata dal servitore, e se questa manca non c'è credo, poiché ciò che non viene afferrato non viene creduto.

Se Allah, sia Egli esaltato, fa contemplare a chi vuole dei Suoi servitori ciò che vuole della scienza di Lui, per mezzo della presenza di uno dei Suoi Inviati, o per mezzo della presenza di Muhammad, che Allah faccia scendere su di lui la Sua salāt e la Pace - ed egli è il più perfetto, ed essi [gli Inviati] sono persone in cui non è concepibile che l'immaginazione abbia potere sulle loro forme $\left({ }^{713}\right)$, a differenza della visione di Dio in queste vedute (mašăhid) [prima] citate [cioè le credenze] - l'aspirante sa, per la presenza di quel signore eletto, che egli è preservato nello svelamento e nella contemplazione diretta perché non può essere disconosciuta per lui la presenza del signore nell'accadimento (wāqi $\left.{ }^{\prime} a\right)$ $\left.{ }^{714}\right)$ e perché ciò non viene negato [dalla tradizione]. Egli si basa quindi su una visione interiore in ciò che vede, e lo vede dall'orizzonte più elevato, non dall'orizzonte elevato, poiché il Suo detto, sia Egli esaltato: "dall'orizzonte più elevato" (Cor. LIII-7) si riferisce alla visione della contemplazione diretta, mentre il Suo detto, quanto è Potente e Magnificente: "e lo vide un'altra volta” (Cor. LIII-13),

tradotta: "e la ragione rigetta di ciò che essa vede, sia esso assente o presente, Colui che la governa", oppure "e la ragione esclude da ciò che essa vede, sia esso assente o presente, chi la giudica", ma il testo probabilmente non è corretto.

713) Nel Cap. VI dei Fusuus al-hikam, a pag.91 dell'edizione di 'Abd al-'Azīz Sulțān al-Manșūb, Ibn 'Arabī afferma: "È noto che la forma del Profeta, che Allah faccia scendere su di lui la Sua șalāt e la Pace, che i sensi hanno visto è ora seppellita a Medina, e che nessuno ha contemplato la forma del suo spirito e della sua modalità sottile [...] Quindi lo spirito del Profeta, che Allah faccia scendere su di lui la Sua șalāt e la Pace, prende corpo, per chi lo vede in sogno, nella forma del suo corpo per come era quando morì, senza che gli manchi nulla: egli è dunque Muhammad, che Allah faccia scendere su di lui la Sua salät e la Pace, che viene visto quanto al suo spirito in una forma corporea non grossolana (ğasadiyya) che assomiglia a quella sepolta. Satana non può prendere la forma del suo corpo, che Allah faccia scendere su di lui la Sua salāt e la Pace, per preservazione da parte di Allah nei confronti di colui che vede. Per questo chi lo vede in questa forma apprende da lui tutto ciò che gli viene ordinato, proibito o comunicato", e nel Cap. 419 [IV 28.6] aggiunge: "Chi lo vede, che Allah faccia scendere su di lui la Sua șalāt e la Pace, in sogno lo vede [come se fosse] nella veglia [hadīt], a meno che la forma non sia diversa, poiché Satana non prende mai la sua forma, in quanto essa è preservata per lui sia da vivo che da morto".

714) Nel Cap. 73, questione CLIII [II 130.35] Ibn 'Arabī precisa: "L'accadimento è tutto ciò che arriva al cuore dal Mondo superiore, in qualsiasi modo ciò avvenga: discorso, immagine o altro", e nel Cap. 207 [II 491.6] aggiunge: "Gli accadimenti sono le visioni che annunciano buone novelle (mubǎšrirāt), ed esse sono gli inizi della rivelazione (wahy) divina: esse sono interiori e tra gli uomini c'è chi le vede durante il sonno, chi durante l'estinzione e chi durante lo stato di veglia, senza che esse lo velino nel momento dalla percezione delle cose sensibili". 
cioè in una visione precedente a quella, si riferisce alla visione immaginativa, e se è uno che ha una considerazione razionale si tratta della visione speculativa mentale. La contemplazione diretta di ciò che afferra la speculazione mentale è superiore allo stato della speculazione in quello, e per questo Egli l'ha definita più elevata.

La presenza del Profeta, che Allah faccia scendere su di lui la Sua șalāt e la Pace, negli accadimenti sta ad indicare l'elevatezza del rango di chi realizza quell'accadimento, e la sua infallibilità ed elevatezza in ciò che vede, poiché lo osserva dallo specchio di colui che è presente, non dal suo specchio, come nel caso del giovane che riteneva che la visione di Allah gli rendesse superflua la visione di Abū Yazīd, e quando Abū Yazìd fu presente e questo giovane vide Allah, sia Egli esaltato, non resse il carico immenso di ciò che vide e morì all'istante $\left.{ }^{715}\right)$. E cos'è [221] questa percezione per mezzo della presenza di Abū Yazīd in confronto alla percezione che gli era propria [ad Abū Yazīd], e chi è Abū Yazīd in confronto a Muḥammad, che Allah faccia scendere su di lui la Sua șalāt e la Pace?

Ci è stato riferito da Abū Mūsā ad-Daybalī che Abū Yazīd al-Bistāmī chiese ad Allah, sia Egli esaltato, di vedere la stazione dell'Inviato di Allah, che Allah faccia scendere su di lui la Sua șalāt e la Pace, rispetto al suo Signore, e gli venne detto: "Non ne sei in grado" $\left({ }^{716}\right)$, cioè "la tua luce, per mezzo della quale vedi, è troppo debole per cogliere ciò che chiedi di quello", malgrado in questo stato il Vero fosse la sua vista, e che ne sarebbe se Egli non fosse stato la sua vista? Egli insistette nella richiesta; disse Abū Yazīd: "Mi venne dischiusa di quello la misura della cruna di un ago e non fui capace di resisterle e fui incenerito" $\left.{ }^{717}\right)$. Questo è ciò che disse di se stesso, e se non fosse per la contemplazione di lui [l'Inviato] nelle forme abituali nessuno resisterebbe alla visione di qualcosa della sua stazione.

715) L'episodio è già stato citato alla pagina 31 del manoscritto.

716) Nel Cap. 462 [IV 75.32] Ibn 'Arabī precisa: "Quanto alle dimore spirituali dei Poli muhammadiani [antecedenti alla Missione di Muhammad], che sono gli Inviati, che Allah faccia scendere su tutti loro la Sua salāt e la Pace, non c'è modo per noi di parlare di esse. il nostro discorso deriva da un gusto spirituale e noi non possiamo gustare le stazioni degli Inviati, su di loro la Pace, poiché il nostro gustare riguarda esclusivamente l'eredità. Non parla degli Inviati se non un Inviato, né dei Profeti se non un Profeta o un Inviato, né degli eredi se non un Inviato, un Profeta o un Intimo. Questo è l'adab divino". Va osservato che i Fusūs al-hikam non infrangono questo adab, poiché vennero consegnati a Ibn 'Arabī direttamente dall'Inviato di Allah.

$717)$ Nel Cap. 38 [I 230.12] Ibn 'Arabī afferma: "Tra coloro che hanno realizzato come noi questa stazione [della Missione (risāla)] c'è Abū Yazìd al-Bisțāmī: dopo aver chiesto ed implorato gliene venne svelata la misura della cruna di un ago, ed egli volle mettere piede in essa e fu incenerito, e seppe così che essa non può essere ottenuta per mezzo del gusto spirituale e che essa consiste nella perfezione della servitù ('ubüda). Noi abbiamo ottenuto di lui, che Allah faccia scendere su di lui la Sua șalāt e la Pace, un pelo (ša ra ), e questo è molto per chi conosce [...] E quando Allah ce lo fece conoscere non fu per una richiesta, ma solo per sollecitudine da parte di Allah". Altri riferimenti a questo pelo si trovano nel prologo [I 3.3], nel Cap. 5 [I 106.4], nel Cap. 382 [III 514.4] e nel Dīwān al-ma ârif, manoscritto Parigi BN 2348, f. 37a. L'aneddoto di Abū Yazìd è riportato anche nei Dahă îr al-álāq, a pag. 72 dell'edizione di Beirut del 1894, ed a pag 185 della traduzione di Maurice Gloton, L'interprète des désirs, Albin Michel, 1996. 
Noi non abbiamo dubbi sulla forza dell'Inviato di Allah, che Allah faccia scendere su di lui la Sua salāt e la Pace, sulla sua fermezza, e sull'elevatezza del suo rango e della sua stazione nella conoscenza del suo Signore, quanto è Potente e Magnificente, e malgrado ciò gli venne detto riguardo a ciò che Egli conferì ai compagni della caverna: "Se tu fossi riuscito a vederli ti saresti dato alla fuga" (Cor. XVIII-18), cioè per timore che la tua anima morisse, "e saresti stato colmo di terrore di loro" (Cor. ibidem), cioè nel tuo cuore, poiché essi sono un gruppo e ciascuno di loro ha uno stato con Allah, sia Egli esaltato, nella sua fede in Lui, che è diverso da quello degli altri, e se tu fossi riuscito a vederli insieme avresti visto un miscuglio (ihtilat t) nella faccenda ed una diversità in un solo colpo d'occhio, ed avresti temuto per te stesso a causa dello sconcerto per ciò che avresti visto in un solo colpo d'occhio, e ti saresti dato alla fuga ed il tuo cuore si sarebbe colmato di terrore per la potenza (hawl) della faccenda, vedendo ciò che non potevi respingere, poiché sapevi che Allah ha reso tutto quello vero, e non c'è cosa che sarebbe stata afferrata [222] da te ad esclusione di un'altra e quindi saresti stato sconcertato e colmo di terrore della morte:

\section{Le gazzelle si disperdono alla [vista di] Kadā̌s \\ e Kadā̌̌ non sa quale cacciare $\left.{ }^{718}\right)$}

e non è nel potere di questo cacciatore afferrare il tutto, ed egli non sa cosa sia preferibile, sì da dirigersi verso di esso tralasciando il resto, poiché egli vede l'entità unica in forme molteplici, così come l'umanità viene vista unica in molte persone con regimi diversi e si vuole afferrarla ma essa non viene afferrata, poiché ciò che è infinito non si afferra e se venisse afferrato sarebbe finito. Se colui che ha l'accadimento vedesse il Vero in un accadimento alla presenza di tutti gli Inviati, il suo stato sarebbe quello del Profeta, che Allah faccia scendere su di lui la Sua salāt e la Pace, se fosse riuscito a vedere i compagni della caverna. Per questo Allah, sia Egli esaltato, non fa vedere a chi ha l'accadimento ciò che gli fa vedere della scienza di Lui se non per mezzo della presenza del solo Inviato, che Allah faccia scendere su di lui la Sua salāt e la Pace, poiché Allah, sia Egli esaltato, ha accordato ad ogni Inviato riguardo a Lui una Legge ed una Via $\left({ }^{719}\right)$, cioè egli non vede se non ciò che gli conferisce la realtà essenziale della sua costituzione spirituale, che procede dalla complessione della sua natura.

Come una complessione non si ripete, così una ascensione ( i $^{\prime} r \bar{a} g ̆$ ) non si annovera tra due [persone], ed ogni ascensione ha una meta e non c'è meta che sia unica per due, bensì ogni complessione ha una ascensione ed ogni ascensione ha una meta $\left({ }^{720}\right)$. Il singolo uomo ha numerose ascensioni e numerose

718) Questi versi sono riportati anche nel Cap. 292 [II 661.14] ove Ibn 'Arabī commenta: "Lo sconcerto (hayra) del conoscitore riguardo al Lato divino è il più grande degli sconcerti, poiché Egli esula dalla restrizione e dal condizionamento: Egli possiede tutte le forme e tuttavia non ha una forma che Lo condizioni, e per questo egli, che Allah faccia scendere su di lui la Sua șalät e la Pace, diceva: "Allähumma, accresci il mio sconcerto riguardo a Te", poiché questa è la stazione più elevata".

719) Cfr. Cor. V-48.

720) Analogamente, nel Cap. 19 [I 167.10] Ibn 'Arabī precisa: "Al momento della sua salita sul gradino (sullam) 
mete, nel numero delle sue ascensioni, ma nella sua complessione egli non ha che una sola ascensione, poiché la sua complessione non dura per due tempi, anche se essa è inerente all'entità di un'unica sostanza (ğawhar); non è un segreto che quella sostanza unica riceve differenti forme e la differenza delle forme non ha senso se non per l'esistenza della complessione [223] ed ogni complessione è diversa dall'altra. E quando consideriamo la sostanza che riceve, che non ha esistenza se non per la forma, siamo autorizzati a dire ciò che abbiamo detto, cioè che "il singolo uomo $\left({ }^{721}\right)$ ha numerose ascensioni”, e la faccenda in realtà non è se non come abbiamo detto: la creazione è nuova negli attimi e molteplice nelle forme, mentre il Vero non è nuovo, bensì è persistente e fisso, Uno nell'entità e nell'accettazione ( $q a b \bar{u} l)$. Sappilo!

Quest'uomo ha detto a questo aspirante: "Allah non è stato sollecito con te con la tua presenza di fronte a questo signore Muhammad, che Allah faccia scendere su di lui la Sua salāt e la Pace, se non per l'aspirazione di chi ha menzionato, cioè il Maestro, il Maestro del Maestro, i fratelli del Maestro ed i ragazzi del Maestro".

Poi, dopo quello, ha detto: "E affrettati a stare fermo di fronte a lui, metti la terra (turāb) sulla tua testa e premi la tua guancia sulla terra, e ciò è poco anche se annientassi te stesso, ringraziando Allah, quanto è Potente e Magnificente, per quello, in quanto ti è stato già assegnato nell'eternità ed Egli ha fatto del tuo Maestro un mezzo per fartelo apparire per opera sua". Egli, Allah sia soddisfatto di lui, dice: quando vedi nella sede di contemplazione il tuo signore Muhammad, che Allah faccia scendere su di lui la Sua salāt e la Pace, "affrettati a stare fermo di fronte a lui". Egli dice quello affinché tu veda ciò che ti ordina, poiché egli non viene invano, e o è un nunzio o è un ammonitore: egli è la lampada che illumina e con la sua illuminazione ti dà in conformità allo stato in cui ti trovi [224].

Se sei in una condizione che allieta egli è un nunzio di bene nei tuoi confronti, e se sei in una condizione che non è gradita allora è un ammonitore nei tuoi confronti, cioè ti istruisce affinché tu ti allontani da quello fintanto che resti nella sede dell'accettazione del pentimento, che è la vita di questo basso mondo. E tu non riconosci il tuo stato spirituale nel tuo stare fermo di fronte a lui se non

dell'ascensione l'uomo ha una epifania divina conforme al gradino della sua ascensione. Ogni persona della gente di Allah ha un gradino che gli è proprio e sul quale non sale altri che lui; se un altro salisse sul suo gradino sarebbe possibile acquisire la Profezia, poiché ogni gradino conferisce per se stesso un rango specifico a colui che sale su di esso, ed i sapienti potrebbero così salire sul gradino dei Profeti ed ottenere la Profezia salendo su di esso, ma la faccenda non è così, perché la ripetizione annullerebbe la Vastità divina”, e nel Cap. 314 [III 55.29] aggiunge:"Quando gli Intimi [di Allah] (awliy $\bar{a}$ ) salgono lungo le vie ascendenti delle loro aspirazioni (himam), la meta del loro arrivo sono i Nomi divini, poiché i Nomi divini li cercano. Quando arrivano ad essi, i Nomi elargiscono le loro scienze e le loro luci nella misura della predisposizione che gli Intimi portano con sé [...] In ciò gli Intimi non hanno bisogno di un Angelo o di un Inviato, poiché non si tratta di scienza a carattere legiferante, ma piuttosto di luci che consentono loro di comprendere ciò che l'Inviato ha apportato nella sua rivelazione o nel Libro che è stato fatto discendere su di lui, o la Scrittura (sahîfa), nient'altro".

721) In tutti i manoscritti al posto di insān si trova mizăğg, ma si tratta evidentemente di un errore, poiché la frase a cui si riferisce riporta insān, e la sostituzione con mizăğ contraddice le considerazioni che precedono. 
per ciò che ti ordina e sappi che ciò che tu comprendi da lui nel tuo stargli di fronte non lo conferisce se non il tuo stato, ed in base al tuo stato egli si rivolge a te: sii dunque conforme a ciò che comporta quel discorso, poiché esso è quello che il tuo stato esige.

Quanto al suo detto: "metti la terra sulla tua testa", la Terra (ard) è tua madre e dalla terra Allah ha creato il tuo corpo, e dalla sua complessione si è manifestata la forma del tuo spirito e della tua modalità sottile, e per il figlio è obbligatoria la riverenza verso sua madre, poiché il Legislatore lo ha confermato. Un uomo disse all'Inviato di Allah, che Allah faccia scendere su di lui la Sua șalät e la Pace: "Chi devo riverire?" ed egli rispose "Tua madre", poi egli chiese di nuovo: "Chi devo riverire?" ed egli rispose "Tua madre", poi chiese per la terza volta: "Chi devo riverire?” ed egli rispose "Tua madre", poi alla quarta [domanda] rispose: "e poi tuo padre" $\left.{ }^{722}\right)$. Questi è lo Spirito Universale $\left({ }^{723}\right)$ che ha conferito questo spirito particolare che emerge sulla forma della complessione del corpo, come l'embrione si sviluppa nell'utero della madre, ed in rapporto al padre è ciò che non ha forma se non la sua entità, e quindi non acquisisce la forma se non nella madre, ed è lei che lo dà alla luce, e quindi la riverenza del figlio verso di lei è maggiore ${ }^{(724)}$. Se vuoi magnificare una cosa la metti sulla tua testa, cioè le conferisci su di te il rango dell'elevatezza rispetto a te, magnificandola senza dubbio, poiché essa è pia (bārra) verso di te, come disse l'Inviato di Allah, che Allah faccia scendere su di lui la Sua

722) Hadīt riportato da al-Buhārī, LXXVIII-2, Muslim, XLV-1 a 4, Ibn Māğah, XXXIII-1 e da at-Tirmidīi, XXV-1. Ibn 'Arabī lo riporta nel Cap. 178 [II 354.24] e nel Cap. 560 [IV 478.25].

723) Come la madre corrisponde alla Terra, così il padre corrisponde allo Spirito Universale. Nel Cap. 271 [II 575.14] Ibn 'Arabī afferma: "Gli spiriti particolari sono generati dallo Spirito Universale, attribuito al Vero, e dai corpi naturali oscuri, dopo che essi sono stati proporzionati e che hanno ottenuto la loro predisposizione a ricevere. Tra i due si manifesta nel corpo lo spirito particolare, che è lo spirito dell'uomo", e nel Cap. 364 [III 320.30] aggiunge: "Gesù, su di lui la Pace, ha detto: "Il cuore di ogni uomo è là dov'è la sua ricchezza: ponete le vostre ricchezze in Cielo ed i vostri cuori saranno in Cielo", e chi accumula la sua ricchezza imprigiona il suo cuore nella Terra della sua Natura e non godrà mai della visione di suo padre, che è lo Spirito divino".

724) Nel Cap. 52 [I 276.35] Ibn 'Arabī precisa: "Se egli conosce le sue due origini preferisce l'origine più vicina a lui, cioè il lato di sua madre, poiché è certamente figlio di sua madre. Non vedi che la Sunna prescrive che per istruire il morto quando arriva alla sua tomba gli si dica: "O servitore di Allah, e o figlio dell'ancella (ama) di Allah", facendolo risalire a sua madre [...] Egli viene attribuito a sua madre perché ella ha più diritto a ciò, per la manifestazione [da parte sua] della sua costituzione e dell'esistenza della sua entità. Per suo padre egli è un figlio di letto (firās), mentre per sua madre è realmente un figlio". D'altra parte, nel Cap. 302 [III 11.20] Ibn 'Arabī precisa: "L'uomo non ha alcuna superiorità sul Cosmo nel suo insieme, che invece è superiore all'uomo perché ha un grado in più rispetto a lui, che consiste nel fatto che l'uomo [il microcosmo] ha ricevuto l'esistenza dal macrocosmo: esso possiede il grado della causalità (sababiyya), poiché l'uomo è stato generato a partire da esso. Egli, sia esaltato, ha detto: "Gli uomini hanno un grado [di superiorità] su di esse [le donne]" (Cor. II228) poiché Eva procede da Adamo, e questo grado non cessa di accompagnarli nei rapporti dei maschi con le femmine. Anche se la madre è la causa [seconda] nell'esistenza del figlio, suo figlio ha in più di lei il grado del maschio, poiché egli assomiglia in tutti gli aspetti a suo padre. È necessario che l'uomo magnifichi i suoi genitori: sua madre è il Cosmo nella sua totalità, e suo padre è noto e non disconosciuto, e l'unione coniugale corrisponde all'orientamento [divino] ed il figlio esce nella forma dei suoi genitori. E poiché il figlio non viene chiamato se non per suo padre [nei nomi arabi il lignaggio (nasab) è di norma attribuito al padre], la sua origine non viene fatta risalire alla madre, perché il padre ha un grado di superiorità". 
salāt e la Pace, quando ordinò di onorarla, cioè la Terra, dicendo: "Essa è pia verso di te" ${ }^{725}$. [225]

Chi sente il discorso di questo Maestro riguardo al mettere la terra sulla testa si immagina che ciò sia a guisa di chi è colpito da una disgrazia, poiché vige l'usanza per chi è colpito da una disgrazia di mettere la terra sulla sua testa $\left.{ }^{726}\right)$, ma non è questo ciò che intende chi ha proferito questo discorso in questa sede, poiché la Via non comporta quello, e non si tratta se non di ciò che abbiamo menzionato. Egli ha indicato ciò per magnificare la stazione spirituale e la sollecitudine [divina], poiché Allah, sia Egli esaltato, ha reso la Terra umile $(\underline{d} a l \bar{u} l)$ e tu non hai ottenuto questa Potenza divina se non per il tuo abbassamento e la tua quiete (sakina), e quindi non hai ottenuto ciò se non per l'attributo della tua umile madre: riconosci dunque il suo valore e sollevala sulla tua testa magnificandola.

Quanto al suo detto: "e premi la tua guancia sulla terra", ciò corrisponde al suo detto, su di lui la Pace: "Il Paradiso è sotto i piedi delle madri" ${ }^{727}$ ). Se poni la tua guancia al posto del piede di tua madre, essendo il piede di tua madre premuto sulla terra, essa [guancia] tratta la terra a guisa del Paradiso, poiché il Paradiso è sotto i piedi delle madri. Questa è la stazione della ricchezza [o: indipendenza] per Allah, secondo l'espressione "l'uomo ha una ricchezza abbondante quanto la terra (atraba)" quando diventa ricco (istagnāa), oppure la stazione della povertà [o: dipendenza] verso Allah, secondo l'espressione "l'uomo si è impolverato (tariba)" ${ }^{728}$ ) quando diventa povero (iftaqara). Per questo ti ha ordinato di premere la tua guancia sulla terra, cioè metti in essere l'attributo della indipendenza per Allah o della dipendenza da Allah $\left({ }^{729}\right)$, e per colui a cui Allah provvede l'indipendenza per Lui o la dipendenza da Lui, quello è un favore per il quale nessuno riuscirà mai a ringraziare, poiché nelle due condizioni tu non sei che occupato con Lui. Non vedi che il Profeta, che Allah faccia scendere su di lui la Sua șalāt e la Pace, non restò in piedi, nell'atto di adorazione di Allah, tanto che i suoi piedi furono tumefatti, se non nel ringraziamento quando Allah gli perdonò i suoi peccati passati e [226] futuri, e quando gli venne chiesto riguardo all'indulgenza verso se stesso egli, su di lui la Pace, rispose:

725) Hadīt non recensito nelle raccolte canoniche.

726) Nel Cap. 68 [I 340.32] Ibn 'Arabī precisa: "Questo è il motivo per cui la Legge non prescrive di strofinarsi la testa durante il tayammum, poiché mettere della terra sulla testa indica la separazione (fria $q$ ), che è la più grande disgrazia: se è la persona amata che è morta ci si mette la terra sulla testa. Poiché lo scopo del rito è la connessione (wasla) e non la separazione, non è prescritto strofinarsi la testa durante il tayammum”.

727) Hadīt non recensito nelle raccolte canoniche.

728) I verbi tariba, prima forma, e atraba, quarta forma, hanno la stessa radice di turāb, che significa terra, polvere. Nel Cap. 68 [I 370.21] Ibn 'Arabī afferma: "Il tayammum è il dirigersi verso la buona Terra (ard), quale che essa sia, purché sia chiamata Terra, come la terra $($ turāb), la sabbia, i sassi, o la terra gialla [(zarnīha $)=$ arsenico]. Ma non è lecito il tayammum con una di queste cose, o di cose simili, se essa si separa dalla Terra, ad eccezione della terra [...] in quanto dalla terra è stato creato colui di cui noi siamo figli, e per il significato che è rimasto in essa di povertà ed indigenza nell'espressione araba: "la mano dell'uomo si è impolverata (taribat yad ar-rağul)" quando egli diventa povero".

729) Ibn 'Arabī ha già menzionato questi due attributi a pag. 121-122 del manoscritto. 
"Non sarò forse un servitore che ringrazia molto $(s a k \bar{u} r)$ ?" $\left({ }^{730}\right)$, e sarà dei pochi, poiché Allah, sia Egli esaltato, ha detto: "Pochi tra i Miei servitori ringraziano molto" (Cor. XXXIV-13); quanto a coloro che ringraziano essi sono molti, ed Allah ha descritto Se stesso come Colui che ringrazia (šak kir) e come Colui che ringrazia molto con l'aumento dei favori, e da parte del servitore con l'aumento dell'opera.

Ed il suo detto: "anche se annientassi te stesso, ringraziando Allah, quanto è Potente e Magnificente" è ciò che fece quell'aspirante a Minā; era sincero e povero e per la sua povertà gli era impossibile, tra i riti del pellegrinaggio, fare il sacrificio (qurbān), poiché non aveva nulla con cui comprare una vittima da immolare o da sgozzare. Egli disse: "O mio Dio, la gente ricca si avvicina a Te con i beni che le loro mani hanno ottenuto e che Tu hai elargito loro, mentre il Tuo servitore povero non ha nulla. Allāhumma, accetta la mia anima come offerta sacrificale, prendendola presso di Te", e pose la sua guancia sulla Terra, come si fa adagiare il montone per il sacrificio, rantolò e morì $\left({ }^{731}\right)$. La sua anima fu quindi la sua offerta sacrificale in quel giorno come ringraziamento ad Allah, sia Egli esaltato, e questo è il significato del suo detto: anche se annientassi te stesso ringraziando per quanto ti è stato già assegnato nell'eternità del far presenziare questo Inviato nella tua veduta (mašhad) divina.

Poi ha detto riguardo al premere la sua guancia sulla terra: "e se non vieni invitato a sederti resta fermo nello stato in cui sei, con la guancia sulla Terra e con la terra posta sulla tua testa, finché l'Inviato, su di lui la Pace, non ti ordina di sollevare il tuo volto dalla terra. Allora togli la terra dalla tua testa [227] e quando ti siedi, siediti dove ti viene ordinato di sederti, rotto nell'aspirazione (himma), a capo chino e con la testa abbassata". Questa è una allusione allo stato in cui si trova il Vero con la creazione ${ }^{732}$ ), poiché per mezzo del Mondo si manifestano i Suoi Nomi, e per mezzo delle

730) Hadīt riportato da al-Buhārī, XIX-6, LXV, Sūra 48-2, Muslim, L-79 a 81, at-Tirmid̄ī, II-187, Ibn Māğah, V-200, an-Nasā'̀̄, XX-17, e da Ibn Ḥanbal, IV-251 e 255, VI-1 15. Ibn ‘Arabī lo riporta nei capitoli 69 [I 503.32 e 513.23], 339 [III 152.20], 491 [IV 128.6] e 560 [IV 454.5], ove afferma: "Quando Allah perdonò al Suo Profeta Muhammad, che Allah faccia scendere su di lui la Sua salāt e la Pace, i suoi peccati passati e futuri, e lo informò di ciò con il Suo detto: "affinché Allah ti perdoni i tuoi peccati passati e futuri" (Cor.XLVIII-2), egli stette in piedi per ringraziare di ciò Allah, sia Egli esaltato, senza smettere né cedere alla stanchezza, tanto da avere i piedi tumefatti. Quando riguardo a questo episodio venne interrogato sull'indulgenza $(r i f q)$ verso se stessi, egli, che Allah faccia scendere su di lui la Sua șalāt e la Pace, disse: "Non sarò forse un servitore che ringrazia molto?". Ciò perché aveva sentito Allah, sia Egli esaltato, dire: "Invero Allah ama coloro che ringraziano". Se egli non fosse stato nella stazione della gratitudine di colui che ha ricevuto un favore, gli sarebbe sfuggito da parte di Allah questo amore che è specifico per questa stazione, amore che non ottiene da Allah se non colui che ringrazia; Allah ha detto: "Pochi tra i Miei servitori ringraziano molto" (Cor. XXXIV-13). Ora, se gli sfugge ciò, gli sfugge quello che gli spetta quanto a scienza di Allah, a teofania, ed al favore particolare che riceverà nella dimora della Grazia e sul Monticello $(k a \underline{t} \bar{b} b)$ della visione nel Giorno della Visita suprema. Ogni amore divino derivante da uno specifico Attributo comporta necessariamente una scienza, una teofania, una grazia ed un grado (manzila) per mezzo dei quali il possessore di quell'Attributo si differenzia dagli altri”.

731) Lo stesso episodio è riportato nel Cap. 69 [I 467.18].

732) L’allusione riguarda la posizione seduta, che si riferisce allo "stato in cui si trova il Vero con la creazione" e quindi alla prospettiva dell'immanenza $(t a s ̌ b i h h)$ divina, mentre la posizione con la guancia posata sulla terra si riferisce alla trascendenza (tanzīh) divina ed allo stato in cui "c'era Allah e nessuna cosa con Lui". 
creature si manifesta il Suo regime in esse. Egli non ha attribuito il sedersi a lui, poiché gli ha detto: "e se non vieni invitato a sederti resta fermo nello stato in cui sei", e lo stato divino a cui egli ha fatto allusione corrisponde al Suo detto: "Ed Allah è indipendente dai Mondi" (Cor. III-97) ( $\left.{ }^{733}\right)$, ma questa condizione non implica la continuazione (dawām) ed è quindi necessario che egli si sieda e che colui che lo invita a sedersi sia l'Inviato che il Maestro gli fa contemplare.

Ed il suo detto che egli non si sieda se non dove gli è stato ordinato di sedersi corrisponde al nostro detto che Egli non governa la creazione se non per mezzo di ciò che conferisce la creazione ed essa è quella che impone il regime e che è sottoposta al regime (al-hākim al-mahkūm) $\left.{ }^{734}\right)$.

Ed il suo detto "allora togli la terra dalla tua testa", ti raccomanda di ricondurre ogni cosa alla sua origine e quindi ciò che appartiene al Vero in quanto Vero restituiscilo a Lui e ciò che appartiene alla creazione in quanto creazione restituiscilo ad essa.

Ed il suo detto "con la testa abbassata e rotto nell'aspirazione", anche se è già stato commentato in precedenza, l'abbassare la testa si riferisce qui al tratto mite malgrado l'elevatezza (rif'a), cioè non palesare agli uomini l'elevatezza ('uluwrw) del tuo grado, poiché se esso fosse manifesto solo tu ci arriveresti, ma sii con gli uomini per come essi sono, così come il Vero discende verso i Suoi servitori al Cielo di questo mondo nella vicinanza a loro dal Suo assidersi [sul Trono] come il Misericordioso. Se Egli fosse assiso con un Nome diverso non scenderebbe affatto, e non Lo ha fatto sedere se non una Misericordia verso di te, e per questo tu hai acconsentito [228] di stare a testa bassa e tenere un tratto mite con chi ti ha cercato [( $l i$ man arāda-ka), o: per Chi ti ha voluto].

Quanto è lontana la stazione della dimora iniziatica di Mosè rispetto al suo Signore quando parlò a lui in modo esclusivo ed innalzò la sua mansione ${ }^{(735)}$, in confronto alla sua mitezza (līn) con il Faraone nel parlargli quando lo chiamò $\left({ }^{736}\right)$ ! Cerca la saggezza di questa mitezza, la troverai nella sua [del Faraone] asserzione della Signoria (rubübiyya); Mosè era comunque in se stesso una creatura,

733 ) Nel Cap. 427 [IV 62.18] Ibn 'Arabī afferma: "Considera le entità delle possibilità prima della loro manifetazione: non è possibile che il Vero Si manifesti in esse se non nella forma di ciò che esse possono ricevere, e quindi esse non sono in realtà sulla forma del Vero. Il governatore è solo secondo la forma del governato, poiché nulla di lui si manifesta da parte del governato se non nella misura della sua ricettività, nient'altro. Il Vero non è altro che lo stato in cui si trova la creazione: del Vero non si vede e non si sa se non questo. In Se stesso Egli è secondo ciò che sa, ed in Se stesso Egli ha ciò che non è affatto possibile conoscere, e ciò che è assolutamente inconoscibile è ciò che Egli ha in Se stesso, a cui ha alluso con il Suo detto: "Ed Allah è indipendente dai Mondi" (Cor. III-97)".

734) Si potrebbe anche tradurre: "ed Egli è Colui che impone il regime e che è sottoposto al regime". Questo argomento è già stato affrontato nella seconda nota alla pag. 178 del manoscritto e nella prima nota alla pag. 195.

735) Dicendogli: "Ti ho scelto per Me stesso" (Cor. XX-41).

736) Riferimento ai versetti: "Vai, tu e tuo fratello, con i Miei segni, e non stancatevi di menzionare Me. Andate dal Faraone, poiché egli ha trasgredito, e parlategli in modo mite: forse egli si ricorderà o avrà paura" (Cor. XX-42 a 44). L'argomento è già stato trattato a pag. 74 del manoscritto. 
nel suo stato e nella sua essenza, e quindi era indispensabile il tratto mite a fronte della Potenza della Signoria che il Faraone asseriva di avere, ed egli non lo chiamò con mitezza se non perché la stazione lo esigeva.

Gli Uomini di Allah sono in conformità alle loro stazioni ed ai loro stati spirituali, non in conformità alle loro essenze, e se [il Faraone] non avesse asserito la Signoria, Mosè non sarebbe stato inviato a lui con la mitezza dallo stato di potenza in cui si trovava per il Discorso [divino], né Aronne a sostegno di Mosè - ed egli aveva la potenza del sostegno - e se essi avessero affrontato la potenza del Faraone con la loro potenza avrebbero avuto un conflitto e non ci sarebbe stato il giovamento per il Faraone nel suo dire: "Ho fede in ciò in cui hanno fede i figli di Israele" (Cor. X-90), che corrisponde al Suo detto: "Forse egli ricorderà", e ricordò, "o avrà paura" (Cor. XX-44), ed ebbe paura, poiché Allah non spera se non ciò che accadrà $\left({ }^{737}\right)$.

Quanto alla rottura (inkisār) dell'aspirazione in questa circostanza, poiché l'aspirazione è collegata con ciò che al momento non è conseguito, essa cerca di arrivare alla contemplazione di Colui con cui è collegata ed al suo conseguimento, e quando il possessore dell'aspirazione vede che ciò che cerca è in lui stesso, la sua aspirazione si spegne ed è incapace (inkasarat) di cercare di arrivare. Ciò corrisponde al suo detto:

Talvolta l'uomo parte verso ciò che cerca, mentre il motivo ricercato è in colui che parte ${ }^{\left({ }^{738}\right)}$

E quando scopri che ciò che tu cerchi non è altro che la tua entità e la tua entità non si separa da te, poiché è te, allora la tua aspirazione non è collegata a qualcosa $\left({ }^{739}\right)$ di esteriore a te $\left.{ }^{740}\right)$ [229] e

737) Quest'ultima affermazione è ribadita nei capitoli 61 [I 298.30], 69 [I 504.32], 167 [II 276.15], 198 [II 411.24], 358 [III 264.27], 386 [III 533.5] e 525 [IV 168.6.

738) Si tratta di versi del poeta andaluso Ibrahīm ibn Mašūd al-Ilbīrī, riportati anche nel Cap. 5 [I 113.11], ove Ibn 'Arabī li introduce affermando: "Quando Allah, sia Egli esaltato, ha dato l'esistenza al Verbo (kalima), denominato lo Spirito Universale, gli ha dato l'esistenza nella stazione dell'ignoranza e nel luogo della spoliazione (salb), cioè gli ha impedito di vedere se stesso, ed egli restò senza sapere né da dove né come fosse venuto. Il nutrimento, che è il motivo della sua vita e del suo permanere, era in lui, senza che lui lo sapesse. Allah allora mise in movimento la sua aspirazione (himma) affinché cercasse ciò che aveva dentro di sé, senza che sapesse che ciò che cercava era in lui. Egli si mise dunque in viaggio per mezzo della sua aspirazione, ed il Vero, sia Egli esaltato, gli fece vedere se stesso, sì che egli si quietò, e seppe che non aveva mai smesso di essere caratterizzato da ciò che cercava. Ibrahīm ibn Mas'ūd al-Ilbīrī ha detto: "Talvolta l'uomo parte verso ciò che cerca, mentre il motivo ricercato è in colui che parte".

739) Tutto questo brano, da: "quando l'aspirazione è collegata" in poi, è riportato testualmente da Muhammad az-Zuhrī al-Gamrāwī in calce al commento di al-Qāšānī ai Fusūs al-hikam [pag. 90-91 dell'edizione del Cairo del $1321 \mathrm{H}]$ e attribuito alla Ğamăliyya di Ibn 'Arabī.

740) A questo riguardo si può ricordare lo hadît: "Chi conosce se stesso conosce il suo Signore" e quanto afferma Ibn 'Arabī nel Cap. 364 [III 319.23]: "Non c'è nulla di esteriore a te, quindi non sperare di conoscere 
questo è ciò che conferisce la contemplazione diretta che egli ha menzionato, ed Allah è più sapiente.

Poi egli, Allah abbia misericordia di lui, ha detto, dopo l'ottenimento di questo stato: "e mostra l'abbassamento, l'essere a pezzi e l'indigenza a colui che ti parla e che ti fa cenno". Egli dice: quando vedi te stesso come Vero e loro ti considerano una creatura, è obbligatorio per te discendere al loro livello, affinché traggano vantaggio dal tuo favore (nawāl).

Per questo ha completato la sua raccomandazione dicendo: "Non sollevare la tua testa verso alcuno di loro, poiché essi non arriverebbero a te se lo facessi. Essi ti cercano e se sollevi la tua testa verso di loro la potenza prenderebbe il sopravvento in loro, e si immaginerebbero di essere più elevati di te e non trarrebbero alcun beneficio da te. Se invece il tuo sguardo è verso il basso essi riconoscerebbero che sei superiore a loro e che essi sono inferiori a te, e sarebbero pronti a trarre vantaggio da te e tu saresti utile a loro con il tuo stato".

Ed il suo detto: "Poiché essi sono i Re (mulūk) di questo mondo e dell'altro", cioè gli Inviati e chi è simile a loro, in quanto sono stati inviati per governare le masse; quanto alla loro mansione riguardo alla scienza di Allah essi non sono i Re di questo mondo e dell'altro, bensì sono solo i Re di Allah $\left.{ }^{741}\right)$, ed in questo rango il Vero è il Regno del Regno (mulk al-mulk) ${ }^{(742)}$, come ha menzionato at-Tirmidīi, il

te stesso tramite altri che te stesso".

741) Nel Cap. 73, questione LIII [II 76.18] Ibn 'Arabī afferma: "Quanto ai Profeti che sono Inviati, essi ricevono dalla Presenza del Regno, che è il Regno del Regno (mulk al-mulk), mentre i Profeti non inviati dalla Presenza dell'elezione".

742) Nei testi arabi non vocalizzati questa espressione può anche essere letta malik al-mulk, cioè Re del Regno, e molti traduttori di Ibn 'Arabī l'hanno letta erroneamente in questo modo, ma nell'edizione delle Futūhāt di 'Abd al-'Azīz Sulțān al-Manșūb, in tutte le 25 occasioni in cui essa ricorre è vocalizzata mulk al-mulk. Nel Cap. 24 [I 182.31] Ibn 'Arabī afferma: "Allah, sia Egli esaltato, ha detto: "Il vostro Signore ha prescritto a Se stesso la Misericordia" (Cor. VI-12), associando Se stesso con il Suo servitore nell'essere soggetto all'obbligatorietà $(w u g ̌ u ̆ b)$, anche se è Lui che ha imposto a Se stesso ciò che Si è imposto. Ed il Suo discorso è veridico e la Sua promessa è vera. Analogamente l'uomo impone a se stesso, di sua iniziativa, con il voto (nadr r) ciò che il Vero non gli ha imposto, ed Allah gli impone di rispettare il voto che ha imposto a se stesso, e gli ordina di rispettarlo. Abbiamo visto che Egli, sia Egli esaltato, non risponde se non dopo la preghiera rivolta a Lui dal servitore come prescrive la Legge, così come il servitore non obbedisce al Vero finché il Vero non gli chiede ciò che gli chiede. [...] Le cose stanno come abbiamo detto, cioè il Vero esaudisce l'ordine del servitore quando egli Lo prega e Gli chiede, così come il servitore obbedisce all'ordine di Allah quando gli dà un ordine, e questo corrisponde al Suo detto: "Rispettate il Mio patto, Io rispetterò il vostro patto!" (Cor. II-40), rendendoSi partecipe nell'atto legale (qadiyya) [...] Poiché Allah ha prescritto al servitore delle opere, se egli le compie ha prescritto a Se stesso di ricompensare questo servitore per aver fatto ciò che gli ha imposto, e quindi il Lato Supremo diventa Regno per questo Regno, che è il Mondo [...] Per questo si applica a Lui un attributo che viene indicato come "Regno del Regno" [cioè suddito del suddito]. Egli, Gloria a Lui, è Padrone (mālik) e Re (malik) per ciò che ordina ai Suoi servitori, ed Egli, Gloria a Lui, è Regno per ciò che Gli ordina il servitore. Il servitore dice: "O mio Signore, perdonami!", come il Vero gli ha detto: "Fai la șalät in Mio ricordo!" (Cor. XX-14); ciò che viene dal lato del Vero al servitore si chiama ordine $(a m r)$, e ciò che viene dal lato del servitore al Vero si chiama preghiera ( $d u(\bar{a})$, per adab divino, anche se in realtà si tratta di un ordine in entrambi i casi. A mia conoscenza, il primo che 
saggio $\left.{ }^{743}\right)$. Quindi il Regno del Regno è il Vero, in quanto Egli risponde all'invocazione di chi invoca quando invoca Lui $\left({ }^{744}\right)$, e l'atto del servitore Lo soddisfa o Lo indigna $\left({ }^{745}\right)$, e non c'è segreto in questo effetto, né razionalmente, né per Legge, ed il Regno è perennemente la sede degli effetti, ovunque sia:

Da un lato esso è il Vero * e da un lato esso è la creazione

e da un lato non è questo * e non è quello. Che cos'è dunque il Vero?

[230] Di riguardo a Lui ciò che vuoi. *Nella Sua purezza non c'è rattoppo. $\left({ }^{746}\right)$

Talvolta colui che segue $(t \bar{a} b i$ ) si manifesta in una stazione più elevata, nello stato in cui si trova colui che è seguito ( $f \bar{\imath} h \bar{a} l$ qiyām al-matbū $)$ in uno stato più basso, per via di colui a cui è stato inviato, ed egli è un argomento (huğğa ) per ciascuno, anche se gli argomenti si fronteggiano, ma tu non sei così se non riguardo ai tuoi aspiranti, che sono per te a guisa della comunità dell'Inviato per l'Inviato $\left.{ }^{747}\right)$.

ha impiegato questa espressione [Regno del Regno] è stato Muhammad ibn 'Alī at-Tirmid̄ī, il saggio, e non abbiamo sentito usare questa espressione se non da lui; forse altri l'hanno usata prima di lui, ma ciò non ci è pervenuto", e nel Cap. 559 [IV 393.29], commentando l'espressione Regno del Regno, aggiunge: "Il servitore (hădim) della gente è il loro signore (sayyid) [hadit t], ed essi sono i Re. Se non fosse per i Nomi il Signore non sarebbe il suddito [...] Egli risponde quando viene chiamato con il Nome. Osserva quanto è stupefacente il rango del Nome [...] Il Vero non risponde se non a chi Lo chiama, e non viene chiamato se non con i Suoi Nomi: questa è la scienza dei Suoi Intimi e dei Suoi Profeti. Il Signore si serve del servitore con ciò che dice, ed il servitore si serve del Signore con il suo stato e la lingua dello stato è più chiara della lingua di ciò che è detto".

743) Muhammad ibn 'Alī at-Tirmidīī, originario di Termez, nell'attuale Uzbekistan, morì ultracentenario nell'anno 318 dall'Egira: autore prolifico, scrisse una sessantina di opere, la più nota delle quali è il Kitäb hatm al-awliy $\bar{a}$, il Libro del "Sigillo degli Intimi", espressione che lui stesso coniò, che contiene una lista di oltre 150 questioni a cui solo coloro che hanno la vera conoscenza sanno rispondere. Ibn 'Arabī dedicò al suo questionario prima un'opera succinta, il Kitāb al-ğawāb al-mustaqìm, redatto nell'anno 603 dall'Egira, poi una cospicua parte del Cap. 73 delle Futūhāt [Vol. II, pag. 39-143].

Su di lui si possono consultare gli studi e le traduzioni di Bernd Radtke [Al-Hakim at-Tirmid̄i. Ein islamischer Theosoph des 3.19. Jahrhunderts. Schwarz Verlag, 1980, Drei Schriften des Theosophen von Tirmidh, Bibliotheca Islamica, Beirut-Stuttgart, 1992] e di Geneviève Gobillot [Le livre de la profondeur des choses, Presses Universitaires du Septentrion, 1996, Le livre des nuances, Geuthner, 2006].

744) Riferimento a Cor. II-186.

745) Nel Cap. 73, questione XVI [II 51.1] Ibn 'Arabī precisa: "Colui che riceve un ordine e che risponde [ad esso] può essere correttamente denominato "comandato" e questo è il significato del termine mulk. Quando il signore risponde all'ordine del suo servitore egli è un mulk, e per mezzo della sua risposta diventa in se stesso un mulk del mulk. Questo è il massimo della discesa divina verso il Suo servitore, cioè che gli dica: "Chiedi a Me, Io ti risponderò" [...] Talvolta l'effetto è determinato da un atto che non comporta un ordine, come il servitore che disobbedisce ed il suo essere disobbediente suscita la collera nell'anima del suo signore, e ne consegue la punizione: il servitore ha quindi fatto sì che il signore lo punisse per la sua disobbedienza, e se non avesse disobbedito non si sarebbe manifestato da parte del suo signore ciò che si è manifestato, oppure egli lo perdona. Lo stesso vale per l'obbedienza che viene ricompensata. Anche sotto questo rapporto [il signore] è Regno del Regno (mulk al-mulk), cioè un regno per colui che è per lui un regno. E questo è ciò che tutte le Leggi apportano”.

746) Questi versi sono riportati anche nel Dīwān al-ma ârif, manoscritto Parigi BN 2348, f. 139b, linee 18-19.

747) Colui che segue e colui che è seguito sono rispettivamente il servitore ed il signore, o l'aspirante ed il Maestro, o il Maestro ed il Profeta. Questo passaggio, un po' oscuro, sembra indicare che il Maestro, anche se 
Poi ha detto: "E se l'Inviato fa cenno a te o ti parla, affrettati a star fermo di fronte a lui, povero e in attesa". Egli dice: "se fa cenno a te" ed esso è il discorso dello stato, "o ti parla" ed Egli fa parlare quella forma in cui Si è manifestato a te, stai fermo di fronte a lui "povero", per ciò che non hai, "in attesa" di ciò che egli deve concederti, e se ti ordina di sederti da quella stazione eretta, siediti secondo ciò che hai compreso del suo ordine a te di sederti, e non vincolarlo con uno stato ad esclusione di un altro interpretando il sedersi.

Poi egli, Allah abbia misericordia di lui, ha detto: "e se ti lascia la scelta in una faccenda, rendi la scelta a lui". Egli ti dice di non scegliere al posto suo, poiché tu non sai ciò che ti è profittevole del tuo stato, mentre lui lo sa, e se egli sceglie per te ciò che sceglie, attieniti a quello e non discostarti da ciò, che si tratti di una cosa che è facile per te o di una cosa che è difficile, poiché Allah, sia Egli esaltato, è Colui che Si manifesta a te nella forma dell'Inviato, e chi obbedisce all'Inviato obbedisce ad Allah. Per quello questo Maestro ti ha detto: "rendi dunque la faccenda ad Allah, sia Egli glorificato ed esaltato".

Poi ti ha detto: "e dì con buona educazione: non ho volontà riguardo [231] a nulla, poiché mi sono staccato da tutta la mia volontà in quanto mia, e non mi è rimasta volontà distinta al di fuori di te, e ciò che tu vuoi è ciò che io voglio, come ha detto Abū Yazīd: Voglio non volere, giacché la mia volontà non conta nulla, poiché non c'è se non ciò che Tu vuoi”, e questo, pur essendo elevato, corrisponde ad una stazione specifica, ma quella che si contrappone ad essa è più elevata: la maggior parte degli uomini considera che "la volontà del servitore" sia una conseguenza (taba), mentre la gente della conoscenza ha il giudizio opposto a questo, ed abbiamo già alluso a ciò in quanto precede $\left({ }^{748}\right)$.

Non penso che Abū Yazīd abbia fatto un simile discorso se non nel momento del suo velo ed all'inizio della sua faccenda, poiché ogni discorso con cui le realtà essenziali vengono rigettate, anche se corrisponde ad una realtà essenziale [relativa] non procede se non da un principiante debole, appena entrato nella via, al colmo dell'ordinarietà, e per questo il principiante parla male della sua anima e pone la sua anima come scudo al Vero affinché non Lo colpiscano i dardi degli atti biasimevoli. Gli Uomini di Allah hanno scienza di ciò e se un simile discorso procede da un grande si tratta di un atto conforme alla circostanza, e deriva dall'elevatezza dello stato e dalla saldezza nella stazione; se invece procede da un piccolo allora si tratta del suo stato e basta, e l'apparenza nelle due persone è unica, mentre il motivo è diverso.

Quanto è bello l'insegnamento di Allah nel Suo detto, quanto è Potente e Magnificente: "E non parlate male di coloro che essi invocano al di fuori di Allah, poiché essi parleranno male di Allah per inimicizia, senza sapere" (Cor. VI-108) ed ha collegato il "senza sapere" al primo "parlate male"

non è arrivato al termine della sua via, per la funzione che esercita rappresenta comunque l'Inviato per i suoi discepoli.

748) L'argomento è stato già affrontato alle pagine 2 e 3 del manoscritto. 
ed al secondo "parleranno male" ed entrambi sono un modo di agire incluso in questa espressione. Quanto al secondo modo di agire in esso [versetto] esso è noto a tutti per comprensione immediata ${ }^{749}$, quanto al primo modo di agire in esso è noto ai nostri simili [232] per il Suo detto, sia Egli esaltato: "Ed il tuo Signore ha decretato che voi non adorerete se non Lui" (Cor. XVII-23), e quindi non è mai adorato altri che Dio. $\left({ }^{750}\right)$ Dunque non parlate male di coloro che essi invocano al di fuori di Allah senza sapere, poiché così parlereste male di Allah senza sapere.

Guardati dal parlar male di qualcuno se non raccontando, cioè riferendo l'offesa ad Allah attribuita a lui nel Suo Libro in base alla Sua Scienza di ciò, e stai in disparte in quel parlar male, poiché chi riferisce non ha il regime di colui di cui riferisce se non nella forma, come ha detto il poeta arabo riguardo a quello:

749) Nel Cap. 560 [IV 484.17] Ibn 'Arabī afferma: "Guardati dal parlar male del padre di uno o di sua madre poiché egli parlerà male di tuo padre e di tua madre e ciò fa parte della irriverenza [ai genitori] ('uqūq). Allo stesso modo, se sei seduto in compagnia di un associatore, non parlar male di chi egli ha preso come Dio assieme ad Allah, e se sei seduto in compagnia di chi tu sai che parla male degli aderenti alla setta dei Rafiditi, non accennare e non alludere, menzionandolo, a qualcuno di coloro di cui tu sai che chi siede con te parla male, dicendo qualcosa che va a loro biasimo, poiché la sua insistenza lo porterebbe a parlar male di loro e saresti tu ad averli esposti alla maldicenza menzionandoli. Allah ha detto: "E non parlate male di coloro che essi invocano al di fuori di Allah, poiché essi parleranno male di Allah per inimicizia, senza sapere" (Cor.VI-108). L'Inviato di Allah, che Allah faccia scendere su di lui la Sua salāt e la Pace, ha vietato all'uomo di parlar male dei suoi genitori. Gli fu chiesto: “O Inviato di Allah, come fa l'uomo a parlar male dei suoi genitori?”, ed egli, che Allah faccia scendere su di lui la Sua șalat e la Pace, rispose: "Egli ingiuria il padre di un uomo e quello ingiuria suo padre ed egli ingiuria la madre di lui e quello ingiuria sua madre"”.

750) Nel Cap. 331 [III 117.6] Ibn 'Arabī afferma: "Non vedi che per la gelosia divina Egli Si è manifestato con il Suo regime [di Dio] nelle entità che vengono prese come divinità, in quanto Egli ha deciso e decretato che nessun'altro sarebbe stato adorato? E lo ha notificato dicendo: "Ed il tuo Signore ha decretato $(q a d \bar{a})$ che voi non adorerete se non Lui" (Cor. XVII-23). I sapienti exoterici intendono il verbo qadā nel senso di "ha ordinato", ma in base allo svelamento noi lo intendiamo nel senso di "ha decretato" [1'ordine può essere eluso, il decreto no] e questo è il senso corretto"; nel Cap. 70 [I 589.17] aggiunge: "Ciò fa parte della gelosia divina e della discesa divina generale, come nel Suo detto, sia Egli esaltato: "ed il tuo Signore ha decretato che non adorerete se non Lui" (Cor. XVII-23), malgrado ciò che viene adorato sulla Terra, come le pietre, le piante e gli animali, e in Cielo, come gli astri e gli Angeli: ciò dipende dalla loro credenza che ogni cosa che adorano è Dio, non per il suo essere una pietra, né un albero, né altro, ed anche se sbagliano nell'attribuzione, non sbagliano in ciò che viene adorato. Per questo Egli ha detto: "ed il tuo Signore ha decretato che non adorerete se non Lui", e fa parte del Suo decreto che essi credano in Dio e quindi adorino ciò che adorano. Ciò fa parte della gelosia divina, affinché non venga adorato se non Chi ha questo attributo [di essere Dio]: in realtà non è che Allah, Gloria a Lui"; e nel Cap. 470 [IV 102.1], ponendosi da un punto di vista ancor più elevato, conclude: "Egli ha detto: "ed il tuo Signore ha decretato che non adorerete se non Lui" e "O uomini, voi siete dipendenti da Allah" (Cor. XXXV-15) e non ha mai menzionato la dipendenza di una creatura da altri che Allah, né ha decretato che venisse adorato altri che Allah. È quindi necessario che Egli sia identico ad ogni cosa, cioè identico a tutto ciò da cui si dipende ed identico a ciò che viene adorato, così come è identico all'adoratore per ogni adoratore, poiché ha anche detto: "Io sono il suo udito", quando Si rivolge a lui prescrivendo le incombenze legali ed istruendo. Il servitore non sente il Suo discorso se non con il Suo udito, ed è così per tutte le facoltà, senza le quali non sarebbe un adoratore di Allah. Nulla dunque si manifesta nell'adoratore e nell'adorato se non la Sua Ipseità (huwiryya). [...] Egli adora ed è adorato". 


\section{Ho sentito [dire]: "Gli uomini vanno in cerca di un luogo irrorato dalla pioggia (gayt)" ${ }^{751}$ )}

e la proposizione è in caso accusativo e "gli uomini" sono stati messi al nominativo (nāsu) per via del racconto, e se "ho sentito" venisse usato nel discorso diretto "gli uomini" sarebbero in caso accusativo $(n \bar{a} s a)$.

I sapienti di Allah, sia Egli esaltato, raccontano e non emettono mai giudizi, mentre la gente comune emette giudizi e non racconta; quest'uomo parla spesso male dell'anima e se è uno che riferisce si tratta della caratteristica dei grandi tra gli Uomini di Allah, sia Egli esaltato, e se invece non ha riferito allora fa parte della gente del velo. Ciò che vela gli uomini è solo la mancanza di comprensione del Discorso di Allah, sia Egli esaltato, quando recita: "Certo l'anima ordina il male" (Cor. XII-53), ove Allah sta riportando in questo versetto la frase di chi l'ha proferita, cioè la frase di Zulayha, o la frase di Giuseppe, su di lui la Pace, per chi la attribuisce a lui $\left({ }^{752}\right)$.

Se essi sapessero da quale stazione essa ordina il male non sarebbero velati da questo versetto sì da biasimare l'anima, ed Allah, sia Egli esaltato, dice il Vero e dirige sul sentiero verso di Lui chi ha eletto tra i Suoi servitori, la gente della Sollecitudine.

Poi questo Maestro ha accostato il tuo star fermo di fronte all'Inviato, su di lui la Pace, con il tuo star fermo di fronte al Maestro, [233] ed ha detto: "e di fronte al Maestro che Allah, quanto è Potente e Magnificente, ha eletto come arbitro nel darti l'esistenza e nel manifestarti in questo Mondo eccelso"; egli dice che devi avere con il Maestro per mezzo di cui Allah ti guida lo stesso adab che devi avere con l'Inviato, su di lui la Pace.

Ed il suo detto che il Maestro ti ha dato l'esistenza e ti ha manifestato in questo Mondo eccelso, cioè con la sua direzione e la sua aspirazione congiuntamente alla tua accettazione si manifesta a te ciò che si manifesta. Ed è come se egli ti facesse nascere in un'altra nascita, poiché l'uomo si manifesta in ogni sede [(mawtin) o: circostanza] con una forma diversa da quella che aveva in un'altra sede, ed egli non si trova in questa sede se non per ciò che il Maestro gli ha spiegato nella sua guida, e quindi ha attribuito a lui il dare l'esistenza ed il manifestare. Quanto al suo legare ciò che si manifesta a lui con il Mondo eccelso $\left({ }^{753}\right)$ - e non lo ha collegato con Allah - ciò è perché egli sa che Allah non

751) Lo stesso verso è riportato nel Cap. 198 [II 414.21] ove però vi è 'ayn, fonte, al posto di gayt.

752) Nel Cap. 57 [I 286.33] Ibn 'Arabī afferma: "L'anima non ordina il male da se stessa e questo viene attribuito ad essa soltanto perché è ricettiva all’ispirazione della scelleratezza da parte di Satana e per la sua ignoranza del regime giuridico di ciò che le viene ispirato [...] L'affermazione di Allah, sia Egli esaltato: "Certo l'anima ordina il male" (Cor. XII-53), non è il giudizio di Allah su di essa, poiché Allah ha soltanto riportato ciò che ha detto la moglie del potente [Putifarre] di fronte a lui, e se lei abbia colto nel segno o meno in questa attribuzione è un'altra questione, di cui non si parla [nel Corano]. Certo è che l'anima biasima se stessa quando accetta ciò che Satana le ha ordinato di fare. Quindi questa notificazione che l'anima incita al male non è il giudizio di Allah, né fa parte di ciò che ha detto Giuseppe, su di lui la Pace".

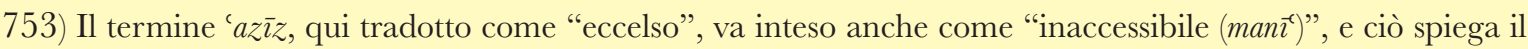


Si manifesta a nessuna delle Sue creature in quanto a Se stesso, ma Si manifesta in quanto a noi, e quindi Si manifesta nella teofania con una delle forme del Mondo, ed in qualsiasi forma Si manifesti quella forma è troppo eccelsa perché ciò che è il supporto di manifestazione del Vero [cioè l'entità ('ayn)] penetri il suo territorio proibito $(\operatorname{him} \bar{a})\left({ }^{754}\right)$, ed il Mondo non cessa di essere il supporto di manifestazione del Vero, solo che Egli non viene riconosciuto.

Per questo la sacralità (hurma) di quella forma è denigrata dalla gente comune ignorante, mentre il conoscitore non denigra una forma del Mondo perché sa che essa è la forma del Vero ( ${ }^{755}$ ), e per questo [nella raccomandazione] lo ha descritto come eccelso, poiché se il Mondo fosse eccelso/ inaccessibile per se stesso il Vero non Si manifesterebbe in esso, per la sua impossibilità intrinseca all'accettazione. La realtà è una Ipseità (huwiyya) nel regime di una forma, una forma nel regime di un Nome divino [234] ed un Nome divino nel regime dell'Ipseità di Colui che è denominato, per la Sua accettazione di quel Nome, poiché Essa governa per mezzo della sua [del Nome] manifestazione; e per questo [il Nome] viene applicato ad Essa e si dice: Egli (huwa) è Allah così e così, come ciò che è menzionato dei Nomi.

Poi ha detto dopo una lunga preghiera e la menzione del tuo chinare la testa: "e non solleva la tua testa se non l'Inviato ed il Maestro, e ogni volta che altri che loro accennano ad alzartela non permetterlo, e non alzarla mai di tua iniziativa, e sii attento a quello". Questa è la sua raccomandazione e l'ha corroborata dicendo: "poiché tu non sai, né altri che loro sanno verso dove sollevi la tua testa", in quanto il sollevare è diverso a seconda del proposito, e chi vuole l'elevatezza sulla Terra perisce, mentre chi Allah innalza nel rango sulla Terra non perisce, e l'Inviato o il Maestro sanno dove loro sollevano la tua testa, in che momento e con quale caratteristica, mentre tu e gli altri lo ignorate.

Quanto al suo detto: "e sii attento" si riferisce a ciò che ha detto dopo di questo, e cioè: "E quando l'Inviato, su di lui la Pace, solleva la tua testa di sua iniziativa, o il Maestro con la sua autorizzazione, su di lui la Pace, vedrai presso di te una cosa terribile $\left(h \bar{a}\right.$ 记 $\left({ }^{756}\right)$, l'accettazione da parte di quel gruppo dei presenti e un saluto da parte loro su di te, ed essi si congratuleranno con te per ciò con cui Allah

successivo riferimento al "territorio proibito".

754) Nel Cap. 73, questione CIII [II 103.5] Ibn 'Arabī afferma: "Poiché l'eccelsitudine ('izza) è un terreno inaccessibile che impedisce a qualsiasi creatura o essere creato ex-novo di essere realmente caratterizzato da essa, poiché l'abbassamento è il loro compagno inseparabile ed esso contraddice l'eccelsitudine, quando il Vero indossò il panno cinto ai lombi $(i z \bar{a} r)$ dell'eccelsitudine impedì alle intelligenze di cogliere l'accettazione da parte delle entità dell'esistenza che esse ricevevano [...] e nessuno al di fuori di Allah conosce la forma del suo dargli l'esistenza, né della sua accettazione, né di come diventi supporto di manifestazione del Vero".

755) Nel Cap. 385 [III 528.1] Ibn 'Arabī afferma: "Quanto alla gente dello svelamento e dell'esistenza realizzata, per loro ogni parte del Mondo, anzi ogni cosa nel Mondo, ha ricevuto l'esistenza da Allah e quindi inevitabilmente si basa nella sua esistenza su una realtà divina. Chi la disprezza o la denigra disprezza e denigra in questo modo il suo Creatore".

756) Anche Ibn ‘Arabī usa questa espressione nei capitoli 11 [I 139.18], 37 [I 228.14], 188 [II 380.7] e 273 [II 583.20]. 
ti ha favorito. Quando vedi ciò guardati dall'attribuire un valore a te stesso". Egli dice: vigila sulla tua anima quando vedi la Sollecitudine di Allah nei tuoi riguardi, poiché è stato l'Inviato di Allah, che Allah faccia scendere su di lui la Sua salāt e la Pace, ad assumersi l'incarico di sollevare [235] la tua testa, o di autorizzare il Maestro a farlo, ed in entrambi i casi la sollecitudine viene da lui, su di lui la Pace, ed essa è un annuncio per te da parte di Allah, sia Egli esaltato, del [tuo] posto presso Allah.

Il Profeta, che Allah faccia scendere su di lui la Sua șalāt e la Pace, non si comporta in questo modo nella sede dello svelamento e dell'immaginazione (haya $\bar{l}$ ) se non per chi è oggetto della Sollecitudine di Allah, elevato nel grado [letteralmente: di immenso valore], a differenza della sfera sensibile, poiché se egli facesse quello nella sfera sensibile potrebbe trattarsi di una insidia (makr).

Per chi ha questo svelamento, la sede [non sensibile] implica che quell'atto è stato autorizzato per la Sollecitudine divina nei suoi confronti, poiché colui per cui l'Inviato, su di lui la Pace, ha avuto sollecitudine nella sede dello svelamento, Allah ha avuto Sollecitudine per lui, come avviene nello stato in cui è soggetto all'incombenza legale nella sfera sensibile, cioè nella dimora più vicina: chi obbedisce all'Inviato invero obbedisce ad Allah, e quella Sollecitudine è il corrispettivo di questa notifica. Sappilo.

Poi l'accettazione da parte di chi è presente in quella sede di svelamento tra gli spiriti che si manifestano nelle forme corporee non grossolane (ğasadiyya), ed il loro saluto a te ed il loro complimentarsi con te sono cose che confermano e corroborano che tutto ciò deriva dalla Sollecitudine di Allah verso di te e che tu stai cogliendo in esso il frutto di ciò che hai seminato (gars) per aver seguito la Sunna nello stato in cui sei soggetto all'incombenza legale.

Sennonché egli ti ha raccomandato, quando contempli questo stato spirituale, di non "attribuire un valore $(q a d r)$ a te stesso" $\left({ }^{757}\right)$, cioè non pensare di averlo ottenuto per un merito (istihqaa $\left.q\right)\left({ }^{758}\right)$. Egli ti avverte che anche se quella sollecitudine e quel favore sono per il tuo aver seguito l'Inviato e per l'abbellimento delle tue azioni, devi considerare che quelle azioni e quel seguire che hanno determinato quello per te hanno luogo per la Sollecitudine di Allah, non per un merito, poiché l'aiuto

757) La frase può essere intesa in due sensi: non attribuire un valore alla tua anima, perché non ne ha, oppure non attribuire un determinato valore ad essa perché tale valore in realtà è incommensurabile. La prima lettura corrisponde alla frase ricorrente nei testi di al-Muhāsibī ed al-Gazālī: "Tu hai un valore presso di Me fintanto che non attribuisci un valore alla tua anima, e se attribuisci un valore alla tua anima non hai valore presso di Me", ed è quella che è oggetto della spiegazione che segue subito dopo, mentre la seconda lettura sarà oggetto di un successivo commento.

758) Il termine istihq $\bar{a} q$, che ha la stessa radice del termine $h a q q$, verità, dovere e diritto, ha il significato di diritto, merito, spettanza, ed in quest'ultimo senso è già stato usato a pag. 163 del manoscritto. Nel Cap. 69 [I 403.1] Ibn 'Arabī afferma: "Sappi che questa ricompensa è una ricompensa di favore divino che il Signore (sayyid) ha assegnato al Suo schiavo, poiché lo schiavo non ha diritto ad alcuna ricompensa da parte del suo Signore per ciò in cui viene impiegato, in quanto dipende da Lui ed è Sua proprietà. Ma il suo Signore è benevolo con lui assegnandogli una ricompensa per la sua opera". 
da Allah, sia Egli esaltato, non è ottenuto per il merito, poiché nulla di ciò è obbligatorio per Allah $\left.{ }^{759}\right)$, [236] e quindi la ricompensa $(a g ̆ r r)$ di ciò che ha generato l'inizio della tua faccenda è come quella dell'inizio [cioè un favore]. Poi, anche se quel favore è frutto di questa azione, esso è frutto dell'azione e dell'opera, non il tuo frutto, ed il merito va all'opera, non a te, anche se tu sei caratterizzato da essa, poiché tu sai che sei spogliato dell'opera e che l'opera appartiene ad Allah, per il Suo detto, quanto è Potente e Magnificente: "ed Allah ha creato voi e ciò che voi fate" (Cor. XXXVII-96). Ed anche se l'opera si manifesta da te, essa è una creazione di Allah, non tua, e quindi non hai merito presso Allah, sia Egli esaltato, né primariamente né secondariamente; tutto questo [cioè l’illusione di avere un merito] è la quota spettante a chi non ha scienza di come stanno le cose realmente, mentre quanto ho detto è ciò che è noto all'élite della gente di Allah, sia Egli esaltato, coloro che sono qualificati dalla scienza.

Quanto all'élite dell'élite, essi sono coloro che hanno una profonda conoscenza (rāsihūn), la gente dello svelamento realizzato e della conoscenza del segreto del Destino, ed essi vedono le cose diversamente da ciò che ha affermato questo Maestro e che abbiamo affermato noi nel commento a questo discorso, anzi, in modo opposto: tutto quello non si attualizza per lui se non perché ne ha diritto (istihqāq).

Egli, sia Egli esaltato, ha imposto a Se stesso quanto esigono quegli stati, e gli stati non hanno diritto a ciò per loro stessi, poiché non sussistono per loro stessi, bensì solo per colui per cui quegli stati sono la sua situazione e per i quali egli è lodato. Innanzitutto egli ha diritto ad essi nell'aiuto (tarefìq) [divino] per la predisposizione (isti ${ }^{\prime} d \bar{a} d$ ) che ha in se stesso, poiché senza di essa egli non accetterebbe l'adeguatezza (muwāfaqa) divina in ciò che Egli gli ha imposto, sì da essere tra i timorati; ed egli non ottiene quella predisposizione nella forma esteriore, cioè nello stato dell'essere soggetto all’incombenza legale, se non per ciò che è la sua forma interiore nella Scienza di Allah $\left.{ }^{760}\right)$.

759) Nel commento alla seconda lettura della frase: "Non attribuire un valore alla tua anima" anche questa asserzione verrà rovesciata. Nel Cap. 73, questione VII [II 44.34] Ibn 'Arabī afferma: "L'adab divino [ci impone di affermare che] non impone ad Allah una cosa, per l'imposizione di chi esige, se non Lui stesso, e se Egli impone a Se stesso una cosa Egli, e solo Lui, è Colui che impone l'obbligo e Colui a cui è imposto. Tuttavia l'obbligo che Egli impone a Se stesso a favore di colui per cui lo impone corrisponde al Suo detto: "La prescriverò per coloro che sono timorati" (Cor. VII-156), cioè la Misericordia che [tutto] comprende e che, dopo essere stata incondizionata, Egli fa entrare nel regime del condizionamento (taquìd) a causa dell'obbligo, e corrisponde [anche] al Suo detto: "Egli ha prescritto a Se stesso la Misericordia" (Cor. VI-54)".

760) Non si tratta quindi della forma interiore dell'essere manifestato, bensì dell'archetipo non-manifestato, esistente nella Scienza divina, ma non esistente nell'esistenza individuale o entificata ('ayn $\vec{\imath}$ ). Nel Cap. 415 [IV 21.9] Ibn 'Arabī afferma: "La forma esteriore è simile alla forma interiore, tanto che uno dei teologi ha sostenuto riguardo alla scrittura ed alla recitazione del Corano che per ogni lettera del Corano che lo scriba scrive o che il recitatore recita, in quella lettera pronunciata o scritta, che è contingente, vi è una lettera simile che è eterna. Ciò che lo ha indotto ad affermare questo è il fatto che il contingente non è indipendente nella sua esistenza ed è quindi necessario che l'eterno lo accompagni: questa è la dottrina del più eminente dei Mu'taziliti [...] Per questo il Mondo è sulla forma del Vero e l’Uomo Perfetto è sulla forma del Mondo e del Vero". 
Egli è quindi interiore/esteriore ed il comando $(a m r)$ non gli viene meno e si dice che il Vero non ha diritto su di lui, come [237] ha affermato nel Suo detto, sia Egli esaltato: "Nulla ti spetta del comando" (Cor. III-128) ${ }^{761}$ ) e queste due affermazioni si contrappongono, ma Egli [nella seconda affermazione] Si è rivolto solo alla forma esteriore [del Profeta], poiché ha detto, quanto è Potente e Magnificente: "Nulla ti spetta del comando" nei riguardi di costoro $\left({ }^{762}\right)$ per due aspetti. Il primo è che il comando appartiene alla forma interiore, ed il secondo aspetto è che il comando appartiene a loro, non a te, e la realtà essenziale implica che il Vero non ha diritto nelle faccende (umūr) che si manifestano negli esseri contingenti $(a k w \bar{a})$, per chi comprende la faccenda [(amr), o: il comando] come è realmente. Ed esso [diritto] Gli appartiene per l'aspetto in cui Egli è qualificato da esso, poiché l'ha ricevuto per mezzo della Sua Epifania in ciò in cui Si manifesta delle forme del Mondo, e non l'ha ricevuto se non per il diritto (istihqāq), e quindi in tutto ciò il diritto (haqq) appartiene ad Allah, sia Egli esaltato $\left.{ }^{763}\right)$. Ma dove stanno questo aspetto e la Scienza rispetto all'aspetto di cui parlano i

761) Il termine $a m r$ in questo versetto è generalmente inteso come faccenda, ma Ibn 'Arabī gli attribuisce invece il significato di comando. Nel Cap. 351 [III 226.13] egli afferma: "Il comando divino è efficace in colui a cui viene impartito [direttamente] e costui non esita a compierlo. Quando il comando divino viene impartito tramite la lingua dell'essere contingente esso si manifesta nei simili e le anime trovano duro essere gestite dagli ordini dei loro simili e quindi rigettano gli ordini del Vero, o ignorando che si tratta degli ordini del Vero, oppure sapendo che essi sono gli ordini del Vero, ma in loro influisce l'intermediario, poiché la sede fa risalire colui che vi risiede alla sua forma, come l'acqua nel recipiente. Sennonché colui a cui viene impartito l'ordine, se si basa su una evidenza da parte del suo Signore, riconosce che non è in grado di far esistere l'entità di ciò che gli viene ordinato a meno che il comando divino, che è efficace, non sia connesso con essa e quindi predispone il suo ricettacolo all'esistenza di ciò che gli viene ordinato al momento in cui il Vero lo fa esistere. Se egli prepara il suo ricettacolo il Vero lo fa esistere e riguardo al ricettacolo si dice che è un servitore obbediente ad Allah in ciò che gli ha ordinato, e la lingua dello stato e dello svelamento dice: "Nulla ti spetta del comando" (Cor. III128). E se non prepara il suo ricettacolo all'esistenza di ciò che gli viene ordinato non si manifesta nulla di ciò che viene ordinato e si dice che è un servitore disobbediente all'ordine del suo Signore e la lingua dello stato e dello svelamento gli dice: "Nulla ti spetta del comando" indipendentemente dal fatto che l'intermediario ordini o parli con una lingua di verità o senza una lingua di verità".

762) Il versetto si riferisce ai nemici dei credenti. Nel seguito del testo citato nella nota precedente Ibn 'Arabī aggiunge: "Quando coloro che avvertono non hanno effetto su coloro che ascoltano, la gente comune dice: "Se il discorso viene dal cuore esso cade nel cuore, e se viene dalla lingua non va al di là dell'orecchio", volendo indicare con ciò che se colui che avverte fosse veridico in ciò con cui chiama gli uomini ad Allah avrebbe effetto. Ora, è noto che i Profeti Inviati, su di loro la Pace, sono veridici nei loro stati, anzi sono i più veridici tra coloro che chiamano ad Allah; inoltre essi chiamano ad Allah in base ad una visione interiore e nella forma di ciò che è stato loro rivelato, e quindi sono veridici sotto ogni aspetto. Ciò nonostante Noè, su di lui la Pace, ha detto: "Ho chiamato la mia gente giorno e notte * ma il mio appello non li ha fatti accrescere se non nella fuga" (Cor. LXXVII-5 e 6), ed Egli ha detto: "Quando venne da loro un ammonitore" cioè la chiamata del Vero tramite la lingua dell'Inviato, che Allah faccia scendere su di lui la Sua șalāt e la Pace, "non accrebbe loro se non in avversione * e nell'essere arroganti sulla Terra" (Cor. XXXV-42 e 43). Dunque non ingannare te stesso ed osserva ciò a cui sei chiamato: se è vero, anche se venisse da Satana, accettalo, poiché così facendo accetti il Vero, e non curarti di chi lo dice".

763) La traduzione di questo paragrafo pone diverse difficoltà, per l'ambiguità del termine amr che può significare tanto comando che faccenda, per il ricorso a pronomi che potrebbero riferirsi a diversi antecedenti, come nel caso della frase "ed esso Gli appartiene", ove "esso" può riferirsi sia al diritto che al comando o 
sapienti, Allah sia soddisfatto di loro, per mezzo della riflessione speculativa in questa questione? Tra i due [aspetti] c'è la stessa differenza che c'è tra la negazione e l'affermazione.

Se non fosse che conosco colui che ha riferito, a cui questo Maestro ha fatto proferire questo discorso, non lo avrei commentato in questo modo, e se l'avessi commentato in base alla scienza di chi lo ha fatto parlare, che è il Maestro, lo avrei commentato con ciò che è stabilito tra la gente del velo, "che conoscono il lato esteriore della vita di quaggiù ma che sono noncuranti dell'aldilà" (Cor. XXX-7). Il nostro discorso, in questo caso come in altri, è il nostro discorso con Allah, quanto è Potente e Magnificente, che fa parlare ogni cosa $\left({ }^{764}\right)$, e quindi il nostro discorso è con Lui, anzi anche per mezzo di Lui, non per mezzo nostro, poiché Egli è Colui che parla da me e che ascolta da te, per il regime delle due forme, non per Se stesso.

$$
\begin{aligned}
& \text { Il comando [(amr) o: la faccenda] è tra me e Lui }\left({ }^{765}\right) \text {, } \\
& \text { se hai realizzato la sua essenza ('ayn). }
\end{aligned}
$$

alla faccenda, ed infine per la mancanza di simili affermazioni nelle Futūhāt, mancanza che non corrobora la correttezza del manoscritto.

Nel Cap. 73, questione LXXXVIII [II 94.25], Ibn 'Arabī afferma: "Il Vero è stato chiamato haqq per il Suo esigere (iqtid $\bar{a}$ ) dai Suoi servitori, quanto alle loro entità (aya $\bar{a} n)$ ed al loro essere dei supporti di manifestazione (mazähir), ciò a cui Egli ha diritto (yastahiqqu), poiché il dovuto (haqq) non è richiesto se non per il diritto (haqq) [...]. Esso [il dovuto] è ciò che colui a cui è imposto deve dare quando gli è richiesto. "Il vostro Signore ha prescritto a Se stesso la Misericordia" (Cor. VI-54), cioè l'ha resa obbligatoria e quindi è diventata un dovere (haqq) per Lui. Egli ha detto: "Ed è un dovere per Noi soccorrere i credenti" (Cor. XXX-47). Egli è nient'altro che la Verità, ed è Colui che ha diritto (al-mustahiqq), Colui che impone il dovere (al-muhiqq) e Colui a cui sono imposti i doveri $(h u q u \bar{q} q)$ quanto alla Sua imposizione $(\bar{\imath} g \bar{g} a b)$, no, anzi, quanto alla Sua Essenza. Se le entità non avessero diritto di essere dei supporti di manifestazione, il Vero non Si sarebbe manifestato in esse e non sarebbe Saggio ( hakim), per la lacuna (halal) che sarebbe inseparabile da ciò. Se la Personalità (huwiryya) non avesse diritto alla manifestazione in questi supporti essenziali, per manifestare l'autorità della Signoria (rubūbiyya), non Si manifesterebbe in queste entità. La cosa non si manifesta in se stessa per se stessa, quindi è indispensabile un'entità in cui e per cui Egli Si manifesta e contempla Se stesso nel supporto di manifestazione, ed è chiamato Contemplato $(m a s ̌ h \bar{u} d)$ e Contemplante $(s \bar{a} h i d)$. Le entità non hanno diritto [per loro stesse], e per questo ha detto: "Il vostro Signore ha prescritto a Se stesso la Misericordia" (Cor. VI-54), e non ha detto che le entità hanno diritto alla Misericordia; le entità non hanno altro diritto che quello di essere dei supporti di manifestazione".

764) Nel Cap. 387 [III 535.29] Ibn 'Arabī afferma: "Egli fa dire loro ciò che essi dicono di Lui. Egli ha detto che riguardo a ciò che viene testimoniato contro di loro essi "hanno detto alle loro epidermidi: Perché testimoniate contro di noi? Ed esse risposero: È Allah che ci fa parlare, Colui che fa parlare ogni cosa" (Cor XLI-21). Non c'è quindi cosa che non parli senza che Allah la faccia parlare e vi è differenza in ciò che viene detto (al-mantūq $b i-h i)$ : vi è una parola $(n u t q)$, cioè ciò che viene detto, con cui è connessa una lode, una con cui è connesso un biasimo, una connessa con una metafora di una condivisione (tağawreuz li-tawäț ) che Allah ha posto nel Mondo, ed una riguardante ciò che Lo indica in Se stesso, che consiste nel notificare una verità. Non c'è altro oltre a ciò che abbiamo menzionato. La parola della lode è la testimonianza ( $\check{s} a h a \bar{a} d a)$ di coloro che hanno scienza dell'Unità di Allah; la parola del biasimo è quella di chi dice: "Invero Allah è povero" (Cor. III-181) e: "La mano di Allah è serrata" (Cor. V-64), riferendosi all'avarizia; l'esprimere la verità è: "Allah ha creato voi" e l'esprimere metaforicamente la condivisione è "e ciò che voi fate" (Cor. XXXVII-96) ed il versetto è lo stesso"

765) L'argomento è già stato affrontato a pag. 8 del manoscritto. 
L'essere in divenire fa essere il suo divenire (al-kawn kawwana kawna-hu), per chi ha realizzato il suo divenire $\left.{ }^{766}\right)$.

Chi dice: "dove?" (ayna), il Vero è per l'essere in divenire il suo "dove" $\left.{ }^{767}\right)$. [238]

Allusione esoterica del suo detto: "non attribuire un valore a te stesso", poiché tu sei al di fuori della misura e non sei compreso da una forma che ti racchiude, ma ogni volta che ti manifesti in una forma essa è seguita da una forma diversa ed il tutto è la tua entità. La faccenda è senza fine e quindi incomprensibile e la misura non può afferrare ciò che non è comprensibile, ma ogni ignorante attribuisce a se stesso un valore e si ferma ad esso.

Non ho visto tra la gente comune chi conoscesse il valore di questo, al di fuori di questo contesto [iniziatico], se non una moglie che ho avuto $\left.{ }^{768}\right)$. Quando volli stipulare il contratto matrimoniale con lei, l'incaricato al contratto le chiese: "Cosa vuoi che venga stabilito come dote per te?", ed ella rispose: "Il minimo che renda lecito il matrimonio". L'incaricato, che non conosceva il suo proposito nel dire ciò, le disse: "Tu sei una donna di nobile rango, sorella di un grande $\operatorname{Re}\left({ }^{769}\right)$, ed è quindi

766) I testi in versi di Ibn 'Arabī sono ancora più difficili da comprendere e tradurre di quelli in prosa. Il termine kawn, spesso contrapposto ad 'ayn che indica l'entità immutabile, si riferisce all'entità contingente e mutevole, e quindi al divenire o al venire ad essere. Il kun divino attribuisce l'esistenza (wuǧŭd) alla cosa o entità non-esistente ed essa viene ad essere conformemente alle possibilità che comporta in se stessa ed è quindi la cosa stessa che genera il suo divenire, rivestito dall'esistenza divina. Nel Cap. 48 [I 265.14] Ibn 'Arabī afferma: "Allah, sia Egli esaltato, ha esplicitamente affermato che noi facciamo parte dell'insieme dei vegetali della Terra; Egli ha detto: "Ed Allah vi ha fatto crescere (anbata-kum) dalla Terra come dei vegetali (nabātan)" (Cor. LXXI-17), intendendo "siete cresciuti come vegetali (nabattum nabātan)", in quanto l'infinito di anbata-[kum] è inbātan. Analogamente ha detto, attribuendo il venire ad essere [(takwīn), o: genesi] a ciò stesso a cui è stato ordinato: "Invero la Nostra Parola ad una cosa, quando la vogliamo, è che le diciamo "Siï" (kun) ed essa viene ad essere" (Cor. XVI-40), ed ha attribuito (ğa ala) il venire ad essere ad essa [cosa], così come ha attribuito la manifestazione dei vegetali ai vegetali".

767) Nel Cap. 415 [IV 21.15] Ibn 'Arabī afferma: "Il Vero è uno specchio per il Mondo, in cui si manifestano le forme del Mondo; quindi le possibilità vedono loro stesse [come] ciò che esiste nello specchio del Vero e dipendono nell'esistenza da Lui ed Egli dipende nella scienza di Sé $(b i-h i)$ dalla scienza di esse $(b i-h \bar{a})$ ”.

768) Nelle Futūhăt Ibn 'Arabī cita per nome due mogli, Maryam, figlia di Muhammad ibn 'Abdūn ibn 'Abd al-Raḥmān al-Biğā̄ì [Cap. 53 (I 278.25), 198 (II 417.7) e 352 (II 235.14)], e Fāṭima, figlia di Yūnus ibn Yūsuf, comandante dei due luoghi sacri (harämayn) [Cap. 560 (IV 554.1)] entrambe viventi all'epoca della redazione di questo testo, e, senza riportarne il nome, una moglie deceduta [Cap. 560 (IV 474.12)], che potrebbe essere quella qui menzionata.

769) Nella introduzione alla sua terza edizione [2018] delle Futūhāt 'Abd al-'Azīz Sulțān al-Manșūb, riferendosi alla moglie menzionata in questo manoscritto, ha precisato: "Nel suo libro "Natā ǐg al-adkār", a pag. 15 [dell'edizione del Cairo, Dār al-haqūqa, 2007, Ibn 'Arabī] riferisce che nell'anno 631 dall'Egira, tra i suoi compagni a Damasco c'era suo cognato $(s i h r)$ Šams ad-dīn Muḥammad ibn Șa'd ad-dīn Yaranquš, ed è noto che nella famiglia Yaranquš c'erano stati dei Qādī e dei Re che avevano goduto di grande prestigio a Bagdād, Moṣul, Diyārbakir e Damasco dalla fine del V secolo fino all'inizio del VII secolo dall'Egira. È possibile che 
necessario che la tua dote sia conforme al tuo valore", ed ella rispose: "Fa così chi ha in se stesso un'importanza e un valore quantificabile (qīma). Quando la donna determina [una dote] superiore a quanto rende lecito il matrimonio dichiara ciò che per lei è il suo valore, ma la mia anima, ed Allah è più sapiente, è per me più elevata dall'avere in cambio del suo valore questo mondo e l'altro e quindi io non sono da poco secondo la mia anima. Se nella mia dote non c'è se non quanto rende lecito il matrimonio si sa certamente che quello non è il mio valore, e quindi voglio solo il minimo legale, sì che il mio valore resti ignoto". L'incaricato ed i dottori della Legge furono stupefatti dalla nobiltà della sua intenzione. Ciò che avete sentito è quanto ella mi riferì verbalmente ed a questa donna della gente comune era giunto un profumo divino di realizzazione di come la faccenda è realmente, senza che fosse consapevole del valore di ciò che diceva, poiché ella parlava in base a ciò che era per lei un'anima eccelsa e grande, [239] non in base ad una scienza dell'aspetto che menzionano i nostri simili riguardo a questa questione.

Quindi questo Maestro gli ha raccomandato di non attribuire valore a se stesso, sia nei riguardi dell'anima di costui che ha fatto la raccomandazione, per la sua [dell'aspirante] meschinità, bassezza e piccolezza, che nei riguardi di Chi gli ha fatto proferire quello, per l'elevatezza del Suo rango $\left(\check{s}^{3} n\right)$ e per l'inaccessibilità della faccenda in se stessa, e vi è molta differenza tra i due propositi $\left({ }^{770}\right)$.

Poi dopo aver detto: "non attribuire un valore a te stesso", ha detto: "e considera il tuo stato, di cui non hai merito, ed attribuisci scarsa importanza a te stesso per quella faccenda" e anche questo fa parte di ciò che ha proferito senza conoscere ciò che diceva, e per questo lo ha rovinato con ciò che ha aggiunto dicendo: "e considera il tuo stato", cioè rifletti sul tuo stato, "di cui non hai merito", e se egli riflette sul suo stato e non si ritiene meritevole di esso, invero Allah, quanto è Potente e Magnificente, non gli ha conferito se non ciò che spetta alla disposizione (ahliyya), poiché Egli è Saggio e mette le cose al loro posto. E se egli attribuisce scarsa importanza a se stesso per quella faccenda, allora vuol dire che il Saggio ha messo la cosa nel posto sbagliato, ma la realtà non è così. Se colui che è favorito non avesse in lui la disposizione a ricevere il favore non lo riceverebbe: non vedi che allo scarabeo nuoce il profumo della rosa, malgrado la sua bontà, perché in lui non c'è disposizione per esso e non ha una complessione che comporti per lui il piacere di quel profumo? $\left.{ }^{771}\right) \mathrm{E}$ così ogni favorito o punito non lo favorisce o lo punisce se non la realtà essenziale dello stato in cui si trova. Chi attribuisce scarsa importanza a se stesso riguardo a ciò con cui è stato favorito accusa di ignoranza Colui che ha collocato quel favore, in quanto lo ha collocato nel posto sbagliato, ma egli [240] non l'ha ricevuto se

questa signora, oppure la signora Fāțima bint Yūnus, sia la madre di sua figlia Zaynab, che egli menziona due volte nelle Futühăt [Cap. 303 (III 17.11) e Cap. 480 (IV 117.14)] insieme a sua madre ed a sua nonna, dicendo che era una bambina che aveva meno di due anni quando fece il pellegrinaggio insieme a sua madre ed al suo zio materno, mentre egli [Ibn 'Arabī] si recava da Damasco a Bagdād, e da lì alla Mecca".

770) Cioè tra le due letture della frase: "non attribuire un valore a te stesso" o tra il proposito di sua moglie e quello di colui che ha fatto la raccomandazione.

771) Lo stesso esempio è riportato nel Cap. 289 [II 648.28]. 
non perché ne aveva la capacità e quindi non è piccolo rispetto ad esso, e Colui che elargisce il favore non lo ha posto in lui se non perché egli ne è capace, e può darsi che per la sua accettazione diventi più grande per un altro favore che gli viene da Allah, sia Egli esaltato.

Tutto il Mondo è fatto parlare di ciò di cui conosce il valore e di ciò che non conosce, ed il nostro discorso ed il nostro commento è soltanto per il discorso di Allah, che sa ciò che ha fatto dire a questa persona, quindi non trasporlo se non quando scendiamo dalle realtà essenziali a ciò che è noto nel costume dei sapienti ed a ciò che conferisce la loro facoltà.

Talvolta procediamo in questo modo per la comprensione di chi ascolta e per protezione nella situazione contingente; Allah, sia Egli esaltato, ha detto :"a meno che non vi proteggiate da loro per timore" (Cor. III-28) permettendoci una cosa simile, e quando viene meno ciò che lo rende necessario viene meno anche la necessità.

$\grave{E}$ in questo ambito che l'Inviato di Allah, che Allah faccia scendere su di lui la Sua șalāt e la Pace, amava il buon presagio $\left(f a^{\prime} l\right)\left({ }^{772}\right)$, e se chi lo proferiva non intendeva dire ciò che ne apprendeva il destinatario esso era comunque inteso così da Allah che glielo aveva fatto proferire nei riguardi del destinatario. Vi sono due aspetti in ciò: un aspetto per il proposito di colui che viene fatto parlare, ed un aspetto per il proposito di Colui che fa parlare nei confronti del destinatario del buon presagio. Rifletti su questo, ed Allah è più Sapiente.

Poi egli, Allah abbia misericordia di lui e sia soddisfatto di lui, ha detto: "E se provi nella tua anima un rinvigorimento (nahda), alzati e menziona Allah, quanto è Potente e Magnificente, con ciò di cui è degno, e lodaLo con ciò che Allah ti ha dischiuso, poi fai la salāt sul Profeta, che Allah faccia scendere su di lui la Sua salāt e la Pace, e prega per il Maestro e per coloro per cui ti ha ordinato di pregare in ciò che precede". Egli, Allah sia soddisfatto di lui, [241] dice che vi sono stati che quando arrivano sull'uomo intorpidiscono le sue estremità e gli attenuano il movimento con tutte le sue membra perché la forza dello stato lo pervade. Allah, sia Egli esaltato, ha conferito gli stati ed ha conferito al servitore una forza, e per quanto riguarda lo stato che arriva al suo possessore si danno tre situazioni, in relazione alla forza di colui su cui esso arriva, e cioè che ciò che arriva dello stato sia equivalente alla forza di colui su cui arriva, o al di sotto di essa o al di sopra di essa, non c'è una quarta categoria $\left({ }^{773}\right)$.

772) Hadīt riportato da Ibn Hanbal. In un altro hadīt riportato da al-Buhārī, LXXVI-43, 44 e 54, Muslim, XXXIX-110 a 112 e Abū Dāwud, XXVII-24, il termine " $f a$ ’" viene spiegato come la "parola favorevole" (alkalima as-säliha). Ibn 'Arabī parla del buon presagio nei capitoli 69 [I 505.5], 77 [II 149.9], 351 [III 220.5], ove precisa: "[Egli, sia esaltato, ha detto:] "Quanto a chi è venuto da te di corsa e che aveva paura, a lui tu non hai prestato attenzione" (Cor. LXXX-8 a 10), per il fatto che egli era cieco, cioè non trarre un cattivo auspicio. Egli gli proibì il cattivo auspicio (tīra) e da allora egli [il Profeta] amò il buon augurio e biasimò il cattivo auspicio, che è la sorte (hazz) della disgrazia, mentre il buon augurio è la sorte e il destino del bene", 558 [IV 309.22] e 560 [IV 479.19]. Su questo argomento si può consultare lo studio di Toufic Fahd, La divination arabe, Sindbad, Paris, 1987, pag. 431-479.

773) Nel Cap. 44 [I 248.27] Ibn 'Arabī precisa: "Sappi che in questa stazione gli uomini si suddividono in tre 
Se [la forza dello stato] è simile alla sua ne risulta una parità e colui che lo possiede è dotato di equilibrio: come lo stato non ha giurisdizione su di lui con la sua manifestazione, così egli non ha giurisdizione sullo stato nel suo disporre. Se ciò che arriva è più forte esso intorpidisce le sue estremità ed indebolisce i sensi, ed egli dice: "Avvolgetemi in un mantello, copritemi!" (774).

Se infine ciò che arriva dello stato è inferiore alla forza che c'è nel ricettacolo, egli dispone dello stato come vuole e prova la forza ed il rinvigorimento nel suo corpo, e per questo ha detto: "se provi un rinvigorimento", cioè lo stato è al di sotto della tua forza, "allora mettiti con vigore a menzionare Allah, quanto è Potente e Magnificente, ed a lodarLo con ciò di cui è degno", e per la menzione egli intende qui la menzione della gratitudine, poiché tu hai ricevuto un favore con questo stato.

Ed il suo detto: "poi fai la șalāt sul Profeta, che Allah faccia scendere su di lui la Sua salāt e la Pace", ti dice di non dimenticare in quello stato di far sapere ciò che lo ha determinato, essendo tu della gente

categorie: vi è colui per cui ciò che arriva è maggiore della forza che egli ha in se stesso e quindi ciò che arriva lo domina e lo stato prevale su di lui; lo stato dispone di lui con il suo regime ed egli non ha alcun governo su se stesso finché resta in quello stato. Se lo stato perdura per lui fino al termine della sua vita egli viene chiamato in questa Via folle, come Abū 'Iqāl al-Magribī. Talvolta, anche se la ragione [umana] gli viene tolta, gli resta la ragione della sua animalità, ed egli mangia, beve e si comporta senza ponderazione né deliberazione: costoro sono chiamati folli dotati di ragione [...] Talvolta infine il regime di ciò che arriva non perdura per lui e lo stato cessa per lui, ed egli torna dagli uomini con la sua ragione, governa la sua faccenda e capisce ciò che dice e ciò che gli viene detto, e si comporta con ponderazione ed in modo deliberato, come tutti gli uomini: questo è il caso del Profeta, e quello degli Intimi che hanno degli stati. [Nella seconda categoria] vi è colui per cui ciò che arriva e la teofania equivalgono alla sua forza, nel qual caso non si vede un effetto palese del regime di ciò che è arrivato, ma ci si rende conto quando lo si vede, per una consapevolezza nascosta, che qualcosa gli è successo, poiché necessariamente egli deve prestare attenzione a ciò che gli arriva per cogliere ciò che gli viene da parte del Vero. Il suo stato è come quello di chi sta seduto a conversare con te ed arriva un'altra persona a recargli un ordine da parte del Re: egli smette di parlare con te per prestare attenzione a ciò che gli dice quella persona e quando questa gli ha comunicato ciò che doveva, egli torna a conversare con te. Ed anche se tu non lo vedessi [colui che gli ha parlato] e lo vedessi prestare attenzione ad una faccenda, sapresti che vi è qualcosa che lo ha distratto da te [...]. [Nella terza categoria] vi è colui la cui forza è maggiore di ciò che arriva, e quando gli viene ciò che arriva ed egli sta conversando con te non te ne accorgi, poiché egli apprende da ciò che arriva ciò che gli viene proiettato, ed apprende da te ciò che gli stai dicendo. Non vi è una quarta categoria riguardo a ciò che arriva da parte del Vero sui cuori della gente di questa Via”.

774) Si tratta delle parole pronunciate dal Profeta Muhammad in occasione della rivelazione, conformemente agli ahādī̄ riportati da al-Buhārī, I-3, LXV, ad Sūra LXXIV-4 e 5, e ad Sūra XCVI-1 e 2, XCI-1, Muslim, I-252 e 255, at-Tirmidīi, XLIV, ad Sūra LXXIV-1, e da Ibn Ḥanbal, III-325 e 377 e VI-223 e 233. Ibn 'Arabī riporta queste parole nel Cap. 44 [I 248.21], ove afferma: "Sappiamo che l'Inviato di Allah, che Allah faccia scendere su di lui la Sua salāt e la Pace, quando la rivelazione lo colse all'improvviso fu atterrito da essa ed andò da Hadīğa tremante e disse: "Avvolgetemi in un mantello, avvolgetemi in un mantello!", e ciò per la teofania di un Angelo: che cosa sarebbe stato di lui per la teofania del Re? "Quando il suo Signore Si manifestò alla montagna Egli la fece diventare polvere e Mosè cadde svenuto" (Cor. VII-143). Quando la rivelazione arrivava all'Inviato di Allah, che Allah faccia scendere su di lui la Sua salāt e la Pace, e lo Spirito fedele discendeva con essa sul suo cuore, egli veniva sottratto ai suoi sensi e brontolava come brontolano i cammelli, finché la rivelazione non lo lasciava. Tuttavia ricordava ciò che gli era arrivato e lo riferiva ai presenti e lo trasmetteva a coloro che ascoltavano", e nel Cap. 69 [I 430.23]. 
di Allah, e non lo ha determinato se non l'aver seguito l'Inviato di Allah, che Allah faccia scendere su di lui la Sua șalāt e la Pace, quindi fai la șalāt sul Profeta, che Allah faccia scendere su di lui la Sua salāt e la Pace, ringraziando perché Allah ti ha guidato tramite lui a ciò in cui ti trovi.

Quanto alla preghiera per il Maestro, è perché è lui che [242] ti ha indirizzato e dato spiegazioni, essendo l'Inviato già morto e trapassato; quanto alla preghiera per i tuoi fratelli è perché essi ti sono di supporto in ciò che sei, e quanto agli altri della gente di Allah, è perché la loro aspirazione (himma) è collegata ad Allah, quanto è Potente e Magnificente, riguardo al successo [accordato da Allah] ai Suoi servitori, ed essendo tu uno dei Suoi servitori sei tenuto a pregare per loro.

Poi egli, Allah sia soddisfatto di lui, ha detto riguardo ad un simile consesso: "E se il Profeta, che Allah faccia scendere su di lui la Sua șalāt e la Pace, sa dal tuo discorso che Allah, quanto è Potente e Magnificente, ti ha dato un'apertura nel discorso, può darsi che ti inviti con un cenno a parlare, mostrando stima per te presso i presenti: affrettati a stare fermo di fronte a lui”".

Egli dice: alcuni uomini hanno ricevuto un'apertura nell'espressione, che nella Via è chiamata l'apertura dell'espressione (futūh al- $\{b \bar{a} r a)\left({ }^{775}\right)$, ed egli, che Allah faccia scendere su di lui la Sua salāt e la Pace, ti ordina di parlare, e ciò è quanto il possessore dello stato trova in se stesso da esprimere, e se ciò lo sopraffà egli parla sopraffatto e se volesse tacere non ne sarebbe capace. Colui che è sopraffatto parla di ciò che capisce e di ciò che non capisce per comunicarlo ai presenti o a un ascoltatore a cui arriverà nel futuro e che ne trarrà beneficio, ed egli lo profferisce nei confronti di chi ne trae beneficio quando lo raggiunge, fosse anche dopo mille anni. Se conosce il valore di ciò che dice egli è nel contempo colui che parla e colui che ascolta, e parla per una visione interiore e questa è la condizione più completa. Se non è sopraffatto ed è in grado di parlare o di tacere, allora osservi la scienza che trova in se stesso [243] e se il consesso la tollera ne parli e se il consesso non la tollera non ne parli ma la metta per iscritto in modo da fissarla per un altro momento in cui essa arrivi alla sua gente ed essa la attesti e ne tragga beneficio. È quindi indispensabile che egli la comunichi o a voce o per iscritto, e se non ne prova l'impulso allora sa che si vuole che nulla di ciò venga manifestato, se non a lui stesso. Egli si comporta conformemente a ciò che trova presso di sé, e se esamina bene la cosa trova che non può essere se non così, poiché il rinvio dell'esposizione in occasione del bisogno non è ammissibile: questo è il regime di Allah, quanto è Potente e Magnificente, nelle cose. Per chi mantiene il riserbo $(\mathrm{katm})$ la sua esposizione è per se stesso, e se scrive è per un altro che non è presente, e se parla è nel contempo per chi è presente, per chi è assente e per se stesso.

775) Questa espressione, che è già stata menzionata a pag 77 del manoscritto, ricorre nei capitoli 73, questione CLIII [II 131.6], 198 [II 475.10], 216 [II 505.12 e 506.2], 326 [III 99.27], 339 [III 153.3] ove Ibn 'Arabī precisa: "È per mezzo di questa apertura [dell'espressione] che il Corano è inimitabile. A nessuno è stata data l'apertura dell'espressione nella perfezione con cui è stata data all'Inviato di Allah, che Allah faccia scendere su di lui la Sua salät e la Pace, poiché Egli ha detto: "Se gli uomini ed i ğinn si mettessero insieme per produrre qualcosa di simile a questo Corano, non produrrebbero nulla di simile ad esso, anche se si aiutassero gli uni gli altri”" (Cor. XVII-88)", e 558 [IV 264.33], ove afferma che Abū Madyan non aveva ottenuto questa apertura. 
Egli [il Profeta] gli ordina [di parlare] quando riconosce [in lui] la forza di parlare e di trasmettere ed egli si trova in quella contemplazione $(s ̌ h u \bar{u} d)$ per uno stato spirituale o nella sua immaginazione, come il suo detto: "Adora Allah come se lo vedessi". In quest'ultimo caso è un cercare di aver presente (istihdāar), non una presenza $(h u d \bar{u} r)\left({ }^{776}\right)$, ma il comportamento del servitore con il suo Signore nel cercare di averLo presente è come il suo comportamento nella Sua presenza: non trascurare questo.

Quando egli parla alla presenza [del Profeta] è fermo di fronte a lui e allo stesso modo è fermo nel cercare di averlo presente, ed il significato di "è fermo di fronte a lui" è che non si sforza al di sopra di ciò che trova e si ferma ad esso senza aggiunta, in quanto si teme che il discorso di chi si sforza sia una prova ( fitna), a differenza di chi non si sforza in quello, e l'aggiunta a ciò che è necessario nel momento è uno sforzarsi [(takalluf) o un'affettazione]. Nel tuo fermarti e nel tuo trasmettere sii dunque conforme a ciò che fornisce lo stato del momento ed a ciò che tu vedi del cenno di chi ti ha ordinato di parlare, e non fare aggiunte a quello $\left({ }^{777}\right)$. E tu conosci bene lo stato poiché sei colui che tiene il consesso (șạhib al-mağlis), e non ti è stato specificato uno stato particolare se non lo stato generale, che è l'adab [244] con colui che dà l'ordine, di fronte a cui tu sei, ed il fermarsi alle sue prescrizioni (marāsim). E non aggiungere altro alla scienza che trovi nel tuo intimo e che vuoi trasmettere, poiché non conosci ciò che è in più, o in meno, o equivalente ad essa se non con il pensiero (fikr), che è la tua bilancia. E quando trovi che nel discorso una parte suscita in te l'altra parla finché permane con te questa caratteristica, e se la faccenda d'un colpo si interrompe per te, in quanto ricorri al tuo pensiero per vedere ciò che si addice a quel consesso e lo fai apparire nell'espressione, quello è sforzo: non farlo, e non parlare se non in assenza di pensiero e di veduta riguardo a ciò che dici, e taci quando l'assistenza divina finisce per te.

Guardati dal pensiero per quanto ti è possibile, poiché non c'è cosa più nociva per la gente di Allah, quanto è Potente e Magnificente, dei pensieri $\left({ }^{778}\right)$, ed esso è ciò che si aggiunge al primo proposito

776) Questi due termini potrebbero essere anche tradotti con "richiamare alla coscienza" e "coscienza effettiva". 777) Nel Cap. 216 [I 505.14] Ibn 'Arabī afferma: "Nel corso di un accadimento spirituale ho chiesto riguardo a questa questione [dell'apertura dell'espressione] e mi venne risposto: "Non dire se non ciò che è vero e che esiste realmente, senza aggiungervi una particella o forgiare qualcosa in te stesso: se il tuo discorso ha questa caratteristica allora è inimitabile"”."

778) Anche se nelle Futūhăt non ricorre una frase così forte, più volte è ingiunto di svuotare il cuore dai pensieri, ad esempio nell'Introduzione [I 31.5], e nel Cap. 2 [I 56.18 e 89.21], e di stare in guardia da essi, come nei capitoli 276 [II 594.27], 475 [IV 110.33], 515 [IV 154.33] e 559 [IV 401.15]. Nel Cap. 231 [II 531.23] si trova invece l'affermazione: "Non c'è cosa più nociva per il servitore dell'interpretazione $\left(t a^{2} w i \imath l\right)$ ", ribadita in una forma leggermente diversa anche nel Cap. 559 [IV 400.17]. L'affermazione che per la gente di Allah i pensieri sono nocivi può sembrare in contraddizione con quella precedente secondo cui il fatto di non perdere la ragione rappresenta per l'iniziato un grado di maggior perfezione rispetto a colui che la perde; ma i due termini arabi fikr (pensiero) ed 'aql (ragione e intelligenza) non sono per nulla sinonimi: mentre il primo indica la facoltà pensante (al-quwwa al-mufakkira) caratteristica dell'essere umano, il secondo indica la facoltà intellettiva (al-quwrwa al-'aqliyya), la quale può essere "informata" non solo dal pensiero, ma anche da realtà di ordine sopraindividuale. Nel Cap. 3 [I 94.27] Ibn 'Arabī afferma: "Quanto alla facoltà riflessiva, l'uomo non riflette se 
che si presenta (hätir), ed il secondo è sempre mentale $\left({ }^{779}\right)$. Guardati dal profferirlo, anche se fosse vero, poiché è prova: in questa Via colui che parla lo fa per costrizione, non per scelta, e per questo è stato detto all'Inviato: "Trasmetti" (Cor. V-67) ed egli ha ricevuto un ordine e l'ordine è identico alla costrizione, tanto che gli è stato detto nell'asseverazione: "e se non lo farai non avrai trasmesso il Suo messaggio" (Cor. ibidem), e la lingua dello stato disse: "Ho paura degli uomini” e gli venne risposto: "Ed Allah ti proteggerà dagli uomini” (Cor. ibidem) $\left.{ }^{780}\right)$.

La Sua protezione per i Suoi Intimi in ciò che essi dicono di realtà come queste è che i presenti non afferrano ciò che l'Intimo vuole dire, anche se ricordano la sua frase, e dicono: "Questo è un discorso senza senso ed un guscio vuoto", in quanto non rientra nella bilancia delle loro intelligenze. E quando Allah, quanto è Potente e Magnificente, vuole che qualcuno tragga giovamento da quello, fa dire in modo canzonatorio al negatore ignorante quella frase che [245] aveva detto quell'Intimo,

non su cose che trova in se stesso e che riceve o da parte dei sensi o dai principi ( $a w \bar{a}$ ì $)$ della ragione. Per mezzo dell'operazione del pensiero $(f i k r)$ su queste cose nel deposito dell'immaginazione, egli ottiene la scienza di un'altra cosa, legata da una correlazione (munāsaba) con le cose su cui egli ha riflettuto. Ma non c'è correlazione tra Allah [in quanto Essenza] e le Sue creature e quindi non è possibile la Sua conoscenza mediante il pensiero. Per questo è stato proibito ai sapienti di riflettere sull'Essenza di Allah, sia Egli esaltato. Quanto alla facoltà razionale non è dato che la ragione ('aql) Lo percepisca, poiché la ragione non riceve se non ciò che conosce intuitivamente o ciò che le apporta il pensiero. Ora, come il pensiero non è in grado di percepirLo, così la ragione non è in grado di conoscerLo per mezzo del pensiero. Tuttavia, in quanto ragione [cioè intelligenza], essa per definizione comprende ed afferra ciò che le arriva: talvolta il Vero le dona la conoscenza di Lui ed essa la comprende in quanto ragione, non per mezzo del pensiero. Questo è quanto noi non dichiariamo impossibile. Questa conoscenza che il Vero dona a chi vuole dei Suoi servitori, la ragione da sola non è in grado di comprenderla, tuttavia la riceve".

779) Il primo proposito non è intenzionale, mentre il secondo implica una volontà. Nel Cap. 70 [I 561.33] Ibn 'Arabī afferma: "Quanto alla quota minima per le membra soggette all'osservanza delle Leggi, questa è per ognuna di esse il passare dal primo [atto] al secondo, ma dal primo che è perdonato, non dal primo che è raccomandato, in quanto il primo [atto] che è perdonato non comporta alcuna zakät, poiché appartiene ad Allah. Il secondo invece appartiene a te e riguardo ad esso è senza dubbio d'obbligo la zakăt, che si tratti del primo sguardo, del primo ascolto, della prima parola, del primo atto di afferrare o del primo passo, o del primo proposito improvviso. Insomma, ogni movimento di un membro in cui non vi sia intenzione non comporta $z a k a \bar{t}$, e quando lo segue il secondo, che non può che essere di intenzione dell'anima, la zakāt, cioè la sua purificazione, è obbligatoria. La zakāt riguardo ad esso è il pentimento per esso, niente altro e così il secondo [atto] raggiunge il primo movimento nella purezza, a causa del pentimento che è la sua zakāt", e nel Cap. 326 [III 97.14] accenna alla: "scienza della differenza tra il primo proposito ed il secondo proposito, e del fatto che [il servitore] non è punito per il primo proposito, ma è punito per il secondo proposito, malgrado il secondo abbia la forma del primo".

780) Nel Cap. 50 [I 272.30] Ibn 'Arabī precisa: "L’Inviato di Allah, che Allah faccia scendere su di lui la Sua șalät e la Pace, non cessò di essere protetto [di notte] da una sentinella finché non scese il versetto: "...ed Allah ti proteggerà dagli uomini!" (Cor.V-67)", e nel Cap. 198 [II 390.22] aggiunge: "L'Inviato di Allah, che Allah faccia scendere su di lui la Sua salāt e la Pace, prima che venisse informato di essere protetto dagli uomini, per mezzo del Suo detto, sia Egli esaltato: "Ed Allah ti proteggerà dagli uomini" (Cor. V-67), quando entrava in una dimora [per la notte] chiedeva: "Chi ci farà da guardia questa notte?", malgrado sapesse che Allah "è il custode di ogni cosa" (Cor. XI-57)". 
citandone il suo guscio, affinché egli ['Intimo] sia giudicato sfavorevolmente per ciò da chi ascolta, ma chi ascolta coglie invece lo spirito di ciò che dice senza che egli se ne renda conto, ed è nei riguardi di quell'ascoltatore che Egli ha fatto ricordare a questo ignorante ciò che ha ascoltato dall'Intimo di Allah, sia Egli esaltato, ed invero è a ciò che alludeva. Ad oggi abbiamo constatato personalmente questo molte volte, ed Allah è più sapiente.

Poi ha detto, Allah abbia misericordia di lui e sia soddisfatto di lui, dopo una lunga preghiera: "E se parli, sappi che Allah, quanto è Potente e Magnificente, ti ha ispirato da parte Sua”. Egli dice ciò che ha detto Allah, sia Egli esaltato, del Hiḍr: "Gli abbiamo accordato una misericordia da parte Nostra e gli abbiamo insegnato una scienza da presso di Noi" (Cor. XVIII-65), ed ha detto: "Ed abbiamo rivelato alla madre di Mosè: Allattalo" (Cor. XXVIII-7) e fu una ispirazione in cui ella ebbe successo, e così il Suo detto: "Ed il tuo Signore ha rivelato alle api" (Cor. XVI-68) e così il Suo detto, sia Egli esaltato: "e le ha ispirato [all'anima] la sua iniquità", [le ha insegnato] che ciò è essere iniqui, "ed il suo essere timorata" (Cor. XCI-8) che ciò è essere timorati, ed ha distinto con questa ispirazione tra l'essere iniqui e l'essere timorati: sappilo.

Poi dopo quello, questo Maestro, Allah abbia misericordia di lui, descrivendo ciò che era presso di lui [discepolo] e ciò che contemplava del suo stato nel suo segreto (sirr), ha detto: "Poi l'Inviato ha ordinato per chi ha questo stato una cattedra (sarīr) su cui sedersi". Egli dice che gli ha assegnato un rango speciale che ha soprannominato cattedra, e lo ha manifestato nel mondo della similitudine (mita $\bar{a} l$, la Presenza dell'immaginazione, come una cattedra, così come ha manifestato [246] la scienza nella forma del latte $\left({ }^{781}\right)$, e non voleva se non determinare il rango $\left({ }^{782}\right)$. L'Intimo di Allah deve osservare quel rango, ciò che esso esige e ciò che deriva da esso, e non esporre nel discorso se non nella misura di quel grado, e tacere di ciò che resta presso di lui, se è in più rispetto a quello; infatti, quando al servitore viene attribuita la cattedra del discorso, egli non ha meno di ciò che esige quella cattedra, ma ha una scienza equivalente o superiore ad essa, non inferiore.

Nel trasmettere egli è tenuto ad osservare quell'adab che [il Maestro] ha stabilito nella sua raccomandazione e che abbiamo commentato in ciò che precede. Egli lo ripete nella sua raccomandazione ad ogni stazione spirituale di cui parla, anche se le regole dell'adab per la singola forma sono diverse a seconda dei consessi, ed egli non ci ha reso possibile parlare di esse e spiegarle in quanto non ha menzionato nel suo discorso ciò di cui parlava. Se l'avesse menzionato avremmo spiegato per quanto è possibile le regole dell'adab che esigeva quel discorso specifico, ma poiché ha

781) Riferimento ad uno hadịt riportato da al-Buhārī, III-22, LXII-6, XCI-15, 16 e 34, Muslim, XLIV-16, e da ad-Dārimī. Ibn 'Arabī fa riferimento ad esso nei capitoli 2 [I 57.29] ove precisa: "È in questo senso che egli, che Allah faccia scendere su di lui la Sua salāt e la Pace, interpretò il latte che aveva bevuto in sogno e del cui resto aveva gratificato 'Umar. Gli fu chiesto: "Come lo interpreti, o Inviato di Allah?" ed egli rispose: "È la scienza"”, 70 [I 592.6], 73, questione XXV [II 58.9] e questione XXXIX [II 66.22], 158 [II 257.6], 167 [II 279.23], 172 [II 292.7], 249 [II 550.10 e 551.8], 367 [III 341.12], 381 [III 507.12], e 558 [IV 219.30 e 220.1].

782) Come si vedrà nel seguito del testo colui che ha questa contemplazione non deve sedersi sulla cattedra, ma al più porre un piede su uno dei suoi gradini. 
taciuto noi tacciamo. E se la faccenda fosse stata ristretta noi l'avremmo specificata dal lato della ristrettezza, ma poiché la faccenda non è ristretta non possiamo attenerci ad un aspetto ad esclusione di un altro, perché non sappiamo ciò che ha detto in quel consesso specifico; e se avesse specificato il consesso forse sarebbe specificato il discorso e sarebbe specificato l'adab che conviene tenere con quel consesso che richiede quel discorso specifico.

In questa sezione vi è nel discorso di quest'uomo molta ridondanza ( hašw $)$ e ripetizione, a differenza di quanto ha detto in precedenza, sennonché in questa raccomandazione egli ha aggiunto il suo ordine a te di baciare in quel consesso il piede del Profeta, che Allah faccia scendere su di lui la Sua salāt e la Pace, segnalandoti così il fatto che egli [Profeta] fa dei passi su di esso per arrivare a te, ed è noto [247] che tu sei al di sotto di lui, ed il suo fare dei passi è una discesa dal più alto al più basso. Si tratta di un piede esteriore che discende da un santuario (quds) più elevato e da un livello più luminoso verso un cielo più basso, per mezzo di un attributo più distinto $(m u t l a \bar{a})$, collegato con l'ultima [dimora] e con la prima, ed egli non ha menzionato dell'adab se non il baciare il piede.

Poi ha detto, riguardo alla caratteristica di quella cattedra e al tuo stato rispetto ad essa: "Se essa cioè la cattedra - ha un solo gradino, metti la tua mano su di esso e non salire su di esso; se invece ha due o più gradini, sali sul primo e basta". Con il solo gradino egli richiama la tua attenzione sul Nome onnicomprensivo $\left(\check{g} \bar{a} m i^{c}\right)$ [Allah] $\left({ }^{783}\right)$, e tu non devi salire su quel [gradino] con il tuo piede, poiché non è possibile che uno venga fatto stare [come servitore] nel Nome divino onnicomprensivo $\left.{ }^{784}\right)$, così come non è possibile che sia fatta una richiesta ad esso [Nome] in modo assoluto, poiché esso è la sintesi dei contrari, ed ogni volta che esso vuole una cosa si leva l'opposto e lo segue, e da esso non deriva mai un modo d'essere (kawn) $\left({ }^{785}\right)$ : per questo Egli ha vietato di invocarLo con esso in quanto Lui $\left.{ }^{786}\right)$.

783) L'identificazione del Nome onnicomprensivo con il Nome Allah è ribadita nei capitoli 5 [I 102.5], 67 [I 329.5], 69 [I 428.27], 71 [I 613.20 e 623.17], 72 [I 669.10], 148 [II 236.5], 198 [II 468.8], 240 [II 541.6], 270 [II 571.21], 295 [II 676.5], 469 [IV 99.1], 486 [IV 122.19] e 559 [IV 352.22].

784) Nel Cap. 216 [II 506.30] Ibn 'Arabī afferma: "Quando il Vero mi chiamò servitore dei Suoi Nomi e mi dischiuse questa dolcezza, non provai un effetto più intenso che dal Nome l'Inaccessibile ('azīz). Quando Egli mi chiamò: "O 'Abd al-'azīz" - il significato di ciò è che l'uomo viene fatto stare come servitore in ogni Nome divino, in modo che sappia discriminare tra le realtà essenziali ed attualizzi le scienze divine - provai per questa chiamata una dolcezza che non ho provato per nessun altro Nome".

785) Nel Cap. 240 [II 541.6] Ibn 'Arabī afferma: "Nulla di ciò che viene da Allah ai Suoi servitori può venire dal regime del Nome Allah, poiché Allah è il Nome che comprende tutte le realtà essenziali dei Nomi divini. Quindi non c'è cosa che accada nell'esistenza contingente ad una determinata persona che non derivi da un Nome determinato, anzi non si manifesta in tutta l'esistenza contingente, cioè in tutto ciò che è altro che Allah, una cosa che lo contenga se non da un determinato Nome specifico: non è possibile che sia il Nome Allah".

786) Nel Cap. 72 [I 669.10] Ibn 'Arabī afferma: “Se si obietta: non è possibile che [l'appello di Colui che chiama al pellegrinaggio nel versetto III-97] sia la realtà essenziale di questo Nome onnicomprensivo, [rispondo:] certo esso interviene, ma Colui che fa l'appello è un Nome specifico che dipende dallo stato di colui che è chiamato e che è determinato da esso. Ad esempio, l'affamato dice: "O Allah, dammi da mangiare"; è Allah che egli 
E se la cattedra ha due o più gradini, si tratta di ciò che si manifesta dei Nomi divini, poiché oggi noi non disponiamo se non dei Nomi che ha apportato il testo del Legislatore, ed essi sono cento meno uno, per via della disparità (witriyya) $\left({ }^{787}\right)$, ed il Nome onnicomprensivo è il centesimo quanto alla sua realtà onnicomprensiva in modo speciale, e ciò che è in più dell'entità di ogni Nome è l'entità dell'insieme $(m a g ̆ m a \bar{u})$ : così dunque essi sono novantanove, non altro, sia nello stato di distinzione (tamyiz) che di riunione (iğtimã $)$. Sappilo.

Quanto al suo ordine [248] di limitarti al primo gradino, ciò corrisponde a ciò che ha detto Ibn Qasī $\left.{ }^{788}\right)$ e cioè che ognuno dei Nomi divini è denominato con ognuno dei Nomi divini e ciascuno di essi

invoca, ma [questo Nome] comprende sia Colui che dà $\left(a l-m u\lfloor ̣ \imath)\right.$ che Colui che rifiuta $\left(a l-m \bar{a} n \imath^{i}\right)$. La risposta è quindi impossibile se colui che chiama intende propriamente ciò che questo Nome implica, e quindi colui che chiama non intende se non Colui che dà da mangiare, Colui che dà, Colui che nutre (ar-razzāq), e non intende Colui che rifiuta. E se Allah gli dà da mangiare, Colui che gli ha risposto non è se non Colui che dà da mangiare. Lo stesso vale per il Suo detto: "Per Allah [è stato imposto] agli uomini il pellegrinaggio alla Casa" (Cor. III-97); con questo Nome [Allah] non si intende l'entità che esso indica, poiché tra le realtà indicate vi sono dei Nomi divini che impediscono la risposta di colui che è soggetto all'incombenza legale, e dei Nomi che invece comportano la sua risposta. Quindi non lo chiama di questo Nome [Allah] se non il Nome che cerca la risposta di colui che è chiamato e che è tenuto a rispondere, e per questo chi non risponde all'appello è di fatto disobbediente, mentre se l'appello venisse dal Nome Allah non sarebbe disobbediente [chi non risponde], né ubbidiente [chi risponde]: le [due] cose sono comparabili. Per questo non è concepibile che qualcuno invochi Allah per ciò che attiene alla realtà essenziale di questo Nome, né che questo Nome Allah chiami qualcuno per ciò che attiene alla Sua realtà essenziale. Invero Egli chiama o è chiamato per ciò che attiene ad un Nome specifico che Egli comprende, riconosciuto dallo stato [del momento]. Sappi che da entrambi i lati [cioè sia da quello divino che da quello umano] non è l'Essenza [d $\bar{a} \bar{t}]$ che è ricercata (matlüba), poiché essa c'è (mareǧüda); invero la ricerca è connessa con ciò che non c'è ( $m a^{\prime} d \bar{u} m$ ), affinché si trovi [o: venga all'esistenza]'. Analoghe affermazioni si trovano nel Cap. 198 [II 462.7]. Va precisato che l'invocazione di cui si parla è la preghiera $(d u ' \bar{a})$, non l'incantazione $(d i k r)$.

Quanto al divieto di invocarLo con il Suo Nome onnicomprensivo in quanto tale non ho trovato dei riferimenti nelle Futūhăt, né nelle raccolte canoniche di hadīt, ma il versetto: "Ad Allah appartengono i Nomi più belli: invocateLo quindi con essi" (Cor. VII-180) potrebbe essere letto in questo senso.

787) Riferimento allo hadît: "Allah, sia Egli esaltato, ha 99 Nomi, 100 meno uno (ahad), e chi li enumera entrerà in Paradiso. Allah è senza pari (witr) ed ama il dispari (witr)", riportato da al-Buhārī, LXXX-69, Muslim, XLVIII-5 e 6, Abū Dāwud, VIII-1, at-Tirmidīi, III-2, an-Nasā̄̄ị, XX-27, Ibn Māğah, V-114, ad-Dārimī, II209, e da Ibn Hanbal, I-100, 110, 143, ecc. Nel Cap. 172 [II 291.8] Ibn 'Arabī precisa: "Sappi che il witr, nel linguaggio degli arabi, è la ricerca della vendetta: l'Unità (ahadiyya) del Vero è caratterizzata dal witr per la Sua ricerca della vendetta rispetto all'unità dell'uno/Uno (wähid) che ha manifestato, per la sua esistenza, il due e ciò che lo segue nella serie indefinita dei numeri. Poiché con questa manifestazione ha fatto cessare il regime dell'Unità, l'Unità del Vero Si è messa a cercare la vendetta per l'Unità cessata, che questo uno/Uno per la cui esistenza si è manifestata la molteplicità ha fatto venir meno, e cerca l'Unicità (wahdāniyya) e si chiama witr per questa ricerca", e nel Cap. 558 [IV 276.17] aggiunge: "L'Inviato di Allah, che Allah faccia scendere su di lui la Sua salât e la Pace, ha detto: "Allah, sia Egli esaltato, ha 99 Nomi, 100 meno uno (ahad), e chi li enumera entrerà in Paradiso. Allah è senza pari (witr) ed ama il dispari (witr)", ed ha reso dispari il 90 con il 9 ed ha escluso l'uno dal 100, e non ha detto 100 meno un dispari (witr) o un singolare (fard), poiché nella singolarità (fardiyya) e nella disparità (witriyya) c'è la condivisione, mentre nell'Unità (ahadiyya) non c'è condivisione".

788) Questo Maestro è già stato menzionato a pag. 70 del manoscritto. 


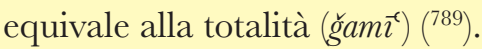

Tu non hai trovato se non il primo gradino e non hai da allontanarti da esso per salire al secondo ed a ciò che c'è in più, poiché il secondo e ciò che c'è in più sono nel primo stesso, come nella scienza dell'Unità ( $a l$ - $\{l m b i$-tawhīd) di Allah, sia Egli esaltato, dal punto di vista del numero ('idda): l'uno equivale alla totalità [dei numeri], poiché la totalità non si manifesta se non per l'uno e non cessa se non per la sottrazione dell'uno $\left.{ }^{790}\right)$, e l'entità di ciò per cui essa sussiste è l'entità di ciò per cui essa viene esclusa dal numero $\left({ }^{791}\right)$; per mezzo dell'uno si manifestano le classi dei numeri $\left({ }^{792}\right)$ : comprendilo. Vi è un gruppo che ha sostenuto questo $\left({ }^{793}\right)$ trasponendo il loro discorso alla scienza di Allah, quanto è Potente e Magnificente, ed anche se alcune vie sono superiori alle altre, tuttavia, nell’insieme, [ciò che sostiene questo gruppo] è una delle vie.

E se costui che ha parlato di limitarsi al primo gradino ha alluso ai ranghi (marātib), [sappi che] i ranghi dell'elezione (ihtișass) non hanno che tre gradini: Intimità (walāya), Profezia e Missione. La fede fa parte dell'Intimità, poiché chi considera la fede come un rango unico per la associazione

789) La frase è riportata nel "Libro della deposizione dei sandali (kitāb hal' an-na qayn)", a pag. 379 dell'edizione araba curata da Muhammad al-Amrānī, pubblicata a Marrakesh nel 1997. Nel commento di Ibn 'Arabī, edito a Marrakesh dallo stesso curatore nel 2013, a pag. 234 si legge: "Ogni Nome divino ha due denotazioni (dalālatān): una denotazione relativa all'Essenza che è denominata, ed una denotazione relativa alla realtà essenziale che distingue quel Nome da Colui che lo possiede, e, per via della denotazione relativa all'Essenza che c'è in ogni Nome da parte di quella realtà essenziale, ogni Nome è denominato da tutti i Nomi e qualificato da tutti gli Attributi. Ciò corrisponde al Suo detto, sia Egli esaltato: "Quale che sia [(dei due) il Nome] che invocate ad esso appartengono i Nomi più belli" (Cor. XVII-1 10)", cioè Allah o il Misericordioso [come nel caso di questo versetto], ma in realtà ciò vale per tutti i Nomi”. La stessa frase è commentata anche nel Cap. 297 [II 686.25], e nei Fusūss al-hikkam, capitoli IV, pag. 83, e XXI, pag. 185 dell'edizione di 'Abd al-'Azīz Sulțān al-Manșūb.

790) Nel Cap. 2 [I 63.10] Ibn 'Arabī afferma: "Il due non esisterà mai senza che all'uno non sia aggiunto il suo simile; il tre non può esserci senza che uno venga aggiunto al due, e così di seguito indefinitamente. L'uno non è il numero e tuttavia è il numero in sé, nel senso che per mezzo di lui il numero è stato manifestato. Il numero nella sua totalità (kull) è uno. Se si sottraesse uno al mille (alf), il nome e la realtà essenziale di mille scomparirebbero, e resterebbe allora un'altra realtà, il 999; e se si sottraesse ad essa uno, essa stessa scomparirebbe. Dal momento in cuil l'uno non è più in una cosa questa non è più, ed inversamente".

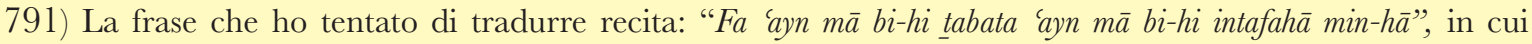
l'ultimo pronome, di genere femminile, ha come antecedente in arabo il termine 'idda, numero, poiché in arabo il termine che indica la totalità è di genere maschile. Se la frase fosse riferita ai Nomi, il senso sarebbe che i novantanove [Nomi] affermati sono identici al centesimo che è negato ad essi.

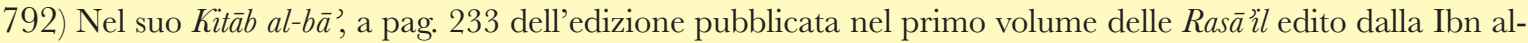
'Arabī Foundation nel 2013, Ibn 'Arabī afferma: "Le classi (marātib) dei numeri sono quattro: le unità, le decine, le centinaia e le migliaia".

793) Nel Cap. Cap. 368 [III 358.15] Ibn 'Arabī afferma: "Il suo [Ibn al-Sīd al-Bațalyawsī, morto nell'anno 521 dall'Egira] punto di vista riguardo alla scienza dell'Unità (tawhīd) era quello dei Pitagorici, che affermavano la dottrina dell'Unità per mezzo del numero, usandolo per dimostrare l'Unità (ahadiyya) del Vero". Ma il "gruppo" potrebbe riferirsi anche agli Ihwān aș-safâa', la cui prima Epistola è dedicata al numero. 
della gente comune in essa, li fa diventare quattro gradini, mentre il numero corretto è tre $\left.{ }^{794}\right)$. Il primo gradino è l'Intimità e per questo ti ha ordinato di non oltrepassarlo, poiché se lo oltrepassassi asseriresti [di avere] la Profezia legiferante e la Sua Missione, e ciò è vietato: non resta quindi che l'Intimità, che è il primo gradino. Non oltrepassarlo poiché sarebbe un varcare ciò in cui tu non hai piede e ciò è temuto per te; parla della tua Intimità, non parlare dello stato di un Profeta legiferante o di un Inviato.

Questo avvertimento che egli ha proferito è straordinario, e se egli ne era consapevole [249] allora ne aveva il gusto spirituale, e se invece non ne era consapevole ha fatto pervenire il deposito a chi ne è degno, ed avrà la ricompensa dell'adempimento, ed Allah è più sapiente.

Poi, Allah abbia misericordia di lui, ha detto: "E quando hai finito con questa sessione e provi un'alterazione (tagayyur) nella tua complessione e nel tuo corpo, non cercare un rimedio per esso, e non lamentarti di quello con nessuno, e lo stesso per ciò che ti colpisce nella tua anima, nella tua famiglia [(ahl), o: moglie] e nei tuoi figli ed in tutto ciò che è connesso a te, e non essere inquieto per quello, e prendi atto con te stesso che la tua anima è presso di te un prestito ('āriya) $\left({ }^{795}\right)$, ed a maggior ragione ciò che è estraneo ad essa, ed il prestito va reso, ed Allah è più sapiente". Egli ti ordina in questa raccomandazione di rimetterti all'ordine di Allah e ti indica l'origine da cui si manifesta tutto ciò riguardo a cui hanno luogo le asserzioni del possesso (milk); è come se egli ti raccomandasse di abbandonare il superfluo $(f u d \bar{u} l)\left({ }^{796}\right)$, poiché chi dispone di ciò che non possiede [essendogli stato dato

794) Nel Cap. 73 [II 5.12] Ibn 'Arabī afferma: "Sappi che Allah ha, in ogni specie di esseri creati, degli esseri privilegiati (has $\bar{a}$ is $s$ ), di cui abbiamo già parlato in questo libro. Questa specie umana fa parte dell'insieme delle specie, ed anche in essa Allah ha degli esseri privilegiati ed una élite (safwa): il sommo grado dell'élite (hawāss) tra i servitori è costituito dagli Inviati, su di loro la Pace, a cui spetta [oltre alla stazione della Missione, anche] la stazione della Profezia, dell'Intimità e della fede. Queste quattro stazioni sono gli angoli (arkān) dell'edificio (bayt) di questa specie, e l'Inviato è il più eccellente quanto a stazione ed il più elevato quanto a stato spirituale, in quanto la stazione da cui è stato inviato, rispetto alle altre stazioni, è la più elevata in rango (manzila) presso Allah. Costoro [cioè questi Inviati] sono i Poli, gli Imām ed i Pilastri (awtād) con cui Allah custodisce il Mondo, così come la casa è protetta dai suoi angoli, e se uno di questi viene a mancare, la casa cessa di essere una casa. Invero la Casa (bayt) è la Tradizione $(d \bar{\imath} n)$ ed i suoi angoli sono la Missione, la Profezia, l'Intimità e la fede. La Missione d'altronde è l'angolo che racchiude in sé tutta la casa ed i suoi angoli, ed essa è lo scopo perseguito dalla specie umana". Altri passaggi in cui la fede è annoverata come un rango a sé stante si trovano nei capitoli Cap. 73, questione XVIII [II 52.13], 270 [II 573.2], 272 [II 582.5], 304 [III 21.2] e 407 [IV 9.34 e 10.17], ma in questo manoscritto il riferimento è solo ai ranghi dell'elezione, mentre la fede è un attributo anche della gente comune.

795) La 'âriya si distingue come forma di prestito dal qard perché riguarda oggetti non fungibili, mentre il qard riguarda il denaro o altri oggetti fungibili e consumabili.

796) L'abbandonare ciò che è superfluo rientra nelle caratteristiche della rinuncia (zuhd). Nel Cap. 51 [I 274.23] Ibn 'Arabī precisa: "Ti abbiamo così esposto chiaramente gli stati spirituali degli iniziati di cui tratta questo capitolo, ciò che deriva loro dalla rinuncia agli uomini e ciò che trovano per questo da parte del Soffio del Misericordioso. Su questa norma [la rinuncia] si conformano gli atti di tutte le membra, i quali hanno come denominatore comune l'abbandono del superfluo in ciò di cui ogni organo ha bisogno, sia interiormente che 
in prestito] è dotato di qualcosa di superfluo, cioè un sovrappiù di ciò che possiede e di cui può disporre. Per questo la gestione (tasarruf) da parte di chi non è proprietario (al-fudūl $\vec{\imath}$ ), nella sua vendita e nel suo acquisto, è subordinata al Possessore dell'uomo, e se Egli la ratifica [o: lascia passare] passa: quindi anche se egli [chi non è proprietario] dispone, la faccenda in ciò è subordinata all'autorizzazione del Padrone (mālik). È in questa misura che l'uomo dispone di se stesso, e la sua ricchezza è in mano Sua ${ }^{797}$ ) ed egli non [ne] è il proprietario, poiché chi ne detiene il possesso è il Legislatore, e ciò che Egli autorizza di [250] quello è così, e ciò che vieta è così.

I nostri compagni hanno punti di vista divergenti riguardo a chi è colpito da qualcosa di ciò [che è stato citato nella raccomandazione] nella sua anima ed in ciò che possiede quanto a famiglia, ricchezza e figli, se sia lecito per lui fare ricorso per quello [lamentandosi] presso Allah, quanto è Potente e Magnificente, o no.

Tra loro c'è chi lo vieta per la remissione (tastīm) ed il deferimento (tafwīe $)$ e tra loro c'è chi permette di fare ricorso per quello presso Allah, quanto è Potente e Magnificente, come Giobbe $\left({ }^{798}\right)$, Dū n-Nūn $\left({ }^{799}\right)$ e altri, e fa rientrare nell'adab il lamentarsi con Allah, sia Egli esaltato, come ha detto il

esteriormente. I primi a conformarsi sono le mani ed i piedi; il più elevato, per quanto concerne gli organi interni, è il pensiero. Gli iniziati di cui parliamo non pensano mai a ciò che non li riguarda, perché ciò porta alla confusione mentale (hawas), ai desideri (amann $\vec{\imath}$ ) ed alla mancanza di concentrazione nell'esecuzione degli atti di devozione. Invero l'uomo non manca mai di pensare a ciò che possiede di questo mondo, oppure a ciò che non possiede. Se il suo pensiero è rivolto a ciò che possiede, non c'è altro rimedio, per la gente del nostro Ordine ( $t \bar{a}$ i fa $a$ ), che quello di staccarsi da ciò, rinunciandovi [per quanto non è indispensabile]: di questo hanno parlato in dettaglio Abū Ḥāmid [al-Gazālī] ed altri. Se invece il suo pensiero è rivolto verso ciò che non possiede, costui, per la gente del nostro Ordine, è privo di intelligenza e stolto e non c'è altro rimedio per lui che la pratica assidua dello $\underline{d i k r}$ e la frequentazione della gente di Allah, che manifesta soprattutto la coscienza di essere costantemente osservati da Allah (murāqaba) ed il pudore (hayā $)$ nei Suoi riguardi".

797) Il manoscritto Yūsuf Aga recita: " $\square \square \square \square \square \square \square \square \square$ " che può essere letto sia come "wa mālu-hu bi-yadihi", ed è su questa lettura che si basa la nostra traduzione, che come: "wa māli-hi bi-yadi-hi" nel qual caso la traduzione sarebbe: "e della sua ricchezza in mano sua". Il manoscritto Husein Celebi riporta la seconda lettura con una successiva cancellatura del $l i$-hi di "māli-hi", per cui il testo alla fine recita: "wa mā bi-yadi-hi", cioè: "e di ciò che è in mano sua".

798) Nel Cap. 73 [II 28.34] Ibn 'Arabī precisa: "[I pazienti] sono coloro che quando sono colpiti da una prova o da una tribolazione si trattengono dal chiedere ad altri che Allah di essere sollevati da quella prova [...] e la loro lagnanza presso Allah affinché li sollevi da quella prova non inficia la loro pazienza. Non vedi che Giobbe chiese al suo Signore di sollevarlo dalla prova dicendo: "Mi ha colpito la sventura, ma Tu sei il più misericordioso dei misericordiosi" (Cor. XXI-83), lamentandosi di ciò con il suo Signore, quanto è Potente e Magnificente, e Gli ha detto: "Tu sei il più misericordioso dei misericordiosi". In questa frase vi è l'affermazione dell'intervento delle cause seconde [per il riferimento alla sventura] ma parlando di esse egli si è rivolto direttamente al suo Signore perché lo sollevasse dalla prova, ed il suo Signore gli rispose e tolse il danno che lo aveva colpito. Ed Egli ha confermato con il Suo detto, sia Egli esaltato: "E gli rispondemmo" (Cor. XXI-84) che la sua richiesta era di sollevarlo dalla prova [...] Malgrado ciò Egli lo lodò per la pazienza e la attestò dicendo: "Invero lo abbiamo trovato paziente" (Gor. XXXVIII-44)".

799) Essendo citato dopo il Profeta Giobbe questo nome non si riferisce a D̄ū n-Nūn al-Misrī, ma al Profeta 
conoscitore: "Egli mi ha fatto affamare sì che io piangessi" $\left({ }^{800}\right)$.

E chi non fa ricorso per quello presso Allah, quanto è Potente e Magnificente, e non Gli chiede di sollevarlo da esso, guasta l'adab, in quanto la sua pazienza si contrappone alla coercizione divina, e ciò non gli compete $\left({ }^{801}\right)$. Colui che ha questo gusto spirituale deve far ricorso presso Allah e lagnarsi con Lui, quanto è Potente e Magnificente, e non con altri, affermando l'esclusività della servitù a Lui, sia Egli esaltato.

Colui [invece] il cui oggetto di contemplazione è il confortarsi alla vista (tafarruğ) del disporre divino nel Regno e non gli viene in mente di competere con la coercizione divina, non deve far ricorso presso Allah, quanto è Potente e Magnificente, né chiedere a Lui di togliere quello e di sollevarlo da esso, poiché egli è conformemente alla stazione in cui è fatto stare.

Talvolta il servitore è anche fatto stare in una stazione diversa da queste due, cioè è fatto stare nella [stazione della] sua servitù relativa ('ubüdiyya) ${ }^{\left({ }^{802}\right)}$ e dell'esistenza (wuğūd $)$ di se stesso, e questo [servitore] chiede e supplica Allah, e non altri, che gli venga tolto ciò che lo ha colpito.

Giona (Yūnus), che viene denominato Dַū n-Nūn in Cor. XXI-87. Nel Cap. 505 [IV 144.4] i due nomi ricorrono insieme, e si tratta certamente dei due Profeti, poiché la loro menzione è seguita dall'eulogia: "la Pace sia su di loro".

800) Si tratta di una frase di Abū Yazīd, riportata nei capitoli 73 [II 29.8], 125 [II 208.6], 505 [IV 143.31] e 559 [IV 408.22].

801) Nel Cap. 125 [II 208.6] Ibn 'Arabī precisa: "Sappi che nella pazienza da parte della gente comune vi è un competere con la costrizione divina ed un cattivo adab nei confronti di Allah. Allah mette alla prova le Sue creature solo affinché esse Lo implorino e Gli chiedano di togliere loro ciò con cui li ha provati”.

802) Ibn 'Arabī distingue la servitù relativa ('ubüdiyya) dalla servitù assoluta ('ubüda), che è gerarchicamente superiore alla prima. Nel Cap. 73, questione LXXVIII [II 88.26] egli precisa: "La servitù assoluta è il rapportare (intisāb) il servitore a Lui; dopo di che viene la servitù relativa, che è il rapportarlo al supporto di manifestazione. Per mezzo della servitù assoluta [il servitore] segue il comando senza alcuna opposizione. Quando Egli gli dice: "Sii”" egli viene all'esistenza senza esitazione, poiché non c'è altro che l'entità immutabile, recettiva per la sua essenza ad essere generata. Poi quando il supporto di manifestazione è attualizzato, Allah gli dice: "Fai questo ed evita quello". Se essa [entità] si oppone al comando, questo dipende dal suo essere un supporto di manifestazione, ma se essa obbedisce senza esitazione, ciò dipende dal suo essere un'entità"; nella questione CLIII [II 128.24] aggiunge: "Se la servitù assoluta è una realtà esistente allora è identica a Lui, poiché l'esistenza appartiene solo a Lui" e poco oltre [II 128.30] afferma: "La servitù assoluta è l'attribuzione del servitore ad Allah, non a lui stesso, e se egli viene rapportato a se stesso allora si tratta della servitù relativa, non di quella assoluta", e nel Cap. 223 [II 518.35] precisa: "Quanto a colui che dice che la separazione (farq) è la contemplazione della servitù relativa, egli rapporta al servitore l'attributo che sussiste in lui, ma esso deve essere rapportato solo ad Allah. La servitù relativa è un attributo che appartiene al servitore e chi contempla la sua servitù relativa appartiene a colui che contempla. Per questo i servitori di Allah vengono rapportati alla servitù assoluta, non alla servitù relativa, in quanto essi sono gli schiavi di Allah, senza [altra] attribuzione, al contrario del loro essere rapportati alla servitù relativa. Il Vero non ammette l'attribuzione della servitù relativa in quanto Egli è identico all'attributo del servitore, non al servitore. Chi contempla la servitù relativa non contempla il suo essere servitore di Allah e quindi distingue tra ciò che è rapportato all'attributo e ciò che è rapportato ad Allah". Mentre in questo paragrafo si tratta della servitù relativa e dell'esistenza del servitore, in quello successivo si tratta della servitù assoluta e dell'esistenza del Vero, in cui il servitore non c'è, o, come afferma nel Cap. 130 [II 215.1] riferendosi alla servitù assoluta, è: "servitore/non servitore". 
E se è stabilito nel [la stazione che comporta la conoscenza del] fatto che egli è il supporto di manifestazione del Vero e che il Vero è identico a ciò che si manifesta, egli porta pazienza e non Lo contrasta se non Lui stesso, poiché il servitore non c’è.

E talvolta è fatto stare anche nella [stazione della] lamentela ( $\left.\check{s}^{2} a k w \bar{a}\right)$ da parte del Vero ai Suoi servitori e del Suo far conoscere loro ciò da cui è offeso affinché essi Lo difendano e facciano resistenza, per il bene che essi ne ricavano; egli prende esempio dal suo Signore in questo [251] ed anche lui fa ricorso presso di Lui per ciò che gli capita e ne viene sollevato da Lui, così come Allah, sia Egli esaltato, difende Se stesso da ciò che Lo offende per mezzo dei Suoi servitori credenti. È infatti stato tramandato che: "Non c'è nessuno che sopporti di più l'offesa che Allah" ( $\left.{ }^{803}\right)$ e malgrado questo Egli ci ha fatto sapere che patisce l'offesa e non ce l'ha fatto sapere se non affinché Lo difendessimo $\left({ }^{804}\right)$.

Tra loro c'è chi è stabilito nel [la stazione che comporta la conoscenza del] fatto che l'offesa che viene rapportata ad Allah, quanto è Potente e Magnificente, e che Egli/egli $\left({ }^{805}\right)$ patisce, appartiene all'entità del supporto di manifestazione, non all'entità di Chi Si manifesta.

Tra loro c'è chi è fatto stare nella contemplazione diretta che ciò per cui patisce non è qualcosa di aggiunto alla sua entità, e la sua lamentela non lo solleva da ciò che gli appartiene, poiché la cosa non viene meno alla sua realtà essenziale, e non gli giova l'intercessione degli intercessori: "e che serve loro scostarsi dal richiamo?” (Cor. LXXIV-49), ed essi [quelli del versetto] sono come ha detto Allah, quanto è Potente e Magnificente: "asini impazziti che fuggono da un leone" (Cor. LXXIV-50 e 51). [Colui che fugge] non è un animale che fugge da un animale [in quanto tale], poiché la cosa non fugge da se stessa, ma un asino che fugge da un leone, o un essere animato da una vita specifica che fugge da un altro essere animato da una vita specifica, ed è la specificazione che lo determina: colui che fugge non è identico a colui da cui fugge ${ }^{(806)}$.

803) Hadīt riportato da al-Buhārī, LXXIII-71, XCVII-3, Muslim, L-39 e 40, e da Ibn Ḥanbal, IV-395, 401 e 405. Ibn 'Arabī lo cita, con alcune varianti, nei capitoli 49 [I 268.25], 68 [I 356.6], 72 [I 680.21 e 730.29], 73 [II 26.34], 84 [II 158.29], 124 [II 206.29], 178 [II 343.13], 309 [III 36.9], 315 [III 58.13], 558 [IV 263.1 e 317.30] e 560 [II 492.6].

804) Nel Cap. 558 [IV 317.25] Ibn 'Arabī afferma: "Allah, sia Egli esaltato, ha detto: "Coloro che offendono Allah" (Cor. XXXIII 57), descrivendo Se stesso come Colui che patisce l'offesa", ed Egli non punisce sul momento colui che Lo ha offeso, descrivendo Se stesso come Golui che ha molta pazienza. Ma Egli ci ha menzionato chi Lo offende e con cosa Lo offende affinché noi Lo solleviamo da essa [offesa], malgrado persista per Lui il Nome di Colui che ha molta pazienza. Egli ci ha così insegnato che quando ci lamentiamo con Lui per una prova che ci è capitata da parte di uno dei Nomi divini, quella lamentela non inficia l'attribuzione della pazienza a noi. Quindi malgrado questa lamentela a Lui affinché ci tolga la prova noi siamo pazienti, così come Lui è Paziente malgrado ci abbia fatto sapere chi Lo offende e come Lo offende perché noi Lo aiutassimo e Lo difendessimo da ciò".

805) Entrambe le letture sono possibili.

806) Colui che contempla che ciò per cui patisce è parte integrante della sua entità non può sfuggire ad esso. Analogamente, nel Cap. 82 [II 156.11] Ibn 'Arabī afferma: "Ė noto che se ciò da cui si fugge è identico a ciò 
Le stazioni spirituali nelle quali la gente di Allah, sia Egli esaltato, viene fatta stare in una simile situazione sono molte, e di esse ve ne sono di elevate e più elevate, ma mai più basse: l'uomo deve quindi agire in conformità a ciò in cui è fatto stare, e non deve imporsi altro che quello.

Poi ha detto: "Stai in guardia che qualcosa ti colpisca e che ti venga in mente la morte a causa di quello, ma sii con Allah, quanto è Potente e Magnificente, in ciò in cui ti stravolge (yuqallibu) $\left({ }^{807}\right)$ ". Egli dice ciò che ha detto l'Inviato di Allah, che Allah faccia scendere su di lui la Sua șalāt e la Pace: "Che nessuno di voi si auguri la morte per un male che gli è sopravvenuto, [252] ma piuttosto dica: Allāhumma, dammi la vita finché la vita è meglio per me, e dammi la morte se la morte è meglio per me, e se vuoi mettere alla prova qualcuno, prendimi a Te senza che io sia provato" $\left.{ }^{808}\right)$. Ciò invero non deriva se non dall'afflizione e dalla mancanza di sopportazione, e tra i requisiti della gente di Allah, sia Egli esaltato, anzi tra i requisiti della fede, vi è l'acquiescenza (sukūn) nelle avversità del destino ${ }^{\left({ }^{809}\right)}$. D'altra parte se la persona si augura la morte per ciò che lo ha colpito non lo fa se non perché si immagina che quello che lo ha colpito, e da cui è afflitto, cessi con la morte: ma cosa gli dice che dopo la morte non sarà fatto andare a ciò che è ancora più intenso di ciò che lo ha colpito?

Per questo gli è stato vietato di augurarsi la morte per ciò che lo ha colpito, poiché la morte è definitiva, e finché l'uomo resta nella vita dell'incombenza legale (taklīf) non gli manca la possibilità, se è credente, di acquisire un bene in tutto ciò che lo colpisce della prova di questo mondo, indipendentemente dal fatto che ciò lo renda insoddisfatto (ashata) o lo renda soddisfatto, poiché Allah ha menzionato che il servitore rende insoddisfatto di lui il suo Signore con il suo atto $\left({ }^{810}\right)$, ed il servitore è più degno di

verso cui si fugge - senza differenza di relazione - non è ammissibile la fuga. è quindi necessaria la differenza di relazioni".

807) Uno hadīt non recensito dalle raccolte canoniche recita: "Il cuore è tra due dita del Misericordioso ed Egli lo rigira come vuole", e nel Cap. 348 [III 199.5] Ibn 'Arabī precisa: "Nello hadīt delle dita vi è una buona novella divina, perché le ha attribuite al Misericordioso. Egli quindi non rigira il cuore se non da una misericordia ad una misericordia, anche se nei vari giramenti vi è una prova; ma nelle sue pieghe vi è una misericordia nascosta all'uomo e che il Vero conosce, poiché le due dita appartengono al Misericordioso".

808) Hadīt riportato da al-Buhārī, LXXV-19, LXXX-30, Muslim, XLVIII-10 e 13, Abū Dāwud, XX-9, anNasā̄ì, VIII-1, Ibn Māğah, XXXVII-31, ad-Dārimī, XX-45, e da Ibn Ḥanbal, II-263, 309, 316, ecc. Ibn 'Arabī lo cita nel Cap. 560 [IV 501.13].

809) Questa espressione non è riportata nel Corano, né negli ahădīt, ma ricorre spesso nei testi del Tașawwuf. Ibn 'Arabī la riporta nei capitoli 73 [II 36.29], riferendola a coloro che stanno quieti, immobili (muhbitūn) [cfr. Cor. XXII-35], 84 [II 158.29], 175 [II 294.29], ove afferma: "L'immobilità (sukūn) è preferibile al movimento ed al servitore è stato ordinata l'acquiescenza nelle avversità del destino, ed in ciò che Allah gli apporta di notte e di giorno. Egli ha detto riguardo a colui che affretta le misure destinate [con il suicidio]: "Il Mio servitore Mi ha anticipato con se stesso ed Io gli ho vietato il Paradiso", e l'affrettarsi è un movimento. Allah non ci ha ordinato di prenderLo come procuratore se non perché noi stessimo immobili e fosse Lui, sia Egli glorificato, a disporre della faccenda del Suo servitore", e 376 [III 481.4], ove la riferisce a colui che è indigente, miskinn, termine che deriva dalla radice sakana che significa letteralmente stare immobile, quieto.

810) Riferimento a Cor. V-80 e XLVII-28. 
questo attributo, non essendo esso un Attributo di Allah $\left({ }^{811}\right)$. Allah non punisce il servitore per esso, ed Egli, sia glorificato, chiude un occhio su coloro che non sono soddisfatti di ciò che viene loro da Allah e che non corrisponde ai loro obiettivi personali (agrāed), poiché gli obiettivi personali da parte del servitore sono come le faccende prescritte legalmente da parte di Allah ${ }^{\left({ }^{812}\right)}$.

Lo stato è lo stato, e non essere rattristato da una cosa che non ti soddisfa, ma malgrado la tua insoddisfazione chiedi ad Allah, quanto è Potente e Magnificente, di sollevarti da quella cosa che ti rende insoddisfatto, poiché l'insoddisfazione per le anime spirituali è come le sofferenze sensibili per lo spirito vitale, e non è altro che la non corrispondenza con gli intenti, così come le sofferenze sono la non conformità con la complessione. E se tu sai che Allah, sia Egli esaltato, ti riprende per queste sofferenze [253] dell'anima, come l'insoddisfazione e l'afflizione, sappi che quello è un riprendere per far conoscere, non un imporre una punizione, poiché la punizione riguarda solo ciò che tu sei in grado di allontanare da te; quanto a ciò che esula dal tuo potere, nel suo riprendere Allah è uno che fa conoscere non uno che punisce, poiché Egli punisce i comportamenti non l'attributo stesso, in quanto esso è il Suo attributo e tu sei responsabile per i comportamenti, ed è da qui che nasce la punizione. Se sei presente in ciò che tu sei, insoddisfatto della realtà essenziale in cui ti trovi da parte del Vero, la cosa conta poco per te e non sarai ripreso per essa con l’imposizione di una punizione.

E quanto al suo detto: "sii con Allah, quanto è Potente e Magnificente, in ciò in cui ti stravolge", sappi che Egli non ti stravolge se non in ciò in cui tu sei recettivo, e se non ci fosse in te la realtà essenziale dell'accettazione non ti stravolgerebbe; e quanto al significato del suo detto: "con Allah, quanto è Potente e Magnificente" egli ha usato la particella di compagnia [con], perché la faccenda è tra te e Lui. A Lui appartiene l'influenza ( $t a \underline{\text { At}} \bar{r} r)$, che è ciò che ti capita, ed a te appartiene l'accettazione, e come Egli non ricorre contro Se stesso per ciò con cui ti colpisce, così non ricorre contro di te per la tua insoddisfazione di quello, poiché per la natura dell'anima tu lo respingi così come Egli per l'Essenza lo fa scendere, e qui vi è un terreno scivoloso per chi non ha scienza dei segreti del Vero

81 1) Nel Cap. 431 [IV 44.8] Ibn ‘Arabī precisa: “Dov'è la circostanza (mawtin) della collera divina rispetto alla circostanza della [Sua] soddisfazione? Il servitore compie un atto ed il suo Signore è insoddisfatto di lui per esso: egli fa del male a se stesso ed il Vero in base a quell'avvenimento Si trova tra l'indulgenza e la punizione; e quel servitore compie un atto di cui il suo Signore è soddisfatto ed è lui che Lo rende soddisfatto così come Lo rende insoddisfatto. Quindi il Vero è con i Suoi servitori in conformità ai loro stati, non può essere altrimenti”. L'insoddisfazione e la soddisfazione divine non sono degli Attributi intrinseci (sif $\bar{a} t)$, ma solo Attributi di relazione $(n u$ üt $)$, dipendenti dal comportamento del servitore.

812) Nel Cap. 113 [II 195.17] Ibn 'Arabī precisa: "Sappi che l'anima ha due obiettivi personali (agrāe): uno essenziale ed uno accidentale. Quello essenziale è l'acquisizione dei vantaggi e l'allontanamento degli svantaggi, mentre quello accidentale le viene presentato dal lato della Legge. Talvolta [però] l'obiettivo accidentale viene dal lato del desiderio, talvolta dal lato di ciò che è confacente alla natura e talvolta dal lato della ricerca della perfezione. Tutto ciò, nella via che noi percorriamo, non va considerato se non dal lato specifico della Legge: è essa che stabilisce i mezzi migliori per i quali, mediante il compimento di ciò che essa ha ordinato di fare e l'abbandono di ciò che essa ha vietato di fare, è resa necessaria la felicità e si ottiene l'Amore divino, di modo che il Vero è l'udito del servitore e la sua vista". 
riguardo ai Suoi servitori, cioè a coloro che si chiamano servitori.

Non c'è che il Vero ed il servitore, niente altro.

Non c'è che il servitore, ed il Vero ha potere di giudicare.

Già è apparso agli sguardi ciò che ho fatto loro vedere,

e chi vuole parta, e chi vuole stia.

Non prendere le parole falsamente, poiché esse

sono il vestito delle idee, e di: "Si", quando le senti. [254]

Ed abbi coraggio con esse e non essere

pauroso, poiché saresti cieco di fronte a te. Sii saldo e non mollare. $\left({ }^{813}\right)$

Poi ha detto: "E se tu vieni indicato come colui da cui apprendere, osserva l'adab e riconosci l'insufficienza (taqsīr)". Egli dice: se il Vero ti fa stare nella stazione del prendere esempio (iqtidā) da te e del seguire affinché l'altro apprenda da te, "osserva l'adab" - egli dice - sii consapevole di ciò in cui prende esempio da te, e sappi che ciò non ti appartiene, ma appartiene a chi te lo ha conferito, ed il tuo riconoscere l'insufficienza sta a significare che devi dire alla tua anima che essa è insufficiente per quello, anche se le appartiene l'accettazione, e che se non fosse per l'elargizione divina non avresti ciò che hai ricevuto, e quindi il favore dipende da Allah: questo è il significato del riconoscere l'insufficienza.

Tutta la Via è scienza, non altro, ed il prendere esempio da te non ti distolga da ciò per cui sei stato creato e su cui ho attirato la tua attenzione, poiché Egli non ti ha eretto come esempio se non perché ti ha dato le vesti d'onore dell'infallibilità e della protezione: occupati quindi di ciò che ti riguarda tra te e Lui, e ciò che Egli fa lo osservi chi segue l'esempio, non tu. E non vantarti di te stesso in questa stazione, a meno che non sia un vanto per il tuo Signore, poiché è stata riportata, riguardo al colloquio intimo, [l'affermazione]: "con Me $(b \vec{\imath})$ " da parte di Allah $\left(^{814}\right)$ : sii dunque fiero per il discorso di Allah, sia Egli esaltato, al Suo servitore.

'Utba l'adolescente (gulām) $\left({ }^{815}\right)$ fu visto incedere con ostentazione e gli venne chiesto: "Cos'è questo vanto che traspare da te?", ed egli rispose: "Come potrebbe non spettarmi? Egli è diventato per me

813) Questi versi sono riportati anche nel Dīwān al-ma ärif, manoscritto Parigi BN 2348, f. 139b, linee 20-22.

814) Riferimento allo hadīt: "Io sono con il Mio servitore quando Mi menziona e le sue labbra si muovono per Me (bù)", riportato da al-Buhārī, XCVII-43, e da Ibn Hanbal, II-540, e citato da Ibn 'Arabī nel Cap. 560 [IV 534.32] e ne "La niche des lumières", pag.32, oppure allo hadīt qudsĩ: "Io sono il suo udito e la sua vista e per Me egli sente, per Me egli vede e per Me egli si muove", non recensito nelle raccolte canoniche, ma riportato da Ibn 'Arabī nei capitoli 31 [I 203.2], 69 [I 448.21] e 72 [I 697.14].

815) Si tratta di 'Utba ibn Abān, soprannominato l'adolescente non per la sua età, ma perché nei riti si comportava come un adolescente pieno di timori. Morì martire nella battaglia contro i bizantini (rüm). Cfr. AšŠa'rānī ,"at-Tabaqāt al-kubră’, Maktabat Muḥammad 'Alī Sabīh, il Cairo, senza data, Vol. I, pag. 40. 
un Padrone ed io sono diventato per Lui un servitore" $\left({ }^{816}\right)$, ed egli si vantava, di fronte agli schiavi delle loro passioni, della purezza della sua servitù, libera dalla schiavitù delle passioni, verso Allah, quanto è Potente e Magnificente, e non si vantò se non dopo essersi liberato da quello ed avere consacrato il dominio ad Allah, quanto è Potente e Magnificente.

Poi ha detto, Allah sia soddisfatto di lui: "E se ti si presenta ciò che hai ottenuto, [255] prendi di quello il latte (laban) e basta, e non prenderlo se non con adab". Questo è ciò che gli ha conferito il suo stato, ma è opportuno che tu prenda ogni bevanda che ti viene conferita da parte del Vero, tra ciò che è nutrimento o rimedio, poiché non c'è che nutrimento e rimedio ed ogni rimedio è un nutrimento per chi capisce, poiché con il nutrimento si allontana la sofferenza della natura, sia psichicamente che sensibilmente, ed anche se esso venisse bevuto sotto il profilo del trarne piacere non cesserebbe d'essere un rimedio.

Ciò che lo ha fatto restringere la sua raccomandazione al latte non è altro che la novella del viaggio notturno profetico $\left({ }^{817}\right)$, il sogno profetico e la sua interpretazione di esso con la scienza $\left({ }^{818}\right)$; ed in una delle recensioni [è riportato]: "Se tu avessi bevuto il vino la tua comunità sarebbe stata sviata" ( ${ }^{819}$ ).

Sappi che coloro che bevono sono gente comune ed eletti, e l'interpretazione riguardo alla gente comune è diversa dall'interpretazione riguardo alla gente di Allah, quanto è Potente e Magnificente, poiché gli stati sono differenti. Bere vino in sogno è male per la gente comune, mentre per la gente di Allah è la scienza degli stati spirituali, e l'acqua è la scienza delle idee spogliate dalle parole, il latte la scienza delle espressioni ed il miele la scienza dell’ispirazione (ilhām) ${ }^{(20)}$, ed essa è una delle modalità della rivelazione (wahy).

816) L'episodio è riportato anche nel Cap. 39 [I 233.21].

817) Nel Cap. 367 [III 341.10] Ibn 'Arabī afferma: "Gabriele gli portò il Burāq ed egli [il Profeta] lo montò insieme a Gabriele ed il Burāq s'involò con lui nell'aria ed attraversò l'atmosfera. [Il Profeta] ebbe sete e bisogno di bere e Gabriele, su di lui la Pace, gli portò due recipienti, uno contenente latte e l'altro vino - questo avvenne prima del divieto di bere vino - ed egli prese quello contenente il latte. Gabriele, su di lui la Pace, gli disse allora: "Hai colto la natura primordiale (fitra)"”. Hadīt riportato da al-Buhārī, LX-24 e 48, LXIII-42, LXV, ad Sūra XVII-3, LXXIV-1 e 12, Muslim, I-259, 264 e 272, XXXVI-92, at-Tirmid̄ī, XLIV, ad Sūra XVII-1, ad-Dārimī, IX-1, e da Ibn Hanbal, I-257, III-148, IV-208 e 209.

818) Nel Cap. 2 [I 57.29] Ibn 'Arabī afferma: "È in questo senso che egli, che Allah faccia scendere su di lui la Sua salāt e la Pace, interpretò il latte che aveva bevuto in sogno e del cui resto aveva gratificato 'Umar. Gli fu chiesto: "Come lo interpreti, o Inviato di Allah?" ed egli rispose: "È la scienza"”. Hadīt riportato da al-Buhārī, III-22, LXII-6, XCI-15, 16 e 34, e Muslim, XLIV-16. Altri riferimenti ad esso si trovano nei capitoli 70 [I 592.6], 73, questioni XXV [II 58.9] e XXXIX [II 66.22], 158 [II 257.6], 167 [II 279.23], 172 [II 292.7], 249 [II 550.10, 23 e 551.8], 367 [III 341.12], 381 [III 507.12], e 558 [IV 219.30 e 220.1] delle Futūhät, e nei capitoli VI e XVI dei Fușuss al-ḥikam, rispettivamente alle pagine 91 e 164 dell'edizione di 'Abd al-'Azīz Sulțān al-Manșūb.

819) Hadīt riportato da al-Buhāāī, LX-24, 48, LXXIV-1, Muslim, I-272, XXXVI-92, e da ad-Dārimī, IX-1.

820) A queste quattro bevande corrispondono i quattro fiumi paradisiaci citati in Cor. XLVII-15. Nel Cap. 249 [II 550.10] Ibn 'Arabī afferma: "Poiché il Paradiso è la dimora della visione e della teofania ed Allah non ha menzionato in esso se non quattro fiumi: "Fiumi di acqua incorruttibile, fiumi di latte dal gusto inalterato, fiumi 
Quanto al caso in cui quello si presenta a te nel dominio sensibile (al-hiss), se fai parte della gente dello svelamento e della visione trascendente $\left(i t t i l \vec{a}^{c}\right)$, osserva da quale Presenza si presenta a te quella bevanda, e se essa ti si è presentata dalla Presenza del dominio sensibile dai la precedenza al latte, secondo la dottrina degli iniziati (qawm), poi al miele mescolato con l'acqua, ed anche il latte mescolalo con l'acqua - e se lo hai mescolato con il miele va bene lo stesso - ma evita assolutamente il vino per via della sede da cui si è presentato, [256] poiché Allah, sia Egli esaltato, ha vietato il vino nella sede del dominio sensibile.

E se ciò si presenta a te nel dominio sensibile dalla Presenza dell'immaginazione, poiché la gente dello svelamento e della presa di visione vede nella veglia ciò che chi dorme vede nel sonno, sappi che Allah, quanto è Potente e Magnificente, non ha vietato il vino nel sonno, cioè nella Presenza dell'immaginazione, né nell'altra dimora che è la vita (hayawān) $\left.{ }^{821}\right)$, quindi bevilo nel dominio sensibile se esso viene da questa Presenza immaginativa come ti ho ordinato di berla nel sonno in sogno, poiché nel berlo proverai l'effetto della scienza degli stati, ed essa è la scienza di uno stato che si è incorporata per te nella forma del vino. Ed ogni volta che bevi qualcosa di queste bevande e ti nutri di esse, se viene dalla Presenza del dominio sensibile dì: "Allăhumma dacci la baraka in esse e dacci da mangiare un bene da esse", salvo che per il latte, per il quale devi dire: "Allähumma dacci la baraka in esso e daccene di più" ${ }^{822}$. E se viene dalla Presenza dell’immaginazione nello stato di veglia dì

di vino delizioso per coloro che bevono, e fiumi di miele purificato" (Cor. XLVII-15), sappiamo per certo che la teofania della Scienza ha luogo solo in quattro forme: acqua, latte, vino e miele", e poco oltre [II 551.12] aggiunge: "Sappi che quando Allah conferisce a qualcuno i significati spogliati dal discorso o i sensi (nusüs) [racchiusi] nel discorso, ciò dipende dalla Sua teofania nella forma dell'acqua incorruttibile, e si tratta della Scienza divina che non ha connessione con la Natura. Quando Allah conferisce a qualcuno la scienza dei segreti della Legge e dei suoi statuti, e la scienza della saggezza del Suo detto: "Non abbiamo inviato un messaggero se non con la lingua della sua gente" (Cor. CXIV-4) [...] ciò fa parte della scienza della Sua teofania nella forma del latte [...]. Quando Allah gli conferisce la scienza della perfezione, degli stati e della bellezza, ciò dipende dalla teofania della scienza nella forma del vino. E quando Allah conferisce a qualcuno la scienza per mezzo della rivelazione, della fede e della purezza dell'ispirazione [...] questa scienza deriva dalla teofania nella forma del miele". Nello stesso capitolo [II 550.7] Ibn 'Arabī afferma di aver dedicato a questo argomento un breve trattato intitolato Marätib ulüm alwahb, la cui traduzione francese è accessibile in rete: https://www.scribd.com/document/335565469/Ibn-ArabiEpitre-concernant-les-degres-des-sciences-donnees-Ulum-al-wahb.

821) Riferimento a Cor. XXIX-64. Nel Cap. 560 [IV 451.5] Ibn 'Arabī afferma: "In realtà ogni forma del Mondo possiede uno spirito, ma Allah ha distolto i nostri sguardi dal cogliere la vita di ciò di cui si dice che è inanimato. Nell'aldilà la realtà diverrà manifesta per la generalità degli uomini e per questo esso si chiama la dimora della vita. In questa dimora non vedrai nulla che non sia animato e dotato di parola, al contrario della tua condizione in questo mondo, così come viene riportato nel Sahīh che i sassolini [posti] nella mano dell'Inviato, che Allah faccia scendere su di lui la Sua șalāt e la Pace, glorificarono Allah".

822) Hadīt riportato da Abū Dāwud, XXV-21, e da at-Tirmid̄ī, XLV-54. Nel Cap. 249 [II 550.22] Ibn 'Arabī afferma: "L'Inviato di Allah, che Allah faccia scendere su di lui la Sua șalät e la Pace, amava mescolare l'acqua col latte e berla, come pure mescolare il miele col latte, e non restò che il vino, ma nella dimora di quaggiù esso non è lecito nella Legge di Muhammad, che Allah faccia scendere su di lui la Sua salāt e la Pace, in vigore al momento in cui morì [...] Ed anche per questo, quando l'Inviato di Allah, che Allah faccia scendere su di lui la Sua salāt e la Pace, beveva il latte diceva: "Allāhumma dacci la baraka in esso e daccene di più", poiché 
per tutto quello: "e daccene di più", come hai detto del latte che veniva dalla Presenza del dominio sensibile.

Allo stesso modo riguardo a tutto ciò che si presenta a te dei nutrimenti verifica da quale Presenza ti è arrivato e trattalo conformemente alla Presenza da cui è venuto, per lo stato in cui ti trovi, e questo è il significato del suo detto, Allah abbia misericordia di lui, nella sua raccomandazione: "e non prenderlo se non con $a d a b$ ", poiché in quello l'adab comporta che tu compia riguardo ad esso ciò a cui ha diritto e che tu dia ad ogni avente diritto il suo diritto dallo stato in cui ti trovi. Tu fai parte di coloro che sono ricollegati ad Allah, quanto è Potente e Magnificente, non fai parte della massa degli uomini, ed Allah non ti chiede conto se non della tua stazione, e può essere che un'opera buona da parte di altri sia da parte tua, se la compi, un'opera cattiva, [257] per l'elevatezza del tuo rango, come hanno detto gli iniziati: "Le opere buone dei pii sono le opere cattive degli approssimati" ${ }^{823}$ ).

L'approssimato $\left.{ }^{824}\right)$ beve in modo puro dalla fonte del Tasnìm $\left({ }^{825}\right)$, da cui non bevono i pii se non quando esso [Tasnīm] è mescolato con il vino (rahīq) sigillato a causa loro, ed essi quindi non lo percepiscono puro come lo percepiscono gli approssimati. Allah, sia Egli esaltato, ha detto riguardo ai pii: "Essi vengono dissetati da un vino sigillato il cui sigillo è il muschio" (Cor. LXXXIII-25 e 26), ed ha alluso al fatto che essi fanno parte della gente dei soffi $\left({ }^{826}\right)$, e non li ha fatti uscire da ciò che

in lui sussisteva la forma della similitudine del latte con la scienza [...] e gli era stato ordinato di chiedere l'accrescimento nella scienza".

823) Frase ricorrente nei più antichi testi del Tașawwuf. Ibn 'Arabī la riporta nei capitoli 73, questione CLIV [II 136.30], 329 [III 109.3] e 472 [IV 105.2].

824) Il termine muqarrabūn, approssimati, fatti avvicinare, ricorre otto volte nel Corano: III-45, IV-172, VII114, XXVI-42, LVI-1 1 e 88, LXXXIII-21 e 28. Nel Cap. 73 [II 3.20] Ibn 'Arabī precisa: "Costoro [cioè coloro che hanno ottenuto la stazione spirituale della Profezia generale] sono gli approssimati (muqarrabūn), di cui Allah ha detto: "una fonte a cui bevono gli approssimati" (Cor. LXXXIII-28). Con lo stesso termine Allah ha caratterizzato il Suo Profeta Gesù, su di lui la Pace, dicendo: "eminente in questo mondo e nell'altro, e [uno] tra gli approssimati" (Cor. III-45), come pure ha caratterizzato con esso gli Angeli, dicendo: "e non gli Angeli approssimati" (Cor. IV-171). È d'altronde noto che Gabriele è disceso con la rivelazione sull'Inviato di Allah, che Allah faccia scendere su di lui la Sua salāt e la Pace, ma non è stato designato nel Libro della legge con il nome di Profeta, malgrado ne fosse degno". Nello stesso capitolo [II 19.9] precisa anche che i Solitari (afrād) sono denominati approssimati nel linguaggio della Legge.

825) Il nome Tasnīm ricorre solo in Cor. LXXXIII-27 e la maggior parte dei commentatori lo interpreta come il nome di una bevanda (̌̌arăb); Ibn 'Arabī, invece, nel Cap. 559 [IV 352.9] afferma che: "esso è un fiume (nahr) elevato che discende dall'alto verso una fonte più in basso", fonte che si trova nel Paradiso e da cui si abbeverano sia gli approssimati che i pii. I primi però bevono pura l'acqua del Tasnīm, mentre gli altri la bevono mescolata al vino.

826) Il seguito del versetto 26 non riportato nel manoscritto recita: "ed è a questo che devono anelare coloro che gareggiano [per averlo]" in cui il verbo tanāfasa, sesta forma del verbo nafusa, essere prezioso, esprime contemporaneamente i significati di anelare e di gareggiare. Dalla stessa radice derivano sia nafas, soffio, che nafs, anima, persona, essere, se stesso. Nel Cap. 559 [IV 417.35] Ibn 'Arabī correla tra loro tutti questi termini, affermando: "Di ciò [i segreti] fa parte l'astenersi dal competere (tanāfus), attinente al capitolo 477 [dedicato 
esige la Natura; poi ha completato dicendo: "e la sua mescolanza", cioè la mescolanza di quel vino "con il Tasnim" (Cor. LXXXIII-27), cioè con un'acqua che è superiore in posizione e rango rispetto ad esso; poi ha commentato il Tasnim dicendo: "una fonte da cui bevono gli approssimati" (Cor. LXXXIII-28), ed ha reso il bere da questa fonte puro per gli approssimati, e con esso ha mescolato il vino dei pii, perché essi hanno mescolato la Natura con il Vero e sono quindi rimasti secondo la loro costituzione naturale sotto tutti gli aspetti, cioè della loro costituzione spirituale e corporea: essi sono divini (ilahiyyūn) ${ }^{827}$ ) e sono la gente della connessione (iḍa fa) e laddove c'è una connessione l'uno non si separa dall'altro che è connesso con lui.

al Polo la cui dimora iniziatica è il versetto: "ed è a questo che devono anelare coloro che gareggiano"]. Egli ha detto: "I compagni delle aspirazioni (himam) competono tra di loro nella gara per i nomi della Generosità (karam) e della Magnanimità ( $\check{g} \bar{u} d)$ divine, per essere posti in essi ed essere così chiamati con essi”. Ed ha detto: "Il competere riguarda solo le cose preziose (nafä is) e non ci sono cose preziose se non gli esseri (anfus) e negli esseri non c'è cosa più preziosa (anfas) dei soffi (anfās)"'”.

827) Il termine ilahiyyūn in riferimento agli uomini ricorre una decina di volte nelle Futūhät e non può essere tradotto se non con "divini", ma qual'è il significato di questa espressione? Dal manoscritto si evince che i pii sono divini per quanto concerne il rango [di Allah come Dio], mentre gli approssimati lo sono per quanto concerne Colui che è nominato Allah, e d'altra parte gli approssimati sono superiori ai pii: essi considerano Allah indipendente dai Mondi, e quindi considerano Allah quanto alla Sua Essenza come nell'espressione: "C'era Allah e nessuna cosa con Lui", mentre i pii considerano Allah nella sua connessione con il Mondo e quindi come Dio, al rango della Divinità (ulühiyya). Nel Cap. 100 [II 184.10] Ibn 'Arabī afferma: "Sappi che la paura (hazef) è la stazione dei divini e ad essa compete il Nome Allah". La chiave di lettura di questa affermazione si trova nel Cap. 91 [II 176.12] ove egli precisa: "Ogni stazione spirituale è o divina (ilah $\vec{\imath}$ o dominicale $(r a b b \bar{a} n \hat{\imath})$ o del Misericordioso (rahmān $\vec{\imath}$; non vi sono stazioni appartenenti a Presenze divine (hadarăt) diverse da queste tre, che comprendono sinteticamente tutte le Presenze. Tutta l'esistenza ruota intorno a queste tre Presenze, per mezzo delle quali discendono i Libri sacri e verso le quali si innalzano le Scale; su di esse vegliano tre Nomi divini: Allah, il Signore $(r a b b)$ ed il Misericordioso ( $a r-r a h m \bar{a} n)$. Colui che è governato da uno degli altri Nomi divini viene nello stesso tempo qualificato da uno dei tre Nomi che abbiamo appena citato; il regime $(\mathrm{hukm})$ che uno di questi tre Nomi esercita sul servitore è in proporzione alla sua stazione spirituale, e l'influenza che ha su di lui varia a seconda che si tratti di un semplice musulmano, di un credente oppure di qualcuno che pratichi anche l'ihsānn". D’altra parte nel Cap. 140 [II 226.22] aggiunge: "Sappi che la libertà (hurriyya) è una stazione dell'Essenza, non una stazione divina; essa non può essere assolutamente attribuita al servitore, poiché egli è un servitore di Allah per una servitù che non ammette emancipazione. Quanto al Vero l'abbiamo considerata impossibile in quanto è Dio, per il Suo legame con colui che gli è asservito, legame [di dipendenza] che corrisponde a quello del signore per l'esistenza dello schiavo, del proprietario per la ricchezza e del Re per il Regno. [...] Non vi può essere libertà laddove c'è una connessione, e la Signoria e la Divinità sono connessioni. Ma tra il Vero [inteso come Essenza, non come Dio] e le creature non c'è corrispondenza né connessione, anzi Egli è indipendente dai Mondi, e ciò non appartiene all'essenza di alcun essere se non all'Essenza del Vero".

Quanto alla denominazione di "divini" attribuita agli approssimati, cioè ai Solitari che hanno realizzato la stazione della Prossimità (maqām al-qurba), nel Cap. 381 [III 506.32] Ibn 'Arabī afferma: "Il gruppo più elevato è quello di coloro che non hanno alcuna stazione spirituale. Le stazioni spirituali infatti dominano coloro che si trovano in esse, e non c'è dubbio che il gruppo più elevato sia costituito da coloro che dominano, non da quelli che sono dominati. Essi sono i divini (ilahiyyunn), per il fatto che il Vero è la loro entità [o: è identico a loro], poiché Egli è "Colui che ha più autorità" (Cor. XCV-8). Tra gli uomini ciò è riservato esclusivamente ai muḥammadiani [cioè agli Eredi di Muhammad]". 
Quanto agli approssimati, anche se sono divini - ma quanto a Colui che è denominato [Allah], non quanto al rango [della Divinità] - essi sono staccati dalla realtà essenziale della mescolanza e della connessione, ed essi considerano il Suo detto, sia Egli esaltato: "Invero Allah è indipendente dai Mondi" (Cor. III-97) e quindi sono soli [privi di connessioni] ed è loro riservata la fonte del Tasnīm, che essi non bevono mescolato.

Allah, sia Egli esaltato, ha stabilito per ogni stazione una gente ed ha elevato gli uni sugli altri in grado; il pio non riconosce mai l'approssimato, ed ogni approssimato era pio, ma non ogni pio [258] raggiunge o viene fatto passare alla stazione della prossimità. All'approssimato spetta la perfezione e la somma dei gradi, e se ha bevuto una mescolanza è in quanto era pio, non perché è un approssimato, e se ha bevuto puro dalla mescolanza è perché è un approssimato, ciò di cui i pii non hanno gusto.

Costui che ha parlato si è limitato nella sua raccomandazione a ciò che abbiamo menzionato e non se ne è allontanato affidandosi da parte sua all'intendimento dell'ascoltatore perfetto, il cui udito è il Vero, come ugualmente il Vero è la lingua di questo portavoce.

Per questo, quando ci è pervenuto ciò che ha detto, lo abbiamo commentato ugualmente secondo il grado della scienza di chi ha parlato ed abbiamo dettagliato il suo compendio, e se era questa la sede da cui si è manifestato questo portavoce della gente della riunione e dell'esistenza realizzata, ci siamo conformati al suo proposito nel commento, e se non è così ed egli era possessore di uno stato spirituale e gli veniva fatto proferire ciò che sapeva e ciò che non sapeva abbiamo dato tutto ciò che spetta alla stazione da cui parlava ed alla parola, e non abbiamo tralasciato nulla di ciò, ed Allah è più sapiente.

Poi ha detto: "E se ti viene consegnato un abito [(malbūs) usato], non prenderlo assolutamente", poi ha spiegato, e se avesse taciuto sarebbe stato meglio per lui, ed ha detto: "poiché il viaggio è lungo ed esige l'alleggerimento ( $\operatorname{tah} f \hat{i} f)$ ". Noi diremo nel commento di questa [raccomandazione] ciò che è necessario, cioè nel commento dell'abito, e vi inseriremo il proposito di questo Maestro, sì che risulti il profitto per coloro che ascoltano.

Sappi che l'abito è di due tipi: l'abito del timore di Dio (taqwā) e l'abito di ornamento $(z \bar{\imath} n a)\left({ }^{828}\right)$. L'abito del timore di Dio è lo scopo ed è ciò con cui ti ripari dai danni del tuo corpo o del tuo spirito - questo è il significato dell'abito del timore di Dio - [259] e ti metti al riparo dal mostrare il tuo segreto ('awra) $\left.{ }^{829}\right)$, ed esso è il migliore degli abiti, poiché è un abito di obbligazione divina. Quanto all'abito di ornamento, esso è l'abbigliamento esteriore (rî̌s ed è l'abito dell'abbellimento (tağammul), ed esso gode da parte di Allah di un amore speciale. Il vestito dell'ornamento è di vari tipi: vi è quello

828) A seconda del contesto ho tradotto questo termine con ornamento o abbellimento.

829) Nel linguaggio della Legge islamica il termine 'awra indica le parti del corpo che non vanno esposte, cioè le pudenda, e che vanno coperte dall'abbigliamento intimo. Qui si tratta però di un abito interiore e nel Cap. 69 [I 407.9] Ibn 'Arabī precisa che la trasposizione simbolica della copertura delle pudenda è che: "colui che è intelligente deve velare il segreto divino, perché quando viene svelato tale svelamento induce colui che non sa e che non è intelligente a non avere venerazione per il Lato divino". 
che è obbligatorio per il testo sacro, ed esso ha una sede specifica, malgrado sia un ornamento, e la sua sede è lo stato del colloquio intimo con il Vero e dello stare di fronte a Lui, e quello è l'ornamento di Allah. L'ordine che lo riguarda è il Suo detto: "Indossate il vostro ornamento [cioè il vostro abito più bello]" - ed Egli ha ordinato ed il Suo ordine è obbligatorio - "presso ogni luogo di adorazione (masğid)" (Cor. VII-31), ed ha menzionato lo stato e la sede che esige l'abbellimento in esso per Allah, sia Egli esaltato, con il suo/Suo ornamento $\left({ }^{830}\right)$.

Il Profeta, che Allah faccia scendere su di lui la Sua salāt e la Pace, ci ha detto riguardo al Vero: "Egli è più degno che ci si abbellisca per Lui" ${ }^{831}$ ) ed ha detto nella notificazione autentica sia per trasmissione che per svelamento, all'uomo che gli aveva detto: "O Inviato di Allah, a me piace che il mio sandalo sia bello e che il mio abito sia bello" temendo che quella fosse vanità, e l'Inviato di Allah, che Allah faccia scendere su di lui la Sua salāt e la Pace, gli rispose: "Allah è Bello ed ama il bello" ${ }^{(832)}$, ed ha assegnato alla bellezza un amore divino che non ottiene se non chi indossa l'ornamento di Allah presso ogni luogo di adorazione ${ }^{(833)}$. Colui che è costante nella sua șalāt nella totalità dei suoi stati - e l'ornamento non cessa su di lui - fa parte di "coloro che sono costanti nella loro salä " (Cor. LXX-23) nella totalità dei loro stati $\left({ }^{834}\right)$, a differenza di chi non ha questo stato e lo assume solo in

830) Nel Cap. 560 [IV 453.18] Ibn 'Arabī afferma: "Allah, sia Egli esaltato, ha detto: "O figli di Adamo, mettete il vostro ornamento presso ogni luogo di adorazione" (Cor. VII-31) ed a proposito di chi lo vieta ha detto: "Dì: Chi ha proibito l'ornamento di Allah che Egli ha preparato per i Suoi servitori, e le buone cose della Sua provvidenza? Dì: Tutto questo è destinato a quelli che credono, qui nella vita terrena, e nel modo più puro nel Giorno della Resurrezione. Così Noi precisiamo i Segni per gente che possa conoscere" (Cor. VII-32). A questo proposito non c'è nel Corano spiegazione più chiara di questa. Ora, non c'è differenza tra l'ornamento di Allah e l'ornamento della vita di questo mondo, se non per lo scopo e l'intenzione. In effetti l'ornamento è quello che è, non è un'altra cosa, ed è l'intenzione lo spirito delle cose: ognuno riceverà secondo la sua intenzione".

831) Hadīt non recensito nelle raccolte canoniche. Ibn 'Arabī lo riporta nei capitoli 71 [I 654.19], 72 [I 740.28], e 558 [IV 269.21].

832) Hadīt riportato da Muslim, I-147, at-Tirmid̄ī XXV-61, Ibn Māğah, XXXIV-10, e da Ibn Hanbal, I-399, IV-133, 134 e 151. Ibn 'Arabī lo cita nei capitoli 12 [I 145.35], 77 [II 149.33], 558 [IV 269.20] e 560 [IV 453.25] mentre riporta la sola risposta finale nei capitoli 71 [I 654.19], 72 [I 685.15 e 740.28], 73, questione CXVIII [II 1 14.8], 167 [II 282.3], 178 [II 323.1, 326.24 e 345.16], 369 [III 394.30], 372 [III 449.7] e 559 [IV 379.30].

833) Nel Cap. 560 [IV 453.30] Ibn 'Arabī precisa: "Chi trascura di farsi bello per Allah, come abbiamo detto, si lascia sfuggire questo amore designato e speciale da parte di Allah, e se gli sfugge questo amore designato e speciale, gli sfugge da parte di Allah ciò che ne deriva quanto a scienza, teofania, grazia nella Dimora della beatitudine, rango sul Monticello della visione e contemplazione (šhüd) intellettuale, conoscitiva e spirituale nella dimora di questo mondo, durante il suo cammino iniziatico (sulük) e nelle sue sedi contemplative (mašăhid). Tutto ciò, beninteso, a condizione che nell'adornarsi abbia l'intenzione di farsi bello per Allah e non lo faccia invece per l'ornamento, o per la vanagloria $(f a h r)$ di mettersi in mostra in questo mondo, o per vanità o per ottenere l'ammirazione di altri che Lui".

834) Nel Cap. 68 [I 385.18] Ibn 'Arabī precisa: "Per colui che vede lo spirito della salāt, che è la presenza costante con Allah ed il colloquio con Lui, tutti gli atti sono una salät", e nel Cap. 351 [III 222.27] aggiunge: "Colui che fa la șalät è in colloquio intimo con il suo Signore ed il colloquio è uno dikkr. Egli, sia glorificato, siede 
occasione della salāt prescritta dalla Legge e in un momento specifico ad esclusione di altri, mentre costoro nella totalità dei momenti colloquiano con Allah e sono in una salät costante, anche se i loro gusti [(mašārib), letteralmente: bevande] variano in essa.

La differenza dei gusti [260] si trova anche nella salāt comunemente nota: il gusto (dawq) dello stare in piedi in essa è diverso dal gusto dell'inchinarsi, diverso dal gusto dell'alzarsi dall'inchino, diverso dal gusto del mettersi in piedi dall'inchino e dalla prosternazione, diverso dal gusto della prima prosternazione, diverso dal gusto del sollevarsi dalla prosternazione, diverso dal gusto dell'essere seduti tra le due prosternazioni, diverso dal gusto della seconda prosternazione, diverso dal gusto dello stare seduti della pausa (istirāha), diverso dal gusto dello stare seduti dell'attestazione (tašahhud), e questi sono gusti diversi nella șalāt comunemente nota.

Colui che fa la șalāt colloquia con il suo Signore dalla Presenza della comunanza (šrka) e della spartizione (qisma), e chiunque ha una parte è assegnato (múayyan) alla sua parte, e così il perfetto in tutti i suoi stati fa la sua parte e dà ad Allah la Sua parte del suo stato, poiché Allah ha in ogni stato una parte assegnata ed un diritto obbligatorio, e per questo gli ha detto che in ogni stato, movimento o immobilità vi è un regime per agire o astenersi secondo obbligatorietà, raccomandazione, proibizione, biasimo o liceità. Sappi ciò.

E questi regimi sono per la conoscenza a guisa delle forme dei corpi per gli spiriti che li governano o per le facoltà che sussistono in essi: sappilo, e non rifiutare, se sei in questa stazione, un abito che ti viene presentato poiché esso è il culto $(d \bar{\imath} n)$, ed è così che lo ha interpretato l'Inviato di Allah, che Allah faccia scendere su di lui la Sua salāt e la Pace, e lo ha spiegato riguardo al sogno, ed ha attribuito

con colui che Lo menziona e la costanza nel colloquio con Lui consiste nel fatto che il servitore è con Allah in tutti i suoi stati ed i suoi modi di agire così come nella sua salāt è in colloquio con Lui in ogni attimo. Il motivo di questo è che è inevitabile che egli si trovi in uno degli stati ed è altrettanto inevitabile che il Legislatore, che è Allah, abbia un regime in quello stato, quale che sia questo regime, ed Egli, Gloria a Lui, è presente nei Suoi regimi dovunque essi siano [...] Gli atti e le astensioni, che sono gli stati del servitore con cui sono connessi i regimi del Vero, sono decretati ed è inevitabile che avvengano, ed Egli, sia glorificato, è Colui che li crea ed è quindi indispensabile la Sua presenza in essi. Il servitore che conosce la presenza del Vero con lui nel suo stato è colui che è costante nella salāt. 'Á'iša, parlando dello stato dell'Inviato di Allah, che Allah faccia scendere su di lui la Sua salāt e la Pace, ha detto che egli menzionava Allah in tutti i suoi momenti, alludendo a ciò che abbiamo detto. Ed egli andava di corpo, e gli era vietato di menzionare con la lingua il suo Signore in quello stato, e talvolta scherzava con il vecchio e con il bambino, e parlava con gli arabi, ed in tutti questi momenti egli stava menzionando [Allah]: questo è quello che si chiama lo $\underline{d i k r}$ del cuore, che non ha niente a che fare con lo $\underline{d} i k r$ della parola e con lo $\underline{d} i k r$ dell'immaginazione. Colui che menziona Allah con questo $\underline{d} i k r$ siede costantemente con Lui, ed è colui che il suo Signore ha elogiato ascrivendolo a "coloro che sono costanti nella loro șalät" (Cor. LXX-23). E quando Allah ha commentato la salät lo ha fatto solo per lo $\underline{d i k r}$ [senza menzionare i movimenti del corpo], che è la recitazione. Egli ha detto: "Il servitore dice: "La lode spetta ad Allah, il Signore dei Mondi" ed Allah dice: "Il Mio servitore Mi loda"”, spartendo il colloquio tra Lui ed il Suo servitore, ed il colloquio è l'essenza della salāt, ed è l'atto di due attori'. Alla spiegazione di questo versetto è anche dedicato l'ultimo capitolo del suo Kitāb at-tanazzulāt al-Mazesiliyya. 
l'abito (tawb) al culto ed ha fatto l'esempio del suo essere lungo o corto $\left.{ }^{835}\right)$. Se invece non hai questo stato distingui tra le cose con i tuoi stati $\left({ }^{836}\right)$ ed indossa l'ornamento di Allah nella sua sede e rifiuta di indossare l'ornamento di Satana e l'ornamento della vita di questo mondo che non ha uno spirito ${ }^{(837)}$ [261].

Non ci sono che questi tre ornamenti: l'ornamento di Satana, l'ornamento della vita di questo mondo e l'ornamento di Allah, sia Egli esaltato, che è nel tuo ornamento, ed Egli, sia esaltato, ha collegato a te l'ornamento di Allah, ad esclusione degli altri, dicendo: "Indossate il vostro ornamento" (Cor. VII-3 1) e lo ha connesso a te, e dopo di ciò ha detto: "Dì: chi vieta l'ornamento di Allah" (Cor. VII32) e lo ha attribuito a Sé, poi ha detto: "Di” o Muhammad "esso spetta a coloro che credono", ed ha precisato il suo possessore con il suo attributo, "nella vita di questo mondo", dotato dello spirito, "puro nel Giorno della Resurrezione" dalla mescolanza con l'ornamento di questo mondo che non ha spirito, poi ha detto: "così noi distinguiamo", e così ha fatto, distinguendo ogni ornamento dagli altri, "per gente che sa” (Cor. VII-32), mettendo l'accento sull'eccellenza della scienza.

E quando questo Maestro ha spiegato il rifiuto dell'abito a causa del viaggio abbiamo capito che egli si riferiva ad un abito determinato, poiché l'abito del timore di Dio è indispensabile, come abbiamo menzionato, ed egli si è limitato ad esso, limitandosi così a ciò che è obbligatorio. E poiché l'abito è il culto, ed esso è di tue tipi, obbligatorio e supererogatorio, questo Maestro voleva nella sua raccomandazione che in tutti i tuoi movimenti inerenti al culto tu facessi ciò che è obbligatorio, non ciò che è supererogatorio, e non c'è dubbio che fare le opere obbligatorie è più elevato e più caro ad Allah, sia Egli esaltato, di tutto ciò con cui ti avvicini a Lui. Ed è come se egli ti dicesse: se ti si presenta un'opera supererogatoria non accettarla ed occupa il tuo momento con ciò che

835) Riferimento ad uno hadīt riportato da al-Buhārī, II-15, LXII-6, XCI-17 e 18, Muslim, XLIV-15, atTirmidīi, XXXII-9, an-Nasā̄î̀, XLVII-18, ad-Dārimī, X-13, e da Ibn Ḥanbal, II-86, V-373. In esso è riportato che il Profeta vide in sogno degli uomini che indossavano un camice (qamiss) che era tanto corto da coprire solo i seni, mentre 'Umar indossava un camice che si trascinava per terra. Quando gli venne chiesto come interpretasse questo sogno rispose che si trattava del culto.

836) Nel Cap. 560 [IV 494.11] Ibn 'Arabī precisa: "Guardati dalla prova [o: tentazione] di questo mondo e dal suo abbellimento (zīna) [delle opere] e distingui tra l'abbellimento di Allah, l'abbellimento di Satana e l'abbellimento della vita di questo mondo. Quando l'abbellimento avviene in modo anonimo, senza essere attribuito a qualcuno, e non sai quindi chi ha abbellito [la tua opera], osservalo in un'altra situazione e prendi questa come prova per capire ciò che ti è oscuro. Egli, sia esaltato, ha detto: "Noi abbiamo abbellito le loro opere" (Cor. XXVII-4) ed ha detto: "E colui a cui è stata abbellita la sua opera cattiva?" (Cor. XXXV-8) e non ha menzionato chi l'ha abbellita. In questo caso deduci chi l'ha abbellita dall'opera stessa, poiché l'abbellimento di Allah non è vietato, l'abbellimento di Satana è vietato e l'abbellimento di questo mondo ha due aspetti: uno verso il lecito ed il raccomandato e l'altro verso il proibito. La vita di questo mondo è la sede della prova; Allah lo ha fatto attraente e verdeggiante ed ha nominato i Suoi servitori come rappresentanti in esso ed Egli sta ad osservare come si comportano, come ha riportato la tradizione profetica. Stai in guardia dalla sua tentazione e discerni il suo abbellimento e recita: "O mio Signore, accresci la mia scienza"”.

837) L'ornamento della vita di questo mondo in se stesso non ha spirito, ma viene vivificato da esso quando è indossato come abbellimento per Allah. 
è obbligatorio, e ciò è meglio per te, e se si tratta di un'opera supererogatoria deve trattarsi di un aumento di obbligo, non altro. La veglia di notte era un obbligo per l'Inviato di Allah, che Allah faccia scendere su di lui la Sua salāt e la Pace, per il Suo detto, sia Egli esaltato: "O tu che sei avvolto in un mantello veglia di notte salvo per poco" (Cor. LXXIII-1 e 2), ed Egli ha stabilito quello come un atto supererogatorio per lui, cioè un sovrappiù in ciò che gli aveva imposto, dicendo: [262] "E parte della notte veglia" - e gli ha dato un ordine - "come opera supererogatoria per te" (Cor. XVII79) $\left.{ }^{838}\right)$ cioè ti ha ordinato un accrescimento di obbligo. Così è anche nel caso del credente, se egli traesse la sua intelligenza da Allah, sia Egli esaltato, poiché Allah, sia Egli esaltato, ha detto riguardo al servitore che ha mancato in qualcosa nei suoi atti obbligatori: "Completate il suo atto obbligatorio con ciò che ha fatto volontariamente" ${ }^{(839)}$, cioè con ciò che ha imposto a se stesso di fare. Ciò che è

838) Nel Cap. 69 [I 487.25] Ibn 'Arabī precisa: "L’arabo chiese: "O Inviato di Allah! C'è altro che devo fare?” ed egli rispose: "No, a meno che tu non lo faccia volontariamente". La sua risposta, che Allah faccia scendere su di lui la Sua salāt e la Pace, "No, a meno che tu non lo faccia volontariamente" si applica anche alla salāt, e quindi essa si impone a te con l'obbligatorietà degli obblighi di istituzione divina. La sua affermazione: "C'è altro che devo fare?" vuol dire rispetto a ciò che Allah mi ha imposto di fare di [Sua] iniziativa. E se decidi di fare volontariamente la salät - come nel caso del voto - Allah ti impone l'obbligo di farla, per la tua imposizione a te stesso di farla. [...] La salāt comporta la servitù ('ubūdiyya) e poiché la salāt è stata divisa in due parti - come abbiamo detto prima - cioè in una salāt che è d'obbligo di istituzione divina per gli individui ed una salāt che non lo è, così la servitù è divisa in due parti: una servitù di costrizione (idtirārr), per mezzo della quale faccio le salāt d'obbligo di istituzione divina, ed una servitù di libera scelta (ihtiyār), per mezzo della quale facciamo le altre salāt, che il Vero, sia Egli esaltato, ha chiamato "supererogatorie (nawāfil)", e che il Suo Inviato, che Allah faccia scendere su di lui la Sua salāt e la Pace, ha chiamato atti di obbedienza volontaria (tatawrerc). Egli, sia esaltato, ha detto: "E parte della notte veglia, come opera supererogatoria per te" (Cor. XVII-79). Uno dei pii ha detto: "A nessuno è stato imposto un atto supererogatorio se non all'Inviato di Allah, che Allah faccia scendere su di lui la Sua șalāt e la Pace, in quanto gli atti supererogatori non sono realmente tali [cioè un sovrappiù] e non sono stati attestati da Allah per nessuno se non nel caso del Suo Inviato, che Allah faccia scendere su di lui la Sua salät e la Pace, ed Egli gli ha ingiunto: E parte della notte veglia, come opera supererogatoria per te" (Cor. XVII-79)". Egli, sia esaltato, ha detto nella Sua notificazione autentica: "Ed il servitore non cessa di avvicinarsi a Me con i riti supererogatori", chiamando supererogatorio ciò che va oltre gli obblighi di istituzione divina. L'Inviato di Allah, che Allah faccia scendere su di lui la Sua salāt e la Pace, insegnando all'arabo ciò su cui si fonda l'Islām, gli aveva menzionato gli obblighi di istituzione divina, ed egli gli aveva chiesto: "C'è altro che devo fare?" ed egli gli aveva risposto: "No, a meno che tu non lo faccia volontariamente", ed ha quindi chiamato ciò che va oltre gli obblighi di istituzione divina "obbedienza volontaria". L'obbligo di istituzione divina è servitù di costrizione, in quanto la disobbedienza si verifica con il suo farlo [se l'obbligo è un divieto] o con l'astenersi dal farlo, il resto è servitù di libera scelta: il servitore è libero di intraprendere questi atti di sua iniziativa, ma, secondo noi, una volta che lo ha intrapreso gli si impongono necessariamente le regole della servitù di costrizione ed egli non può sfuggire alle sue regole finché non ha completato quell'atto di adorazione [o rito]. Per questo, quando l'arabo gli chiese: "C'è altro che devo fare?", egli, su di lui la Pace, rispose: "No", cioè Allah non ha reso obbligatorio per te, di Sua iniziativa, se non ciò che ti ho menzionato, "a meno che tu non lo faccia volontariamente", cioè a meno che tu non intraprenda un atto simile, di cui il Vero ti ha ispirato il desiderio, e quando hai deciso spontaneamente [di farlo] e lo hai intrapreso, è necessario per te compierlo, così come è necessario per gli obblighi di istituzione divina. Questo è il significato del suo detto: "No, a meno che tu non lo faccia volontariamente", e diventa obbligatorio per te ciò che hai imposto a te stesso. Di questo genere è il voto ed atti simili. Egli, sia esaltato, ha detto: "Non vanificate le vostre opere" (Cor. XLVII-33)".

839) Hadīt riportato da Abū Dāwud, II-105, Ibn Māğah, V-202, an-Nasā̄̄ì, V-9, ad-Dārimīe II-91, e da Ibn 
obbligatorio non si completa se non con ciò che è obbligatorio, come il voto (nadr), che Allah ha reso obbligatorio per lui in quanto egli lo ha imposto a se stesso $\left({ }^{840}\right)$

È stata riportata la notificazione riguardo a colui che all'Inviato di Allah, che Allah faccia scendere su di lui la Sua salāt e la Pace, quando egli affermò gli obblighi di istituzione divina ad ogni obbligo chiese: "C'è altro che devo fare?", ed egli rispose "No!", cioè Allah non ti ha imposto di Sua propria iniziativa se non ciò che vi ho trasmesso, poi disse: "A meno che non [lo] faccia volontariamente" ${ }^{(841)}$, cioè se fai volontariamente ciò che hai imposto a te stesso, Allah, sia Egli esaltato, lo rende obbligatorio per te, come ha fatto per il voto. La conseguenza necessaria del discorso comporta ciò nel suo detto: "C'è altro che devo fare?", [a cui il Profeta] rispose: "No! A meno che non faccia qualcosa volontariamente", ed è tuo dovere assolvere l’impegno, poiché tu ti sei caricato di un'opera che non ti era imposta, e ti sei imposto spontaneamente di farla, ed Allah ti ha ordinato di non vanificare la tua opera che ti sei imposto volontariamente e l'ha resa obbligatoria per te dicendo: "e non vanificate le vostre opere" (Cor. XLVII-33), e le prescrizioni legali sono vincolanti, e per questo è stato riportato che chi la vanifica [con delle mancanze o degli errori] deve recuperarla.

Realizza ciò che ha menzionato questo Maestro, e non ha raccomandato se non di fare ciò che è obbligatorio in tutti i tuoi atti, poiché il tralasciare il sovrappiù è un alleggerimento [nel viaggio].

Per chiunque abbia un intendimento sano è evidente che l'uomo è costantemente in viaggio senza fine, in questo e nell'altro mondo, e se gli viene attribuito il risiedere (istîtān) quello è soltanto il tempo $(a w \bar{a} n)$ [263] del suo pernottamento (mabīt) nella mansione a cui arriva, e quando si alza al mattino

Hanbal, II-425, IV-25 e 103, V-72 e 377. Ibn 'Arabī lo cita nei capitoli 47 [I 256.21], 69 [I 488.1], 70 [I 567.12 e 600.5], 71 [I 619.11], 73, questione CLIII [II 134.2], 165 [II 268.5], ove precisa: "Le opere di bene supererogatorie non sono realmente tali se non dopo il completamento degli atti obbligatori e tale completamento implica l'osservanza dei loro diritti. Per questo neghiamo che un atto sia veramente supererogatorio per qualcuno se non in presenza di notificazioni o di una contemplazione, poiché gli atti obbligatori assorbono quelli supererogatori nel loro venire completati da essi. È stato riportato nel Sahı̄h da parte di Allah, sia Egli esaltato, che nel Giorno della Resurrezione Egli dirà: "Osservate la salāt del Mio servitore: l'ha completata o è stato manchevole in essa?". Se essa è completa gli verrà ascritta come tale, ma se qualcosa manca in essa Egli dirà: "Osservate se il Mio servitore ha degli atti di obbedienza volontari", e se egli ha compiuto degli atti di obbedienza volontari, che sono quelli supererogatori, Egli dirà: "Completate al Mio servitore il suo atto obbligatorio con ciò che ha fatto volontariamente" [...] Allah non ha attestato a nessuno un'opera supererogatoria se non all'Inviato di Allah, che Allah faccia scendere su di lui la Sua salāt e la Pace, dicendo: "E parte della notte veglia, come opera supererogatoria per te" (Cor. XVII-79)", 176 [II 296.1], 299 [II 691.23 e 28], 376 [III 476.20], 471 [IV 103.20] e 560 [IV 450.5].

840) Per ottenere un favore da Allah il servitore si impegna nel voto a compiere un atto supererogatorio, come un digiuno al di fuori del mese di Ramaḍān o una șadaqa, e per via del voto quell'atto supererogatorio diventa obbligatorio per lui.

841) Had̄̄t riportato da al-Buhārī, II-34, XXX-1, LII-26, XC-3, Muslim, I-8, Abū Dāwud, II-1, at-Tirmid̄̄in, V-2, an-Nasā̄î, V-4, XXII-1, XLVII-23, e da Mālik, IX-94. Ibn 'Arabī lo cita nei capitoli 69 [I 487.25 e 488.2 ], 70 [I 547.9 e 591.1] 71 [I 651.27], 471 [IV 103.24], 532 [IV 176.1] e 560 [IV 462.30]. 
parte ${ }^{842}$. Se si considera il suo pernottamento nella mansione è uno che risiede, e [se si considera] il suo viaggio quando si alza al mattino è uno che parte, o [se si considera] la sua partenza quando si alza al mattino è uno che è in viaggio: dì quello che vuoi dopo aver compreso il senso.

E non si chiama sovrappiù se non ciò che è in più della misura del bisogno, e non c'è se non chi ha bisogno, ed il bisogno non si toglie $\left({ }^{843}\right)$. Il Vero non ti accorda una cosa se non perché tu hai bisogno di essa, che tu lo sappia o meno; prendila dunque con accettazione e cerca chi ha bisogno di essa da parte tua: lo troverai necessariamente, perché Allah non dà una cosa se non nella misura del bisogno e così è per colui a cui è dato, e coloro che hanno bisogno sono differenti e di gradi diversi. Il Nome di colui che dà [nella misura del bisogno] ${ }^{844}$ è sempre il Liberale (sahı $)$, e se ciò avviene prima della richiesta da parte del servitore è compagno del Liberale il Magnanime (ğawād), e se è dopo la richiesta è suo compagno il Generoso (karim), e se è il modo di fare un favore è suo compagno il Munificente $(w a h h \bar{a} b)$, e se è il modo di dare la ricompensa è suo compagno Colui che tiene conto (hasīb) $\left({ }^{845}\right)$, e non vi è quindi un dare divino che sia per abnegazione (îtâr $)$, a meno che Egli non dia per mezzo del servitore, allora il Suo dare è abnegazione, ed è lo strumento [cioè il servitore] che lo rende necessario per il suo bisogno $\left.{ }^{846}\right)$, e ciò non ha luogo se non da parte del Signore, sia Egli glorificato, e di ogni Nome divino di relazione, come il Creatore, Colui che nutre, Colui che dà potenza, Colui che abbassa, e tutti quelli simili.

\section{Indossa per ogni condizione il suo abito \\ che sia di felicità o di infelicità}

Sappi che il perfetto è colui che il Vero nomina Suo rappresentante e rende vigilante su se stesso, affinché veda gli effetti del suo Signore nel suo cuore ed affronti quegli effetti con le vesti di onore che essi esigono [264], e [cosi] fu l'uomo riguardo a cui Allah, sia Egli esaltato, disse: "E gli insegnammo l'arte del vestire per voi", cioè a causa vostra, "per proteggervi”, cioè con essi [abiti], "dalla vostra infelicità", dai mali che vi capitano, "Mi ringrazierete dunque?" (Cor. XXI-80) per quel [favore], sì che Noi ve lo aumenteremo, "e ringraziateMi e non siate ingrati" (Cor. II-152), poiché Egli ha [pronto] un abito di fame e di paura per chi è ingrato nei confronti del favore di Allah dopo che gli è arrivato. Ed Egli ha detto a mo' di esempio: "Ed Allah ha fatto l'esempio di una città sicura ed in pace, a cui il nutrimento arriva in abbondanza da ogni luogo" - e quale città è più grande dell'insieme

842) Nel Cap. 69 [I 461.17] Ibn 'Arabī afferma: "La gente della Via di Allah è di due tipi: tra loro vi sono coloro i cui stati spirituali cambiano ad ogni attimo ed essi ne sono consapevoli nei loro cuori. Essi sono i più grandi tra gli iniziati (riğa $\bar{l})$ e sono costantemente in viaggio ed è impossibile per loro risiedere".

843) La povertà, o dipendenza, è il regime esistenziale di ogni creatura.

844) Questa è la definizione di Liberalità (sahā y riportata nel Cap. 70 [I 586.10].

845) L'argomento è già stato affrontato alle pagine 86, 87 e 190 del manoscritto.

846) Allah è Indipendente dai Mondi per cui non è bisognoso ed il Suo dare non può essere abnegazione poiché questa presume un bisogno da parte di colui che dà. 
sintetico dell'uomo in se stesso? - "ed essa fu ingrata per i favori di Allah ed Allah fece gustare loro l'abito della fame e della paura" (Cor. XVI-1 12) $\left({ }^{847}\right)$, e lo ha denominato abito, e poiché un simile abito è una punizione, cioè è venuto in seguito all'ingratitudine, è opportuno che chi comprende respinga da se stesso ciò che lo porta ad indossarlo ed alleggerisca il carico delle sue spalle per il suo viaggio, siccome egli lo indossa già, cioè l'abito della fame per purificarsi e della paura (hawf) di Allah per questa paura, poiché esse [la fame e la paura] fanno parte delle parole di Allah lodate nella loro sede appropriata, e non vi è mai qualcosa che sia biasimato in modo assoluto $\left({ }^{848}\right)$.

Devi avere conoscenza degli stati e delle sedi, poiché sono esse che discriminano per te le cose e ti fanno apprendere le realtà essenziali delle cose per come esse sono in se stesse.

Poi ha detto: "E se ti parlano delle pietre, o del legno, o un animale, o altro delle cose create, non badare assolutamente a nulla di ciò e non legare il tuo cuore a nulla, anche se si presentasse a te il Regno (mulk), il Dominio (malakūt) dei Cieli [265] e della Terra, il Paradiso, il Fuoco infernale ed altro, non badare a nulla di ciò, poiché l’insieme di quelle cose fa parte della tua vendita”.

Egli dice: se si rompe per te il corso abituale degli eventi per via del discorso da parte di chi per sua natura non senti proferire parola, come i minerali, i vegetali e gli animali, oppure da parte di chi si sente [comunemente] parlare, ma che si rivolge a te in modo specifico con un discorso in cui vi è una magnificazione del tuo valore, egli ti ha raccomandato di non attaccare il tuo cuore a ciò, cioè alla sede da cui ti viene rivolta la parola, e [di non] fermarti ad esso, bensì devi stare al fianco di Colui che parla tramite ciò in tutto ciò che fa parlare. Egli non ti ha proibito se non di fermarti alla forma da cui Egli ha parlato, sì da essere legato ad essa mentre il Vero ti fa conoscere tramite essa. Tu, all'inizio della faccenda, hai venduto ogni possibilità ad Allah, quindi non tornare su ciò che è stato oggetto della vendita, poiché ne ha preso possesso il compratore e non ti è lecito chiederne la restituzione, a meno che il compratore te lo renda come favore, e per ciò vi è uno stato specifico.

847) Nel Cap. 369 [III 406.30] Ibn 'Arabī afferma: "Il senso del termine kufr [che significa sia miscredenza che ingratitudine] è quello di celare, coprire (satr). Egli, sia esaltato, ha detto: "Ed Allah ha fatto l'esempio di una città sicura ed in pace, a cui il nutrimento arriva in abbondanza da ogni luogo", e questo è il colmo dei favori da parte di Colui che li elargisce, "ed essa fu ingrata", cioè la comunità a cui Colui che elargisce ha accordato questi favori, "per i favori di Allah ed Allah fece gustare loro l'abito della fame", facendo cessare l'approvvigionamento, "e della paura", facendo cessare la sicurezza, "per ciò che hanno compiuto" (Cor. XVI112), quanto al celare i favori, al negarli e, ciò che è peggio, all'essere malcontenti di essi. Egli, sia esaltato, ha detto: "Se voi ringrazierete, Noi vi aumenteremo [il favore]" (Cor. XIV-7), ed ha detto: "e ringraziateMi e non siate ingrati" (Cor. II-152), e ciò malgrado la Sua ricchezza [(gina $)$, o: indipendenza] rispetto ai Mondi. E che dire del povero bisognoso quando elargisce al suo simile una parte del favore che Allah gli ha generosamente accordato? Egli ha più diritto al ringraziamento ed è più felice per esso di quanto lo sia il Ricco assoluto, Colui che è indipendente dai Mondi”.

848) L'argomento è già stato trattato a pag. 169 del manoscritto. 
Chi ha intendimento deve distinguere, da parte di Allah, tra ciò che Egli ti mostra e ciò che ti dà, poiché quando ti dà ti ordina e ti incombe per l'adab seguire l'ordine del tuo Signore; e quando ti mostra ti lascia la scelta e colui che ha la scelta, quando accetta ciò in cui può scegliere lo accetta sempre per la passione (hawā) della sua anima e ciò in cui subentra la passione perisce (hawāa). Ma malgrado questo osserva ciò che Egli ti dice in quella forma e se ti parla di ciò in cui vi è per te una ascesa ed un aumento di scienza, presta ascolto a Lui come presti ascolto a colui che dà il buon consiglio e come presti ascolto a questo Maestro che ti ha fatto le raccomandazioni e ti ha dato il buon consiglio, poiché è il Vero che parla presso di te con la sua lingua. E se ciò [266] di cui ti parla non comporta un aumento di scienza né un profitto, ma è un discorso di prova (fitna), osserva ciò che ti annuncia con esso, e soppesalo con il tuo stato che ha determinato per te quel discorso specifico, e se lo stato lo richiede da parte tua ascoltalo ed accettalo in base alla procura (wakäla) che ha quello stato, non da te stesso.

Prendi ciò come una buona novella da parte di Allah, quanto è Potente e Magnificente, ed applicati con zelo ad essa, poiché si tratta di uno dei più grandi favori, soprattutto se ciò è collegato con la ricchezza $(m \bar{a} l)^{\left({ }^{849}\right)}$. E se vedi che il tuo stato non ha determinato quel discorso specifico, sappi che quella è una prova: guardati dunque dalla prova, poiché essa è un mettere alla prova (ihtibarr) da parte del Vero per sapere se sei tratto in inganno o no, e se dimentichi lo stato in cui ti trovi o lo ricordi. Questo è il significato delle parole di Mosè al suo Signore: "Essa non è se non la Tua prova", cioè il Tuo mettere alla prova ed il Tuo cercar di sapere, "per mezzo di essa svii chi vuoi" cioè sconcerti in essa chi vuoi, "e guidi chi vuoi", alla scienza di quello, affinché sia evidente per Te che è la verità, "Tu sei il nostro patrono", cioè Colui che ci aiuta contro ciò con cui ci hai messo alla prova, "perdonaci dunque" (Cor. VII-155), cioè copri a causa nostra ciò che ci sconcerta della tua prova e ci svia $\left({ }^{850}\right)$.

849) In tutti i manoscritti che ho potuto consultare si legge chiaramente $m \bar{a} l$, ma il senso della frase sarebbe più compiuto se al posto di $m \bar{a} l$ vi fosse $h \bar{a} l$, stato.

850) Nel Cap. 560 [IV 453.34] Ibn 'Arabī afferma: "Un'altra cosa amata da Allah è il ritorno ad Allah in occasione della prova (fitna), poiché, come ha detto l'Inviato di Allah, che Allah faccia scendere su di lui la Sua salāt e la Pace, Allah ama tutti coloro che messi alla prova si pentono. Allah, sia Egli esaltato, ha detto: "Egli ha creato la morte e la vita per mettervi alla prova [e verificare] chi di voi ha la migliore condotta" (Cor. LXVII-2); i termini balä' [che ricorre come verbo nel versetto] e fitna hanno lo stesso significato, non essendo altro che la verifica (ihtibarr) di ciò che l'uomo afferma. "Essa non è altro che la Tua prova", cioè la Tua verifica, "con essa Tu fai deviare chi vuoi", cioè lo disorienti, "e con essa Tu guidi chi vuoi" (Cor. VII155), cioè gli mostri la via della sua salvezza mediante essa", e nel Cap. 108 [II 189.9] precisa: "Sappi, che Allah ti assista, che la prova (fitna) è il mettere alla prova (ihtibār). Tu dici: "Ho provato (fatantu) l'argento col fuoco" nel senso che lo hai saggiato. Egli, sia esaltato, ha detto: "Invero le vostre ricchezze ed i vostri figli sono una prova" (Cor. LXIV-15 e VIII-28), cioè Noi vi abbiamo messi alla prova con essi, per vedere se vi velano da Noi e da ciò che vi abbiamo imposto come limite a cui attenervi. E Mosè, su di lui la Pace, ha detto: "Ciò non è che la Tua prova, per mezzo di essa svii chi vuoi - cioè lo sconcerti - e guidi chi vuoi!” (Cor.VII-155). Una delle prove più grandi con cui Allah mette alla prova l'uomo sta nel fatto di avergli notificato che Egli lo ha creato sulla Sua forma, per vedere se l'uomo si attiene alla sua condizione di servitù ed alla sua possibilità (imkān), oppure se si monta la testa per il rango elevato della sua forma". 
Sappi che la radice del mettere alla prova divino e della prova non è altro che l'asserzione $($ da $氏 \bar{a})\left({ }^{851}\right)$ - a chi non fa asserzioni Allah non chiede di dare dimostrazione della veridicità della sua asserzione - chiunque sia colui che asserisce, io non specifico chi fa una asserzione da un altro, sappilo - al punto che la persona che asserisce di non fare asserzioni viene messa alla prova e provata riguardo a quello, poiché egli asserisce di essere lui stesso al di sopra delle asserzioni. Così a colui che afferma la negazione viene detto: "Mostra l'evidenza e la prova della tua affermazione di questa negazione, non della negazione", poiché colui che nega non è tenuto a dimostrare la negazione, se non quando afferma [267] la negazione, in quanto la dimostrazione richiede l'affermazione, non la negazione. Non vi è quindi se non chi asserisce, e non vi è quindi se non chi è provato, veridico o non veridico che sia. Colui che è veridico nella sua asserzione è Allah in modo assoluto, mentre la creatura talvolta è veridica nella sua asserzione e talvolta non lo è; chiunque faccia una asserzione per Allah è veridico nell'asserzione, mentre chiunque faccia una asserzione per se stesso, delle due l'una: o asserisce nello stato del suo gusto che la sua creazione è secondo la Forma divina e dice quindi il vero in tutto ciò che asserisce in questo stato, oppure il suo gusto spirituale non è quello, e talvolta dice il vero e talvolta no.

La prova è inevitabile: cerca quindi l'aiuto di Allah in quello, come ha affermato Mosè, su di lui la Pace. Questo mettere alla prova esige la concomitanza dell'imposizione legale, poiché senza l'imposizione legale non è possibile né mettere alla prova, né la prova, dove che sia, né la procura (tawkīl) di un

851) Spesso questo termine viene tradotto come pretesa, ma in italiano la pretesa implica una richiesta, che invece esula dal significato del termine arabo. Nel Cap. 355 [III 248.18] Ibn 'Arabī precisa: "Quando Allah ha creato questa natura umana, nobilitandola con ciò che le ha attribuito di sinteticità, ha inserito in essa l'asserzione $(d a \& \bar{a})$, per completare così la sua forma, poiché l'asserzione è un attributo divino. Egli, sia esaltato, ha detto: "Io sono Allah, non c'è Dio al di fuori di Me: adorateMi dunque" (Cor. XX-14) ed ha affermato che "non c'è Dio se non Lui" e questa è una asserzione veridica [...] L'asserzione è una notificazione (habar) e questa, in quanto tale, può essere vera o falsa ed ammette quindi sia la veridicità che la menzogna: sappiamo da ciò che è indispensabile la verifica [o la messa alla prova (ihtibār)]. Il credente afferma di avere la fede, che consiste nel credere all'esistenza di Allah ed alla Sua Unità, che non c'è Dio se non Lui e che "ogni cosa è peritura salvo il Suo volto" (Cor. XXVIII-88) e che la faccenda appartiene ad Allah prima e dopo; quando egli afferma con la sua lingua che questo è ciò che nutre nel suo interno ed a cui è legato il suo cuore, è possibile che dica il vero in ciò che afferma di avere come attributo ed è possibile che dica il falso nell'affermare che quell'attributo gli appartiene. Per questo Allah lo mette alla prova [...] Se tu dici: "L'idolatra [(mušrik), l'associatore] che afferma di essere idolatra dice il vero nell'affermare di esserlo. Perché la sua veridicità non gli è di giovamento?", noi rispondiamo che egli dice il falso nella sua affermazione riguardo all'attribuzione della Divinità a ciò che non è Dio: questa è la sua affermazione per la quale è giudicato infedele. Quindi egli è veridico quando afferma di essere idolatra ma non è veridico quando afferma che l'associazione nella Divinità è autentica [...] Per questo coloro che dicono il vero saranno interrogati riguardo alla loro veridicità su ciò che hanno detto essere vero: hanno detto il vero riguardo a ciò che è stato loro ordinato e spiegato o hanno detto il vero riguardo al loro aver fatto ciò che era stato loro proibito, insieme al fatto di essere veridici? Verrà chiesto loro: su cosa avete detto il vero? Coloro che parlano male dicono il vero e coloro che denigrano dicono il vero, e tuttavia Allah li ha biasimati ed ha pronunciato minacce contro ciò, malgrado si tratti di veridicità. Per questo coloro che dicono il vero verranno interrogati su cosa hanno detto di vero. Questo fa parte del metterli alla prova da parte di Allah, e la radice di tutto questo è l'asserzione che Egli ha inserito nella loro natura". 
Angelo, né l'inseparabilità (mulāzama) da un compagno satanico ${ }^{852}$, e la faccenda sarebbe da Allah al Suo servitore, e dal servitore al suo Signore, come sarà nel Paradiso e nell'Inferno.

Poi egli ti ha messo in guardia dagli impedimenti che si presentano nella tua via, ed è già stato fatto il commento degli impedimenti e degli attaccamenti che si frappongono tra te e la tua felicità ( $\left.{ }^{853}\right)$, ed essi sono molti e non possono essere enumerati, e [ti ha ingiunto] che nulla di ciò ti stacchi dal tuo Amato, che è ciò che cerchi, ma ti insegno una cosa che questo Maestro ha trascurato nella sua raccomandazione, non essendo essa il suo gusto spirituale, poiché gli iniziati, per la loro veridicità, non parlano se non di ciò di cui hanno gusto.

Sappi che Allah, sia Egli esaltato, ha un volto specifico (wağh hășṣ) ${ }^{854}$ ) in ogni impedimento ed attaccamento, e non devi allontanarti da quell'impedimento [268] ed attaccamento finché non contempli il volto di Allah in esso e quell'attaccamento ed impedimento diventa una via che conduce alla conoscenza di quel volto specifico che Allah ha in esso. Per mezzo di quel volto Egli preserva ad esso la sua esistenza ${ }^{(85)}$ e per mezzo di quel volto gli ha dato l'esistenza ${ }^{(856)}$, e per colui che realizza il volgere il viso (tawağğuh) da parte del Vero in tutte le cose che si presentano a lui non c'è cosa che

852) Riferimento ad uno hadīt riportato da Muslim, L-69, ad-Dārimī, XX-25, e da Ibn Ḥanbal, I-385, 397, 401 e 460, in cui è detto: [Il Profeta ha detto:] "Non c'è nessuno di voi a cui Allah non abbia assegnato come procuratore il suo compagno inseparabile (qarinn) tra i ğinn [demoniaci] ed il suo compagno inseparabile tra gli Angeli". Gli chiesero: "E tu?" ed egli rispose: "Anch'io, ma Allah è stato sollecito con me contro di lui [il ğinn] ed egli si è sottomesso e non mi ordina se non il bene"'”. Ibn 'Arabī lo menziona nei capitoli 9 [I 134.9], 69 [I 516.11], 264 [II 564.23], 369 [III 381.30], 371 [III 439.20] e 560 [IV 503.35] ove raccomanda: "Sii un eccellente compagno per l'Angelo custode che è incaricato di te ed ascoltalo; guardati dal secondo compagno, che è Satana, e non far trionfare Satana sull'Angelo, accettando da lui ciò che ti ordina di fare, ma deludilo e chiedi aiuto contro di lui all'Angelo, accettando [ciò che ti ingiunge]".

853) L'argomento è stato trattato a pag. 163 del manoscritto.

854) Si tratta del volto (wağh) del Vero che c'è in ogni cosa, di cui Ibn 'Arabī ha già parlato a pag. 174 del manoscritto. Questo volto è menzionato almeno 150 volte nelle Futühăt, per cui non è possibile riassumere in una nota quanto Ibn 'Arabī ha scritto al riguardo; la trattazione più estesa di questo aspetto dottrinale in una lingua occidentale si trova nell'opera di William Chittick, The Self-Disclosure of God, SUNY Press 1998, pag. 135-155.

855) Nel Cap. 314 [III 54.11] Ibn 'Arabī afferma: "In ogni essere Allah ha una teofania ed un volto specifico con cui lo custodisce".

856) Nel Cap. 70 [I 599.6] Ibn 'Arabī afferma: "Essa [la trasposizione simbolica della zakāt sulla miniera] consiste nel dare ciò che spetta ad Allah, sia Egli esaltato, per quella genesi (takwinn), attribuendola al volto divino specifico che Egli ha in ogni cosa possibile (mumkin), senza considerare la sua causa occasionale (sabab). Questo è il mondo della creazione (halq) e del comando $(a m r)$, ed il primo è specificamente il mondo del comando"; nel Cap. 198 [II 423.21] spiega: "[...] ciò che Allah proietta nella tua anima da quel volto divino specifico che esula dalla creazione e che [ciò che viene proiettato] è il comando divino. A Lui appartengono la creazione ed il comando [cfr. Cor. VII-54] e ciò che viene da quel volto è il comando, e ciò che viene da altro che quel volto è la creazione"; e nel Cap. 480 [IV 116.21] aggiunge: "Tutto il mondo è il mondo del comando, che faccia parte del mondo della creazione o non ne faccia parte. Già abbiamo spiegato cos'è il mondo del comando e della creazione, ed esso [il mondo del comando] è il volto specifico che c'è nel mondo della creazione". 
possa essere un velo in modo assoluto. Tu sai per una scienza generale (kullit) che nessuna cosa esce da Lui, sia Egli esaltato, e che Lui non esce da alcuna cosa, ma il vantaggio che risulta alla gente di Allah dalla scienza di quel volto in ogni cosa è la scienza della specificazione ( $\operatorname{tafș} \bar{l})$, e ciò non avviene se non per una contemplazione diretta ed una teofania, a differenza della scienza del tutto. E questa è una raccomandazione complementare da parte mia per te, che questa sezione comporta, poiché questo volto specifico che noi abbiamo reso noto non l'ha palesato nessuno prima di noi $\left({ }^{857}\right)$, anche se lo conosceva, e noi abbiamo ottenuto di renderlo noto alla gente di Allah, sia Egli esaltato, come raccomandazione per essa.

Poi disse, Allah abbia misericordia di lui: "Sappi, figlio mio", questo è il discorso di 'Alī immaginato a Yūsuf il reale, "che il Vero ti mostra in circostanze diverse cose diverse, ed in alcune di quelle circostanze provi paura, in altre ti senti al sicuro, in altre provi gioia, in altre provi tristezza ed in altre provi speranza, ed in altre ancora si manifesta sulla tua anima amore. Figlio mio, in tutte queste circostanze stai di fronte al tuo Amato e non badare a nulla [269] di ciò [che ti viene mostrato], poiché anche ciò fa parte del genere di questo mondo da cui tu sei uscito prima di quello".

Sappi innanzitutto che ogni raccomandazione e conoscenza che si è manifestata sulla lingua di questo Yūsuf di ciò che egli conosce viene da lui per altri che lui, anche se chi ne parla è 'Alī al-Kurdī, il suo Maestro, e tutto ciò che si è manifestato sulla sua lingua di ciò che non conosce è la lingua di 'Alī al-Kurdī che lo raccomanda a Yūsuf, il suo discepolo, di volta in volta. Così esige la saggezza che è racchiusa in questi fogli $\left.{ }^{858}\right)$. Se 'Alī era a conoscenza di quello, cioè sapeva quello che il Maestro immaginato gli aveva esposto, allora era 'Alī che vi provvedeva, se invece non lo sapeva in modo specifico allora ciò veniva dalla veridicità di Yūsuf nei confronti di 'Alī, ed è quella veridicità che ha prodotto la forma di questo Maestro nella sua immaginazione (hayāl). Se invece 'Alī sapeva quello allora è l'aspirazione (himma) di 'Alī che ha prodotto la sua immagine nell'immaginazione di Yūsuf.

857) Analogamente, nel Cap. 72 [I 720.33] Ibn 'Arabī afferma: "Per quanto ne sappia non ho visto nessuno di coloro che ci hanno preceduto, né dei nostri contemporanei, che abbia richiamato l'attenzione sull'affermazione di questo volto specifico in ogni cosa possibile, anche se essi non lo ignoravano", nel Cap. 167 [II 273.27] aggiunge: "La scienza di questo volto è la scienza dell'elisir nell'alchimia naturale. Si tratta dell'elisir dei conoscitori, e io non ho mai visto nessuno, oltre a me, che abbia attirato l'attenzione su di esso, e se non avessi ricevuto l'ordine di dare il buon consiglio a questa comunità, anzi ai servitori di Allah [in generale], non ne avrei parlato", e nel Cap. 396 [III 559.8] precisa: "Per quanto ne sappiamo nessuno ha richiamato l'attenzione su questo volto e su ciò che viene generato da esso nel cuore di colui che si è ritirato nella Sua contemplazione salvo Abū Bakr, il confessore [nella sua affermazione: "Non ho visto nessuna cosa senza vedere Allah prima di essa"]. Tuttavia non lo abbiamo appreso dalla segnalazione di Abū Bakr, il confessore, perché non avevamo capito cosa volesse dire con ciò, né vi avevamo riflettuto. È solo per la sollecitudine di Allah verso di noi riguardo ad esso che la sua scienza ci è arrivata d'improvviso, ma noi non lo conoscevamo e quindi l'abbiamo negato ed abbiamo detto: "Da dove viene questo?". Allora Allah ha aperto tra noi e Lui quella porta e siamo venuti a sapere cosa abbiamo da parte del Vero in modo specifico [per noi] e che questo è il volto specifico che è dato da parte di Allah, quanto è Potente e Magnificente, ad ogni essere da Lui generato".

858) Si tratta dei fogli in cui Yūsuf ha trascritto gli insegnamenti ricevuti da 'Alī al-Kurdī e che ha dato ad Ibn 'Arabī perché li commentasse. 
E poiché Yūsuf mi disse: "Di tutto ciò che abbiamo menzionato, il Maestro 'Alī non mi ha parlato a tu per tu in un colloquio esteriore" seppi che tutto quello veniva dall'immagine del Maestro creata dall'aspirazione di 'Alī, se ne era al corrente, o dalla veridicità di Yūsuf se 'Alī non ne aveva scienza.

La prima cosa di cui [il Maestro] ha parlato riguardo a ciò che si presenta a lui [l'aspirante] nelle circostanze diverse delle cose diverse, è ciò che lo spaventa e di cui ha paura. Sappi che la faccenda $(a m r)$ che determina la paura si può suddividere in due categorie in base alla scienza o alla mancanza della scienza di come le cose stanno realmente.

Quanto alla categoria della mancanza della scienza, essa consiste nella paura dell'uomo che la sua anima ritorni [270] alla non-esistenza dopo la sua esistenza, e la forma dell'ignoranza in questo è che se l'esistenza è in realtà già fissata, per costui che teme, nell'esistenza del Vero, è impossibile il suo ritorno alla pura non-esistenza, sia dal punto di vista della Legge che della ragione. La Legge al riguardo è nota, e la ragione sancisce che la pura non-esistenza appartiene all'impossibile, non al possibile, e questa è invece una possibilità e quindi la pura non-esistenza è impossibile per essa, soprattutto se è già stata qualificata dall'esistenza e dalla preponderanza $\left({ }^{859}\right)$.

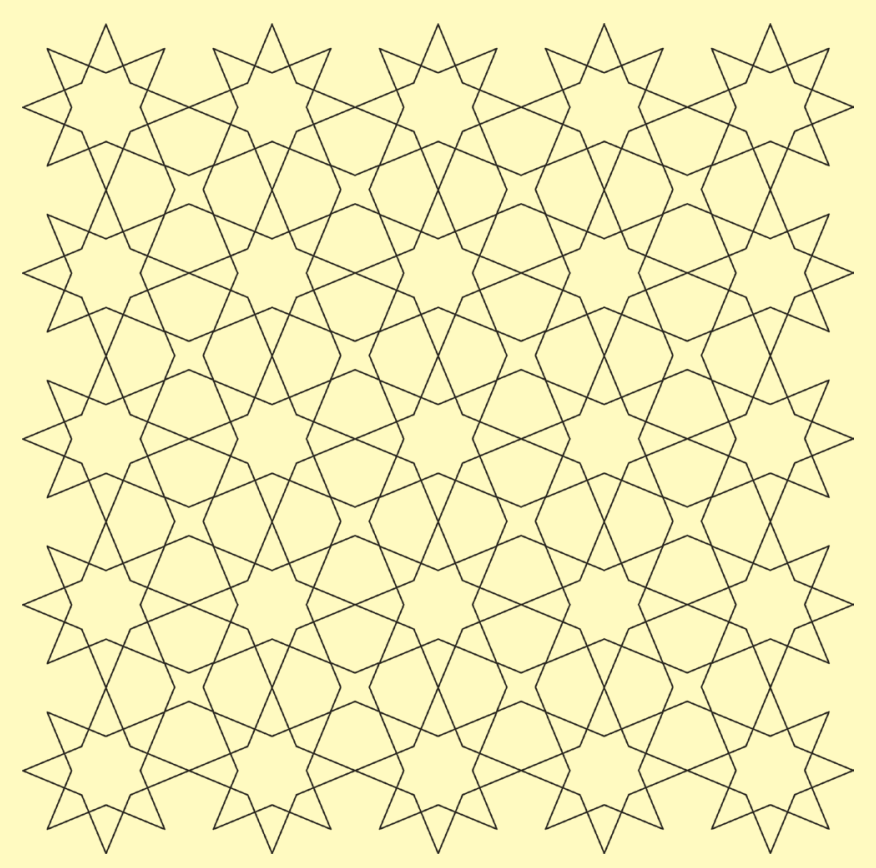

859) Il significato della preponderanza è stato già spiegato nei testi riportati nella seconda nota alla traduzione della pag. 178 del manoscritto. 
Tra coloro che sono collegati ad Allah, abbiamo visto uno che aveva paura di quello, ed era Abū al'Abbās al-Harrār ${ }^{860}$ ) uno dei veridici: egli era Imām presso la moschea di Zuqāq al-Qanādīl ( $\left.{ }^{861}\right)$ al Cairo, Allah abbia misericordia di lui.

E se l'esistenza appartiene al Vero, non al servitore, in una entità immutabile, per questo ciò che viene indicato come il Mondo è conforme a ciò che comporta la realtà essenziale di quell'entità nella esistenza del Vero, e [il servitore] non è stato mai esistenziato perché avesse paura della non-esistenza, e questo è il senso della nostra affermazione: "se l'esistenza è in realtà già fissata per lui", e questo è il motivo della paura in questa forma, dovuta alla mancanza della scienza.

Quanto alla sua paura fondata su una scienza è che egli vede che la paura fa parte degli stati della sua entità nella sua immutabilità $(t u b u \bar{t})$, e [vede] l'attualizzazione in essa [entità] di questo regime, che è la paura, nella forma che egli osserva, e in questa circostanza è inevitabile la paura, per la specificità di questo regime che è indispensabile per questa entità, se è venuta all'esistenza, o per la forma in cui si manifesta, conformemente alla sua scienza riguardo a quello: tutto ciò è scienza verificata.

860) Abū l-'Abbās Aḥmad al-'Aș̣āà al-Ḥarrār o al-Ḥarīīī, come viene denominato nelle Futūhāt, originario di Siviglia, morì al Cairo nell'anno 611 dall'Egira. È citato nel Cap. 52 [I 276.20] ove Ibn 'Arabī afferma: “Torniamo a colui che ha uno svelamento e che rifugge verso il mondo visibile quando vede nel suo svelamento qualcosa che lo terrorizza, come il nostro compagno Aḥmad al-'Așsāa al-Ḥarīrī, Allah abbia misericordia di lui. Quando era preso [da uno svelamento] egli tornava rapidamente ai suoi sensi, scosso e tremante. Io lo sgridavo e gli parlavo di quello, ed egli diceva: "Ho paura e terrore della non-esistenza della mia entità per ciò che vedo". Se solo il poveretto avesse saputo che se si fosse separato dalle cose materiali il soffio sarebbe ritornato alla sua residenza, che è la sua entità, ed ogni cosa sarebbe ritornata alla sua origine! Ma se fosse così si annienterebbe il beneficio nei confronti del servitore in ciò che si manifesta, e la faccenda non è così. Per questo abbiamo detto: "ed essa è la sua entità", cioè l'entità del servitore. La permanenza $(b a q \bar{a})$ che il Vero vuole è preferibile con l'esistenza di questo edificio corporeo, che è elementare in questo mondo e naturale nell'aldilà. Colui che sta fermo qui - cioè quando gli arriva qualcosa [da Allah] - sta fermo solo quando vi entra come servitore, così come colui che non sta fermo vi entra come servitore ma con una parte di signoria nella sua anima ed egli ha paura che qui essa cessi e fugge quindi verso l'esistenza in cui si è manifestato il suo attributo dominicale, e per questo il beneficio è scarso", nel Cap. 69 [I 410.7 e 13] e nel Cap. 230 [II 529.13], ove aggiunge: "Questo esilio (gurba) è lo stato di due [tipi di] iniziati: un iniziato che non è familiare con questa stazione spirituale e che non vi è arrivato per mezzo di una salita graduale e di una progressione da stato a stato, ma gli è arrivato all'improvviso ciò che non conosceva e con cui non era familiare ed ha ritenuto la sua anima troppo debole per sostenerlo ed ha temuto la non-esistenza della propria entità. Egli quindi è stato confuso dall'ottenimento di questa conoscenza ed ha fatto immediatamente ritorno ai suoi sensi, ma in questo modo si è posto in esilio dal Vero. Della gente di questa stazione abbiamo visto Abū l-'Abbās Aḥmad al-'Așșād, noto al Cairo come al-Harīīī, e non abbiamo incontrato altri che lui’".

Altre notizie su di lui si trovano nella Risāla rūh al-quds, pag. 91-95 della traduzione di Ralph Austin, Sufis of Andalusia, Allen \& Unwin 1971, ove viene erroneamente chiamato al-Ǧarrār, e nella Risāla di Șafiyuddīn ibn Abī l-Manșūr ibn Zāāir, pag. 83-110 della traduzione di Denis Gril, Institut Français d'Archéologie Orientale du Caire, 1986.

861) Si tratta del vicolo delle lanterne, una via vicino alla casa ed alla moschea di 'Amr ibn al-`̄̄s, abitata all'epoca da molti sūfi andalusi. 
Il Vero non si distingue dalle creature se non perché porta su di Sé i due opposti, ed Egli accetta questo carico per la Sua realtà essenziale, mentre ciò avviene per la creatura solo in relazione ad un certo aspetto, non come entità unica ('ayn wähida) [271], cosa che per il Vero avviene come entità unica. Egli è il Primo in quanto è Ultimo, e così in tutti i regimi opposti, poiché Egli è l'entità di ogni cosa, mentre nel Mondo è Primo in quanto tale e Ultimo in quanto tale ${ }^{\left({ }^{82}\right)}$. Chi ha scienza della Primità (awrwaliyya) del Vero e della Sua Ultimità per mezzo di questa relazione non ha scienza se non del Mondo in quanto è Mondo, non in quanto il Vero è la sua entità, e la percezione [di questa distinzione] è molto difficile. Realizzala e metti in rapporto con essa, cioè con questa distinzione (tafșîl), tutto ciò che Egli ha vincolato per mezzo di essa in ogni circostanza (mawtin), di gioia e di tristezza, di costrizione e di dilatazione, di sicurezza e di speranza, ecc.

Quanto al caso in cui un amore sovrasta il tuo cuore in qualche circostanza, ed Egli ha stabilito che esso domini il tuo cuore, tu sei sopraffatto in esso ed esso non si manifesta finché non domina il tuo cuore, e ciò, da parte di colui che ama, comporta l'assenza di dissimulazione del suo amore, a causa dell'immensità del suo potere (sultān), come ha detto uno di loro:

Chi asserisce che nasconderà il suo amore, tanto che se ne dubiti, è un bugiardo.

L'amore sovrasta cosi il cuore con la sua forza coercitiva che non si vede effetto del velo su di esso.

Se appare il segreto [amore] di colui che è assennato (labīb) esso appare soltanto quando il giovane è sopraffatto.

Io invidio chi ha una passione ben custodita, che né gli occhi, né i cuori, riescono a supporre! (863)

Quanto a colui in cui l'amore non sopraffà il suo cuore, egli fa a suo giudizio: se vuole lo manifesta e se vuole lo nasconde, per il suo potere su di esso. A questo riguardo uno di loro $\left({ }^{864}\right)$ ha detto:

\section{Il folle degli 'Amir palesò la sua passione}

862) In Se stesso il Vero è Primo in quanto Ultimo, mentre in relazione al Mondo è Primo in quanto Primo e Ultimo in quanto Ultimo. L'uomo invece può essere padre per un aspetto e figlio per un altro, ma non può essere padre in quanto figlio.

863) Gli stessi versi, di Abū l-'Atāhiya, sono riportati nel Cap. 178 [II 361.18], accompagnati dal seguente commento: "L'amore è soverchiante tanto da non lasciare velo senza strapparlo, né segreto senza divulgarlo. I sospiri dell'amante sono ben udibili e le sue lacrime inarrestabili; le sue membra tradiscono i suoi malesseri e la sua insonnia, stati questi che esprimono il suo amore. Se parla dice cose incomprensibili. Egli non ha pazienza né costanza; le sue preoccupazioni si succedono incessantemente e le sue afflizioni si moltiplicano".

864) Nella sua Risālat ibn al-Qārih [in Risālat al-gufrān, Dār al-ma'ārif, Cairo, 1977, pag. 582] Abū l-'Alā’ alMa'arrī attribuisce questi versi ad Abū Bakr aš-Šiblī. 
ed io nascosi la [mia] passione e morii con il mio amore

Quando nella Resurrezione verrà chiamato:

"Chi è vittima della passione?" avanzerò da solo [272] $\left.{ }^{865}\right)$

Egli ha detto che è vittima della passione perché l'ha nascosta e nessuno sapeva del suo amore e di ciò che provava, né egli aveva un amico che lo sostenesse nella forza del potere del suo amore, per cui restò solo con esso, isolandosi, e ciò lo uccise, e questa è l'uccisione (qatl). Ma l'amore non ha potere finché non sovrasta il cuore dell'amato $(m a h b u \bar{u} b)$ e quando non si manifesta, il suo potere è debole: questa è la spiegazione.

Gli stati non esercitano il loro regime se non per il loro potere e quando non esercitano il loro regime non sono realmente degli stati per colui in cui sussistono, ma si tratta solo di fantasticheria (hadīt nafs) ${ }^{\left({ }^{66}\right)}$, non di uno stato, come i colori dell'arcobaleno per l'occhio di chi guarda, mentre nel cielo non c'è nessuno di questi colori che l'osservatore vede in esso.

Lo stato autentico è come il colore che sussiste in ciò stesso che è colorato, come il colore giallo della codardia ed il colore rosso della vergogna ${ }^{\left({ }^{87}\right)}$, ed essi sono nell'entità di ciò che è rosso o giallo, non nell'occhio dell'osservatore. Allo stesso modo è la forma degli stati, di cui l'amore fa parte: se è autentica essa palesa il suo regime sul cuore dell'amante ed il suo potere si manifesta in esso, e se è una fantasticheria non ha la forza di un potere, e questi sono stati di fantasticheria, nient'altro. Medita su ciò che abbiamo detto riguardo al discorso di questo Maestro in questa sezione: troverai una scienza elevata.

Poi ha detto: "Stando in guardia, quando ti viene accordata questa presentazione ('ard), dall'inquietudine (qalaq) e dalla scontentezza spontanee (ihtiyār $\vec{\imath}$ "). Egli dice, e la tua intelligenza sia con te, che se qualcuno [o qualcosa] ti ha preso, distogliendoti da te, la tua complessione si altera, e ciò dipende da chi ti ha preso non da te. È inquieto e scontento soltanto colui che pone Colui che cerca al di fuori di tutto ciò che si presenta a lui, mentre chi Lo riconosce nell'entità stessa di tutto ciò che si presenta a lui non ha inquietudine né scontentezza. Egli Lo deve quindi cercare in ciò stesso che si manifesta,

865) Il primo verso si riferisce alla storia di Laylā e Mağnūn, entrambi appartenenti alla tribù nomade degli 'Amir, gli altri alla vicenda amorosa del poeta. Ibn 'Arabī li riporta nel suo commento al Tarğumān al-ašwāa al canto XV, ove commenta: "L'amore non ha dominato questo poeta come ha dominato l'altra persona, che il potere dell'amore non ha abbandonato. Colui che cela l'amore, impedendo al suo potere di manifestarsi, è più forte di esso, prevalendo la sua ragione. Non c'è bene in un amore che è governato dalla ragione, poiché le regole dell'amore si oppongono al governo della ragione", nel Kitäb al-huğ̌ub, [pag. 143 delle Rasāill Ibn al-'Arabì, Volume I, Ibn al-'Arabī Foundation, 2013] e in Muhạdarat al-abrār, Vol. II, Dār Sāder, senza data, pag. 211.

866) Nel Cap. 178 [II 326.4] Ibn 'Arabī precisa: “Ogni amore che lascia sussistere nell'amante una razionalità, sì che possa pensare ad altro che il suo amato, o un senno, non è vero amore, ma solo fantasticheria. Uno di loro ha detto: "Non c'è bene in un amore che è governato dalla ragione"".

867) Lo stesso esempio è riportato nel Cap. 198 [II 472.13] e nel Cap. 559 [IV 420.35]. 
[273] poiché Egli lo chiama a Sé da vicino, non da lontano.

Quanto al suo detto: "e se è valida la tua determinazione con il tuo Amato di eliminare la condivisione (mušăraka), Allah fa andar via (adhaba) dal tuo cuore ciò che è diverso da Lui”.

Il gruppo degli iniziati, la gente del gusto spirituale, ha detto, senza divergenza: "Quando il servitore è sincero nel suo lasciare un desiderio a causa di Allah, Allah se ne va (dahaba) con esso dal suo cuore" ( $\left.{ }^{868}\right)$.

Quanto è bella questa precisazione da parte loro, Allah sia soddisfatto di loro, poiché in quel desiderio o in quella cosa è inevitabile che vi sia un volto (wağh) che appartiene al Vero $\left({ }^{869}\right)$, e quando l'aspirante è sincero o è autentica la sua determinazione di lasciare una cosa a causa di Allah, sia Egli esaltato, ciò non accade da parte sua se non perché non riesce a vedere il volto divino che appartiene a quella cosa, poiché se lo vedesse non sarebbe sincero nel suo lasciarla, ma sarebbe inseparabile da essa a causa di quel volto divino. In effetti egli è sincero solo nel lasciarla a causa di Allah, ma gli sfugge il bene di quel volto divino da cui quella cosa è caratterizzata, ed Allah Se ne va con quella cosa dal suo cuore.

Così hanno detto i realizzati, attribuendo l'andarsene ad Allah insieme a quella cosa, cioè l'andarsene di quel volto vero con l'andarsene della cosa; essi hanno detto: "Allah Se ne va" e questo Maestro ha detto: "Allah fa andar via ciò che è diverso da Lui dal suo cuore", e vi è molta differenza tra le due espressioni ed ognuna ha un significato. Il volto divino che c’è in ogni cosa non si separa da essa, poiché è il suo custode e da esso procede, ed è impossibile che l'entità di Allah non accompagni ogni cosa di cui è detto che è altro che il Vero, per via del Suo detto: "Egli è con voi" - intendendo ciò che è altro che Lui - "dovunque voi siate" (Cor. LVII-4), e del Suo detto: "e non Lo affatica la loro custodia" (Cor. II-255) e del Suo detto: "E chi è dunque Colui che bada ad ogni anima in base a ciò che essa ha guadagnato?" (Cor. XIII-33); tutto ciò che è altro che il Vero è anima, essenza, entità, realtà essenziale e persino ciò che [274] essa ha guadagnato, ma solo l'anima guadagna.

Chi non ha scienza della Via si immagina che quando Allah fa andar via $\left({ }^{870}\right)$ quel desiderio dal cuore di colui che è sincero nel lasciarlo a causa di Allah, si tratti di un elogio e una lode ed una sollecitudine nei confronti di questo [servitore] sincero: no, per Allah, quella è la rovina evidente ed è soltanto il frutto della sincerità nel rinunciare.

868) Nella Risāla di al-Qušayrī, a pag. 16 dell'edizione di Muștafā al-Bābī al-Ḥalabī, il Cairo, 1959, questa frase è attribuita ad Abū Sulaymān ad-Dārānī, che però intendeva dire che Allah toglie quel desiderio dal cuore, tant'è che prosegue dicendo: "poiché Allah, sia Egli esaltato, è troppo nobile per tormentare il cuore con un desiderio che esso ha abbandonato a causa Sua". L'espressione dahaba Allah bi-hā può significare sia che Allah la fa andare via, sia che Allah se ne va con essa. Nel Cap. 279 [II 608.7] commentando il versetto 17 della Sūra II, ove ricorre dahaba Allah bi, Ibn 'Arabī spiega che ciò significa che Allah fa andare via (azāla).

869) Riferimento al versetto: “Ovunque vi volgiate là c'è il volto di Allah" (Cor. II-115).

870) In questo caso ho tradotto dahaba Allah bi con "Allah fa andar via", perché l'altro senso sarebbe incompatibile con la lode attribuita a questo atto dall'ignorante. 
Talvolta la veridicità $(s i d q)$ è lodata e talvolta è biasimata, poiché il miscredente è veridico nella sua fede nel falso e nella sua miscredenza in Allah, ed Allah Se ne va con la luce della fede in Allah dal suo cuore, così come Se ne va con la fede nel falso dal cuore del musulmano, e la fede nel falso in quanto falso $\left({ }^{871}\right)$ è una verità autentica.

Per questo Allah, sia Egli esaltato, ha detto: "che coloro che dicono il vero saranno interrogati riguardo alla loro veridicità" (Cor. XXXIII-8) su cosa è connesso ad essa. La fede è il credere $(\operatorname{tas} d \bar{\imath} q)\left({ }^{872}\right) \mathrm{e}$ talvolta ciò che è connesso con essa è il credere nel falso, e quindi [il miscredente] è veridico nella fede nel falso, e ciò corrisponde al Suo detto: "e coloro che hanno fede nel falso e che non credono in Allah" (Cor. II-52) e talvolta ciò che è connesso con essa è la fede, che è il credere in Allah, ed essa è la veridicità, poiché Allah ha detto: "e colui che non crede nell'idolo prevaricatore ed ha fede in Allah" (Cor. II-256) ed ha usato per entrambe le persone il termine fede $\left({ }^{873}\right)$. Per questo il veridico sarà interrogato riguardo alla sua veridicità, in cosa è veridico, e se è veridico nel rinunciare ad un desiderio o una cosa a causa di Allah, il volto di Allah che è custode di quella cosa dirà: "Non sapevi che quando tu rinunci ad una cosa con cui Io non smetto di stare, invero rinunci a Me con la tua rinuncia ad essa?” E quale ignoranza e rimprovero è più grande di questo?

871) Nel Cap. 580 [IV 325.15] Ibn 'Arabī precisa: "[...] e coloro che credono nel falso: il Vero li ha definiti credenti ma è fuori di dubbio che nella loro fede nel falso essi non credono nel falso in quanto è falso, bensì credono in esso in quanto sono convinti della sua verità così come è convinta del Vero la Gente del Vero, ed è per questo che viene attribuita loro la fede".

872) Tasdīq è l'infinito della seconda forma del verbo șadaqa, dire il vero, e significa ritenere o affermare che qualcuno dice il vero o che una affermazione è vera.

873) Nel Cap. 366 [III 328.19] Ibn 'Arabī precisa: "Il Vero ha distinto (qayyada) un credente dall'altro, ma ha imposto a Se stesso di far trionfare (nasr) i credenti [cfr. Cor. XXX-47], senza dire in chi, ma esprimendoSi senza restrizioni ed in modo certamente chiaro. Egli ha detto: "O voi che credete, credete" (Cor. IV-136), e "non è dato al credente di uccidere un credente se non per sbaglio" (Cor. IV-91), e "coloro che credono nel falso" (Cor. XXIX-52), chiamandoli tutti credenti (mu'minin). Egli ha anche detto: "..e se Gli venissero attribuiti dei soci, voi credereste" (Cor. XL-12), chiamando colui che associa credente: questi sono i credenti a cui Allah si rivolge nel Suo detto: "O voi che credete, credete in Allah e nel Suo Inviato e nel Libro che è sceso sul Suo Inviato e nel Libro che ha fatto scendere prima" (Cor.IV-136), distinguendoli dai credenti della Gente del Libro e dei Libri. E poiché non ci sono informatori che portino una notificazione (habar) [divina] se non gli Inviati, è così definito che i credenti a cui viene ordinato di credere sono coloro che credono nel falso e che credono nel socio, per delle confusioni $(\check{s} u b a h)$ che li distolgono dalla prova evidente (dalīl $)$. Coloro che credono nel falso non credono in Allah, e quanto a coloro che credono nel socio, i loro cuori si contraggono quando si menziona Allah da solo (cfr. Cor. XXXIX-45). Questa notificazione [inerente al socio] non è stata portata loro che dai loro capi, i quali li hanno preceduti e li hanno indotti in errore. Secondo quanto essi affermano, vale a dire i capi, ciò sarebbe basato su un argomento decisivo (burhān), e non su una ristrettezza (qusürr) [di comprensione]; anzi, essi hanno dato alla speculazione tutto quanto le è dovuto e sono stati fedeli a ciò che ha conferito loro la predisposizione (isti $\left.{ }^{\prime} \bar{a} d\right)$ che Allah ha dato loro ed "Allah non impone ad un'anima se non ciò che le ha dato" (Cor.LXV-7), e non le ha dato se non ciò che essa produce. I loro seguaci credono in quello [che i loro capi hanno apportato] e sono veridici nella loro fede: essi perseguono solo la via della salvezza (nağâ) e non ciò che li farebbe perire". 
Questo Maestro ha detto: "Allah fa andar via" ed il gruppo degli iniziati ha detto: "Allah Se ne va con essa dal suo cuore", e questo Maestro o lo sapeva ed ha mantenuto il velo dell'aspirante [275] che lascia nella veridicità del suo lasciare, poiché chi è veridico in ciò non ha cognizione del volto che ha Allah in quella cosa lasciata, oppure [il Maestro] non lo sapeva, ed è la cosa più probabile, soprattutto perché ha detto: "Allah ha fatto andar via dal suo cuore ciò che è diverso da Lui", in modo assoluto, senza specificare un'entità. Soffermati su quest'allusione e non tralasciare di osservare le cose con l'occhio che esse meritano, sì da dare ad ogni cosa che ha un diritto (haqq) il suo diritto ( $\left.{ }^{874}\right)$ - e non c'è cosa che non abbia un diritto - come Allah lo ha dato ad essa nel Suo detto: "Egli ha dato ad ogni cosa la sua creazione" (Cor. XX-50), e quello è il suo diritto.

Quanto al suo detto: "Egli ti ha scelto e ti ha tenuto occupato con Lui, [distogliendoti] da chi è altro che Lui" dopo questo fare andar via, egli ha fatto riferimento al detto di Allah a Mosè: "Ti ho scelto $\left({ }^{875}\right)$ per Me stesso" (Cor. XX-41), e quella è una elezione di prossimità divina in una faccenda individuale.

Egli [il Vero] ha correlato l'anima di colui che mandava in missione da lui [il Faraone] (man wağğahahu ilay-hi) con Allah, sia Egli esaltato, in quanto lo mandava in missione, e per questo gli ha ordinato di parlare in modo mite nella speranza di una sua risposta al momento dell'avvertimento $\left(\underline{d i k r a \bar{~}}\left({ }^{876}\right)\right.$, perché egli [il Faraone] era velato dalla Potenza divina implicita nel rango in cui si trovava, cioè il Regno (mulk), poiché il Regno appartiene ad Allah, l'Unico, Colui che costringe (al-qahhār) $\left.{ }^{877}\right)$. E quando egli si ricordò di quello tornò verso di Lui, anche se qualche tempo dopo [l'avvertimento], e così l'avvertimento gli fu di giovamento. Egli si ricordò mentre stava annegando ed ebbe paura di perdere l'occasione (fawt) e si affrettò a [fare] ciò che lo avrebbe vincolato alla fede dei figli di Israele $\left.{ }^{878}\right)$, e passò nella fede dal lignaggio degli Egiziani a quello degli Israeliti, per allontanare l'ambiguità

874) Riferimento allo hadīt: "Dai a chiunque ha un diritto il suo diritto" riportato da al-Buhārī, XXX-51, LXXVIII-86, e da at-Tirmidīi, XXXIV-64.

875) L'espressione istana \&u-ka può significare sia "ti ho scelto", sia "ti ho impiegato". Nel Cap. 308 [III 32.9] Ibn 'Arabī precisa: "Una creatura non ha per se stessa nobiltà (šaraf) rispetto ad un'altra se non perché Allah l'ha nobilitata e la dimora più elevata presso Allah è quella in cui Allah preserva incessantemente al Suo servitore la contemplazione della sua servitù, indipendentemente dal fatto che lo rivesta con una delle vesti di onore della Signoria o non lo rivesta. Questa è la più nobile dimora che viene conferita al servitore e corrisponde al Suo detto, sia Egli esaltato: "Ti ho scelto per Me stesso" (Cor. XX-41) [...] Non c'è nobiltà più elevata per un lavoro [( $\left.\operatorname{san}^{\prime} a\right)$ dalla stessa radice di istana $\left.q u\right]$ che la sua attribuzione a colui che l'ha fatto, e per questo una creatura non ha nobiltà se non per il volto specifico che essa ha da parte del Vero".

876) Riferimento ai versetti successivi a quello citato: "Vai, tu e tuo fratello, con i Miei segni, e non stancatevi di menzionare Me* Andate dal Faraone, poiché egli ha trasgredito, * e parlategli in modo mite: forse egli si ricorderà o avrà paura" (Cor. XX-42 a 44).

877) Riferimento a Cor. XL-16.

878) "Quando stette per annegare, [il Faraone] disse: Credo che non c'è Dio se non Colui in cui credono i figli di Israele, e sono uno dei sottomessi”" (Cor. X-90). Tutto questo episodio è commentato ampiamente nella sezione dedicata ad Aronne del capitolo 167 delle Futūhăt, che è senza dubbio il capitolo più tradotto nelle 
e l'equivoco ${ }^{879}$. Per questo Allah gli disse: "Adesso?" (Cor. X-91) e parlò con lui, e gli spettò da Mosè l'eredità del Discorso, poiché Allah, sia Egli esaltato [276] aveva parlato direttamente a Mosè quando lo fece avvicinare a Lui in colloquio intimo $\left({ }^{880}\right)$. Ed Allah, quanto è Potente e Magnificente, disse al Faraone, senza menzionare l’intermediario: "Adesso? E prima avevi disobbedito", e non disse che adesso era disobbediente, "ed eri tra coloro che portano corruzione" (Cor. X-91) nel tempo passato $\left.{ }^{881}\right)$.

Quanto al suo detto: “e ti ha tenuto occupato con Lui [distogliendoti] da chi è altro che Lui” se c'è [altro che Lui]; questo [è il significato] se egli è un conoscitore di come è realmente la faccenda, poiché Allah, sia Egli esaltato, non Si manifesta se non nelle cose $(a \bar{y} y \vec{a})$, e se non ci fosse alcuna cosa non si manifesterebbe per il Vero alcuna entità, quindi sono indispensabili le cose $\left({ }^{882}\right)$.

Per mezzo di noi il Vero Si manifesta, e per mezzo di Lui noi ci manifestiamo ( $\left.{ }^{883}\right)$ :

per questo noi siamo riconoscenti e per questo noi siamo ingrati,

per una divergenza verificata (bi-ihtilāf muhaqqaq). Sappiatelo e riflettete,

e quando contemplate ciò che ho detto stendete un velo.

Certo Allah è geloso! Guardatevi dall'ispirare avversione,

e quando vi viene affidato un incarico rendete le cose facili, non rendetele difficili $\left.{ }^{884}\right)$

lingue occidentali [Asín Palacios, Anawati, Ruspoli, Jevolella, Winkel e Hirtenstein], come pure nel capitolo dedicato a Mosè nei Fusüs al-hikam.

879) Nel Cap. 324 [III 90.16] Ibn 'Arabī spiega che: "se avesse detto: "Credo in Allah", avendo prima affermato che egli non riconosceva per la sua gente altro Dio al di fuori di lui [Faraone], essi avrebbero detto che egli faceva una professione di fede a se stesso e non a Colui che aveva inviato Mosè a loro [...] ed egli ha allontanato l'ambiguità con ciò che ha detto".

880) Riferimento a Cor. XIX-52.

881) Tutto questo brano, da: "per questo gli ha ordinato di parlare in modo mite" in poi, è riportato da Muḥammad az-Zuhrī al-Gamrāwī in calce al commento di al-Qāšānī ai Fusūs al-ḥikam [pag. 258-259 dell'edizione del Cairo del $1321 \mathrm{H}]$ e attribuito alla Ğamāliyya di Ibn 'Arabī.

882) Il termine "cosa", nella sua indeterminazione, non viene usato solo per ciò che è esistente, ma anche per il suo principio immutabile, che è l'entità ('ayn) in quanto possibile (mumkina). Nel Cap. 558 [IV 319.35] Ibn 'Arabī precisa: "ed ha usato il termine šay', che si applica alle entità immutabili (tāabita) ed a quelle esistenti". In questo caso il riferimento è alle entità immutabili.

883) Analogamente nel Cap. 73, questione VII [II 45.24] Ibn 'Arabī recita: "Se non fosse per Lui noi non saremmo * se non fosse per noi Lui non sarebbe" e nel Cap. 380 [III 503.12] aggiunge: "Egli per noi dà esistenza ad un'entità e noi per Lui diamo esistenza ad un Signore. Se non ci fosse il Vero non ci sarebbe l'esistenza * e se non ci fosse l'essere generato non ci sarebbe Dio".

884) Anche questi versi e parte del brano precedente sono riportati in calce al commento di al-Qāšānī ai Fusūs al-hikam [pag. 25 dell'edizione del Cairo del $1321 \mathrm{H}$ ] e attribuiti alla Ğamāliyya di Ibn 'Arabī. L'ultimo verso riprende un Hadīt riportato da al-Buhārī, LVI-164, LXIV-60, LXXVIII-80, XCIII-22, Muslim, XXXII-71, Abū Dāwud, XL-17, e da Ibn Hanbal, III-131 e 209, IV-399, 412 e 417. I versi del manoscritto sono riportati anche nel Dì̌ān al-ma âriff, manoscritto Parigi BN 2348, f. 140a, linee 14-16. 
Dopo la sua raccomandazione di ringraziare Allah per questo favore - cioè il tenerlo occupato con Allah lungi da ciò che è altro che Lui - per mezzo del quale [favore] non sussiste nulla delle cose create, egli ha detto: "poiché le cose create hanno una fine, mentre questo favore non ha fine", intendendo dire che esso è continuo, ed ha attribuito la fine solo alle cose create, in quanto tutto ciò che entra nell'esistenza, delle cose create, giunge alla fine, poiché non è possibile che entri nell'esistenza ciò che è senza fine $\left.{ }^{885}\right)$. Se egli non voleva dire ciò che abbiamo menzionato allora non aveva cognizione di come stanno realmente le cose, o per dimenticanza o per ignoranza, e ciò che è corretto dire è che sia per dimenticanza [277] poiché dalla sua anima l'uomo sa [già] tutte le cose che apprende, e delle quali si dice che prima di apprenderle egli non aveva scienza, in quanto originariamente l'anima non è né torbida, né arrugginita, e gli oggetti della scienza sono incisi in essa come le forme nello specchio levigato $\left.{ }^{886}\right)$, anche se lo specchio non ne è consapevole. Colui che guarda in esso non percepisce se non una parte di ciò che vi è inciso o impresso, e per questo è descritto come uno che accresce in scienza, in quanto non è nella facoltà dell'osservatore svelare tutto ciò che ha ricevuto lo specchio della sua anima. Quindi la cosa è impressa in lui ed egli non la conosce se non in occasione del suo sguardo in essa [anima] e non si manifesta in essa se non ciò che è corretto che egli sappia, non altro $\left({ }^{887}\right)$.

Quanto alla frase di chi dice che se l'anima è pura si incidono in essa le forme del Malaküt $\left({ }^{888}\right)$, si tratta di un discorso non preciso $\left.{ }^{889}\right)$, poiché ha detto: "se è pura", ma essa non ha mai cessato di essere pura; e se precisasse dicendo: "se osservi lo specchio della tua anima, vedi ciò che è impresso in essa delle forme del Malaküt che si manifestano", sarebbe il massimo della precisione.

885) L'affermazione che "tutto ciò che entra nell'esistenza è finito" è riportata in una dozzina di capitoli delle Futūhăt: 59 [I 292.19], 178 [II 353.29], 198 [II 399.35], 250 [II 551.27], 251 [II 552.19], 337 [III 143.7], 369 [III 361.13 e 363.22], 371 [III 419.15], 375 [III 472.24], 404 [IV 6.15], 524 [IV 167.4] e 558 [IV 320.1]. Nel Cap. 404 Ibn 'Arabī precisa: "Il Vero è identico alla Sua esistenza. Non si può dire di Lui che entri nell'esistenza poiché allora sarebbe finito, in quanto tutto ciò che entra nell'esistenza è finito. Il Produttore ( $\operatorname{bar} \bar{\imath})$ è l'esistenza stessa. Egli non entra nell'esistenza: l'esistenza è la Sua quiddità (mähiyya). D'altra parte, tutto ciò che è altro che il Vero, o entra nell'esistenza ed è finito per questo stesso fatto, oppure non vi entra e non può essere descritto come finito. Realizza ciò, poiché non lo troverai menzionato altrove".

886) È evidente l'analogia con la dottrina della reminiscenza di Platone, che qui è esposta in modo più chiaro che nelle Futūhăt, ove nei capitoli 190 [II 383.1 1], 268 [II 569.28], 344 [III 176.29], e 365 [III 322.24] l'incisione delle forme del Mondo superiore nell'anima è il frutto non pre-esistente della sua levigatura.

887) Nel Cap. 365 [III 322.29] è affermato: "Non è menzionato nessun Profeta e nessun sapiente che avesse scienza di tutto ciò che il suo stato comprendeva in ogni respiro da lui compiuto sino al momento della propria morte, ma ognuno di loro avrà avuto scienza di una parte di ciò, e ne avrà ignorato una parte".

888) Per Ibn ‘Arabì il Malakūt è la Sfera dell’Intelletto Primo, mentre il Ğabarūt è la Sfera dell'Anima Universale. Per Abū Ṭālib al-Makkī questi due termini sono invertiti.

889) La frase in questione è citata in un aneddoto riportato nel Cap. 167 [II 279.7], ma in quella sede non viene corretta. 
Quanto al suo detto nella sua preghiera di ringraziamento: "A Lui spetta la lode sulla lode (al-hamd 'ala l-hamd), per ciò per cui spetta la lode, ed a Lui spetta il ringraziamento sul ringraziamento, per ciò per cui spetta il ringraziamento", si tratta di un discorso verificato (muhaqqaq) che si riferisce a ciò che è chiamato la lode della lode (hamd al-hamd) ${ }^{\left({ }^{800}\right.}$ ) e il ringraziamento del ringraziamento, di cui il conoscitore ha detto nel prologo del suo libro: "La lode spetta ad Allah, con una lode che soddisfa se stessa (hamd ${ }^{a n}$ yuwäfì huwa nafsa-hu)" (891). Il pronome huwa è qui riferito alla lode, non ad Allah, e ciò perché il più veridico degli elogi e quello più lontano dal sospetto è la lode della lode. In effetti la lode della lode ha luogo solo se gli attributi lodati sussistono in colui che è lodato, mentre la lode della cosa da parte di se stessa [278] o da parte di altri è una asserzione $(d a \Leftarrow \bar{a})$, ed entrambe richiedono una prova di veridicità, che non è necessaria nella lode della lode; per questo egli ha detto: "per ciò per cui spetta la lode".

Lo stesso vale per il ringraziamento, sennonché egli ha menzionato [separatamente] la lode e il ringraziamento, perché tra esse vi è una differenza: la lode è generale mentre il ringraziamento è specifico. La lode spetta a Colui che è lodato per ciò che Egli è e per ciò che procede da Lui, mentre il ringraziamento spetta a Colui che è ringraziato specificamente per ciò che procede da Lui, e per questo il ringraziamento esige l'accrescimento di ciò per cui viene ringraziato ${ }^{892}$, mentre la lode non esige l'accrescimento di ciò per cui viene lodato, a meno che non venga interpretata come

890) Questa espressione ricorre nei seguenti capitoli delle Futūhät: Prologo [I 4.7 e 9.16], 73, q. LXXVI [II 88.5], q. XCIX [II 100.20], 198 [II 403.14], 272 [II 578.32], 415 [IV 20.15], 453 [IV 68.15], 558 [IV 287.9] e 559 [IV 441.11]. Nel Cap. 2 [I 64.8] Ibn 'Arabī precisa che come "non conosce il Vero se non la Scienza [e non il sapiente], così non Lo loda se non la lode [e non colui che loda]" e nel Cap. 198 [II 403.14] aggiunge: "La lode è un elogio generale che colui che la proferisce non vincola a qualcosa. Essa ha tre gradi: la lode della lode, la lode da parte di colui che è lodato e la lode [di qualcuno] da parte di un altro, non c'è un quarto grado nella lode. Per quanto riguarda la lode con cui la cosa loda se stessa o la loda un altro vi sono due suddivisioni: o la loda con un aggettivo verbale o la loda con un aggettivo di trascendenza; qui non c'è una terza lode. Quanto alla lode della lode a Lui, Egli è in entrambe le lodi con la Sua Essenza, poiché se non ci fosse non sarebbe possibile per Essa la lode.

La lode della lode è ciò che conferisce la lode riguardo a Lui, e se non ci fosse la lode non ci sarebbe il Lodevole (hamīd)

Quanto alla lode per chi è lodato vi sono due suddivisioni: la prima è che sia lodato per ciò che è e questa è la lode più generale; la seconda è che sia lodato per ciò che viene da lui, e questa è la gratitudine, che è la lode più specifica [...] Non c'è chi loda se non Allah, e non c'è lodato se non Allah, e la lode della lode è il Suo Attributo, ed il Suo Attributo è Lui stesso, poiché Egli non Si moltiplica e non è completato dall'aggiunta [di qualcosa], sia Allah esaltato. Quindi la lode della lode è Lui e non è altro che Lui.

Non loda Allah se non Dio * e Colui che è lodato è Lui stesso, nessun'altro".

891) Questa frase non è riportata nelle Futūhāt, ma ricorre nel suo Kitāb kašf al-ma'ñ̄ 'an sirr asmä’i-Llähi-l-husnā, ove è attribuita a Ibn Barrağān [pag. 217 della traduzione di Pablo Beneito, El secreto de los nombres de Dios, Editora Regional de Murcia, 1996]. Il libro in questione è il suo commento al Corano intitolato Kitāb $\bar{\imath} d \bar{a} h$ alhikmah bi-ahkām al-\{bra, che inizia appunto con questa frase, in cui però dopo yuwāfì è inserito hamda-hu [pag. 69 dell'edizione araba curata da Gerhard Böwering e Yousef Casewit, A Qur'an commentary by Ibn Barrağan of Seville, Brill, 2016].

892) "E quando il vostro Signore ha annunciato: Se ringrazierete Noi vi accresceremo" (Cor. XIV-7). 
ringraziamento, nel qual caso [il servitore] richiede l'aumento di ciò per cui Lo loda. Ciò corrisponde a quanto Egli ha detto, ordinando al Suo Profeta, su di lui la Pace, nel Suo detto: "Dì: mio Signore, accrescimi in scienza" (Cor. XX-114) cioè [scienza] di Te, affinché Ti possa lodare con ciò che Tu mi hai insegnato dei Tuoi elogi, non con l'insieme dei Tuoi elogi, poiché non c'è somma per essi, in quanto la faccenda in se stessa non ha fine.

Quanto al suo detto: "avendo cura di chiedere perdono per i peccati”, sappi che il [termine] chiedere perdono (istigfâr r) deriva dal gafr, che è il coprire (sitr) $\left({ }^{893}\right)$; quando il conoscitore parla del chiedere perdono per i peccati egli chiede ad Allah solo l'impeccabilità, sì che Egli lo protegga da che i peccati sussistano in lui, non intende la copertura dalla punizione per il peccato. Ed il sapiente dice [279]: "Perdona a noi i nostri peccati" (Cor. III-147), cioè coprili per noi affinché non ci vedano e non si attacchino a noi e sussistano in noi facendoci diventare peccatori. E la gente comune parla della remissione (gufrān) del peccato volendo che Allah la copra dalla punizione del peccato, che è la retribuzione, chiedendo ad Allah di non tenere conto di quello e di non ricambiarli con la punizione e la retribuzione che i peccati esigono ${ }^{\left({ }^{894}\right)}$.

E chi sa che la retribuzione del peccato può essere ciò che fa piacere, come l'indulgenza ('afw), e ciò che fa male, come la vendetta (intiqām), ed entrambi sono la retribuzione del peccato, [per lui] nessuno dei due è preferibile all'altro nella retribuzione, a meno che uno dei due si rafforzi per un'altra faccenda, come "la Misericordia precede la Collera" $\left({ }^{895}\right)$ e quindi la retribuzione dell'indulgenza prevalga sulla vendetta. Comprendi.

Il primo aspetto è quello che ha apportato il testo del Corano, ad esempio nel Suo detto, sia Egli esaltato: "O nostro Signore, perdona a noi i nostri peccati” (Cor. III-147), cioè coprici da essi affinché non ci colgano e noi non pecchiamo, e questa formula è la preferibile per la richiesta di perdono.

893) La stessa affermazione si trova nei capitoli 72 [I 745.12 e 755.27], 73 [II 30.24 e 138.22], 349 [III 209.30], 473 [IV 107.10] e 558 [IV 214.8 e 257.24].

894) Nel Cap. 247 [II 547.9] Ibn 'Arabī precisa: "Per noi, nella Via di Allah, la richiesta di perdono ha luogo in due situazioni: la prima situazione è quella che abbiamo menzionato, cioè quella in cui il servitore ha manifestato qualcosa che è necessario che venga coperto, ed è quindi obbligatorio per lui chiedere perdono. Talvolta la richiesta di perdono ha luogo da parte di qualcuno che non ha fatto nulla che la richieda, e chi è in questa situazione chiede il perdono, cioè chiede che Allah lo copra al riparo della Sua Sollecitudine dall'essere governato da uno stato per il quale, se Allah non lo coprisse al riparo della Sua Sollecitudine, egli manifesterebbe qualcosa che è necessario che venga coperto: questa è la seconda situazione in cui si possono trovare coloro che chiedono perdono. Essi cominciano a chiedere la copertura da parte di Allah nei confronti del regime di uno stato che imporrebbe loro di chiedere scusa per il suo accadimento, e questa è la richiesta di perdono dei più grandi tra gli Uomini che sono impeccabili”".

895) Riferimento ad uno hadīt riportato da al-Buhārī, LIX-1, XCVII-15, 22, 28, 55, Muslim, XLIX-14 a 16, at-Tirmidīi, XLV-99, Ibn Māğah, XXXVII-35, e da Ibn Ḥanbal, II-243, 258, ecc. 
Poi ti ha ordinato di stare basso $(\underline{d} a \bar{l} \bar{l})$ di fronte a questo favore, ed ha detto: "in quanto l'elevatezza (' $i z z a)$ ${ }^{\left({ }^{966}\right)}$ non si ottiene se non con l'abbassamento" intendendo basso per mezzo dell'atto di adorazione del ringraziamento per esso [quel favore], in quanto l'atto di adorazione è l'abbassamento, e l'atto di adorazione è un favore e l'abbassamento è un favore, ed esso è la tua realtà essenziale, poiché tu sei originalmente basso per l'elevatezza di Allah, e quando Allah ti dà elevatezza te la dà solo presso i tuoi simili, non presso di Lui, e quindi non cessi di essere basso presso di Lui ed elevato presso gli altri. Quindi tu riunisci l'abbassamento e l'elevatezza, e ti resta da stabilire qual'è il tuo modo di essere, cioè se prevale su di te la contemplazione diretta dell'elevatezza e quindi prevale su di te l'elevatezza per Allah, oppure se prevale su di te la contemplazione diretta del Vero e quindi prevale su di te l'abbassamento sotto all'inaccessibilità di Allah. Tu sei conformemente alla tua esistenza (anta bi-ḥasabi wuğūdi-ka) ${ }^{\left({ }^{897}\right)}$.

Oppure non sei [280] né elevato né basso, se la tua contemplazione è che Egli è la tua entità e l'entità di ogni contemplazione, poiché Egli è un'Esistenza priva dell'elevatezza e dell'abbassamento, non essendoci un termine di paragone, e questo è il significato del Suo detto: "ed Allah è indipendente dai Mondi” (Cor. III-97), e la parte che spetta al servitore di questo versetto nella realizzazione di esso è di stare in questa stazione spirituale ${ }^{(898)}$.

Ciò corrisponde alla frase di Abū Yazīd ed alla sua stazione spirituale, quando gli venne detto: "Come stai stamane?” ed egli rispose: "Per me non c’è né mattina né sera. La mattina e la sera sono solo per chi è vincolato dall'attributo, ed io non ho attributi” $\left.{ }^{899}\right)$, negando a se stesso gli attributi.

896) Il termine 'izza ha molteplici significati, tra cui potenza, forza, elevatezza, inaccessibilità, invincibilità, insuperabilità, esaltazione, auto-esaltazione e rarità. In questo caso ho usato "elevatezza", ma anche "potenza" sarebbe stato confacente.

897) Wuğüd non significa solo esistenza, ma anche trovare, e ciò che esiste è solo ciò che l'uomo trova in ogni istante presente, poiché il passato ed il futuro sono non-esistenti.

898) L'elevatezza e l'abbassamento sono degli attributi e la stazione a cui si riferisce Ibn 'Arabī è quella che comporta la spogliazione dagli attributi. Nel Cap. 2 [I 83.33] egli afferma: "Quindi la sfera delle conoscenze conferisce il tratto di carattere (huluq), gli stati spirituali ed i carismi; la sfera delle opere conferisce le realtà essenziali, le stazioni spirituali e le stazioni delle condiscendenze; e la sfera della contemplazione conferisce l'esenzione (barā’a) da tutto questo. Venne chiesto ad Abü Yazìd: "Come stai stamattina?", ed egli rispose: "Non c'è mattina per me, né sera: invero la mattina e la sera riguardano colui che è vincolato dall'attributo, ed io non ho attributi che mi appartengano". Questa è la stazione dei luoghi elevati (al-a râaf)"; nel Cap. 25 [I 187.19] precisa: "Gli uomini dei luoghi elevati (al-a răff) sono gli uomini del limite (hadd). Allah, sia Egli esaltato, ha detto: "Nei luoghi elevati ci sono degli uomini" (Cor. VII-46) la gente del fiuto (samm), del discernimento (tamyiz) e della liberazione (sarăh) dagli attributi, ed essi non hanno attributi ed Abū Yazīd era uno di loro"; e nel Cap. 34 [I 215.10] aggiunge: "La stazione di questa persona è all'interno dei luoghi elevati (al-a $r \bar{a} f)$ [...] ed i luoghi elevati hanno degli uomini, che sono coloro che non sono vincolati da attributi, come Abū Yazīd ed altri".

899) Questa frase è riportata e commentata nei capitoli: 2 [I 83.35], 73, questione XLVII [II 73.30] e questione CLIII [II 133.20], 105 [II 187.11], 289 [II 646.29], 388 [III 539.23], 427 [IV 40.6] e 467 [IV 97.15]. 
Non c'è dubbio che l'indipendenza è un attributo di trascendenza e l'essere vincolato dalla mattina e dalla sera non ha luogo se non per il Nome "il Tempo (dahr)" ( $\left.{ }^{900}\right)$ ed Abū Yazīd ha attestato di non aver parte nel Nome "il Tempo", ma è inevitabile per il realizzato di avere una partecipazione $\left(\right.$ nasīb) in ogni Nome divino, come è realmente $\left({ }^{901}\right)$; chiunque parla per l'ebbrezza (sukr) dello stato non oltrepassa il suo stato, e chiunque parla per sobrietà (sahw) mette le sentenze (hikam) al loro posto. Non vedi che egli [Abū Yazīd], Allah sia soddisfatto di lui, si era sottratto alla limitazione della forma della sua costituzione $(\operatorname{tark} \bar{b})$ ) [fisica] vincolata dalla mattina e dalla sera e così gli è sfuggito della contemplazione di se stesso ciò che è richiesto da questo vincolo, e gli è mancata la contemplazione del Vero nel Nome "il Tempo"?

Per chi ha questa stazione spirituale si teme che in un momento parli male del Tempo, mentre Allah ha vietato di parlarne male, in quanto Egli, sia esaltato, è l'entità del Tempo $\left.{ }^{902}\right)$, ed è l'entità della mattina e della sera, come è l'entità di ogni cosa, il Signore di ogni cosa ed il suo Sovrano (malīk).

Poi ti ha ordinato che il tuo ringraziamento sia "nella misura di ciò con cui Allah ti ha favorito": queste sono le parole di un conoscitore o di uno che si conforma, poiché il ringraziamento nella misura del favore può esistere [281] ed è il riscontro (muqābala) di una cosa creata con una cosa creata, ed egli ha escluso quello, e [d'altra parte] non ha detto "nella misura di Colui che accorda il favore", poiché ciò non è possibile, anche se tu Lo ringraziassi per mezzo di Lui, in quanto se Egli ringraziasse Se stesso per mezzo di te, essendo in Se stesso la Ipseità (huwiyya) della tua lingua nel ringraziarLo, non potrebbe bastare a ringraziare Colui che accorda il favore o [bastare] alla Sua misura in Se stesso, in quanto il Suo ringraziamento di Se stesso è svincolato da te, poiché quel ringraziamento è più elevato. Non ho detto più completo, poiché il completamento del ringraziamento e la sua perfezione è che venga da parte di chi ringrazia nelle due stazioni e nelle due forme, la prima forma per il suo essere vincolato da te, e la seconda per il suo essere svincolato da te nel tempo stesso del suo essere vincolato da te. Per questo ti ha affermato quando ti ha escluso, dicendo: "Non sei tu che hai gettato quando hai gettato" e "Non sei tu che li hai uccisi, ma è Allah che li ha uccisi" (Cor. VIII-17).

Poi ha detto: "Sappi che quando Egli ti concede la veste d'onore dell'amore, del desiderio ardente $($ śawq), della soddisfazione e dell'accettazione, devi stare nella stazione del ringraziamento a Lui per quello”, parlando del ringraziamento degli amanti, ed egli ['aspirante] accresce nel suo amore di Lui

900) Il termine $d a h r$, che è usato sia per indicare il tempo in senso illimitato o riferito a lunghi periodi, sia per sottolineare il suo aspetto "divoratore", ricorre due volte nel Corano: "Essi dicono: Non c’è che la nostra vita di quaggiù, moriamo e viviamo e non ci fa perire se non il Tempo" (XLV-24) e "Non è forse capitato all'uomo un periodo del tempo in cui non era una cosa menzionata?" (LXXVI-1). Inoltre dahr ricorre in una ventina di hadît, tra cui quello più frequentemente citato da Ibn 'Arabī è: "Non parlate male del tempo poiché Allah è il Tempo", riportato da al Buhārī, LXXVIII-101, Muslim, XL-4 e 5, e da Ibn Ḥanbal, V-299 e 311.

901) La stazione di Abū Yazīd era una stazione di trascendenza e incomparabilità, chiamata anche la "nonstazione (lā maqūm) [cfr. Cap. 289 (II 646.28)], ma ad essa mancava l'aspetto della comparabilità (tašbīh), che pure deve essere realizzato affinché l'universalizzazione dell’Uomo sia completa.

902) L'espressione 'ayn ad-dahr potrebbe anche essere tradotta come "identico al Tempo". 
$\vdots$

per il suo ringraziamento per quello, poiché Egli ha garantito per il ringraziamento l'accrescimento di ciò per cui viene ringraziato, ed [il Maestro] ha detto $\left({ }^{903}\right)$ :

Le vesti d'onore del desiderio ardente, della soddisfazione e della accettazione:

ad esse non c'è accesso con lo sforzo (ta'ammul) ( $\left.{ }^{904}\right)$.

Su di Lui si fonda la dimostrazione del mio essere

nella mia visione diretta, nel mio argomento e nella mia prova.

Apprendi il Vero da un Sapiente Saggio,

che non ha nulla a che fare con la gente del "ha detto" e del "si dice".

Egli è il Vero stesso, null'altro che Lui; seguiLo dunque:

sarai al riparo di un'ombra!

Certo il servitore del Potente non è altro

che chi è in se stesso umile per bassezza.

Non vedi che il Vero Si è descritto come Colui che ringrazia molto $(\check{s} a k \bar{u} r)\left({ }^{905}\right)$ il Suo servitore che

903) I versi che seguono non sono di 'Alī al-Kurdī, ma di Ibn 'Arabī stesso, poiché si trovano nel suo Dìwān al-ma ārif, manoscritto Parigi BN 2348, f. 140a, linee 18-21, opera che raccoglie solo le poesie da lui stesso redatte [gentile comunicazione di Julian Cook]. "Ha detto" non va quindi inteso come se si trattasse delle parole di 'Alī al-Kurdī, ma come la traduzione in versi da parte di Ibn 'Arabī di quanto egli ha detto nella sua raccomandazione.

904) Per Ibn 'Arabī gli stati spirituali non sono il frutto di uno sforzo, mentre le stazioni spirituali implicano uno sforzo assiduo di acquisizione, ma il frutto dello sforzo è l'arrivo alla stazione, non ciò che viene elargito dal Vero in essa. Nel Cap. 73, questione II [II 41.17], egli precisa: "L'avvicinamento (taqrīb) al Vero si realizza in due modi: un modo di elezione (ihtisāas), senza sforzo (ta 'ammul), come è il caso di colui che si leverà alla fine dei tempi [cioè il Mahdī] e dei suoi simili; ed un altro modo che comporta lo sforzo, come nel caso del Hidr e dei suoi simili. La stazione è unica, ma è il suo ottenimento ad essere [diversificato] come abbiamo menzionato, ed è in questo modo [cioè per l'elezione] che l'Inviato si distingue dal Profeta [non legiferante]. [...] La stazione in quanto tale rientra nel dominio dell'acquisizione $(k a s b)$, per quanto talvolta possa essere ottenuta per elezione: per questo si dice della Missione che essa è una elezione e ciò è corretto, poiché il servitore non acquisisce ciò che proviene dal Vero, Gloria a Lui. Al servitore compete lo sforzo per arrivare, ma non c'è sforzo per ciò che gli viene da parte del Vero al momento dell'arrivo (wusūll): è da là che trae origine "la scienza [ricevuta] da presso di Me" ('ilm ladunnî) riguardo alla quale Allah ha detto, riferendoSi al Suo servitore Hidr: "gli abbiamo accordato una Misericordia da parte Nostra e gli abbiamo insegnato da parte Nostra una scienza" (Cor. XVIII-65)".

905) Questo Nome ricorre in Cor. XXXV-30 e 34, XLII-23, LXIV-17; ho preferito tradurre šukr con ringraziamento piuttosto che con gratitudine, perché quest'ultimo termine può indicare un'attitudine interiore che resta tale, mentre il ringraziamento traduce quest'attitudine in un atto. Nel Cap. 120 [II 202.15] Ibn 'Arabī precisa: "Sappi, che Allah ti assista, che il ringraziamento consiste nel lodare Allah per ciò che deriva da Lui in modo specifico, per un Attributo che Egli possiede e per il quale merita di essere ringraziato. Tra i Suoi Nomi vi è "Colui che ringrazia" (šakir) e "Colui che ringrazia molto " (šakür), ed Egli ha detto: "Se voi sarete riconoscenti, Noi vi daremo di più [o: vi faremo accrescere]" (Cor. XIV-7). Quindi questo è un Attributo che comporta l'accrescimento di colui che ringrazia da parte di Colui che viene ringraziato. Ed esso è considerato necessario all'unanimità, razionalmente per certuni e secondo la Legge per altri. Ringraziare colui che ha accordato un 
obbedisce, che sa e che opera [282], sottolineando che Egli lo accresce nell'obbedienza e nell'opera, in quanto il ringraziamento esige l'accrescimento di ciò per cui si ringrazia, e come tu Lo ringrazi affinché Egli aumenti i Suoi favori a te, e la tua opera fa parte dei Suoi favori, così Egli ti ringrazia affinché tu Gli dia di più nell'opera per Lui in occasione della incombenza legale, ed Egli ti favorisce con ciò che Egli crea in te del favore dell'opera per il tuo ringraziamento a Lui. Quindi tu agisci ed Egli ti ringrazia per darti di più nell'opera: "Operate, o famiglia di Davide, ringraziando" (Cor. XXXIV-13), $\left.{ }^{906}\right)$ ed Allah ama coloro che ringraziano, poiché Egli non vuole smettere di essere Creatore, ed ogni volta che tu Lo ringrazi Egli ti accresce in favore, cioè per mezzo del tuo ringraziamento Gli fai creare per te dei favori ed Egli te li fa arrivare, poi Egli ti ringrazia per quello affinché si moltiplichi la tua richiesta a Lui riguardo all'aumento dei favori dell'opera in occasione della incombenza legale; ed Egli non ti ama se non per Se stesso, anche se malgrado ciò Egli mantiene [l'affermazione] che ti ama per te; la prima [affermazione] è la scienza autentica ad esigerla, la seconda è l'adab: "Noi lo abbiamo fatto capire a Salomone e ad ognuno [dei due] abbiamo dato un giudizio e una scienza" (Cor. XXI79) ed ogni giurisprudente è nel giusto $\left.{ }^{907}\right)$.

favore è obbligatorio sia razionalmente che per Legge. Allah non Si è definito Colui che ci ringrazia se non affinché noi Gli diamo di più nell'opera che Lo ha portato a ringraziarci, per accrescerLo con essa come Egli ci accresce con un favore quando Lo ringraziamo per i Suoi favori ed i Suoi benefici. Il ringraziamento non è possibile che per i favori. Approfondisci l'attribuzione del ringraziamento a Lui, sia Egli esaltato, con la forma del superlativo $(\check{s} a k \bar{u} r)$, nei confronti di chi Gli conferisce ciò che è obbligatorio dell'opera per tutte le sue membra e le sue facoltà interne ed esterne, in ogni stato con ciò che è corretto ed in ogni momento con ciò che è corretto. Il Vero lo ringrazia per tutto questo con il Nome "Colui che ringrazia molto" e ciò riguarda l'élite della gente di Allah. Quanto alla generalità essi sono al di sotto di questa categoria nelle opere dello stato e del momento [e non di ogni stato e di ogni momento], e quando compiono l'opera secondo questa definizione di difetto li accoglie il Nome "Colui che ringrazia", non "Colui che ringrazia molto". Essi vengono comunque ringraziati, ma Allah, sia Egli esaltato, ha detto: "e pochi dei Miei servitori ringraziano molto" (Cor. XXXIV-13). Questi sono l'élite di Allah, coloro che vedono tutto ciò che viene da Allah, nei loro confronti e nei confronti dei Suoi servitori, come un favore divino, sia che ciò faccia loro piacere, sia che faccia loro male. Essi ringraziano in ogni condizione e questa categoria è esigua per l'esistenza e per la notificazione di Allah a noi della loro esiguità".

906) Nel capitolo 17 dei Fusūs al-hikam, a pag. 165, Ibn 'Arabī afferma: "Sappi che poiché la Profezia, cioè la Profezia legiferante, e la Missione sono un'elezione divina e non possono in alcun modo essere acquisite, i doni che Egli, sia esaltato, accorda loro, su di loro la Pace, sono delle elargizioni, non una ricompensa e non è richiesta a loro una ricompensa per essi [...] Ed Egli ha detto riguardo a Davide: "Noi abbiamo dato a Davide da parte Nostra una grazia" (Cor. XXXIV-10) senza collegare ad essa una ricompensa che Egli esigeva da lui e senza informare che Egli gli accordava ciò che ha menzionato come una ricompensa. E quando Egli chiese il ringraziamento per questa grazia con l'opera, lo chiese alla famiglia di Davide, senza arrivare a menzionare direttamente Davide, affinché fosse la famiglia a ringraziarLo per il favore accordato a Davide. Questo [favore] a Davide era un elargire un favore ed una grazia, mentre per la sua famiglia era diverso, per via della richiesta della compensazione [dei benefici ricevuti tramite la grazia accordata a Davide], ed Egli, sia esaltato, disse: "Operate, o famiglia di Davide, ringraziando" (Cor. XXXIV-13)".

907) Il versetto si riferisce ad una divergenza di giudizio su una questione da parte di Salomone e Davide, in cui il padre accettò il giudizio del figlio. Nel capitolo 16 dei Fusūs al-hikam, a pag. 161, Ibn 'Arabī precisa: "Quanto alla sua [di Salomone] scienza, Egli ha detto: "Noi lo abbiamo fatto capire a Salomone" malgrado il giudizio contrario [formulato da suo padre] e ad ognuno" Allah ha dato "un giudizio ed una scienza" (Cor. 
Poi ha detto: "Sappi, caro mio, che quando sei adornato da queste vesti d'onore, che ti sono giunte per mano del tuo Maestro, devi conoscere il valore di queste ed il valore di ciò che Allah ha incaricato il tuo Maestro di fare".

Venne riferito ad 'Abd al-Qādir al-Ǧīlī (908), Maestro dei Maestri a Bagdād, il quale esercitava esteriormente il controllo per mezzo del potere di governare (tahakkum), che Muhammad ibn Qāàid al-Awānī $\left({ }^{909}\right)$ - che era il turbolento nella Presenza (múarbid al-hadra) $\left({ }^{910}\right)$ per la sua ebbrezza $(s u k r)$ aveva detto: "Ho percorso la mia via verso il Vero e non ho visto in essa piede (qadam) di altri, se non un piede che mi precedeva, e fui geloso. Mi venne detto: "Esso è il piede del tuo Profeta" e la mia agitazione si quietò ${ }^{911}$ ). Quando fui vicino venne collocato per me uno scanno (minassa) e mi sedetti su di esso e mi vennero presentate le vesti d'onore (hila ) divine [283] e mi vennero concesse". 'Abd alQādir disse: "Oh povero Ibn Qā’id, ero presente a quella seduta (mağlis), ed è da me che è emerso per lui il favore (nawāla)", cioè quelle vesti d'onore. Gli venne chiesto: "Dov'eri in quel momento, poiché

XXI-79). La scienza di Davide era una scienza ricevuta, che Allah gli aveva conferito, mentre la scienza di Salomone era la scienza di Allah riguardo alla questione, poiché era Lui il Giudice, senza intermediario, e Salomone fu l'interprete del Vero su un seggio di verità. Analogamente il giurisprudente che coglie il giudizio che Allah avrebbe formulato sulla questione se se ne fosse fatto carico direttamente, o [indirettamente] tramite ciò che ha rivelato al Suo Inviato, ha due ricompense, mentre colui che sbaglia in questo giudizio ha una [sola] ricompensa, malgrado [il suo giudizio] comporti una scienza ed un giudizio".

908) 'Abd al-Qādir al-Ǧìlī, nato a Ǧīl nell'anno 470 dall'Egira e morto a Bagdād nel 561, è uno dei Sūfĩ più celebri. Su di lui si può consultare l'opera di Mehmmed Ali Aïnî "Un grand saint de l'Islam: Abd-al-Kadir Guilān $\vec{\imath}$ ", Parigi, Geuthner, 1938, e la biografia di at-Tādifi, tradotta da Muhtar Holland con il titolo "Necklaces of Gems", Al-Baz Publishing, 1998. Ibn 'Arabī lo cita una ventina di volte nelle Futūhāt.

909) Le poche notizie biografiche di questo Maestro riportate nei testi agiografici di al-Munāwī, di al-Ǧāmī e di an-Nabhānī sono tutte mediate dalle Futūhăt, ove egli è citato una dozzina di volte.

910) Nel Cap. 73 [II 19.19] Ibn 'Arabī precisa: "Tra essi vi sono i Solitari (afrād), che sono vincolati da un numero [definito], ed essi nel linguaggio della Legge sono gli Approssimati. Faceva parte di loro Muhammad al-Awānī, noto come Ibn Qā̄id, originario di Awāna, nei dintorni di Bagdād. Egli era tra i compagni dell'Imām 'Abd al-Qādir al-Ǧīlì, che diceva che Ibn Qā'id era il turbolento nella Presenza (mu'arbid al-hadra) ed attestò [...] che Muhammad ibn Qā’id al-Awānī faceva parte dei Solitari (mufradūn)".

911) Nel Cap. 73, questione LVIII [II 80.5] Ibn 'Arabī precisa: "Il nostro Maestro Muhammad ibn Qā’id ha detto: "Quando vi entrai vidi l'impronta di un piede davanti a me e fui geloso. Mi venne detto: "Questo è il piede del tuo Profeta" e mi quietai". Sappi che questa predominanza [ciclica] (dawla) muhammadiana include i piedi degli [altri] Profeti ed Inviati, su di loro la Pace, e quando un Intimo vede un piede davanti a sé quello è il piede del Profeta di cui lui è erede. Quanto al piede di Muhammad, che Allah faccia scendere su di lui la Sua salāt e la Pace, non c'è nessuno che cammini sulla sua traccia come non c'è nessuno che sia sul suo cuore. Il piede che vide Muhammad ibn Qāìd, o quello che vide chiunque lo vide, era il piede del Profeta di cui era erede, ma in quanto Muhammadiano, non altro. Per questo gli venne detto: "Il piede del tuo Profeta" e non: "Questo è il piede di Muḥammad, che Allah faccia scendere su di lui la Sua șalāt e la Pace". Se il Maestro [Ibn Qầid] ha compreso da questa frase ciò che abbiamo menzionato allora fa parte della gente dello hadīt e della perfezione, se invece ha inteso che si trattava del piede di Muhammad, che Allah faccia scendere su di lui la Sua salāt e la Pace, allora è un'incrinatura che ha colpito l'occhio della sua comprensione". 
egli non ti ha visto?", ed egli rispose: "Nella camera segreta (muhda $)^{c}$ " $\left.{ }^{912}\right)$. Poi menzionò la forma delle vesti d’onore ed Ibn Qāàid le riconobbe e disse: “Abd al-Qādir ha detto il vero".

Questo è il significato della sua affermazione che le vesti d'onore giungono per mano del Maestro, e ciò che capitò in quella occasione a Ibn Qā'id fu per l'istruzione iniziatica dello Šayh 'Abd al-Qādir, senza che egli se ne accorgesse.

Talvolta l'Intimo si immagina per la sua aspirazione (himma) di essere solo con se stesso e non si accorge di quello, ed il caso di Ibn Qā'id è di questo genere. Il piede che egli vide era il piede di 'Abd al-Qādir, poiché egli era l'Inviato per lui ed il suo Profeta senza che se ne accorgesse, e non lo ha guidato se non la Legge dell'Inviato. Per questo venne detto ad Ibn Qā'id: "Esso è il piede del tuo Profeta", e così si calmò dalla sua turbolenza ('arbada).

Per questo 'Abd al-Qādir disse che era nella camera segreta, come disse Allah riguardo a coloro che cercano di ingannare Allah e coloro che credono: "Essi non ingannano (yahda ūna) se non loro stessi" (Cor. II-9) ${ }^{913}$ ) e la camera segreta non è altro che ciò che gli venne detto riguardo al piede, cioè che era il piede del suo Profeta, e questa attribuzione e notificazione è identica alla camera segreta, poiché quando egli arrivò e ricevette le vesti d'onore non vide la forma del Profeta, su di lui la Pace, in quella Presenza, ma se egli lo avesse preceduto l'avrebbe trovato in essa; egli non vide se non il piede e non vide traccia dell'entità ( $m \bar{a}$ ra ā li-l-'ayni atar) $\left.{ }^{914}\right)$. Così è lo stato dei Maestri: egli non ha visto altra entità che la sua nell'arrivo (wus ūl) $\left.{ }^{915}\right)$ e non ha visto alcun piede se non nella via. In se stessa la

912) Cap. 73, questione CLIII [II 130.15] Ibn 'Arabī precisa: "La camera segreta (muhdă $)$ è la sede in cui il Polo è nascosto ai Solitari che arrivano, quando vengono conferite loro le vesti d'onore. Essa è il magazzino delle vesti d'onore ed il magazziniere è il Polo. Muhammad ibn Qāeid al-Awānī disse: "Sono salito finché non ho visto davanti a me se non un solo piede, sì che fui invidioso. Mi venne detto: "Quello è il piede del tuo Profeta" e la mia agitazione si calmò". Egli era uno dei Solitari e si immaginò che non ci fosse nessuno sopra di lui se non il suo Profeta e che nessun'altro lo aveva preceduto. Egli, Allah sia soddisfatto di lui, diceva il vero, poiché vedeva solo la sua Via e nessun'altro l'aveva percorsa se non il suo Profeta. Gli venne chiesto: "Hai visto 'Abd al-Qādir?", ed egli rispose: "Non ho visto 'Abd al-Qādir nella Presenza". Quando ciò venne riferito ad 'Abd al-Qādir questi disse: "Ibn $Q^{-} a ̂$ id ha detto il vero: io l'ho visto là quando egli parlò". Gli venne chiesto: "E tu dov'eri, o signore?" ed egli rispose: "Ero nella camera secreta ed è da me che è emerso per lui il favore (nawäla)" e lo denominò con il suo nome. Venne chiesto a Ibn Qāi id cosa fosse il favore ed egli disse la stessa cosa che aveva detto 'Abd al-Qādir”.

913) La radice del termine muhdāc camera segreta, ha la stessa radice del verbo hada'a, ingannare.

914) La prima affermazione riguarda la via da lui percorsa, la seconda la stazione di arrivo, in cui non vide alcuna impronta di piedi.

915) Nelle Futühät il termine wusül è anche impiegato per indicare l'arrivo ad una specifica scienza, stazione o luogo, ma quando è determinato dall'articolo ed è privo di specificazione, come in questo caso, va inteso come l'arrivo a Lui, cioè il termine del percorso "ascendente" della via, in cui l’iniziato realizza il Sé nella Solitudine perfetta. Ne L'homme et son devenir selon le Vêdânta, René Guénon, traducendo un testo di Shankarāchārya, scriveva [pag. 195]: "Il n'y a donc et il ne peut y avoir évidemment aucun degré spirituel qui soit supérieur à celui du Yogî: celui-ci, envisagé dans sa concentration en soi-même, est aussi désigné comme le Muni, c'est-à-dire le «Solitaire», 
faccenda è come abbiamo detto: per ogni persona [284] vi è da parte di Allah una manifestazione di Sé (tağall $\overrightarrow{)}$ che gli appartiene ed egli non vedrà nella Sua Presenza altri che sé e sarà solo in essa $\left({ }^{916}\right)$.

Il sapiente ne ha scienza e chi non ha questa scienza, come Ibn Qā’id, considera quello un onore nei suoi confronti, cioè il suo essere solo con il Vero, ignorando che tutti si trovano in questa situazione. Questa è una stazione in cui non ha luogo disparità di rango (tafadū $)$, che riguarda soltanto le vesti d'onore, così come gli Inviati hanno tutti in comune la stazione della Missione, senza distinzione tra di essi, poi si differenziano in rango per ciò con cui ed a cui sono inviati, e per ciò che hanno da parte del Vero nella loro Missione.

Poi ha detto: "Poi, quando sei arrivato a questo punto, sii fiducioso di dominare i cuori di tutti i servitori, e chi vorrai prendere da te nel momento presente potrai [prenderlo]. Stai all'erta da ciò per quanto ti è possibile e sii custode della tua anima che da questo stato esercita il potere sui cuori dei servitori”.

Quanto al suo detto che egli domina i cuori dei servitori, intende dire che ha ricevuto il potere di disporre nel Mondo, ed i possessori di questa stazione spirituale si suddividono in due gruppi: tra essi vi è un gruppo che esercita il potere di disporre, ed essi sono coloro che spendono di ciò di cui sono stati resi depositari $\left({ }^{917}\right)$. [Chi fa parte di questo gruppo] investe e destituisce, dà e toglie, vivifica e fa morire, e fa ciò che vuole, poiché il suo volere deriva dal Volere del Vero: "essi non vogliono se non che voglia Allah”' (Cor. LXXVI-30), come 'Abd al-Qādir al-Ǧīlī, Maestro dei Maestri a Bagdād, Allah, sia Egli esaltato, sia soddisfatto di lui, e Abū l-'Abbās as-Sabtī (918), sennonché 'Abd al-Qādir

non au sens vulgaire et littéral du mot, mais celui qui réalise dans la plénitude de son être la Solitude parfaite, qui ne laisse subsister en l'Unité Suprême (nous devrions plutôt, en toute rigueur, dire la «Non-Dualité») aucune distinction de l'extérieur et de l'intérieur, ni aucune diversité extra-principielle quelconque".

916) Nel Cap. 73, questione LVIII [II 80.12] Ibn 'Arabī precisa: "Ibn Qâ̄ì era stato interrogato riguardo a lui ['Abd al-Qādir] ed aveva detto: "Non l'ho visto nella Presenza", e ciò venne riferito ad 'Abd al-Qādir, ed è per questo che disse: "Ero nella camera segreta" e denominò il favore ed esso era come egli disse. Ed egli disse solo: "nella camera segreta" senza precisare il nome del posto ove stava protetto [dalla vista] e lo designò con questo nome in modo da far sapere a Muhammad ibn Qầ'id l'inganno (hidāa) di Allah quando aveva sentenziato di non aver visto 'Abd al-Qādir nella Presenza allorché gli venne offerta la preziosa veste d'onore. In effetti la Presenza [incontrata] da Muhammad ibn Qāid in questo accadimento spirituale era la sua [stessa] Presenza, corrispondente alla sua specifica conoscenza del suo Signore, non era la Presenza del Vero quale era conosciuta da 'Abd al-Qādir o da altri dei più grandi [realizzati]. La stazione spirituale di 'Abd al-Qādir gli fu celata per un inganno [divino], ed 'Abd al-Qādir lo capì e disse: "Ero nella camera segreta". Quanto alla sua affermazione che era da lui che era emerso per lui [Ibn Qā'id] il favore, essa sta a significare che 'Abd al-Qādir era il suo Maestro in quella Presenza e che Ibn Qầid aveva ricevuto quel favore dalle sue mani, cosa che egli ignorava”.

917) Cfr. Cor. LVII-7.

918) Si tratta dello Šayh Abū l-'Abbās as-Sabtī, uno dei sette patroni di Marrakesh. Nato a Ceuta nell'anno 524 dall'Egira, all'età di sedici anni si trasferì a Marrakesh ove morì nell'anno 601. Ibn 'Arabī, che lo aveva incontrato personalmente, lo menziona nei capitoli 70 [I 577.11], 248 [II 548.20], 360 [III 292.16], 397 [III 560.25] e 485 [IV 121.22 e 29] e riporta un suo aneddoto, senza però citarne il nome, nei capitoli 70 [I 572.13 
disponeva per mezzo della stazione spirituale, mentre as-Sabtī disponeva per mezzo della bilancia $(m \bar{\imath} z \bar{a} n)$, e quindi il suo potere di disporre (tasarruf) era secondo una via specifica: se fosse venuto meno ad essa [285] avrebbe sbagliato, a differenza di 'Abd al-Qādir $\left({ }^{919}\right)$.

Abū as-Sưūd ibn aš-Šibl $\left.{ }^{920}\right)$, a Bagdād, aveva ottenuto questa stazione ma quando gliene fu data possibilità egli non la manifestò. Egli faceva parte dell'altro gruppo, che è quello di coloro che hanno rimandato [il disporre] ad Allah, conformandosi al Suo ordine riguardo al regime della procura (wakāla), ed hanno preso Allah come Procuratore nel disporre. Se un certo giorno essi dispongono riguardo ad una cosa per un ordine divino, ciò dipende dalla stazione della procura, non dalla stazione originale, poiché essi sono usciti da essa per adab e per mostrare eccellenza (tazarruf) $\left({ }^{921}\right)$. Se il Procuratore un certo giorno ordina ad uno di loro, per il bene di una certa faccenda, di disporre riguardo ad essa per Lui stesso, egli agisce per ordine del suo Procuratore, sia Egli esaltato, e si limita a fare quello che gli è stato assegnato, ma in base alla stazione del regime del Procuratore su colui che gli ha dato la procura, e questa è una stazione rara, di cui non tutti sono capaci.

Ibn Qāìid al-Awānī aveva ricevuto il potere di disporre, secondo quanto asseriva riguardo a se stesso, ma Abū as-Su'ūd non glielo riconobbe, perché era più equo di lui, malgrado la veridicità di Ibn Qā’id nella Via. Egli non aveva ricevuto il potere di disporre in modo generale, ma si immaginava di averlo ricevuto in modo generale, in quanto gli fu svelato il suo [micro]cosmo, che è simile al macrocosmo (al-'`alam al-kabīr), ed egli si immaginò di essere quel macrocosmo. Quindi egli fu veridico nella sua asserzione e [nello stesso tempo] non fu veridico, in quanto ignorava che esso era il suo mondo, e per

e 560 [IV 496.5]. Cfr. su di lui: Emile Dermenghem, Vie des Saints musulmans, Editions Sindbad, 1981, pag. 265273, Ibn al-Zayyāt at-Tādilī, Regards sur le temps des Soufis, Editions EDIDIF, 1994, pag. 325-348, e Vincent J. Cornell, Realm of the Saint, University of Texas Press, 1998, pag. 80-92. I brani delle Futūhāt in cui è citato sono stati tradotti e commentati da William Chittick in The Self-Disclosure of God, SUNY Press, 1998, pag.371-374.

919) Nel Cap. 397 [III 560.25] Ibn 'Arabī afferma: "Quando colui che ha questa visione contemplativa non ha realizzato l'Ipseità (huwiryya), ma Lo contempla come Re nel Dominio - ed è inevitabile che chi contempla assuma la forma dell'oggetto della sua contemplazione - egli si manifesta nel mondo contingente per mezzo del Nome "l'Esteriore", con l'influenza, il potere di disporre, il governo, l'ampia asserzione e la forza divina, come nel caso di 'Abd al-Qādir al-Ǧìlī e di Abū l-'Abbās as-Sabtī a Marrakesh. Io l'ho incontrato [quest'ultimo]

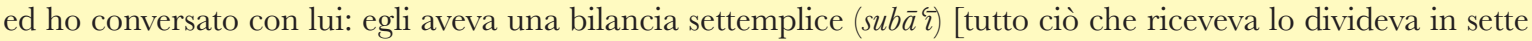
parti (in at-Tādilī, cit., pag. 333)] ed aveva ricevuto la bilancia della Magnanimità, mentre 'Abd al-Qādir aveva ricevuto la bilancia dell'impeto (sawla) e dell'aspirazione (himma), e per questo era più completo di as-Sabtī nella sua occupazione".

920) Originario di Bagdād, fu discepolo (tilmēê) di 'Abd al-Qādir al-Ǧìlī e morì nell'anno 540 dall'Egira. A differenza del Maestro, che esercitò un ruolo esteriore e lasciò opere scritte, $\mathrm{Abu}$ as-Su'ū úd rinunciò all'esercizio di ogni potere esteriore e, come è riportato nel Cap. 39 [I 233.29]: "fu costante nella servitù, prescritta in ogni attimo, fino alla sua morte". Ibn 'Arabī, che lo menziona una quarantina di volte nelle Futūhăt, gli attribuisce nel Cap. 25 [I 188.9] il rango dei Malāmiyya, precisando che fu uno dei più grandi di essi.

921) Riferimento all'affermazione di Abū as-Su'ūd, in risposta a chi gli aveva chiesto se Allah gli aveva dato il potere di disporre: "Si, da quindici anni, ma l'ho abbandonato per mostrare eccellenza ed è il Vero che dispone di noi", riportata nel Cap. 73, questione CXXXIV [II 121.6], nel Cap. 185 [II 370.34] e nei Fususs al-hikam, Cap. XIII, pag. 134. Il termine tazarruf ricorre anche nel Cap. 559 [IV 358.33 e 359.2]. 
questo Abū as-Su'ūd non gli riconobbe [il potere di disporre], poiché sapeva dell'ambiguità che lo aveva colpito per la sua ebbrezza, e per la sobrietà di Abū as-Sưūu.

All'epoca di Abū as-Su'ūd non c'era nessuno più perfetto di lui nell'intelligenza ('aql), e ciò perché egli sapeva che il Vero non dispone nel Mondo se non per ciò che il Mondo stesso Gli fornisce in quanto [286] oggetto della Scienza ( $m a^{`} l \bar{u} m$ ), e per questo in un momento Si affretta a fare ciò per cui è stato invocato e in un altro momento Si attarda, in un momento ripaga ed in un altro momento rifiuta, e la Parola non cambia presso di Lui $\left({ }^{922}\right)$ e la Sua Parola è la Sua Scienza e la Sua Scienza è conforme a ciò che è connesso con essa, poiché Egli conosce gli oggetti della Scienza per ciò che essi sono in loro stessi.

E quando Abū as-Su'ūd vide come è realmente la faccenda, non ritenne di avere in ciò un'influenza che fosse generale, e neppure il Principio $(a s \underline{l})$, per cui rimandò la faccenda ad Allah e per questo disse che egli vi aveva rinunciato per mostrare eccellenza. Riguardo a ciò abbiamo detto:

Il sapiente esperto (naḥīr) è ineccepibile, in quanto egli è secondo l'oggetto della sua scienza (bi-ḥukmi ma'lūmi-hi).

I suoi giudizi (ạ̣kām) giudicano l'oggetto della scienza, e quindi il suo giudizio dipende dall'entità di ciò che è soggetto al suo giudizio (fa ḥukmu-hu min 'ayn maḥkūmi-hi) $\left({ }^{923}\right)$.

Quanto al suo detto: "stai all'erta da ciò per quanto ti è possibile" egli ti fa questa raccomandazione per timore che abbia presa su di te la potenza per via di quello e che tu sia velato. In realtà è inevitabile, al momento della tua separazione dalla vita di questo mondo, che tu ritorni al Principio e ti abbassi al Potere coercitivo (qahr) divino, come fece 'Abd al-Qādir al-Ǧìlī, dopo aver detto: "Questo mio piede [cioè: rango] è sulla nuca di ogni Intimo di Allah”, per la sua funzione di Polo (qutb) e di Califfo, in quanto gli Intimi, che sono i Sostituti ( $a b d \bar{a} l)$, i Pilastri (awtād), gli Imām, i Rappresentanti (nuqabā), i Nobili (nuğaba $\bar{a}$ ), ecc., sono tutti sotto la sua giurisdizione, ed alla sua giurisdizione sfuggono solo i Solitari $(a f r a \bar{d})$, che sono gli Intimi di maggior grado presso Allah. Il Polo non sa ciò che è presso di loro, ed essi non sanno ciò che è presso il Polo perché sono occupati con Allah, ed ogni qualvolta uno di loro si occupa di una faccenda specifica è per l'ordine di Allah impartitogli riguardo a quella cosa specifica, per una saggezza che Allah ha in vista e per cui gli ordina quello, poi egli torna alla sua stazione ed al suo stato spirituale, come fece il Hiḍr con Mosè, la Pace sia su di lui, in quanto egli [287] è $\left.{ }^{924}\right)$ tra i Solitari (mufradūn).

922) Riferimento a Cor. L-29.

923) Questi versi si trovano anche nel suo Dī̌ān al-ma ārif, manoscritto Parigi BN 2348, f. 139b, linee 28-29.

924) Nel Cap. 366 [III 336.30] Ibn 'Arabī precisa: "Hुaḍir [o: Huiḍr], il cui nome era Tillayā ibn Malakkān ibn Qālic ibn 'Ābir ibn Šālị̣ ibn Arfahšad ibn Sām ibn Nūḥ, su di lui la Pace, si trovava in un esercito ed il comandante dell'esercito lo inviò a cercare dell'acqua per gli altri, poiché erano rimasti senza. È così che egli cadde nella Fontana della Vita e bevve di essa, così che rimase in vita fino ad ora". 
Quando 'Abd al-Qādir, giunse al suo termine pose la sua guancia sulla terra e si abbassò e riconobbe che tutto ciò in cui si era trovato era solo per uno stato mutevole e che il reale (sahịh) era ciò verso cui tornava: questa è la sua testimonianza su se stesso. Il punto estremo ( $g \bar{a} y a)$ di 'Abd al-Qādir fu dunque lo stato di Abū as-Su'ūd, ed Abū as-Su'ūd sapeva quello e cominciò con esso dall'inizio, poiché sapeva che è verso di Lui il ritorno, come è stato detto:

\section{Vide che la faccenda giungeva ad un termine}

e fece diventare il suo termine un inizio $\left({ }^{925}\right)$

Gli Inviati Califfi, che le șalāt di Allah scendano su di loro, se non sono costretti a gestire specificamente delle faccende non esercitano il potere di disporre, poiché in quanto Inviati non spetta a loro se non la trasmissione, ed in quanto Califfi esercitano il potere di disporre in ciò che è stato definito per loro, ed i loro sguardi sono rivolti al Principio (așl), da cui non si discostano mai. Allah, sia Egli esaltato, ha detto al più grande di loro in grado ed al più perfetto di loro per svelamento, avendo ottenuto la scienza dei primi e degli ultimi $\left.{ }^{926}\right)$ : "Certo non guidi chi ti piace" - e dov'è il potere di gestire tutto? - "ma Allah guida chi vuole" (Cor. XXVIII-56), e non vuole se non ciò che è [pre]stabilito nella Sua Scienza che Egli lo vorrà, e non ha scienza della faccenda se non di come essa è in se stessa. Allah è indipendente dai Mondi per la Sua Essenza, ed il Mondo, in quanto invisibile $(\mathrm{gayb})$ per come è in se stesso, percepisce quello [cioè: come è] nel visibile (šahâda): non vi è dunque che una percezione (idrāk) e per mezzo di essa ha luogo la distinzione tra i sapienti - c'è sapiente e più sapiente - e oltre a questa percezione, se essa include tutto, non c'è stazione per il sapiente più perfetta di essa. Ma questo fa parte di ciò che compete esclusivamente ad Allah, sia Egli esaltato, nel Suo mistero (gayb) e non spetta ad altri che Allah, e non è possibile se non che Egli Si manifesti a lui [il sapiente] attimo per attimo, e questa manifestazione ininterrotta su di lui è ciò [288] con cui Allah gli aggiunge scienza alla sua scienza, e fede alla sua fede, e per questo gli ha ordinato di dire: "O mio Signore, accrescimi in scienza" (Cor. XX-114) e se egli Lo avesse contemplato con una contemplazione diretta globale (šuhūd 'āmm) [la scienza] non ammetterebbe l'accrescimento. E poiché globalmente la faccenda non ha fine non è possibile che ciò che è infinito entri nell'esistenza $\left({ }^{927}\right)$.

925) Gli stessi versi sono riportati nel Cap. 365 [III 326.29].

926) Riferimento ad uno hadīt, non recensito nelle raccolte canoniche, che nel Cap. 10 [I 137.14] Ibn 'Arabī riporta nei seguenti termini: "Egli [il Profeta] ha detto del suo Signore: "Egli ha battuto con la Sua mano tra le mie scapole ed ho sentito il freddo delle Sue dita tra le mammelle ed ho appreso la scienza dei primi e degli ultimi"”." La prima parte dello hadītè è riportata da at-Tirmidīi, XLIV, Sūra XXXVIII-4 e da Ibn Hanbal, V-243. 927) Analoghe affermazioni si ritrovano nei capitoli 46 [I 253.21], 59 [I 292.19], 167 [II 282.35], 178 [II 353.29], 198 [II 399.35 e 403.21], 203 [II 482.33], 250 [II 551.27], 251 [II 552.19], 297 [II 686.16], 337 [III 143.7], 366 [III 339.33], 369 [III 361.13, 363.22 e 399.23], 375 [III 472.24], 381 [III 506.25], 404 [IV 6.15], 451 [IV 65.30], 558 [IV 310.24] e 559 [IV 425.14].

L'espressione "entri nell'esistenza" implica che si tratta dell'esistenza condizionata (muqayyad), cioè della manifestazione, non dell'Esistenza incondizionata (mutlaq) propria del Principio, in cui nulla entra e da cui nulla esce. D'altra parte ciò che entra nell'esistenza deve essere in se stesso non-esistente, e questo è il caso delle 
Allah, sia Egli esaltato, ha detto da questa stazione: "Vi metteremo alla prova in modo da sapere" (Cor. XLVII-31) ${ }^{928}$ ), facendo rilevare in modo specifico la novità (hudūt $)$ della connessione, non la novità della scienza. Egli sa ciò che avverrà di loro ma non sa che è avvenuto finché non avviene, cioè la Sua Scienza non è connessa con l'accadimento di ciò che non è avvenuto ${ }^{929}$, e quindi non si tratta di scienza. Sappi ciò!

possibilità o entità immutabili che sono infinite. Ibn 'Arabī non sta qui negando che le possibilità si manifestino o entrino nell'esistenza, ma nega che le infinite possibilità entrino tutte in un sol colpo nell'esistenza, come precisa nel Cap. 559 [IV 425.14]: "Le possibilità sono infinite e ciò che è infinito non entra nell'esistenza se non gradualmente [(tartīban $)$ o: in modo ordinato]".

928) Questo versetto è uno di quelli che sconcertano le menti speculative poiché sembra attribuire ad Allah l'acquisizione di una scienza che non aveva, in contrasto con l'Attributo della Scienza incondizionata che Gli è proprio. Nel Cap. 355 [II 249.10] Ibn 'Arabī afferma: "[...] affinché Allah sappia chi è veridico nella sua asserzione e chi non lo è ed Egli ha fatto discendere Se stesso, in questo mettere alla prova, al rango di chi acquisisce così una scienza, malgrado, sia Egli glorificato, sappia ciò che sarà di loro in quello prima che essi siano. Tra coloro che ritengono di far salva la trascendenza vi è chi dice che Allah non ottiene da quello una scienza, poiché non ha scienza della faccenda per come essa accade da parte di un tale in modo determinato: egli così rigetta la Parola di Allah e la interpreta per timore che Egli subisca un torto per quello. Tra gli Zāhiriti vi è chi persiste nell'affermare che Egli sa per mezzo di quella prova, attenendosi al senso letterale del versetto. Vi è poi chi intende ciò come la connessione della scienza con essa al momento dell'accadimento, ritenendo che la scienza sia eterna e che la connessione sia nuova. Infine tra i credenti c'è chi rimette la scienza di ciò ad Allah e crede in esso senza una determinata interpretazione [...] Tutto ciò è da parte di Allah un mettere alla prova i Suoi servitori che asseriscono con le loro lingue di credere in Lui, poiché Egli ha detto: "[vi metteremo alla prova] in modo da sapere" (Cor. XLVII-31)".

929) L'espressione "in modo da sapere (hattā na qama)", che nel Cap. 69 [I 463.19] Ibn 'Arabī assimila ad un Nome divino, è citata una cinquantina di volte nelle Futūhăt e spiegata sotto diverse sfaccettature. La spiegazione riportata nel manoscritto è quella dei teologi, come è affermato nei Fușus al-hikam, Cap. II, pag. 63, ma nel Cap. 299 [II 692.10] Ibn 'Arabī ne precisa il limite: "Il Nome "il Beninformato [dello stato interiore mediante una prova] (al-habìr) è tra i regimi (ahkām) più stupefacenti dei Nomi, in quanto la prova (hibra) serve per acquisire la scienza dello stato interiore (mahbar) da parte di chi mette alla prova (muhtabir), ma nel caso del Lato divino la scienza di ciò che sarà di colui che è messo alla prova (muhtabar) è sicura, e quindi Colui che mette alla prova non acquisisce alcuna scienza [che già non abbia], e quindi è manifesto che questo Nome non ha alcun regime [per Lui]. [Questo Nome] è invece appropriato per il servitore, poiché egli non sa cosa sarà di colui che è messo alla prova, ed al servitore è precluso il mettere alla prova (ihtibār) a meno che non sia per un ordine divino. Quindi Allah, sia Egli esaltato, Si è denominato con ciò che spetta al servitore, ed il suo [del Nome] regime riguardo al Lato del Vero è l'ottenimento della scienza da parte di colui che è messo alla prova riguardo a se stesso per mezzo di questo mettere alla prova, per stabilire l'argomento decisivo (huğğa) a suo sfavore o a suo favore. Per questo [il Nome] "il Beninformato" non si collega all'Attributo della Scienza, come lo hanno collegato Abū Ḥāmid [al-Gazālī] ed al-Isfarāyīn̄i, e la maggior parte degli uomini. Se fosse come essi pensano si tratterebbe di una deficienza, sennonché li ha spinti in quello il Suo detto, sia Egli esaltato: "in modo da sapere" (Cor. XLVII-31) ed esso [tuttavia] è un argomento decisivo contro di loro, se la realtà corrispondesse alla sua apparenza, poiché il mettere alla prova è un mezzo per ottenere la scienza, non è la scienza stessa, e per la prova Egli Si chiama Beninformato, e quando ottiene la scienza si chiama Sapiente riguardo a quello stato. Ed il massimo per coloro che affermano la trascendenza, come Ibn al-Hațīb ed altri, riguardo al Suo detto: "in modo da sapere", è la connessione della Scienza con questa condizione. La connessione della Scienza è un evento nuovo e non conduce alla novità della Scienza, quindi la Scienza resta caratterizzata dall'eternità anche se la connessione è nuova, e questo è il massimo a cui arrivano nella loro affermazione della trascendenza. Essi dicono: se la Scienza fosse connessa con ciò che per sua natura un essere sarà o era, Egli saprebbe la cosa 
In questa raccomandazione, dopo averti ordinato di sorvegliare la tua anima in questo stato per quanto ti è possibile, la sua frase: "affinché non eserciti il potere sui cuori dei servitori se non per il bene" indica che egli non appartiene alla gente di questa stazione sulla quale abbiamo richiamato l'attenzione, poiché se lo fosse non direbbe questo, anche se la spiritualità di Damasco $\left({ }^{930}\right)$ conferisce la scienza di una cosa simile a questa, ma l'autore di questa raccomandazione non è arrivato a questa stazione spirituale.

Io l'ho percepito e l'ho visto ed ho saputo che il suo stato non era questo, e se non lo avessi saputo mi sarei orientato in questo suo discorso verso un altro aspetto, secondo il quale sarebbe confermato che egli faceva parte della gente di questa stessa stazione. Ma poiché abbiamo determinato la stazione spirituale di chi parla in base al suo stato, non aggiungiamo nulla nel commento, e se [altrove] abbiamo fatto delle aggiunte abbiamo avvertito che quell'aggiunta non riguardava lo stato di chi parlava [cioè l'autore del testo oggetto del commento] ma era soltanto lo stato di chi ne parlava [cioè il commentatore], poiché la potenza dell'espressione che aveva usato quest'uomo comportava quello in aggiunta a ciò che implicava il suo stato, e quindi il suo stato faceva parte di ciò che era espresso, ma al di sotto di ciò a cui alludeva l'espressione, [289] come spesso succede. Talvolta la comprensione di un'espressione da parte di chi ascolta è superiore alla comprensione di chi la profferisce, a meno che egli non abbia una scienza globale, nel qual caso necessariamente non gli sfugge alcun aspetto di ciò che quell'espressione comporta, e chi la commenta fa apparire di essa ciò che vuole, e vela ciò che vuole.

Questa $\left({ }^{931}\right)$ è la stazione della rottura del corso abituale (harq al-'awä $\left.\mathrm{i} d\right)\left({ }^{932}\right)$ nel dominio esteriore $(f \bar{\imath}$ $\check{s}$-šăhid), ed i più grandi dei sapienti alludono ad essa quando parlano dell'influenza dell'aspirazione delle anime (ta țīr hamm an-nufüs), e gli uomini hanno gradi diversi in ciò ${ }^{933}$ ).

diversamente da ciò che è. [...] Essi senza accorgersene introducono Allah nel tempo, nella precedenza e nella posteriorità riguardo alle cose. Essi non sanno che Allah, sia Egli esaltato, contempla le cose e le conosce per ciò che esse sono in loro stesse, ed i tempi che appartengono ad esse fanno parte dell'insieme dei Suoi oggetti di conoscenza inerenti ad esse [...] Tutto ciò è oggetto di contemplazione per il Vero fuori dal tempo, e non è qualificato né dalla precedenza, né dalla posteriorità, né dall’istante presente $(\bar{a} n)$ che è il limite tra i due tempi". D'altra parte nel Cap. 558 [IV 323.27] aggiunge: "Del Suo mettere alla prova fa parte il Suo detto: "Vi metteremo alla prova in modo da sapere" (Cor. XLVII-31), per vedere se Gli viene attribuita la novità della scienza (hudüt al- $\{l m$ ) oppure no".

930) Ibn 'Arabī ha già usato questa espressione enigmatica a pag. 32 del manoscritto.

931) Cioè la stazione spirituale che comporta il potere di disporre (tasarruf).

932) Questa espressione ricorre un centinaio di volte nelle Futūhăt, sia nella forma qui riportata che nelle varianti harq al- '̄ada e harq al- $\bar{a} d \bar{a} t$, ed alla sua stazione spirituale è dedicato il Cap. 186.

933) La rottura del corso abituale nel dominio esteriore, come il camminare sull'acqua o il volteggiare nell'aria, è un fenomeno e come tale può avere diverse origini. Qui Ibn 'Arabī fa riferimento solo ai poteri psichici ma altrove specifica che tali fenomeni possono anche avere una origine divina, come nel Cap. 289 [II 647.28]. Vi è però anche una rottura del corso abituale nel dominio interiore, ed è a questa che devono aspirare gli iniziati; nel Cap. 73 [II 16.10] viene infatti precisato che "la rottura del corso abituale presso coloro che sono veridici 
Quanto al suo ordine all'aspirante di pregare per il suo Maestro $\left({ }^{934}\right)$, ciò fa parte della sua gratitudine verso di lui, poiché egli è un genitore tradizionale e spirituale, ed Allah ci ha ordinato di essere riconoscenti verso Allah ed i nostri genitori, senza indicare in particolare un genitore rispetto ad un altro $\left.{ }^{935}\right)$, voglio dire il genitore del lignaggio (nasab) rispetto al genitore della tradizione (dīn). Allah, sia Egli esaltato, ha fatto del genitore della tradizione un padre, ed ha detto alla comunità di Muhammad, su di lui la Pace, che è stato inviato a chi risale nella sua genealogia ad Abramo e ad altri che Abramo tra chi non è venuto sulla via di Abramo: "La comunità di vostro padre Abramo" (Cor. XXII-78) facendo di lui un padre per noi nella tradizione.

I Maestri sono padri di tradizione e ci è imposto di essere riconoscenti verso di loro, e non c’è maggior segno di gratitudine che la preghiera per loro, così come Allah, sia Egli esaltato, ci ha ordinato la șalāt sul Suo Profeta, su di lui la Pace, malgrado la nostra scienza del suo rango, ed egli, su di lui la Pace, ci ha chiesto di domandare per lui ad Allah, sia Egli esaltato, la Wasīla $\left({ }^{936}\right)$.

Per quello questo Maestro ti ha ordinato di pregare per il tuo Maestro, poiché il Profeta, che Allah faccia scendere su di lui la Sua salāt e la Pace, ha detto nella tradizione autentica, sia per trasmissione che per svelamento: "Invero l'uomo quando muore si separerà dalla sua opera salvo che per tre cose: una scienza che ha diffuso tra gli uomini, o l'elemosina che dura nel tempo $\left({ }^{937}\right)$, o un figlio pio che prega per lui" ${ }^{938}$ ) attribuendo alla preghiera la sua opera dopo la sua morte, [290] poiché suo figlio è opera sua, e per questo è giunta la notificazione, autentica per svelamento, secondo la quale l'Inviato di Allah, che Allah faccia scendere su di lui la Sua șalāt e la Pace, ha detto: "Il cibo più eccellente di cui si nutre l'uomo è quello [frutto] del suo operato (kasb), e suo figlio fa parte del suo operato" ${ }^{939}$ ).

è solo qualcosa che riguarda la loro interiorità ed i loro cuori, per mezzo di ciò che Allah dona loro della comprensione di Lui, e che non condivide con loro per gusto spirituale chi non è del loro genere".

934) Si tratta di una raccomandazione di cui non è riportato il testo nel manoscritto.

935) Riferimento a Cor. XXXI-14.

936) Il significato di questo termine è stato spiegato a pag. 190 del manoscritto.

937) Nel Cap. 560 [IV 447.17] Ibn 'Arabī precisa: "Se si tratta poi di una delle opere buone che oltrepassano [il momento della loro esecuzione] e che sono dotate di permanenza, allora la ricompensa si rinnova su di essa fintanto che essa resta, fino al Giorno della Resurrezione, come ad esempio l'elemosina che dura nel tempo, come le donazioni pie $(a w q \bar{a} f)$, o la scienza che il servitore diffonde tra gli uomini o la buona regola [da lui stabilita], ecc.".

938) Hadīt riportato da Muslim, XXV-14, Abū Dāwud, XVII-14, at-Tirmidīī, XIII-36, an-Nasāà', XXX-8 e da Ibn Ḥanbal, II-316, 350 e 372. Ibn ‘Arabī lo cita nel Cap. 489 [IV 125.34].

939) Hadīt riportato da an-Nasā'î, XLIV-1, Ibn Māğah, XII-1 e da Ibn Hanbal, VI-31. Ibn 'Arabī lo cita nel Cap. 70 [I 577.19] ove afferma: "Il conoscitore per Allah (al-'arīf bi-lläh) in punto di morte, per se stesso, se fosse in grado di parlare, insegnerebbe agli uomini una scienza riguardante il loro Signore, ma ormai la sua lingua è impastoiata. Se però un discepolo riferisce una questione [da lui trattata] riguardo alla scienza profittevole, si tratti della dottrina dell'Unità o di altro, e la insegna così ai presenti che ascoltano, quel conoscitore coglie il frutto di essa ed il discepolo coglierà presso Allah il frutto della sua trasmissione. Allah ricompensa per quello il morto con una ricompensa obbligatoria, perché ciò fa parte del suo sforzo (say), ed Allah ha detto: "All'uomo 
Senza dubbio il figlio nella tradizione è più prossimo nel grado della parentela del figlio genealogico e dei lombi, poiché il figlio dei lombi (walad aṣ-sulb) eredita da suo padre per la sua tradizione, non per i suoi lombi, in qualsiasi tradizione sia; la Legge non considera se non la tradizione e per questo [il Profeta, su di lui la Pace] ha detto: "Aqīl non ci ha lasciato alcuna casa” $\left({ }^{940}\right)$. Se l'eredità dipendesse dai lombi e non dalla tradizione 'Alī avrebbe ereditato da lui [Abū Ṭālib] come ha ereditato 'Aqīl, e chi riunisce le due parentele ha più diritto alla eredità di colui che ha una sola parentela, ed erediterà per avere soltanto la parentela tradizionale e non erediterà per l'assenza di questa parentela.

Quanto al suo ordine, rivolto a te, di essere umile (tawā $\left.u^{c}\right)$ con la tua gente (ahl) e con i servitori pii di Allah $\left({ }^{941}\right)$ - e l'essere umile non concerne se non chi possiede un grado elevato $\left(r f^{\prime} a\right)\left({ }^{942}\right)$ - egli ti dice: "Non trattare la tua gente dall'alto al basso perché essi ti guardano convinti al loro proposisto di essere inferiori a te", e chiunque ti ordini di essere umile ti riconosce il grado elevato in virtù della stazione a cui sei arrivato. E la tua gente non è altri che la gente della tua via che compete con te riguardo al tuo rango, del quale Allah ha fatto loro la sua gente (ahhala-hum) $\left({ }^{943}\right)$. Il tuo essere umile con loro non dipende da un grado elevato rispetto a loro, bensì il tuo essere umile corrisponde al tuo riconoscere che hai appreso da loro per come sono senza che essi se ne accorgano, e li hai superati

non spetta [una ricompensa] se non [per] ciò per cui si è sforzato" (Cor. LIII-39). "Il cibo più eccellente di cui si nutre l'uomo è quello [frutto] del suo operato, e suo figlio fa parte del suo operato", ed il discepolo è senza dubbio un figlio tradizionale. Lo sforzo garantisce all'uomo [una ricompensa] presso Allah, per via dell'obbligo divino che Allah Si è imposto".

940) "Venne chiesto all'Inviato di Allah: "Starai nella tua casa alla Mecca?" ed egli rispose: "Aqī non ci ha lasciato alcuna casa. 'Aqīl e Țālib [in quanto non musulmani] hanno ereditato da [loro padre] Abū Ṭālib, mentre 'Alī e Ğa'far non hanno ereditato nulla da lui essendo musulmani’”'. Hadīt riportato da al-Buhārī, XXV-44, Muslim, XV-439 e 440, e da Ibn Māğah, XXIII-6.

Ibn 'Arabī distingue tra la parentela di lignaggio (qarāba) e la parentela tradizionale (qurbāa) e nel Cap. 342 [III 168.28] precisa: "Per questo [nel versetto: "Non vi chiedo alcuna ricompensa per ciò se non l'amore verso la parentela tradizionale" (Cor. XVII-23)] ha usato il termine qurbā e non qarāba. In effetti non c'era differenza nella parentela di lignaggio tra 'Aqīl ed 'Alī poiché entrambi erano figli dello zio dell'Inviato di Allah, che Allah faccia scendere su di lui la Sua șalāt e la Pace, ma 'Alī riuniva la parentela di lignaggio e quella tradizionale e tra i parenti di sangue dell'Inviato di Allah, che Allah faccia scendere su di lui la Sua șalāt e la Pace, noi amiamo coloro che hanno la parentela tradizionale, cioè i credenti [...] Osserva ciò nel Corano riguardo al bottino di guerra nel Suo detto, sia Egli esaltato: "Il quinto di esso spetta ad Allah, al Suo Inviato ed a coloro che hanno una parentela tradizionale" (Cor. VIII-41) ove ha usato il termine qurbā e non qarāba, poiché i parenti di lignaggio se non sono parenti nella fede non hanno diritto a quello, come pure all'eredità. Per questo il Profeta, che Allah faccia scendere su di lui la Sua șalāt e la Pace, quando entrò alla Mecca disse: "Aqīl non ci ha lasciato alcuna casa" perché fu lui ad ereditare da suo padre ad esclusione di 'Alī, a causa della fede di 'Alī e della miscredenza di 'Aqīl”. Analoghe considerazioni sono riportate nel Cap. 386 [III 532.11] ove però non usa il termine qurba e distingue tra la parentela (qarāba) della tradizione e quella dell'argilla (tinn).

941) Si tratta di una raccomandazione di cui non è riportato il testo nel manoscritto.

942) Nel Cap. 69 [I 414.11] è riportata la stessa frase, ma il contesto in cui è inserita riguarda i movimenti del fedele durante la salāt, per cui la traduzione cambia: "l'abbassarsi [nella prosternazione] concerne solo chi si è innalzato".

943) Il verbo ahhala ha la stessa radice di ahl. 
per questa misura e sei superiore a loro, quindi è tuo dovere essere umile con loro affinché non diventi palese per loro il loro aver bisogno (iffiqār) [291] di te, poiché essi ignorano di te ciò che tu sai di te. Colui che si comporta umilmente cerca solo una copertura (sitr) da colui con cui è umile, poiché il rango elevato della sua stazione implica di norma l'essere umili, e se non lo implicasse non sarebbe elevato. E se essi sanno quello di te, come sanno che l'Inviato era umile con i suoi Compagni ed il Re umile con i sudditi, ciò fa aumentare il loro amore verso di te, la loro riconoscenza, e la loro scienza dell'elevatezza della tua stazione spirituale. Il fondamento di tutto questo è ciò che è affermato nella notificazione autentica, sia per trasmissione che per svelamento: "Invero Allah, sia Egli esaltato, discende ogni notte verso il Cielo di questo mondo, nella Sua Potenza e nella Sua Maestà, verso i Suoi servitori, dicendo: C'è qualcuno che si pente? C'è qualcuno che chiede perdono? C'è qualcuno che prega?" $\left({ }^{944}\right)$ e non scende se non da un grado elevato. Dov'è la Sua indipendenza dai Mondi rispetto a questo rango e rispetto al Suo chiedere il prestito ai Suoi servitori? ${ }^{945}$ )

Quanto all'appartenenza alla gente (ahliyya), anche essa trova il fondamento in questa sede, poiché è affermato dalla tradizione che: "La gente del Corano è la gente di Allah e la Sua élite" (946) ed Egli ha detto, sia Egli esaltato: "Chiedete alla gente dello $\underline{d i k}$ ”" (Cor. XVI-43), intendendo il Corano, poiché esso è il discorso di Allah ed il Suo discorso è Lui stesso, e quindi essi sono la gente di Allah, sia Egli esaltato. E se Allah, sia Egli esaltato, è disceso verso la Sua gente, a maggior ragione tu devi abbassarti ad essa da questo grado elevato accidentale, poiché la tua relazione con loro è più grande e più profonda della relazione del Mondo con Allah, in ciò che è manifesto per i credenti, avendo con loro una relazione di somiglianza, mentre il Mondo non ha questa relazione con Allah, e malgrado questo Allah, sia Egli esaltato, ne ha fatto la Sua gente.

Poi ha detto: "Se vedi uno degli Intimi nascondere il suo stato spirituale agli uomini e mostrare loro [292] altro che il suo stato, guardati dal farlo notare ad una delle creature". Il fondamento di questo

944) Hadīt già menzionato a pag. 210 del manoscritto. Nel Cap. 558 [IV 244.27] Ibn 'Arabī afferma: "Poiché il Vero ha attribuito a Se stesso la discesa, questa stessa discesa è la prova dell'attribuzione a Lui dell'elevatezza, poiché se Si fosse fermato al Suo detto: "Egli Si è assiso sul Trono" (Cor. XX-5) e Si fosse accontentato [di esso] - e non aveva menzionato la discesa ed ogni parte del Mondo è un Trono per Lui, poiché è il Suo Regno - non sarebbe accertata per Lui l'elevatezza se non per mezzo dell'attribuzione a Lui della discesa verso il Cielo più basso".

945) Riferimento a Cor. LXXIII-20. Nel Cap. 70 [I 563.31] Ibn 'Arabī precisa: "I creditori sono coloro che hanno fatto ad Allah un bel prestito, seguendo il Suo ordine espresso nel Suo detto, quanto è Potente e Magnificente: "Fate ad Allah un bel prestito" (Cor. LXXIII-20), collegato con due ordini a carattere obbligatorio, che sono: "... e fate la salāt e date la zakāt" (Cor. ibidem), a cui ha aggiunto il terzo: "e fate ad Allah un bel prestito", ed il prestito è il terzo di essi. Allah [in questo versetto] non ha determinato quello che tu presti, come non ha determinato ciò che dai in zakāt né una salāt particolare: il versetto quindi comprende tutte le salāt che ci ha ordinato di fare, tutte le zakāt e tutti i prestiti. Ma Egli ha attribuito al fare il prestito l'aggettivo bello, insieme alla ripetizione del verbo, e la ragione di quello è che nella șalāt e nella zakāt il servitore è tale per necessità [o costrizione], mentre riguardo al prestito è un servitore per scelta

946) Hadìt riportato da Ibn Hanbal, III-128 e 242. 
è la [seguente] notificazione autentica, sia per trasmissione che per svelamento: "Nel Giorno della Resurrezione, quando il Vero Si manifesterà ai Suoi servitori in una forma diversa da quella che essi conoscono, essi Lo disconosceranno" $\left({ }^{947}\right)$ e coloro che Lo conoscono, come i Profeti, in quella sede non avvertiranno gli altri di ciò, poiché essi sanno da parte del Vero che quello è ciò che Lui vuole in quella sede, ed essi non si oppongono a Lui in quello.

Il suo obiettivo, Allah sia soddisfatto di lui, in quello che ha detto è l'adab, poiché fa parte dell'adab nei loro riguardi comportarsi con loro come essi vogliono. Quanto all'accertamento della verità (tahqīq) in quello - e può darsi che questo Maestro non lo sapesse, oppure, sapendolo, trascurò di esprimerlo - devi sapere che quella forma in cui si è manifestato questo Intimo fa parte anch'essa dei suoi stati spirituali, e quindi egli non si è manifestato in qualcosa di diverso dal suo stato, ma si è soltanto manifestato diversamente dallo stato che la gente comune crede essere lo stato dell'Intimo. Un Intimo non nasconde il suo stato agli uomini, se non per la sua adozione di uno dei loro comportamenti abituali in cui non è violata la sacralità legale, e la gente comune non vede di quest'Intimo se non ciò che essi sono abituati a fare e per loro ciò non è distinto dallo stato dell'Intimo che essi si immaginano e costituisce quindi per loro una maschera su questo stato immaginato, ma anche in questo caso egli non si maschera se non con il suo stato $\left.{ }^{948}\right)$. E se si maschera con qualcosa in cui sembra loro che egli violi la sacralità legale, l'errore sta nel loro modo di vedere, non in come le cose stanno realmente, ed è lungi che una cosa simile accada ad un grande della Via, fermamente stabilito [nella sua stazione spirituale], né a chi ha uno stato spirituale, essendo occupato nel suo stato.

Chi ha uno stato spirituale è sotto il regime del suo stato, e non gli passa per la mente [293] né di mascherare, né di manifestare, ma egli è come dispone di lui il suo stato; quanto ai più grandi il mascherare ha luogo soltanto con le cose lecite ed abituali, che non sono specificamente biasimate dalla Legge, e se capita che all'osservatore appaia che in quello egli viola una sacralità legale, ciò non è voluto da parte di quell'Intimo, poiché egli procede secondo la sua abitudine in quello con Allah, sia Egli esaltato, e la sua occupazione in quel momento è con Allah, in base a ciò a cui si è abituato da Lui, e non con le creature. L'estraneo si immagina che quell'Intimo voglia mascherarsi con quel comportamento di cui l'aspetto esteriore è riprovevole e quello interiore approvato, ma non è così. Quest'Intimo non fa se non una cosa corretta e lodata nella Legge, se quest'osservatore fosse equo, come un uomo che beve un bicchiere di vino $\left({ }^{949}\right)$ sotto gli occhi di chi è presente e che sa della natura alcolica di quel bicchiere - ed egli beve ciò che gli è lecito bere - mentre chi è presente non lo sa fintanto che egli non glielo offre da parte sua se rivolge la propria attenzione a lui, sempre che egli

947) Riferimento ad uno hadìt riportato nella prima nota alla pag. 141 del manoscritto.

948) Contrariamente a ciò che ha affermato l'estensore della raccomandazione l'Intimo non dissimula il suo stato, cosa che sarebbe biasimevole.

949) Ibn 'Arabī si riferisce qui all'esempio riportato a pag. 67 del manoscritto, in cui il discepolo si accorge, bevendo dal bicchiere del Maestro, che non si trattava di vino ma di una bevanda più dolce del miele. 
non intenda mascherare il suo stato $\left.{ }^{950}\right)$, e l'estraneo lo beve come una bevanda lecita. L'estraneo che non sa quello è lodato presso di Lui nella sua disapprovazione, dando ciò che spetta alla sua stazione, e l'Intimo è lodato nel suo gesto se non intende mascherarsi, ma se in quel modo intende mascherarsi è biasimato nella Via. Una cosa simile non ha luogo da parte di un Intimo con la gente comune, ma talvolta ha luogo intenzionalmente da parte di un Intimo nei confronti dei suoi compagni, per [verificare] la veridicità della loro asserzione di rimettersi a lui, il che non è vietato.

Di questo genere sarà l'epifania del Vero, sia Egli esaltato: nel Giorno della Resurrezione Egli Si manifesterà nella forma disconosciuta per mettere alla prova i bene educati $(u d a b \bar{a})$ che prendono sul serio [294] il pegno, [per verificare] se in quella occasione si comporteranno con Lui nel modo che è dovuto a Dio o se passeranno sotto silenzio quello e non disconosceranno, ed essi faranno così $\left.{ }^{951}\right)$.

Così fece Qaḍīb al-Bān con Aḥmad al-Bazzār $\left({ }^{952}\right)$ quando si manifestò a lui in forme diverse, pur essendo la forma unica, ed Aḥmad restò stupefatto. E quando ebbe completato lo spettacolo, in base ai suoi intendimenti, Qaḍīb al-Bān disse: "O Aḥmad, chi è il Qaḍīb al-Bān che non fa la salāt e che trascura ciò che Allah gli ha imposto? O Aḥmad, per Allah, non ho mai trascurato un rito obbligatorio impostomi da Allah, e la faccenda è come tu hai visto". Aḥmad mi informò di ciò a Mossul, nel luogo stesso in cui gli era stato fatto vedere quello da parte sua, cioè presso la porta del sepolcro del Profeta Giorgio (ğirğiss), su di lui la Pace $\left({ }^{953}\right)$. Per questo abbiamo detto: "Talvolta l'Intimo manifesta ad uno dei suoi fratelli qualcosa di simile per istruire e per mettere alla prova".

E Qaḍīb al-Bān, per come appariva alla gente comune, non intendeva mascherarsi a loro, ma era il suo stato spirituale che gli conferiva quello ed egli non si curava di ciò che la gente credeva di lui. E la gente venne ricompensata per averlo criticato, ritenendolo dotato di ragione e non un folle, ed egli venne ricompensato e lodato in quanto con quello non voleva far sì che la gente intaccasse il suo onore, ed essi avrebbero commesso una colpa $\left.{ }^{954}\right)$ se Allah avesse realizzato le loro richieste riguardo a quel [comportamento], ma Allah, sia Egli esaltato, chiude gli occhi sulle cattive azioni dei Suoi servitori.

Uno degli Intimi aveva, vicino a una moschea, un negozio in cui faceva il sarto. La comunità non lo aveva mai visto fare la șalāt con loro nella moschea, e ciò era enorme per loro sì che lo colpirono

950) Nel qual caso probabilmente il vino resta tale e non si trasforma in una bevanda lecita.

951) L'argomento è già stato trattato a pag. 140-141 del manoscritto.

952) Personaggio ignoto che non è menzionato nelle Futūhăt.

953) Il mausoleo di San Giorgio, patrono di Mossul e venerato sia dai cristiani che dai musulmani, è stato distrutto nel 2014 dai miliziani dell'ISIS. Su San Giorgio dal punto di vista islamico si può consultare la Chronique de Tabari, tradotta in francese da Hermann Zotenberg, Imprimerie Impériale, 1869, Vol. II, pag. 54-66, e The History of al-Tabarī, tradotta in inglese da Moshe Perlmann, SUNY Press, 1987, Vol. IV, pag. 173-186.

954) Come nell'esempio riportato nel paragrafo successivo. 
a sassate, ed egli non disse loro nulla, finché lo uccisero. Arrivò chi lo conosceva e li informò del suo stato, e che egli non aveva mai mancato [295] una șalāt obbligatoria; poi riferì che egli faceva la salāt del mezzogiorno alla Mecca, quella del pomeriggio a Medina, quella del tramonto a Gerusalemme, quella della notte sulla costa e quella dell'alba alle spalle del monte Qāf $\left.{ }^{955}\right)$. Essi si pentirono amaramente di averlo ucciso e cercarono la baraka presso la sua tomba dopo la sua morte. Il Maestro non voleva nascondersi, né tacere di avere questa qualità perché sapeva che essi non gli avrebbero creduto, ma è il suo stato che lo distolse dal comunicare quello. Tra gli Uomini di Allah abbiamo visto qualcuno che aveva questa stazione spirituale.

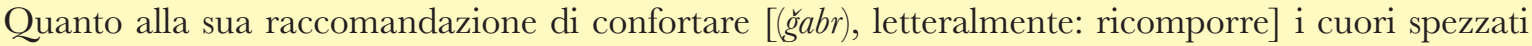
$\left.{ }^{956}\right)$, essa dipende da una faccenda verificata, poiché Allah, sia Egli esaltato, è presso coloro che hanno i cuori spezzati $\left({ }^{957}\right)$. Con questo egli vuol dire che colui che conforta, se realizza questo stato, poco manca che Allah gli sveli Se stesso ed egli veda il Vero che è presso questo scoraggiamento, poiché Egli è presso di loro per confortarli, e se questa persona li conforta, egli è il Vero che è presso di loro, se tu sapessi. Così è riportato nella notificazione, autentica sia per trasmissione che per svelamento, che Allah, sia Egli esaltato, ha detto: "O Mio servitore, ero malato e non Mi hai fatto visita! Il servitore disse: O mio Signore, come puoi essere malato, Tu che sei il Signore dei Mondi? ed Egli rispose: O Mio servitore, non sapevi che un tale era malato? Se tu gli avessi fatto visita Mi avresti trovato presso di lui”" $\left.{ }^{958}\right)$.

955) Alcuni esempi simili sono riportati da aš-Ša' rānī nel suo Kïtāb al-yawāqūt wa-l-ğawāhir fì bayān 'aqā ïd al-akābir, a pag 271 dell'edizione Dār ihyā̄' at-turāt al-'arabī, Beirut, senza data.

956) Si tratta di una raccomandazione di cui non è riportato il testo nel manoscritto.

957) Riferimento ad uno hadīt riportato a pag. 22 del manoscritto.

958) Hadīt quds̄̄ riportato da Muslim, XLV-43 e da Ibn Hanbal, II-404; esso è menzionato sedici volte nelle Futūhāt. Nel Cap. 69 [I 407.12] Ibn 'Arabī afferma: "Colui che ha la scienza deve velare all'ignorante i segreti del Vero contenuti in affermazioni come [...] "Ero affamato e tu non Mi hai nutrito; ero malato e tu non Mi hai fatto visita; ero assetato e tu non Mi hai dato da bere". Egli quindi vela questa scienza all'ignorante e non aggiunge nulla al commento che Egli, sia glorificato, ha fatto. D'altra parte il Vero stesso l'ha velata dicendo: "Non sai che un tale, dei Miei servitori, si è ammalato? Se l'avessi visitato avresti trovato Me presso di lui". Questa affermazione è ancora più oscura della prima, ma con questo commento Egli ha conferito ai sapienti in Allah una scienza di Lui, sia Egli esaltato, che essi non avevano. Nella prima Egli, sia glorificato, ha identificato Se stesso con colui che è malato ed affamato, mentre nel Suo commento, sia Egli esaltato, ha posto Se stesso come colui che visita l'ammalato, essendo presso di lui, poiché chi visita un ammalato è presso di lui. Ma dov'è allora Colui che Si è identificato all'ammalato?", e nel Cap. 560 [IV 451.13] aggiunge: "È tuo dovere, fratello mio, rendere visita agli ammalati, per l'insegnamento e per l'avvertimento che ciò comporta. Allah ha creato l'uomo di debolezza e l'osservarla nella tua visita [agli ammalati] richiama la tua attenzione sulla tua origine e sul fatto che tu hai bisogno di Allah perché ti rafforzi nell'obbedienza a Lui. Inoltre Allah è presso il Suo servitore quando è malato: non vedi che il malato non chiede che l'aiuto di Allah e non menziona che Allah? Il Vero dunque non cessa di essere menzionato dalla sua lingua ed egli non cessa di cercare in cuor suo rifugio in Lui. Quindi il malato continua ad essere con Allah, qualunque malato sia, e anche se si fa curare [da un medico] ed accetta i mezzi abituali per l'ottenimento della guarigione, malgrado ciò non trascura Allah, e questo per la presenza di Allah presso di lui. Il Giorno della Resurrezione Allah dirà: "O figlio di Adamo, ero malato e 
Questo è un ritrovamento (wiğdān) specifico come il ritrovamento di Lui presso colui che ha il cuore spezzato a causa di Allah, sia Egli esaltato; e chiunque faccia una visita senza trovare Allah presso il malato non gli ha fatto visita, poiché Egli ha detto, e la Sua Parola è veridica: "Mi avresti trovato presso di lui". Il minimo del ritrovamento è che il visitatore trovi presso il malato Allah menzionato da lui, mentre Gli chiede la guarigione e si rimette al Suo Decreto $(q a d \bar{a})$ riguardo a lui, poiché nello [296] stato della sua malattia è afflitto e sopraffatto, chiunque sia il malato ed a chiunque correli il suo credo. Per ogni malato il suo Dio è colui a cui fa affidamento per la sua guarigione ed il suo ristabilimento, ed Allah, sia Egli esaltato, Si manifesta a lui in quella forma su cui fa affidamento. Egli, sia esaltato, non ha specificato in questa notificazione un malato ad esclusione di un altro, ed è noto che i malati sono diversi per quanto riguarda le convinzioni su ciò che essi adorano, e ciò che mette insieme tutti - lo scopo vero in ciascuno di loro - è che Allah, sia Egli esaltato è Colui che guarisce e che ridà la salute, mentre il medico cura. Il Vero [Si manifesta] nella forma del rimedio (daw $\bar{a})$, non nella forma del medico, e quando il Vero Si manifesta nella forma di un rimedio specifico, in esso vi è la guarigione da questa malattia specifica per questo malato specifico

All'anima di colui che conforta questo scoraggiamento il Vero non Si manifesta se non nel suo conforto, non nella forma della persona che conforta in quanto uomo, ma in quanto conforta. Questa è la Teofania nelle forme dei significati ${ }^{959}$ ), e con qualsiasi cosa avvenga la ricomposizione di colui che ha il cuore spezzato, quella ricomposizione è il Vero che è presso costui che ha il cuore spezzato, e se non viene ricomposto da quello non si tratta di questo Vero specifico per questo scoraggiamento specifico.

Quando il rimedio è appropriato per respingere la malattia esso ha un effetto benefico ed usandolo quella malattia cessa, poiché la correlazione tra il rimedio e la malattia è la correlazione dell'opposto, e per questo la fa cessare. Se invece la correlazione fosse quella del simile (nažîr) esso aumenterebbe l'intensità del suo scoraggiamento o della sua malattia, poiché lo scoraggiamento è una malattia psichica che ha il sopravvento in certi momenti tanto da manifestarsi ai sensi, ed a causa sua si altera la complessione dell'edificio corporeo. Per la malattia delle anime si alterano sempre le complessioni [297] dei corpi, ma ciò non significa che una malattia umorale sia sempre legata ad una alterazione psichica, bensì capita in alcune malattie specifiche.

Quanto alla sua raccomandazione: "Non rispettare il ricco per la sua ricchezza, né chi ha prestigio $(g \bar{g} a h)$ per il suo prestigio", egli intende dire: "quando quella ricchezza ti vela dalla manifestazione del Vero nella sua forma, o nella forma di quel prestigio". Ciò perché tu distingui tra chi ha ricchezza

tu non Mi hai visitato!" [L'uomo] risponderà :"O Signore, come avrei potuto visitarTi, Tu che sei il Signore dei Mondi?" [Allah] dirà: "Non sai che un tale, dei Miei servitori, si è ammalato? Ora, tu non l'hai visitato! Non sai che se l'avessi visitato avresti trovato Me presso di lui?". Le Sue parole "Avresti trovato Me presso di lui" corrispondono alla menzione ( $\underline{d i k r}$ ) da parte del malato del suo Signore, nel suo segreto ed esteriormente". 959) Ibn 'Arabī contrappone qui la teofania nelle forme dei significati, o delle idee, alla teofania nelle forme delle entità. 
e prestigio e chi non ha ricchezza, e non rispetti l'indigente (muqtir) e colui che viene disprezzato (mustahdam): questa è la tua bilancia. Se tu rispetti il povero nello stato della sua povertà e colui che viene disprezzato nello stato del suo essere disprezzato, allora il rispettare il ricco per la sua ricchezza non inficia la tua stazione spirituale, né il rispettare chi ha prestigio per il suo prestigio, poiché sai da te chi è Colui che contempli (mašhüd) in quello. Per questo fa parte dell'educazione impartita da Allah al Suo Profeta nella Sūra "Si accigliò" (Cor. LXXX) ciò che avvenne quando egli discriminò, e quando Allah lo istruì egli si mostrò paziente con coloro con cui gli fu ordinato di essere paziente, ed essi erano disprezzati per la [loro condizione di] servitù $\left({ }^{960}\right)$.

Questa stazione non la attualizza per gusto spirituale se non chi vede Allah prima di ogni cosa, come Abū Bakr il confessore, Allah sia soddisfatto di lui: quando Egli Lo vide prima di ogni cosa Lo conobbe e quando Lo ebbe conosciuto Egli non Si manifestò a lui, per mezzo della [Sua] trasmutazione visibile (bi-t-tahawreulfí 'ayn) ${ }^{961}$ ) di una cosa $\left({ }^{962}\right)$, senza che egli non Lo distinguesse e non Lo riconoscesse. Per questo egli disse: "Non ho visto cosa senza aver visto Allah prima di essa" (963), e questa è una stazione

960) L'episodio in questione è stato già riportato e commentato a pag. 62-63 del manoscritto.

961) Nelle Futūhāt è affermato decine di volte che la trasmutazione del Vero ha luogo nelle forme non nelle entità, che in se stesse sono immutabili, per cui ho tradotto $f \grave{i}$ 'ayn in riferimento alla visione e non all'entità. D'altra parte nel Cap. 167 [II 227.28] lo stesso Ibn 'Arabī usa l'espressione: "la Sua trasmutazione nell'occhio di chi vede (tahawreulu-hu fì 'ayn ar-rā $\grave{\imath})$ '.

962) Nei due manoscritti più antichi si trova li-šay in , mentre negli altri cinque manoscritti il testo riporta $a s^{2}-\check{s} a y^{\prime}$ ', per cui il significato sarebbe "nell'occhio della cosa" o "nell'entità della cosa".

963) Nel Cap. 73 [II 4.34] Ibn 'Arabī afferma: "L'entità ('ayn) del Vero è unica e l'entità del servitore è unica, ma l'entità del servitore è fissa: essa non abbandona la sua origine, né esce dalla sua miniera, ed è il Vero che la riveste col manto della Sua esistenza. L'entità del servitore è quindi il lato interiore della sua esistenza, e la sua esistenza è identica a Colui che le ha dato l'esistenza. Non appare dunque che il Vero e nient'altro che Lui, mentre l'entità del servitore rimane nella sua origine (așl), ottenendo però ciò che non possedeva quanto a scienza di se stesso e di Chi lo ha rivestito col manto della Sua esistenza, ed a conoscenza dei suoi simili (amtāa $l$. Così le creature del mondo si vedono, le une le altre, con l'occhio dell'esistenza del loro Signore: chi guarda se stesso con l'occhio del suo Signore e non discerne, si discosta da ciò che è desiderabile per lui, ed è il servitore a cui viene attribuita l'ignoranza riguardo all'entità del Vero. Il suo regime in questa attribuzione e in questa condizione è come quello di chi non è qualificato dall'esistenza, poiché l'ignoranza è non-esistenza ('adam). Chi invece afferma, riguardo alla sua visione, che Allah non vede che Allah, quello è il servitore perfetto. E così per ogni relazione (nisba): questo è il più elevato dei gradi delle conoscenze. Ad esso fa seguito il secondo grado di conoscenza, il cui possessore dice: "Avevo gli occhi chiusi e li ho aperti e non mi sono imbattuto in nulla che non fosse Allah, non ho visto che Allah, mentre le entità, nella loro origine [cioè nel loro stato di non manifestazione], non avevano alcun effetto sulla mia visione di esse". Quanto al terzo grado di conoscenza esso è quello riguardo al quale il suo possessore dice: "Non ho visto nessuna cosa". Il quarto grado infine corrisponde a colui che dice: "Non ho visto alcuna cosa senza aver visto prima di essa Allah", ma questa è una visione implicante una limitazione ( $t a h d \bar{\imath} d$ ), come pure quelle che derivano da tale grado di conoscenza, [sostituendo a "prima di essa"] "in essa", "dopo di essa" o "presso di essa", ecc. Queste ultime sono quelle conoscenze che comportano l'affermazione di un limite e che derivano dalla relazione della discesa divina, presupposto della comparabilità. Le prime conoscenze che abbiamo menzionato sono invece inerenti solo alla stazione spirituale del servitore che è tra queste due relazioni [incomparabilità e comparabilità]. Quanto alle 
più completa come scienza di quella di chi ha detto: "Non ho visto cosa senza aver visto Allah in essa" $\left.{ }^{964}\right)$. Quanto a colui che ha detto: "Non ho visto cosa senza aver visto Allah con ( $m a$ 'a $a$ essa" $\left({ }^{965}\right)$ è necessario che la scienza di Allah fosse precedente per lui.

Questa è la fine del libro $\left.{ }^{966}\right)$

conoscenze che risultano dalla relazione di incomparabilità, non è possibile parlarne: esse sono inesprimibili e non si addice loro neppure l'allusione". Quanto ai vari tipi del quarto grado di conoscenza quello che è più spesso riportato nelle Futūhāt, è quello che corrisponde alla affermazione di Abū Bakr, ma nel Cap. 463 [IV 83.21] precisa: "Questo [la contemplazione del Vero nella Sua genesi (takwinn) della cosa] è lo stato di chi ha detto: Non ho visto una cosa senza aver visto Allah con essa" e costui è più elevato in stato di chi ha detto: "Non ho visto una cosa senza aver visto Allah prima di essa", poiché la prima è una frase di accertamento della verità (tahquq $)$ ed anche se la seconda è simile nell'accertamento della verità tuttavia vi è una differenza tra le due. La frase del primo è come quella di chi dice: "Ho visto Zayd fare così", mentre il secondo è come colui che dice: "Ho visto colui che fa fare così". Questa è la differenza tra le due persone in ciò che esse contemplano".

964) Nelle opere che ho potuto consultare Ibn 'Arabī non indica mai chi l'ha detto.

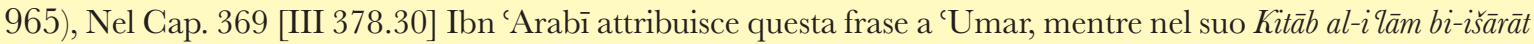
ahl al-ilhām, a pag. 96 dell'edizione Dār Sāder, Beirut, 1997, attribuisce a 'Uțmān la frase: "Non ho visto cosa senza aver visto Allah dopo di essa".

966) Nel manoscritto Yūsuf Aga si legge: "È completata l'Epistola di Yūsuf, grazie al Suo aiuto, sia Egli esaltato". 